Departamento de Construcción y Tecnología Arquitectónicas Escuela Técnica Superior de Arquitectura

\title{
Trazas de montea y cortes de cantería en la obra de Rodrigo Gil de Hontañón
}

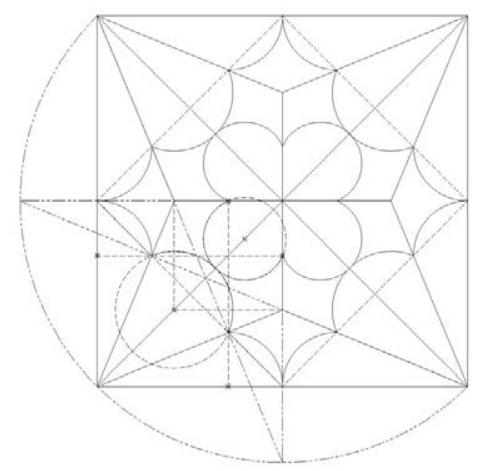

Autor: Pablo Moreno Dopazo - Arquitecto

Director: José Carlos Palacios Gonzalo - Doctor Arquitecto 

Tribunal nombrado por el Sr. Rector Magfco. de la Universidad Politécnica de Madrid, el día. de..... de $20 \ldots$

Presidente:

Vocal:

Vocal:

Vocal:

Secretario:

Suplente:

Suplente:

Realiza do el acto de defensa y lectura de la Tesis el día de....... de $20 \ldots$ en la E.T.S.I. / Fa cultad...

Calificación

EL PRESIDENTE

LOSVOCALES

EL SECRETARIO 



\section{Índice}

RESUMEN | ABSTRACT

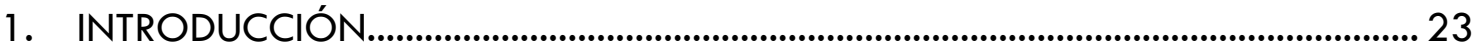

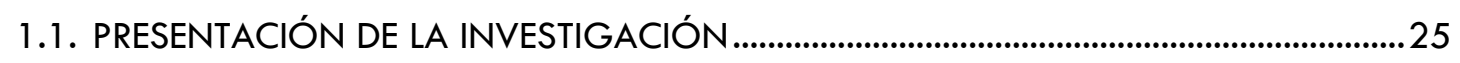

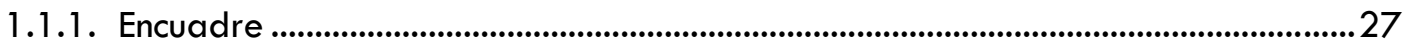

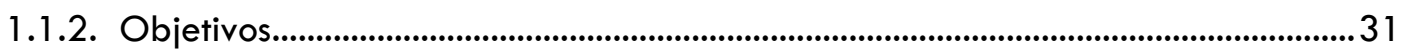

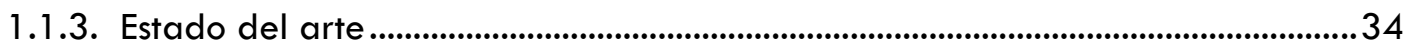

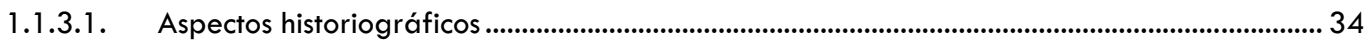

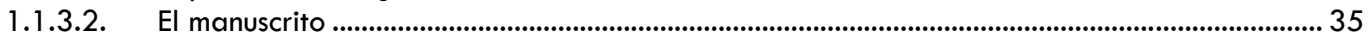

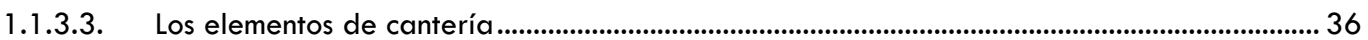

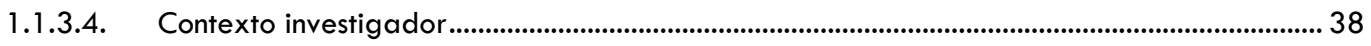

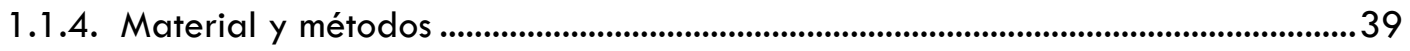

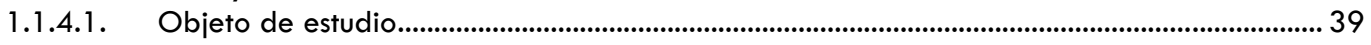

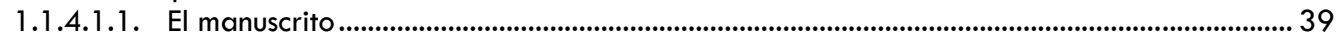

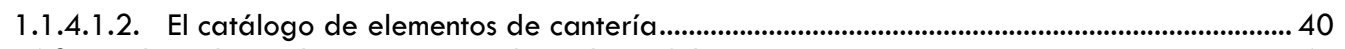

1.1.4.2. El cuaderno de arquitectura de Rodrigo Gil................................................................................... 41

1.1.4.3. Las bóvedas de crucería de Rodrigo Gil ......................................................................................4 43

1.1.4.3.1. Sistema empleado para la toma de datos ................................................................................... 43

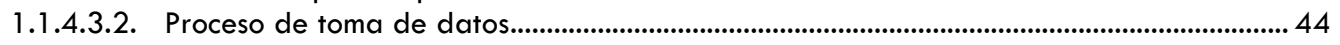

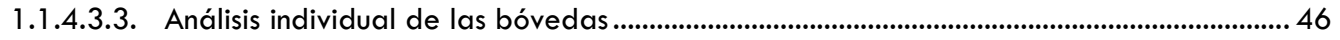

1.1.4.3.4. Análisis comparativo de las bóvedas ................................................................................... 47

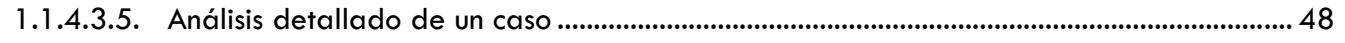

1.1.4.4. Otros elementos de cantería en la obra de Rodrigo Gil........................................................... 48

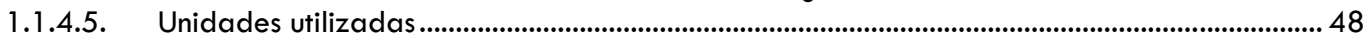

1.1.4.6. Estructura de la Tesis ........................................................................................................................... 49

\subsection{RODRIGO GIL: ASPECTOS BIOGRÁFICOS, HISTÓRICOS Y PROFESIONALES..............51}

1.2.1. Biografía ................................................................................................................................53

1.2.2. Contexto histórico...............................................................................................................60

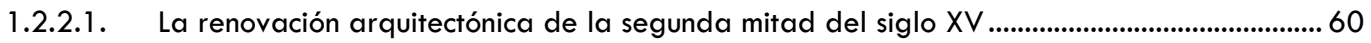

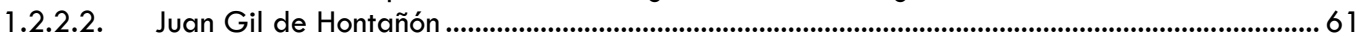

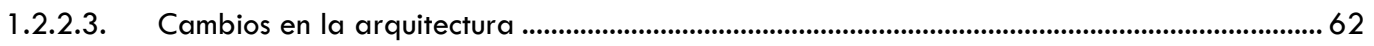

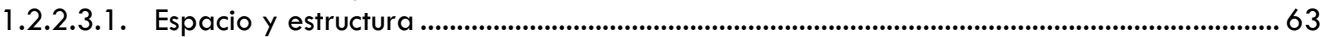

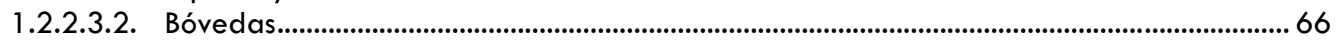

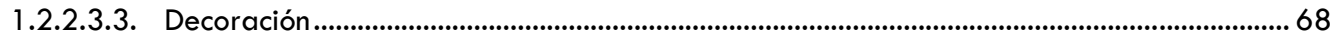

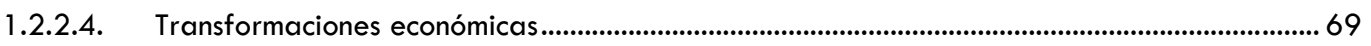

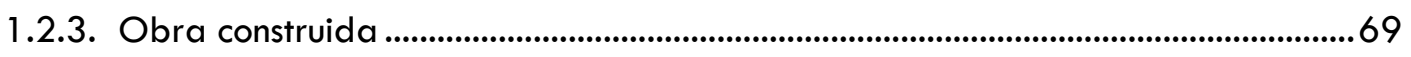

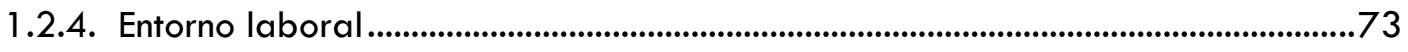

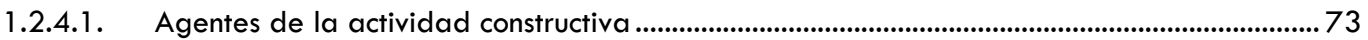

1.2.4.1.1. Maestro .......................................................................................................................................... 73

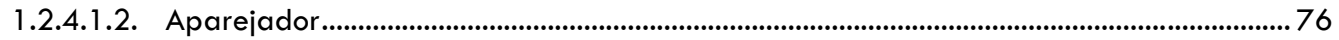

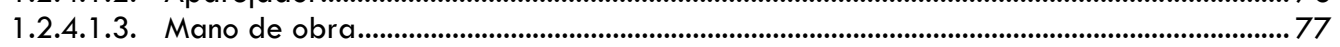

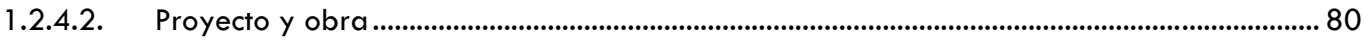

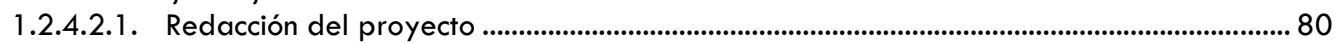

1.2.4.2.2. Adjudicación y ejecución de las obras ......................................................................................... 80

1.2.5. Actividad profesional .......................................................................................................84

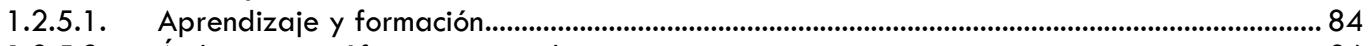

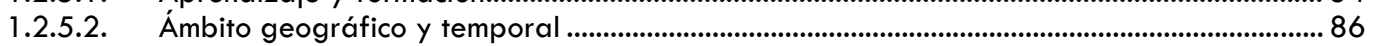




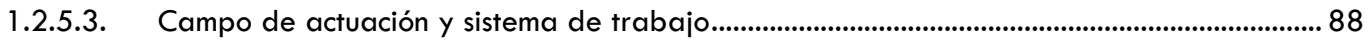

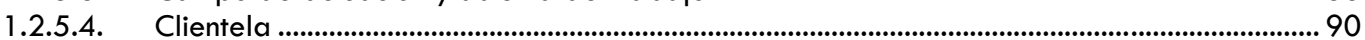

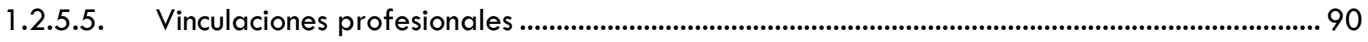

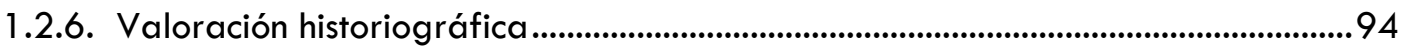

2. EL CUADERNO DE ARQUITECTURA DE RODRIGO GIL.......................................99

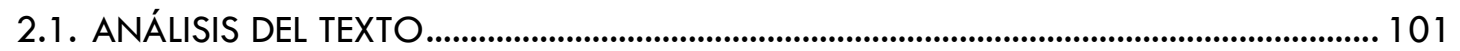

2.1.1. El Compendio de Architectura y simetría de los templos......................................... 103

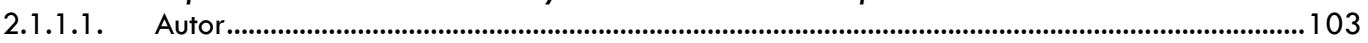

2.1.1.2. Parte atribuida a Rodrigo Gil............................................................................................................ 105

2.1.2. El cuaderno de arquitectura de Rodrigo Gil...................................................... 107

2.1.2.1. Objetivo y fecha de redacción ........................................................................................................107

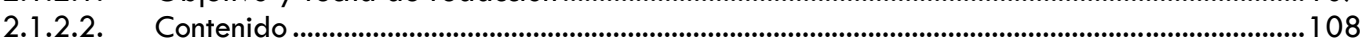

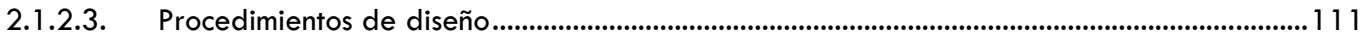

2.1.3. Métodos para el trazado arquitectónico .............................................................. 114

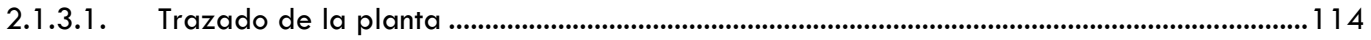

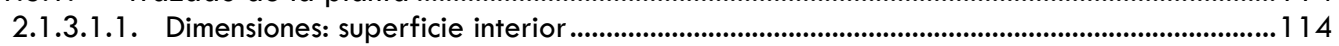

2.1.3.1.2. Tipología: modelos de aplicación proporcional .......................................................................115

2.1.3.1.3. Tipología: trazados geométricos ............................................................................................. 121

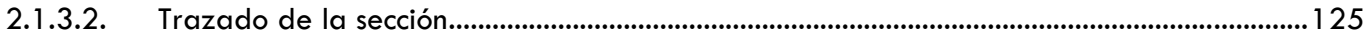

2.1.3.2.1. Relación entre las alturas de las naves ............................................................................ 125

2.1.3.2.2. Altura de la clave del arco perpiaño de la nave mayor .................................................... 125

2.1.3.2.3. Altura de la clave del arco perpiaño de la nave mayor para plantas duplas ............... 126

2.1.3.2.4. Altura de la línea de imposta de la nave mayor para plantas duplas............................. 126

2.1.4. Métodos para el dimensionado estructural ........................................................ 127

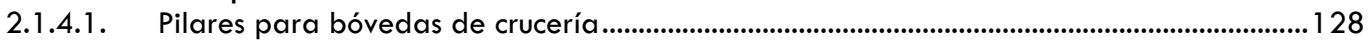

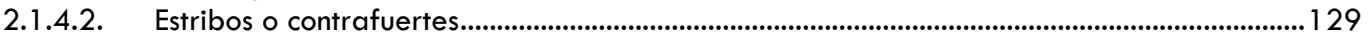

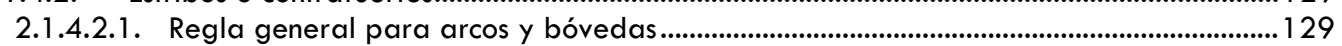

2.1.4.2.2. Regla particular para bóvedas de crucería ............................................................................. 129

2.1.4.3. Estribos o contrafuertes para arcos semicirculares.............................................................131

2.1.4.3.1. Reglas geométricas para arcos semicirculares ........................................................................ 132

2.1.4.3.2. Regla aritmética para arcos semicirculares ............................................................................. 135

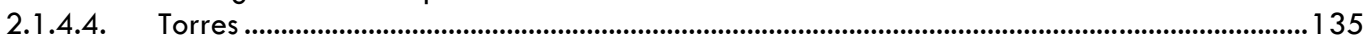

2.1.5. Dimensionado, construcción y montaje de una bóveda de crucería .................... 136

2.1.5.1. Elementos que componen la bóveda. Dimensionado de los elementos estructurales............ 137

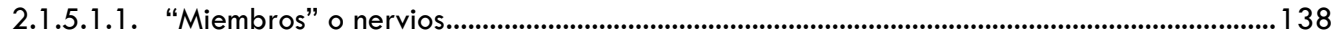

2.1.5.1.2. Claves .............................................................................................................................. 140

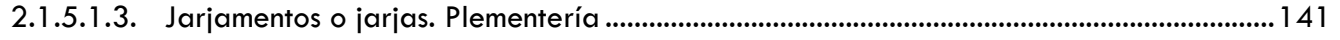

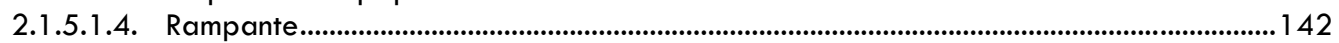

2.1.5.2. Construcción y montaje de la bóveda ...................................................................................... 143

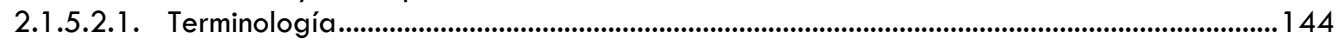

2.1.5.2.2. Descripción del proceso ................................................................................................ 145

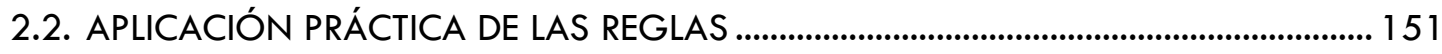

2.2.1. Métodos para el trazado arquitectónico............................................................... 158

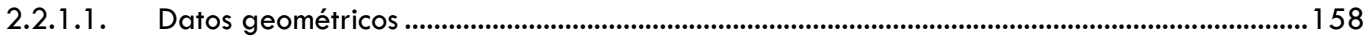

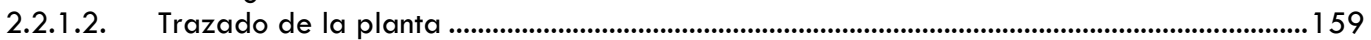

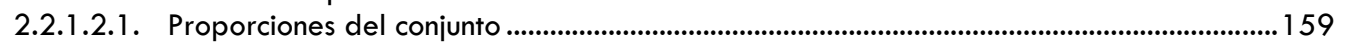

2.2.1.2.2. Proporciones de cada tramo cubierto por una bóveda ......................................................... 160

2.2.1.2.3. Relación entre las anchuras de las naves..........................................................................161

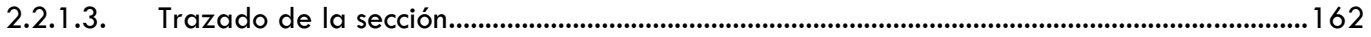

2.2.1.3.1. Altura de la línea de imposta. Relación entre las alturas de las naves............................... 163

2.2.1.3.2. Altura de la clave del arco perpiaño de la nave mayor .................................................. 164

2.2.2. Métodos para el dimensionado estructural .......................................................... 166

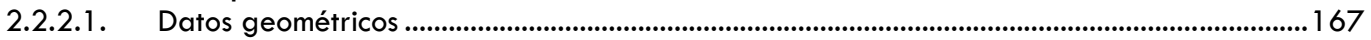

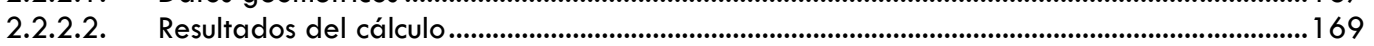

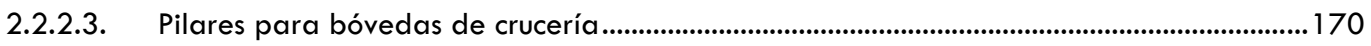

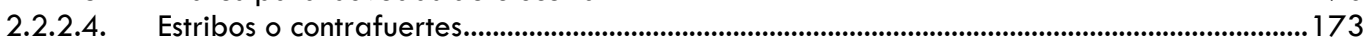

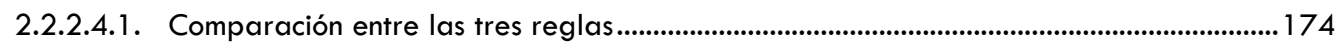


2.2.2.4.2. Comparación entre los valores de cálculo y los reales......................................................... 175

2.2.2.4.3. Proporción entre las dimensiones en planta del contrafuerte................................................ 176

3. LAS BÓVEDAS DE CRUCERÍA DE RODRIGO GIL ..................................................179

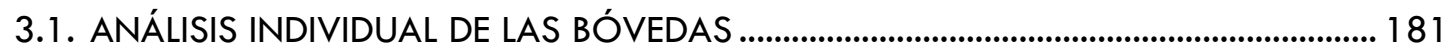

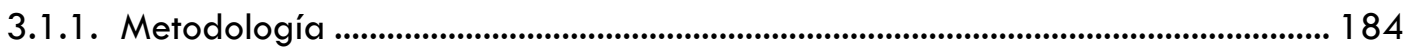

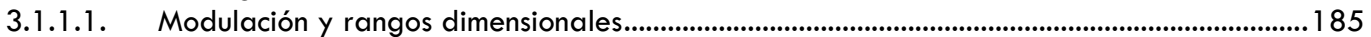

3.1.1.2. Sistemas de composición................................................................................................................... 185

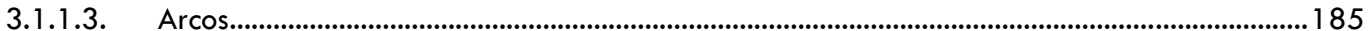

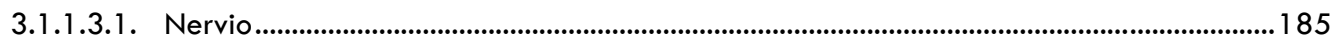

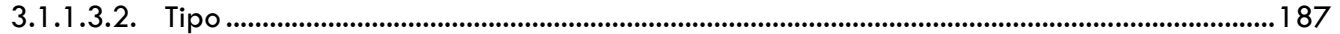

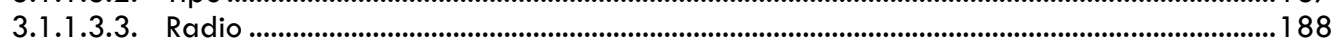

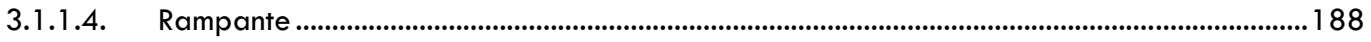

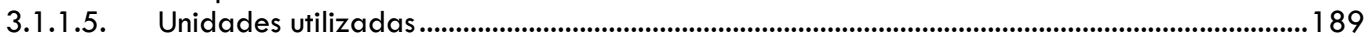

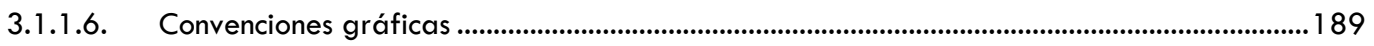

3.1.2. Astorga (León) · Catedral de Santa María ........................................................... 191

3.1.2.1. Bóveda de la capilla de San Juan Bautista (costado sur del falso crucero) ........................... 192

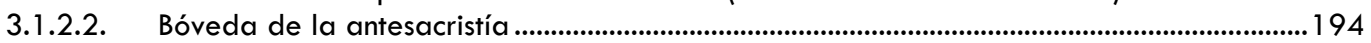

3.1.3. Cáceres • Iglesia de San Mateo............................................................................. 197

3.1.3.1. Bóveda de la antigua capilla de los Sande (actual sacristía) .................................................. 198

3.1.4. Cáceres • Iglesia de Santiago de los Caballeros .................................................. 201

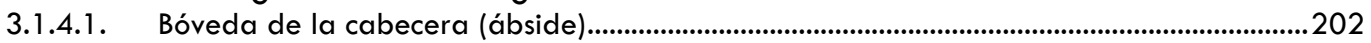

3.1.4.2. Bóveda de la cabecera (presbiterio) ..................................................................................................204

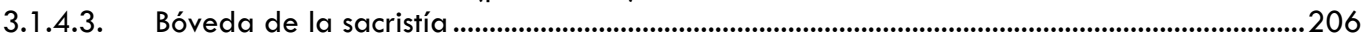

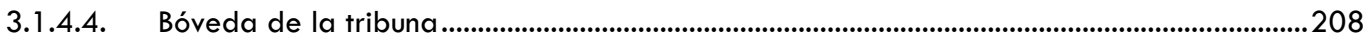

3.1.5. Castellanos de Villiquera (Salamanca) • Iglesia de San Juan Bautista............... 211

3.1.5.1. Bóveda del cuerpo inferior de la torre .......................................................................................2 212

3.1.6. Ciudad Rodrigo (Salamanca) · Catedral de Santa María .................................... 215

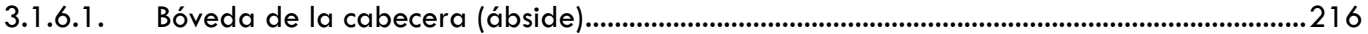

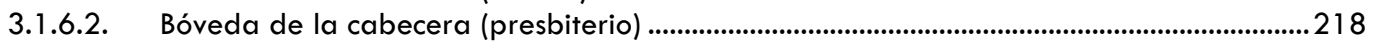

3.1.7. Fontiveros (Ávila) • Iglesia de San Cipriano ........................................................ 221

3.1.7.1. Bóveda del crucero (tramo central)..........................................................................................222

3.1.7.2. Bóveda del crucero (tramo lateral norte) ............................................................................................2224

3.1.8. Fuente el Saz de Jarama (Madrid) • Iglesia de San Pedro Apóstol.................... 227

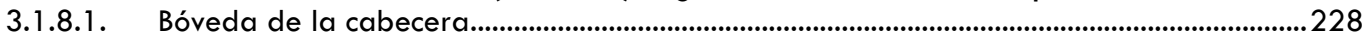

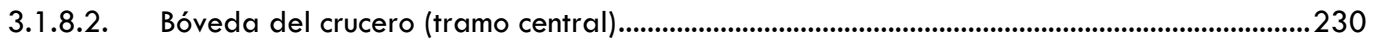

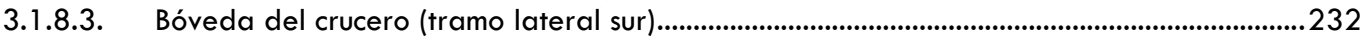

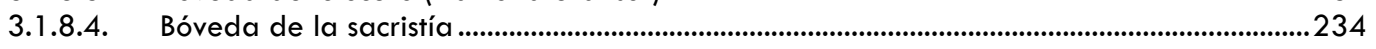

3.1.9. Fuenteguinaldo (Salamanca) • Iglesia de San Juan Bautista .............................. 237

3.1.9.1. Bóveda de la nave (tramo 1) ...........................................................................................................238

3.1.1 10.Guareña (Badajoz) • Iglesia de Santa María de la Asunción............................... 241

3.1.10.1. Bóveda de la nave (tramo 3) ........................................................................................................242

3.1.1 1.Laguna de Duero (Valladolid) • Iglesia de la Asunción de Nuestra Señora ..... 245

3.1.1 1.1. Bóveda de la nave central (tramo 3) ...................................................................................................246

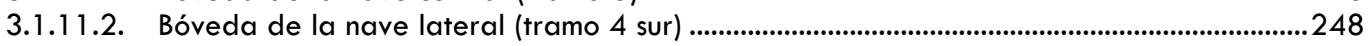

3.1.1 2.Medina de Rioseco (Valladolid) • Iglesia de Santiago de los Caballeros ........ 251

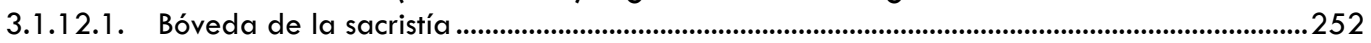

3.1.13.Medina del Campo (Valladolid) • Colegiata de San Antolín................................. 255

3.1.13.1. Bóveda de la nave central (tramo 1) .........................................................................................256

3.1.13.2. Bóveda de la nave lateral (tramo 1 sur) ........................................................................................258

3.1.14.Miraflores de la Sierra (Madrid) - Iglesia de la Asunción de Nuestra Señora 261

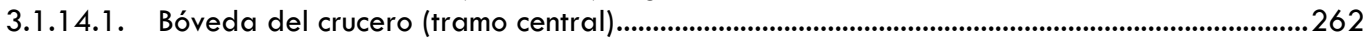

3.1.14.2. Bóveda del crucero (tramo lateral sur)..........................................................................................264

3.1.1 5.Mota del Marqués (Valladolid) • Iglesia de San Martín....................................... 267

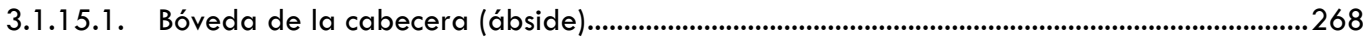

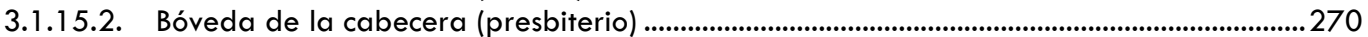

3.1.15.3. Bóveda de la nave central (tramo 2) ........................................................................................ 272 


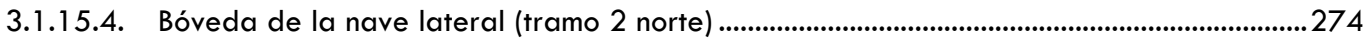

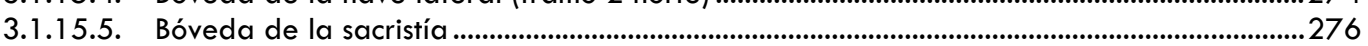

3.1.1 6.Nava del Rey (Valladolid) • Iglesia de los Santos Juanes..................................... 279

3.1.16.1. Bóveda de la capilla de la Asunción o del canónigo Juan Gil de Nava (cabecera) ...........280

3.1.16.2. Bóveda de la capilla de la Asunción o del canónigo Juan Gil de Nava (cuerpo)................282

3.1.17.Ourense • Catedral de San Martín........................................................................... 285

3.1.17.1. Bóveda del pórtico del Paraíso (tramo central) ...........................................................................2.286

3.1.17.2. Bóveda del pórtico del Paraíso (tramo lateral norte) ..........................................................28

3.1 1 18.Ourense • Iglesia de la Santísima Trinidad ............................................................ 291

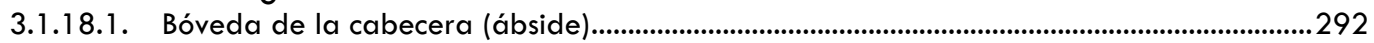

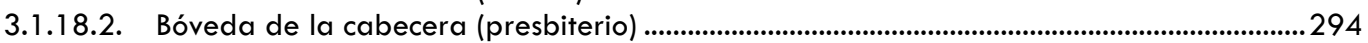

3.1.1 9.Peñaranda de Duero (Burgos) • Iglesia (excolegiata) de Santa Ana................. 297

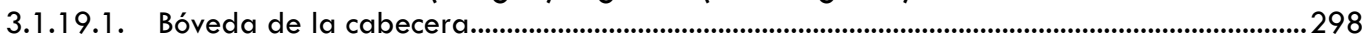

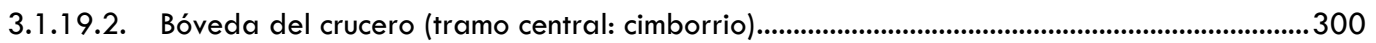

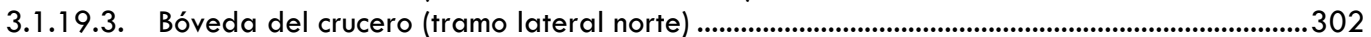

3.1 20.Plasencia (Cáceres) • Catedral Nueva de Santa María de la Asunción ............ 305

3.1.20.1. Bóveda de la nave lateral (tramo 1 norte) ...................................................................................306

3.1.21.Salamanca - Capilla del Colegio Mayor del Arzobispo Fonseca, de Santiago el

Zebedeo 0 de los Irlandeses .............................................................................................. 309

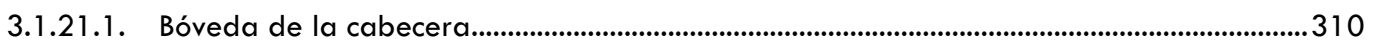

3.1.21.2. Bóveda del crucero (tramo central: cimborrio)..........................................................................312

3.1.21.3. Bóveda del crucero (tramo lateral sur).......................................................................................314

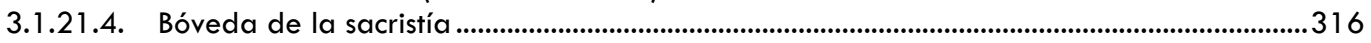

3.1.22.Salamanca • Catedral Nueva de la Asunción de la Virgen .................................. 319

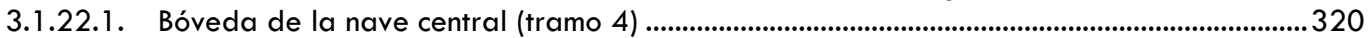

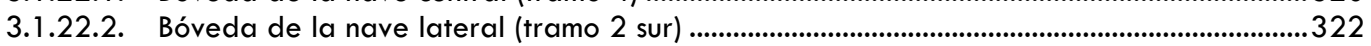

3.1.22.3. Bóveda de la nave lateral (tramo 3 sur) .........................................................................................324

3.1 23.Salamanca • Colegio Menor de San Pelayo ........................................................... 327

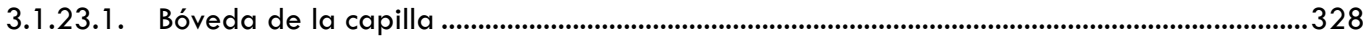

3.1 24.Salamanca • Iglesia del convento de San Esteban................................................ 331

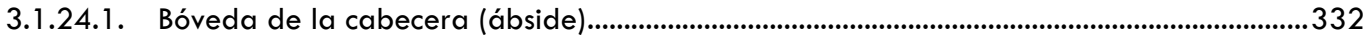

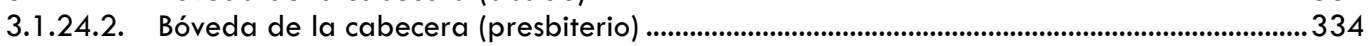

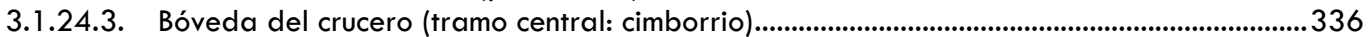

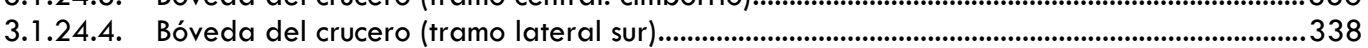

3.1.24.5. Bóveda de la capilla de Santa Teresa o de Limoges (costado norte del presbiterio) ........340

3.1.24.6. Bóveda de la capilla de los Bonal (costado sur del presbiterio) ...............................................342

3.1.24.7. Bóveda de la capilla del Rosario o de los Anaya (costado norte del crucero)........................344

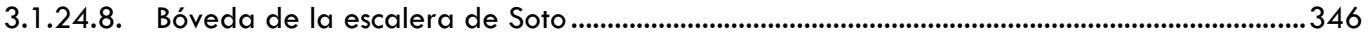

3.1.25.Salamanca - Iglesia del monasterio de las Bernardas o del Buen Nombre de Jesús.

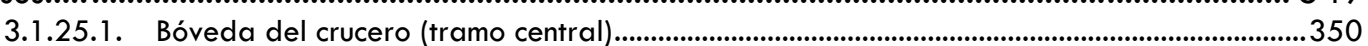

3.1 26.Saucelle (Salamanca) • Iglesia de la Purísima Concepción.................................... 353

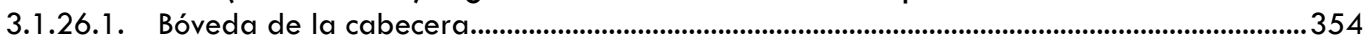

3.1.26.2. Bóveda del crucero (tramo central)...................................................................................................356

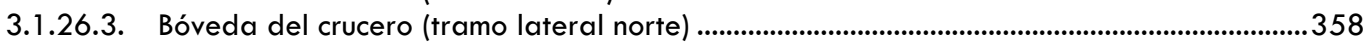

3.1.26.4. Bóveda de la capilla lateral (costado norte de la cabecera) .....................................................360

3.1 27.Segovia • Catedral de Nuestra Señora de la Asunción y San Frutos.................. 363

3.1.27.1. Bóveda de la nave central (tramo 4) ...............................................................................................364

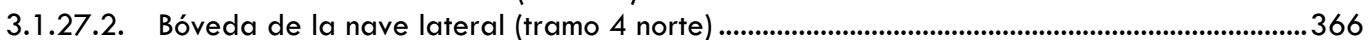

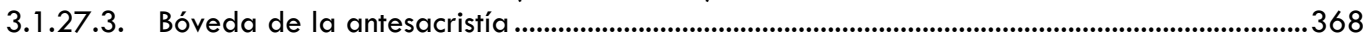

3.1.27.4. Bóveda de la antigua sacristía (actual capilla del Santísimo Sacramento).............................370

3.1.27.5. Bóveda de la capilla de la Piedad o del Santo Entierro (tramo 1 norte) ..................................372

3.1.27.6. Bóveda de la capilla de San Cosme y San Damián (tramo 3 norte) ......................................374

3.1.27.7. Bóveda de la capilla de San Gregorio (tramo 4 norte) ..............................................................376

3.1.27.8. Bóveda de la capilla de Santa Catalina (cuerpo inferior de la torre) ....................................378

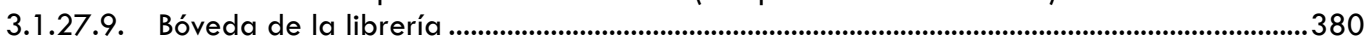

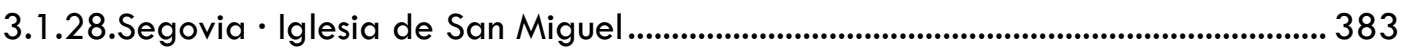

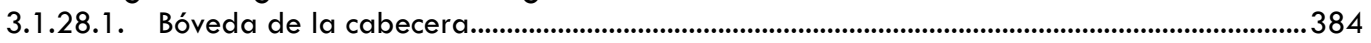

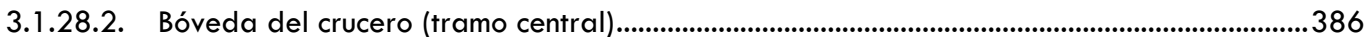

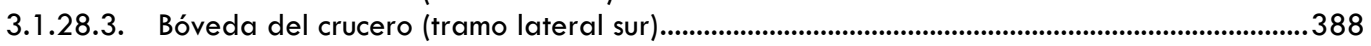

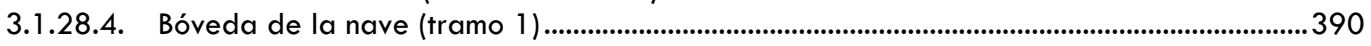


3.1.28.5. Bóveda de la capilla de los Tapia (tramo 1 sur) ...................................................................392

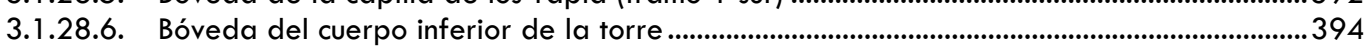

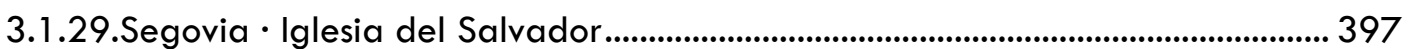

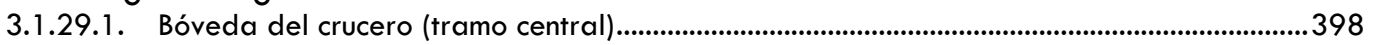

3.1.30.Torrelaguna (Madrid) • Iglesia de Santa María Magdalena ............................... 401

3.1.30.1. Bóveda de la capilla de San Gregorio o del inquisidor Gregorio Vélez (cabecera) .........402

3.1.30.2. Bóveda de la capilla de San Gregorio o del inquisidor Gregorio Vélez (cuerpo)...............404

3.1.31.Valladolid • Iglesia de Santa María Magdalena.................................................. 407

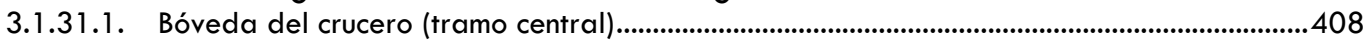

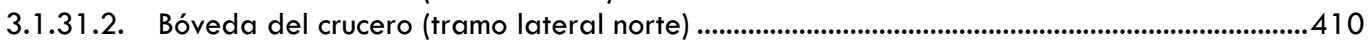

3.1.31.3. Bóveda de la nave (tramo 1) ...............................................................................................412

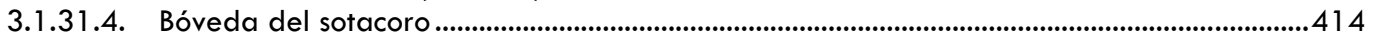

3.1.32.Vegas de Matute (Segovia) • Iglesia de Santo Tomás ........................................... 417

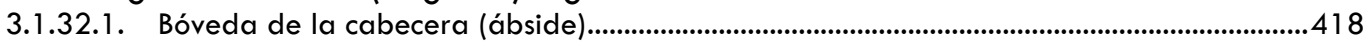

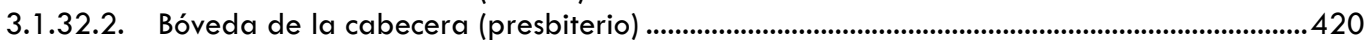

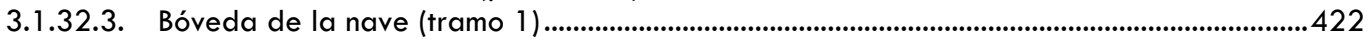

3.1.32.4. Bóveda de la capilla de Santo Tomás o de los Segovia .........................................................424

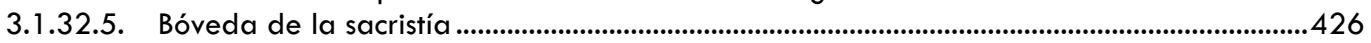

3.1.33.Villacastín (Segovia) • Iglesia de San Sebastián ....................................................4 429

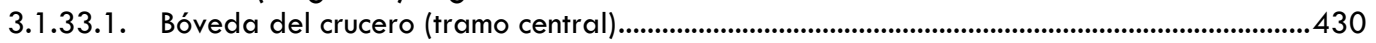

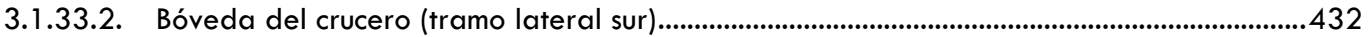

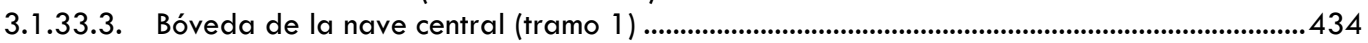

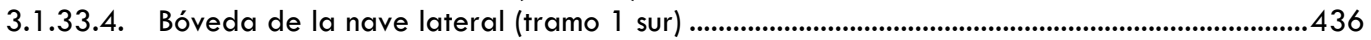

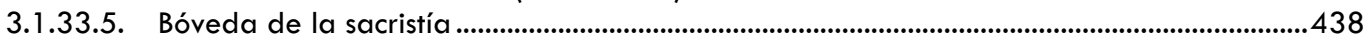

3.1.34.Villamor de los Escuderos (Zamora) - Iglesia de la Asunción de Nuestra

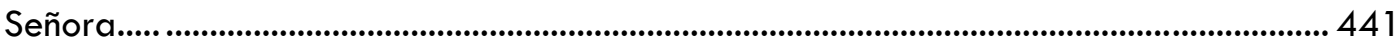

3.1.34.1. Bóveda de la cabecera (presbiterio) .........................................................................................442

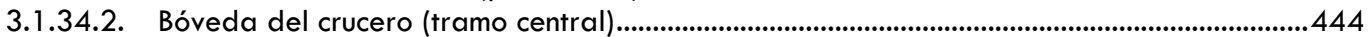

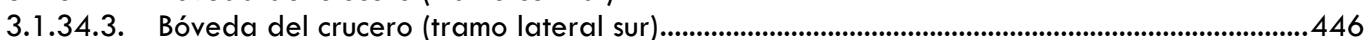

3.1.34.4. Bóveda de la nave (tramo 1) ...................................................................................................................448

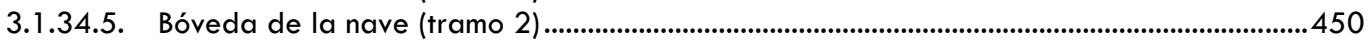

3.1.35. Villavieja de Yeltes (Salamanca) • Iglesia de San Pedro Apóstol ....................... 453

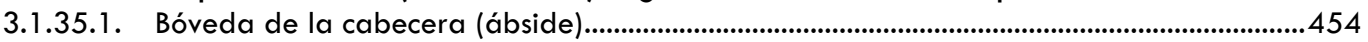

3.1.35.2. Bóveda de la cabecera (presbiterio) ...................................................................................................456

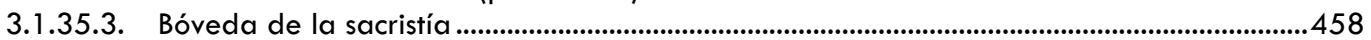

3.1.36.Zamora - Capilla del deán Diego Vázquez de Cepeda en el convento de San

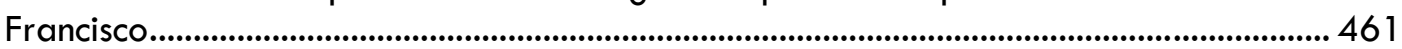

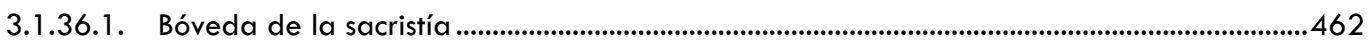

3.1.37.Zamora • Iglesia de San Juan de Puerta Nueva.................................................... 465

3.1.37.1. Bóveda de la cabecera (tramo central) ....................................................................................466

3.1.37.2. Bóveda de la cabecera (tramo lateral sur) .......................................................................................468

\subsection{ANÁLISIS COMPARATIVO DE LAS BÓVEDAS: CARACTERÍSTICAS GEOMÉTRICAS. 471}

3.2.1. Modulación y rangos dimensionales................................................................... 473

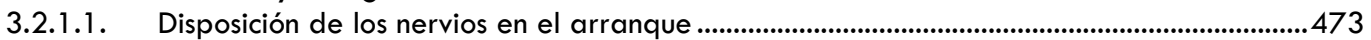

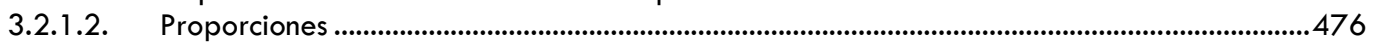

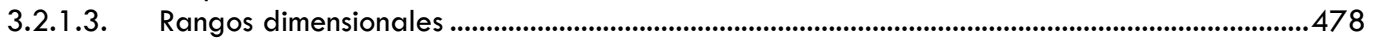

3.2.2. Sistemas de composición................................................................................ 479

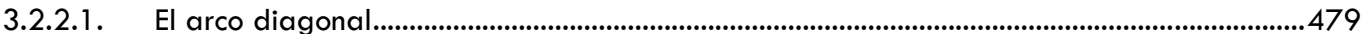

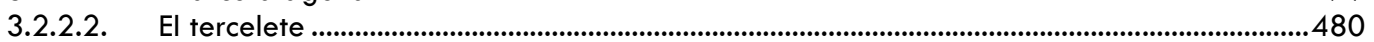

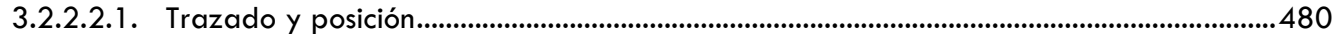

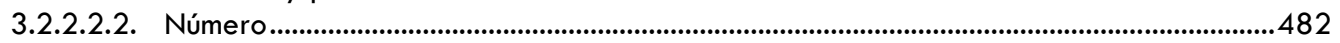

3.2.2.3. Las nervaduras decorativas ...........................................................................................................484

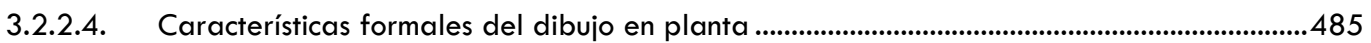

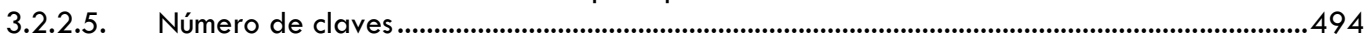

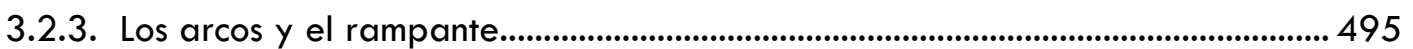

3.2.3.1. Aspectos generales de su trazado ......................................................................................................495

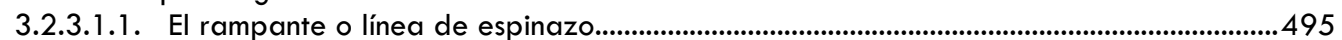

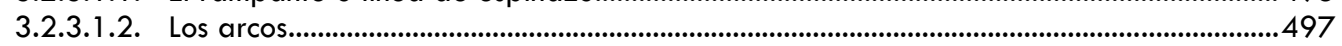

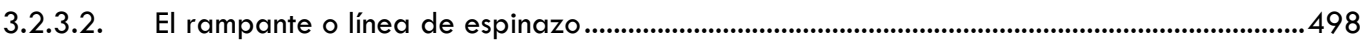

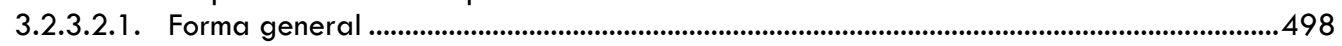




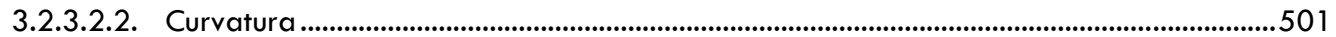

3.2.3.2.3. Diferencia de altura entre la clave central y las de los arcos del perímetro....................502

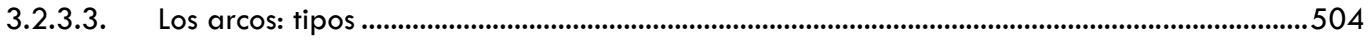

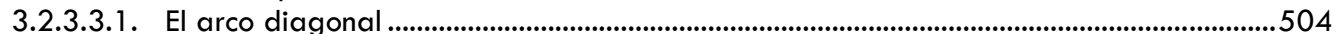

3.2.3.3.2. El perpiaño y el formero...................................................................................................506

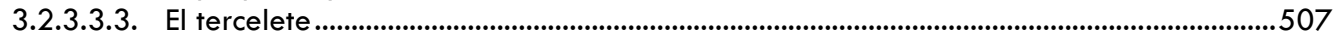

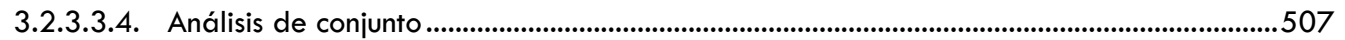

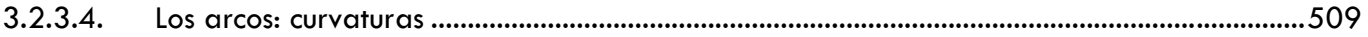

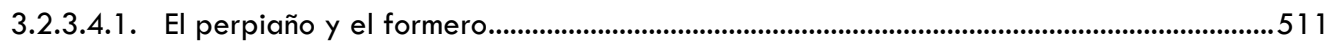

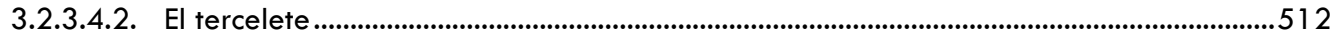

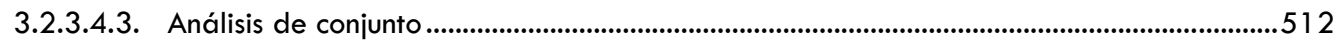

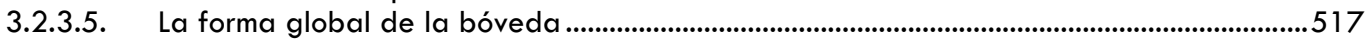

3.3. ANÁLISIS COMPARATIVO DE LAS BÓVEDAS: CARACTERÍSTICAS

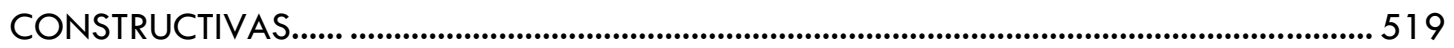

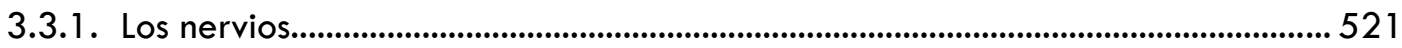

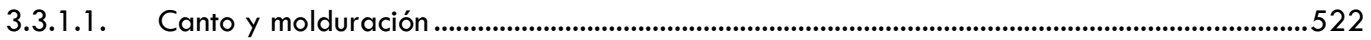

3.3.1.1.1. El perpiaño: bóvedas dispuestas a la misma altura ...........................................................523

3.3.1.1.2. El perpiaño: bóvedas dispuestas a distinta altura ....................................................................526

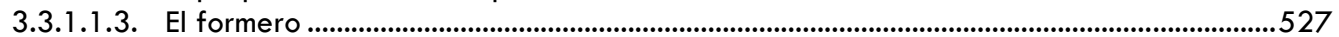

3.3.1.1.4. La crucería interior ....................................................................................................................530

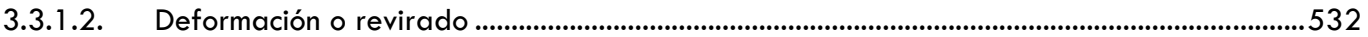

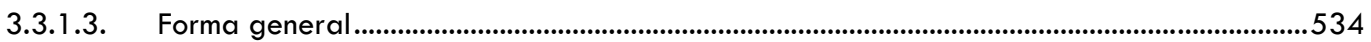

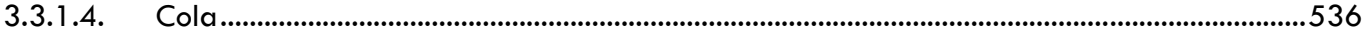

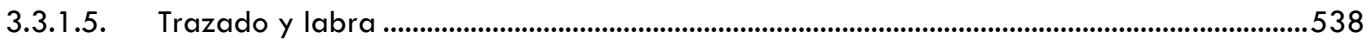

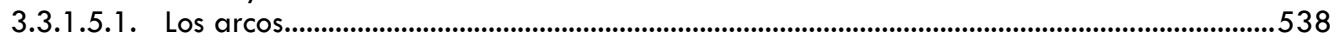

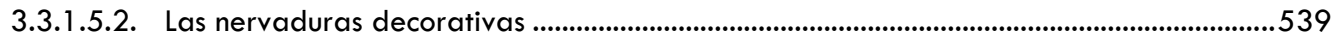

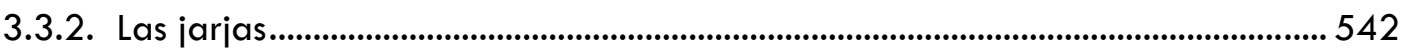

3.3.2.1. Disposición general de las hiladas ..................................................................................542

3.3.2.2. Disposición de los nervios en el arranque ...........................................................................543

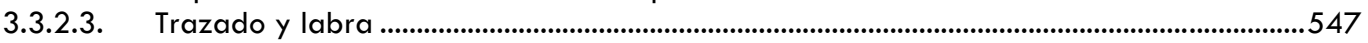

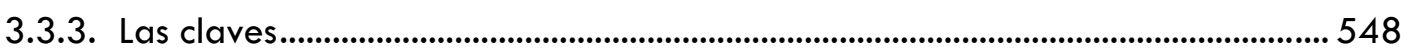

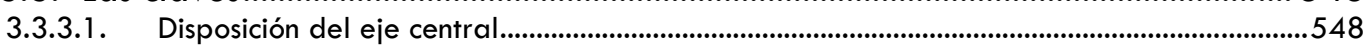

3.3.3.2. Disposición del cilindro central y de las acometidas o brazos.................................................552

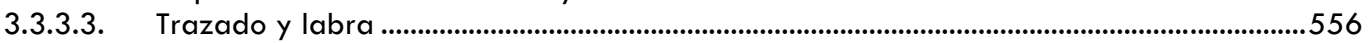

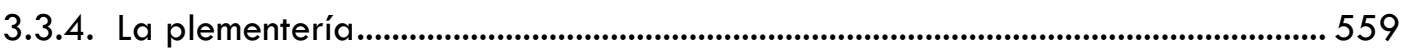

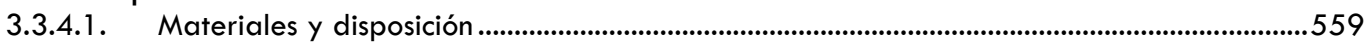

3.3.4.1.1. Cantería dispuesta a la francesa .......................................................................................561

3.3.4.1.2. Cantería dispuesta por otros procedimientos ....................................................................563

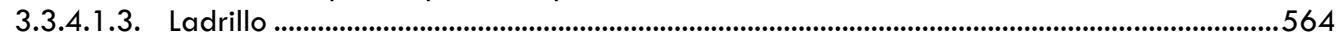

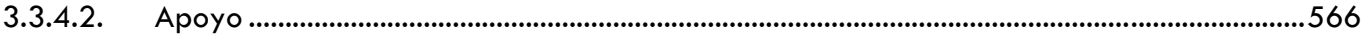

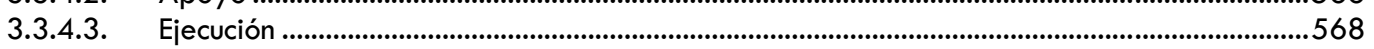

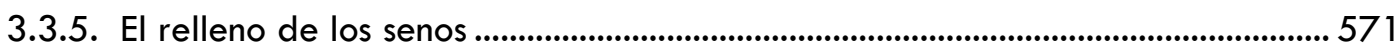

3.4. ANÁLISIS DETALLADO DE UN CASO: LA BÓVEDA DEL CIMBORRIO DE LA CAPILLA DEL COLEGIO MAYOR DEL ARZOBISPO FONSECA EN SALAMANCA .............................575

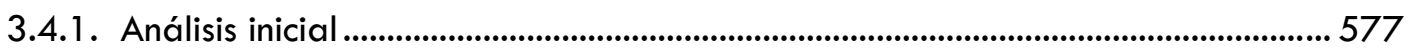

3.4.1.1. El diseño en planta de la bóveda ...........................................................................................5.57

3.4.1.2. Los arcos y el rampante: la forma de la bóveda.........................................................................579

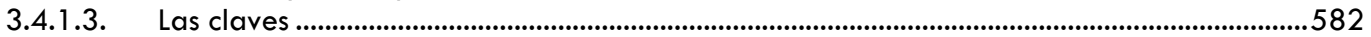

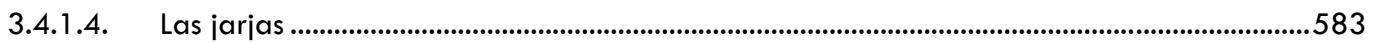

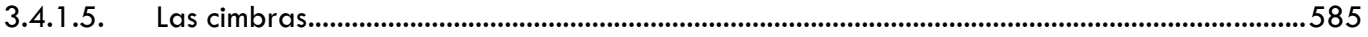

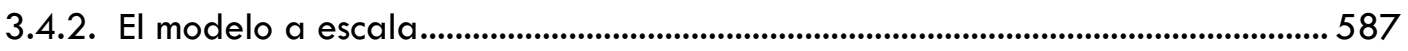

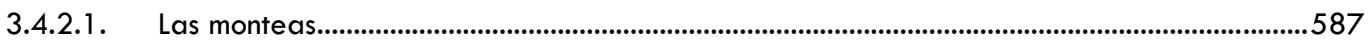

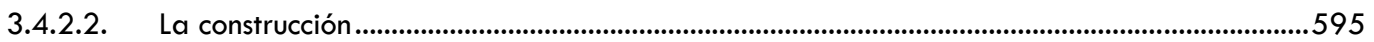

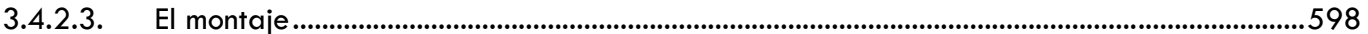

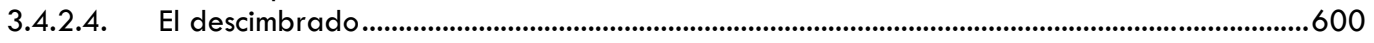

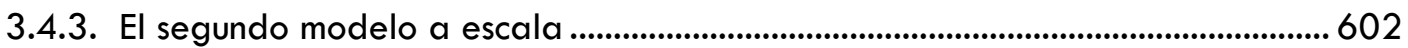

3.4.4. Participantes en la ejecución de los modelos a escala............................................. 602 
4.1. ARCOS

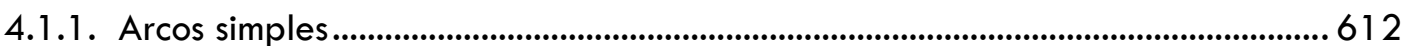

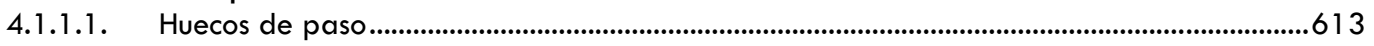

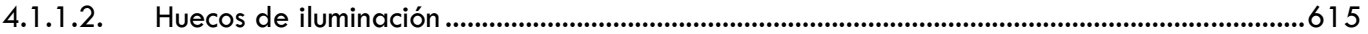

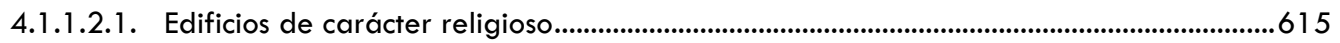

4.1.1.2.2. Edificios de carácter civil ...........................................................................................................618

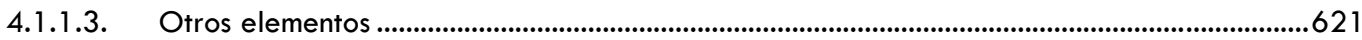

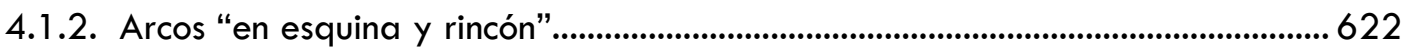

4.1.3. Arcos "en torre cavada y redonda" ............................................................................. 623

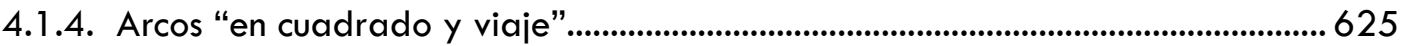

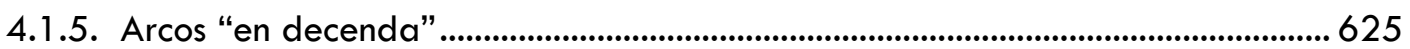

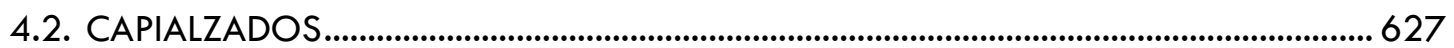

4.2.1. Capialzados "en puerta cuadrada" ................................................................... 629

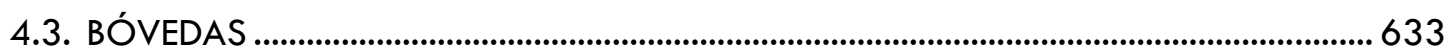

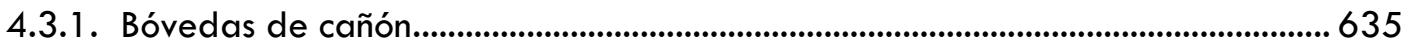

4.3.2. Bóvedas en vuelta de horno o de media naranja................................................638 63

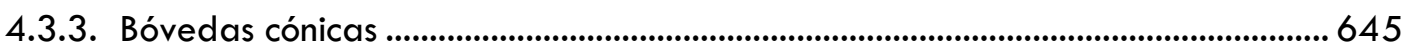

4.3.4. Bóvedas de planta oval y lechos horizontales.................................................. 646

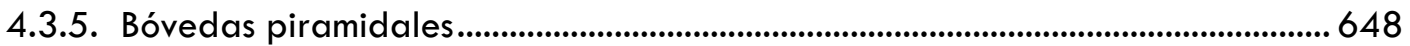

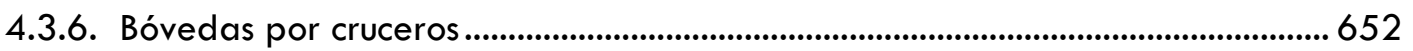

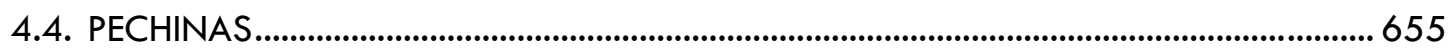

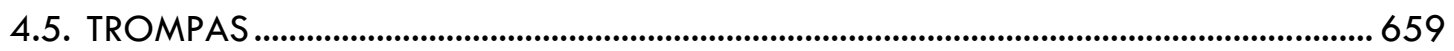

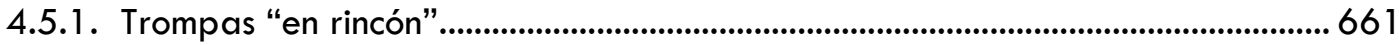

4.5.2. Trompas "en rincón" "en torre cavada" ................................................................. 662

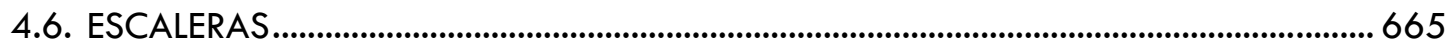

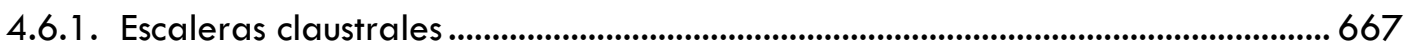

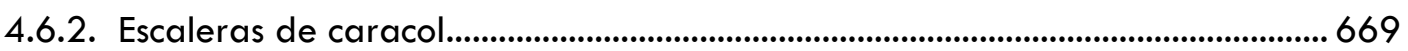

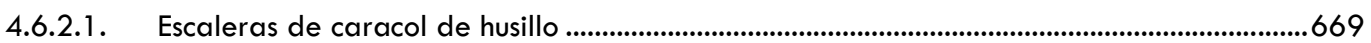

4.6.2.2. Escaleras de caracol "de Mallorca".........................................................................................670

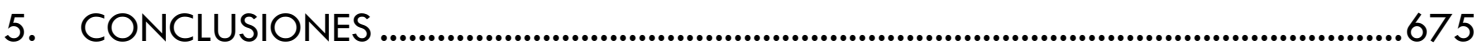

6. DIFUSIÓN DE RESULTADOS Y FUTURAS LÍNEAS DE INVESTIGACIÓN.................691

7. ANEXO A. CATÁLOGO DE OBRAS E INTERVENCIONES ......................................695

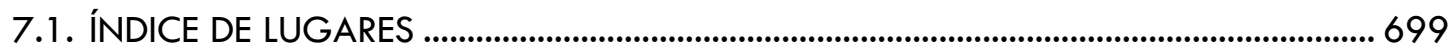

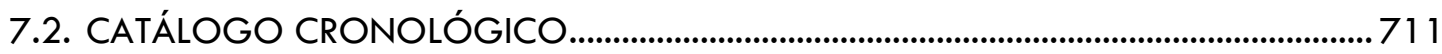

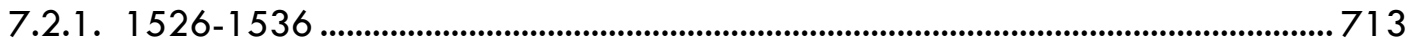

7.2.1.1. Cuéllar (Segovia) · Convento de San Francisco ...........................................................................713

7.2.1.2. Segovia · Catedral de Nuestra Señora de la Asunción y San Frutos ........................................713 
7.2.1.3. Medina del Campo (Valladolid) · Colegiata de San Antolín....................................................721

7.2.1.4. Villamor de los Escuderos (Zamora) · Iglesia de la Asunción de Nuestra Señora ...................722

7.2.1.5. Miraflores de la Sierra (Madrid) • Iglesia de la Asunción de Nuestra Señora ......................723

7.2.1.6. Zamora - Capilla del deán Diego Vázquez de Cepeda en el convento de San Francisco724

7.2.1.7. Oñati (Gipuzkoa) • Iglesia de San Miguel Arcángel...................................................................726

7.2.1.8. Villaveta, Castrojeriz (Burgos) - Iglesia de la Inmaculada Concepción .....................................726

7.2.1.9. Alcalá de Henares (Madrid) · Catedral-Magistral de los Santos Justo y Pastor .....................727

7.2.1.10. Villacastín (Segovia) • Iglesia de San Sebastián......................................................................728

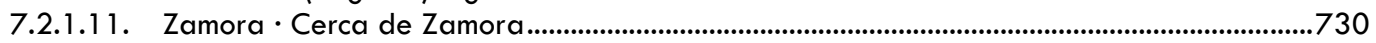

7.2.1.12. Zamora Iglesia de San Juan de Puerta Nueva..................................................................730

7.2.1.13. Alcalá de Henares (Madrid) · Colegio Mayor de San Ildefonso..................................................732

7.2.1.14. Alcalá de Henares (Madrid) - Iglesia de Santa María la Mayor.............................................733

7.2.1.15. Cigales (Valladolid) • Iglesia de Santiago Apóstol......................................................................734

7.2.1.16. Medina de Rioseco (Valladolid) · Iglesia de Santiago de los Caballeros.................................736

7.2.1.17. Villaumbrales (Palencia) - Iglesia de San Pelayo ............................................................................737

7.2.1.18. Torrelaguna (Madrid) • Iglesia de Santa María Magdalena........................................................738

7.2.1.19. Colmenar Viejo (Madrid) • Iglesia de la Asunción de Nuestra Señora....................................740

7.2.1.20. Ávila · Catedral de Cristo Salvador ......................................................................................741

7.2.1.21. Tudela de Duero (Valladolid) • Iglesia de la Asunción de Nuestra Señora .............................741

7.2.1.22. Valladolid • Colegiata de Santa María ...................................................................................741

7.2.1.23. Laguna de Duero (Valladolid) • Iglesia de la Asunción de Nuestra Señora.............................743

7.2.1.24. Becerril de Campos (Palencia) - Iglesia de Santa Eugenia..........................................................744

7.2.1.25. Valdefinjas (Zamora) • Iglesia de la Asunción de Nuestra Señora...........................................745

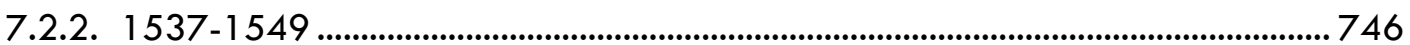

7.2.2.1. Salamanca · Catedral Nueva de la Asunción de la Virgen.....................................................746

7.2.2.2. Plasencia (Cáceres) · Catedral Nueva de Santa María de la Asunción....................................750

7.2.2.3. Santiago de Compostela (A Coruña) · Catedral de Santiago el Mayor .....................................75 1

7.2.2.4. Segovia - Iglesia de San Miguel.........................................................................................................753

7.2.2.5. Tendilla (Guadalajara) - Iglesia (excolegiata) de la Asunción de Nuestra Señora..............754

7.2.2.6. Valladolid • Iglesia de Santa María la Antigua ............................................................................755

7.2.2.7. Mota del Marqués (Valladolid) • Iglesia de San Martín ............................................................756

7.2.2.8. Salamanca P Palacio de Monterrey.....................................................................................................758

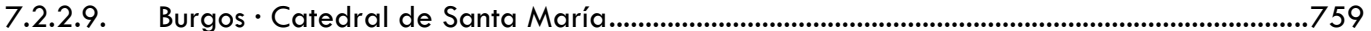

7.2.2.10. Ciudad Rodrigo (Salamanca) · Catedral de Santa María ..........................................................759

7.2.2.11. Salamanca - Colegio Mayor del Arzobispo Fonseca, de Santiago el Zebedeo o de los

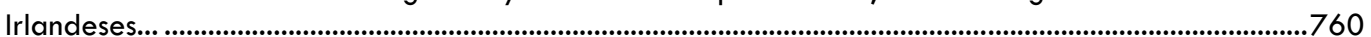

7.2.2.12. Fuente el Saz de Jarama (Madrid) • Iglesia de San Pedro Apóstol ........................................764

7.2.2.13. Meco (Madrid) • Iglesia de la Asunción de Nuestra Señora.........................................................765

7.2.2.1 4. Vegas de Matute (Segovia) - Iglesia de Santo Tomás ..................................................................767

7.2.2.15. Salamanca P Palacio o Casa de la Salina .......................................................................................768

7.2.2.16. Astorga (León) · Catedral de Santa María......................................................................................770

7.2.2.17. Mota del Marqués (Valladolid) · Palacio de los Ulloa..............................................................772

7.2.2.18. Medina de Rioseco (Valladolid) • Iglesia de Santa Cruz .........................................................772

7.2.2.19. Ourense · Catedral de San Martín......................................................................................................773

7.2.2.20. Coslada (Madrid) • Puente de Viveros sobre el río Jarama .....................................................774

7.2.2.21. Toro (Zamora) · Iglesia de San Julián de los Caballeros .........................................................775

7.2.2.22. Castellanos de Villiquera (Salamanca) • Iglesia de San Juan Bautista ...................................776

7.2.2.23. Fuenteguinaldo (Salamanca) · Iglesia de San Juan Bautista .........................................................777

7.2.2.24. Villalobón (Palencia) • Iglesia de la Asunción..........................................................................777

7.2.2.25. Arcediano (Salamanca) • Iglesia de San Miguel Arcángel ..........................................................778

7.2.2.26. Ciguñuela (Valladolid) • Iglesia de San Ginés ..........................................................................779

7.2.2.27. Velilla (Valladolid) • Iglesia de la Asunción de Nuestra Señora.................................................779

7.2.2.28. Tamames (Salamanca) Iglesia de la Asunción..............................................................................780

7.2.2.29. Villasandino (Burgos) • Iglesia de la Asunción de Nuestra Señora .............................................781

7.2.2.30. Cáceres · Iglesia de Santiago de los Caballeros .......................................................................782

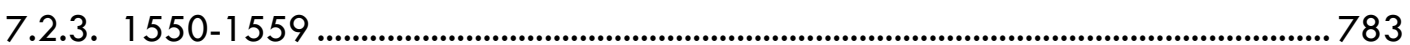

7.2.3.1. Coria (Cáceres) · Catedral de Santa María de la Asunción ..........................................................783

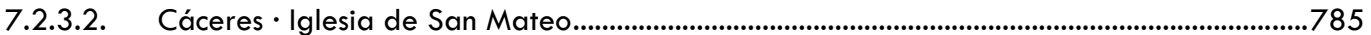

7.2.3.3. Villavieja de Yeltes (Salamanca) · Iglesia de San Pedro Apóstol.............................................786

7.2.3.4. Peñaranda de Duero (Burgos) - Iglesia (excolegiata) de Santa Ana .......................................786

7.2.3.5. Santiago de Compostela (A Coruña) · Hospital de los Reyes Católicos....................................788

7.2.3.6. Salamanca - Monasterio de las Bernardas o del Buen Nombre de Jesús.................................790

7.2.3.7. Salamanca - Colegio Menor de Huérfanos de la Inmaculada Concepción u Hospital de

Nuestra Señora de la Concepción.....................................................................................................................792

7.2.3.8. Salamanca · Convento de las Dueñas o de Santa María ........................................................793

7.2.3.9. Nava del Rey (Valladolid) • Iglesia de los Santos Juanes .......................................................793 
7.2.3.10. Saucelle (Salamanca) • Iglesia de la Purísima Concepción ..........................................................795

7.2.3.11. Ourense Iglesia de la Santísima Trinidad ................................................................................796

7.2.3.12. Ciudad Rodrigo (Salamanca) - Iglesia de San Pedro y San Isidoro .........................................797

7.2.3.13. Garrovillas de Alconétar (Cáceres) • Puente de Alconétar sobre el río Tajo..........................797

7.2.3.14. Valladolid · Ayuntamiento .....................................................................................................................797

7.2.3.15. Salamanca Colegio Menor Trilingüe.........................................................................................798

7.2.3.16. Salamanca · Convento de San Esteban ...............................................................................................799

7.2.3.17. Terrones, Narros de Matalayegua (Salamanca) - Casa-palacio de Francisco Pereira y

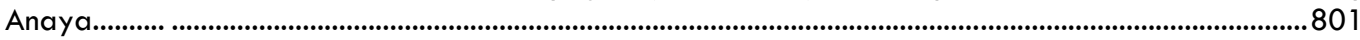

7.2.3.18. Salamanca · Casa-torre de García de Arce o de Villagrán ....................................................801

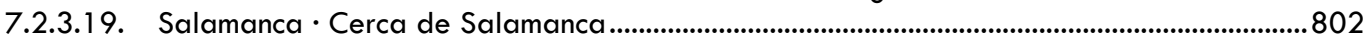

7.2.3.20. León · Catedral de Santa María de Regla .....................................................................................802

7.2.3.21. Salamanca · Convento de la Madre de Dios ..........................................................................803

7.2.3.22. Fontiveros (Ávila) - Iglesia de San Cipriano..........................................................................................803

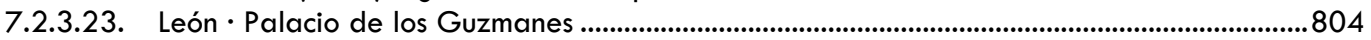

7.2.3.24. Cuacos de Yuste (Cáceres) - Iglesia de Nuestra Señora de la Asunción .....................................805

7.2.3.25. Don Benito (Badajoz) • Iglesia de Santiago Apóstol ....................................................................805

7.2.3.26. Mirabel (Cáceres) - Iglesia de Santa María de la Asunción...........................................................806

7.2.3.27. Trujillo (Cáceres) · Iglesia de Santa María la Mayor ...................................................................806

7.2.3.28. Guareña (Badajoz) • Iglesia de Santa María de la Asunción ....................................................806

7.2.3.29. Salamanca · Colegio Menor de San Millán .............................................................................808

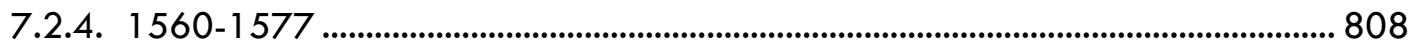

7.2.4.1. Ledesma (Salamanca) - Iglesia de Santa María la Mayor .......................................................808

7.2.4.2. Aldeanueva de Figueroa (Salamanca) • Iglesia de la Asunción .................................................810

7.2.4.3. Carrión de los Condes (Palencia) - Iglesia (excolegiata) de San Andrés ................................810

7.2.4.4. Salamanca · Convento de Santa María de la Vega ................................................................811

7.2.4.5. Medina del Campo (Valladolid) • Reales Carnicerías ..................................................................8 812

7.2.4.6. Toro (Zamora) · Colegiata de Santa María la Mayor ................................................................813

7.2.4.7. San Lorenzo de El Escorial (Madrid) - Real Monasterio de San Lorenzo de El Escorial .......813

7.2.4.8. Toro (Zamora) · Puente Mayor sobre el río Duero .......................................................................813

7.2.4.9. Madrid P Puente de Toledo sobre el río Manzanares...............................................................8 813

7.2.4.10. Madrid P Puente de la Segoviana sobre el río Manzanares.....................................................8 814

7.2.4.11. Madrid • Edificio de las Fuentes del Peral ..............................................................................814

7.2.4.12. Castromocho (Palencia) · Iglesia de San Esteban ...................................................................814

7.2.4.13. Valladolid · Iglesia de Santa María Magdalena ..........................................................................815

7.2.4.14. Salamanca · Colegio de la Orden Militar de Santiago o Colegio del Rey............................817

7.2.4.15. Salamanca · Capilla del Hospital de la Vera Cruz .........................................................................817

7.2.4.16. Valladolid · Monasterio de San Benito el Real............................................................................818

7.2.4.17. Salamanca - Generales de Teología y Cánones de la Universidad de Salamanca.............820

7.2.4.18. Salamanca • Iglesia de San Bartolomé de los Apóstoles ........................................................820

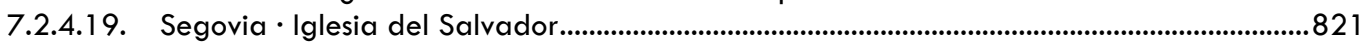

7.2.4.20. Santa Olaja de Eslonza, Gradefes (León) · Monasterio de San Pedro de Eslonza ...............821

7.2.4.21. Boecillo (Valladolid) • Puente sobre el río Duero........................................................................822

7.2.4.22. Segovia Iglesia del Hospital de la Misericordia ...................................................................822

7.2.4.23. Navalcarnero (Madrid) - Puente de la Zarzuela sobre el río Guadarrama ...........................823

7.2.4.24. Oviedo (Asturias) · Catedral de San Salvador ..................................................................................823

7.2.4.25. Villagarcía de Campos (Valladolid) • Iglesia (excolegiata) de San Luis ................................825

7.2.4.26. Oviedo (Asturias) • Universidad de Oviedo........................................................................................826

7.2.4.27. Villafranca del Bierzo (León) · Colegiata de Santa María o de la Asunción.........................827

7.2.4.28. Salamanca · Colegio Menor de San Pelayo .............................................................................828

7.2.4.29. Colmenar Viejo (Madrid) - Capilla de San Francisco de Asís o del alférez Francisco

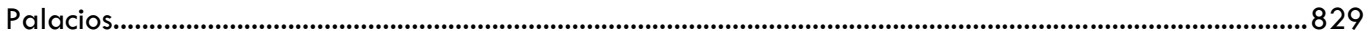

7.2.4.30. Pampliega (Burgos) • Iglesia de San Pedro Apóstol ..................................................................830

7.2.4.31. San Felices de los Gallegos (Salamanca) • Iglesia de Nuestra Señora entre dos Álamos .831

7.2.4.32. Valladolid P Puente Mayor sobre el río Pisuerga ............................................................................. 831

7.2.4.33. Villanueva de Cañedo, Topas (Salamanca) • Ermita de la Virgen de los Remedios .............831

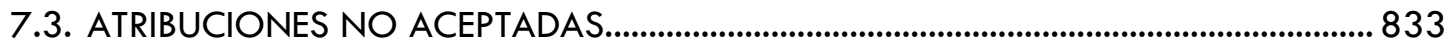

7.3.1.1. Medina de Rioseco (Valladolid) • Convento de San Francisco..................................................835

7.3.1.2. Santiago de Compostela (A Coruña) · Colegio de Fonseca o de Santiago Alfeo .................836

7.3.1.3. Medina del Campo (Valladolid) - Iglesia del convento de Santa María Magdalena .........837

7.3.1.4. Medina del Campo (Valladolid) · Iglesia de Santiago el Real .................................................838

7.3.1.5. Alcalá de Henares (Madrid) · Colegio Menor Trilingüe o de San Jerónimo ............................839

7.3.1.6. Valladolid • Iglesia de San Pedro Apóstol ................................................................................840

7.3.1.7. Támara de Campos (Palencia) • Iglesia de San Hipólito ..............................................................84 1 
8. ANEXO B. BÓVEDAS DE CRUCERÍA: DATOS DE MEDICIÓN ...............................843

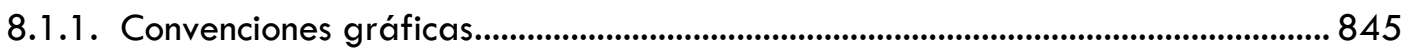

8.1.2. Astorga (León) · Catedral de Santa María ................................................................. 846

8.1.2.1. Bóveda de la capilla de San Juan Bautista (costado sur del falso crucero) ..............................846

8.1.2.2. Bóveda de la antesacristía ........................................................................................................... 847

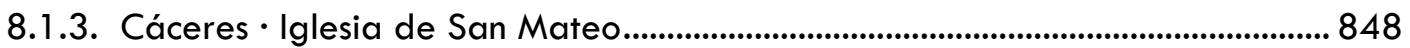

8.1.3.1. Bóveda de la antigua capilla de los Sande (actual sacristía) ...................................................848

8.1.4. Cáceres • Iglesia de Santiago de los Caballeros ....................................................... 849

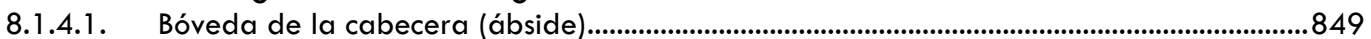

8.1.4.2. Bóveda de la cabecera (presbiterio) ..........................................................................................850

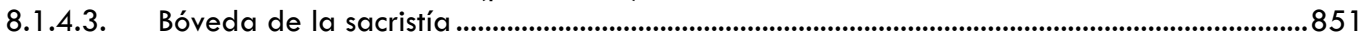

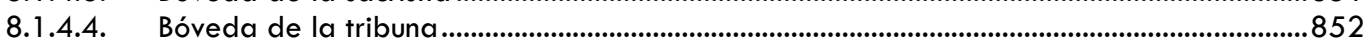

8.1.5. Castellanos de Villiquera (Salamanca) • Iglesia de San Juan Bautista ................ 853

8.1.5.1. Bóveda del cuerpo inferior de la torre ........................................................................................853

8.1.6. Ciudad Rodrigo (Salamanca) · Catedral de Santa María ........................................ 854

8.1.6.1. Bóveda de la cabecera (ábside)....................................................................................................854

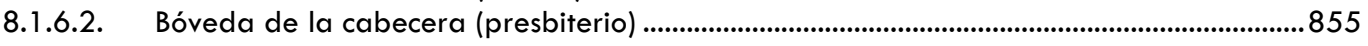

8.1.7. Fontiveros (Ávila) • Iglesia de San Cipriano ...........................................................856

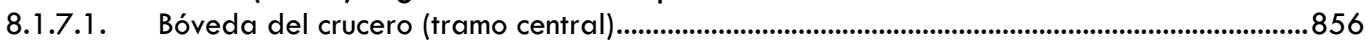

8.1.7.2. Bóveda del crucero (tramo lateral norte) ..........................................................................................857

8.1.8. Fuente el Saz de Jarama (Madrid) • Iglesia de San Pedro Apóstol...................... 858

8.1.8.1. Bóveda de la cabecera......................................................................................................................858

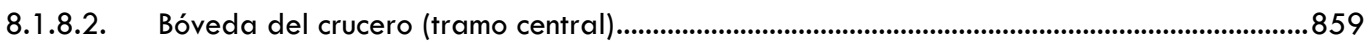

8.1.8.3. Bóveda del crucero (tramo lateral sur).............................................................................................860

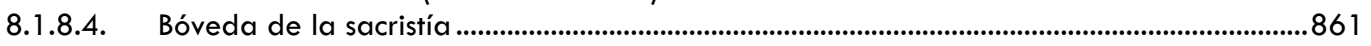

8.1.9. Fuenteguinaldo (Salamanca) · Iglesia de San Juan Bautista ................................ 862

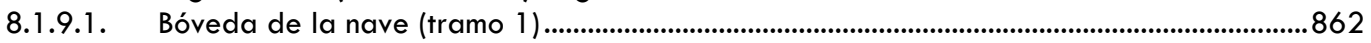

8.1.1 0.Guareña (Badajoz) • Iglesia de Santa María de la Asunción............................... 863

8.1.10.1. Bóveda de la nave (tramo 3) ........................................................................................................863

8.1.1 1.Laguna de Duero (Valladolid) • Iglesia de la Asunción de Nuestra Señora ......864

8.1.1 1.1. Bóveda de la nave central (tramo 3) ..........................................................................................864

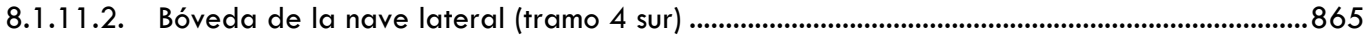

8.1.1 2.Medina de Rioseco (Valladolid) - Iglesia de Santiago de los Caballeros ......... 866

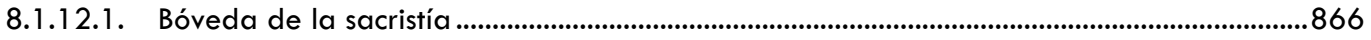

8.1.1 3.Medina del Campo (Valladolid) • Colegiata de San Antolín.................................. 867

8.1.13.1. Bóveda de la nave central (tramo 1) .....................................................................................8. 867

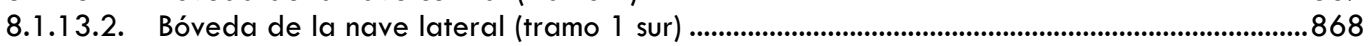

8.1.14. Miraflores de la Sierra (Madrid) - Iglesia de la Asunción de Nuestra Señora 869

8.1.14.1. Bóveda del crucero (tramo central).................................................................................................869

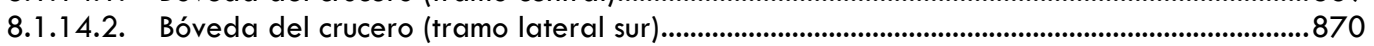

8.1 1 15.Mota del Marqués (Valladolid) • Iglesia de San Martín........................................ 871

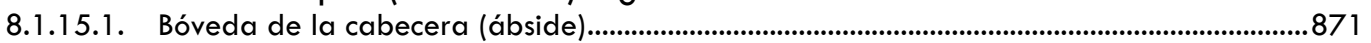

8.1.15.2. Bóveda de la cabecera (presbiterio) ..................................................................................................8. 872

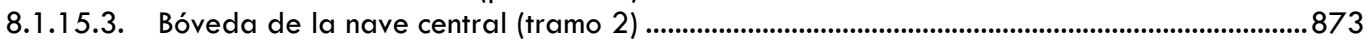

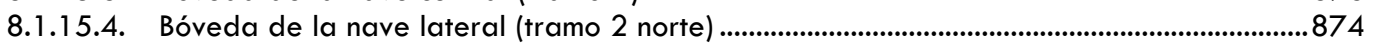

8.1.15.5. Bóveda de la sacristía .........................................................................................................875

8.1.1 6.Nava del Rey (Valladolid) • Iglesia de los Santos Juanes..................................... 8.876

8.1.16.1. Bóveda de la capilla de la Asunción o del canónigo Juan Gil de Nava (cabecera) ............876

8.1.16.2. Bóveda de la capilla de la Asunción o del canónigo Juan Gil de Nava (cuerpo)..................877

8.1.17.Ourense • Catedral de San Martín........................................................................878

8.1.17.1. Bóveda del pórtico del Paraíso (tramo central) .............................................................................878

8.1.17.2. Bóveda del pórtico del Paraíso (tramo lateral norte) ...............................................................879

8.1 1 18. Ourense • Iglesia de la Santísima Trinidad .............................................................. 880

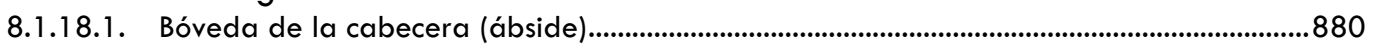

8.1.18.2. Bóveda de la cabecera (presbiterio) .................................................................................................8 881

8.1.1 9.Peñaranda de Duero (Burgos) • Iglesia (excolegiata) de Santa Ana................. 882

8.1.19.1. Bóveda de la cabecera.......................................................................................................................882

8.1.19.2. Bóveda del crucero (tramo central: cimborrio)..........................................................................8 883 
8.1.19.3. Bóveda del crucero (tramo lateral norte) ......................................................................................884

8.1 20.Plasencia (Cáceres) - Catedral Nueva de Santa María de la Asunción ............ 885

8.1.20.1. Bóveda de la nave lateral (tramo 1 norte) ...................................................................................885

8.1.21.Salamanca - Capilla del Colegio Mayor del Arzobispo Fonseca, de Santiago el

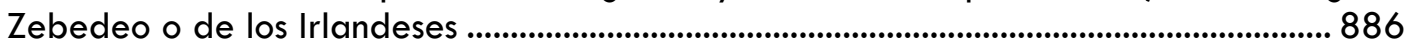

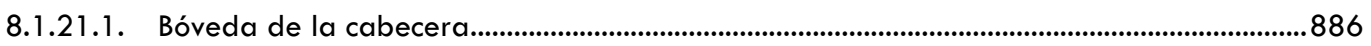

8.1.21.2. Bóveda del crucero (tramo central: cimborrio) .................................................................................88

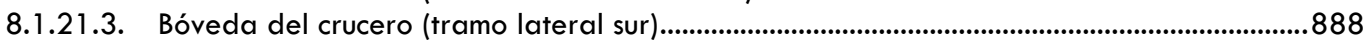

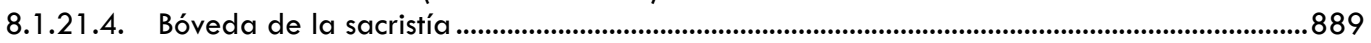

8.1.22.Salamanca · Catedral Nueva de la Asunción de la Virgen ..................................890

8.1.22.1. Bóveda de la nave central (tramo 4) ..................................................................................................890

8.1.22.2. Bóveda de la nave lateral (tramo 2 sur) ................................................................................891

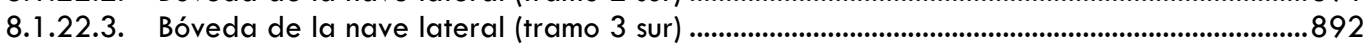

8.1 23.Salamanca • Colegio Menor de San Pelayo ............................................................. 893

8.1.23.1. Bóveda de la capilla ......................................................................................................................893

8.1.24.Salamanca • Iglesia del convento de San Esteban.................................................894 89

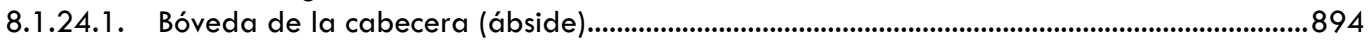

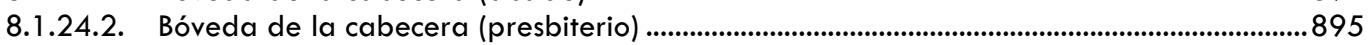

8.1.24.3. Bóveda del crucero (tramo central: cimborrio) .................................................................................896

8.1.24.4. Bóveda del crucero (tramo lateral sur).......................................................................................897

8.1.24.5. Bóveda de la capilla de Santa Teresa o de Limoges (costado norte del presbiterio) .........898

8.1.24.6. Bóveda de la capilla de los Bonal (costado sur del presbiterio) .............................................899

8.1.24.7. Bóveda de la capilla del Rosario o de los Anaya (costado norte del crucero)..........................900

8.1.24.8. Bóveda de la escalera de Soto ..........................................................................................901

8.1.25.Salamanca - Iglesia del monasterio de las Bernardas o del Buen Nombre de Jesús...

902

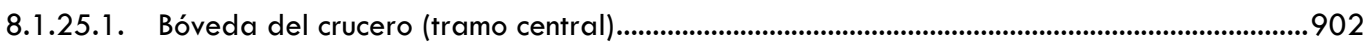

8.1 26.Saucelle (Salamanca) • Iglesia de la Purísima Concepción..................................... 903

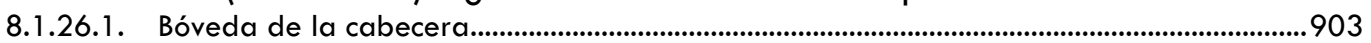

8.1.26.2. Bóveda del crucero (tramo central)..................................................................................................904

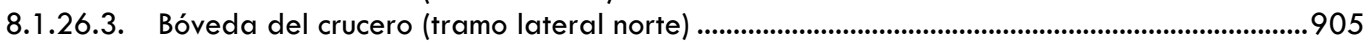

8.1.26.4. Bóveda de la capilla lateral (costado norte de la cabecera) ....................................................906

8.1 27.Segovia · Catedral de Nuestra Señora de la Asunción y San Frutos.................. 907

8.1.27.1. Bóveda de la nave central (tramo 4) .............................................................................................907

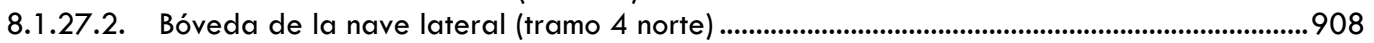

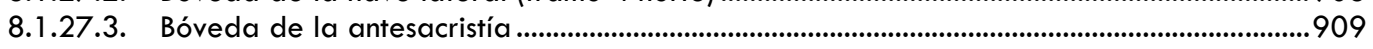

8.1.27.4. Bóveda de la antigua sacristía (actual capilla del Santísimo Sacramento).............................910

8.1.27.5. Bóveda de la capilla de la Piedad o del Santo Entierro (tramo 1 norte) ...................................91 1

8.1.27.6. Bóveda de la capilla de San Cosme y San Damián (tramo 3 norte) .......................................912

8.1.27.7. Bóveda de la capilla de San Gregorio (tramo 4 norte) .........................................................913

8.1.27.8. Bóveda de la capilla de Santa Catalina (cuerpo inferior de la torre) ....................................914

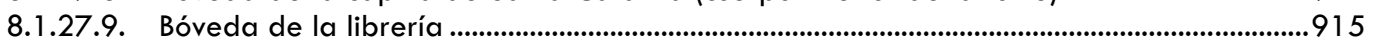

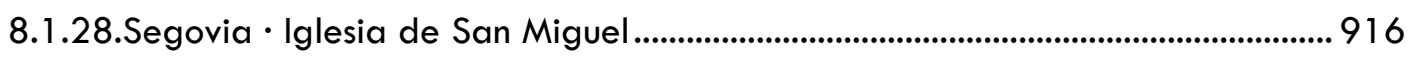

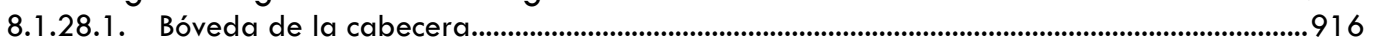

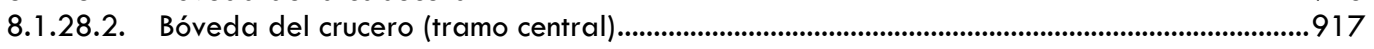

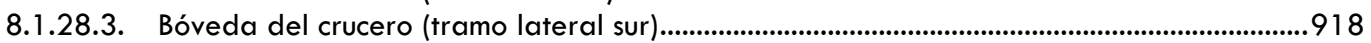

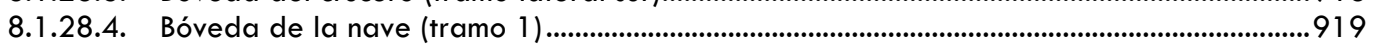

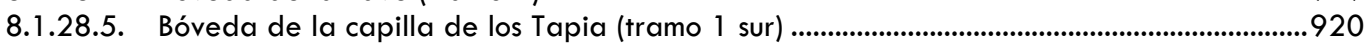

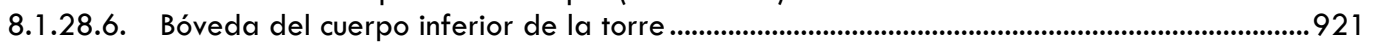

8.1 29.Segovia • Iglesia del Salvador............................................................................. 922

8.1.29.1. Bóveda del crucero (tramo central)...............................................................................................922

8.1 30.Torrelaguna (Madrid) • Iglesia de Santa María Magdalena .............................. 923

8.1.30.1. Bóveda de la capilla de San Gregorio o del inquisidor Gregorio Vélez (cabecera) .........923

8.1.30.2. Bóveda de la capilla de San Gregorio o del inquisidor Gregorio Vélez (cuerpo)...............924

8.1.31.Valladolid • Iglesia de Santa María Magdalena.................................................. 925

8.1.31.1. Bóveda del crucero (tramo central)..........................................................................................925

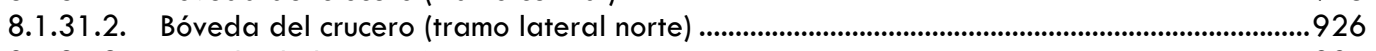

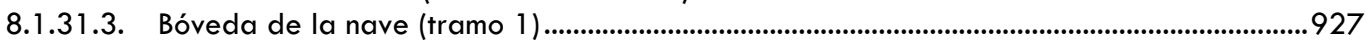

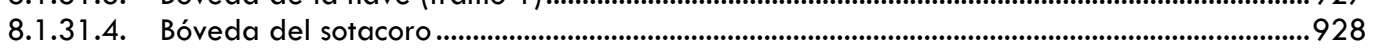

8.1.32.Vegas de Matute (Segovia) • Iglesia de Santo Tomás ........................................... 929

8.1.32.1. Bóveda de la cabecera (ábside)..................................................................................................929 


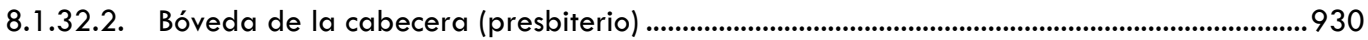

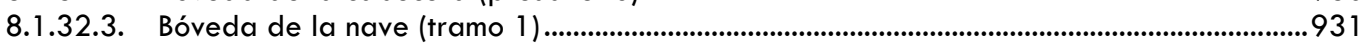

8.1.32.4. Bóveda de la capilla de Santo Tomás o de los Segovia ...........................................................932

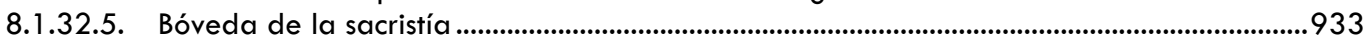

8.1 33. Villacastín (Segovia) • Iglesia de San Sebastián ................................................... 934

8.1.33.1. Bóveda del crucero (tramo central)........................................................................................934

8.1.33.2. Bóveda del crucero (tramo lateral sur)...............................................................................................935

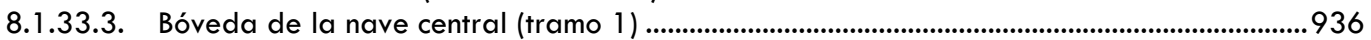

8.1.33.4. Bóveda de la nave lateral (tramo 1 sur) .................................................................................937

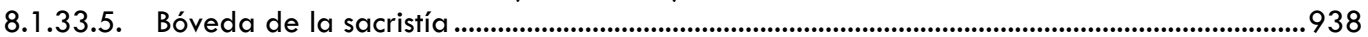

8.1.34.Villamor de los Escuderos (Zamora) - Iglesia de la Asunción de Nuestra

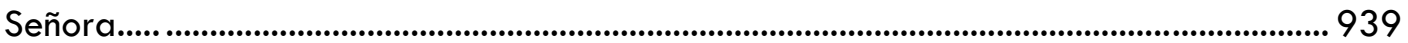

8.1.34.1. Bóveda de la cabecera (presbiterio) ...........................................................................939

8.1.34.2. Bóveda del crucero (tramo central)....................................................................................................940

8.1.34.3. Bóveda del crucero (tramo lateral sur).......................................................................................941

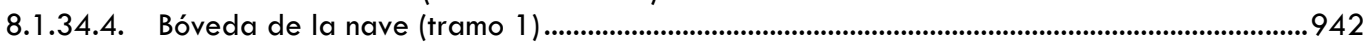

8.1.34.5. Bóveda de la nave (tramo 2) ..........................................................................................................943

8.1.35.Villavieja de Yeltes (Salamanca) • Iglesia de San Pedro Apóstol ....................... 944

8.1.35.1. Bóveda de la cabecera (ábside)..............................................................................................944

8.1.35.2. Bóveda de la cabecera (presbiterio) ............................................................................................945

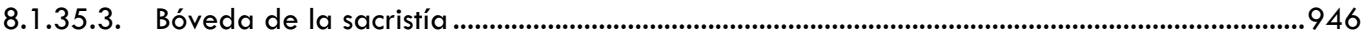

8.1.36.Zamora - Capilla del deán Diego Vázquez de Cepeda en el convento de San

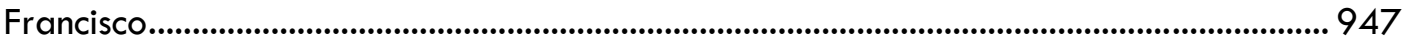

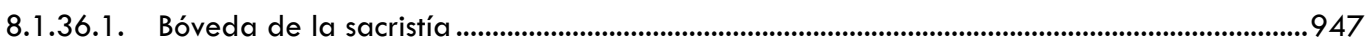

8.1 37.Zamora • Iglesia de San Juan de Puerta Nueva................................................... 948

8.1.37.1. Bóveda de la cabecera (tramo central) .............................................................................948

8.1.37.2. Bóveda de la cabecera (tramo lateral sur) ....................................................................................949

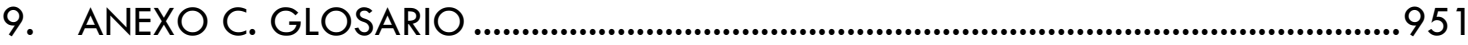

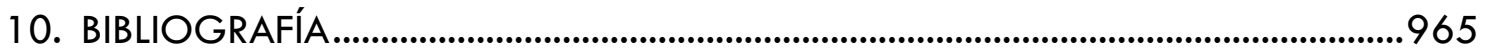

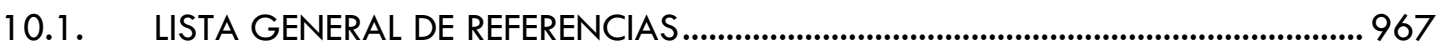

10.2. LISTA DE REFERENCIAS DEL ANEXO A. CATÁLOGO DE OBRAS E

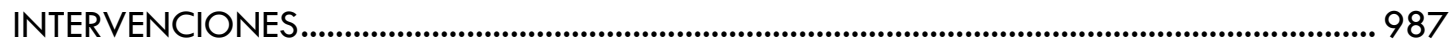

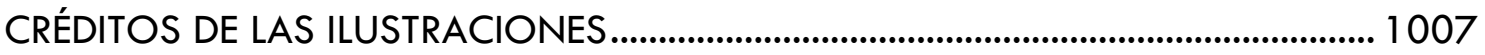





\section{RESUMEN}

Rodrigo Gil de Hontañón (1500-1577) es considerado como uno de los arquitectos españoles más importantes del siglo XVI. Hijo del prestigioso cantero Juan Gil de Hontañón, constituye el último representante de la tradición gótica en nuestro país. Su labor se extendió sobre un vasto territorio de la Corona de Castilla, en el que construyó un sinnúmero de edificios religiosos y civiles. Participó en la construcción de dos de las fábricas más destacadas de su tiempo, las catedrales de Salamanca y Segovia. Por otro lado, es autor del más completo manuscrito sobre construcción gótica existente en Europa. Su figura ha sido objeto de numerosos estudios, referidos fundamentalmente a los aspectos históricos de su obra y, en menor medida, a los de teoría del diseño estructural contenidos en sus textos. Sin embargo, son prácticamente inexistentes los que analizan las prácticas empleadas por este maestro de cantería en el trazado y la construcción de sus edificios.

Los elementos más relevantes en la obra de Rodrigo Gil, desde el punto de vista del corte de piedras, son, sin duda, las bóvedas de crucería. A ellas se dedica la parte principal de la presente Tesis Doctoral, articulándose en dos categorías. La primera de ellas se refiere a las características geométricas de estas estructuras, analizando, por un lado, su modulación, rangos dimensionales y sistemas de composición en planta, y, por otro, el trazado de sus arcos y de su rampante $\circ$ línea de espinazo. La segunda investiga las características constructivas de los elementos que las constituyen, examinando sucesivamente sus nervios, jarjas, claves y plementería. El estudio individual y comparativo de un conjunto de 104 bóvedas, realizado bajo los criterios indicados, ha permitido establecer los procedimientos más habituales de montea y labra empleados por Rodrigo Gil, desvelando que, tras sus elaborados diseños formales, se ocultan unas técnicas bastante restringidas, orientadas a simplificar notablemente el trazado, la ejecución y el montaje, y muy eficaces en sus resultados. La construcción de un modelo a escala 1:3 de una de dichas bóvedas ha puesto de manifiesto algunos de estos recursos.

Junto a los anteriores, otros elementos arquitectónicos de cantería se encuentran también presentes en los edificios de Rodrigo Gil, tales como arcos, capialzados, pechinas, trompas, escaleras y bóvedas diversas. A ellos se reserva un pequeño apartado.

La investigación se ocupa, asimismo, del cuaderno de arquitectura de Rodrigo Gil. Un análisis minucioso ha dado como resultado la identificación de una serie de procedimientos orientados al trazado arquitectónico de un edificio religioso gótico. A continuación se ha seleccionado un conjunto de quince iglesias trazadas por este maestro, a fin de examinar, por una parte, la aplicación práctica de estos criterios de diseño, $y$, por otra, la de algunas de las ya conocidas reglas para el dimensionado estructural.

La comprensión de esta realidad construida se completa con un estudio del contexto histórico y profesional en que Rodrigo Gil desarrolló su actividad, así como una breve reseña histórica de cada uno de los edificios en los que intervino.

Palabras clave: bóvedas de crucería · cantería $\cdot$ diseño arquitectónico $\cdot$ diseño estructural $\cdot$ estereotomía - fábrica de piedra - geometría - Historia de la Construcción - montea • Renacimiento $\cdot$ Rodrigo Gil de Hontañón $\cdot$ siglo XVI $\cdot$ sillería $\cdot$ tardogótico $\cdot$ traza $\cdot$ trazado geométrico. 


\section{ABSTRACT}

Rodrigo Gil de Hontañón: geometric drawing and stonecutting in his work

Rodrigo Gil de Hontañón (1500-1577) is considered one of the most important Spanish architects of the sixteenth century. Son of the prestigious stonemason Juan Gil de Hontañón, he is the last representative of Gothic tradition in Spain. His work expanded over a vast territory of the Crown of Castile, where he built countless religious and civil buildings. He took part in the construction of two of the most noted buildings of his time, the cathedrals of Salamanca and Segovia. Besides, he is the author of the most complete manuscript on Gothic construction in Europe. His figure has been the subject of numerous studies, mainly referring to the historical aspects of his work and, to a lesser extent, to those of structural design theory contained in his texts. However, virtually none of them analyzes the practices used by this master in the design and construction of his buildings.

Ribbed vaults are without a doubt the most relevant elements in the work of Rodrigo Gil, from the point of view of stonecutting. The main part of this Doctoral Thesis is devoted to them, and focuses on two categories. The first one refers to the geometric features of these structures, analyzing, on the one hand, their proportion, dimensional ranges and plan layout, and, on the other hand, the design of their arches and ridge. The second one investigates the constructive features of the elements that make them up, examining successively their ribs, tas-de-charges, bosses and web. The individual and comparative study of a set of 104 vaults, carried out under the specified criteria, has enabled to establish the most usual procedures of drawing and cutting utilized by Rodrigo Gil: the analysis has disclosed that rather limited techniques are hidden behind their elaborate patterns, aimed at considerably simplifying vault drawing, execution and erection, and very effective in their results. The construction of a 1:3 scale model of one of these vaults has brought some of these devices to light.

Along with the aforementioned ones, other architectural stonework elements are also present in the buildings by Rodrigo Gil, such as arches, arrière-voussures, pendentives, squinches, stairs, and varied vaults. A small section is dedicated to them.

Additionally, the research deals with Rodrigo Gil's architectural booklet. A detailed analysis has resulted in the identification of a series of procedures oriented to establish the architectural layout of a Gothic religious building. Next, a set of fifteen churches designed by this master has been selected, in order to examine the application, on the one hand, of these design criteria, and, on the other hand, of some of the well-known rules for structural sizing.

A study of the historical and professional context in which Rodrigo Gil developed his activity, as well as a brief historical review of each of the buildings in which this master took part, is included, for the purpose of complementing the understanding of this architecture.

Keywords: architectural design $\cdot$ ashlar masonry $\cdot$ Construction History $\cdot$ geometric drawing geometry · Late Gothic $\cdot$ Renaissance $\cdot$ ribbed vaults $\cdot$ Rodrigo Gil de Hontañón $\cdot$ sixteenth century $\cdot$ stereotomy $\cdot$ stone masonry $\cdot$ stonecutting $\cdot$ stonework $\cdot$ structural design. 


\section{AGRADECIMIENTOS}

La presente Tesis Doctoral no hubiera sido posible sin la ayuda de varias personas. En primer lugar, quiero expresar mi reconocimiento al profesor José Carlos Palacios Gonzalo, a quien se debe, sin duda, parte de esta investigación. También es preciso recordar a todas aquellas instituciones y particulares que permitieron el acceso y toma de datos en cada uno de los edificios estudiados. Finalmente, agradezco su apoyo incondicional a mis padres, y, por supuesto, a Mercedes. 
L'architecture et la construction du moyen âge ne peuvent se séparer, car cette architecture n'est autre chose qu'une forme commandée par cette construction même. (E. Viollet-le-Duc, Dictionnaire Raisonné de l'Architecture Française du Xle au XVle siècle' ${ }^{1}$.

1 Viollet-le-Duc 1854-1868: vol. IV, 245 (“Construction”) 



\section{INTRODUCCIÓN}



1.1. PRESENTACIÓN DE LA INVESTIGACIÓN 



\subsubsection{Encuadre}

La construcción en piedra ha sido utilizada de modo continuado desde los orígenes de la humanidad hasta bien entrado el siglo XIX. Podemos diferenciar, a grandes rasgos, dos maneras fundamentales de construir en piedra, la cantería y la mampostería, dependiendo de si el material se labra o no para su colocación en obra. A diferencia de la mampostería, la construcción en cantería lleva implícita la definición geométrica previa de las distintas piezas, en cuanto a forma y dimensiones. Esta tarea, designada modernamente como estereotomía, recibía históricamente los nombres de "Trazas de montea" y "Cortes de cantería", que podemos encontrar todavía en 1802 en el Diccionario de arquitectura civil de Benito Bails:

MONTEA. Parte de la Arquitectura que enseña el corte de los sillares para formar una fabrica, sea pared, arco, \&c. ${ }^{2}$.

CORTES DE CANTERÍA. El arte de labrar los sillares y dovelas con arreglo al dibuxo de la fábrica: de manera que viene á ser la segunda parte de la montea ${ }^{3}$.

La cantería utiliza, en líneas generales, dos tipos de elementos labrados, el sillar y la dovela. El primero tiene forma escuadrada, esto es, de ortoedro, y permite la construcción de elementos verticales tales como muros. El segundo tiene forma de cuña, y es utilizado en la generación de arcos y bóvedas. La definición geométrica de los sillares no reviste dificultad alguna, pero no ocurre lo mismo con las dovelas, que requieren de un cuidadoso diseño para que puedan acoplarse y cubrir un espacio. La determinación de su forma y dimensiones se llevaba a cabo a tamaño natural, como nos indican otras dos acepciones ofrecidas por Bails para el término montea:

MONTEA. El dibuxo que se hace de una bóveda de tamaño natural en una pared ó suelo para tomar las medidas y formas de sus diferentes partes ${ }^{4}$.

TRAZAR LA MONTEA DE UN ARCO Ó BÓVEDA ○ MONTEAR. Dibuxarla del mismo tamaño que se ha de fabricar, señalando las dovelas con sus diferentes juntas, caras y lechos, de modo que vengan bien unos con otros, y pueda sacar todas sus dimensiones el Cantero 5 .

Efectivamente, la montea o dibujo a tamaño real permite la obtención de la forma y dimensiones de cada una de las piezas, llevándose a cabo sobre un pavimento o una pared del propio edificio a construir, o cualquier otra superficie plana dispuesta en la obra a tal fin. El traslado de estos datos, variables en función de la complejidad del elemento arquitectónico a ejecutar, se realiza por medio de tres instrumentos fundamentales: la plantilla, el baivel y la saltarregla. La plantilla, también llamada patrón, proporciona el contorno de alguna de las caras de la pieza, recortado en madera o metal, y puede ser rígida o flexible según el caso. El baivel y la saltarregla permiten el traslado de los ángulos que forman entre sí las distintas caras y las curvaturas que presentan estas, estando fabricados en madera: el baivel es una especie de escuadra no articulada, que tiene uno de sus brazos curvos y el otro recto, adaptándose el primero al intradós de la dovela y el

\footnotetext{
2 Bails 1802: 68 .

${ }^{3}$ Bails 1802: 30 .

${ }^{4}$ Bails 1802: 68.

5 Bails 1802: 68 .
} 
segundo a su lecho; la saltarregla es una escuadra falsa que permite transportar ángulos ${ }^{6}$. Como la forma y curvaturas son variables para cada caso concreto, la plantilla y el baivel se deben construir ex profeso, desechándose tras su uso. El sistema descrito impide, por una parte, los errores que se podrían introducir en caso de realizar los trazados a un tamaño menor para luego cambiarlos de escala, y por otra los que se podrían producir durante la ejecución debido a una mala interpretación de estos complejos dibujos ${ }^{7}$.

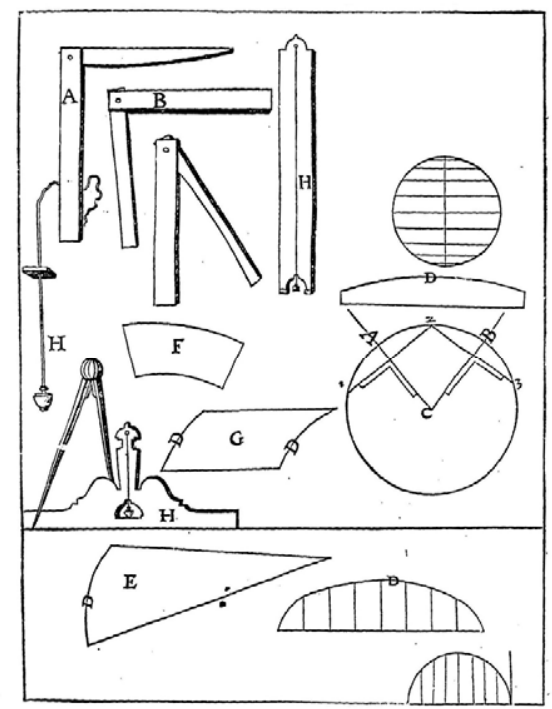

Figura 1. Instrumentos utilizados por los canteros en el siglo XVI, según L'Orme (1567: libro III, cap. IV, il. 56v): A buveau; $B$ sauterelle; C, D cherche r'alongée; $E, F, G$ paneaux; $H$ niveau

Los procedimientos geométricos necesarios para el trazado de la montea permanecieron durante siglos celosamente guardados en el seno de los gremios de origen medieval, comenzando a ser recogidos y divulgados en tratados especializados a mediados del siglo $\mathrm{XVI}$, y experimentando al tiempo una notable evolución. La instrumentación indicada más arriba procede, de hecho, de dicha tratadística. Sin embargo, es evidente que la base de dichos conocimientos arranca de la más profunda Edad Media, siendo la misma que permitió al románico construir sus bóvedas de cañón y esféricas, y más tarde al gótico sus bóvedas de crucería.

Aunque ya durante la segunda mitad del siglo XI se construyeron en Inglaterra bóvedas románicas de nervaduras, es opinión generalizada que el gótico como tal tuvo sus inicios hacia 1140 en la región francesa de Île-de-France, cuando comenzó la construcción a las

\footnotetext{
${ }^{6}$ Alonso de Vandelvira (copia del manuscrito original en Vandelvira [1575-1591] c.1671, edición facsímil en Vandelvira [1575-1591] 1977; otra copia del manuscrito original, con ligeras divergencias, en Vandelvira [1575-1591] 1646) también utiliza el término saltarregla para designar un baivel cuya curvatura se aplica no a toda la superficie de intradós sino a una junta entre piezas (Palacios 2003). Para Philibert de l'Orme tanto el baivel como la saltarregla son articulados (L'Orme 1567: libro III, cap. IV, 54v-57v, il. 56v ("Declaration d'aucuns instruments, desquels les ouvriers s'aydent, à fin q'en lisant les chapitres et discours des traicts, on les puisse mieux entendre"), edición facsímil en L'Orme [1567] 1988).

7 Bails 1802: 14, 43, 83, 94; Palacios 1998: 98-99; Palacios 2003: 16-18; Rabasa 2007b: 237-241 ("Glosario").
} 
afueras de París de la cabecera de la iglesia abacial de Saint-Denis ${ }^{8}$. A partir de ese momento los países de Occidente fueron adoptando progresivamente el nuevo lenguaje artístico, incorporándose la península ibérica a esta corriente hacia finales del siglo XII9. Durante la centuria siguiente, con influencias fundamentalmente de la región de París, comenzó en nuestro país la construcción de edificios significativos como las catedrales de Burgos, Toledo y León ${ }^{10}$. Sin embargo, la crisis de la baja Edad Media tuvo, como en el resto de Europa, importantes repercusiones. A los ciclos de malas cosechas y las continuas sublevaciones nobiliarias, sufridos ya desde comienzos del siglo XIV, se unieron a mediados de la centuria la epidemia de peste negra y el inicio de las guerras civiles. Esta situación, sin duda, dificultó tanto un posible desarrollo regional del estilo como la difusión de los avances producidos en el resto de Europa, y motivó que la arquitectura española permaneciera ligada durante ese periodo a los principios formales y constructivos del gótico clásico francés. Por esta razón, determinados elementos, como las bóvedas de crucería, no experimentaron prácticamente evolución alguna en su configuración: tras el ensayo de algunos modelos iniciales, como las bóvedas denominadas angevinas o anglonormandas y las bóvedas sexpartitas ${ }^{11}$, se asentó en nuestro país el prototipo de bóveda resuelta con un simple cruce de dos arcos diagonales, manteniéndose inalterado durante dos siglos y medio. Esta situación cambió hacia mediados del $X V$, cuando comenzaron a importarse del ámbito centroeuropeo nuevas técnicas y modelos, junto con maestros canteros que las pusieran en práctica $^{12}$.

La renovación del gótico que se produjo en España a partir de entonces alcanzó a distintos aspectos, entre ellos la bóveda de crucería, operándose en ella un importante cambio formal traducido fundamentalmente en la multiplicación de los nervios. A diferencia de lo que ocurre en las bóvedas romanas o renacentistas, se ha indicado ${ }^{13}$ que en las bóvedas de crucería góticas la forma de la superficie generada no es el aspecto más relevante del diseño, ya que queda subordinada a la de los nervios. Esta afirmación es discutible. En las bóvedas carentes de terceletes del gótico clásico la forma de la superficie puede ser, efectivamente, una consecuencia más o menos aleatoria de las curvaturas asignadas a los nervios. Sin embargo, ya tempranamente se aprecia un interés por generar algunas formas concretas, como por ejemplo la bóveda de cañón apuntada, presente en el gótico inglés, con un nervio de ligadura estrictamente horizontal en el sentido de la nave, y en el gótico

\footnotetext{
8 Klein 2004: 28; Toman 2004: 8.

9 Según Frankl (2002: 163) las primeras bóvedas de crucería construidas en España, relacionadas con las normandas, son tal vez las de la cripta y el nártex de la catedral de Santiago de Compostela (A Coruña), levantadas las primeras hacia 1170 por el Maestro Mateo, que se había hecho cargo de la dirección del edificio en 1168. La revisión del texto a cargo de Crossley hace referencia también a otras bóvedas contemporáneas del ámbito cisterciense (monasterio de Santa María la Real de la Oliva, Carcastillo, Navarra: empezada en 1164; monasterio de Santa María la Real de Fitero, Navarra: ábside del coro y capillas del deambulatorio empezados poco después de 1170; Real Monasterio de Santa María de Veruela, Zaragoza: en construcción a principios de la década de 1170; Real Monasterio de Santa María de Santes Creus, Aiguamurcia, Tarragona: empezado en 1174; monasterio de Santa María la Real de Sacramenia, Segovia: década de 1170) (Frankl 2002: 163 Nota 70C).

10 Klein 2004: 100-103.

1 Entre las angevinas podemos señalar las de la Catedral Vieja de Salamanca, la colegiata de Santa María la Mayor en Toro (Zamora) o la catedral de Ciudad Rodrigo (Salamanca). Entre las sexpartitas, las de las catedrales de Ávila, Cuenca y Sigüenza (Guadalajara), o las del monasterio de Santa María la Real de Las Huelgas en Burgos.

12 Gómez 1998: 45-52.

13 Willis $2012: 34$.
} 
alemán, con un diseño en red que prescinde del nervio de ligadura. Del mismo modo, la introducción en España de los terceletes y los nervios decorativos hizo que la forma general de la superficie de la bóveda comenzara a cobrar importancia, persiguiéndose muchas veces la consecución de una forma preconcebida, generada por la nervadura ${ }^{14}$, con un planteamiento cercano en cierto modo al renacentista, caracterizado por el uso de geometrías estrictas. En este sentido el gótico tardío español desarrolló un amplio repertorio de superficies, si bien su naturaleza no es fácilmente perceptible debido a la supremacía visual del nervio ${ }^{15}$.

La construcción de estas complejas estructuras supone la utilización de unos procedimientos geométricos que permiten definir tanto la forma de sus nervaduras, que son las que en definitiva modelan la superficie de la bóveda, como la del resto de sus elementos, esto es, las claves, jarjas (o arranques) y plementería. Estos conocimientos, empleados durante la Edad Media, experimentaron importantes avances en la época, permitiendo resolver cada vez con mayor precisión la relación entre las proyecciones ortogonales, es decir, planta y alzado ${ }^{16}$, y por tanto el trazado y talla de cada una de las piezas. Del mismo modo, la repetición seriada de elementos, característica del gótico, se siguió aprovechando para la construcción de los distintos componentes de la bóveda, y principalmente de los nervios, empleando lo que se ha definido como estandarización, esto es, la simplificación del proceso de construcción de la bóveda llevando a cabo su trazado con un mínimo de curvaturas diferentes, lo que permite homogeneizar las dovelas y cimbras empleadas para la construcción de los $\operatorname{arcos}^{17}$.

El gótico español experimentó un florecimiento desconocido hasta entonces, que se prolongó hasta el último tercio del siglo XVI. Por otro lado, desde comienzos de la centuria se produjo la penetración progresiva del Renacimiento italiano, por lo que ambas corrientes artísticas confluyeron durante ese periodo. La construcción española de la época, como la francesa, continúa la tradición medieval y utiliza de modo generalizado la cantería, a diferencia de lo que ocurre en Italia, donde la arquitectura renacentista hace uso habitual de la albañilería. Por esta razón la introducción del nuevo repertorio de formas esféricas, cilíndricas, cónicas... para las bóvedas clásicas trajo consigo una profunda renovación de la geometría a fin de resolver su trazado, desarrollándose, fundamentalmente en Francia y en España, una moderna estereotomía, y una tratadística que la describía. Hasta ese momento, la cantería gótica resolvía el trazado y la talla de los distintos elementos de un modo relativamente sencillo y sistemático: basándose, como hemos indicado, en la simple correspondencia entre planta y alzado, determinaba la posición y características geométricas tanto de las curvas que representan cada uno de los nervios como de las claves y jarjas con ellos relacionados, procediendo a la talla de cada una de las piezas mediante un corte "por robos". La cantería renacentista, en cambio, concibe un método que parte de la proyección de la dovela sobre un plano tangente a su superficie de intradós, cuya

\footnotetext{
${ }^{14}$ Chueca 1951: cap. V: 111-140.

${ }^{15}$ Se trata de una de las ideas fundamentales que desarrolla Palacios (2009: 15, 17, 76, 117-120) en su investigación.

16 Las representaciones geométricas utilizadas en la época no son propiamente planta y alzado, en el sentido actual de los términos: en el primer caso se trata de una superposición de distintas secciones horizontales, generadas por planos a diversas alturas; en el segundo se trata de los abatimientos correspondientes a los perfiles verticales o elevaciones de cada uno de los elementos, de nuevo superpuestos (Rabasa, Alonso y Pliego 2015: 1399-1401; Ruiz y Rodríguez 2000: 966). Sin embargo, a lo largo de nuestro estudio utilizaremos dicha reducción terminológica.
}

17 Palacios 2009: 18-19, 76, 117-120. 
obtención requiere un desarrollo geométrico más evolucionado que el gótico, y acomete la labra mediante un corte "directo". La codificación del conjunto de técnicas de representación utilizadas para la montea y el corte de piedras daría origen ulteriormente al sistema diédrico, fundado como disciplina por el matemático francés Gaspard Monge a finales del siglo XVIII' ${ }^{18}$.

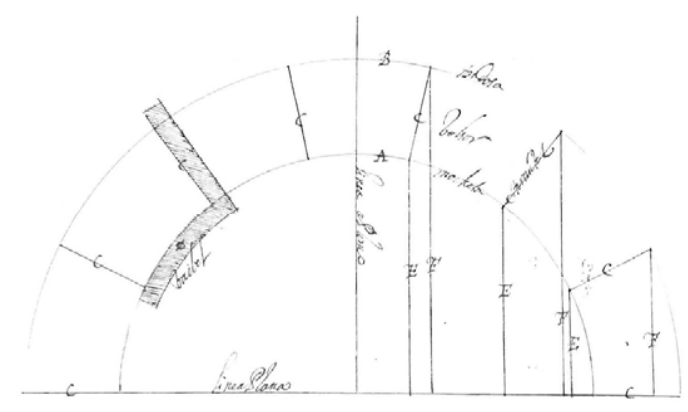

Figura 2. Baivel aplicado al trazado de un arco, según Vandelvira ([1575-1591] c.1671: 4v ("Difiniciones"))

Estos hechos fueron sin duda posibles gracias a dos factores: por un lado, la existencia de una dilatada tradición gótica de construcción en piedra, que permitió la adaptación de las nuevas formas renacentistas a unas técnicas ya en parte conocidas; por otro, la particular situación política y económica de la Corona de Castilla, que fomentaba las nuevas realizaciones arquitectónicas y proporcionaba los recursos necesarios. Varias generaciones de maestros de cantería se encargaron desde mediados del siglo XV de convertir las primitivas bóvedas en cruce de ojivas en las refinadas tracerías elaboradas a lo largo del $\mathrm{XVI}$; ellos fueron también los que adecuaron el lenguaje renacentista a las tradiciones y modos de hacer propios de la Península, desarrollando en los talleres nuevos métodos de trazado.

\subsubsection{Objetivos}

De entre los maestros canteros que renovaron la tradición gótica en España, fundiéndola con elementos renacentistas, destaca la figura de Rodrigo Gil de Hontañón (1500-1577), considerado como uno de los arquitectos españoles más importantes del siglo XVI, y quizás de todos los tiempos ${ }^{19}$. Hijo del prestigioso cantero cántabro Juan Gil de Hontañón (c.14701526), constituye el último representante de la tradición tardogótica ${ }^{20}$. Intervino a lo largo de su carrera profesional en la construcción de un sinnúmero de edificios religiosos y civiles, bien diseñando sus trazas, bien contratando la dirección y ejecución de sus obras, bien ambas cosas simultáneamente. Entre ellos encontramos algunos de considerable importancia,

\footnotetext{
18 Palacios 1998: 97-98; Palacios 2003: 14-16; Palacios 2009: 18, 233-235; Rabasa 2007a: 746-748; Rabasa 2007b: 227.

${ }^{19}$ AAVV 2003b: 9; Camón 1941b: 305; Chueca 1951: 141-144, 245-248; Chueca 2001: vol. II, 83-84, 8687; Huerta 2002: 574; Huerta 2006: 24-25; Lozoya 1931-1949: vol. III, 475; Lozoya 1952: 521 -522; Lozoya 1962: 10; Martín 2000: 12; Morena 2000: 38; Palacios 2006: 2415, 2427-2429; Pereda 1951: XXXIX-XL, CCXLIII.

20 Gómez 1998: 51 ; Hoag 1985: 213, 215-218.
} 
como la Catedral Nueva de Salamanca, la catedral de Segovia, el palacio de Monterrey en Salamanca o el Colegio Mayor de San Ildefonso en Alcalá de Henares (Madrid), pero también multitud de edificios menores.

El conjunto de conocimientos, herramientas geométricas y técnicas constructivas que Rodrigo Gil pudo asimilar durante los años en que trabajó como ayudante a las órdenes de su padre se vio completado a la muerte de este con otro legado igualmente importante: su posición y prestigio como maestro de cantería, un complejo entramado de relaciones en el hermético mundo del trabajo de la piedra y en el de los potenciales clientes, y un área de influencia en la que mantener un cierto control sobre los encargos profesionales ${ }^{21}$. Todo ello, unido a su asombrosa capacidad de trabajo, hizo que se convirtiera en el arquitecto más prolífico y versátil del siglo $\mathrm{XVI}$ en España ${ }^{22}$, desarrollando su labor en un ámbito geográfico considerablemente amplio, que abarca fundamentalmente la zona septentrional de la Corona de Castilla. Aunque no intervino en la actual Andalucía, y no se tiene constancia de actividad alguna en la Corona de Aragón, el desarrollo de la arquitectura en España durante los cincuenta años centrales del siglo XVI no puede entenderse sin la personalidad dominante de Rodrigo $\mathrm{Gi}^{23}$.

La dispersión de los edificios cuya construcción tenía al cargo, unida a la realización esporádica de informes, peritaciones y tasaciones relativos al proyecto o la marcha de la construcción de obras ajenas, obligaba a Rodrigo Gil a continuos desplazamientos que le impedían atender adecuadamente sus responsabilidades. Para solventar este problema supo rodearse de un amplio taller, compuesto tanto por aparejadores como por canteros, que atendieran la marcha cotidiana de los trabajos y llevaran a buen término cada una de las obras ${ }^{24}$. Estos mismos colaboradores trabajarían en otras ocasiones de modo independiente, construyendo numerosos edificios a semejanza de aquellos levantados junto a Rodrigo $\mathrm{Gi}^{25}$, quien, al final de su vida, tenía la conciencia de haber creado de algún modo una escuela en torno a su figura ${ }^{26}$.

Desde el punto de vista teórico, Rodrigo Gil constituye uno de los escasos ejemplos de maestro de tradición gótica que abordó la redacción de un cuaderno que recogiera los conocimientos adquiridos en el ejercicio de su profesión, ya fuera para su propio uso o para la transmisión de esos saberes a sus discípulos. El texto, parte de cuyo contenido pudo haber sido elaborado ya por su padre ${ }^{27}$, pasó quizá a la muerte de Rodrigo Gil a manos de Juan del Ribero Rada, y de él al archivo de la fábrica de la Catedral Nueva de Salamanca, terminando finalmente en las de Simón García, quien lo insertó entre 1681 y 1683 en su manuscrito titulado Compendio de Architectura y simetría de los templos ${ }^{28}$. Trata de modo sistemático los distintos procedimientos de diseño, tanto arquitectónico como estructural, de un edificio religioso de tradición gótica, y constituye, junto con el tratado del cantero

\footnotetext{
${ }^{21}$ Redondo 2003: 20.

22 Sanabria [1982] 1999: [282-283] 2-3.

23 Gómez 1998: 51; Redondo 2003: 15-17.

${ }^{24}$ Agapito 1922: 152; Pereda 1951: XLIII-XLVI; Sendín 1977: 192-193; Redondo 2003: 15-17.

25 Aramburu-Zabala 2003: 99-100.

26 Castro 1997: 50 doc. IV.

27 Casaseca 1988: 13-14, 91; Gómez 1998: 24-25, 51, 169.

28 García 1681, edición facsímil y transcripción paleográfica en García [1681] 1991. En lo sucesivo utilizaremos en muchas ocasiones el término Compendio como título abreviado para referirnos a García 1681.
} 
mallorquín Joseph Gelabert, el único texto de origen medieval conocido en Europa que explica el proceso de construcción y montaje de una bóveda de crucería ${ }^{29}$.

La figura de Rodrigo Gil ha sido objeto de numerosos estudios, referidos fundamentalmente a los aspectos históricos de su obra y, en menor medida, a los de teoría del diseño estructural contenidos en sus textos. Sin embargo, son prácticamente inexistentes los que analizan las prácticas empleadas por este maestro de cantería en el trazado y la construcción de sus edificios. La presente Tesis Doctoral tiene, por ello, dos objetivos fundamentales. El primero consiste en la determinación de las herramientas geométricas y de las técnicas constructivas empleadas por Rodrigo Gil y su taller para acometer el diseño y la ejecución de los distintos elementos de cantería presentes en sus edificios, tales como arcos, capialzados, bóvedas, pechinas, trompas y escaleras. El segundo persigue, por un lado, la identificación de las distintas reglas de trazado recogidas en su cuaderno de arquitectura, $y$, por otro, el análisis de su aplicación práctica en los edificios diseñados por este maestro.

Los objetivos de nuestra investigación hacen que se enmarque globalmente dentro del campo de la Historia de la Construcción. Este enfoque racionalista en el estudio de la historia de la arquitectura tiene como principal precursor a Robert Willis ${ }^{30}$, cuya obra más conocida, On the Construction of the Vaults of the Middle Ages (La construcción de las bóvedas en la Edad Media) ${ }^{31}$, abrió en 1842 toda una nueva rama de estudio, planteando por primera vez el análisis de los propios edificios. El citado artículo constituye un estudio pormenorizado acerca de algunas bóvedas góticas inglesas, con la finalidad de establecer los procedimientos utilizados en su trazado geométrico y construcción. Aplicando el método científico, realiza una separación consciente entre los datos de las mediciones, recogidos en forma de tablas, y el proceso de análisis y planteamiento de hipótesis, permaneciendo todavía hoy como un modelo de precisión y rigurosidad. Sus valoraciones, por otro lado, se centran fundamentalmente en los aspectos constructivos, y dejan a un lado tanto los aspectos estructurales, considerados secundarios, como los decorativos, propios de la Historia del Arte.

Siguiendo un procedimiento análogo, la presente Tesis Doctoral se ha basado primordialmente en el estudio directo de las construcciones, complementándolo con el análisis del cuaderno de arquitectura atribuido a Rodrigo Gil. Los distintos edificios y elementos de cantería susceptibles de análisis se han discriminado atendiendo tanto a la propia realidad material como a razones históricas, proporcionadas por la bibliografía. Se ha desarrollado un trabajo de campo sobre los ejemplares seleccionados, recogiendo, de modo riguroso y sistemático, datos dimensionales y fotografías, tras el cual se ha llevado a cabo una restitución gráfica de algunos de ellos. Paralelamente, se ha investigado el contenido del manuscrito de Rodrigo Gil. El estudio individual y comparativo de los especímenes elegidos, la confrontación con los procedimientos de diseño recogidos en el manuscrito y la construcción de un modelo a escala 1:3 de una de las bóvedas de crucería analizadas ha permitido la identificación de las técnicas geométricas y constructivas más relevantes empleadas por este maestro. Esperamos que la investigación sirva para

${ }^{29}$ García 1681: cap. 6: 24r-25v, ilustración 25r; Gelabert [1653] 1977, Gelabert [1653] 201 1; Huerta 2013 : 108-109; Palacios 2006: 2420; Palacios 2009: 89; Rabasa 2007a: 748-749.

${ }^{30}$ Albuerne 2007: 11 ; Huerta 2009: xv-xvii.

31 Willis 1842, Willis [1842] 1910; traducción española en Willis 2012. 
profundizar en el conocimiento de una de las etapas más destacadas de la historia de nuestra arquitectura.

\subsubsection{Estado del arte}

\subsubsection{Aspectos historiográficos}

Existen amplios estudios relativos a los aspectos biográficos, históricos y estilísticos de la figura y la obra de Rodrigo Gil, como ya hemos avanzado. El primer análisis en profundidad sobre este maestro fue realizado por Manuel Pereda de la Reguera en 1951 (Pereda 1951), ofreciendo sin embargo una visión demasiado tradicional y en este momento desfasada. A este trabajo le siguió la Tesis Doctoral elaborada por John Douglas Hoag en 1958 (Hoag [1958] 1999), que presenta un enfoque mucho más actual y crítico, alejado de la historiografía española del momento, y que fue revisada por su autor en 1985 (Hoag 1985). Finalmente, la Tesis Doctoral redactada por Antonio Casaseca Casaseca en 1986 (Casaseca 1986) y publicada parcialmente en 1988 (Casaseca 1988) supone el estudio más reciente y definitivo y destaca por su minuciosidad y extensión.

Pese a la rotundidad de esta última monografía, desarrollada originalmente en seis volúmenes, nuevos enfoques siguen despertando el interés de los investigadores, como demuestra la celebración en el año 2000 tanto de un congreso como de una exposición acerca de Rodrigo Gil con motivo del quinto centenario de su nacimiento. El catálogo de la muestra (AAVV 2000) presenta cuatro contribuciones a cargo de distintos autores (Casaseca 2000; Martín 2000; Morena 2000; Ruiz 2000), que, sin embargo, no aportan grandes novedades con respecto a lo conocido hasta ese momento. Sin embargo, el congreso, cuyas actas fueron publicadas tres años después de su celebración (AAVV 2003b), presenta un conjunto más amplio y relevante de ponencias y comunicaciones, que indagan acerca de distintos aspectos, como el entorno profesional en el que se desenvuelve la actividad de Rodrigo Gil (Aramburu-Zabala 2003; Castro 2003a; Redondo 2003), o la visión que de su figura ha tenido la historiografía española a lo largo de las distintas épocas (Crespo 2003a).

Desde el punto de vista de nuestra investigación, una adecuada comprensión de la obra de Hontañón requiere, indudablemente, de un conocimiento tanto de su figura como del contexto en el que se desarrolla su actividad; por esta razón hemos incluido en la presente Tesis Doctoral un apartado inicial que aclara los distintos aspectos biográficos, históricos y profesionales relativos a este maestro, reuniendo las principales aportaciones que sobre estos campos han realizado los autores citados, así como otros estudiosos de la Historia del Arte y de la Arquitectura.

Por otro lado, el examen de los datos históricos relativos a cada una de las obras construidas por Rodrigo Gil es igualmente necesario para el desarrollo de nuestro estudio. Este análisis toma como punto de partida la Tesis Doctoral de Casaseca (Casaseca 1986, Casaseca 1988), quien, a través de su exhaustiva investigación, establece el catálogo de las obras en las que intervino Hontañón. Sin embargo, dada la amplitud de la obra desarrollada por este maestro, multitud de autores, consignados en la bibliografía, ofrecen igualmente otras informaciones que completan los datos ofrecidos por Casaseca. 


\subsubsection{El manuscrito}

Como hemos indicado, el cuaderno de arquitectura atribuido a Rodrigo Gil fue recogido, al menos parcialmente, y reelaborado entre 1681 y 1683 por Simón García (García 1681). Ha sido publicado sucesivamente por Eduardo de Mariátegui (García [1681] 1868), José Camón (García [1681] 1941) y Manuel Pereda de la Reguera (García [1681] 1951), y las ediciones más actuales se deben a Antonio Bonet Correa y Carlos Chanfón Olmos (García [1681] 1979, García [1681] 1991).

Los estudios críticos realizados por estos investigadores, entre los que podemos destacar los que corresponden a Bonet (1991) y Chanfón (Chanfón 1991a, Chanfón 1991b), se han centrado fundamentalmente en los aspectos históricos del texto, tales como sus problemas de autoría, su posible origen, su relación con la tratadística del momento, o la doble naturaleza, geométrica y antropométrica, de las distintas reglas de diseño en él contenidas. A ellos podemos sumar el análisis realizado por John Douglas Hoag en su Tesis Doctoral (Hoag [1958] 1999: 403-459), que fue eliminado de la edición revisada de dicha Tesis (Hoag 1985); y también los breves estudios elaborados por Javier Gómez Martínez (Gómez 1998: 20-25) y Áurea de la Morena Bartolomé (Morena 2000). Uno de los aspectos en los que más se han detenido los investigadores es el de los métodos geométricos para el trazado arquitectónico de la planta que se recogen en el manuscrito, comprobando su aplicación, aunque de modo aislado, en algunos edificios construidos por Rodrigo $\mathrm{Gi}^{32}$. No obstante, en el texto pueden rastrearse muchas otras reglas para el trazado arquitectónico que no han sido todavía ni identificadas ni analizadas.

Por otra parte, en el manuscrito se proporcionan una serie de métodos para el dimensionado de distintos elementos estructurales del edificio gótico, cuyo estudio fue iniciado por George Kubler (Kubler 1944) y Hoag ([1958] 1999: 426-443). Entre ellos encontramos una regla aritmética para el cálculo de los pilares para bóvedas de crucería, así como otras dos para los estribos o contrafuertes, que han sido investigadas por Sergio Luis Sanabria (Sanabria [1982] 1999) y Santiago Huerta Fernández (Huerta 2002, Huerta 2006). Se han identificado también tres reglas geométricas para el cálculo de los estribos o contrafuertes para arcos semicirculares, así como una regla aritmética válida para el mismo problema estructural, que han sido estudiadas con detalle por Sanabria ([1982] 1999). Las reglas aritméticas para el cálculo de las torres y para el dimensionado de los nervios y claves de una bóveda de crucería han sido investigadas por Huerta (Huerta 2002, Huerta 2006, Huerta 2013). Sin embargo, a pesar del interés que ha despertado el estudio teórico de todos estos métodos de diseño, son prácticamente inexistentes los análisis de su aplicación práctica en los edificios trazados por Rodrigo $\mathrm{Gi}^{33}$.

Por último, la sección del texto en la que se describe el método a seguir para la construcción y montaje de una bóveda de crucería fue analizada por Hoag ([1958] 1999: 439-450), y más recientemente por Huerta (2013). Tanto estos autores como Gómez (1998: 124-130) ○

\footnotetext{
32 Los métodos geométricos para el trazado arquitectónico de la planta han sido aplicados a los siguientes edificios: iglesia de San Pedro Apóstol en Fuente el Saz de Jarama (Madrid) y de la Asunción de Nuestra Señora en Meco (Madrid) (Morena 1972: fig. 3, fig. 6); iglesia de San Martín en Mota del Marqués (Valladolid) (Casaseca 1988: 70-74; Martín, Cámara y Murillo 2013: 624-626); iglesia del monasterio de las Bernardas en Salamanca (Camón 1941 b: 302-303); colegiata de Santa María en Valladolid (Chueca [1947] 1998: 89-96); iglesia de San Sebastián en Villacastín (Segovia) (Casaseca 1988: 70-74).

33 Los métodos para el dimensionado estructural han sido aplicados a los siguientes edificios: iglesia de San Martín en Mota del Marqués (Valladolid) (Martín, Cámara y Murillo 2013: 626-628); iglesia de la Asunción de Nuestra Señora en Villamor de los Escuderos (Zamora) (Sanabria 2003: 1797-1799).
} 
José Carlos Palacios Gonzalo (Palacios 2009: 89-91) han dedicado largas reflexiones a la forma de la línea de espinazo de la bóveda descrita en el manuscrito. Sin embargo, el análisis de dicha forma en las bóvedas construidas por Rodrigo Gil únicamente ha sido llevado a cabo por Palacios en los casos aislados que se citan más adelante. Por otro lado, dos estudios recientes, a cargo de David Wendland y María José Ventas Sierra (Wendland 2013; Wendland y Ventas 2010), no han podido ser consultados.

De lo expuesto podemos deducir que no parece existir un análisis completo de los distintos métodos para el trazado arquitectónico recogidos en el texto, debido fundamentalmente a la falta de coherencia que presentan los contenidos originales del cuaderno en su estado actual, y a la gran dificultad que esto produce en la identificación e interpretación de los citados métodos. Por ello parece indicado, como ya señaló Casaseca ${ }^{34}$, realizar este estudio sobre el manuscrito. Por otra parte, en los edificios examinados existe una práctica identidad entre estructura, cerramiento y acabado. Por esta razón, y a pesar de que los métodos para el dimensionado estructural han sido ampliamente investigados, se hace prácticamente ineludible considerarlos en la presente Tesis Doctoral, ya que, si los obviáramos, estaríamos dejando a un lado una parte fundamental de un proceso de diseño en el que los distintos aspectos son interdependientes. Además, consideramos de gran interés la aplicación de los procedimientos de diseño arquitectónico y estructural descritos en el texto a algunos de los edificios trazados por Rodrigo Gil, a fin de determinar el nivel de correspondencia entre teoría y praxis, algo que, como hemos indicado, solo se ha realizado de modo aislado para algunos edificios y reglas. Por lo que respecta al método descrito en el manuscrito para la construcción y montaje de una bóveda de crucería, su análisis es especialmente relevante a fin de poder compararlo con los procedimientos encontrados en las bóvedas diseñadas por Hontañón.

En todo caso, únicamente realizando un estudio completo del conjunto del manuscrito atribuido a Rodrigo Gil es posible ofrecer una visión coherente del mismo, y superar tanto el estado fragmentario del texto original como el carácter independiente de las distintas investigaciones existentes. Por esta razón, las aportaciones realizadas por los autores indicados han sido incluidas en los apartados de esta Tesis Doctoral referidos al análisis del manuscrito.

\subsubsection{Los elementos de cantería}

El primer autor que abordó el análisis geométrico y constructivo de un elemento de cantería diseñado por Rodrigo Gil fue Fernando Chueca Goitia, quien, en su monografía sobre la Catedral Nueva de Salamanca, dedicó un apartado a las bóvedas de la nave central (Chueca 1951: 111-140), observando ya entonces el interés de un estudio relativo al trazado y construcción de las bóvedas españolas de los siglos XV y XVI. José Miguel Merino de Cáceres realizó, bastante tiempo después, un concienzudo trabajo acerca del trazado geométrico de la catedral de Segovia, incluyendo en él unas breves observaciones acerca del diseño de las bóvedas de la nave central, naves laterales y capillas hornacinas (Merino 1991: 14). No fue hasta la primera década del presente siglo cuando José Carlos Palacios Gonzalo acometió la ingente labor de analizar de modo sistemático un conjunto de bóvedas construidas en el último gótico español, entre las que encontramos algunas diseñadas por Rodrigo Gil (Palacios 2006; Palacios 2009: 122-127, 167-171, 201-203, 229-232):

\footnotetext{
34 Casaseca 1988: 13-14.
} 
- Capillas de los costados del falso crucero de la catedral de Astorga (León).

- Nave central de la iglesia de San Martín en Mota del Marqués (Valladolid).

- Nave central y tramos 2 y 4 de las naves laterales de la Catedral Nueva de Salamanca.

- Nave central y antigua sacristía de la catedral de Segovia.
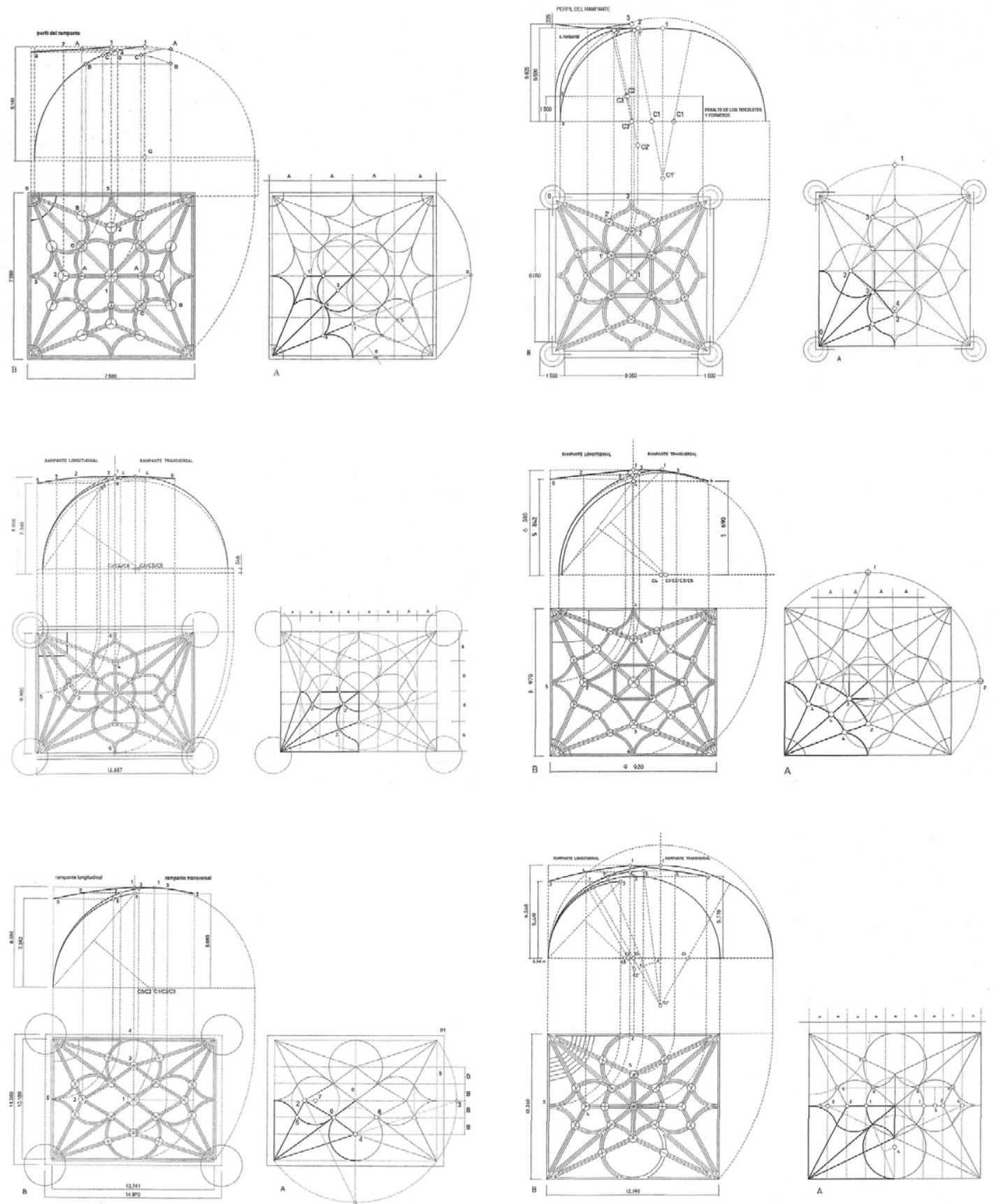

Figura 3. Análisis geométrico de algunas bóvedas de crucería trazadas por Rodrigo Gil, según Palacios (2009: 123 fig. 48, 126 fig. 50, 167 fig. 98, 169 fig. 100, 201 fig. 137, 231 fig. 175): (a) Capillas de los costados del falso crucero de la catedral de Astorga (León). (b) Nave central de la iglesia de San Martín, Mota del Marqués (Valladolid). (c, d) Nave central y tramos 2 y 4 de las naves laterales de la Catedral Nueva de Salamanca. (e, f) Nave central y antigua sacristía de la catedral de Segovia 
En todo caso, es tal la envergadura de la obra realizada por Hontañón que multitud de elementos de cantería, ya sean bóvedas de crucería u otros distintos, continúan aún desconocidos desde el punto de vista geométrico y constructivo, justificando, como ya observó en su momento Hoag ${ }^{35}$, la oportunidad de la presente Tesis Doctoral. Por otro lado, los estudios citados, referidos a determinadas bóvedas de crucería, presentan algunas discrepancias con los realizados por nosotros, que se recogen, para mayor claridad, en los apartados de nuestra investigación referidos al análisis individual de cada una de las bóvedas indicadas.

Para el estudio de los distintos elementos de cantería se hace imprescindible la consulta de las diversas publicaciones existentes acerca de la construcción en piedra, que quedan recogidas en la bibliografía de la presente Tesis Doctoral, y entre las que podemos sin duda destacar, en el ámbito nacional, las realizadas por José Carlos Palacios Gonzalo y Enrique Rabasa Díaz. Ambos han analizado la configuración geométrica y constructiva de las bóvedas de crucería tardogóticas españolas (Palacios 2009; Rabasa 1996), así como la de otros elementos pétreos de naturaleza diversa (Palacios 2003; Rabasa 2000), sin olvidar la puesta en práctica de las distintas técnicas y procedimientos de trazado y talla (Palacios et al. 2015; Rabasa 2007b). Por otra parte, la investigación de Javier Gómez Martínez (Gómez 1998) acerca de las bóvedas de crucería españolas, llevada a cabo desde el punto de vista de la historia del arte, aporta datos de gran relevancia para la comprensión no solo del contexto histórico en que se producen estas estructuras, sino también de sus procesos de generación geométrica y ejecución.

\subsubsection{Contexto investigador}

La Historia de la Construcción, en la que, como hemos comentado, se encuadra nuestra investigación, ha comenzado a perfilarse como disciplina independiente tan solo en los últimos treinta años. Al mencionado estudio de Robert Willis le siguieron en la segunda mitad del siglo XIX el célebre Dictionnaire Raisonné de l'Architecture Française du Xle au XVle siècle, publicado por Eugène-Emmanuel Viollet-le-Duc entre 1854 y $1868^{36}$, también dedicado a la arquitectura gótica, y la igualmente conocida Histoire de l'Architecture de François-Auguste Choisy, editada en 189937, primera obra que abarca de modo global las distintas formas de construir a lo largo de la historia. Este interés por la construcción histórica, que desapareció con la eclosión del movimiento moderno en arquitectura, surgió de nuevo en los años cincuenta de la pasada centuria, y se ha visto reforzado a partir de la década de los ochenta, iniciándose gradualmente la constitución de distintas sociedades nacionales de Historia de la Construcción y la organización de congresos especializados ${ }^{38}$.

La construcción en cantería, de importancia fundamental durante siglos, empezó a ser desplazada del panorama arquitectónico a mediados del siglo XIX debido a la aparición de nuevos materiales, como el hierro fundido, el hormigón armado y el acero, hasta quedar relegada a una posición marginal durante el siglo pasado. Afortunadamente, el conocimiento de sus métodos de trazado y ejecución, fundamental para comprender nuestro patrimonio construido, despierta en la actualidad un interés creciente, como demuestra la

\footnotetext{
35 Hoag 1985: 15.

36 Viollet-le-Duc 1854-1868.

37 Choisy 1899, edición facsímil en Choisy [1899] 1991.

38 Huerta 2009: xiii, xv-xvii.
} 
existencia de un número relevante de investigadores y publicaciones dedicados a este campo, dentro de la citada corriente de análisis de la construcción histórica ${ }^{39}$. En nuestro país podemos destacar los estudios desarrollados en el ámbito de la Universidad Politécnica de Madrid (José Carlos Palacios Gonzalo y Enrique Rabasa Díaz), la Universidad de Sevilla (Juan Carlos Gómez de Cózar, Alfonso Jiménez Martín, Francisco Pinto Puerto, Juan Clemente Rodríguez Estévez y José Antonio Ruiz de la Rosa), la Universitat de València (Juan Carlos Navarro Fajardo y Arturo Zaragozá Catalán), la Politécnica de Cartagena (José Calvo López) y la Universidade de Santiago de Compostela (Miguel Taín Guzmán). Son especialmente reseñables las experiencias docentes iniciadas por Palacios y Rabasa bajo la forma de talleres de formación a nivel académico ${ }^{40}$. Fuera de nuestro país, un buen número de estudiosos se concentran en el sur de Italia (Marco Rosario Nobile, Università degli Studi di Palermo; María Mercedes Bares, Università degli Studi di Catania; Giuseppe Fallacara y Claudio D'Amato, Politecnico di Bari), si bien son igualmente reseñables las investigaciones realizadas en Alemania, Portugal, México y Estados Unidos (David Wendland, Technische Universität Dresden; Soraya Genin, Universidade Técnica de Lisboa; Marisol Ordaz, Universidad Autónoma de Yucatán; Benjamín lbarra-Sevilla, University of Minnesota). En el ámbito de la formación profesional, por otro lado, están presentes distintos talleres en los que se imparten regularmente cursos de cantería, como el Centro de los Oficios de León, el Atelier de la Pierre d'Angle en Brignoles, Marsella (Romain Moule) o Les Compagnons du Devoir, también en Francia (Luc Tamborero). Es en este contexto de investigación y práctica profesional en el que nuestro estudio pretende insertarse.

\subsubsection{Material y métodos}

\subsubsection{Objeto de estudio}

La investigación se articula, como hemos indicado, en torno a dos aspectos fundamentales: el estudio de las reglas de trazado contenidas en el manuscrito de arquitectura atribuido a Rodrigo Gil, y el análisis geométrico y constructivo de los distintos elementos de cantería presentes en sus edificios. El marco de trabajo queda, por tanto, definido por la figura de este maestro.

\subsection{El manuscrito}

El análisis se ha limitado a la parte del Compendio de Architectura y simetría de los templos mayoritariamente atribuida a Rodrigo Gil, que corresponde a los capítulos 1 a 6 y 75, como veremos en el apartado correspondiente de esta Tesis Doctoral. Se ha tomado como texto de referencia el original del manuscrito de Simón García, conservado en la Biblioteca Nacional de España con la signatura MSS/8884 (García 1681), y disponible en formato digital en la página web de dicha institución. Su estudio minucioso ha dado como resultado

\footnotetext{
39 El estudio de la construcción en piedra y de las técnicas que la hacen posible se ha visto reflejado en la formación de una moderna bibliografía especializada, entre cuyos títulos se pueden citar, a título meramente indicativo: Acland 1972; Castellanos y Martín 1999; Cunrath 2007; Leedy 1980; Müller 1990; Nussbaum y Lepsky 1999; Palacios 2003, Palacios 2009; Pérouse de Montclos 1982; Rabasa 2000, Rabasa 2007b.

40 Ambos profesores han puesto en marcha, dentro de los estudios de grado de la Escuela Técnica Superior de Arquitectura, sendas asignaturas denominadas respectivamente Taller de construcción gótica y Taller de cantería.
} 
la identificación de una serie de procedimientos orientados al trazado arquitectónico de un edificio religioso gótico, que vienen a sumarse a los otros aspectos del Compendio ya conocidos por los investigadores, como las reglas para el dimensionado estructural y la descripción del proceso de construcción y montaje de una bóveda de crucería.

Una vez concluido el estudio teórico de las distintas reglas recogidas en el cuaderno, se ha investigado su aplicación práctica en los edificios trazados por este maestro. Para ello se ha seleccionado una muestra formada por quince edificios religiosos, $y$, tras la recogida de datos dimensionales y de fotografías, se han analizado las condiciones geométricas que definen sus "tramos-tipo", entendiendo como tales al conjunto formado por nave central, laterales y capillas hornacinas entre contrafuertes (cuando estas existen), considerado entre dos pilares o contrafuertes contiguos. La selección de edificios y tramos ha tomado como criterio discriminatorio su claridad tipológica: todos ellos son tramos intermedios de nave, cubiertos por bóvedas de planta cuadrangular, ya sea cuadrada o perlongada.

\subsection{El catálogo de elementos de cantería}

Dado lo dilatado de la obra construida por este maestro de cantería, parecería indicado imponer unos límites a la investigación, para lo cual existirían opciones de distinta índole. Podríamos utilizar marcos funcionales o tipológicos, que separaran la arquitectura religiosa, donde se concentra la práctica totalidad de las bóvedas de crucería, de la civil, donde a su vez encontramos muchas soluciones relacionadas con la estereotomía renacentista; o los edificios catedralicios, que presentan con frecuencia ejemplares de mayor interés aunque más conocidos, al menos desde la óptica de la Historia del Arte, de otros edificios de menor entidad que puedan permanecer poco investigados. Otra posibilidad sería establecer un marco territorial, circunscribiendo nuestro estudio a la región donde se concentra la mayor parte de su obra, Castilla y León, pero dicho marco sería artificial y no tendría correspondencia con los que existían en el siglo XVI. Ninguno de estos límites parece apropiado, por lo que se ha prescindido de ellos.

Para la identificación de los elementos de cantería objeto de estudio ha sido imprescindible, en primer lugar, el análisis de los datos históricos ofrecidos por la bibliografía. Un problema fundamental, en este sentido, al que se ha enfrentado la investigación planteada es el de la ingente cantidad de referencias bibliográficas existente, ya sea sobre el conjunto de la obra de Rodrigo Gil, ya sobre edificios particulares, y que desborda con creces la capacidad de cualquier estudioso. La inmensa mayoría de las referencias están orientadas hacia objetivos relacionados con la Historia del Arte, por lo que muchas veces requieren de un atento análisis para la elaboración de la más sencilla historia constructiva del edificio, a fin de determinar el alcance en cada caso de la intervención de Rodrigo Gil, y los elementos a él atribuibles. Esta contextualización histórica, necesaria, por otra parte, para la comprensión del hecho arquitectónico en su conjunto, ha sido recogida en el Anexo A de esta Tesis Doctoral, permitiendo de este modo la consulta de cualquiera de los datos referidos a cada uno de los edificios en los que se ubican los elementos de cantería estudiados, e intentando ofrecer una visión complementaria a la del historiador del arte.

Por otro lado, la selección de los distintos elementos de cantería ha tenido también en cuenta el examen directo de la realidad construida, atendiendo a criterios relacionados con su singularidad y calidad de ejecución. Una observación detenida, desde el punto de vista del corte de la piedra, pone de manifiesto que los elementos más relevantes en la obra de Rodrigo Gil son las bóvedas de crucería góticas. Otros elementos arquitectónicos de 
cantería presentes en sus edificios, tales como arcos, capialzados, pechinas, trompas, escaleras y bóvedas diversas, tienen, comparativamente, una menor importancia. Por esta razón se han establecido dos niveles de estudio:

- El primero se ha aplicado a las bóvedas de crucería, seleccionando un conjunto formado por 104 ejemplares, presentes en 36 edificios de 27 localidades distintas, y realizando un análisis pormenorizado de ellos, a partir de una serie de datos dimensionales y de fotografías. Este análisis se ha desarrollado primero de modo individual para cada una de las bóvedas, y después de modo comparativo para su conjunto. Es preciso tener en cuenta que, en muchos casos, aparecen dentro de un mismo edificio varias bóvedas cuya configuración geométrica y constructiva es la misma, al menos en apariencia; la elección durante el trabajo de campo de una de ellas para su investigación se ha realizado buscando aquella cuyas características se manifiestan con mayor claridad, o cuya ejecución fue llevada a cabo, fuera de toda duda, bajo la dirección de Rodrigo Gil.

- El segundo se ha utilizado para el resto de los elementos de cantería, empleando unos datos dimensionales mucho más limitados, así como fotografías, a partir de los cuales se ha desarrollado un análisis básico.

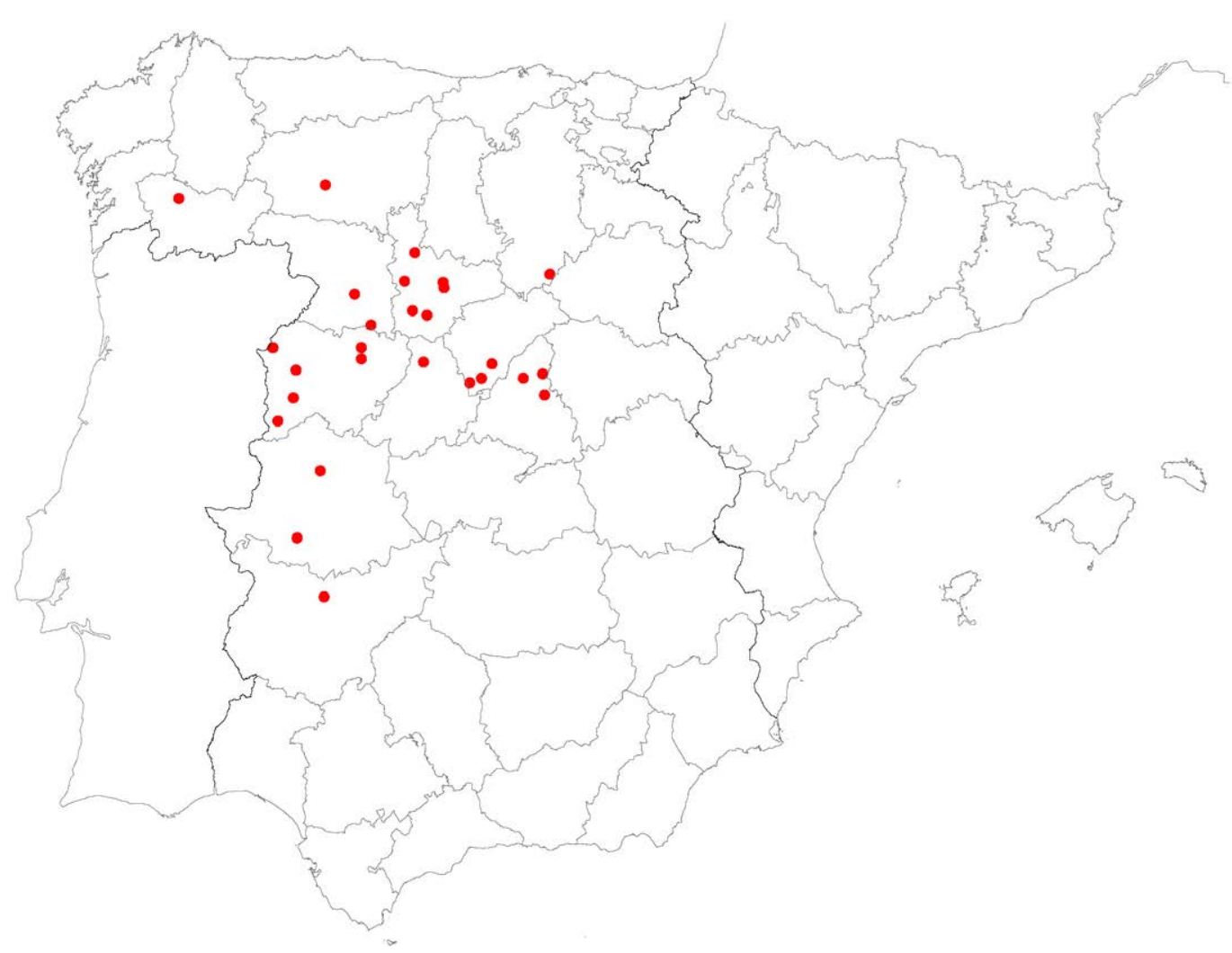

Figura 4. Localización geográfica de los 36 edificios en los que aparecen bóvedas de crucería trazadas por Rodrigo Gil (P. Moreno. IGN)

\subsubsection{El cuaderno de arquitectura de Rodrigo Gil}

El estudio teórico del manuscrito atribuido a Rodrigo Gil se ha dividido en tres partes fundamentales: métodos para el trazado arquitectónico, métodos para el dimensionado 
estructural, y dimensionado, construcción y montaje de una bóveda de crucería. La aplicación práctica de las reglas contenidas en las dos primeras ha sido examinada en el conjunto de quince edificios seleccionados. Para ello ha sido necesario contar con los correspondientes levantamientos arquitectónicos. Trece de las plantas de conjunto han sido realizadas por nosotros, llevando a cabo la toma de datos con un distanciómetro láser, en concreto un dispositivo Leica Disto D3a. Como explicamos con detalle en el siguiente apartado, referido a las bóvedas de crucería, podemos considerar que la precisión de los levantamientos realizados con este instrumento es suficiente, teniendo en cuenta las dimensiones de los elementos a medir y los propósitos del análisis. Las dos plantas restantes han sido elaboradas por otros autores, y debidamente contrastadas con nuestra propia toma de datos. La procedencia de cada una de estas planimetrías se recoge en la siguiente tabla:

\begin{tabular}{|c|c|}
\hline Localidad· Edificio & $\begin{array}{r}\text { del levantamiento arquitectónico } \\
\text { (planta de conjunto) }\end{array}$ \\
\hline Becerril de Campos (Palencia) $\cdot$ Iglesia de Santa Eugenia & P. Moreno \\
\hline Fuenteguinaldo (Salamanca) · Iglesia de San Juan Bautista & P. Moreno \\
\hline Guareña (Badajoz) · Iglesia de Santa María de la Asunción & P. Moreno \\
\hline Meco (Madrid) • Iglesia de la Asunción de Nuestra Señora & P. Moreno \\
\hline Medina de Rioseco (Valladolid) • Iglesia de Santiago de los Caballeros & P. Moreno \\
\hline Mota del Marqués (Valladolid) • Iglesia de San Martín_ & P. Moreno \\
\hline Nava del Rey (Valladolid) · Iglesia de los Santos Juanes & P. Moreno \\
\hline Salamanca $\cdot$ Catedral Nueva_ & Berriochoa 1996 \\
\hline Salamanca $\cdot$ Iglesia del monasterio de las Bernardas & P. Moreno \\
\hline Segovia $\cdot$ Catedral & Merino, Espejel y Navarro 1995 \\
\hline Tendilla (Guadalajara) • Iglesia de la Asunción de Nuestra Señora & _P. Moreno \\
\hline Valladolid · Iglesia de Santa María Magdalena_ & P. Moreno \\
\hline Vegas de Matute (Segovia) · Iglesia de Santo Tomás & P. Moreno \\
\hline Villacastín (Segovia) • Iglesia de San Sebastián & P. Moreno \\
\hline Villamor de los Escuderos (Zamora) $\cdot$ Iglesia de la Asunción de Nuestra & -P. Moreno \\
\hline
\end{tabular}

Tabla 1. Procedencia de los levantamientos arquitectónicos (plantas de conjunto) de los quince edificios cuyo trazado ha sido objeto de estudio en relación con el cuaderno de arquitectura de Rodrigo Gil (P. Moreno)

Además de los datos referentes a la planta, el análisis planteado precisa contar con los que corresponden a la sección del edificio. Estas mediciones de alturas han sido tomadas por nosotros en todos los casos, utilizando igualmente un distanciómetro láser.

Todos los datos geométricos empleados para el desarrollo de la investigación, debidamente tabulados, se han consignado en el apartado de esta Tesis Doctoral dedicado a la aplicación práctica de las reglas del manuscrito de Rodrigo Gil.

El análisis de los tramos-tipo utilizados en estos quince edificios religiosos afecta, en primer lugar, a las condiciones geométricas del espacio arquitectónico generado, en lo que se refiere a trazado de la planta y de la sección. En segundo lugar, concierne a las dimensiones en planta de los elementos de apoyo y contrarresto. En este último caso debemos señalar que, de entre las distintas fórmulas para el dimensionado estructural recogidas en el manuscrito, únicamente se ha examinado la aplicación práctica de cuatro de las reglas aritméticas, concretamente la que permite el cálculo de los pilares para bóvedas de crucería y las tres que sirven para el dimensionado de los contrafuertes en circunstancias distintas. 


\subsubsection{Las bóvedas de crucería de Rodrigo Gil}

\subsection{Sistema empleado para la toma de datos}

El análisis geométrico y constructivo de cualquier elemento arquitectónico se basa en la realización de una adecuada toma de datos, que permita elaborar el correspondiente levantamiento. A tal fin existen distintos sistemas a nuestra disposición, que difieren tanto en la cantidad de datos que aportan como en su precisión. La elección de una u otra técnica debe tomar en consideración su adecuación al objeto medido, a los propósitos del análisis y al número de ejemplares considerados en el estudio.

En este sentido, una mayor abundancia de los datos no tiene por qué ser más recomendable. Evidentemente, la ausencia de la información imprescindible para cubrir los requerimientos del estudio impide el desarrollo de este, pero, de modo análogo, el exceso de ella también lo dificulta: tras la recogida de datos se hace precisa una selección de aquellos que permiten alcanzar el objetivo de la investigación, descartando los superfluos, lo cual se traduce en un aumento del tiempo dedicado tanto al trabajo de campo como al análisis de la información acumulada.

Por lo que respecta a la precisión de los datos, debemos tener siempre en cuenta, como hemos señalado, la adecuación de la técnica elegida al objeto medido. Las bóvedas de crucería son estructuras de fábrica, en las que encontramos habitualmente irregularidades debidas al proceso de labra y montaje de las piezas, que se encuentran en el orden de los centímetros. Junto a ellas, aparecen también deformaciones producidas tanto durante el descimbrado de la bóveda como a lo largo de la vida del edificio, cuya entidad es difícil de cuantificar, y variable para cada situación específica, pero que podemos estimar en el orden de los decímetros. Por estas razones, los datos proporcionados por cualquier instrumento de medición cuya precisión se encuentre en torno al centímetro pueden ser válidos para el desarrollo de un análisis de estas bóvedas.

Entre los distintos sistemas de medición existentes, podríamos señalar, en primer lugar, los más precisos, que son, sin duda, aquellos basados en el empleo de la estación total o el escáner láser: el primero permite la medición discriminada de un conjunto de puntos, mientras que el segundo suele utilizarse para la obtención de una mayor cantidad de información más inespecífica. Ambas herramientas tienen a su favor la exactitud de los datos de medición obtenidos. No obstante, la primera implica un proceso prolongado de toma de datos, que suele alargarse a varios días; la segunda reduce el tiempo necesario, pero no permite discriminar la información durante el proceso de recogida.

Actualmente es posible la utilización de multitud de aplicaciones informáticas basadas en la fotogrametría, que permiten, a partir de la toma de fotografías con una cámara debidamente calibrada, la restitución geométrica del elemento arquitectónico estudiado. La ventaja de este sistema se encuentra, indudablemente, en la rapidez del proceso de toma de datos. Sin embargo, la exactitud de los modelos obtenidos no se encuentra todavía, a nuestro juicio, totalmente contrastada en su aplicación a un elemento arquitectónico de cierto tamaño.

El sistema elegido para la recogida de datos dimensionales ha sido el distanciómetro láser, empleando un dispositivo Leica Disto D3a. Por un lado, el nivel de aproximación que nos proporciona este instrumento es de milímetros (precisión de medición $\pm 1.0 \mathrm{~mm}$ ), por lo que puede adecuarse perfectamente a las bóvedas analizadas: como hemos indicado, las variaciones geométricas que estas pueden presentar respecto a su traza teórica, producidas 
durante la ejecución o debidas a deformaciones posteriores, pueden resultar de uno o dos órdenes de magnitud superiores (de 10 a 100 veces mayores) a la precisión del instrumento ${ }^{41}$. Por otro lado, la importante muestra de bóvedas seleccionada para el estudio, motivada por lo abundante de la obra arquitectónica de Rodrigo Gil, no permitiría en la práctica la utilización de la estación total o el escáner láser, debido a la profusión de datos que sería necesario recoger y procesar. Por el contrario, la cantidad de información obtenida utilizando el distanciómetro láser es reducida, permitiendo tanto una rápida toma de datos como un ágil proceso de depurado de los mismos. Estas mediciones se han acompañado de la elaboración de los correspondientes croquis de campo y de un reportaje fotográfico, realizado con una cámara digital Canon EOS 550D, provista de un objetivo zoom Canon EF-S 18-55 IS II.

Sin embargo, este sistema de medición presenta dos limitaciones fundamentales. La primera de ellas es el hecho de que las mediciones en planta se limitan, como veremos a continuación, al contorno de los elementos de apoyo de la bóveda, de manera que la restitución de la proyección horizontal de los nervios se basa en la formulación de hipótesis a partir de fotografías. La segunda es que el resto de las mediciones, referidas a la altura de distintos puntos situados a lo largo del recorrido de los arcos, permiten la restitución de las elevaciones de estos, pero no proporcionan datos relativos a las dimensiones de los distintos elementos que, desde el punto de vista constructivo, configuran la bóveda de crucería (nervios, jarjas, claves y plementería), lo que obliga a que el análisis de dichos elementos sea fundamentalmente de tipo cualitativo. Aunque sería interesante contar con datos que permitieran corroborar las hipótesis enunciadas y profundizar en el análisis de los distintos elementos, nos hemos decantado por el sistema indicado, prefiriendo la realización de un análisis básico de las bóvedas seleccionadas a un estudio mucho más pormenorizado de algunas de ellas, y poniendo de este modo el acento en la visión de conjunto de estas estructuras.

\subsection{Proceso de toma de datos}

El estudio geométrico de las bóvedas se ha comenzado tomando las correspondientes medidas en planta. Para la determinación del perímetro de la bóveda se han medido las dimensiones de sus lados, tomando igualmente las medidas de sus diagonales a fin de comprobar, mediante triangulación, la posible existencia de descuadres relevantes en la estructura.

Aunque cada una de las bóvedas quedaría definida geométricamente por el contorno de sus apoyos (pilares y muros), su presencia condiciona por completo la configuración arquitectónica y el funcionamiento estructural del edificio. Por esta razón nos ha parecido imprescindible incluir los levantamientos correspondientes a estos edificios, de manera que cada bóveda pueda ponerse en relación con sus elementos de contrarresto (pilares y estribos) y con el conjunto. Las plantas de 28 de los 36 edificios en los que se presentan bóvedas de crucería han sido dibujadas por nosotros, empleando para ello, como en el caso de los edificios cuyo trazado ha sido objeto de estudio en relación con el cuaderno de arquitectura de Rodrigo Gil, y como en el de las propias bóvedas de crucería, un distanciómetro láser; las de otros 4 edificios se han basado parcialmente en las confeccionadas por otros autores, o se han redibujado a partir de ellas; por último, para los

\footnotetext{
41 Willis 2012 : ix-xiii.
} 
4 edificios restantes se han tomado directamente planimetrías ajenas. Estas 8 plantas tomadas o basadas parcialmente en otras fuentes han sido debidamente contrastadas y completadas con nuestra propia toma de datos, especialmente en lo que atañe a la definición de las bóvedas objeto de estudio. La procedencia de cada una de las plantas de conjunto se recoge en la siguiente tabla, haciendo referencia, entre corchetes, al número de bóvedas estudiadas en cada uno de los edificios:

\begin{tabular}{lr}
\hline Localidad · Edificio [Número de bóvedas analizadas] & $\begin{array}{r}\text { Autor del levantamiento arquitectónico } \\
\text { (planta de conjunto) }\end{array}$ \\
\hline $\begin{array}{l}\text { Astorga (León) · Catedral [2] } \\
\text { Cáceres · Iglesia de San Mateo [1] }\end{array}$ & basado y Pérez 1995 \\
P. Moreno,
\end{tabular}

basado parcialmente en Jiménez 2012 y Rodríguez 2010

Castellanos de Villiquera (Salamanca) · Iglesia de San Juan Bautista [1] P. Moreno

Ciudad Rodrigo (Salamanca) · Catedral [2] P. Moreno

Fontiveros (Ávila) - Iglesia de San Cipriano [2]

P. Moreno

Fuente el Saz de Jarama (Madrid) • Iglesia de San Pedro Apóstol [4]

P. Moreno

Fuenteguinaldo (Salamanca) - Iglesia de San Juan Bautista [1]

P. Moreno

Guareña (Badajoz) · Iglesia de Santa María de la Asunción [1]

P. Moreno

Laguna de Duero (Valladolid) • Iglesia de la Asunción de Nuestra Señora [2]

P. Moreno

Medina de Rioseco (Valladolid) - Iglesia de Santiago de los Caballeros [1]

P. Moreno

Medina del Campo (Valladolid) · Colegiata de San Antolín [2]

P. Moreno

Miraflores de la Sierra (Madrid) · Iglesia de la Asunción de Nuestra Señora [2]

P. Moreno

Mota del Marqués (Valladolid) · Iglesia de San Martín [5]

P. Moreno

Nava del Rey (Valladolid) • Iglesia de los Santos Juanes [2]

P. Moreno

Ourense $\cdot$ Catedral [2]

P. Moreno

Ourense $\cdot$ Iglesia de la Santísima Trinidad [2]

P. Moreno

Peñaranda de Duero (Burgos) - Iglesia de Santa Ana [3]

P. Moreno

Plasencia (Cáceres) • Catedral Nueva [1]

P. Moreno

Salamanca - Capilla del Colegio Mayor del Arzobispo Fonseca [4]

P. Moreno

Salamanca $\cdot$ Catedral Nueva [3]

Salamanca $\cdot$ Colegio Menor de San Pelayo [1]

P. Moreno

Salamanca $\cdot$ Iglesia del convento de San Esteban [8]

Manzano 2000

Salamanca $\cdot$ Iglesia del monasterio de las Bernardas [1]

P. Moreno

Saucelle (Salamanca) · Iglesia de la Purísima Concepción [4]

P. Moreno

Segovia $\cdot$ Catedral [9]

arro 1995

Segovia $\cdot$ Iglesia de San Miguel [6]

P. Moreno

Segovia $\cdot$ Iglesia del Salvador [1]

P. Moreno

Torrelaguna (Madrid) • Iglesia de Santa María Magdalena [2]

P. Moreno,

redibujado a partir de Berlinches y Humanes 1991: vol. 4, 1017

Valladolid · Iglesia de Santa María Magdalena [4]

P. Moreno

Vegas de Matute (Segovia) - Iglesia de Santo Tomás [5]

P. Moreno

Villacastín (Segovia) · Iglesia de San Sebastián [5]

P. Moreno

Villamor de los Escuderos (Zamora) • Iglesia de la Asunción de Nuestra Señora [5]

P. Moreno

Villavieja de Yeltes (Salamanca) • Iglesia de San Pedro Apóstol [3]

P. Moreno

Zamora · Capilla del deán Diego Vázquez de Cepeda en el convento de San Francisco [1]

P. Moreno

Zamora $\cdot$ Iglesia de San Juan de Puerta Nueva [2]

P. Moreno,

redibujado a partir de Nuño y González 2002: 462

Tabla 2. Procedencia de los levantamientos arquitectónicos (plantas de conjunto) de los 36 edificios donde se localizan las bóvedas de crucería objeto de estudio. Se indica entre corchetes el número de bóvedas analizadas en cada uno de ellos (P. Moreno) 
En la representación gráfica de estas plantas de conjunto se han diferenciado, en la medida de lo posible, las zonas del edificio en las que intervino Rodrigo Gil, o que le son más claramente atribuibles, de aquellas otras que le son ajenas. Para ello se han utilizado dos rayados distintos en el relleno de los muros, correspondiendo el más denso a las partes relacionadas con Hontañón.

A continuación se ha procedido a la toma de alturas, utilizando como plano de referencia el del suelo (cota \pm 0.00 ). Al objeto de garantizar una adecuada disposición del distanciómetro láser durante la realización de las mediciones, el dispositivo se monta en un trípode, comprobando su colocación vertical con un nivel de burbuja. Debemos observar que este sistema de medición presenta el inconveniente de que el plano del suelo, utilizado como referencia, puede presentar irregularidades, de manera que, en determinados casos, puede existir una pequeña diferencia de nivel entre los distintos puntos en los que se toman las medidas; sin embargo, dicha diferencia no supera los pocos centímetros, pudiendo ser considerada como irrelevante.

La estrategia ha sido medir, en primer lugar, la altura de imposta a partir de la cual arranca la bóveda, tomando para ello varias mediciones en el perímetro. Hecho esto, se ha registrado la posición del intradós de la plementería en el entorno próximo a las claves, tomando usualmente una medida de altura en cada uno de los plementos que rodean a cada clave. Se ha comenzado habitualmente por las claves situadas a lo largo de las líneas de espinazo o "rampantes" de la bóveda, a fin de comprobar la simetría o asimetría de dichas líneas, procediendo seguidamente a la medición de las alturas de plementería en el entorno de las claves que corresponden a una de las mitades de la bóveda, o, en caso necesario, de las de un mayor número de ellas. De modo complementario, se han tomado medidas de la posición del intradós de los nervios en su intersección con cada una de las claves, y de la cara inferior de las propias claves, a fin de poder realizar algunas observaciones cualitativas de ambos elementos.

Los datos referidos a las dimensiones generales en planta de las bóvedas y a las mediciones de alturas de imposta y de plementería en el entorno próximo a las claves, recogidos durante la realización del trabajo de campo, se han incluido en el Anexo B de esta Tesis Doctoral, de modo que, llegado el caso, puedan ser utilizados o contrastados por otras investigaciones.

\subsection{Análisis individual de las bóvedas}

Terminado el proceso de toma de datos, se ha realizado un análisis individual de cada una de las 104 bóvedas objeto de estudio. Este análisis tiene como finalidad la formulación de una serie de hipótesis relativas al trazado geométrico teórico con el que pudo ser concebida cada bóveda, así como de algunas observaciones referidas a su configuración constructiva. La interpretación de los datos obtenidos se ve condicionada, como hemos indicado, por las irregularidades y deformaciones que puede presentar la estructura, cuya magnitud es, en muchos casos, difícilmente cuantificable. Por esta razón, las hipótesis de trazado formuladas en esta investigación plantean normalmente, de entre las distintas opciones geométricas, la más sencilla, buscando el acuerdo entre la geometría deformada actual de la bóveda y la lógica constructiva que pudo regir originalmente su trazado teórico.

Con estas premisas, se ha llevado a cabo la restitución de la geometría real aproximada que tiene cada bóveda en su estado actual, incluyendo sus irregularidades y deformaciones. Para ello se ha establecido, a partir del levantamiento arquitectónico, el perímetro de la 
bóveda; el análisis de las dimensiones de sus lados y diagonales permite afirmar que no existen descuadres relevantes, por lo que las plantas se han considerado como rectángulos, o, en su caso, como polígonos con, al menos, un eje de simetría. Determinado el contorno de la estructura, se ha obtenido la posición en planta de las claves a partir del análisis de una fotografía en planta de la bóveda; hecho esto, se ha dibujado la posición en planta de los nervios, uniendo las claves mediante líneas rectas 0 , en el caso de los que presentan un trazado curvo, aproximándolos a un arco o varios tramos de arco conocidos. A continuación se ha determinado la altura hipotética de la línea de imposta y de las claves. Para la línea de imposta se ha realizado una media aritmética de las alturas tomadas en el perímetro de la bóveda. Para las claves, se ha establecido la posición teórica del intradós de la plementería en su hipotética intersección con el eje central de cada clave, tomando la media aritmética de las medidas registradas en el entorno próximo a cada una de ellas. Finalmente se han trazado las elevaciones de los nervios de la bóveda, tomando en cada uno de ellos la línea poligonal que configura el recorrido entre claves y aproximándola, de nuevo, a un arco o varios tramos de arco conocidos.

En relación con las plantas de las bóvedas, debemos señalar que, de modo excepcional, se han encontrado dos casos que presentan un fuerte descuadre, tomando la forma aproximada de un trapecio rectángulo. Se trata de las bóvedas que cubren el tramo central y el lateral sur del crucero de la iglesia del convento de San Esteban en Salamanca. Aunque sus medidas reales se han consignado en el Anexo B de esta Tesis Doctoral, a la hora de llevar a cabo el análisis dichas plantas trapeciales han sido asumidas como rectangulares, por dos razones: en primer lugar, la forma trapecial es resultado de un error producido durante el replanteo de la cimentación en obra, siendo rectangular el trazado teórico en ambos casos; en segundo lugar, esta aproximación no introduce errores importantes ni en el trazado en planta ni en el de las elevaciones de los arcos, y permite acometer el análisis de ambas estructuras del mismo modo que para el resto de bóvedas de planta rectangular, mayoritarias entre las estudiadas. Las dimensiones teóricas consideradas para el análisis son la altura y la mediana del trapecio.

Una vez planteadas estas hipótesis de diseño, la geometría de cada una de las bóvedas se ha plasmado en un dibujo realizado en sistema diédrico, acompañándolo de un modelo tridimensional que facilita la comprensión del trazado. Terminado este análisis geométrico, la observación de la realidad construida, tanto in situ como a través de fotografías, nos ha permitido estudiar sus características constructivas.

Los resultados del análisis individual se han organizado, para cada una de las bóvedas, en una serie de apartados, divididos en características geométricas (modulación y rangos dimensionales, sistemas de composición, arcos, rampante) y características constructivas (nervios, jarjas, claves, plementería). En el caso de los arcos, los resultados geométricos han sido recogidos en tablas. Al comienzo del apartado dedicado al análisis individual de las bóvedas pueden encontrarse algunas precisiones relativas a los criterios metodológicos utilizados tanto en el análisis como en la representación gráfica de estas estructuras.

\subsection{Análisis comparativo de las bóvedas}

Una vez concluido el análisis individual de cada una de las 104 bóvedas seleccionadas, se ha llevado a cabo un estudio comparativo de su conjunto, que se articula en dos partes distintas y gira en torno a las mismas categorías empleadas en aquel. La primera de dichas partes se refiere a las características geométricas de estas estructuras, analizando, por un 
lado, su modulación, rangos dimensionales y sistemas de composición en planta, y, por otro, el trazado de sus arcos y de su rampante o línea de espinazo. La segunda investiga las características constructivas de los elementos que las constituyen, examinando sucesivamente sus nervios, jarjas, claves y plementería.

El estudio estadístico del conjunto de las 104 bóvedas, cuya validez se asienta en la utilización de una muestra suficientemente amplia, ha permitido identificar las herramientas de trazado y construcción más habituales, separándolas de aquellas menos frecuentes.

\subsection{Análisis detallado de un caso}

Con el objeto de poner de manifiesto algunas de las características más usuales observadas en el conjunto de las 104 bóvedas, se ha elegido una de ellas para la realización de un estudio detallado: la que cubre el cimborrio de la capilla del Colegio Mayor del Arzobispo Fonseca en Salamanca. Una vez terminado el análisis inicial, que ha revelado algunas peculiaridades geométricas y constructivas del caso escogido, se ha completado la investigación con la construcción de un modelo a escala 1:3, realizado durante el segundo semestre del curso 2014-2015 en la Escuela Técnica Superior de Arquitectura de Madrid, en el marco de la asignatura Taller de construcción gótica ${ }^{42}$.

\subsubsection{Otros elementos de cantería en la obra de Rodrigo Gil}

Los datos empleados para el estudio de otros elementos arquitectónicos de cantería distintos de las bóvedas de crucería, tales como arcos, capialzados, pechinas, trompas, escaleras y bóvedas diversas, son mucho más limitados que en el caso de aquellas. La toma de datos dimensionales se ha realizado, de nuevo, con un distanciómetro láser modelo Leica Disto D3a, recogiendo una cantidad de información variable para cada caso concreto, y de la que incluso se prescinde en los elementos más sencillos, como arcos y capialzados. El uso conjunto de fotografías ha permitido desarrollar un análisis básico de estos elementos, centrado en sus principales características de tipo geométrico y constructivo.

\subsubsection{Unidades utilizadas}

Una primera reflexión que debemos realizar a la hora de abordar el estudio de cualquier edificio histórico se refiere a las unidades metrológicas en que fue concebido y construido. Estamos acostumbrados a dibujar nuestras planimetrías y realizar nuestros análisis empleando el único sistema que conocemos, que es el métrico, pero es necesario considerar que dicho sistema tiene poco más de 150 años de vigencia, y que antes de él eran otros los que se utilizaban, normalmente de tipo antropométrico. Como señala Merino ${ }^{43}$, un adecuado estudio metrológico debe apoyarse en el mismo sistema de medidas que se utilizó en la construcción, ya que el empleo exclusivo del sistema métrico decimal puede conducirnos a una valoración incompleta. En el caso de España el más extendido en la baja Edad Media era el basado en la vara de Burgos, conocida como vara castellana o de Castilla, sancionada en 1568 por Felipe II como unidad de medida en los reinos peninsulares. Tiene

\footnotetext{
42 La asignatura es dirigida por el profesor José Carlos Palacios Gonzalo desde su creación en 2008. Véase al respecto Palacios et al. 2015.

43 Merino 1999: 33, 35-38.
} 
un valor de 0.835905 metros y se divide en tres pies de 0.278635 metros. Sin embargo la vara y el pie castellanos no tuvieron nunca un uso general en todos los territorios, y cuando se estableció en España en 1849 el sistema métrico decimal se contaban hasta veinte sistemas de medidas distintos en la Península e $\operatorname{~slas~}^{44}$.

La mayoría de los edificios analizados en nuestro estudio se localiza en territorios donde se utilizaba la vara castellana, aunque, dado el desarrollo geográfico de la obra de Rodrigo Gil, algunos de ellos se encuentran en zonas en las que existían otros sistemas de medidas, como Segovia (vara de Segovia, 0.837 metros), Madrid (vara de Madrid, 0.843 metros) o A Coruña (vara de A Coruña, 0.843 metros). Merino ha señalado no obstante el hecho de que ya en algunas obras tempranas de Rodrigo Gil, como la catedral de Segovia, se observa una voluntad de utilizar el pie castellano como unidad de medida estándar. La construcción del edificio fue comenzada por Juan Gil de Hontañón en 1525, utilizando el módulo local, es decir, el pie segoviano, para el replanteo del tramo de naves occidental; a su muerte en 1526 se hizo cargo de la obra Rodrigo Gil, realizando progresivamente el replanteo del resto del edificio, tanto en su parte correspondiente al cuerpo de naves como al crucero y cabecera, en base al pie castellano. Según este estudioso este cambio en el sistema de medidas se debe a un deseo consciente del maestro de homologar el trabajo de todos los agentes que intervenían en la obra, que, por otra parte, procedían con frecuencia, como él mismo, de Cantabria y de las provincias occidentales del País Vasco (Vizcaya y Álava), zonas en las que el pie castellano era el utilizado ${ }^{45}$. Por otro lado, no debemos olvidar que las unidades utilizadas en el manuscrito de Rodrigo Gil son, lógicamente, los pies. Por todas estas razones los datos dimensionales de los distintos elementos analizados en esta Tesis Doctoral, como los tramos-tipo de los edificios estudiados en relación con el manuscrito, las bóvedas de crucería y el resto de elementos arquitectónicos de cantería, se recogen utilizando como unidad común el pie castellano, y ofreciendo en algunos casos, de modo alternativo, su correspondencia en metros. La equivalencia utilizada en la conversión de medidas es la ya señalada, esto es, una vara castellana equivale a 0.835905 metros y se divide en tres pies de 0.278635 metros.

\subsubsection{Estructura de la Tesis}

La investigación se articula en una serie de capítulos, cuya organización detallamos a continuación:

- 1. Introducción

- 2. El cuaderno de arquitectura de Rodrigo Gil

- 3. Las bóvedas de crucería de Rodrigo Gil

- 4. Otros elementos de cantería en la obra de Rodrigo Gil

- 5. Conclusiones

- 6. Difusión de resultados y futuras líneas de investigación

\footnotetext{
${ }^{44}$ Las unidades que desarrollaban el sistema métrico castellano a partir de la vara y el pie, así como sus equivalencias actuales, pueden encontrarse en Merino 1999: 54-55. Véase al respecto la "Real Orden de 9 de diciembre de 1852, por la que se determinan las tablas de correspondencia recíproca entre las pesas y medidas métricas y las actualmente en uso" (Massa 1858-1864: 643-656).

45 Merino 1991: 7-9, 11-13.
} 
- 7. Anexo A. Catálogo de obras e intervenciones

- 8. Anexo B. Bóvedas de crucería: datos de medición

- 9. Anexo C. Glosario

- 10. Bibliografía

El primer capítulo, de tipo introductorio, recoge el encuadre y objetivos del estudio y la metodología empleada en su desarrollo. Incluye, igualmente, un estudio de la figura de Rodrigo Gil que aclara los distintos aspectos biográficos, históricos y profesionales relativos a este maestro.

El segundo se refiere al cuaderno de arquitectura atribuido a Rodrigo Gil, realizando primero un análisis del texto que indaga acerca de la naturaleza teórica de las reglas en él contenidas, y examinando, a continuación, su aplicación práctica en un conjunto de quince edificios religiosos.

El tercer capítulo, dedicado a las bóvedas de crucería, es el más extenso de la Tesis Doctoral, e investiga las características geométricas y constructivas de un conjunto formado por 104 ejemplares. Se desarrolla en cuatro apartados, que comprenden un análisis individual de cada una de las bóvedas, un análisis comparativo del conjunto y un estudio detallado de una de ellas.

El cuarto capítulo está dedicado a otros elementos arquitectónicos de cantería presentes en los edificios trazados por Rodrigo Gil, llevando a cabo un análisis básico de los mismos.

Los capítulos quinto y sexto incluyen las conclusiones de la investigación, la difusión de sus resultados y la propuesta de futuras líneas de investigación.

Los capítulos séptimo, octavo y noveno incluyen los anexos necesarios para el desarrollo de la investigación. El Anexo A recoge la contextualización histórica de los distintos edificios estudiados, así como del resto de edificios en los que intervino Rodrigo Gil a lo largo de su carrera profesional. El Anexo B incluye los principales datos de medición relativos al conjunto de bóvedas de crucería examinadas en la Tesis Doctoral. El Anexo $C$ es un glosario de términos que presenta el uso que se da a cada uno de ellos en el texto.

Por último, el décimo capítulo está dedicado a la bibliografía empleada para la elaboración de la Tesis Doctoral, separando, por una parte, las referencias utilizadas en el conjunto del texto, y, por otra, las relativas al catálogo de obras e intervenciones incluido como Anexo A. 
1.2. RODRIGO GIL: ASPECTOS BIOGRÁFICOS, HISTÓRICOS Y PROFESIONALES 



\subsubsection{Biografía}

El lugar de nacimiento de Rodrigo Gil se situaría en Rascafría (Madrid), ya que allí fue bautizado el 23 de febrero de $1500^{46}$, siendo sus padres naturales Juan Gil de Hontañón y Ana Sanz ${ }^{47}$. Desde el primer momento su progenitor tuvo voluntad de legitimarlo, puesto que declaró su paternidad en la propia partida de bautismo, y el hecho de que Rodrigo heredara posteriormente el escudo de armas de la familia demuestra que dicha legitimación se llevó a efecto ${ }^{48}$. Rascafría, que pertenecía a la Comunidad de Villa y Tierra de Segovia hasta la reestructuración provincial de 1833, destacaba por sus canteras de piedra berroqueña, esto es, granito, de excelente calidad, razón por la cual era punto de encuentro de numerosos profesionales de la piedra a finales del siglo $\mathrm{XV}^{49}$. El cantero Juan Gil se encontraba allí trabajando en la obra de la cartuja de Santa María de El Paular, y debía estar relativamente afincado en el lugar, ya que no solo estaba avecindado ${ }^{50}$, sino que en 1502 vendió al monasterio un molino denominado "El Sotillo" 51 , y en 1509 realizaba un contrato por poderes en dicha localidad 52 .
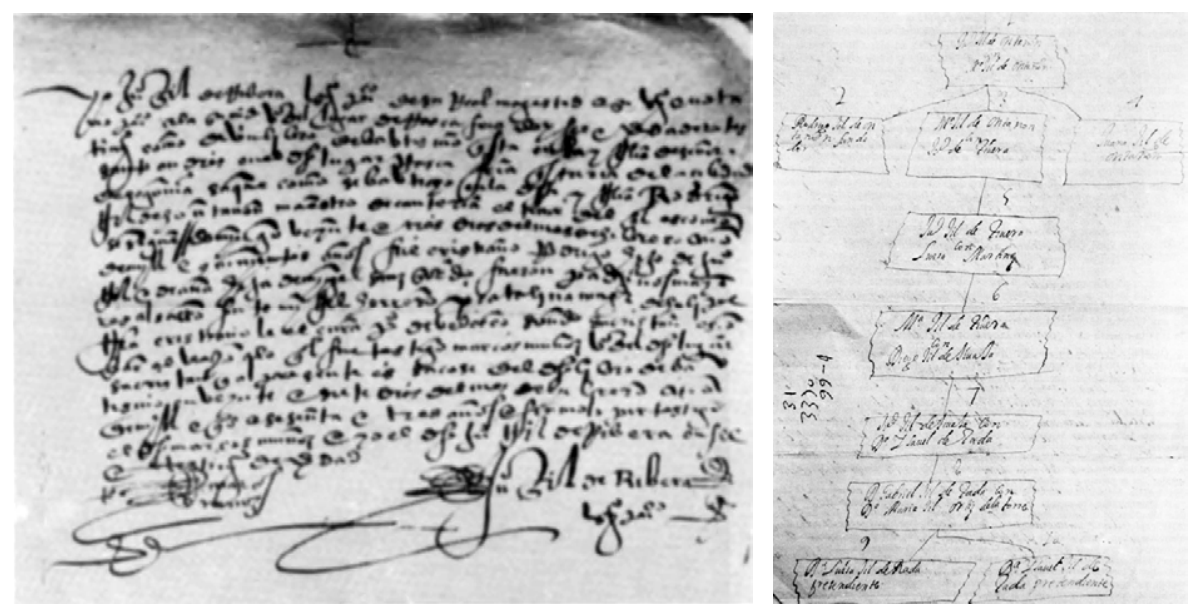

Figura 5. (a) Copia de 1563 de la partida de bautismo de Rodrigo Gil (Casaseca 1984: 56 fig. 1. Archivo de la Diputación de Segovia). (b) Árbol genealógico de Rodrigo Gil de mediados del siglo XVII (Casaseca 1988: 26 lám. A. Archivo de la Diputación de Segovia)

Los orígenes de la familia paterna se encuentran en Hontañón, barrio del pueblo de Carasa $^{53}$, en la Junta de Voto de la Merindad de Trasmiera (Cantabria), comarca que históricamente produjo gran cantidad de canteros trashumantes ${ }^{54}$. El pleito entablado por la construcción de la capilla del deán Diego Vázquez de Cepeda en el convento de San Francisco de Zamora nos proporciona numerosas noticias relativas a las circunstancias

\footnotetext{
46 Transcripción parcial de la partida de bautismo en Hoag 1985: 225; transcripción completa en Casaseca 1988: 25.

47 Casaseca 1988: 25, 27-28.

48 Hoag 1985: 65.

49 Muñoz 2003: 208 nota 5.

50 Pereda 1951: LXX-LXXIV.

51 Hoag 1985: 65.

52 Alonso 2015: 34; Castro 2003a: 154-156.

${ }^{53}$ Sojo 1935: 78-85, citado en Ortiz 1941: 316-317.

54 Hoag 1985: 64.
} 
familiares de Rodrigo Gil, entre otras que en 1534 se declaraba "vezino de Hontañon"55. Este topónimo parece derivar de "fontañón", diminutivo regional de fontana ${ }^{56}$. Tanto Juan Gil como su hijo Rodrigo usaron invariablemente al firmar el apellido patronímico Gil, de origen montañés, y mientras que el primero le añadió en ocasiones el topográfico Hontañón, el segundo solo lo hizo en contadas excepciones ${ }^{57}$.

El padre de Rodrigo era natural del cercano pueblo de Rasines (Cantabria) ${ }^{58}$, donde estuvo avecindado mucho tiempo ${ }^{59}$ con su esposa legítima, María Gil de Hontañón ${ }^{60}$. Allí tenían "unas tierras con su casa e morada e viñas e heredades ... con muchos arboles e hazienda"61. De este matrimonio nació una hija, hermanastra por tanto de Rodrigo: María Gil de Hontañón. Casó esta por tres veces, sucesivamente con Juan de Helguera, Juan de la Montaña y Juan de Rivera; de su tercer matrimonio nacieron María y Juan Gil de Rivera62, sobrinos consiguientemente de Rodrigo, quien sufragó los estudios del segundo en Alcalá de Henares (Madrid) ${ }^{63}$.

Juan Gil tuvo un tercer hijo, Juan Gil "el Mozo", que debió de venir al mundo hacia 1490, ya que en 1509 firmaba en Rascafría, en nombre de su padre, el contrato para la construcción de la iglesia parroquial de Almorox (Toledo, en la época diócesis de Segovia), de lo que se deduce que ya tenía la edad legal para hacerlo64. Este hijo, en contra de lo que sostiene Casaseca ${ }^{65}$, no debió de ser fruto de la relación con María Gil de Hontañón, ya que en la documentación del pleito por la construcción de la capilla del deán Cepeda se recoge expresamente que la heredera legítima y universal de dicho matrimonio era únicamente su hija María ${ }^{66}$. Al parecer permaneció soltero ${ }^{67}$.

\footnotetext{
55 Martí 1907a: 84, 162.

56 Ortiz 1941: 316 nota 1.
}

57 A título de ejemplo, el padre firma sucesivamente en 1502, 1512, 1514 y 1523 como Juan Gil de Hontañón (Hoag 1985: 65; Pereda 1951: LXXII, LXXVI-LXXVII, LXXXII, XCV), mientras que en 1520 y 1524 lo hace simplemente como Juan Gil (Casaseca 1988: 130; Pereda 1951: LXXXIV). En cuanto a su hijo, a lo largo de toda su vida firma de modo preferente como Rodrigo Gil (1528, 1532, 1536, 1538, 1540, 1543, 1544, 1552, 1553, 1556, 1557, 1566, 1569, 1570, 1571) (Bosarte 1804: vol. 1, $401-404$ doc. IX, 405-409 doc. X; Casaseca 1988: 67, 80, 96, 105, 149, 228, 269; Pereda 1951: CX-CXI, CXLVICXLVII, CLXIV, CCXLVII doc. 1, CCXLIX-CCLI doc. 3; Sendín 1977: 282-283 doc. XXVI, 285-286 doc. XXIX, 287-288 doc. XXX). Encontramos añadido el Hontañón en la copia de su partida de bautismo (1563) y en la lápida colocada sobre su tumba (Casaseca 1988: 25, 32), así como en algún otro documento aislado no rubricado por él (1547) (Sendín 1977: 284-285 doc. XXVIII).

58 Pereda 1951: CCLI-CCLIV doc. 4.

59 Aunque a comienzos del siglo XVI era vecino al parecer de Rascafría (Madrid) (Pereda 1951: LXXI-LXXII) a lo largo de su vida se declara vecino de Rasines ("Resines", "Ressines" ○ "Resyna", según los documentos) en distintas ocasiones (1509, 1514, 1520, 1523 y 1524) (Casaseca 1988: 130; Pereda 1951: LXXII, LXXVII, LXXXIV, XCV).

60 Martí 1907a: 141; Ortiz 1941: 316.

${ }^{61}$ Martí 1907a: 137; Pereda 1951: CXV.

62 Casaseca 1988: 27-29.

63 Casaseca 1988: 34. Marías (1990: 32-33) no está de acuerdo, y afirma que quien estudiaba en la Universidad de Alcalá de Henares era el propio hijo de Rodrigo Gil, Juan Gil "Gilillo", al menos desde 1541 a 1545.

${ }^{64}$ Alonso 2015: 34; Castro 2003a: 154-156.

65 Casaseca 1988: 27-29.

66 En 1528 se declaraba que "... el dicho Juan Gil habia muerto e abia dexado muchas deudas y su hija y heredera abia acetado la herencia en beneficio de inbentario ..." (Martí 1907a: 36). En la probanza presentada en 1539 por Rodrigo Gil durante el citado pleito una de las preguntas que se hacía a los testigos era "si saben q al tpo [tiempo] q la dha [dicha] maria gil e juan gil fallescieron dejaron por su vniversal 
Rodrigo fue educado junto a su padre, teniendo probablemente trato con sus hermanastros ${ }^{68}$; quizás se crio en Rascafría, si bien es evidente que conocía también Rasines, como demuestra la precisa descripción de su iglesia parroquial en su testamento ${ }^{69}$. A la muerte de Juan Gil de Hontañón en 1526, y nombrado albacea García de Cubillas ${ }^{70}$, su hija María recibió la herencia, que aceptó a beneficio de inventario ${ }^{71}$. Ella retuvo los bienes y hacienda de Rasines 72 , mientras que Juan Gil "el Mozo" y su hermanastro Rodrigo se repartieron tácitamente las obras que tenía contratadas su progenitor. Rodrigo y su hermanastra María debieron mantener relaciones cordiales, como demuestra el hecho de que en 1528 le cediera los derechos que le correspondían por la construcción de la capilla del deán Cepeda, y que al año siguiente su marido, Juan de la Montaña, trabajara como aparejador en dicha obra ${ }^{73}$.

En 1528 Rodrigo Gil se declaraba vecino de Segovia ${ }^{74}$, y aunque en los documentos del citado pleito, como hemos dicho, manifestaba en 1534 ser vecino de Hontañón, desde su nombramiento en 1538 como maestro mayor de las obras de la Catedral Nueva de Salamanca residió habitualmente en esta $\operatorname{ciudad}^{75}$, declarándose vecino de ella hasta su fallecimiento en $1577^{76}$. De todos modos tuvo casa tanto en Salamanca como en Segovia 77 , entre las que debía alternar su residencia estable, aunque los continuos desplazamientos para visitar las obras a su cargo le obligarían a permanecer algunos periodos de tiempo en las localidades donde trabajaba.

Rodrigo Gil estuvo unido sentimentalmente a Ana Ortiz Romero o Romera, de sobrenombre "la beata", a quien conoció en Lozoya (Madrid), pueblo cercano a Rascafría, y que vivió mucho tiempo en Salamanca. Al fallecimiento de Rodrigo en Segovia, Ana era vecina de Lozoya, aunque desde 1582 volvió a habitar en la casa que el cabildo había cedido al maestro en la ciudad del Tormes ${ }^{78}$. Tuvieron un hijo natural, nacido en Segovia, a quien Rodrigo sufragó los estudios en la Universidad de Salamanca, que profesó en 1548 en el convento de dominicos de San Esteban de esta última ciudad con el nombre de fray Juan de Sancti-Spiritus, y que murió en Chiapas (México). Sin embargo, por razones que se nos

\footnotetext{
heredera a la dha [dicha] maria gil de ontañon e como tal su hija e hered. a quiso y acepto los bienes y herencia de los dhos [dichos] sus padres y los tiene e posee", a lo que contestaron afirmativamente (Martí 1907a: 136-138).

67 Casaseca 1988: 27-29.

68 Pereda 1951: XXX.

69 Llaguno y Ceán 1829: vol. 1, 320-321.

70 Ruiz 2000: 33.

71 Martí 1907a: 36, 136-138.

72 Martí 1907a: 137; Pereda 1951: LXXVII, CXV.

73 Hoag 1985: 64; Martí 1907a: 141-142.

74 Pereda 1951: CX.

75 Chueca 1951: 145-153; Pereda 1951: CXLVII.

76 Se declara vecino de Salamanca sucesivamente en 1540, 1547, 1552, 1557, 1566, 1569, 1571, 1575 y 1577 (Bosarte 1804: vol. 1, 401 -404 doc. IX; Casaseca 1988: 149; Llaguno y Ceán 1829: vol. 1, 315; Pereda 1951: CXXIV, CCXLVII doc. 1, CCXLIX-CCLI doc. 3; Sendín 1977: 282-283 doc. XXVI, 284-285 doc. XXVIII, 287-288 doc. XXX).

77 Casaseca 1988: 35; Llaguno y Ceán 1829: vol. 1, 317, 321.

78 Casaseca 1988: 29-30; Llaguno y Ceán 1829: vol. 1, 323. Una de las obligaciones habituales del cabildo al contratar a un maestro mayor era la de proporcionarle casa; a la muerte de este era igualmente frecuente que se preocupara del bienestar de su viuda y herederos (Alonso 2012: 234-236).
} 
escapan, no fue reconocido por Rodrigo Gil como legítimo hasta 1572, y esto a través de coacciones de los dominicos ${ }^{79}$.

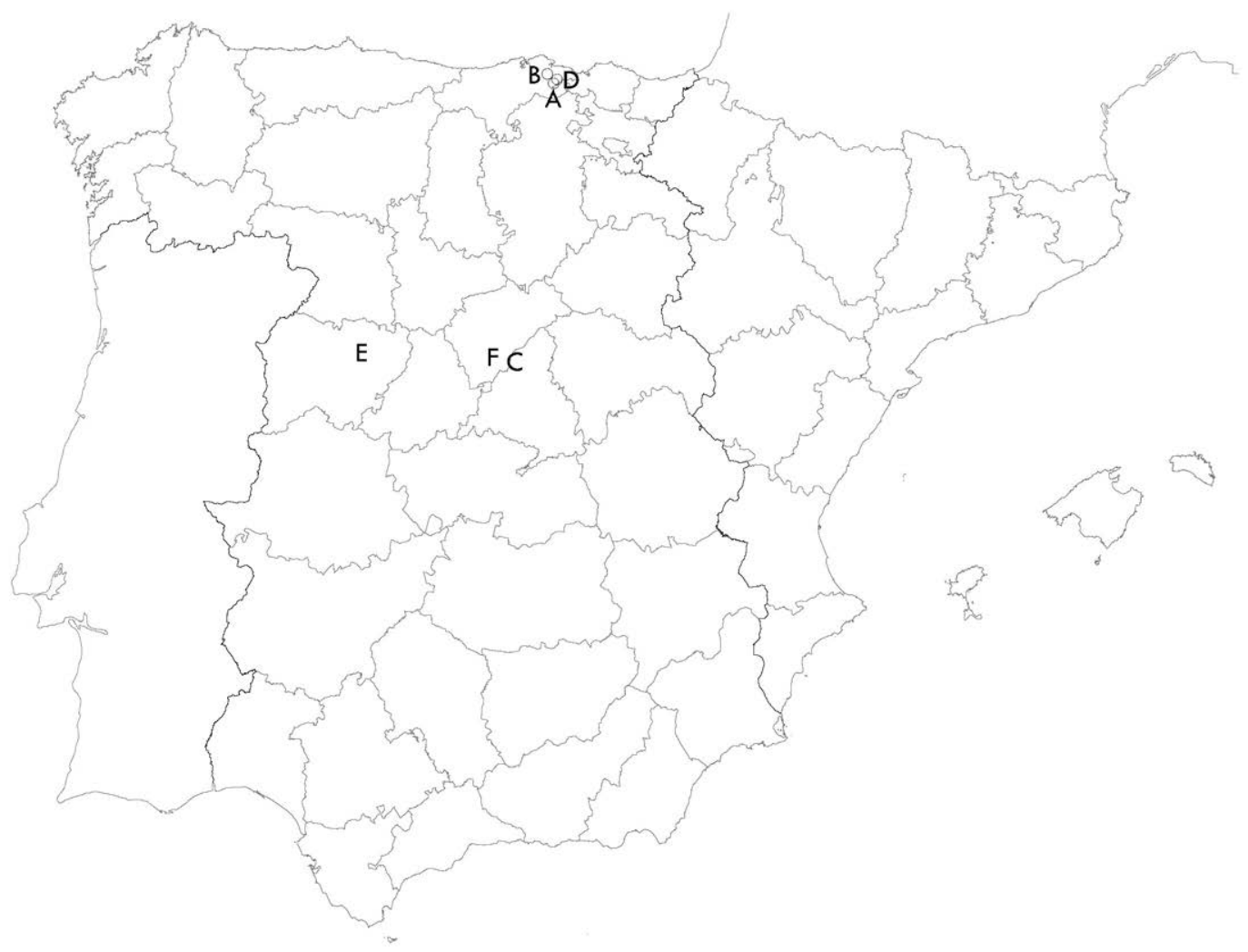

Figura 6. Localidades vinculadas a la trayectoria vital de Rodrigo Gil: A Gibaja, Ramales de la Victoria (Cantabria); B Hontañón, Carasa, Voto (Cantabria); C Rascafría (Madrid) (nacimiento); D Rasines (Cantabria) (origen familiar); E Salamanca (residencia habitual desde 1538); F Segovia (fallecimiento) (P. Moreno. IGN)

En 1576 se firmaban en Segovia las capitulaciones matrimoniales de Diego Gil de Gibaja y María Gil de Rivera, hija esta de Juan Gil de Rivera (vecinos ambos de Rascafría) y por tanto sobrina nieta de Rodrigo Gil. Este, que le tenía "particular afición", le dio una importante cantidad de dinero como dote, y le cedió las posesiones que su padre, Juan Gil de Hontañón, tuvo en Rasines, y que se describen como "una casa e solar e torre e tierras e vienes e arboles", enajenadas en ese momento, pero recuperadas tras la muerte de Rodrigo con cargo a su herencia e incorporadas al mayorazgo de Diego Gil de Gibaja ${ }^{80}{ }^{81}$.

\footnotetext{
79 Casaseca 1988: 29-30, 186-187.

80 Casaseca 1988: 23 nota 2, 34. Diego Gil de Gibaja se declaraba en 1580 y 1581 vecino de Segovia (Pereda 1951: CCLV-CCLVI doc. 5, CCLVI-CCLVII doc. 6).

81 Observamos en Casaseca $(1988: 27,29)$ una cierta confusión que a nuestro juicio se establece entre María Gil de Rivera y su sobrina homónima, ambas sobrina y sobrina nieta respectivamente de Rodrigo Gil. Dicha confusión aumenta si consultamos el árbol genealógico de los Hontañón elaborado por Casaseca (1988: 28 lám. B). A partir del resto de informaciones que da este autor (Casaseca 1988: 34) y del testamento y codicilo de Rodrigo Gil (Llaguno y Ceán 1829: vol. 1, 317, 320) hemos reconstruido la relación familiar como aquí queda recogida. Nos apoyamos además en el hecho de que esta María Gil para la que se preparan capitulaciones matrimoniales no puede ser verosímilmente sobrina de Rodrigo, sino sobrina nieta, por una simple cuestión de edad; ella se casaba en 1576, y al año siguiente su hermana estaba en edad casadera y su
} 
Tenemos constancia de que Rodrigo Gil, además de sufrir algún accidente laboral en $1556^{82}$, tuvo problemas de salud en distintas ocasiones a lo largo de su vida. Estuvo seriamente enfermo en 1552, llegándose a temer por su vida, y sufrió recaídas en 1564, 1572 y 1577 . De la última de ellas no se recuperaría, muriendo en Segovia a las seis de la mañana del 31 de mayo de 1577, a causa de una "enfermedad penosa de la orina" 0 anuria $^{83}$.

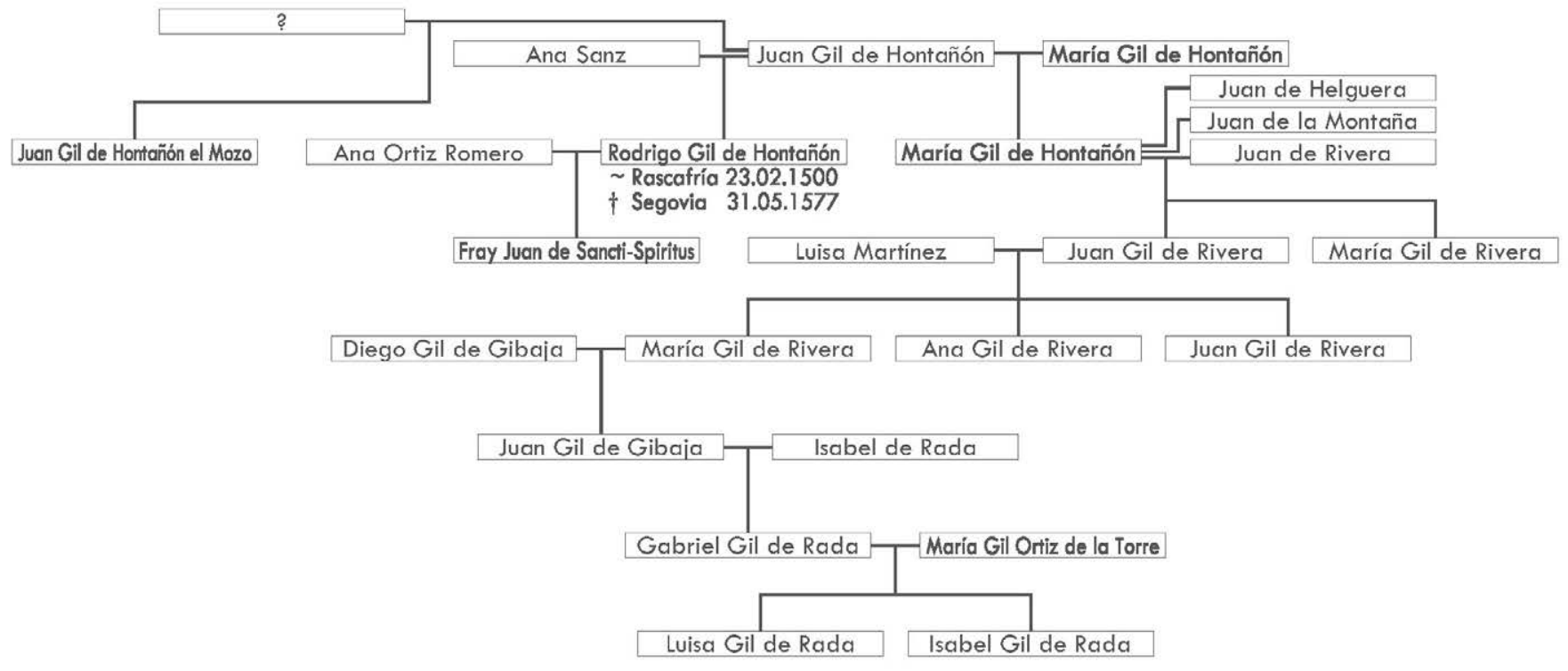

Figura 7. Árbol genealógico de Rodrigo Gil (P. Moreno). Elaborado a partir del de mediados del siglo XVII (Casaseca 1988: 26 lám. A. Archivo de la Diputación de Segovia), modifica parcialmente el confeccionado por Casaseca (1988: 28 lám. B)

El testamento de Rodrigo Gil fue protocolizado en Segovia el 27 de mayo de 1577, añadiéndosele antes del óbito dos codicilos, conservado solo el de 30 de mayo ${ }^{84}$. Las disposiciones relativas a la actividad profesional del maestro recordaban la necesidad de cobrar las deudas pendientes relativas a aquellas iglesias cuyas obras había dirigido, liquidar las cuentas con sus aparejadores y proseguir los pleitos emprendidos por causa de algunas de dichas obras ${ }^{85}$. En lo relativo a la herencia, los principales beneficiados fueron los hijos de su sobrino Juan Gil de Rivera, Ana y Juan ${ }^{86}$. Recordemos que ya había dotado a su sobrina nieta María Gil de Rivera, hermana de los anteriores, muy generosamente al contraer matrimonio en 1576. Mucho menos generoso fue con su hijo fray Juan de SanctiSpiritus, al que ya había donado una cantidad al ingresar en la Universidad de Salamanca, y al que posteriormente en 1572 había favorecido de modo indirecto al hacer importantes concesiones económicas a los dominicos de Salamanca a cuyo convento pertenecía ${ }^{87}$. Lo que no alcanzamos a comprender es la parquedad de la herencia dejada a su pareja Ana

\footnotetext{
hermano tenía pocos años. Además este análisis coincide con el árbol genealógico de mediados del siglo XVII publicado por el propio Casaseca (1988: 26 lám. A).

82 Chueca 1951: 245-248.

83 Casaseca 1988: 25, 29-31.

${ }^{84}$ Casaseca 1988: 33, 35; transcripción en Llaguno y Ceán 1829: vol. 1, 315-325.

85 Llaguno y Ceán 1829: vol. 1, 317-319, 324.

86 Llaguno y Ceán 1829: vol. 1, 317.

87 Casaseca 1988: 27, 29.
} 
Ortiz Romero, a quien solo recordó en el codicilo ${ }^{88}$, y que fue subsanada por sus testamentarios, conocedores según Casaseca ${ }^{89}$ del cariño que Rodrigo Gil le profesaba; quizás el otro codicilo, no conservado, incluyera alguna indicación al respecto. Una de las voluntades recogidas en el testamento era la fundación de una capilla y capellanía en la iglesia de San Andrés de Rasines, que sería panteón familiar, obligación adquirida en 1576 por Rodrigo Gil en las capitulaciones matrimoniales de su sobrina nieta María Gil de Rivera. La fundación de la capilla se encomendaba a su sobrino nieto político Diego Gil de Gibaja, marido de la anterior, que sería su primer patrono, pero nunca llegó a realizarse debido al parecer a la falta de recursos 90 . Otra de las voluntades era la creación de una Pía Memoria (u Obra Pía) destinada a socorrer a doncellas huérfanas, ancianos y viudas, dando preferencia a aquellas personas que demostrasen parentesco con el fundador, que fue efectivamente fundada y funcionó hasta su extinción a mediados del siglo XIX ${ }^{91}$.

Rodrigo Gil fue enterrado en la catedral de Segovia, y sobre la losa de su tumba se labró una inscripción junto con su escudo de armas, cuyos blasones, descritos por el propio Rodrigo en las capitulaciones matrimoniales de su sobrina nieta de 1576, consisten en "... una caldera e una banda en campo berde e siete aspas de San Andrés y un yelmo enlaçado con un brazo de hombre asido con la mano una espada de San Andrés", y corresponden a los "Xilones de Gibaja Hontañón"92. Gil de Gibaja Hontañón era el apellido que llevaba su sobrino nieto político, perteneciente a otra rama de la familia ${ }^{93}$, y como Rodrigo Gil de Gibaja Hontañón se conocía al maestro a comienzos del siglo XVII, como consta documentalmente ${ }^{94}$. La tumba se encontraba inicialmente situada en el trascoro de la catedral, según su voluntad, y su laude fue quizás sustituida en 1620. Con ocasión de la pavimentación del templo realizada a partir de 1787 la lápida fue trasladada al ángulo noreste del claustro, junto al acceso desde la nave, ignorándose si también fueron trasladados entonces sus restos 95 . Su letrero reza lo siguiente: "AQVI IACE RODRIGO GIL DE HOTANON MAES TRO DE LA OBRA DESTA S.A IGL.A FALLESCIO EN 31 DE MAIO DE 1577 EL QVAL ASETO LA PRIMERA PIEDRA QVE AQVI PVSO EL OBISPO DON DIEGO DE RIBERA EN 8 DE JVNIO DE 1525 AÑOS DEXO SV HACIENDA PARA OBRAS PIAS".
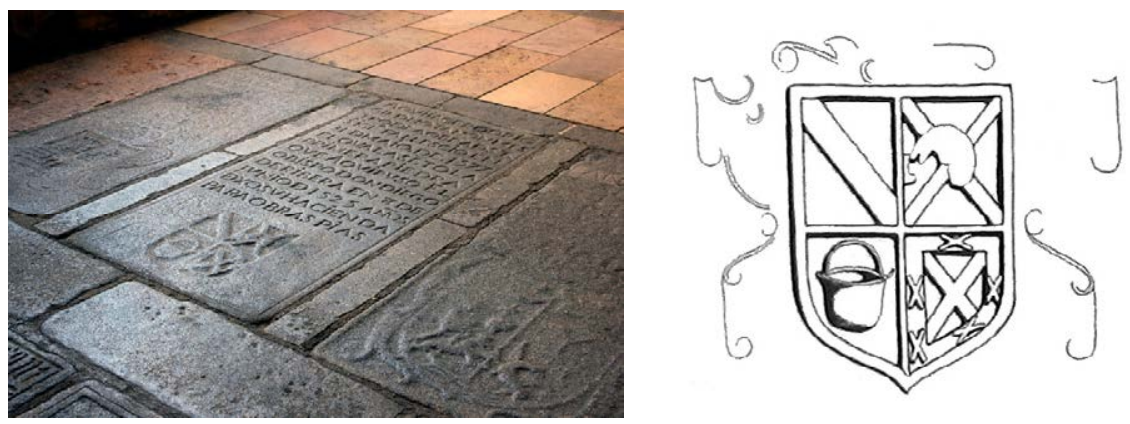

Figura 8. (a) Lápida de la tumba de Rodrigo Gil, en el ángulo noreste del claustro de la catedral de Segovia. (b) Detalle del escudo de armas, según Pérez y Pascual (1998: 42. Francisco Delgado)

\footnotetext{
88 Llaguno y Ceán 1829: vol. 1, 323-324.

89 Casaseca 1988: 30, 36.

90 Casaseca 1988: 34; Llaguno y Ceán 1829: vol. 1, 320-321.

91 Casaseca 1988: 35-36; Llaguno y Ceán 1829: vol. 1, $321-323$.

92 Casaseca 1988: 32.

93 Pereda 1951: CCLV-CCLVI doc. 5, CCLVI-CCLVII doc. 6.

94 Casaseca 1988: 32. La localidad de Gibaja pertenece al municipio de Ramales de la Victoria (Cantabria).

95 Merino 1996: 496.
} 
Para explicar la institución de un mayorazgo y la fundación de una capilla particular es quizás necesario hacer algunas aclaraciones de tipo histórico. Muchos de los canteros que trabajaban en España durante el siglo XVI procedían de La Montaña santanderina y de las provincias costeras vascas ${ }^{96}$. Rodrigo Gil, cuyos orígenes familiares se sitúan, como hemos dicho, en las localidades cántabras de Hontañón, Rasines y Gibaja, no constituía por tanto una figura aislada, sino que se integraba en un grupo social muy numeroso. Desde finales de la Edad Media y a lo largo de toda la Edad Moderna las cuencas de los ríos Asón y Agüera, situadas en el oriente de esta región, en la zona limítrofe con el País Vasco, se convirtieron en un vivero de artesanos y artistas de distintos oficios. La margen del Asón, en concreto, constituye el límite oriental de la Merindad de Trasmiera, a la que pertenece la Junta de Voto, considerada por los estudiosos el crisol de los artistas en Cantabria, especialmente de la cantería y la escultura ${ }^{97}$. A la Junta de Voto pertenecía Hontañón, y en el valle del Asón se encuentran Rasines, Gibaja y otros lugares que dan apellido a muchos de estos artífices (Lanestosa, Ramales, Cubillas, Helguera...).

La región cántabra se caracterizaba históricamente por la importante proporción de hidalgos, no sujetos a servidumbre, que integraba la población, y que, según los lugares, podía llegar al 90 o al 100\% de los vecinos; el censo de población de 1541, por ejemplo, computaba para la Merindad de Trasmiera un total de 2306 vecinos, todos ellos hidalgos ${ }^{98}$. Estos individuos, que, aunque carecían de título, pertenecían al estamento noble, poseían habitualmente escasos recursos, lo cual les obligaba a tomar un oficio, si bien sus privilegios no sufrían menoscabo alguno por ello99. No hemos encontrado una explicación satisfactoria, salvo la existencia de canteras en la zona, para el hecho de que eligieran mayoritariamente el oficio de cantero y no otro cualquiera en su lugar, pero la realidad es que así era. La libertad de movimiento que les proporcionaba su condición, unida a la necesidad, hacían que muchos de ellos decidieran emigrar, trabajando durante largas temporadas en otros puntos del país y volviendo en ocasiones a su lugar de origen para hacer la invernada (con frecuencia pasaban uno o dos meses en casa, cuando el mal tiempo hacía imposible el trabajo en la cantera o en la obra ${ }^{100}$ ). La emigración era muy ventajosa económicamente para ellos; como ejemplo, hacia 1600 los jornales de trabajo en la cantería se estimaban en la Junta de Voto en un real diario, mientras que en la meseta castellana alcanzaban los tres reales ${ }^{101}$. Por otro lado, durante la primera mitad del siglo XVI existía en la meseta una gran demanda de mano de obra, que explicaría, al menos en parte, el inicio de una tendencia que continuaría durante los siglos posteriores.

La categoría de hidalgo, por tanto, no estaba asociada en Cantabria con un superior estatus económico, por lo que aquellos que llegaban a alcanzarlo no se conformaban con su simple disfrute: aspiraban a la fundación de un mayorazgo, que vinculaba en una misma familia parte del patrimonio del fundador, constituido habitualmente por tierras, que eran explotadas directamente por medio de criados $\circ$ bien dadas en arrendamiento para obtener las correspondientes rentas. Esta vinculación patrimonial aseguraba la preeminencia económica, el prestigio social y en definitiva la supervivencia del nombre, del blasón y del solar del fundador, y se veía favorecida por la endogamia, que evitaba la disgregación de

\footnotetext{
96 Ealo 2009: 98; Gómez 1998: 45-52.

97 Aramburu-Zabala 2003: 92; Hoag 1985: 64; Pereda 1951: XI.

98 Crespo 2003b: 425; Pérez 2003: 408.

99 Aramburu-Zabala 2003: 93-94; Pérez 2003: 408.

100 Hoag 1985: 64.

101 Aramburu-Zabala 2003: 93-94.
} 
los bienes familiares libres, esto es, no vinculados al mayorazgo ${ }^{102}$. Este intento de perpetuar el linaje familiar se manifestaba también de modo frecuente en la fundación de capillas particulares dentro de los templos, cuyas inscripciones y escudos heráldicos son otra muestra de autoafirmación ${ }^{103}$.

Rodrigo Gil es ejemplo de todos estos comportamientos, comunes a la hidalguía cántabra adinerada de la época. El mayorazgo instituido en la figura del cantero Diego Gil de Gibaja, que se casaba con su sobrina nieta María Gil de Rivera y que además pertenecía a otra rama de su familia, refleja esa tendencia a las relaciones endogámicas, tanto familiares como gremiales. La preocupación por describir el escudo de la familia y la voluntad de fundar una capilla particular evidencian el mismo deseo de perduración ${ }^{104}$.

\subsubsection{Contexto histórico}

\subsubsection{La renovación arquitectónica de la segunda mitad del siglo XV}

Durante el siglo XIV la situación artística en los reinos peninsulares era desigual. Aunque la Corona de Aragón experimentaba un florecimiento arquitectónico, relacionado con el comercio del Mediterráneo, la de Castilla, por el contrario, atravesaba una época de penuria, guerras civiles y estancamiento artístico: continuaba la construcción de las grandes catedrales sin la introducción de innovaciones, y los edificios que se comenzaban estaban frecuentemente marcados bien por la utilización de arcaísmos góticos o bien por la de modelos musulmanes de tipo mudéjar ${ }^{105}$.

Las primeras muestras de renovación artística comenzaron a producirse en la arquitectura española a partir del segundo tercio del siglo XV, con la introducción del denominado arte flamenco. Con este apelativo se designa al producido por artistas procedentes no solo de Flandes, sino también de distintas zonas donde alcanzaba tanto la influencia flamenca como la borgoñona, desde el noroeste de Francia (como Bretaña) hasta el oeste de Alemania (como Renania). Por una parte, desde mediados del siglo XIV el ducado de Borgoña empezó a cobrar una gran importancia política, extendiéndose hasta Flandes y los Países Bajos; por otra, la potente industria textil desarrollada en estas regiones había fomentado, ya desde antes del siglo XIII pero especialmente durante el XV, las relaciones comerciales entre Flandes y Castilla, que poseía una gran producción de lana y una importante flota para transportarla. El desarrollo artístico producido en dichas regiones, unido a su influencia política y a los vínculos económicos, hizo nacer el deseo de los obispos españoles de renovar el anquilosado repertorio utilizado por los maestros castellanos ${ }^{106}$.

Dejando al margen la escuela de cantería levantina, que desarrolló una trayectoria en cierto modo independiente, los focos principales de expansión de estas innovaciones

\footnotetext{
102 Crespo 2003b: 427-428.

103 Crespo 2003b: $432,434$.

104 Un comportamiento similar lo encontramos en Juan del Ribero Rada, que trabajó junto a Rodrigo Gil en algunas obras al final de la carrera profesional de este, y que instituyó igualmente un mayorazgo en la persona de su primogénito, fundando una sepultura familiar en la Catedral Nueva de Salamanca (Pérez 2003: 410).

105 Merino 1995: 17. Sobre la arquitectura en el ámbito mediterráneo, véanse Mira y Zaragozá 2003; Zaragozá 2000.

106 Merino 1995: 18-21.
} 
artísticas fueron en Castilla las catedrales de Burgos y Toledo, y sus promotores los obispos Alonso de Cartagena y Juan de Cerezuela, respectivamente. Juan $\circ$ Hans de Colonia $(† 1481)$ se trasladó a Burgos en 1431, probablemente procedente de la corte de los duques de Borgoña, iniciando una saga familiar constituida por su hijo Simón y su nieto Francisco, y una escuela a la que se sumarían otros extranjeros como Gil de Siloé y su hijo Diego, o el borgoñón Felipe Bigarny. Por otro lado la escuela toledana inició su andadura durante el periodo 1434-1442, impulsada por una parte por el maestro flamenco Hanequin Coeman de Bruselas y sus dos hermanos, Egas Coeman (padre de Antón y Enrique Egas) y Antón Martínez de Bruselas; y por otra por el bretón Pedro Guas y su hijo Juan, venidos a Toledo con los anteriores. Simón de Colonia $(\dagger 1511)$ sería la figura del foco burgalés con mayor influencia sobre los maestros hispanos, mientras que Juan Guas (†1495) se convertiría en la gran personalidad del foco toledano. A la larga la escuela del gótico burgalés, alimentada por fuentes más modernas, cobraría preeminencia sobre la toledana, que, por otro lado, comenzaría pronto a desviarse hacia la arquitectura renacentista ${ }^{107}$.

Todos estos maestros centroeuropeos, cuya influencia se hizo especialmente acusada desde el enlace entre Juana "la Loca" y Felipe "el Hermoso" en 1496, trajeron a la arquitectura una importante renovación tanto de la concepción espacial, estructural y estética como de las técnicas constructivas.

\subsubsection{Juan Gil de Hontañón}

Fue precisamente Juan Gil de Hontañón, padre de Rodrigo Gil, el principal exponente de la primera generación de canteros hispanos surgida tras esta llegada a nuestro país de maestros flamencos, alemanes y bretones, y uno de los que mejor supieron combinar las doctrinas de las escuelas de cantería toledana y burgalesa. Se formó inicialmente en el taller de Juan Guas, como otros importantes canteros castellanos, entre los que encontramos a Martín Ruiz de Solórzano (†1506), Juan de Ruesga (†a.1511) o García de Cubillas. Posteriormente, al intervenir, como Solórzano y Ruesga, en las obras de la catedral de Palencia, se situó bajo la influencia de la escuela burgalesa liderada por Simón de Colonia. Juan Gil, uno de los maestros más relevantes del gótico tardío español, llegaría a trabajar a lo largo de su vida en algunos de los edificios religiosos más importantes del momento, así como para destacados miembros de la alta nobleza y clero castellanos ${ }^{108}$.

Nacido en Rasines (Cantabria) probablemente hacia 1470, sus comienzos profesionales se sitúan en la última década del siglo XV, interviniendo en algunas obras de su maestro a la muerte de este en 1496, como la portada del monasterio de Santa María del Parral en Segovia, antes de 1500, o la cartuja de Santa María de El Paular en Rascafría (Madrid), ya a comienzos del siglo XVI, apareciendo entonces como avecindado en Rascafría, donde fue bautizado su hijo Rodrigo. Durante estos primeros años lo encontramos trabajando en una portada en la catedral de Sigüenza (Guadalajara), junto con Cristóbal Adonça (1500); en la escalera del zaguán del Colegio Mayor de San Ildefonso en Alcalá de Henares (Madrid) (1502); en el proyecto de la iglesia de Santa María la Mayor en Coca (Segovia) (1503-1504); y en el castillo de Turégano (Segovia).

107 Gómez 1998: 45-52; Merino 1995: 18-21. Sin embargo, sería Diego de Siloé el primer maestro que construyera bóvedas de crucería casetonada en España (Gómez 1998: 114-118).

108 Alonso 2000: 153, 158; Alonso 2009: [7-8]; Aramburu-Zabala 2003: 93-94; Gómez 1998: 45-52. Hoag

(1985: 21 4-215), de hecho, considera a Juan Gil heredero del estilo de Simón de Colonia. 
Al poco tiempo lo vemos ya encargándose de trabajos de envergadura, como el claustro y sala capitular de la catedral de Palencia (a partir de 1505) y la capilla mayor y librería de la antigua catedral de Segovia (a partir de 1508 o 1509). En 1509 se obligaba a construir la iglesia parroquial de Almorox (Toledo). Sin duda en ese momento era un maestro altamente acreditado, ya que en 1512 fue llamado a Salamanca para participar en la junta de nueve maestros que concretaron la traza de la Catedral Nueva, y fue elegido de entre ellos para dirigir sus obras como maestro mayor, cargo que ostentaría hasta su muerte. Comenzó inmediatamente las obras, acudiendo también en 1512 a Granada para inspeccionar y tasar las obras de la Capilla Real, junto con Martín de Bruselas y Juan de Ruesga, visita que quizás repitió en 1514. En 1513 fue nombrado maestro mayor de la catedral de Sevilla, después del hundimiento del cimborrio ocurrido en 1511, compartiendo este cargo con Alonso Rodríguez en una maestría doble; Juan Gil dio trazas en 1513 junto con Juan de Badajoz y Juan de Álava para la reparación de la capilla mayor; en 1514 las dio para el cimborrio y las tres bóvedas que lo rodean, cuya construcción supervisaba con Enrique Egas y Juan de Álava en 1515; cerró el nuevo cimborrio en 1517, concluyendo las obras en 1519, año en que ya no ostentaba la maestría. En 1516 visitó el monasterio de Nuestra Señora de la Piedad en Casalarreina (La Rioja). En 1518 se reunió en Santiago de Compostela (A Coruña) con Juan de Álava, Juan de Badajoz y Alonso de Covarrubias para tratar sobre el claustro de la catedral. En 1521 se le llamó de nuevo a Granada, esta vez para entender en las trazas de la catedral junto con Enrique Egas, aunque no sabemos si acudió.

En los últimos años de su vida comenzó algunas obras que serían continuadas por su hijo Rodrigo, como la construcción del primer tramo de naves de la colegiata de San Antolín en Medina del Campo (Valladolid), contratada en 1521, la capilla del deán Cepeda en el convento de San Francisco de Zamora, contratada en 1523, y la cabecera y crucero de la iglesia de la Asunción de Nuestra Señora en Villamor de los Escuderos (Zamora), contratada en 1524; este mismo año fue nombrado maestro mayor de la catedral de Segovia y dio trazas para su construcción, comenzando las obras en 1525. Hacia 1524 (o quizás ya antes) intervino en la iglesia del monasterio de Santa Clara en Briviesca (Burgos). En 1524 y 1525 trabajaba también en Cuéllar (Segovia) a la vez que era maestro de las obras del duque del Infantado 109. Antes de abril de 1526 participaba junto con su hijo Rodrigo, Diego de Riaño, Juan de Álava y Francisco de Colonia en una junta de maestros reunida en Valladolid con el fin de elaborar las trazas para la construcción de una nueva colegiata ${ }^{110}$. Murió entre el 27 de marzo y el 4 de abril de dicho año, en una fecha aún por precisar ${ }^{11}$.

\subsubsection{Cambios en la arquitectura}

Rodrigo Gil, formado al lado de su padre112, asimiló a través de él y de otros contactos profesionales buena parte de las aportaciones que, como hemos comentado, venían haciendo los maestros centroeuropeos llegados a nuestro país desde mediados del siglo XV, así como otros elementos procedentes de la tradición hispana anterior y del Renacimiento

\footnotetext{
109 Alonso 2005: 21-24, 26-27, 29; Casaseca 1988: 242; Castro 2003a: 154-156; Chueca 1951: 241-242; González et al. 1991: 245-246; Hoag 1985: 99; Pereda 1951: XXII-XXVIII, LXX-CIII; Río 2001: 140, citado en Alonso 2015: 34; Ruiz 2000: 28; Sendín 1977: 188.

110 Alonso 2004: 39-41; Casaseca 1988: 96-97.

111 Casaseca 1988: 87; Hoag 1985: 66.

112 Casaseca 1988: 37; Pereda 1951: LXIII-LXIV; Sendín 1977: 192-193.
} 
italiano que comenzó a penetrar en la Península a finales de la centuria. Estas innovaciones afectan tanto a la naturaleza del espacio arquitectónico como a distintos aspectos estructurales y decorativos del edificio.

\subsection{Espacio y estructura}

Una de las principales innovaciones que se produjeron en la concepción espacial y estructural de los templos fue la introducción del modelo de iglesia de salón, es decir, aquella cuyas naves se elevan a la misma altura, generando un espacio unitario que queda definido por la caja muraria y evitando la compartimentación espacial del gótico clásico, cuyo sistema de iluminación se ve por otro lado alterado. La consecución de este espacio hace que el modelo carezca habitualmente de crucero marcado, girola o cimborrio ${ }^{13}$. Esta tipología, conocida por el término alemán hallenkirche, apareció en Castilla a finales del siglo XV o comienzos del XVI, siendo utilizada con frecuencia durante la mayor parte de la centuria, fundamentalmente para templos parroquiales 114 . Su origen es discutido, dividiéndose los estudiosos entre aquellos que opinan que fue directamente importada de la zona del Bajo Rin y Westfalia, y los que por el contrario piensan que el modelo fue extendido por las dos Castillas por los canteros vascos y montañeses ${ }^{115}$. Según Gómez Martínez ${ }^{116}$ ambas teorías pueden ser válidas, ya que la tipología pudo ser introducida por Juan y Simón de Colonia, maestros del foco burgalés, y desde allí extendida por otros canteros españoles de su círculo. El primer ejemplo, atribuido a estos dos maestros, lo podría haber constituido la catedral de Astorga (León), comenzada en 1471, si bien sus naves se cubrieron finalmente a distinta altura y su planta sufrió varias alteraciones; en ella observamos características directamente importadas de los modelos germanos, como el triple ábside y la proporción alargada de la planta, por encima de la dupla $(2: 1)^{117}$. Para Hoag ${ }^{118}$ uno de los primeros maestros hispanos que utilizaron este modelo fue precisamente Juan Gil de Hontañón, quien, según él, quizás lo planteó hacia 1503 para la colegiata de San Antolín en Medina del Campo (Valladolid), aunque los únicos datos documentales que tenemos no relacionan al maestro con la construcción hasta 1521. El tipo fue empleado por Rodrigo Gil en gran número de iglesias, entre las que podemos destacar la de San Sebastián en Villacastín (Segovia) y la de San Martín en Mota del Marqués (Valladolid). Dos de ellas, la de Santiago de los Caballeros en Medina de Rioseco (Valladolid) y la de Santiago Apóstol en Cigales (Valladolid) conservan como arcaísmo el ábside triple. Por lo que respecta a las proporciones de la planta, los tres métodos geométricos recogidos en el manuscrito de Hontañón para el trazado de templos tanto de tres naves, como son en general las iglesias de salón, como de cinco, generan siempre una planta de proporción dupla $(2: 1)^{119}$, considerada en el texto como recomendable ${ }^{120}$; si examinamos las iglesias de tres naves trazadas por este maestro comprobamos, en líneas generales, el empleo de

\footnotetext{
113 Gómez 1998: 202-206.

114 Gómez 1998: 214.

115 Hoag 1985: 20-21; Polo 2004: 189-191; Weise 1953: 3-4.

116 Gómez 1998: 202-206.

117 Gómez 1998: 202-206.

118 Hoag 1985: 20-21.

119 García 1681: cap. 5: $11 v-12 v$, ilustración 12r (método 1); cap. 5: 12v-13r, ilustración 13r (método 2); cap.

5: $13 \mathrm{v}-14 \mathrm{v}$, ilustración $14 \mathrm{r}$ (método 3).

120 García 1681: cap. 5: 14v.
} 
dicha relación. Esta es utilizada únicamente en España, según Hoag ${ }^{121}$, pudiendo encontrarla, por ejemplo, en la planta de la catedral de Toledo, iniciada en el siglo XIII, y en la de Granada, comenzada en el XVI tomando como modelo aquella ${ }^{122}$. Por tanto, la tipología de iglesia de salón, de origen centroeuropeo, se desarrollaría sobre una planta de carácter hispano que se remonta al menos al siglo XIII, asimilada por Rodrigo a través de su padre.
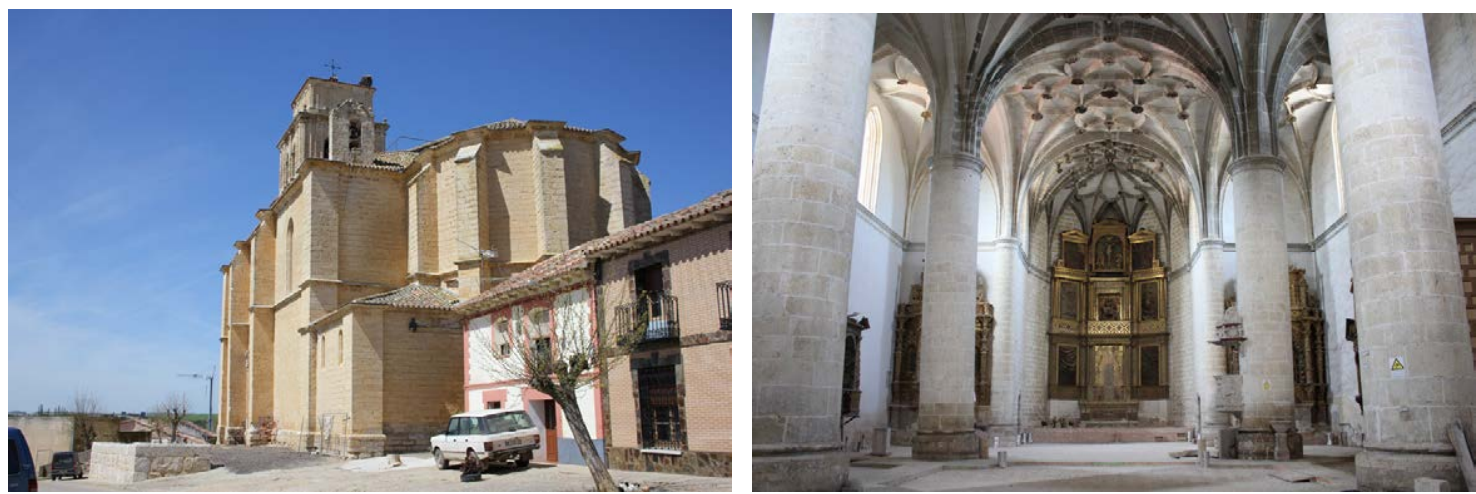

Figura 9. Una de las iglesias de salón trazadas por Rodrigo Gil: $(a, b)$ Iglesia de San Martín, Mota del Marqués (Valladolid)
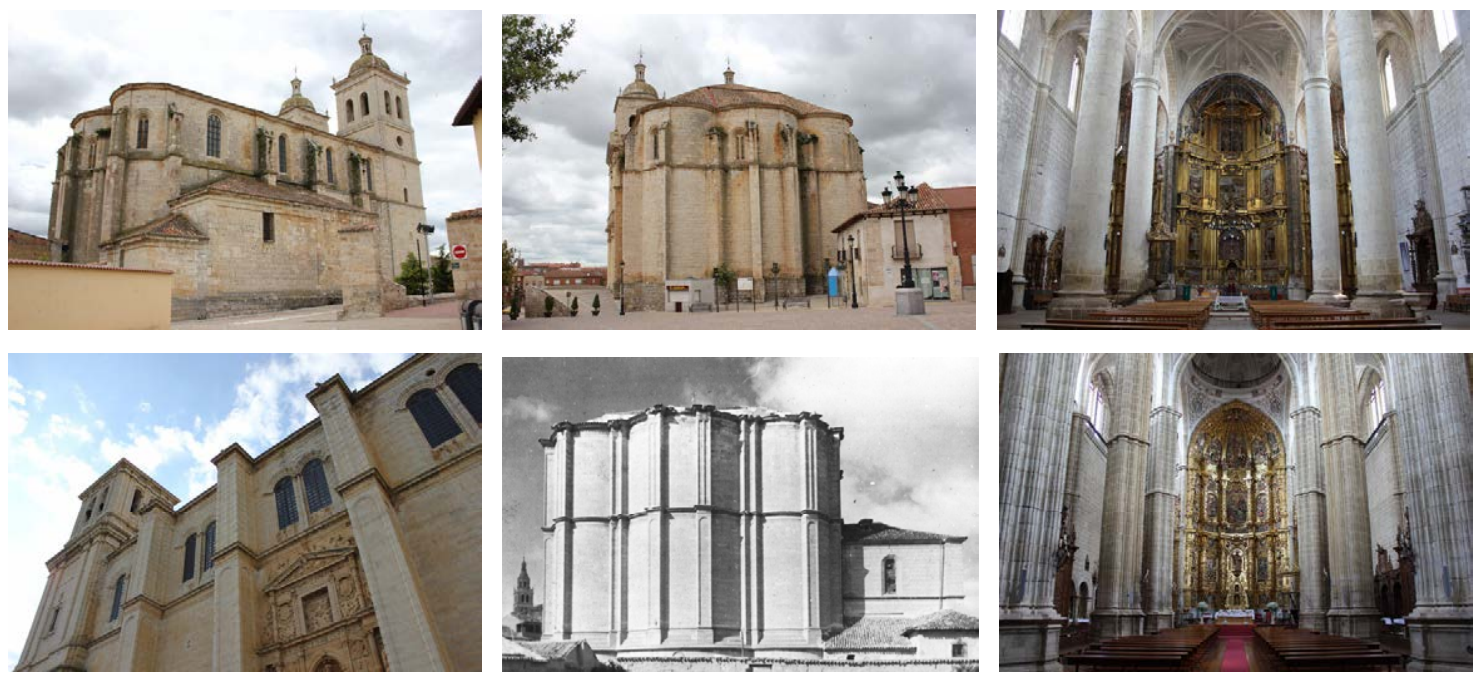

Figura 10. Iglesias de salón con ábside triple trazadas por Rodrigo Gil: $(a, b, c)$ Iglesia de Santiago Apóstol, Cigales (Valladolid). (d, e, f) Iglesia de Santiago de los Caballeros, Medina de Rioseco (Valladolid) (e: Hoag 1985: 90 fig. XVI. Garay)
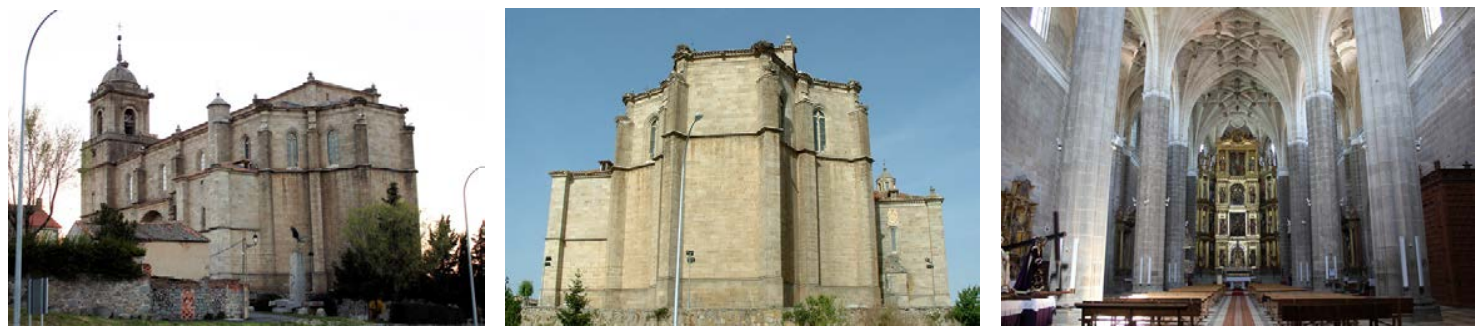

Figura 11. Iglesias de salón con cabecera trebolada o triconque trazadas por Rodrigo Gil: $(a, b, c)$ Iglesia de San Sebastián, Villacastín (Segovia) (b: www.gotik-romanik.de)

\footnotetext{
121 Hoag 1985: 17-20.

122 Lampérez [1908-1909] 1999: vol. 1, 70-72, 78-79, 85.
} 
Otros cambios se introdujeron en la planta de los templos, como la cabecera trebolada o triconque, consistente en un tramo cuadrado con tres de sus lados ocupados por ábsides poligonales (normalmente semihexagonales) y el cuarto abierto a la nave. El primer ejemplo de este tipo, quizás de inspiración germánica, se debe a Juan Guas, de nuevo un maestro de origen extranjero, y lo encontramos en la capilla mayor de la iglesia del monasterio de Santa María del Parral en Segovia, construida entre 1472 y 1485 . Juan Gil de Hontañón la utilizó en la iglesia de Santa María la Mayor en Coca (Segovia), y quizás en la del convento de San Francisco en Medina de Rioseco (Valladolid), que se le atribuye, y su hijo la volvió a emplear en la iglesia de San Sebastián en Villacastín (Segovia) ${ }^{123}$. El espacio generado en el presbiterio de estas cabeceras puede recordar al de una capilla de planta centralizada, como la que forma la cabecera de la iglesia del monasterio de San Salvador de Oña (Burgos), la primera de este tipo, trazada y construida por Juan de Colonia entre 1463 y 1470; o como la del Condestable de la catedral de Burgos, comenzada por Simón de Colonia en 1482 y cuya bóveda ya estaba cerrada en 1492; esta última, convertida en arquetipo de la época, fue tomada por Juan Gil de Hontañón como modelo para la cabecera de la iglesia del monasterio de Santa Clara en Briviesca (Burgos), pero nunca por su hijo para otras construcciones ${ }^{124}$.

Junto a los cambios operados en las plantas, también se produjeron renovaciones en la sección de los edificios religiosos, como la aparición del cimborrio. Este elemento, que tenía su precedente directo en la linterna románica de la alta Edad Media, había desaparecido con la irrupción del gótico, y fueron de nuevo maestros de origen centroeuropeo quienes lo reintrodujeron. El primero de estos cimborrios es el trazado por Juan de Colonia para el crucero de la catedral de Burgos, en construcción en 1466 (reconstruido tras su hundimiento en 1539, y terminado en 1567 por Juan de Vallejo); a este le siguieron el diseñado por Juan Guas en 1477 para la iglesia del monasterio de San Juan de los Reyes en Toledo, cuya bóveda debía estar cerrada en 1486; y el trazado por Simón de Colonia en 1495 para el crucero de la catedral de Sevilla, terminado por Alonso Rodríguez en 1506 y hundido en 1511. Los tres son de planta octogonal, si bien pronto comenzó a utilizarse también la planta cuadrada: tal es el caso de los cimborrios trazados por Antón y Enrique Egas para el crucero del Hospital de los Reyes Católicos en Santiago de Compostela (A Coruña) (1499-1527) y el Hospital de Santa Cruz en Toledo (1504-1514). Juan Gil de Hontañón se encargó de reconstruir el cimborrio de la catedral de Sevilla entre 1513 y 1517, utilizando la planta cuadrada, y a él se atribuye el de planta octogonal colocado sobre el crucero de la iglesia del convento de San Francisco en Medina de Rioseco (Valladolid). Su hijo solo empleó la planta cuadrada en los tres cimborrios por él trazados: el de la iglesia de Santa Ana en Peñaranda de Duero (Burgos) y los de las capillas del Colegio Mayor del Arzobispo Fonseca y del convento de San Esteban, ambos en Salamanca ${ }^{125}$.

Por último, un elemento que se incorporó al alzado de los edificios religiosos fue la flecha calada como remate de las torres. Las primeras agujas construidas en nuestro país fueron las que levantó Juan de Colonia, a partir de 1453, para la fachada occidental de la catedral de Burgos. El modelo fue seguidamente empleado en la torre sur de la catedral de León, relacionada también con Juan de Colonia, y sería de nuevo utilizado en la torre de la catedral de Oviedo (Asturias), cuyo diseño se atribuye a su hijo Simón. Estas tres flechas

\footnotetext{
123 Gómez 1998: 69-70; Hoag 1985: 27-28.

124 Gómez 1998: 67-68, 91; Hoag 1985: 23-26.

125 Gómez 1998: 70-74; Hoag 1985: 17-20.
} 
estarían vinculadas con las que pueden encontrarse en dos zonas de Centroeuropa, cercanas entre sí: por una parte Colonia, y, por otra, el área geográfica formada por Friburgo de Brisgovia, Basilea, Estrasburgo y Ulm. La flecha de Oviedo, destruida por un rayo en 1575, fue rediseñada por Rodrigo Gil, quien probablemente mantuvo su disposición general primitiva, con un cuerpo de apoyo octogonal sobre el que se dispone la aguja, torrecillas en los ángulos y balcón perimetral, modernizando formalmente el conjunto ${ }^{126}$.
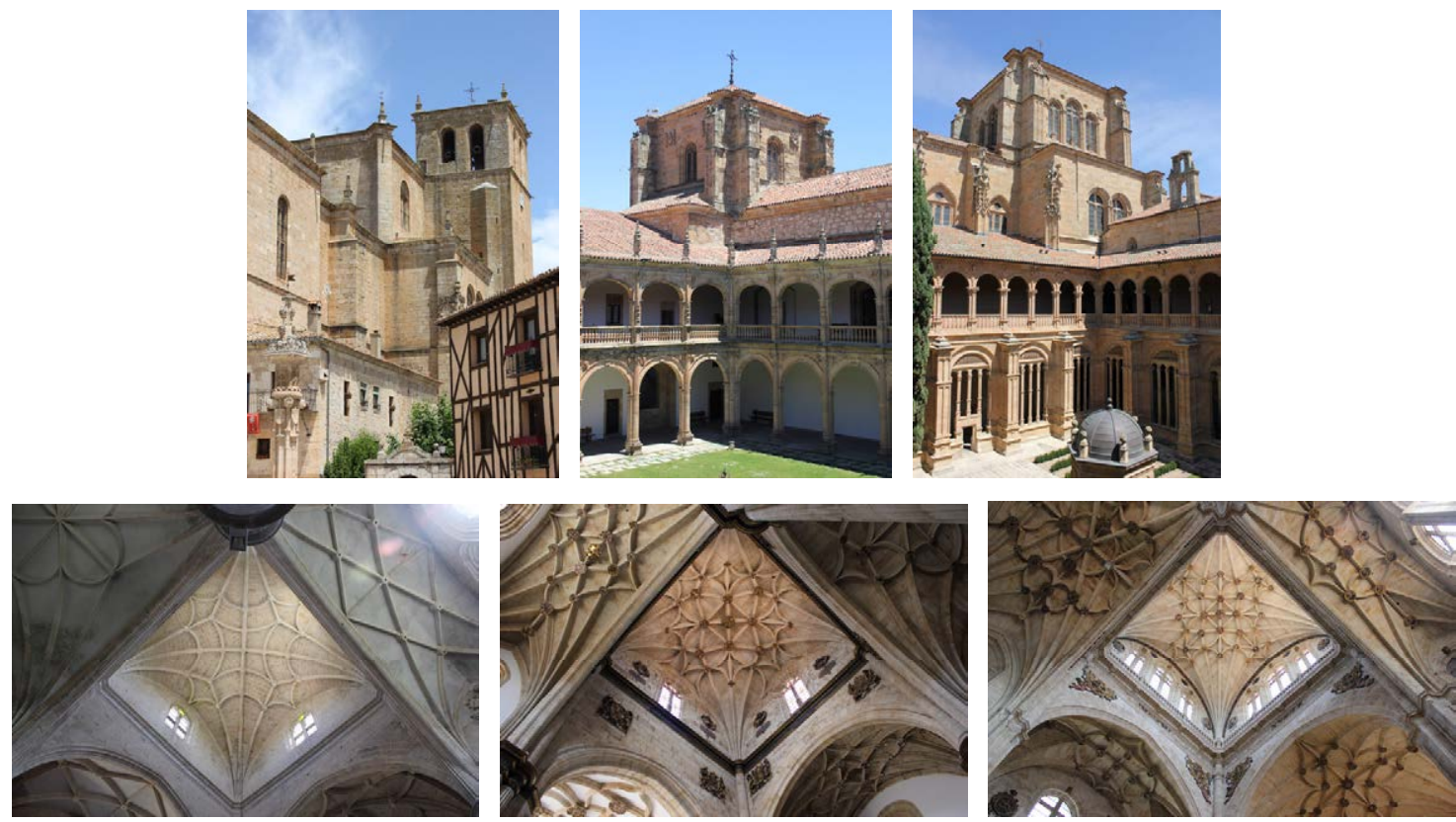

Figura 12. Cimborrios de planta cuadrada trazados por Rodrigo Gil: (a, d) Iglesia de Santa Ana, Peñaranda de Duero (Burgos). (b, e) Capilla del Colegio Mayor del Arzobispo Fonseca, Salamanca. (c, f) Iglesia del convento de San Esteban, Salamanca
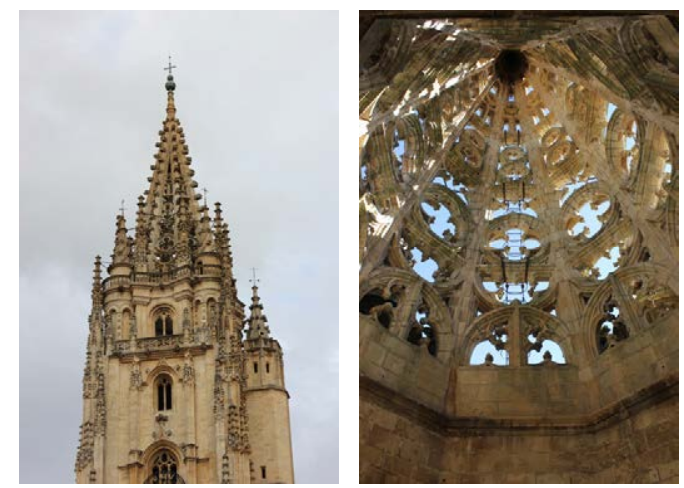

Figura 13. Agujas trazadas por Rodrigo Gil: $(a, b)$ Torre de la catedral de Oviedo (Asturias)

\subsection{Bóvedas}

La tremenda revolución operada en las bóvedas españolas de la época, cuestión de particular interés para nuestro estudio, fue llevada a cabo por maestros centroeuropeos, dentro del contexto de renovación arquitectónica de la época. Efectivamente, hasta la llegada de estos maestros únicamente eran utilizadas en nuestro país las bóvedas cuatripartitas en simple cruce de ojivas, las bóvedas sexpartitas (que incorporan un nervio

126 García 2013: 30, 33-37, 40-41. 
de través y duplican los formeros) y las octopartitas (que introducen dos nervios de ligadura), sin emplearse siquiera los terceletes ${ }^{127}$. Por ello la introducción de estos últimos $y$, sobre todo, de los nervios decorativos en las bóvedas de crucería fue verdaderamente innovadora. La primera bóveda construida en España en la que aparecen nervios decorativos curvos, denominados "combados", es quizás la que cubre el ángulo noreste del claustro de la catedral de Segovia, construido por Juan Guas entre 1471 y 1486, que presenta una figura de cuatro lóbulos circulares limitada por las claves de los terceletes. Esta bóveda guarda semejanza con las construidas por Simón de Colonia entre 1495 y 1503 en el claustro del monasterio de San Salvador de Oña (Burgos), en este caso con una figura de cuatro lóbulos conopiales. No obstante, la primera en la que los nervios combados no se limitan a la zona central sino que ocupan toda la superficie es la que cubre el crucero de la catedral de Palencia, cerrada en 1496, siendo maestro de la obra Bartolomé de Solórzano ${ }^{128}$. Tanto Hoag como Gómez Martínez ${ }^{129}$ atribuyen su trazado a Simón de Colonia, que trabajaba entonces en la ciudad. Este primer diseño polar en cuadrifolio, con dos hojas conopiales y dos convexas, abriría el camino a la multitud de variaciones desarrolladas posteriormente en el gótico hispano ${ }^{130}$. En pocos años las bóvedas con nervios curvos se hicieron habituales, generalizándose un modelo que superpone un diseño polar de combados a la estructura básica de una bóveda de terceletes con cinco claves, y que enfatiza la separación entre los distintos tramos. Esto ocurriría en claro detrimento de las bóvedas con nervios decorativos rectos, como las utilizadas en el seno de la escuela toledana, y de los diseños de tipo reticular, relacionados con modelos centroeuropeos y empleados en nuestro país casi con exclusividad por Juan de Álava ${ }^{131} 132$.

Juan Gil de Hontañón incorporó rápidamente los nervios decorativos curvos a sus trazados, manteniendo siempre, según la tendencia general, el patrón básico de cruceros y terceletes y una clara diferenciación entre los distintos tramos, y no utilizando nunca los terceletes incurvados que aparecen en la bóveda del modelo palentino ${ }^{133}$, características todas ellas que se pueden extender a Rodrigo Gil. En las bóvedas del claustro de la catedral de Palencia, construidas por Juan Gil, encontramos ya todo un repertorio de modelos que constituyen el germen de muchas de las que posteriormente trazó su hijo, consistentes en una bóveda de cinco claves a la que se añade un cuadrifolio de hojas conopiales o cóncavas, y que se puede combinar con otros elementos interiores, como rombos de lados quebrados,

\footnotetext{
127 Gómez 1998: 48.

128 Gómez 1998: 90-94.

129 Gómez 1998: 90-94; Hoag 1985: 28-36.

130 Por lo que respecta a Portugal, las primeras bóvedas con nervios decorativos curvos construidas en este país son las que cubren la capilla mayor de la catedral de Braga, realizadas entre 1505 y 1509 por el maestro de origen cántabro Juan de Castillo (Ealo 2009: 186-191).

131 Gómez 1998: 96, 100.

132 La fragmentación visual de los distintos tramos, debida a la utilización de arcos perpiaños de sección mucho mayor que el resto de los nervios de la bóveda, y la concentración de los nervios decorativos en la parte central de esta son efectivamente características identificadas como invariantes en las bóvedas de crucería españolas de la época, unidas al empleo preferente en ellas de la plementería "a la francesa", esto es, con sus lechos dispuestos como en una bóveda de arista (Gómez 1998: 158-160; Palacios 2000: 746-749; Palacios 2009: 77-79). Frente a ellas, los principales rasgos detectados en las bóvedas centroeuropeas son la ausencia de límites claros entre los distintos tramos de nave, utilizando frecuentemente diseños en forma de red, la supresión de los arcos diagonales, la igualación de la sección transversal de los nervios que forman la crucería interior de la bóveda y la presencia de cruces de nervios en los arranques (López, Martín y Sanjurjo 2015: 938-941). Sobre Juan de Álava, véase Castro 2002; sobre las técnicas geométricas de trazado por él utilizadas, véanse Palacios 2007; Palacios y Martín 2011.

133 Gómez 1998: 96; Hoag 1985: 28-36.
} 
cuadrados u otros cuadrifolios. En la panda oeste observamos el modelo utilizado por Juan Guas en el ángulo noreste del claustro de la catedral de Segovia, lo que nos da otra muestra de cómo Juan Gil fue capaz de combinar en su obra las enseñanzas de las escuelas toledana y burgalesa. Otros edificios de este maestro nos desvelan modelos igualmente repetidos por su hijo, como la iglesia parroquial de Almorox (Toledo), cuya nave se cubre con unas bóvedas sobre planta perlongada adornadas con una figura de lados cóncavos y convexos.
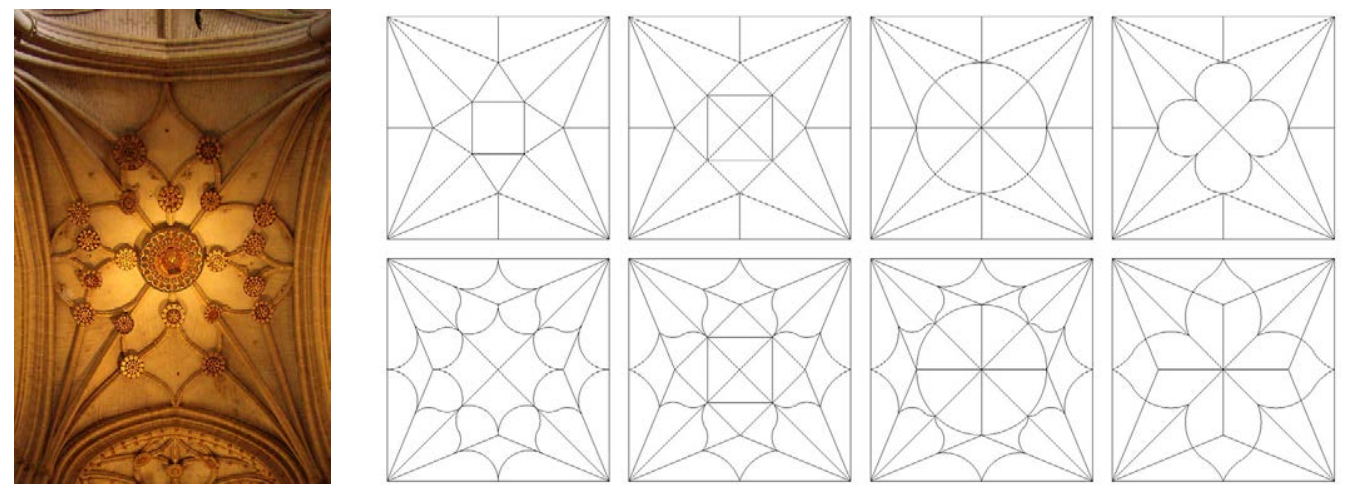

Figura 14. Catedral de Palencia: (a) Bóveda del tramo central del crucero, atribuida a Simón de Colonia. (b) Dibujos en planta empleados por Juan Gil de Hontañón en las bóvedas del claustro y sala capitular (a: commons.wikimedia.org; b: P. Moreno)

Desde el punto de vista puramente decorativo, Juan Gil empleó en ocasiones, como en algunas de las bóvedas del claustro de la catedral de Palencia, los nervios cairelados, introducidos por primera vez por Juan de Colonia en la Cartuja de Miraflores (Burgos) (1454) (134 $^{34}$ presentes también en la bóveda del crucero de la catedral palentina; a veces, como en las bóvedas del crucero de la catedral de Sevilla, adornó la superficie lateral de los nervios con festones o angrelados tallados en las propias piezas de la plementería, y no en las nervaduras como ocurriría si se tratara de caireles. Estos aspectos de tipo ornamental no fueron heredados por su hijo.

\subsection{Decoración}

Las distintas innovaciones operadas en la concepción espacial y estructural de los templos se combinaron con cambios importantes en la decoración. Desde la última década del siglo XV comenzaron a llegar a la Península las primeras manifestaciones artísticas del Renacimiento, que en la arquitectura dieron lugar al estilo plateresco, referido a edificios que, aunque siguen teniendo una estructura tardomedieval, son vestidos con una ornamentación basada fundamentalmente en motivos renacentistas y muy ligada a la personal interpretación de cada artífice. Inicialmente estos motivos convivían de modo caprichoso con elementos tardogóticos, de origen tanto centroeuropeo como autóctono, y se aplicaban sin ninguna relación con la estructura arquitectónica, pero a partir de finales de la década de 1520 comenzó a manifestarse una tendencia hacia una mayor integración entre estructura y ornamentación, y una paulatina depuración de esta última, tomando cada vez mayor

134 Gómez 1998: 150. 
importancia los órdenes clásicos, aunque no siempre utilizados con rigor. Las obras de Rodrigo Gil son representativas precisamente de este cambio de planteamiento ${ }^{135}$.

\subsubsection{Transformaciones económicas}

En el siglo XVI se produjeron en España profundas transformaciones políticas, económicas y sociales, motivadas principalmente por la consecución de la unidad nacional y el descubrimiento de América. Ambas circunstancias propiciaron la realización de importantes obras arquitectónicas desde principios de la centuria, que desarrollaron tanto las innovaciones tardogóticas de origen centroeuropeo como las aportaciones del Renacimiento. En este contexto debemos situar la obra de Rodrigo Gil, auspiciada en muchos casos por importantes clientes favorecidos por la situación del momento. Sin embargo, esta misma coyuntura originó ya desde los primeros años del siglo una progresiva inflación económica, que se disparó en la década de 1550, presagiando la larga crisis económica del XVII. Este hecho afectó especialmente al ámbito de la construcción, produciéndose fuertes subidas en el coste de los materiales y de la mano de obra, e imponiendo fuertes limitaciones en la ejecución de los proyectos, apreciables tanto en la arquitectura de Rodrigo Gil como en la de sus contemporáneos ${ }^{136}$.

\subsubsection{Obra construida}

Rodrigo Gil forma parte de la generación de maestros que comienzan a desarrollar su trabajo pasado el primer cuarto del siglo XVI. Constituye un caso representativo de la polivalencia lingüística que caracteriza la arquitectura española del momento, fundiendo, al igual que sus contemporáneos, distintos elementos de tradición tardogótica, como los modelos espaciales y estructurales, y renacentista, como la ornamentación ${ }^{137}$, y destacando por la depuración formal de sus obras en cuanto a concepción volumétrica y decorativa.

La herencia medieval, integrada tanto por elementos procedentes del ámbito centroeuropeo como por características propiamente hispanas, sería asimilada por Rodrigo Gil no solo a través de su padre, sino también del continuo contacto con los maestros activos en Castilla durante su periodo de formación y primeros años de carrera profesional. Ya hemos comentado las principales aportaciones de la renovación tardogótica a la obra de este maestro. Podemos añadir a ellas la utilización de algunos elementos característicamente medievales, como las ménsulas y baquetones de que se componen los pilares fasciculados cuando estos son los utilizados en el edificio. Sin embargo, otros elementos propios de la ornamentación del último gótico, como las decoraciones menudas a base de elementos vegetales, no se presentan prácticamente nunca.

El intercambio profesional de conocimientos con otros maestros le permitiría también la incorporación de los elementos renacentistas recién llegados de Italia. Los más significativos son quizás los órdenes clásicos, empleados en ocasiones por Rodrigo Gil en la configuración de los soportes verticales. Dichos órdenes, sin embargo, no son generadores de la estructura

\footnotetext{
135 Hoag 1985: 11 -12; Lampérez [1908-1909] 1999: vol. 2, 622-626; Merino 1995: 18-21.

136 Hoag 1985: 167, 169.

137 Hoag 1985: 213, 216.
} 
arquitectónica, ya que el diámetro de la columna no se emplea como módulo que condicione el resto de elementos del edificio: el trazado en planta y sección, tanto general como de los apoyos (tamaño, altura y separación entre ellos) se lleva a cabo por otros procedimientos de tradición medieval. Los órdenes clásicos no son por tanto prioritarios, sino que están sujetos a la voluntad del tracista ${ }^{138}$. Por otro lado, este maestro emplea junto a ellos otros elementos de tradición clásica, que aparecen fundamentalmente en las portadas, como arcos casetonados o adintelados, basamentos, columnas, capiteles y entablamentos, frontones, tondos y hornacinas, siempre con un carácter decorativo.
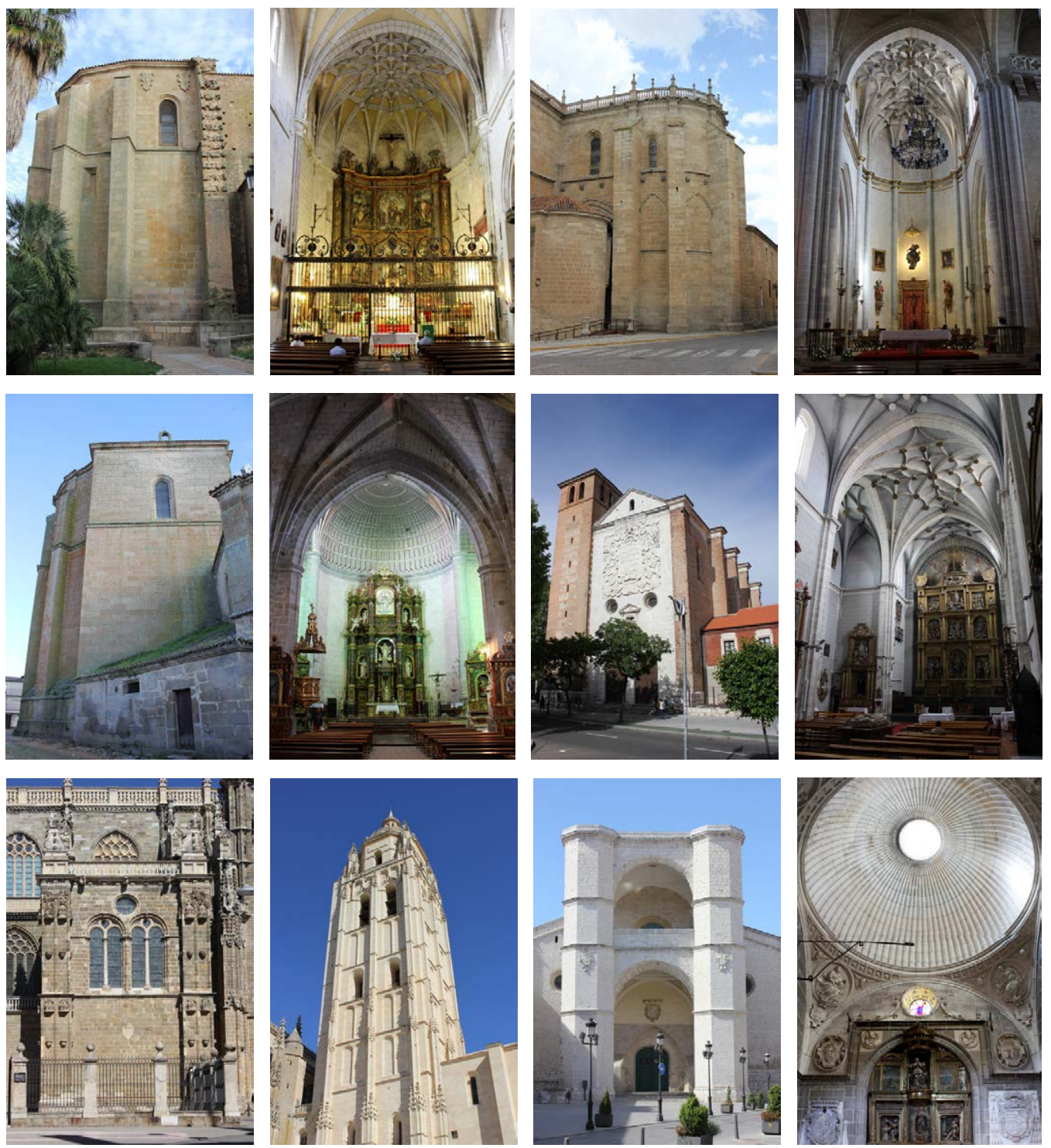

Figura 15. Algunas intervenciones de Rodrigo Gil de carácter religioso: $(a, b)$ Iglesia de Santiago de los Caballeros, Cáceres (cabecera). (c, d) Catedral de Ciudad Rodrigo (Salamanca) (cabecera). (e, f) Iglesia de Santa María la Mayor, Ledesma (Salamanca) (cabecera). (g, h) Iglesia de Santa María Magdalena, Valladolid.

(i) Catedral de Astorga (León) (capilla de San Juan Bautista (costado sur del falso crucero)). (i) Catedral de Segovia (torre). (k) Monasterio de San Benito el Real, Valladolid (torre-pórtico). (I) Iglesia de San Sebastián, Villacastín (Segovia) (capilla de los Mexía-Tovar)

138 Chueca 2001: vol. II, 83-84. 

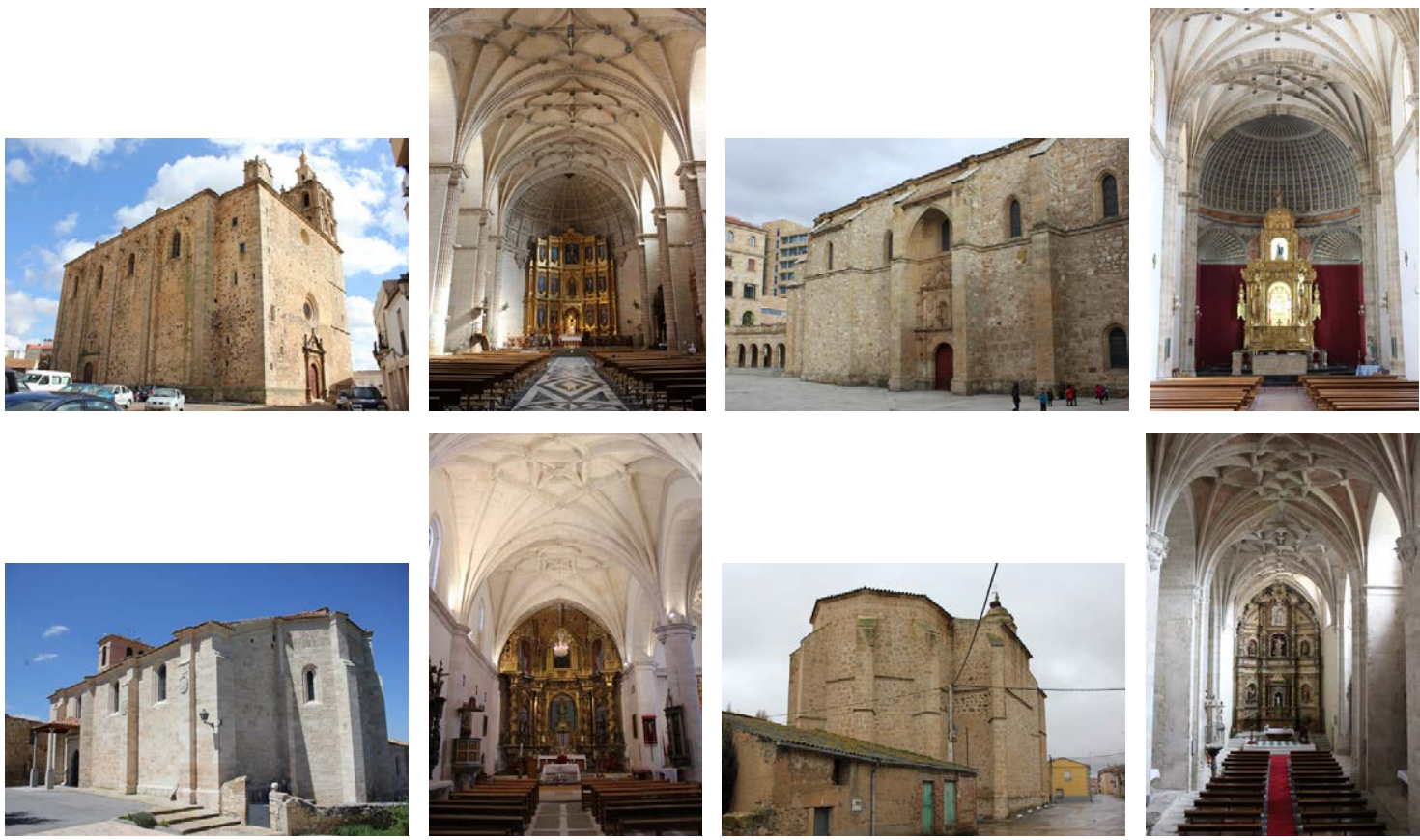

Figura 16. Algunas intervenciones de Rodrigo Gil de carácter religioso: (a, b) Iglesia de Santa María de la Asunción, Guareña (Badajoz). (c, d) Iglesia del monasterio de las Bernardas, Salamanca. (e, f) Iglesia de Santo Tomás, Vegas de Matute (Segovia). ( $g$, h) Iglesia de la Asunción de Nuestra Señora, Villamor de los Escuderos (Zamora)
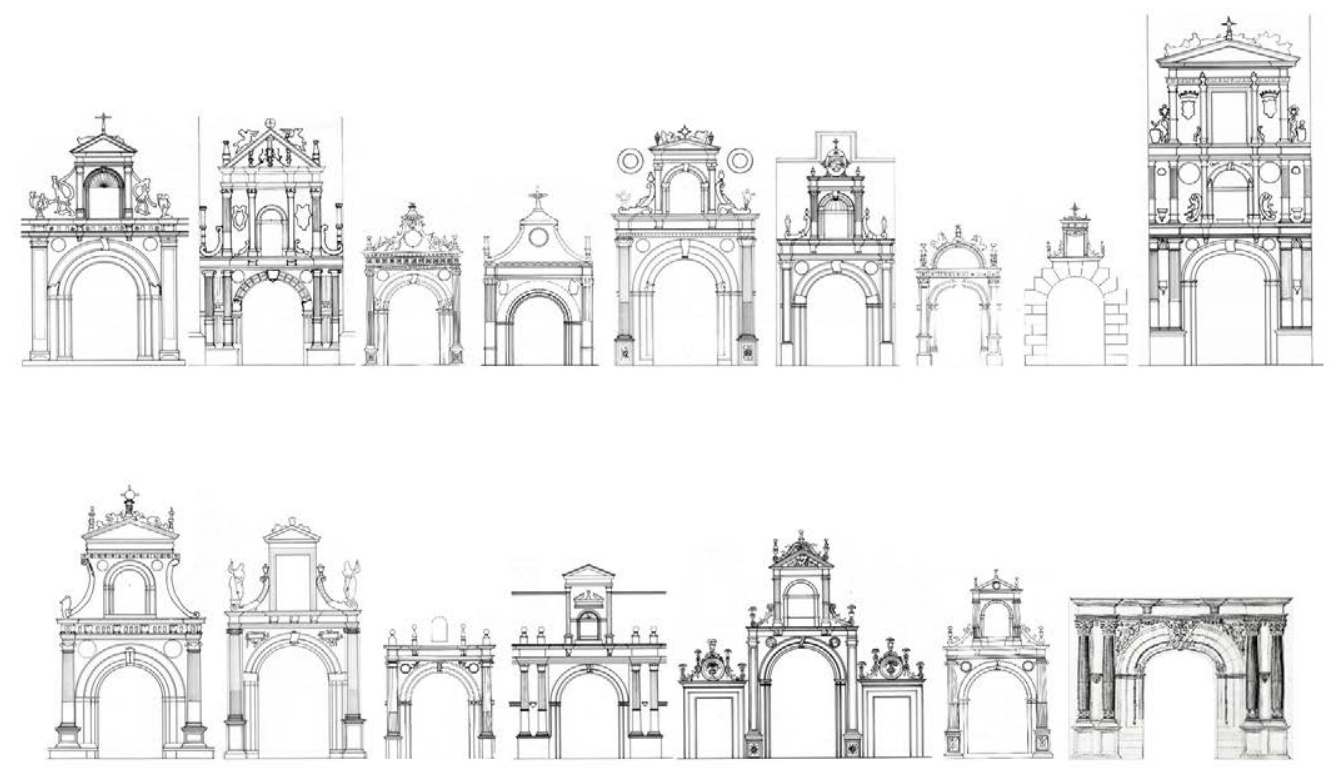

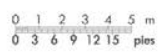

Figura 17. Algunas portadas trazadas por Rodrigo Gil, según Casaseca (a-ñ: Casaseca 1988: 301-303, 310 311 ) y Asas (o: Prieto, Muñoz y García 2008: vol. 14, 185. Manuel de Asas), dispuestas a la misma escala: (a) Iglesia de San Martín, Mota del Marqués (Valladolid) (sur). (b) Monasterio de las Bernardas, Salamanca (iglesia). (c) Convento de San Esteban, Salamanca (escalera de Soto). (d) Monasterio de las Bernardas, Salamanca (cerca). (e) Colegio Menor de Huérfanos de la Inmaculada Concepción, Salamanca (sur). (f) Iglesia de la Asunción de Nuestra Señora, Villamor de los Escuderos (Zamora) (norte). (g) Iglesia de Santiago de los

Caballeros, Medina de Rioseco (Valladolid) (sacristía). (h) Capilla del Hospital de la Vera Cruz, Salamanca (no ejecutada). (i) Iglesia de Santiago de los Caballeros, Medina de Rioseco (Valladolid) (sur). (i) Catedral de Astorga (León) (sur). (k) Palacio de los Guzmanes, León (oeste). (l, m) Iglesia de San Esteban, Castromocho (Palencia) (sur; norte). (n) Catedral de Segovia (antigua sacristía). (ñ) Iglesia del Hospital de la Misericordia, Segovia (oeste). (o) Colegio Mayor de San Ildefonso, Alcalá de Henares (Madrid) 

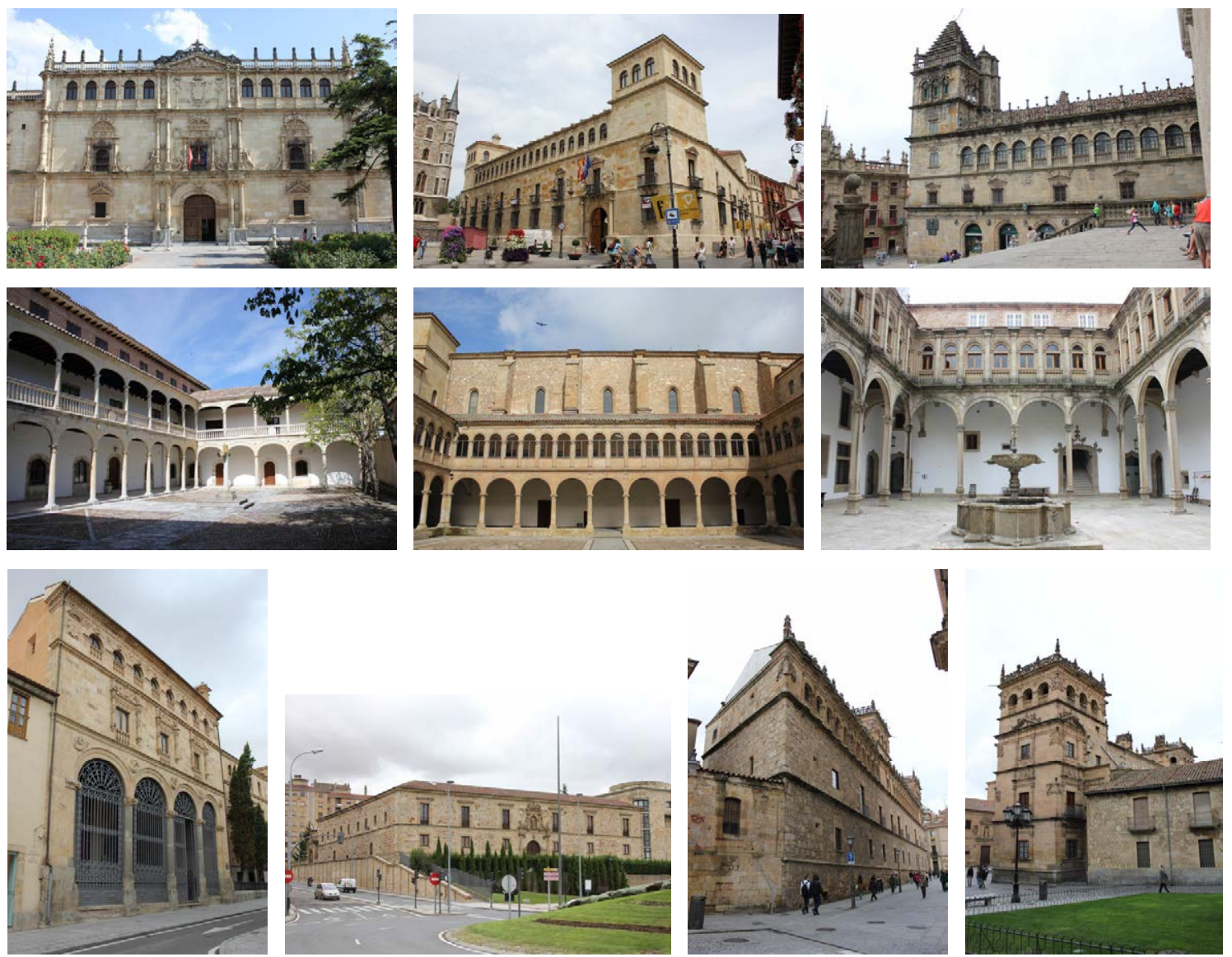

Figura 18. Algunas intervenciones de Rodrigo Gil de carácter civil y religioso: (a) Colegio Mayor de San Ildefonso, Alcalá de Henares (Madrid). (b) Palacio de los Guzmanes, León. (c) Catedral de Santiago de Compostela (A Coruña) (fachada del Tesoro). (d) Palacio de los Ulloa, Mota del Marqués (Valladolid) (patio). (e) Monasterio de las Bernardas, Salamanca (claustro). (f) Hospital de los Reyes Católicos, Santiago de Compostela (A Coruña) (patio de San Juan o de la Cocina). (g) Palacio de la Salina, Salamanca. (h) Colegio Menor de Huérfanos de la Inmaculada Concepción, Salamanca. (i, i) Palacio de Monterrey, Salamanca

El uso que Rodrigo Gil hace de la ornamentación huye del que observamos en las obras del primer Renacimiento español, en las que aquella se extiende muchas veces a gran parte de la superficie exterior. En su arquitectura los elementos decorativos son utilizados siempre de un modo aislado, concentrándose en determinados puntos del edificio, como los pilares, las portadas y los recercados de huecos, y buscando su integración con el conjunto arquitectónico. En este sentido, su empleo de la ornamentación no experimenta, como defendía Chueca ${ }^{139}$, una evolución, sino que desde sus primeros edificios encontramos ese carácter aislado y esa búsqueda de relación entre lo tectónico y lo decorativo, aunque no siempre se consiga por completo: las portadas, con escasas excepciones como la de la fachada del Colegio Mayor de San Ildefonso en Alcalá de Henares (Madrid), se diseñan habitualmente con un carácter independiente con respecto al resto del edificio ${ }^{140}$, siendo el resultado final más o menos afortunado en función de la relación que se haya establecido entre el tamaño de la portada y las proporciones generales. En todo caso, ni Rodrigo Gil ni su padre tuvieron un aprendizaje como escultores, a diferencia de algunos maestros de su entorno, como Juan de Rasines, formado como entallador con Felipe Bigarny, o de otros

139 Chueca 1951: 142; Chueca 2001: vol. II, 83-84.

140 Hoag 1985: 162, 187. 
contemporáneos más alejados, como Diego de Siloé. Esta es quizás una de las razones de que ambos desarrollen una arquitectura muy vinculada a la geometría, rechazando el predominio del ornamento ${ }^{141}$. La expresividad es confiada, tanto al exterior como al interior, a unas superficies de muro lisas, realizadas en cantería de labor muy cuidada, que se articulan con cornisas y entablamentos poco salientes, de carácter lineal, que acentúan la horizontalidad, enfatizada por la ausencia habitual de pináculos, quedando la ornamentación relegada a elementos aislados ${ }^{142}$. Este contraste entre las partes decoradas y desnudas, junto con la rotunda manifestación al exterior de los volúmenes interiores, permitieron a Rodrigo Gil crear un estilo personal, que combina las enseñanzas góticas con los nuevos postulados renacentistas en una arquitectura caracterizada por su sobriedad.

\subsubsection{Entorno laboral}

Contra lo que a priori pudiera parecer desde la óptica actual, la actividad constructiva en el siglo XVI estaba perfectamente regulada en lo que se refiere tanto a los agentes intervinientes como a la redacción del proyecto de arquitectura y la ejecución de las obras. El control de la financiación y el desarrollo del procedimiento administrativo eran especialmente estrictos en el caso de las obras de carácter institucional, como puedan ser las realizadas por los Obispados, los Cabildos, los beneficiados de las iglesias parroquiales, la Corona o las Órdenes religiosas o militares ${ }^{143}$.

\subsubsection{Agentes de la actividad constructiva}

\subsection{Maestro}

Durante la Edad Media y la primera mitad del siglo XVI se utilizaba habitualmente en España el término maestro para referirse en parte al concepto de arquitecto usado en la actualidad. Este último aparece en España probablemente hacia mediados del siglo XVI, siendo usado en 1552 por Francisco de Villalpando para referirse a sí mismo en su traducción de los libros tercero y cuarto del tratado de arquitectura de Sebastiano Serlio, y en 1561 en una cédula de Felipe II que designa a Juan Bautista de Toledo como tal ${ }^{144}$. A pesar de esto, Rodrigo Gil nunca recibió tal denominación: trabajó a lo largo de toda su vida como maestro de cantería, según la terminología heredada de la Edad Media, apareciendo designado como tal en los documentos conservados de modo prácticamente invariable $^{145}$. Juan de Herrera, cuyos inicios profesionales se sitúan en 1561, en plena

\footnotetext{
141 Aramburu-Zabala 2003: 95-96; Hoag 1985: 217.

142 Casaseca 1988: 299; Chueca 1951: 143-144; Hoag 1985: 216.

143 Navareño 1994. Para conocer las condiciones generales en que se desarrollaba la actividad constructiva en la época es de interés el estudio de la documentación generada en torno a proyectos de gran envergadura, como las catedrales de Salamanca, Segovia o Sevilla (véanse respectivamente Chueca 1951; Cortón 1997b; Jiménez et al. 2006), o el Real Monasterio de San Lorenzo de El Escorial (Madrid) (véanse Kubler 1985; Portabales 1952).

144 Lampérez [1908-1909] 1999: vol. 1, 27-28; Llaguno y Ceán 1829: vol. 2, 82.

145 Se le designa así a lo largo de toda su vida (a título de ejemplo, en 1536, 1538, 1540, 1543, 1544, 1552, $1553,1556,1557,1563,1566,1569,1571$ ) (Casaseca 1988: 25, 67, 80, 96, 105, 149, 228, 269; Pereda 1951: CXLVI-CXLVII, CLXIV, CCXLVII doc. 1, CCXLIX-CCLI doc. 3; Sendín 1977: 282-283 doc. XXVI, 285-286 doc. XXIX, 287-288 doc. XXX), y como tal aparece en la lápida de su tumba (Casaseca 1988: 32). Solo en
} 
actividad de Hontañón, se consideraba en cambio ya arquitecto en el sentido de artífice, siguiendo a Vitruvio y Aristóteles ${ }^{146}$. Del mismo modo, Juan del Ribero Rada, que realizó su primera actuación documentada en la década de 1560 en el palacio de los Guzmanes de León, precisamente a las órdenes de Rodrigo Gil, se enorgullecía de su condición de arquitecto, cuyo oficio concebía, en esencia, como ejercicio intelectual, distanciado de la práctica manual $^{147}$.

Como ocurre con la figura actual del arquitecto, el maestro era el técnico que elaboraba el proyecto o "trazas" de un edificio o de una parte de él, designándose también como tal al que dirigía y supervisaba la obra. Sin embargo, lo que diferenciaba al maestro de tradición medieval es que, además de desarrollar estas funciones, también podía ejecutar la obra como contratista, pudiendo coincidir todas las atribuciones anteriores en una misma persona ${ }^{148}$. De acuerdo con esto, una vez que el proyectista o maestro había elaborado las trazas, podía tener distintos niveles de implicación en la obra:

- El maestro que elaboraba el proyecto inicial no participaba en la ejecución. Esta era prevista por el promotor, desarrollándola por alguno de los sistemas descritos más adelante (a jornal, a destajo o una combinación de ambos). Aunque la obra era dirigida por otro técnico, el tracista podía ser llamado puntualmente para que diera su parecer acerca del desarrollo de la misma.

- El maestro que elaboraba el proyecto inicial actuaba también como director o maestro de la obra, proporcionando las trazas necesarias para la materialización de la idea expuesta inicialmente, dirigiendo y supervisando. La ejecución de los trabajos era prevista de nuevo por el promotor.

- El maestro que elaboraba el proyecto inicial actuaba por una parte como director de la obra, proporcionando trazas, dirigiendo y supervisando; y por otra como contratista, controlando la ejecución material y la gestión económica en un sistema de destajo.

El maestro que dirigía la obra tenía entre sus labores fundamentales de dirección y supervisión la de ir proporcionando los distintos planos de detalle para cada una de las partes del edificio a medida que la obra avanzaba, ya que las trazas que se mostraban al promotor antes del comienzo de esta solían ser muy generales y únicamente proporcionaban una idea de conjunto ${ }^{149}$. A título de ejemplo, las bóvedas de crucería se representaban siempre en los dibujos de la época de modo esquemático, con sus nervios reducidos a una

\footnotetext{
escasas ocasiones los documentos se refieren a él como cantero (1528 y 1532) (Pereda 1951: CX-CXI) o como maestro de obras (1566 y 1570) (Bosarte 1804: vol. 1, 401-404 doc. IX, 405-409 doc. X). Por lo que respecta a su padre, Juan Gil, se le designa indistintamente como maestro de cantería (1502) (Hoag 1985: 65), maestro cantero (1512) (Pereda 1951: LXXVI, LXXXII) o cantero (1514, 1520 y 1523) (Pereda 1951: LXXVII, LXXXIV, $\mathrm{XCV})$.

146 Aramburu-Zabala 2003: 96.

147 Pérez 2003: 397, 399, 401, 408.

148 Lampérez [1908-1909] 1999: vol. 1, 57-58.

149 Alonso 2012: 230-232; Hoag 1985: 44-46. Existe una gran cantidad de publicaciones sobre los tipos y funciones del dibujo arquitectónico en la Edad Media, y sobre la naturaleza de los conocimientos geométricos que este requería: véanse Anderson 1986; Bechmann 1991; Branner 1997; Frankl 1945; Marías 1993; Müller 1989; Recht 1995; Ruiz 1987; Sakarovitch 1998; Shelby 1997.
} 
simple línea, dejando la definición de cada uno de sus elementos para la fase de ejecución ${ }^{150}$.

Además de intervenir activamente en los proyectos y obras de construcción, el maestro también podía, como ahora el arquitecto, realizar informes, peritaciones y tasaciones sobre edificios existentes u obras ejecutadas por otros técnicos. En este sentido, el veedor o visitador era el maestro que se encargaba de inspeccionar por cuenta del promotor una determinada obra, a fin de comprobar su correcto desarrollo. El tasador era el que se ocupaba de realizar una valoración económica de lo ejecutado en la obra, por encargo del promotor o del contratista, con el fin de determinar si se ajustaba a lo contratado o, en caso contrario, estimar el valor de los cambios realizados ${ }^{151}$.

La designación genérica de maestro o maestro de obras podía verse particularizada con la indicación de su especialización, encontrando maestros de cantería, albañilería, carpintería, etc. Aparentemente, cuando el edificio se construía en piedra de cantería, el cargo de maestro de la obra, así como el de veedor o visitador si este existía, recaía automáticamente en un maestro cantero, probablemente por su superior cualificación técnica, asignando a su labor una importancia fundamental en detrimento del resto de oficios (fundamentalmente albañilería y carpintería de armar) que forzosamente intervenían también en la construcción ${ }^{152}$, circunstancia que ha sido observada en los contratos $y$ condiciones de obra de los siglos XVI y XVII ${ }^{153}$.

El maestro cantero, gracias a sus conocimientos geométricos, estaba capacitado para realizar los planos de detalle para la ejecución de la obra a que antes aludíamos, desarrollando, a escala natural, los trazados o monteas que permitían la definición de cada uno de los elementos de cantería que componían el edificio. Estos dibujos se hacían habitualmente en la propia obra, sobre un pavimento o una pared, y permitían obtener los correspondientes patrones para la talla de las piezas. El empleo de plantillas de tamaño natural evitaba los posibles errores que se podrían generar por los cambios de escala de los dibujos, y garantizaba que cada una de las piezas, talladas por operarios distintos, pudiera finalmente ensamblarse con el resto para generar el elemento de cantería ideado por el maestro. Los instrumentos fundamentales empleados por el cantero para el traslado de los datos de la montea a la talla de cada pieza eran la plantilla o patrón, el baivel y la saltarregla o escuadra falsa ${ }^{154}$.

De entre los distintos cargos que un maestro podía desempeñar el que representaba el grado más alto de cualificación y prestigio era el de "maestro mayor". Esta denominación podía referirse al técnico que, designado por un Cabildo, está al cargo de las obras de una catedral, pero también al responsable de todas las intervenciones realizadas por un Obispado o una Orden religiosa o militar dentro de su territorio. En la Castilla de la época solo otra figura podía quizás superarle en consideración social: la del "maestro de obras reales", al servicio de la Corona ${ }^{155}$.

\footnotetext{
150 Rabasa 2007a: 748-749.

151 Hoag 1985: 47-48.

152 Hoag 1985: 44-48, 53-55.

153 Tovar 2003: 81.

154 Bails 1802: 14, 43, 83, 94; Palacios 1998: 98-99; Palacios 2003: 16-18; Rabasa 2007b: 237-241

("Glosario").

155 Alonso 2012: 227, 230; Lampérez [1908-1909] 1999: vol. 1, 27-28; Navareño 1994.
} 
No está claro el sistema a través del cual un simple cantero llegaba en nuestro país a la categoría de maestro ${ }^{156}$. Dado el elevado número de trabajadores de la piedra que existía entonces, pocos llegarían a alcanzar dicha calificación profesional. En el caso de Rodrigo Gil, evidentemente, fue determinante su condición de hijo de un maestro reputado, como ocurre con muchos otros como Enrique Egas, Simón y Francisco de Colonia o Pedro de Ibarra $^{157}$.

\subsection{Aparejador}

A las órdenes del maestro director de la obra podía existir un aparejador, término que ya aparece utilizado en los documentos a principios del siglo XV. Esta figura, que correspondía a un técnico de alta cualificación, representaba el cargo inmediatamente inferior al de maestro, y aparecía normalmente en obras de cierta complejidad que requerían de un continuo control de la ejecución a pie de obra ${ }^{158}$. El maestro delegaba en él parte de sus funciones, manteniendo la de dirección y supervisión, llevada a cabo en visitas espaciadas a la obra, de mayor o menor duración, en las que podía dar las órdenes o confeccionar las trazas requeridas en cada momento. Cuando el maestro no podía acudir a la obra, era habitual que el aparejador realizara viajes para hacerle las correspondientes consultas, y, si esto no era posible, ambos se comunicaban por carta, utilizando frecuentemente como emisario a un aprendiz ${ }^{159}$. Si el edificio se levantaba en obra de cantería, el aparejador que dirigía la ejecución de la obra era habitualmente otro maestro cantero, que podía en ocasiones intervenir en otros encargos de modo independiente actuando propiamente como tal, si bien esta posibilidad estaba limitada geográficamente por la necesidad de realizar el seguimiento continuo de la obra en la que intervenía como aparejador. Tenía entre sus labores fundamentales, delegada por el maestro de la obra, la de dibujar planos a tamaño natural y patrones de cada una de las piezas a ejecutar, realizados estos últimos habitualmente sobre tablero de madera ${ }^{160}$, y denominados "plantillas", "tablamientos" "tablerones". Cuando el maestro actuaba como contratista, delegaba frecuentemente en el aparejador la contabilidad y los pagos de mano de obra y materiales, desempeñando entonces el aparejador, junto a su función de control de la ejecución de la obra, la de jefe de obra' ${ }^{161}$.

En relación con las labores que este técnico podía asumir presentamos dos extractos que corresponden a las condiciones firmadas por dos de los aparejadores de las obras de la catedral de Segovia con los que trabajó Rodrigo Gil, Martín Ruiz de Chertudi (1576) y Juan del Valle (1565), como ilustrativas de una parte de su trabajo profesional:

Yten quel tal aparejador sea bastantemente sufiçiente e perito en lo que toca a cumplir con los encargos que se rrequieren en su ofiçio no haciendo más ni menos de lo que el maestro mayor de la dcha [dicha] obra le mandare, e le diere traçado por planta e montea sacado los moldes para cada cosa e miembro de lo que se fuere edificando. Yten que el tal

\footnotetext{
156 Hoag 1985: 43-44.

157 Sobre la figura del arquitecto en el siglo XVI español, véase Marías 1979.

158 Lampérez [1908-1909] 1999: vol. 1, 57-58; Navareño 1994.

159 Hoag 1985: 46-47.

160 L'Orme (1567: libro III, cap. IV, 55v) recoge esta misma circunstancia al referirse a las plantillas para la talla de las dovelas como paneaux, esto es, tableros de madera.

161 Hoag 1985: 46-47.
} 
aparejador traçará todas las piedras mui conformes e uniformes con las traças e plantas e monteas e moldes que se le dieren hordenados e traçados por el dcho [dicho] maestro mayor .... Yten que quando el aparejador no se ocupare ni fuere menester ocuparse en traçar las piedras de la obra e sus cosas q se ocupe en subir a ver e corregir a los asentadores, e así mismo a rrecorrer a los oficales que labran las piedras, para que con más deligençia cada qual haga su ofiçio sin daño de la obra ${ }^{162}$.

Iten que dicho aparejador de que aya trazado sus piedras a los ofiçiales no abiendo asiento ni que visitar ni traçar tenga su piedra aparte donde labre por no estar oçioso porque el dar animo a los otros ofiçiales y dar buen exemplo e quando obiere asiente que se ayan de visitar y rrecorrer los asentadores bastara traçar y bisitar los asientos y hordenar como se les de rrecabdo 163 .

Como veremos más adelante, el trabajo desarrollado por Rodrigo Gil tiene su razón de ser en la colaboración con un gran número de aparejadores de su confianza, en los que delegaba sus funciones y que garantizaban el avance correcto de las obras.

\subsection{Mano de obra}

No vamos a desarrollar el tema de los diversos oficios que intervenían en las obras de construcción $\circ$ el de sus distintos grados de especialización, pero sí queremos dar unas breves pinceladas respecto a los distintos profesionales relacionados con el trabajo de la piedra. El cantero era el obrero especializado que se encargaba de su extracción, talla y colocación; trabajaba a jornal o a destajo, y su retribución variaba según su habilidad, experiencia y tipo de trabajo a realizar. Entre ellos, los sacadores estaban encargados de la extracción de la piedra en las canteras; podían depender directamente del contratista de la obra o bien ser trabajadores independientes que abastecían de material a este; era habitual que su trabajo se desarrollara en invierno, cuando las condiciones climatológicas hacían difícil la colocación. En cuanto a la talla de la piedra, esta se podía realizar en la propia obra, aunque también era al parecer habitual desbastar las piezas en la cantera, e incluso labrarlas totalmente dejándolas dispuestas para su colocación, lo cual suponía un importante ahorro en los costes de transporte al disminuir sensiblemente el volumen de piedra a desplazar. Finalmente, la colocación de la piedra en obra era realizada por los asentadores. Junto a los canteros existían otros profesionales, los entalladores, encargados de aquella labor escultórica y ornamental que requiriera una mayor habilidad manual y un conocimiento de los modelos a utilizar; mientras que los canteros se ocupaban de los elementos propiamente arquitectónicos, los entalladores trabajaban en piezas que dependían en gran medida de su libre criterio. Las categorías inferiores de la pirámide laboral estaban constituidas por los peones o mozos y por los criados o aprendices. Los primeros colaboraban en las labores de transporte y asiento de la piedra y en la preparación de los morteros. Los segundos estaban al cargo de un maestro cantero junto al que teóricamente adquirían, durante un tiempo variable según los casos, las nociones básicas del oficio antes de llegar a ser oficiales; sin embargo muy habitualmente

\footnotetext{
162 Cortón 1997a: 457-459.

163 Sanz 1968: 245-246.
} 
desempeñaban labores de sirvientes, siendo por ejemplo utilizados para el intercambio de mensajes entre el maestro y sus aparejadores ${ }^{164}$.

Por otro lado, queremos comentar otros dos aspectos relativos a la mano de obra, que no están relacionados entre sí pero que se asocian casi automáticamente con la construcción medieval: su organización en entidades gremiales y el empleo de las marcas de cantería en el trabajo. Desde el siglo XII ○ XIII, con el desarrollo de las ciudades en España, los cada vez más numerosos obreros laicos de la construcción comenzaron a asociarse por oficios, apareciendo las corporaciones de obreros, que combinaban muchas veces el carácter técnico con los fines religiosos o benéficos, e integraban a maestros, oficiales y aprendices. Sus atribuciones de orden técnico, económico y restrictivo fueron aumentando progresivamente, estableciéndose en el siglo XV la agremiación obligatoria de todos los oficios e individuos y multiplicándose las imposiciones legales. Carlos I y Felipe II intentaron en la centuria siguiente reducir su carácter técnico, restringiéndolas al de cofradías religiosas ${ }^{165}$. Sin embargo, durante los siglos XVII y XVIII la actividad constructiva siguió estando condicionada por las corporaciones gremiales 166: a título de ejemplo, el cantero mallorquín Joseph Gelabert hubo de someterse a examen para obtener el grado de maestro a mediados del siglo XVII ${ }^{167}$. Desconocemos la influencia real que pudieron ejercer durante el periodo de actividad de Rodrigo Gil.
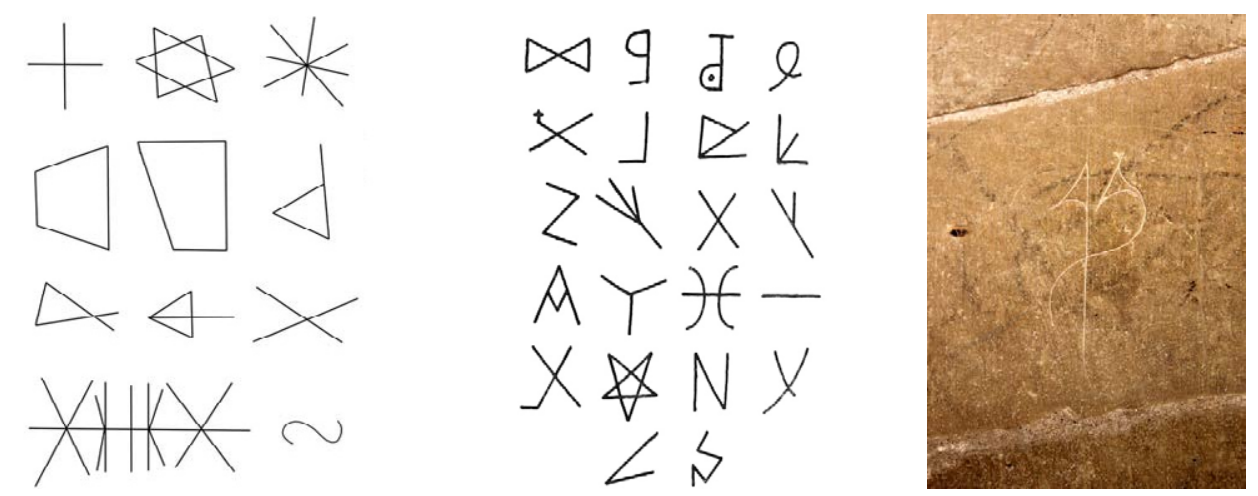

Figura 19. Marcas de cantero documentadas en algunas intervenciones de Rodrigo Gil: (a) Iglesia de San Martín, Mota del Marqués (Valladolid) (cabecera) (Martín, Cámara y Murillo 2013: 624 fig. 6). (b) Capilla del Colegio Mayor del Arzobispo Fonseca, Salamanca (exterior de la cabecera y crucero) (Sendín 1977: 107). (c) Catedral-Magistral de Alcalá de Henares (Madrid) (interior de la escalera de caracol de la torre)

Por lo que respecta a las marcas de cantería, se trata de figuras grabadas a cincel o buril en los paramentos de las piedras, que al parecer tenían por objeto identificar el trabajo efectuado por cada obrero y facilitar así la administración de la obra. Utilizados en España ya en el siglo $X$, su uso se generalizó del siglo XII al XV, disminuyendo paulatinamente su empleo en el $X V I^{168}$. No hemos rastreado en profundidad la utilización de marcas de cantero en las obras de Rodrigo Gil, aunque sí podemos avanzar que se encuentran presentes al menos en algunos ejemplos, como la cabecera de la iglesia de San Martín en

\footnotetext{
164 Alonso 2012: 236; Ealo 2009: $125-128$; Hoag 1985: 48-53, 56-59.

165 Lampérez [1908-1909] 1999: vol. 1, 39-41, 43-44.

166 Arenas 2003: 119, 127.

167 Gelabert [1653] 1977: 3, citado en Gómez 1998: 42 nota 9.

168 Lampérez [1908-1909] 1999: vol. 1, 47, 51, 53.
} 
Mota del Marqués (Valladolid) ${ }^{169}$, la cabecera y el crucero de la capilla del Colegio Mayor del Arzobispo Fonseca en Salamanca ${ }^{170}$ o la torre de la Catedral-Magistral de Alcalá de Henares (Madrid).

Por último, otro elemento relacionado parcialmente con la práctica de la cantería en España, y que consideramos de interés por ser relativamente poco conocido, es el del argot utilizado por los trabajadores. Desde finales de la Edad Media trabajaban por toda la Península canteros de origen cántabro y vasco, que pasaban gran parte del año lejos de sus hogares. Constituían un colectivo unido no solo por su profesión o por su procedencia geográfica, sino también en muchos casos por vínculos de amistad o familiares. Entre ellos se fue desarrollando, a partir de un momento indeterminado, un lenguaje especializado denominado "Pantoja". Esta jerga, fundamentalmente hablada, funcionaba como signo diferenciador del grupo, que buscaba a través de ella su reafirmación en un medio extraño; más que de un verdadero argot profesional (de 857 palabras tan solo unas 50 hacen alusión al mundo de la cantería), se trataba de un lenguaje críptico que perseguía la cohesión de sus hablantes y la exclusión de los extraños al grupo. Por esta razón, muchas de sus palabras se formaban por una simple transposición de consonantes o por la adición de sonidos (al inicio, en el medio o al final de la palabra), que impedían la comprensión por parte de los no iniciados ${ }^{171}$. El vocabulario recogido por los estudiosos cuenta con numerosas voces procedentes del euskera, especialmente en la numeración, debido a la fuerte presencia de vascos entre los canteros de la época. La base del sistema de numeración es la docena, algo que quizás podría estar relacionado con la generación de las unidades en el antiguo sistema métrico castellano. Por otro lado, la "Pantoja" está conectada con otras jergas profesionales utilizadas por los canteros en distintas zonas del norte, como Pontevedra ("Latín dos canteiros", "Verbo dos arginas") y Asturias ("Xíriga"), y también están presentes en ella palabras de la germanía ${ }^{172}$. Ofrecemos a continuación, a título de curiosidad, las palabras de la "Pantoja" relacionadas con la cantería, tomadas de Sojo ${ }^{173}$ y reorganizadas para su mejor comprensión.

- Oficios: albañaque $(T) \circ$ alfañique. Albañil | arguina $(T)$, ergues $\circ$ argin. Cantero | buji (T), tresmo (T) ० busia. Maestro cantero o jefe de los canteros | carcoza $(T) \circ$ corcozo. Carpintero | chanarra. Obrero | ciompa (T). Peón de obra | farrullista (T), escorionero o escoriu. Herrero (farrulla (T). Fragua) | mao. Amo | morcate (T). Entre canteros, el chico que trae el agua | mureador. Trabajador | murear (T), muriar $(T) \circ$ morear $(T)$. Trabajar en general $y$, en especial, en cantería | papelechante. Listero en la obra | pete. Persona que no sea cantero ni tejero | tresmo (T). Ver buji | villarua. Vigilante de obra.

- Herramientas: amarientas (T). Herramientas | ascorea (T) ○ escorea. Hacha | borniega. Piqueta | bujarda (T). Martellina gruesa | cercha. Cimbra, armazón que sostiene un arco; patrón de contorno curvo, sacado de una tabla, que se aplica de canto en un sillar para labrar en él una superficie cóncava o convexa | chamargués. Andamio | chini. Mazo de hierro de cantero para labrar las piedras | escorión o jichu. Martillo de cantero | esdruaca (T). Escuadra de cantero |

\footnotetext{
169 Martín, Cámara y Murillo 2013: 624 fig. 6.

170 Sendín 1977: 107.

171 Sojo [1947] 2003: 9, 13-15, 21, 39, 42-43.

172 Sojo [1947] 2003: 16-19, 35-36, 42-43, 45.

173 Sojo [1947] 2003: 47-132.
} 
farrullos (T). Hierros del oficio de cantero | ferrosa. Pala, azada, zapapico y demás herramientas de hierro | lambiona (T) o lapeta (T). Paleta de cantero | lapeta $(\mathrm{T})$. Ver lambiona | mallo $(\mathrm{T})$, mallua $(\mathrm{T}) \circ$ borniego. Martillo | mallo dangre (T). Martillo de desbrozar | mallua (T). Ver mallo | mandarria (T). Maceta de cantero | melcho (T) o mercha. Hacha | quipos (T). Picos de cantero | zustriágana. Regla de madera.

- Materiales: angosta $\circ$ angustina. Mortero de cal | arria (T) $\circ$ ria. Piedra que se trabaja; sea sillar o mampuesto | mamporrería (T). Mampostería | mamporro (T). Mampuesto | mota (T) ○ angosta. Cal | sotángana. Tabla | zortiángano (T). Ver zustiágano | zustiágano (T), zortiángano $(\mathrm{T})$, zustiágana, sotángano o fuste. Palo o Madera.

Observaciones: (T) Vocabulario de los canteros de la Merindad de Trasmiera, aunque también se usó en otros lugares (resto: Vocabulario de los canteros de la Merindad de las Asturias de Santillana, del Partido de Llanes y de Pontevedra, junto con algunas palabras de la lengua euskera).

\subsubsection{Proyecto y obra}

\subsection{Redacción del proyecto}

Decidida por el promotor la erección de un edificio, le correspondía plantear un programa inicial de necesidades y prever la financiación correspondiente. Hecho esto encargaba la elaboración de las "trazas" y la redacción de las "condiciones" para la construcción. Podía realizarlas un maestro designado específicamente para el proyecto, o bien, si se trataba de una institución, el maestro mayor que atendía todas las obras emprendidas por aquella, o podía incluso encargarse la presentación de propuestas a concurso a distintos maestros a fin de poder elegir de entre ellas la que se considerara más adecuada. Las trazas eran dibujos, en planta, alzado o sección, que pretendían dar una idea general de lo que se proponía hacer al promotor; las condiciones fijaban por escrito tanto los aspectos técnicos como los administrativos y económicos relativos a la obra. $\mathrm{Si}$, en lugar de un edificio de nueva planta, se trataba de realizar una actuación sobre uno existente o en obras, se podía encargar previamente la elaboración de un informe o de una tasación a fin de conocer el estado del edificio, o bien la de un presupuesto estimado incluyendo las soluciones técnicas más adecuadas ${ }^{174}$.

\subsection{Adjudicación y ejecución de las obras}

Elegida la traza y redactadas las condiciones, podían iniciarse las obras, que se podían llevar a cabo por dos procedimientos, administración o maestría y contrata 0 destajo, 0 incluso por una combinación de ambos.

En el sistema de administración o maestría tanto la mano de obra como la maquinaria y los materiales corrían normalmente por cuenta del promotor, que asignaba un salario $\circ$ jornal a cada uno de los técnicos y trabajadores y preveía los medios y materiales necesarios para la ejecución. No se fijaba un plazo para la finalización de los trabajos. El promotor elegía a un maestro de la obra, y este o de nuevo el promotor designaba un aparejador. Estos dos

174 Hoag 1985: 44-46, 60-61; Lampérez [1908-1909] 1999: vol. 1, 57-58, 60; Navareño 1994. 
técnicos se encargaban a su vez de la contratación de los obreros, convirtiéndose así en responsables de su trabajo. La contabilidad de la obra quedaba al cargo del promotor, que normalmente nombraba un representante denominado según los casos obrero mayor, fabriquero, mayordomo o pagador.

Por el contrario, en el sistema de contrata o destajo la obra se ajustaba por un tanto alzado, referido a la obra completa (contrata total) $\circ$ a una determinada unidad constructiva (contrata parcial); o bien se ajustaba el precio unitario de una cierta partida, liquidando al final de los trabajos la cantidad total ejecutada; el promotor podía aportar en ciertos casos mano de obra, maquinaria o materiales. Se fijaba un plazo concreto para la finalización. La responsabilidad económica era asumida por el maestro que contrataba la obra, quien, si la entidad de la actuación lo hacía necesario, delegaba esta función en un aparejador, encargado, entre otras funciones, de llevar la contabilidad ${ }^{175}$.

En ocasiones, principalmente en obras de gran envergadura, podían combinarse ambos sistemas, contratándose destajos parciales que eran supervisados por el maestro de la obra. Tal es el caso, por ejemplo, de las obras de la Catedral Nueva de Salamanca, en las que se produjo la curiosa circunstancia de que Juan Gil de Hontañón, siendo maestro mayor, contrató en 1520 los destajos de cuatro capillas hornacinas del lado norte. Esta pérdida de la imparcialidad en el control de la obra sería una de las causas de los conflictos surgidos con el otro destajista contratado simultáneamente, Juan de Álava176.

A lo largo del siglo XVI el sistema de administración o maestría, habitual durante la Edad Media ${ }^{177}$, fue paulatinamente sustituido por el de contrata 0 destajo ${ }^{178}$, que se impondría definitivamente con la obra de El Escorial ${ }^{179}$. En el sistema de destajo el proceso de contratación se desarrollaba en tres fases: "pregones", "remate" y "fianzas". En primer lugar se hacía pública la convocatoria con una ronda de pregones, dados tanto en la localidad donde se encontraba la obra como en otras villas de la comarca, en los que se notificaba el plazo establecido para conocer las condiciones y presentar las ofertas. La adjudicación se realizaba en subasta pública o remate, realizada a la baja, en la que cada maestro de obras hacía una determinada oferta o "postura", sucediéndose las bajas hasta que no hubiera más intervenciones, momento en el cual se adjudicaba o remataba la obra en el maestro que hubiera presentado la oferta más económica. A continuación se elaboraba el contrato entre el promotor y el adjudicatario, momento en que este debía presentar las fianzas que se le exigían, esto es, el compromiso por escrito de uno o varios fiadores solventes que respondían de modo solidario ante el promotor en caso de incumplimiento de las condiciones, haciendo, si era necesario, la obra a su propia costa ${ }^{180}$. Para fomentar la participación de contratistas en el remate, no solo locales sino también foráneos, existía la figura del "prometido", que consistía en una gratificación económica a la

\footnotetext{
175 Hoag 1985: 53-55; Lampérez [1908-1909] 1999: vol. 1, 60.

176 Hoag 1985: 55-56. El maestro mayor de las obras de la catedral recibía habitualmente en la época un sueldo anual por su labor de dirección y un jornal por cada visita que realizara a la obra (el resto de trabajadores cobraban exclusivamente un jornal) (Alonso 2012: 230-232). Juan Gil, durante el tiempo de ejecución de su destajo, recibió su salario como maestro, pero no los jornales correspondientes (Hoag 1985: 5556).

177 Alonso $2012:$ 230-232.

178 Hoag 1985: 53.

179 Alonso 2012 : 230-232. Un tercer sistema, empleado, aunque con escasa frecuencia, a finales del siglo XV, era el de tasación, que valoraba el trabajo realizado únicamente a su terminación, sin que existiera ningún concierto económico previo, razón por lo cual era origen frecuente de conflictos (Alonso 2012: 230-232).

180 Navareño 1994.
} 
formalización de ofertas que rebajasen las ya presentadas, y que buscaba compensar los gastos del licitador, que no solo debía desplazarse, sino que en ocasiones presentaba trazas y condiciones, de tal modo que una vez elegidas por el promotor las más adecuadas, todos los postores tenían que ceñirse a ellas. Las irregularidades a lo largo del proceso podían ser múltiples: existencia de acuerdos entre maestros para limitar las bajas, aceptación de nuevas ofertas finalizada la subasta 0 incluso ya presentadas las fianzas, 0 preferencia por determinado maestros ${ }^{181}$.
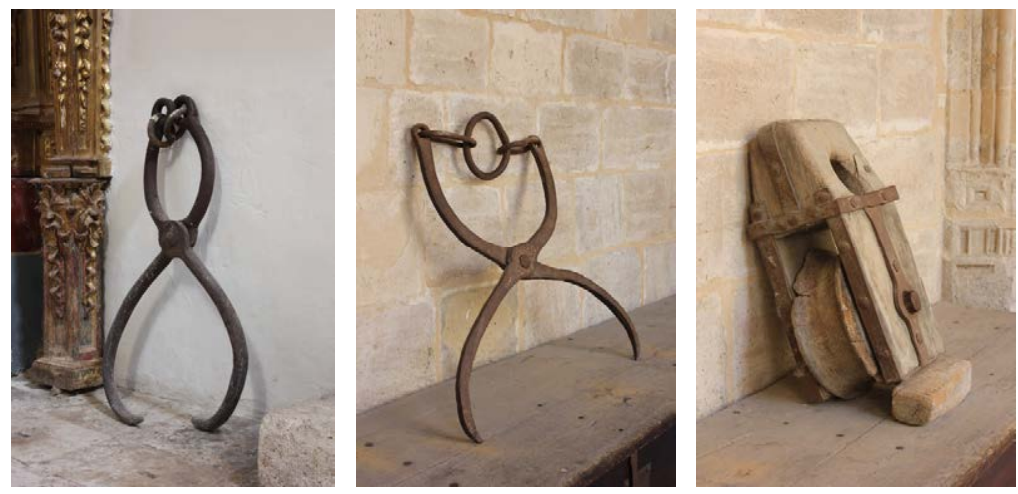

Figura 20. Herramientas utilizadas en la época para el izado de materiales en obra: (a) Tenazas (iglesia de los Santos Juanes, Nava del Rey (Valladolid)). (b) Tenazas (claustro de la catedral de Segovia). (c) Polea (claustro de la catedral de Segovia)

Una vez adjudicada la obra, el sistema de destajo, que perseguía fundamentalmente reducir costes y plazos, presentaba fundamentalmente dos problemas: el cumplimiento de las condiciones contratadas, y la aparición de cambios sobre lo inicialmente previsto. Estas modificaciones, que se denominaban "mejoras" y que eran realizadas a propuesta del promotor, del maestro que supervisara los trabajos o del adjudicatario, generaban habitualmente demasías. Para solventar estas contingencias existía en el siglo XVI el procedimiento de tasación a la finalización de la obra, por el que dos peritos, uno de los cuales actuaba de parte del promotor y otro de la del maestro que contrataba la obra, debían valorar lo ejecutado, verificando su concordancia con lo contratado y la justificación de las demasías en su caso ${ }^{182}$. En algunos contratos el promotor se reservaba la potestad de elegir a un único tasador para realizar esta tasación final, o, caso de haber acordado la presencia de dos técnicos, la facultad de designar a un tercero que actuara como árbitro, si los anteriores no llegaran a acuerdo; en otros contratos se estipulaba la imposibilidad de alegar mejoras para aumentar el coste final, aunque este sí se podía reducir si los peritos así lo consideraban. A pesar de todos estos controles, entre los promotores existía la opinión generalizada de que las valoraciones se alteraban en virtud de intereses personales de los tasadores $^{183}$.

Por otro lado, los pagos podían realizarse, según los casos, no solo a la finalización de la obra, sino también en plazos intermedios, previamente establecidos, siendo habitual un reconocimiento previo de lo ejecutado por parte de un técnico ${ }^{184}$. Los abonos eran

\footnotetext{
181 Vasallo 2015: 1749-1752.

182 Navareño 1994; Vasallo 2015: 1749-1750.

183 Vasallo 2015: 1749-1750.

184 Lampérez [1908-1909] 1999: vol. 1, 57-58; Navareño 1994.
} 
efectuados por el promotor normalmente a través del mayordomo o pagador, recibiéndolos en muchas ocasiones, como veremos más adelante, directamente el aparejador ${ }^{185}$. En caso de incumplimiento del plazo máximo para la conclusión de la obra se podía aplicar una penalización, reteniendo parte de las cantidades pendientes de pago, o se podía incluso llegar a exigir la terminación a costa de los fiadores ${ }^{186}$.

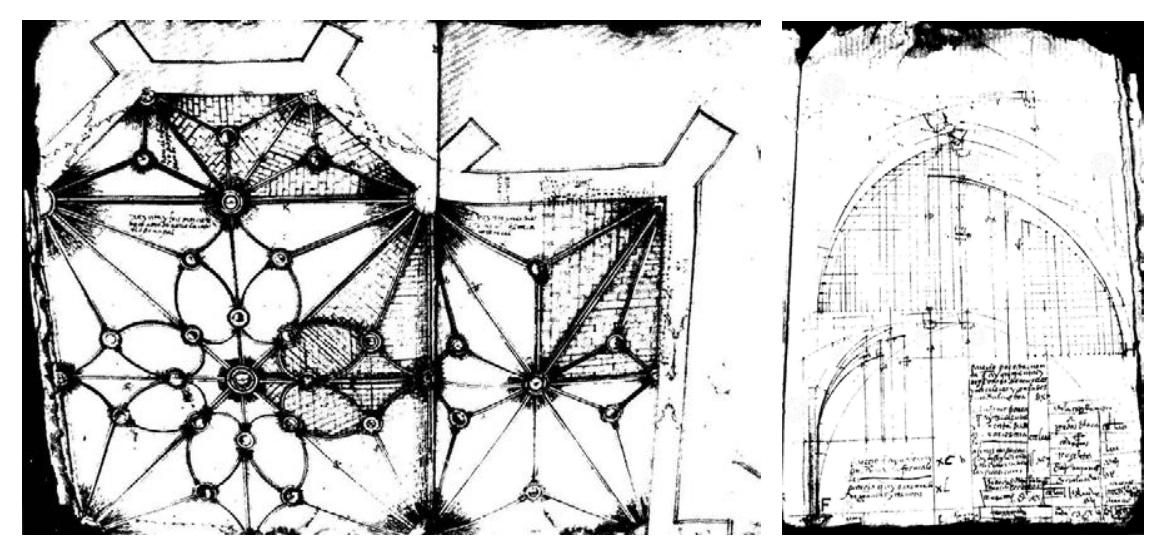

Figura 21. Dibujos utilizados en la época para un procedimiento de tasación a la finalización de la obra: trazas realizadas en 1543 por Francisco de Luna para la tasación de la cabecera de la iglesia parroquial de Priego

(Cuenca), obra ejecutada por Pedro de Albiz (Rokiski 1980: 32-33 dib. I-II): (a) Planta. (b) Alzado de los nervios de las bóvedas

Los frecuentes incumplimientos de una u otra parte, producidos durante la marcha de la obra, o las disputas que surgían por causa de las tasaciones de las demasías, derivaban en multitud de pleitos y conflictos legales. El proceso judicial emprendido por la construcción de la iglesia de San Martín en Mota del Marqués (Valladolid) nos proporciona algunos datos interesantes sobre el sistema de trabajo adoptado por Rodrigo Gil. En 1562 se discutía sobre la cantidad que se le debía pagar, argumentando el promotor que los trabajos se habían contratado a maestría a fin de reducir dicho importe, y que este debía ser similar al que se le pagaba por otras obras, como eran las de

la iglesia mayor de la ciudad de Salamanca, donde hera vecino e residía, ... y desde allí rregía más de otras treinta yglesias que tenía ... a su cargo, como tenía a la dicha yglesia de La Mota, a las cuales en cada un año yba a besitar una vez o quando mucho dos, deteniéndose un día o dos quando mucho, y por ello se le a acostumbrado a dar e a dado su salario por la dicha su yndustria ... en unas obras a ocho y en otras a diez mill maravedís, según distancia del lugar e calidad de la obra, y lo mesmo se usava con su padre Juan Gil, que hera del mesmo oficio e arte.... ${ }^{187}$.

Sin embargo la realidad es que la obra se había suscrito a destajo, modalidad defendida en este caso por Rodrigo Gil por considerarla más económica para el promotor, pues

\footnotetext{
185 Hoag 1985: 54-55.

186 Navareño 1994.

187 Vasallo y Pérez 2011 : 48-49.
} 
... si esta obra se hiziera a maestría y por jornales, no se hiziera con seis mill ducados más de lo que a costado, ni aún con ocho mill ducados ... ${ }^{188}$.

En otros casos, sin embargo, Rodrigo Gil recomendó la utilización del sistema de maestría, como hizo en 1575 en las obras de reparación de uno de los pilares del coro de la iglesia de Santa María la Antigua en Valladolid, ejecutadas a partir del año siguiente por Francisco del Río como maestro ${ }^{189}$. Sería interesante deslindar con precisión el sistema de trabajo empleado por Rodrigo Gil en cada una de sus obras, lo cual requeriría un minucioso estudio de la documentación original relacionada con ellas.

\subsubsection{Actividad profesional}

\subsubsection{Aprendizaje y formación}

Rodrigo Gil pertenecía a una familia profundamente vinculada a la cantería. No solo era cantero su padre, sino también su hermanastro Juan Gil "el Mozo"; los dos primeros esposos que tuvo su hermanastra María, Juan de Helguera y Juan de la Montaña ${ }^{190}$; su sobrino nieto político, Diego Gil de Gibaja, y el hijo de este, Juan de Rivera ${ }^{191}$. Su formación se desarrollaría probablemente desde niño en las propias obras de construcción ${ }^{192}$, estando en contacto con todos los profesionales que intervenían en ellas, e incluso ocasionalmente con algunos de los maestros más importantes de la época, gracias a la posición preeminente de su padre en esos primeros años del siglo XVI.

En los inicios de su carrera profesional trabajaría al lado de su progenitor y de su hermanastro, aprendiendo la profesión junto a ellos ${ }^{193}$, si bien tenemos pocas noticias al respecto. Sabemos que en 1516 Rodrigo Gil acompañaba a su padre en una visita al monasterio de Nuestra Señora de la Piedad en Casalarreina (La Rioja) ${ }^{194}$, y que en 1518 lo hacía a la catedral de Santiago de Compostela (A Coruña), para tratar sobre el claustro ${ }^{195}$. Entre 1521 y 1524 era Juan Gil "el Mozo" y no Rodrigo quien dirigía los destajos de las capillas hornacinas del lado norte de la Catedral Nueva de Salamanca en ausencia de su padre ${ }^{196}$, probablemente por ser mayor en edad que Rodrigo, ya que, como hemos

\footnotetext{
188 Vasallo y Pérez $2011: 48,51$.

189 Pereda 1951: CCXXXI-CCXXXIII.

190 Lozoya 1962: 24; Martí 1907a: 38, 83-84, 142; Ortiz 1941: 316; Pereda 1951: XXXIV.

191 Casaseca 1988: 29, 35, 133, 133 nota 32.

192 Un testimonio de 1843 relativo a los canteros pontevedreses, mucho más tardío pero igualmente significativo, afirma que los varones se iniciaban entonces en la profesión en torno a los quince años, momento en el cual se iban con sus padres hacia el reino de León y de Portugal para el aprendizaje del oficio. La temporada de trabajo abarcaba desde principios de abril hasta Navidad, cuando retornaban a sus casas, y durante el tiempo de ausencia las mujeres permanecían en el hogar ocupadas en las tareas agrícolas (Sojo [1947] 2003: 34).

193 Casaseca 1988: 315; Casaseca 2000: 20. Sendín (1977: 192-193) rechaza la información dada por Llaguno y Ceán (1829: vol. 1, 161), quienes, basándose al parecer en los archivos de la institución, afirmaban que Rodrigo Gil participó en la delineación de las trazas del Colegio Mayor del Arzobispo Fonseca en Salamanca, que copiaba de Pedro de lbarra.

194 Río 2001: 140, citado en Alonso 2015: 34.

195 Hoag 1985: 65.

196 En 1521 Juan Gil "el Mozo" se recibía como fiador de su padre en los citados destajos de la Catedral Nueva de Salamanca, y cobraba del cabildo, en 1522 contestaba a los requerimientos que se le hacían en
} 
comentado, debió nacer hacia 1490197. En el contrato que Juan Gil de Hontañón firmaba en 1523 para la construcción de la capilla del deán Cepeda en el convento de San Francisco de Zamora aparecía como testigo su hijo Rodrigo, refiriéndose a él el citado documento como "Rodrigo xil su criado del dho [dicho] juan gil"198; el término "criado" puede asimilarse al de aprendiz ${ }^{199}$, indicando en cualquier caso una relación de dependencia. Al año siguiente, 1524, actuaba de nuevo Rodrigo Gil como testigo en el contrato de su padre como maestro mayor de la catedral de Segovia ${ }^{200}$. Antes de abril de 1526 participaba, junto con su padre, en una junta de maestros reunida en Valladolid con el fin de elaborar las trazas para la construcción de una nueva colegiata ${ }^{201}$. Su condición subordinada se mantendría seguramente hasta este último año, cuando se produce la muerte de su progenitor $^{202}$.

Fue Juan Gil "el Mozo" quien asumió entonces la dirección de las obras de la Catedral Nueva de Salamanca ${ }^{203}$, y quizás las de la colegiata de San Antolín en Medina del Campo (Valladolid)204, y a él se le ofreció inicialmente la maestría de la catedral de Segovia, aunque finalmente fuera elegido para ella Rodrigo205. Desde luego Juan Gil "el Mozo" no debía ser un maestro de segunda categoría, como algunos estudiosos 206 han pretendido, cuando heredó la maestría de una de las construcciones más importantes de su tiempo, pero el hecho es que no conservamos apenas datos que nos permitan clarificar algo más su figura, desconociéndose incluso la fecha exacta de su muerte, acaecida entre junio y septiembre de $1531^{207}$. Las obras de la catedral de Segovia, y el resto de las contratadas por su padre, como las de la iglesia de la Asunción de Nuestra Señora en Villamor de los Escuderos (Zamora) y las de la capilla del deán Cepeda en Zamora, fueron tomadas por Rodrigo Gil, iniciándose de este modo su práctica profesional independiente.

Este acercamiento a la arquitectura a través de la práctica, en lugar de por la vía del estudio y la formación humanística, o del cultivo de otras artes como la escultura, como era frecuente entonces, lo convirtió quizás más en un hombre de oficio que en un artista o un erudito. No se tiene certeza de si en estos primeros años de su carrera tuvo acceso a manuscritos, dibujos o publicaciones de arquitectura, algo que sí ocurrió más adelante como parecen demostrar las referencias a algunos autores incluidas en su manuscrito sobre construcción gótica. Tampoco se tiene constancia de que realizara algún viaje que completara su educación, aparte de los que hiciera con su padre visitando las obras que este dirigía en distintos puntos de la Península ${ }^{208}$. En cuanto a sus habilidades como dibujante, las trazas realizadas por Rodrigo Gil que se conservan nos muestran siempre representaciones en planta y alzado, evitando la perspectiva; su nivel de definición,

relación con esta obra, y en 1524 recibía de nuevo dinero y concluía las capillas (Castro 2002: 252, citado en Alonso 2015: 37; Chueca 1951: 243-244; Llaguno y Ceán 1829: vol. 1, 163).

197 Alonso 2015: 34; Castro 2003a: 154-156.

198 Martí 1907a: 20; Pereda 1951: XCIV-XCV.

199 Casaseca 1988: 315.

200 Cortón 1997b: apéndice documental, doc. 2, citado en Alonso 2015: 34.

201 Alonso 2004: 39-41; Casaseca 1988: 96-97.

202 Casaseca 1988: 37; Casaseca 2000: 20.

203 Casaseca 1988: 78; Chueca 1951: 243-244.

204 Arias, Hernández y Sánchez 2004: 75 nota 12; Casaseca 1988: 323; García 1954-1956: 54.

205 Alonso 2015: 34-38; Casaseca 1988: 37, 87.

206 Castro 2003a: 154-156.

207 Alonso 2015: 39-40.

208 Chueca 2001: vol. II, 83-84; García-Murga 1981: 23; Lozoya 1962: 24-25. 
variable en función de los objetivos perseguidos, puede llegar a ser bastante alto, como podemos apreciar, por ejemplo, en algunos de los dibujos para la construcción de la catedral de Segovia, o en la planta para la ampliación de la iglesia de Santo Tomás en Vegas de Matute (Segovia).

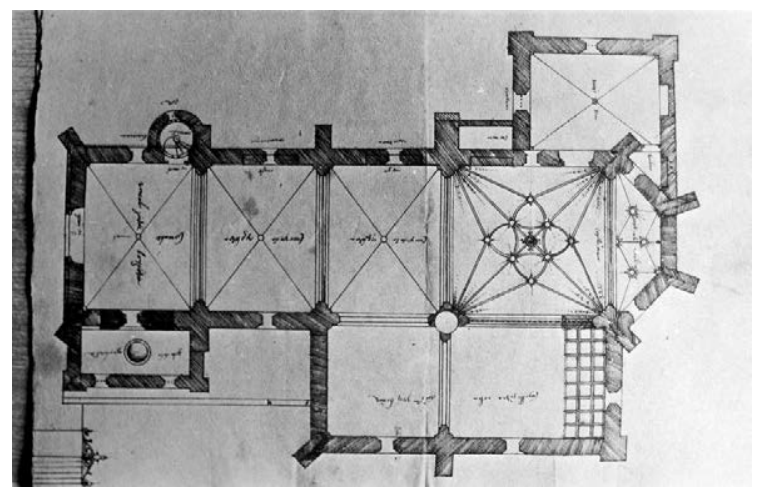

Figura 22. Trazas realizadas por Rodrigo Gil para la ampliación de la iglesia de Santo Tomás, Vegas de Matute (Segovia): planta (Moreno 1973: 208 lám. 13)

Como ha observado oportunamente Redondo209, Juan Gil transmitió a su hijo Rodrigo no solo un conjunto de conocimientos técnicos o la dirección de algunas obras, sino, más importante todavía, su posición y prestigio como maestro de cantería, unas relaciones privilegiadas tanto en el mundo profesional como entre los potenciales clientes, y un área de influencia en la que mantener un cierto control sobre los encargos. Esta ventajosa posición de partida, unida a la extraordinaria capacidad de Rodrigo Gil, le permitiría trabajar para un amplio número de comitentes, disponer de los medios técnicos, económicos y humanos para contratar la ejecución de importantes obras, y alcanzar una desahogada posición económica ${ }^{210}$.

\subsubsection{2. Ámbito geográfico y temporal}

La actividad profesional desarrollada por Rodrigo Gil fue sin duda prodigiosa, teniendo en cuenta la amplitud de su ámbito geográfico y temporal y la abundancia de sus intervenciones. Esta capacidad de trabajo, a la que tradicionalmente se han referido los estudiosos $^{211}$ como "laboriosidad", le permitió desenvolver su labor en un entorno que abarca la zona septentrional de la Corona de Castilla, al norte del sistema central, incluyendo algunas incursiones en Extremadura y Madrid, y ninguna en Cantabria ni probablemente en el País Vasco ${ }^{212}$. Rodrigo Gil era quizás reticente a abandonar esta área de influencia, ya que en 1535 fue llamado a visitar las obras de la catedral de Sevilla pero no acudió ${ }^{213}$, a pesar de que su padre había trabajado anteriormente tanto allí como

\footnotetext{
209 Redondo 2003: 20.

210 La posición privilegiada de otros maestros de la época está comprobada, como demuestra, por ejemplo, el hecho de que Juan Guas fuera propietario de las canteras de donde se extraía la piedra para la obra del monasterio San Juan de los Reyes en Toledo, que él mismo dirigía (Alonso 2012: 243).

211 Agapito 1922; Pereda 1951: XLII.

212 Aunque Rodrigo Gil dio su parecer acerca del claustro de la iglesia de San Miguel Arcángel en Oñati (Gipuzkoa), Casaseca cuestiona su presencia en la localidad (Casaseca 1988: 40, 236-237, 322).

213 Casaseca 1988: 38, 242; Morena 1972: 107 nota 6.
} 
en Granada; tampoco se conoce ninguna actuación suya ni en la Corona de Aragón ni fuera de los dominios peninsulares del reino castellano.

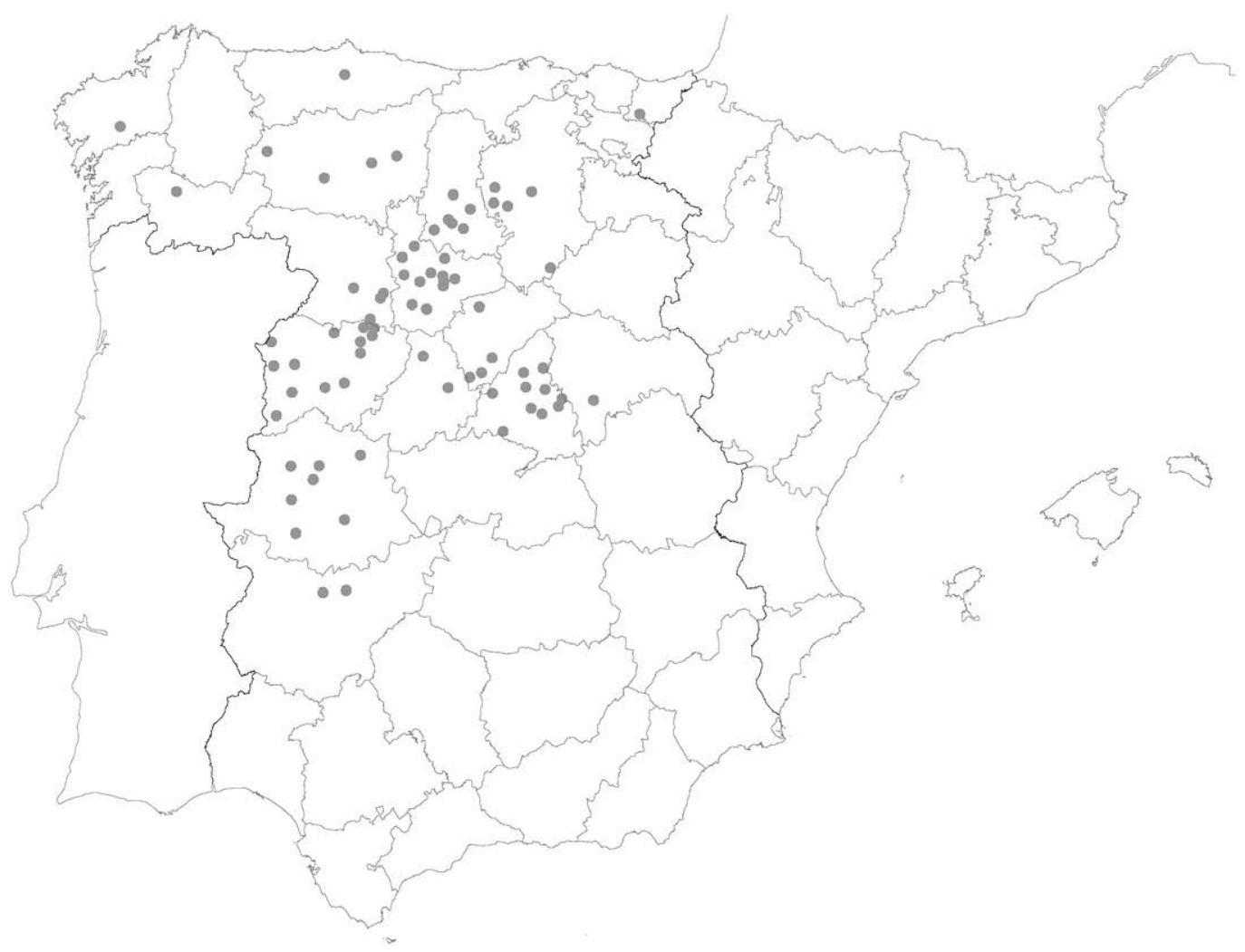

Figura 23. Localización geográfica de las intervenciones profesionales de Rodrigo Gil (P. Moreno. IGN)

Tanto Hoag ${ }^{214}$ como Casaseca ${ }^{215}$ distinguen, desde un análisis formal, tres fases temporales dentro de la obra construida por Rodrigo Gil, que corresponderían a su formación, madurez y últimos años. La etapa central, de plenitud, se extendería para Hoag desde 1533 hasta 1560, mientras que Casaseca desplaza ligeramente estos límites temporales, estableciéndolos en 1538 y 1558 ○ 1565. En todo caso, el periodo de mayor actividad profesional es el que se desarrolla aproximadamente entre 1540 y 1570 : desaparecido en 1537 el único maestro que podía eclipsarlo, Juan de Álava, asumida la dirección de muchas de las obras que este supervisaba, y desplazado a Extremadura el hijo de este, Pedro de lbarra, Rodrigo Gil se convirtió en la figura preponderante en el panorama de la construcción en Castilla la Vieja durante más de treinta años ${ }^{216}$. Consta su presencia en más de siete provincias en un año, llegando a dirigir simultáneamente más de veinte obras, algunas alejadas entre sí más de quinientos kilómetros ${ }^{217}$.

\footnotetext{
214 Hoag 1985: 63.

215 Casaseca 1988: 15-16, 315-318; Casaseca 2000: 20-22.

216 Casaseca 1988: 40; Pereda 1951: XLIII-XLVI.

217 Casaseca 1988: 36, 40.
} 


\subsubsection{Campo de actuación y sistema de trabajo}

Rodrigo Gil desempeñó su actividad trabajando bajo las distintas opciones que se ofrecían a la figura del maestro en su abanico profesional, esto es, como proyectista, como director de la obra y como contratista, y simultaneó con frecuencia las tres tareas en una misma obra. Adicionalmente realizó informes, peritaciones y tasaciones de obras ya ejecutadas o en curso.

El número de obras en que intervino a lo largo de su carrera fue comparativamente muy superior al de muchos de sus coetáneos debido, entre otros factores, a que concibió su actividad con un perfil totalmente moderno: en lugar de contratar la construcción o la dirección de los trabajos de un edificio y permanecer a pie de obra hasta su finalización, supervisando personalmente todo lo concerniente, como era habitual en la Edad Media, prefirió delegar grandes responsabilidades en sus aparejadores, lo que le posibilitó para proyectar, dirigir, construir o peritar simultáneamente tantas obras como los plazos de ejecución impuestos, la lentitud de los procesos constructivos y las dificultades de traslado de la época le permitieron ${ }^{218}$. En esta delegación de funciones coincide con otros maestros del momento, como Juan de Castillo (1470-1552) ${ }^{219}$ o Juan de Herrera (1530-1597) ${ }^{220}$.

Cuando actuaba como contratista el papel de los aparejadores y el trabajo en equipo se hacían todavía más importantes. Aquellos de los que se rodeaba Rodrigo Gil eran en muchos casos maestros de primera línea, con unos conocimientos de geometría que les permitían quedar al frente de la obra durante largos periodos de tiempo, materializando las trazas o lo ordenado verbalmente por Hontañón, y en ocasiones desarrollaban también otros encargos como profesionales independientes. Pero entre sus funciones no solo se contaba la dirección de la ejecución de la obra, sino también su administración económica. Esto incluye por una parte el control de los gastos referentes a mano de obra, materiales, maquinaria y cuanto pueda quedar a su cargo en las cláusulas del contrato; y por otra el de los ingresos que recibían del promotor, y que cobraban en nombre del responsable de la obra, Rodrigo Gil, a quien representaban por carta de poder extendida para cada caso concreto o con quien iban en sociedad. Este, por su parte, visitaba periódicamente los trabajos, supervisándolos como dirección de la obra y revisando las cuentas con sus apoderados como contratista ${ }^{221}$.

Este sistema de trabajo le obligaba a emplear una parte importante de su tiempo en realizar frecuentes viajes de una a otra obra. Evidentemente en muchos de esos desplazamientos no visitaría un solo edificio, sino varios, situados próximos entre sí o de camino ${ }^{222}$. Esta actuación no era fácilmente compatible con la dirección de las obras más importantes, como las catedrales de Salamanca y Segovia, donde como maestro mayor se le exigía una permanencia mínima de cuatro meses a lo largo del año, siendo motivo de queja por parte de los cabildos, y pudiendo incluso haber provocado su despido en algún caso 223 .

\footnotetext{
218 Pereda 1951: XLIII-XLVI; Sendín 1977: 192-193.

219 Ealo 2009: 74-75, 122-1 24.

220 Aramburu-Zabala 2003: 99-100.

221 Agapito 1922: 152; Pereda 1951: XLIII-XLVI; Redondo 2003: 15-17.

222 Casaseca 1988: 40.

223 Alonso 201 2: 234-236; Casaseca 1988: 39, 87, 91.
} 


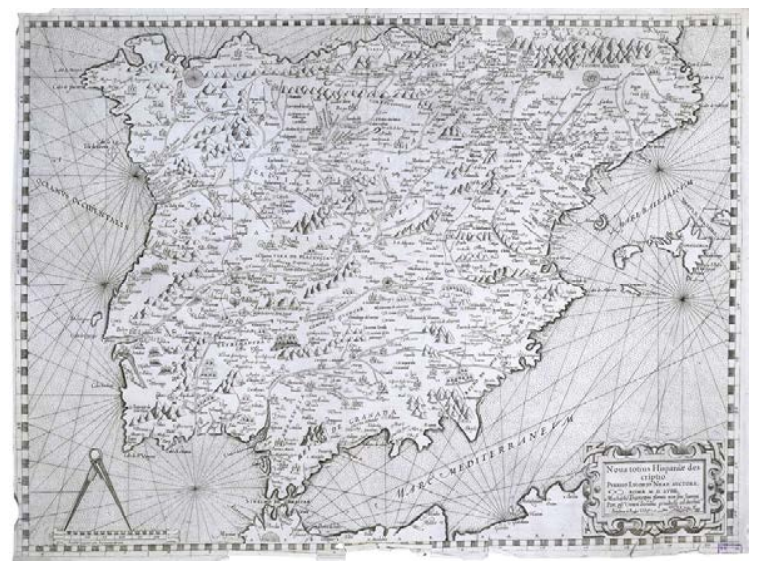

Figura 24. España en 1559, según Pirro Ligorio (Ligorio 1559)

Considerando la magnitud y dispersión de la obra de Rodrigo Gil, podremos aceptar que su capacidad técnica le permitiera, con frecuencia, dar la traza de los elementos más importantes, o incluso, en algún caso, de todos ellos; pero es evidente que muchas veces serían sus aparejadores quienes tuvieran a su exclusivo cargo amplias parcelas relativas al trazado geométrico y al desarrollo constructivo, algo natural dada la dificultad de los desplazamientos para dirigir una obra en la época, y la imposibilidad práctica de paralizarla, hasta la hipotética llegada del maestro, en espera de una decisión de diseño. En los edificios de Hontañón se presenta por esta razón un cierto problema de autoría, ya que, a nuestro juicio, debemos aceptar siempre una mayor o menor aportación a cargo de otros profesionales. Sus obras pueden considerarse el producto de la creación de un individuo, pero enriquecido sin duda con la contribución de todas esas figuras menores que giraban en su órbita.

Entre los aparejadores y colaboradores habituales que intervinieron en las obras de Rodrigo Gil podemos identificar los siguientes (se indica entre paréntesis el número total de obras en que está documentada su presencia):

Miguel de Aguirre (3)

Claudio de Arciniega (2)

Gonzalo de la Atalaya (3)

Juan de Cariga (3)

Pedro de la Cotera (3)

Diego de Cubillas (2)

García de Cubillas (2)

Juan de Escalante (4)

Miguel de Espinosa (4)

Guillén Ferrán o Ferrant (2)

Pedro de Gamboa (3)

Francisco Godino (2)

Pedro de lbarra (4)
Hortuño de Marquina (3)

Juan de la Maza (3)

Martín Navarro (2)

Juan Negrete (3)

Alonso de Pando (6)

Juan de la Puente (4)

Pedro de la Puente (2)

Juan de la Riba (2)

Juan de Ribero (3)

Nicolás de Ribero (4)

Juan del Ribero Rada (3)

Francisco del Río (3)

Hernando del Río (2)
Rodrigo de la Riva (2)

Martín Ruiz de Chertudi (3)

Francisco de Salamanca (2)

Fray Martín de Santiago (2)

Juan de Saravia (2)

Pedro de la Torre (2)

Juan del Valle (4)

Juan de la Vega (2) 


\subsubsection{Clientela}

No cabe duda de que Rodrigo Gil fue un hombre respetado y apreciado, como nos demuestra la gran cantidad de encargos que recibió, tanto de las instituciones eclesiásticas como de la nobleza o incluso de la Corona. Aparte de los cabildos catedralicios, entre los comitentes pertenecientes a la nobleza $\circ$ al alto clero encontramos a personajes importantes de la época como los Fonseca, Gasca, Ulloa, Acevedo Zúñiga o Guzmán. Es significativo el hecho de que en muchas ocasiones el trabajo se desarrolle en centros geográficos de importancia, bien económica (Medina de Rioseco, Medina del Campo, Segovia), cultural (Alcalá de Henares, Salamanca) o religiosa (Santiago de Compostela), lo que nos da idea del tipo de promotores que se dirigían a él para solicitar sus servicios. Junto a ellos se sitúan, por otro lado, los modestos beneficiados de los templos parroquiales rurales, guiados también por la fama del maestro224. Según algunos autores ${ }^{225}$, el prestigio de Rodrigo Gil llegó a ser tal que muchos de sus clientes le consideraban el mejor arquitecto del momento.

Ya desde el principio de su carrera profesional la posición de Rodrigo Gil debía ser bastante sólida, si pensamos que en 1526 había sido nombrado maestro de las obras de un edificio como la catedral de Segovia, y en 1529 y 1533 comenzaba iglesias de la importancia de la de San Sebastián en Villacastín (Segovia) o la de Santiago de los Caballeros en Medina de Rioseco (Valladolid). Este último año, a raíz del pleito entablado por la construcción de la capilla del deán Cepeda en el convento de San Francisco de Zamora, se indicaba "que Rodrigo gil como tomo la dha [dicha] obra fue muy aprovechado ... para dar de comer a muchos oficiales q traia consigo e criados q le syrben ..."226, esto es, se le afeaba precisamente que hiciera ostentación de su condición y que gastara indebidamente parte de los fondos del promotor.

Un ejemplo del prestigio de que gozaba el arquitecto en edad madura era que el propio Felipe II se interesó por los trabajos que dirigía Rodrigo Gil en la catedral de Segovia, ya que tras una visita a la ciudad en 1562 solicitó a Hontañón algunos dibujos del edificio ${ }^{227}$. Poco después, en 1564 y 1566, fue llamado por el monarca, junto con otros maestros, para dictaminar sobre las obras realizadas por Juan Bautista de Toledo en el Real Monasterio de San Lorenzo de El Escorial (Madrid) ${ }^{228}$. Esta intervención aumentó aún más la fama del maestro, siendo considerado una persona de gran importancia entre sus clientes, como el cabildo de la catedral de Oviedo (Asturias) ${ }^{229}$, y entre sus compañeros de profesión, ya que en 1576 se recomendó que informara, junto con su contemporáneo Andrés de Vandelvira, sobre la marcha de las obras del palacio de Carlos V en la Alhambra de Granada ${ }^{230}$.

\subsubsection{Vinculaciones profesionales}

Entre los profesionales, sin embargo, debía existir una división mayor de opiniones, dependiendo de sus relaciones recíprocas, movidas en gran medida, entonces como ahora, tanto por intereses económicos como por vínculos personales. En relación con los motivos

\footnotetext{
224 Casaseca 1988: 14, 21, 40.

225 Redondo 2003: 15-17.

226 Martí 1907a: 66.

227 Casaseca 1988: 92; Hoag 1985: 191-192.

${ }_{228}$ Aramburu-Zabala 2003: 99-100, 102-103; Hoag 1985: 192, 194; Kubler 1985: 43.

229 Casaseca 1988: 43.

230 Rosenthal 1988: 305, citado en Redondo 2003: 15-17.
} 
pecuniarios, existía una fuerte competencia entre unos y otros maestros y era habitual que entre ellos surgieran alianzas 0 desencuentros a causa de adjudicaciones de obras, tasaciones o peritaciones favorables o contrarias a los intereses de unos $u$ otros. A ello hay que añadir la gran importancia que tenían las relaciones familiares, de amistad y de paisanaje entre los compañeros de profesión. En este sentido, debemos observar que los canteros que trabajaban la piedra en España en el siglo XVI procedían fundamentalmente de dos zonas limítrofes: la formada por La Montaña santanderina, caso de la familia paterna de Rodrigo Gil, y las provincias vascas, Bizkaia y Gipuzkoa sobre todo ${ }^{231}$. Vascos y cántabros formaban círculos separados, ya que no era habitual la colaboración entre profesionales de distinto origen geográfico ${ }^{232}$.

La magnitud del trabajo desarrollado por Rodrigo Gil hizo que a lo largo de su carrera tuviera contacto con multitud de canteros, oficiales y maestros, que trabajaban a sus órdenes, con los que colaboraba $\circ$ que realizaban tasaciones o peritaciones sobre sus obras. Las relaciones personales y profesionales, la clientela potencial y las posibilidades de contratación de Rodrigo Gil, dadas por su prestigio y solvencia, eran tales que muchos canteros aspiraban a formar parte de su círculo para asegurarse el trabajo, ya fuera a sus órdenes, ya de modo independiente. En este sentido, debemos pensar que la contratación de una obra no estaba al alcance de cualquiera, ya que, como ahora, aparte de hacer la mejor oferta a la baja, debía garantizarse la solvencia técnica, esto es, la experiencia y dominio del oficio por parte del maestro y la disposición de un equipo de trabajadores; y la solvencia económica, que permitiera finalizar la obra en plazo ${ }^{233}$.

El sistema de relaciones generado era en gran medida de clientelismo, basado en la prestación de favores de los que se esperaba correspondencia. Una de sus manifestaciones la encontramos en los procesos de contratación, en los que se producían en ocasiones irregularidades, como la presentación de ofertas en la subasta o concurso por parte de hombres de paja, y las presiones o pactos bajo cuerda entre los participantes, con la finalidad de conseguir la adjudicación de la obra o unas mejores condiciones económicas en esta. Los informes, peritaciones y tasaciones se podían ver igualmente afectados por este sistema, ya que podían ser la ocasión de devolver un favor recibido anteriormente, o, por el contrario, el origen de desavenencias, roces y enemistades, al considerarse el contratista perjudicado por la valoración del perito que actuaba por parte del promotor. El corporativismo de los profesionales era además constante motivo de queja de los

\footnotetext{
231 Ealo 2009: 98; Gómez 1998: 45-52.

232 Algunos colaboradores de Rodrigo Gil eran parientes, como Juan de la Montaña (cuñado de Rodrigo Gil) (capilla del deán Cepeda en el convento de San Francisco de Zamora), Juan Sánchez de Alvarado (parentesco indeterminado) (colegiata de Santa María de Valladolid y obras en Toro (Zamora)) o Rodrigo de Villaparte (primo segundo de su padre). Otros procedían de su lugar de nacimiento, como Juan de Ribero (colegiata de Santa María de Valladolid, iglesia de San Martín en Mota del Marqués (Valladolid), iglesia de la Asunción de Nuestra Señora en Meco (Madrid)), vecino de Rascafría; y otros del de su padre, como Diego del Cerro y Juan de Saravia (iglesia de Santiago Apóstol en Cigales (Valladolid), iglesia de San Ginés en Ciguñuela (Valladolid)), vecinos de Rasines. Fueron escasos los ejemplos de maestros que mantuvieran una buena relación con ambos grupos, como el cántabro Juan Negrete (Catedral Nueva de Salamanca, catedral de Ciudad Rodrigo (Salamanca), Colegio Mayor del Arzobispo Fonseca en Salamanca), que trabajó con canteros vascos, y el probablemente vasco Hortuño de Marquina (iglesia de Santiago Apóstol en Cigales (Valladolid), iglesia de la Asunción de Nuestra Señora en Laguna de Duero (Valladolid), iglesia de Santa María la Antigua en Valladolid) (Redondo 2003: 38$39,44)$.

233 Alonso 1991: 80-81, citado en Redondo 2003: 17-20; Redondo 2003: 17-20.
} 
comitentes, que juzgaban con frecuencia menoscabados sus intereses económicos ${ }^{234}$ : en 1533, con motivo del pleito iniciado por la construcción de la capilla del deán Cepeda en el convento de San Francisco de Zamora, se afirmaba

que cuando alguna obra de canteria se tasan por maestros ... se tasan en mas de lo q merecen y esta costunbre tienen todos los dhos [dichos] maestros de canteria porque los unos tasan las obras de los unos e los otros de los otros 235 .

Como ejemplo de estas complejas relaciones profesionales, es conocida la animadversión que existía entre el cántabro Juan Gil de Hontañón y el vasco Juan de Álava, surgida por causa de los destajos de las capillas hornacinas de la Catedral Nueva de Salamanca, y extendida a sus respectivos hijos, Juan Gil "el Mozo", Rodrigo Gil y Pedro de lbarra, y a los canteros de ambos círculos ${ }^{236}$. El primer contacto profesional entre Juan Gil de Hontañón y Juan de Álava se produjo en 1512, en la junta de maestros celebrada en Salamanca para la construcción de la Catedral Nueva. Desde entonces coincidieron en varias ocasiones, como en las obras de la catedral de Sevilla, en 1513 y $1515^{237}$, y en las de la Catedral Nueva de Salamanca, donde a finales de 1520 ambos tomaron dos destajos paralelos para la construcción de las capillas hornacinas de la nave ${ }^{238}$. Estos destajos provocarían en 1522 un enfrentamiento abierto entre ambos maestros, y la interrupción de las obras para su peritación. El motivo aparente era la solución técnica dada a las bóvedas, y en concreto a su "rampante" o línea de espinazo, ya que Álava defendía el rampante "llano", mientras que Gil prefería el "redondo" 239 . Sin embargo, la razón subyacente se encontraba no en las cuestiones técnicas o estéticas, sino en la competencia por el control de los encargos profesionales dentro de un determinado ámbito geográfico ${ }^{240}$. Muerto ya Juan Gil, su hijo Juan Gil "el Mozo" y Juan de Álava se encontraron por causa de las obras que el primero dirigía en la Catedral Nueva de Salamanca. Álava fue llamado junto a Alonso de Covarrubias para dar su parecer en 1529, emitiendo ambos un informe contra el maestro, e imponiéndole unas trazas nuevas para el alzado de las naves ${ }^{241}$. Pocos años después se produjo el primer enfrentamiento entre Juan de Álava y Rodrigo Gil con motivo de la tasación realizada en 1533 por Álava de las obras realizadas por Hontañón en la capilla del deán Cepeda en el convento de San Francisco de Zamora ${ }^{242}$. Fallecido Álava, las desavenencias continuaron entre su hijo Pedro de lbarra y Rodrigo Gil con motivo de la tasación en 1537 de las obras ejecutadas por Hontañón en la cabecera y crucero de la iglesia de la Asunción de Nuestra Señora en Villamor de los Escuderos (Zamora), cuando el provisor episcopal nombró como tasador por parte de la iglesia a lbarra. Se produjo entre ellos un intercambio de agrias acusaciones del que incluimos a continuación algunos fragmentos procedentes de los documentos conservados. Rodrigo Gil recusó el citado nombramiento, alegando que lbarra,

\footnotetext{
${ }^{234}$ Aramburu-Zabala 2001, citado en Redondo 2003: 17-20; Redondo 2003: 17-20.

235 Martí 1907a: 66.

236 Casaseca 1988: 42-43; Redondo 2003: 44.

237 Castro 2003a: 149-151.

238 Chueca 1951: 41-44.

239 Chueca 1951: 88.

240 Castro 2003a: 149.

241 Castro 2003a: 154-156.

242 Martí 1907a: 63, 85-86.
} 
demás y allende q ni es maestro experimentado en el ofiçio de cantería ni él ha hecho ni tasado semejantes obras como la q yo he hecho en la dha [dicha] yglia [iglesia], es mi enemigo e hijo de mi enemigo, el qual ha dho [dicho], asy por palabra como por carta firmada de su nombre, q me a de dañar en todo lo q pudiere e ha hecho otras amenazas por sy e por otros criados de su padre ... e parece por carta ... q escrivió a un pariente oficiçial mío, de que hago presentaçión, e, demás, el mesmo ju [juan] de álaba, su padre, consta v.m. [vuestra merced] que con la enemistad q me tenía dixo a v.m. [vuestra merced] q avía engañado a dha [dicha] yglia [iglesia] en la dha [dicha] cantidad ${ }^{243}$.

La carta que se presentaba como prueba iba dirigida por lbarra a Juan Sánchez de Alvarado, que trabajaba para Rodrigo Gil en las obras de la colegiata de Santa María de Valladolid, y dice así:

Muy virtuoso señor, yo estuve este otro día ay, en valladolid, y pregunté por vos y dixéronme $q$ no estávades ay, y después que acá vine soy informado, lo cual es verdad, $q$ vos fystes a demandar aliviçias a $R^{\circ}$ [Rodrigo] gil de la muerte de ju [Juan] de Álava, dios lo ponga en la gloria. Si vos fuérades hombre de buen conosçimiento, no lo hiziérades ansy; mas yo os agradezco la buena voluntad y la misma mia n'os faltará de aquí adelante, q yo espero en dios de os dar el galardón como vos merecéys. $A R^{\circ}$ [Rodrigo] gil, si ay está, le dizi q digo yo q se acuerde de la carta q me enbió diziendo de las mazmorras, y q sepa q aunq mi padre sea muerto yo soy bibo y q, por ser bien criado, $q$ en ausençia $q$ no pierde nada nayde. Nro. [Nuestro] señor os ay en su guarda. De salamanca, a III de nov ${ }^{\circ}$ [noviembre]. A lo q mandáredes, Pedro de ybarra (rubricado) 244 .

Estos textos son ilustrativos no tanto de una animadversión mutua, sino sobre todo de la fuerte competencia que podía existir entre los canteros, ya que, a pesar del encono que ambos se demostraban, poco tiempo después coincidían de nuevo en obras dirigidas por Hontañón, como las del palacio de Monterrey (1539-1566), la Catedral Nueva (15401546) o el Colegio Mayor del Arzobispo Fonseca (1541), todas ellas en Salamanca. Incluso en 1563 lbarra recomendaba, ante los problemas estructurales de la catedral de Coria (Cáceres), la visita de Rodrigo Gil ${ }^{245}$.

Encontramos otro ejemplo significativo del enfrentamiento que muchas veces surgía entre los profesionales en las obras de la iglesia de Santa María de la Asunción en Guareña (Badajoz), para cuya continuación Rodrigo Gil mandó en 1570 como aparejador a Pero Gómez, haciendo una feroz crítica de los canteros trujillanos que habían iniciado la obra en los siguientes términos:

Y bisto, esto, si a V.S. reberend. $m^{a}$ [vuestra señoría reverendísima] se satisface, q.e Pero Gomez vaya a entender en la obra, que bien se la tengo yo dada a entender e bien instruido esta, e mejor la hara con el pie q.e los de Trujillo con las manos, e a menos costa y mas llano onbe es

\footnotetext{
243 Navarro 1983: 111 nota 33.

244 Navarro 1983: 111 nota 33.

245 García 1996a: 37.
} 
e mas obra hara con cien mil marabs. [maravedís] quellos con ciento cincuenta, quesas gentes son mastines que muerden a hurto.$^{246}$.

En el extremo opuesto, tenemos también testimonios referidos a aquellos que se veían favorecidos por este complejo entramado de relaciones, en los documentos referentes al pleito por la construcción de la iglesia de San Martín en Mota del Marqués (Valladolid). En ellos Rodrigo Gil admitía abiertamente que los precios que podía dar por las obras que contrataba eran más baratos que los de otros maestros gracias a su buena relación con los aparejadores y oficiales que trabajaban para él,

... porque Rodrigo Gil es un hombre que haze por muchos ofiçiales, y les da obras en que entiendan, y les haze muy buen tratamiento, y huelgan más de trabajar con él por ocho que con otro por diez, e porque con él siempre deprenden [aprenden o reciben]; e si en esta obra que tiene se contentan con poco, en otras que tiene les haze aparejadores; y los a hecho e pagado de su hazienda mucha parte de dineros y se lo da a ganar ...247.

\subsubsection{Valoración historiográfica}

La influencia ejercida por Rodrigo Gil en la arquitectura castellana durante los años centrales del siglo XVI fue sin duda importante, acaparando muchos de los encargos y dando trabajo de modo directo o indirecto a gran cantidad de profesionales ${ }^{248}$. Muchos de los maestros que trabajaron en sus obras como aparejadores y otros canteros de su entorno, como Juan de Saravia, Juan Negrete, García de Cubillas o Juan Ruiz de Pámanes, asimilaron su estilo ${ }^{249}$, trazando y construyendo edificios en los que reaparecen muchas de las características que encontramos en la obra de Rodrigo Gil. Un ejemplo significativo es la repetición de uno de sus modelos de bóveda de crucería más característicos, compuesto por cruceros, terceletes y ligaduras, y un dibujo de combados formando un cuadrifolio de hojas cóncavas en cuyo interior se dispone otro cuadrifolio de hojas convexas y tangentes al primero. Este modelo conoció un gran éxito en el ámbito castellano y se convirtió en seña de identidad no solo de su círculo de cantería, sino de todo el gótico del siglo XVI en Castilla.

A pesar de que el propio Rodrigo Gil, al final de su vida, tenía la conciencia de haber creado de algún modo una escuela en torno a su figura ${ }^{250}$, la realidad es que con él se extinguió la larga tradición medieval que había heredado ${ }^{251}$ : el desplazamiento del gusto estético desde los postulados góticos y platerescos hacia la severidad herreriana, producido en el último tercio del siglo XVI, impidió que sus discípulos continuaran construyendo bajo los principios hontañonianos, si bien la formación técnica adquirida al lado del maestro les seguiría siendo igualmente válida para la ejecución de obras de cantería en el nuevo estilo, a las que por otro lado seguirían incorporando las tradicionales bóvedas de crucería góticas, aprendidas junto al maestro. A pesar de que desde principios del siglo XVII se

\footnotetext{
246 García-Murga 1981: 60.

247 Vasallo y Pérez 201 1: 52.

248 Gómez 1998: 51; Redondo 2003: 15-17.

249 Aramburu-Zabala 2003: 99-100.

250 Castro 1997: 50 doc. IV.

251 Hoag 1985: 213, 216-218.
} 
produce un lento desplazamiento de la cantería en favor de la albañilería, debido al elevado coste de la primera, y de que comienza entonces el progresivo declive de las distintas escuelas de cantería existentes en la Península, no es menos cierto que el mantenimiento de las bóvedas de crucería, junto a otros usos tardomedievales, es una constante en la arquitectura religiosa española de los siglos XVII y XVIIII252. En este apego a lo gótico, amparado en una idea de suntuosidad contrapuesta a lo clásico 253 , tiene sin duda mucho que ver la influencia de dos de las fábricas en las que participó Rodrigo Gil y que continuaron su construcción durante todo el seiscientos, la Catedral Nueva de Salamanca y la catedral de Segovia, obras que prolongarían el prestigio de Hontañón entre comitentes y maestros.
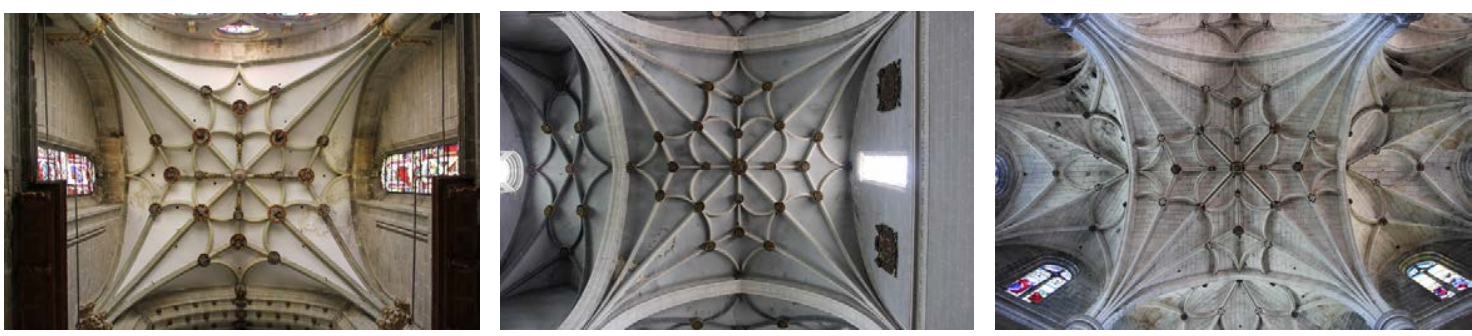

Figura 25. Algunas bóvedas de crucería trazadas por Rodrigo Gil con uno de sus diseños en planta más característicos: (a) Catedral de Astorga (León): capilla de San Juan Bautista (costado sur del falso crucero). (b) Iglesia de Santa María Magdalena, Valladolid: crucero (tramo central). (c) Iglesia de San Sebastián, Villacastín (Segovia): crucero (tramo central)
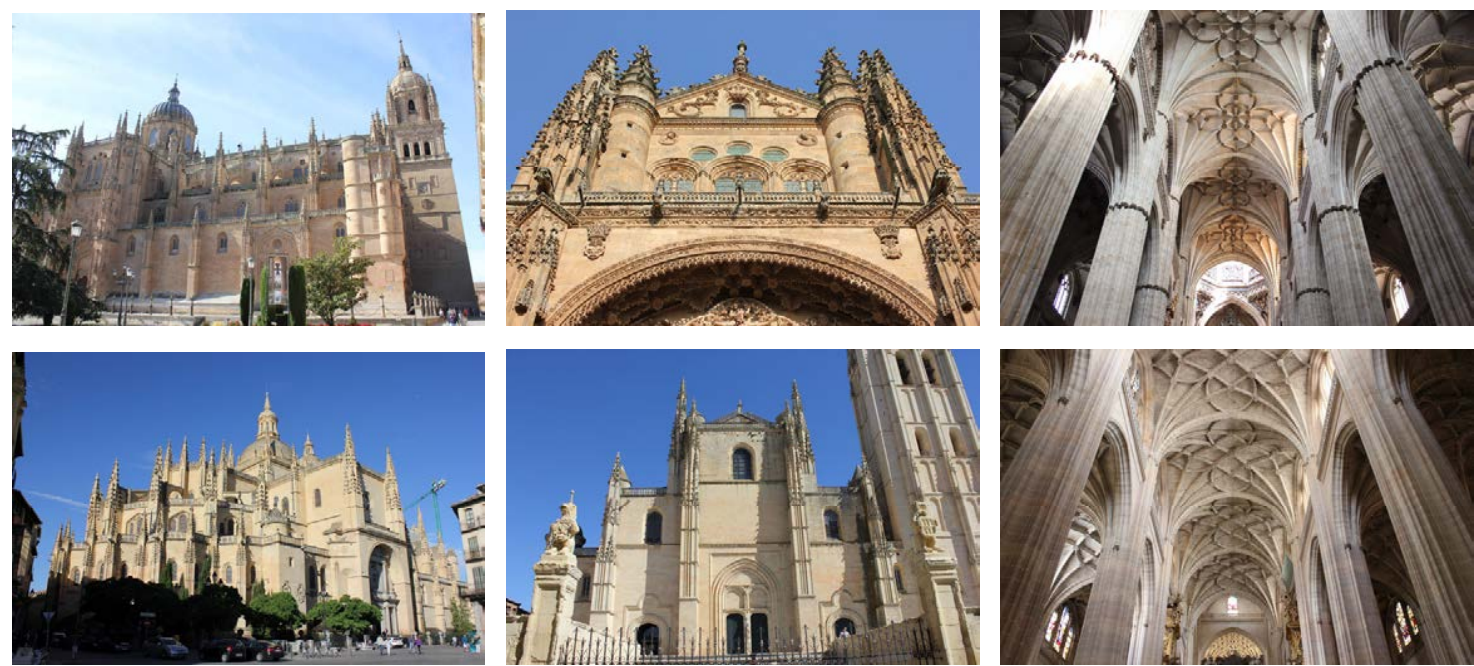

Figura 26. Dos de los edificios más emblemáticos en los que intervino Rodrigo Gil: $(a, b, c)$ Catedral Nueva de Salamanca. (d, e, f) Catedral de Segovia

Por lo que respecta a la valoración que ha merecido la figura y la obra de Rodrigo Gil en la historiografía española, ya en el siglo XVII dos de los cronistas más relevantes del

252 Gómez 1998: 52, 227-228. Las últimas bóvedas de crucería construidas en nuestro país durante la Edad Moderna fueron las de la catedral de Las Palmas, cuyo cimborrio terminó de cerrarse en 1798 (Gómez 1998: 238).

253 Según Gómez Martínez (Gómez 1998: 195-196), el concepto de suntuosidad gótico, basado en la variedad, sería el equivalente al de orden o proporción clásico, fundamentado en la unidad. La misma idea es compartida por Frankl (2002: 387), quien utiliza términos antagónicos de división y suma. 
momento, Gil González Dávila y Diego de Colmenares ${ }^{254}$, le elogiaban respectivamente por su intervención en la Catedral Nueva de Salamanca y en la catedral de Segovia, fundamentalmente como hitos de espiritualidad, disculpando la utilización de una arquitectura no clásica. Dicha tendencia continuó en el siglo XVIII, si bien en los eruditos se produjo un cambio fundamental, ya que comenzaron a reconocer el valor cultural y artístico de la arquitectura gótica, y, por extensión, de las obras de Rodrigo Gil. A finales de siglo figuras como Gaspar Melchor de Jovellanos ${ }^{255}$ destacaron también la aportación de Rodrigo Gil a la recuperación de la arquitectura clásica en España. Estudiosos como Antonio Ponz, Isidoro Bosarte y Juan Agustín Ceán Bermúdez ${ }^{256}$ comenzaron entonces una labor de estudio para delimitar la personalidad del maestro, sacando a la luz en sus transcripciones distintos documentos, como el nombramiento de maestro mayor de la Catedral Nueva de Salamanca en 1538, la memoria redactada por el fabriquero de la catedral de Segovia en 1562, el testamento de Rodrigo Gil de 1577 o la transcripción de su lápida sepulcral ${ }^{257}$.

Durante el siglo XIX y la primera mitad del XX se continuaron valorando las obras de Rodrigo Gil desde posiciones y sensibilidades variables, más cercanas según el momento al romanticismo o al nacionalismo. En las primeras décadas del siglo pasado algunos investigadores 258 destacaban fundamentalmente el carácter prolífico o "laborioso" de este maestro, negando sin embargo su faceta artística y creativa, y limitando su aportación a la de un buen tracista y constructor apegado a usos arcaicos. Desde los años cuarenta, sin embargo, comenzó una fuerte revalorización de su figura, tomada como representativa del siglo más importante en la historia política de España. Así, Camón ${ }^{259}$ lo consideró el arquitecto más característico del plateresco español. Siguiendo esta tendencia, las posturas más tradicionales tendieron a valorar con pocas reservas la figura de Rodrigo Gil, y tal es el caso del trabajo de Pereda, que constituye la primera monografía elaborada sobre este maestro. Este estudioso 260 defendió que lo que otros autores califican de arcaico, esto es, la continuación de los usos góticos en la arquitectura religiosa, es únicamente la utilización del estilo más adecuado por su espiritualidad, siguiendo una idea planteada ya a finales del siglo XVIIII261. Pereda destacó su capacidad creativa y sus conocimientos, situándolo entre los maestros más importantes de la época, no solo españoles, sino también europeos, y calificándolo efusivamente como "el más grande arquitecto de todos los tiempos". El mismo tono, aunque algo más atemperado, comparten otros estudiosos, como el marqués de Lozoya ${ }^{262}$, quien en sus estudios colocó a Rodrigo Gil entre los diez arquitectos españoles más importantes de todos los tiempos, superándolo a su juicio únicamente Juan de Herrera. Destacó su nivel de conocimientos de la construcción gótica, plasmado en el manuscrito que se le atribuye ${ }^{263}$, pero también valoró su arquitectura civil y su carácter prolífico.

\footnotetext{
254 Colmenares 1637; Gonçalez 1606.

255 Jovellanos [1781] 2014, Jovellanos 1790.

256 Bosarte 1804; Llaguno y Ceán 1829; Ponz 1772-1794.

257 Crespo 2003a: 167, 169-171, 172-176.

258 Agapito 1922: 150, 158.

259 Camón 1941 b: 305.

260 Pereda 1951: XXXIX-XL, CCXLIII.

261 Gómez 1998: 240.

262 Lozoya 1931-1949: vol. III, 475 ("Juan de Herrera es quizás el más grande arquitecto español de todos los tiempos. En sabiduría del oficio, sólo su paisano Rodrigo Gil de Hontañón puede comparársele"); Lozoya 1952: 521-522; Lozoya 1962: 10.

263 García 1681.
} 
Ya entonces comienzan a aparecer posturas más críticas. Tal es el caso de Chueca ${ }^{264}$, quien valora positivamente las obras de carácter civil de Rodrigo Gil, destacando su carácter renacentista aunque no purista ni italianizante, sino netamente castellano e independiente, y calificándolo como "el creador más afortunado de nuestra arquitectura civil plateresca". Para él su obra está alejada tanto del plateresco español como del clasicismo impuesto con la construcción de El Escorial. Sin embargo modera los elogios a su abundante arquitectura religiosa, indicando de nuevo su carácter anacrónico, y señala la limitada capacidad creativa del maestro en lo estructural, frente a otros contemporáneos como Diego de Siloé, puente en el sur de España hacia los arquitectos clásicos.

En 1958 elabora Hoag ${ }^{265}$ su Tesis Doctoral sobre Rodrigo Gil, dando una visión más neutral, alejada de la historiografía española del momento. Para este crítico el interés de la obra de Rodrigo Gil radica en la fusión entre elementos tardogóticos y renacentistas que no son exclusivos del maestro, sino comunes al resto de la arquitectura del momento. Por esta razón sus obras deben entenderse, al igual que las de su padre, como una continuación de la tradición medieval, sin que podamos considerar a Rodrigo Gil como un artista verdaderamente individual. Este crítico ${ }^{266}$ destaca sin embargo el carácter único de muchos de los edificios realizados por Rodrigo Gil durante su etapa de madurez, señalando que el proyecto se afronta de un modo autónomo, aplicando soluciones diferentes en cada caso, y observando una cierta continuidad únicamente en algunos detalles tectónicos y decorativos. Establece de nuevo un paralelo con la figura de Diego de Siloé.

La Tesis Doctoral de Casaseca ${ }^{267}$ realiza por fin una investigación exhaustiva para componer el catálogo de las obras en las que intervino el maestro. Para este estudioso ${ }^{268}$, la figura de Rodrigo Gil es relevante para la Historia del Arte fundamentalmente debido a sus obras civiles, y en menor medida por sus actuaciones en las catedrales citadas 0 en otros edificios religiosos, de interés desigual y escasa originalidad, continuando en este sentido la línea de pensamiento de Chueca. Destaca, como Hoag, su capacidad para llevar a cabo simultáneamente obras civiles en las que introduce importantes aportaciones del Renacimiento, y edificios religiosos anclados en la tradición gótica, haciendo gala de una impresionante flexibilidad para adaptarse a los requerimientos de su variada clientela. Por lo que respecta al manuscrito del que se le supone autor, señala que sus contenidos debían ser comunes a la práctica profesional de la época, y apunta la posibilidad de que parte de ellos pudieran haber sido elaborados ya por Juan Gil de Hontañón.

Gómez Martínez 269 valora la figura de Rodrigo Gil no como arquitecto renacentista, sino como último representante de la tradición tardogótica renovada en España desde la segunda mitad del siglo $\mathrm{XV}$, destacando el hecho de que tanto el esquema general de sus edificios religiosos como el de sus bóvedas de crucería fueron heredados, a través de su padre, de los maestros centroeuropeos que protagonizaron dicha renovación. En este sentido coincide parcialmente con Hoag. En relación con el cuaderno de Rodrigo Gil, apunta, como Casaseca, una posible intervención de Juan Gil en su redacción.

\footnotetext{
${ }^{264}$ Chueca 1951: 141-144, 245-248; Chueca 2001: vol. II, 83-84, 86-87.

265 Hoag [1958] 1999, Hoag 1985.

266 Hoag 1985: 115, 167, 213, 215-218.

267 Casaseca 1986, Casaseca 1988.

268 Casaseca 1988: 13-14, 91, 199, 294-299; Casaseca 2000: 18, 24-25.

269 Gómez 1998: 24-25, 51, 169.
} 
Los autores contemporáneos ${ }^{270}$ siguen valorando a Rodrigo Gil como uno de los arquitectos más sobresalientes del siglo XVI español, destacando lo prolífico y versátil de su obra, y subrayando siempre su carácter ambivalente, que le permite utilizar simultáneamente el lenguaje gótico y el renacentista con idéntica maestría, y que por otro lado es representativo de toda la arquitectura de su tiempo. Por otra parte se concede cada vez mayor importancia a su manuscrito sobre arquitectura y construcción gótica.

270 AAVV 2003b: 9; Aramburu-Zabala 2003: 96; Huerta 2002: 574; Huerta 2006: 24-25; Martín 2000: 12 ; Morena 2000: 38; Sanabria [1982] 1999: [282-283] 2-3. 


\section{EL CUADERNO DE ARQUITECTURA DE RODRIGO GIL}



2.1. ANÁLISIS DEL TEXTO 

Aunque Rodrigo Gil es principalmente conocido por la abundancia y calidad de los edificios que construyó a lo largo de su vida, su figura es cada vez más valorada por su producción escrita, a pesar de la escasez de esta y del hecho de haber llegado hasta nosotros incompleta y alterada. Los textos que a él se atribuyen debieron constituir en origen un cuaderno de arquitectura que recopilaba, por una parte, los saberes de tradición medieval recibidos de su padre, y, por otra, los de tradición clásica y renacentista que, procedentes de diversas fuentes, fue asimilando a lo largo de su carrera profesional. Este cuaderno quizás pasó, a la muerte de Hontañón en 1577, a manos de su discípulo Juan del Ribero Rada, maestro de la Catedral Nueva de Salamanca desde 1589 hasta su fallecimiento en 1600, y seguramente se mantuvo, junto con la biblioteca de este último, en los archivos de la fábrica catedralicia hasta finales del siglo XVII271. Pese a que no nos ha llegado íntegro en su forma original, fue recogido, al menos parcialmente, y reelaborado entre 1681 y 1683 por el arquitecto Simón García en su manuscrito titulado Compendio de Architectura y simetría de los templos, en el que este incluyó, además, una serie de conocimientos arquitectónicos procedentes de distintos autores propios de la época, fundamentalmente de la tratadística italiana y española. La mediación de Juan del Ribero Rada parece quedar confirmada, como ha comprobado Gómez Martínez ${ }^{272}$, por la inclusión en el Compendio de citas literales del tratado de arquitectura de Palladio procedentes de la traducción realizada por Ribero en 1572, manuscrito no publicado hasta época reciente ${ }^{273}$.

El cuaderno de Rodrigo Gil, aun en su estado actual, es de gran importancia tanto para la historia de la arquitectura española como europea, ya que se trata de una de las escasas noticias que conservamos de los procedimientos técnicos y constructivos de origen medieval ${ }^{274}$. En el análisis que se presenta a continuación nos referiremos siempre al manuscrito original de Simón García (García 1681), indicando en cada caso el capítulo y el folio correspondiente.

\subsubsection{El Compendio de Architectura y simetría de los templos}

\subsubsection{Autor}

Simón García debió de nacer en Salamanca en torno a 1649275. Aunque en la portada de su manuscrito se califica a sí mismo como "architecto", su formación inicial fue probablemente de cantero, trabajando, según él mismo declara, desde los doce hasta los treinta años en las obras de la Catedral Nueva de Salamanca, esto es, aproximadamente entre 1661 y 1679; sus conocimientos de traza y construcción los recibió principalmente de Juan de Setién Güemes, maestro mayor entre 1666 y 1703, y de los oficiales de este (cap. 12: $51 \mathrm{v}$ ). Esta formación, fundamentalmente de tipo práctico, se vería complementada por la lectura de libros especializados, que le permitiera familiarizarse con los conocimientos teóricos que recoge en su texto; quizás el acceso a estos libros, lo mismo que al manuscrito de Hontañón, fue posible en el propio taller de la obra de la Catedral Nueva, como ya hemos

\footnotetext{
271 Aramburu-Zabala 2003: 99-100; Sanabria [1982] 1999: [282-283] 2-3.

272 Gómez 1998: 21-22.

273 Palladio [1572] 2003.

274 Apraiz 1943: 272-273; Camón 1941b: 300, 305; García [1681] 1868: 119-120; Huerta 2013: 108-109;

Pereda 1951: LXI-LXII.

275 Rupérez 1998: 69.
} 
comentado. Poco después de abandonarlo, entre 1681 y 1683, escribió el Compendio, en el que realiza una síntesis, más o menos ordenada, de los conocimientos que había de tener un arquitecto de la época, mostrándose como un copista que recoge contenidos de distintos autores, como Rodrigo Gil o fray Lorenzo de San Nicolás, y siendo la elaboración propia mínima o completamente ausente ${ }^{276}$. Aunque según algunos estudiosos ${ }^{277}$ el texto constituiría un cuaderno arreglado y ordenado para uso exclusivo de Simón García, para nosotros, al igual que para otros investigadores ${ }^{278}$, la intención del autor de publicarlo es clara, revelando un maestro preocupado no solo de los aspectos teóricos y prácticos de la arquitectura, sino también de su didáctica.

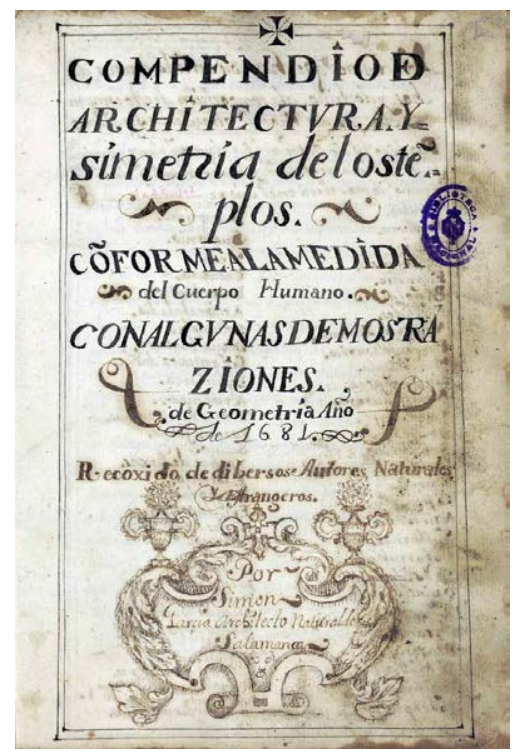

Figura 27. Portada del Compendio (García 1681)

Una vez abandonado el taller en el que se formó, en su carrera profesional aparece siempre como un maestro de segunda o tercera fila. Intervino inicialmente en la ejecución de dos obras para las que había dado trazas Juan de Setién Güemes: en 1683 en la reedificación del santuario de Valdejimena (Salamanca), junto con otros tres maestros, y en 1685 en la construcción de la iglesia del convento de los Basilios en Salamanca. A partir de entonces su labor se circunscribió al ámbito de esta ciudad: en 1686 realizó actuaciones menores en la fachada de la librería del convento de San Esteban; en 1690 fue requerido por el Colegio Real de la Compañía de Jesús para informar sobre la prosecución de las obras en el edificio; en 1691, junto con el maestro de albañilería Francisco Isidro, dio trazas y condiciones para la regularización del trazado de la antigua plaza mayor mediante la adición de tiendas, ejecutadas por Manuel de Ávila; en 1693 redactó condiciones para realizar algunas reparaciones en la puerta de Villamayor de la muralla, ejecutando a continuación las obras; en 1694, junto con otras intervenciones menores, comenzó a desempeñar el cargo de cañero menor de la ciudad, encargado del mantenimiento de la red de abastecimiento de agua, que ocupó hasta su fallecimiento en Salamanca en $1697^{279}$.

\footnotetext{
276 García [1681] 1868: 119-120; Rupérez 1998: 70.

277 García [1681] 1868: $119-120$.

278 Bonet 1991: 15; Rupérez 1998: 70.

279 Rupérez 1998: 71-74.
} 
Simón García nunca llegó a ver impreso su manuscrito, que fue adquirido en 1763 por la Biblioteca Nacional de España de su anterior propietario, Francisco Ruiz de Medrano.

\subsubsection{Parte atribuida a Rodrigo Gil}

El manuscrito del Compendio está constituido por 142 folios, todos ellos numerados excepto el primero, que se dividen en 77 capítulos. A la hora de estudiar su contenido, la primera cuestión consiste en delimitar qué parte de él está basada o fue copiada de un manuscrito de Rodrigo Gil, y cuál fue añadida por el propio Simón García de modo original o a partir de otras fuentes. La autoría de Hontañón de una parte del texto queda asegurada por el propio Simón García desde el comienzo del manuscrito, ya que en su contraportada, cuando enumera, en una demostración de honestidad, las fuentes que ha utilizado en la confección de su obra, dice: "Los Autores que han concurrido con sus dichos, y doctrina, a la composiçion de este compendio, çitados Vnos de otros, Son los Siguit. Rodrigo Gil de Ontañon q. fue el que planto, y prosiguió la $S .{ }^{\text {ta }}$ YGlesia de Salam. ${ }^{\text {ca }}$ y de quien es mucha $p .^{\text {te }}$ de este compendio como se berá en el capt. 12". Si acudimos a dicho lugar (cap. 12: 52r), el autor, refiriéndose a la Catedral Nueva de Salamanca, dice lo siguiente: "hordenola ju $0^{\circ} \mathrm{Gil}$ de Ontañon, Y executola, Rodrigo Gil, su hijo (de quien es lo mas de este compendio por aber venido a mis manos, vn manuscrito suio) ...". Dicha aserción, encontrándose en el capítulo 12, puede referirse quizás solamente a los 11 anteriores, si tenemos en cuenta que el manuscrito fue redactado con cierta lentitud, como mínimo a lo largo de tres años; aunque el Compendio lleva en su portada y en el folio 139v (último antes del índice) la fecha de 1681, que también parece leerse en la cartela de la ilustración del folio 133r, en el folio $52 v$ se alude al año 1683 ("... para q. en este año de 1683. conçeda las bacantes de las rentas eclesiasticas de este Obispado ..."). En cuanto al resto de fuentes utilizadas, encontramos autores clásicos griegos y romanos, autores cristianos alto y bajomedievales, humanistas italianos, franceses, alemanes y españoles, y tratadistas de arquitectura, tanto clásicos (Vitruvio) como renacentistas, italianos (Alberti, Palladio, Scamozzi, Serlio, Vignola) y españoles (Arfe, Rojas, San Nicolás, Torija).

Para determinar la parte del manuscrito que debemos asignar a Rodrigo Gil es conveniente analizar la opinión de los estudiosos, acudiendo a las distintas ediciones que de él se han realizado. La primera publicación parcial del Compendio fue realizada por Mariátegui en $1868^{280}$ a partir del manuscrito depositado en la Biblioteca Nacional de España. Identificó la parte atribuible a Rodrigo Gil como los seis primeros capítulos, basándose fundamentalmente en su contenido referido a la arquitectura gótica; no apreció en el resto del texto ningún aspecto original, sino una copia de distintos autores comunes en la época. Por esta razón, en su edición transcribió íntegros los capítulos 1 a 6 , redibujando sus figuras con distintas alteraciones, y añadió, con el fin de que se apreciara la diferencia de época y contenidos, otros capítulos referidos a la construcción de templos (11-15, 75). Del resto publicó únicamente el título, incluyendo en algunos de ellos un breve resumen $\circ$ alguna observación, y dio finalmente un glosario para la comprensión del texto. La siguiente edición que se realizó del Compendio fue publicada en 1941 por Camón ${ }^{281}$, incluyendo los capítulos $1-17,43$ y 72-76. Poco después, en 1951, Pereda ${ }^{282}$ transcribió en su monografía acerca de Rodrigo Gil íntegramente los capítulos 1 a 6 , utilizando para las ilustraciones una

\footnotetext{
280 García [1681] 1868: 114-115, 118-120, 194 nota 1.

281 García [1681] 1941, citado en Hoag 1985: 11.

282 García [1681] 1951.
} 
reproducción facsimilar. En 1958 Hoag $^{283}$ incluyó en su Tesis Doctoral un estudio relativo al manuscrito, reproduciendo los capítulos 1-6. Ya en 1979 Bonet y Chanfón ${ }^{284}$ publicaron la primera edición completa del Compendio, totalmente facsímil y provista de estudios introductorios, que sería ampliada en $1991^{285}$ con la incorporación de una transcripción paleográfica. Por otro lado Sanabria realizó en $1984^{286}$ una traducción al inglés, incluida en su Tesis Doctoral.

Los investigadores ${ }^{287}$ no ven posible separar los contenidos originales de Rodrigo Gil de las interpolaciones realizadas por Simón García en base al estilo literario, ya que este es común a toda la obra. Por esta razón, el criterio utilizado para deslindar el texto procedente del siglo XVI ha sido siempre, siguiendo la primera edición del Compendio, el del análisis del propio contenido. La mayoría de los estudiosos ${ }^{288}$ parece estar de acuerdo en asignar a Rodrigo Gil los seis primeros capítulos, junto con otras interpolaciones a lo largo de la obra. Camón 289 , aparte de atribuirle, junto a los capítulos anteriores, algunos dibujos indeterminados insertos en otros posteriores, se contradice asignándole en otro lugar también el capítulo 7. Tanto Hoag como Sanabria ${ }^{290}$ le atribuyen, además de los capítulos 1 a 6, el 75, referido a las ilustraciones recogidas en los folios 9v-10r (cap. 4), y una ilustración inserta en el folio 59r (cap. 16), fuera de contexto. Marías ${ }^{291}$ ha atribuido a Rodrigo Gil un pasaje situado en el folio 29v (cap. 7) en el que se defiende el carácter accesorio de los órdenes clásicos en la arquitectura, si bien Bonet ${ }^{292}$ no comparte su opinión. Gómez Martínez ${ }^{293}$ señala que los capítulos 18 a 39, aunque debidos a Simón García, guardarían relación con Rodrigo Gil e incluirían quizás pasajes interpolados de este, ya que contienen las definiciones de algunos principios matemáticos aplicados en los seis primeros capítulos, como el procedimiento geométrico para el cálculo de las proporciones aritméticas (cap. 23: 66v-67v) ○ el de la raíz cuadrada (cap. 30: 76r-77r). Gómez-Moreno ${ }^{294}$, oponiéndose a la mayoría, limita la intervención de Rodrigo Gil a los capítulos 1 a 4, planteando que quizás también son suyos el capítulo 18 y, más probablemente, el 75; siguiendo esta opinión, Bonet y Chanfón 295 únicamente ven una autoría segura en los capítulos 1 a 4 , sin realizar aseveraciones categóricas en lo referente al resto del manuscrito 296 .

Los títulos que corresponden a los capítulos mayoritariamente atribuidos a Rodrigo Gil, y que analizaremos en este estudio, son los siguientes:

- "Cap. 1. que trata de la Composizion de los templos".

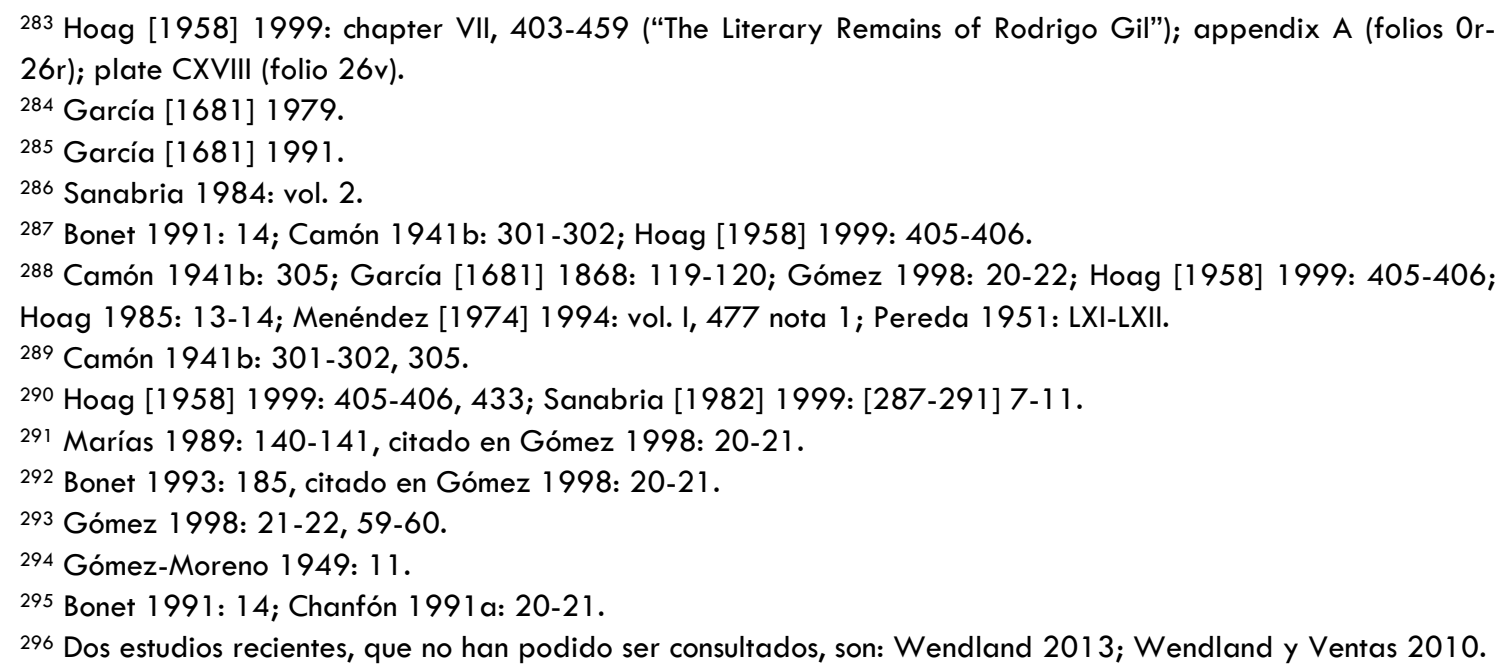


- "Cap. 2. que trata de estas medidas para componer los Templos. Y le rreparte en Rostros de la altura $Y$ anchura".

- "Cap. 3. que trata de la OrtoGrafia Y medidas de los templos".

- "Cap. 4. que trata de luzes, Torres, y caracoles. Figura de luzes".

- "Cap. 5. que trata del Repartimiento de los Templos por leometria".

- "Cap. 6. Sobre los Templos. y sus Alturas con ReGlas Generales".

- "Cap. 75. en q. se ponen vnas condiçiones Generales para proseguir vn edifiçio arruinado".

En todo caso, correspondería a Simón García la reelaboración de los contenidos originales, allí donde no se limitó a su mera copia, y su disposición en el orden actual ${ }^{297}$.

\subsubsection{El cuaderno de arquitectura de Rodrigo Gil}

\subsubsection{Objetivo y fecha de redacción}

Si consideramos la parte del Compendio atribuida a Rodrigo Gil, observamos que está redactada en términos claramente expositivos, buscando facilitar la comprensión de sus contenidos. Ya Pereda ${ }^{298}$ puso de relieve este hecho, avanzando, respecto a la fecha de redacción original, la teoría de que fuera elaborado en su juventud, a fin de atesorar los conocimientos recibidos de su padre por su todavía escasa práctica en las obras, lo cual parece contradecirse con dicho carácter expositivo. La aparente pérdida de vigencia de los modos de construcción góticos en la segunda mitad del siglo XVI hizo que considerara poco probable que fuera escrito en edad madura. De la opinión contraria es Hoag ${ }^{299}$, para quien la obra habría sido redactada por Rodrigo Gil no antes de 1560 y tal vez en torno a 1570, quizás como reacción consciente al Renacimiento representado por El Escorial y con el deseo de preservar las técnicas medievales reunidas a lo largo de su carrera profesional y que desaparecían entonces rápidamente. Volvió a observar el carácter didáctico del manuscrito, destinado a un público amplio y no solo a los iniciados, ya que estos no hubieran requerido los citados métodos expositivos y la frecuente definición de términos técnicos. Otros autores 300 han planteado que el objetivo que movió a Rodrigo Gil a escribir su manuscrito estaría relacionado con su sistema de trabajo, basado en la delegación de atribuciones en sus aparejadores, para quienes dicho texto sería útil. La opinión que nos parece más acertada es la de Gómez Martínez ${ }^{301}$, para quien el tratado de Rodrigo Gil podría tener su origen en unos textos preparados inicialmente por Juan Gil para el aprendizaje de su hijo, que serían reelaborados por Rodrigo al final de su carrera profesional, como avanzaba Hoag, o quizás a lo largo de ella ${ }^{302}$. Bajo este punto de vista el objetivo del texto quedaría dentro de una tendencia común en la baja Edad Media

\footnotetext{
297 Hoag [1958] 1999: 405-406, 433; Sanabria [1982] 1999: [287-291] 7-11.

298 Pereda 1951: LXV- LXVI.

299 Hoag [1958] 1999: 409-410; Hoag 1985: 14-15, 64.

300 Martín 2000: 13.

301 Gómez 1998: 24-25, 51, 169.

302 La atribución de una parte indeterminada de los contenidos del manuscrito a Juan Gil ya había sido defendida por Casaseca (1988: 13-14).
} 
europea, y sería análogo al del manuscrito contemporáneo del germano Lorenz Lechler, titulado Unterweisungen (Instrucciones) y fechado en 1516303, que, con el mismo carácter compilatorio y finalidad de transmisión de conocimientos entre padre e hijo, ofrece los métodos necesarios para el trazado de un templo tomando como medida base la luz de la capilla mayor ${ }^{304}$.

En relación con el problema del momento de redacción, los investigadores 305 han reparado en algunas citas incluidas en los capítulos 1 a 6 y 75 pertenecientes a autores de mediados del siglo XVI, como las varias referencias a "Filandro" (cap. 2: 2r; cap. 75: 136v) y a "Daroçensis" (cap. 6: 22r). Se trata respectivamente de Guillaume Philandrier, que publicó una edición comentada del Vitruvio en Roma en 1544, y Pedro Sánchez Ciruelo, muerto en 1554. Basándose en ellas se ha querido fijar la fecha de redacción del manuscrito con criterios variados. A nuestro juicio, los contenidos del manuscrito pudieron ser elaborados a lo largo de distintas épocas, no teniendo por qué comenzar necesariamente su redacción después de 1544, y, por otro lado, tampoco podemos tener la seguridad absoluta de que dichas referencias no fueran introducidas por Simón García, que acude igualmente a "Filandro" en otros lugares del texto (cap. 7: 30r; cap. 7: 38v).

\subsubsection{Contenido}

Desde la primera publicación parcial del Compendio se ha venido señalando su importancia para el conocimiento de los procedimientos técnicos utilizados en la Edad Media, y se le ha comparado 306 con el cuaderno medieval de Villard de Honnecourt (1220-1240), dado a la imprenta de modo casi contemporáneo, en 1858307. El tratado de Rodrigo Gil, sin embargo, no se encuadra en dicho contexto europeo, sino en el de comienzos de la Edad Moderna, en el que encontramos otros escritos que arrojan igualmente luz sobre distintos aspectos relativos a la arquitectura tardogótica, como los tratados impresos por Mathes Roriczer (1486) y su contemporáneo Hanns Schmuttermayer (c.1486)308 o el citado manuscrito de Lorenz Lechler (1516) 309 .

No obstante, el propósito didáctico al que hemos aludido diferencia en cierta medida el texto de Rodrigo Gil tanto de los cuadernos de origen medieval como de los manuscritos alemanes del siglo XV y XVI citados o de los españoles de la época, como el de Hernán Ruiz "el Joven" (1559) 310 . Todos estos manuscritos, destinados a un público especializado, toman la forma de un repertorio en el que se recogen, sin ningún orden especial, esquemas para la resolución de problemas concretos, estableciendo rara vez reglas de aplicación general $^{311}$. Por el contrario, el texto de Hontañón, a pesar del carácter fragmentario con que nos ha sido transmitido y de su frecuente desajuste con relación a las ilustraciones, manifiesta indudablemente el propósito de describir de modo ordenado la generación de un proyecto arquitectónico, dando reglas que buscan ser generales. En este sentido, su

\footnotetext{
303 Shelby y Mark 1979, Shelby y Mark [1979] 1997.

304 Gómez 1998: 23-25.

305 Hoag [1958] 1999: 8, 410-411; Hoag 1985: 14; Sanabria [1982] 1999: [283] 3.

306 García [1681] 1868: 119; Rivera 1991: 11.

307 Honnecourt 2001.

308 Shelby 1977.

309 Shelby y Mark 1979, Shelby y Mark [1979] 1997.

310 Ruiz el Joven 1559, edición facsímil en Ruiz el Joven [1559] 1974 y Ruiz el Joven [1559] 1998.

311 Hoag [1958] 1999: 447-450; Hoag 1985: 13-14.
} 
propósito se asemeja al de Alonso de Vandelvira en su tratado (1575-1591) ${ }^{312}$, manifestándose en ambos el mismo orden progresivo en la presentación de los contenidos, con la diferencia de que el de Rodrigo Gil se refiere a aspectos de diseño arquitectónico y estructural, y el de Vandelvira a la ejecución práctica de cada uno de los elementos de cantería que puedan estar presentes en ese diseño. Como ha señalado Gómez Martínez ${ }^{313}$, el texto de Rodrigo Gil no versa efectivamente sobre el ars, esto es, la práctica, destreza o técnica del corte de piedras, aspecto desarrollado por los libros de montea, sino sobre la scientia, esto es, la teoría medieval de diseño ${ }^{314}$, si bien debemos precisar que pasada por el tamiz renacentista, como se aprecia en el hecho de que, como veremos más adelante, el proceso de trazado en planta y sección y el de dimensionado estructural son totalmente independientes, no existiendo ya una relación que vincule las distintas partes entre sí y con el todo ${ }^{315}$. Podemos indicar al respecto un párrafo del manuscrito que, aunque localizado en el capítulo 7 y por tanto fuera del texto asignado generalmente a Rodrigo Gil, está relacionado con esta cuestión: "El arte se diferençia, de la çiençia, y del ofiçio; de la çiençia, en $\mathrm{q}^{\circ}$ el arte se puede variar porq ${ }^{\circ}$. depende del vso, y arbitrio de los hombres, pero la çiençia, no; porq..$^{\circ}$ es vna cogniçion çierta, y evidente, echa por demostraçion .... del ofiçio, en q. ${ }^{\circ}$ el ofiçio, no consta de preçeptos, ni estudio alguno, pero el arte si como abemos tho. [dicho]" (cap. 7: 39v).

Considerando la parte del Compendio que se atribuye a Rodrigo Gil, esto es, fundamentalmente los seis primeros capítulos, el manuscrito pudo haber sido originalmente un intento de sistematizar el proceso de diseño de un edificio religioso de tradición gótica, creando una secuencia de procedimientos al objeto de ir definiendo sucesivamente los distintos aspectos relativos a la planta y a la sección, tanto arquitectónicos (dimensiones, tipología y proporciones) como estructurales (apoyos y bóvedas), y describiendo como colofón la construcción y montaje de una bóveda de crucería ${ }^{316}$. La manera incoherente en que nos ha sido comunicado (pasajes de texto incongruentes, falta de correspondencia entre las letras que aparecen en el texto y en las ilustraciones, dibujos sin texto aclaratorio o viceversa), debido tanto al estado fragmentario en que Simón García pudo encontrarlo, más de un siglo después de su redacción, como a las dificultades de este para interpretarlo, impide cualquier percepción unitaria del conjunto, por lo que nos ha parecido adecuado elaborar una tabla de contenidos que facilite la interpretación de las relaciones entre unos y otros:

- $1 r$-3r:...............Proporción y modulación. Canon de proporciones humanas (ilustración $2 r$, ilustración parte izquierda 2v, ilustración parte derecha 2v).

- $\quad 2 v:$....................Estribos o contrafuertes: regla general para arcos y bóvedas.

- 3r:......................Modelo 1 (sin ilustración; podría corresponderse con la ilustración parte inferior $4 \mathrm{r}$ ).

\footnotetext{
312 Palacios 2003: 15-16; Vandelvira [1575-1591] c.1671.

313 Gómez 1998: 23-25.

314 Ackerman 1949.

315 A diferencia de los textos de Rodrigo Gil y Alonso de Vandelvira, el tratado de su contemporáneo Philibert de l'Orme (L'Orme 1567) compatibiliza la teoría de la arquitectura con la estereotomía (Gómez 1998: 19). Sobre Andrés de Vandelvira, de quien procederían muchos de los conocimientos vertidos en el tratado de su hijo Alonso (Palacios 2003: 13), véanse AAVV 1992; Chueca 1971. Sobre Alonso de Vandelvira y Philibert de l'Orme, véase Sanabria 1989. Sobre Philibert de l'Orme, véanse Pérouse de Montclos 2000; Potié 1996.

316 Hoag [1958] 1999: 409-450; Sanabria [1982] 1999: [281-282] 1-2.
} 
- 3v Trazado de la planta: dimensiones: superficie interior.

- $3 v-4 r:$ Modelo 2 (ilustración parte superior $4 \mathrm{r}$ ).

- $4 \mathrm{r}$ : Modelo (ilustración parte inferior 4r); podría corresponderse con el Modelo 1 (3r).

- 4v: Modelo 3 (ilustración $4 \mathrm{v}$ ); se corresponde con texto sobre estribos o contrafuertes en 5r-5v. Relación entre las alturas de las naves (4v).

- 5r-6r: Modelo 4 (ilustración 6r). Rampante de las bóvedas (5r). Torres (5v6r).

[5r-5v: Interpolación: texto sobre estribos o contrafuertes.]

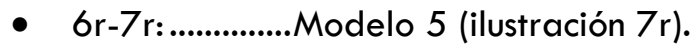

- 7v: .....................Modelo 6 (ilustración 7v).

- 8r-8v:...............Relación entre las alturas de las naves (ilustración 8v). Altura de la clave del arco perpiaño de la nave mayor (ilustración $8 \mathrm{v}$ ). Arbotantes.

- 9r:....................Diseño de arcos (ilustración 9r; podría corresponderse con la ilustración 26r). Relación entre las alturas de las naves (ilustración 9r). Altura de la clave del arco perpiaño de la nave mayor.

- 9r-9v:...............Diseño de torres (ilustración parte izquierda 9v).

[9v: Interpolación: ilustración parte derecha 9v.]

[10r: Interpolación: ilustración 10r.]

- 10v:...................Diseño de puertas (ilustración 10v).

- 10v-11r:..........Diseño de escaleras (ilustración 11 r).

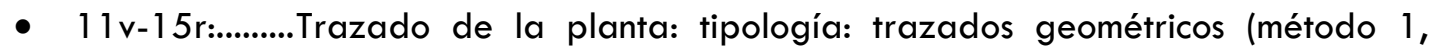
$11 v-12 v$, ilustración $12 r$; método $2,12 v-13 r$, ilustración $13 r$; método $3,13 v-14 v$, ilustración 14r; método 4, 14v-15r, ilustración 15r).

- 15v-16r:..........Modelo (sin ilustración); podría corresponderse con el Modelo 1 (3r).

- 16r-16v:.........Altura de la línea de imposta de la nave mayor para plantas duplas (ilustración 16v).

- 17r-18v:..........Modelo 7 (ilustración 18v). Altura de la clave del arco perpiaño de la nave mayor para plantas duplas (17r). Pilares para bóvedas de crucería (17r). Estribos o contrafuertes: regla particular para bóvedas de crucería (17v-18r, ilustración 18r).

- 18v-19r:.........Estribos o contrafuertes: regla general para arcos y bóvedas.

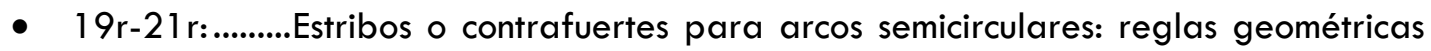
para arcos semicirculares (regla 1, 19r-19v, ilustración 19v; regla 2, 19v-20r, ilustración 20r; regla 3, 20r-20v, ilustración 21 r, se corresponde con ilustración 59r).

- 20v-21v:........Estribos o contrafuertes para arcos semicirculares: regla aritmética para arcos semicirculares. 
- $21 v-22 r$ :..........Arcos perpiaños. Relación entre las alturas de las naves. Rampante de las bóvedas.

- $22 v-24 r$ :..........Elementos que componen la bóveda: miembros o nervios (23r-23v, se corresponde con ilustración 25v); claves (23v-24r).

- 24r-25v:...........Construcción y montaje de la bóveda (ilustración 25r).

[25v: Interpolación: ilustración 25v.]

[26r: Interpolación: ilustración 26r.]

- 26r-26v:..........Estribos o contrafuertes: remate (ilustración 26v). Relación entre las alturas de las naves. Arbotantes y pináculos (ilustración 26v).

[59r: Interpolación: ilustración 59r.]

- 135r-137r:....Diseño de torres (se corresponde con ilustración parte derecha 9v, ilustración 10r).

\subsubsection{Procedimientos de diseño}

En el texto se describen varios métodos para la definición de la planta y de la sección que podemos clasificar en tres categorías, dependiendo fundamentalmente de la manera en que son formulados: aritméticos, proporcionales y geométricos. Los métodos aritméticos definen los distintos elementos arquitectónicos y estructurales a través de operaciones que relacionan distintos parámetros y que se pueden generalizar y expresar algebraicamente. Los proporcionales se presentan casi siempre a modo de casos prácticos, en los que se indican las dimensiones de diversas partes del edificio y las relaciones entre ellas, aplicando en ocasiones un canon de proporciones humanas. Los métodos geométricos, de tradición medieval, definen la planta y la sección a través de construcciones gráficas, que parten de una figura y la manipulan produciendo distintos puntos y líneas que son utilizados para la distribución arquitectónica o el dimensionado estructural ${ }^{317}$. A lo largo del proceso de diseño se persigue, aunque de un modo desarticulado y errático, una síntesis entre los sistemas góticos y renacentistas de trazado, intentando demostrar su coincidencia. Aunque los métodos aritméticos expuestos no precisan de mayores aclaraciones, nos parece adecuado explicar someramente la naturaleza de los otros dos procedimientos.

Los métodos proporcionales pretenden la aplicación de un canon de proporciones humanas a la generación de la arquitectura, relacionando cada uno de los miembros del cuerpo con cada una de las partes del edificio y aplicando en este las relaciones proporcionales que encontramos en aquel. Se trata de una idea que pertenece a la tradición clásica representada por Vitruvio, y que se pretende extender a la planta, a la sección y a los miembros estructurales de edificios que sin embargo son de tradición gótica ${ }^{318}$. Se expone desde el principio del Compendio, señalando la importancia de la proporción y la modulación en la arquitectura, y definiendo dicho canon, que se ilustra con dibujos (cap. 1 y 2: $1 r$-3r; ilustración 2r, proporciones del perfil de la cabeza; ilustración parte izquierda 2v, figura humana inscrita en un cuadrado; ilustración parte derecha 2v, figura humana inscrita en un círculo). El canon se divide en rostros, tercios y cuartos o minutos; cada rostro equivale

317 Sanabria [1982] 1999: [283-284] 3-4.
318 Sanabria [1982] 1999: [283-284] 3-4. 
a tres tercios, y cada tercio a cuatro cuartos o minutos. La altura de la figura humana es de diez rostros $u$ ocho cabezas, coincidiendo con Vitruvio, y la anchura de dos rostros. Pese a que Hoag ${ }^{319}$ avanzó la posibilidad de que el canon pudo ser tomado por Rodrigo Gil de algún escultor, proponiendo incluso el nombre de Alonso Berruguete, según Sanabria ${ }^{320}$ se correspondería en parte con uno de los publicados en 1528 por Alberto Durero en sus Vier Bücher von menschlicher Proportion (Cuatro libros sobre las proporciones humanas), en los que se reflexiona sobre la imposibilidad de sintetizar las proporciones del cuerpo humano en un solo canon, como pretendía Vitruvio, y se analizan trece tipos distintos. En concreto, la propuesta antropométrica que se recoge en el manuscrito se compone según Chanfón ${ }^{321}$ de cincuenta y una normas, tanto originales (de entre las cuales las más interesantes serían dieciocho, según este último estudioso) como recogidas de otros autores como Durero. Junto a esta aportación clásica vitruviana, enriquecida por la reflexión renacentista, Chanfón ${ }^{322}$ distingue también en la antropometría del Compendio un substrato medieval, apreciable quizás en la identificación de templo y hombre como símbolo del cosmos, cuyo equilibrio y proporción es obra de Dios.
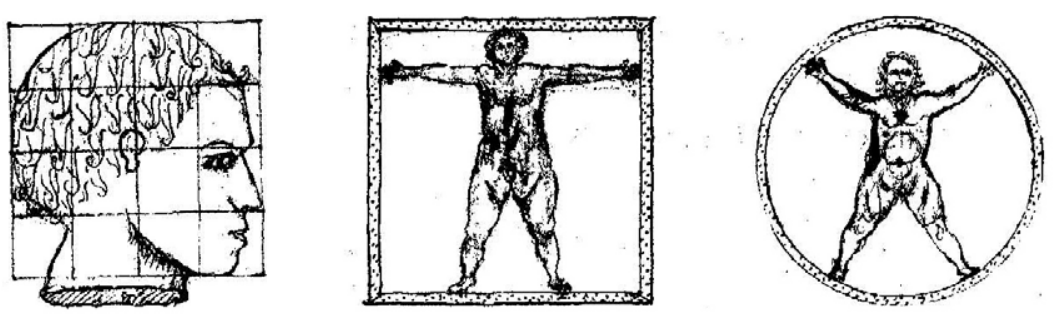

Figura 28. (a) llustración 2r. (b) llustración parte izquierda 2v. (c) llustración parte derecha 2v (a-c: García 1681)

Estos métodos proporcionales se presentan casi siempre a modo de ejemplos prácticos, algunos de los cuales, aunque ni siquiera todos, se vinculan con las proporciones del canon definido previamente. Sin embargo se trata, como ya observó Hoag ${ }^{323}$, de una correspondencia un tanto forzada, destinada a justificar que dichas relaciones proporcionales, generadas quizás por sistemas geométricos o aritméticos de tradición medieval, son esencialmente correctas porque se pueden adaptar a un canon de proporciones de inspiración clásica, más aceptable en el momento de la redacción del texto. Para Chanfón ${ }^{324}$ la aplicación de reglas antropométricas tendría igualmente un carácter más simbólico que de aplicación directa, aunque según él este hecho constituiría un substrato medieval y no tanto renacentista. Otro de los propósitos de la analogía entre las proporciones humanas y las del edificio podría ser el de establecer reglas mnemotécnicas que permitieran la asimilación de estas relaciones a las personas poco versadas en la materia. En cualquier caso, Hoag ${ }^{325}$ opina que, aunque estos contenidos proporcionales

\footnotetext{
319 Hoag [1958] 1999: 410-425.

320 Sanabria [1982] 1999: [283-284] 3-4.

321 Chanfón 1991 a: 28-30.

322 Chanfón 1991 a: 20-21, 26.

${ }^{323}$ Hoag [1958] 1999: 410-425.

324 Chanfón 1991 a: 28-30.

325 Hoag [1958] 1999: 410-425.
} 
fueran probablemente ampliados por Simón García, el canon es con seguridad una aportación de Rodrigo Gil, basándose en dos circunstancias: la primera es que en el siglo $\mathrm{XVI}$ existía un profundo interés por dichos cánones y su aplicación a la arquitectura, a diferencia de lo que ocurría a fines del XVII, cuando el análisis de las medidas del cuerpo humano era objeto de estudio únicamente para la pintura y la escultura, apoyado por otro lado más en el conocimiento de la anatomía que en un canon único de medidas; la segunda es que raramente encontramos alusiones a este sistema de proporciones fuera de los seis primeros capítulos del manuscrito. De la misma opinión es Chanfón ${ }^{326}$, que sitúa la generación de dichas reglas antropométricas, como la que corresponde a la identificación de los nervios de una bóveda de crucería con los dedos de la mano, presente en una de las ilustraciones del Compendio (ilustración 25v), en el periodo de finales del siglo XV 。 principios del XVI.

Por otro lado, junto a los numerosos ejemplos de edificios religiosos, en los que se proporcionan siempre medidas que en casi todos los casos podrían referirse a proyectos realizables, aparecen también en el Compendio otro tipo de modelos de templos, mucho menos abundantes, en forma de métodos geométricos para obtener la planta. A decir del autor del manuscrito, "Abemos tratado de la composiçion y Repartimiento de los templos, por la analogia, segun la llama Vitrubio, que es la medida del cuerpo Humano. Pues aora sera bien por la jeometria darle la mesma medida. porque el que no entendiere la mensura del cuerpo Humano, se aproveche destas lineas" (cap. 5: $11 \mathrm{v}$ ). Queda por tanto implícita la identidad entre ambos métodos de trazado.

Numerosos autores han mostrado su interés por estos sistemas de trazado geométrico en planta. Quizás uno de los primeros en estudiarlos fue Lampérez, quien, en su conocida obra acerca de la arquitectura religiosa medieval española ${ }^{327}$, realizó un breve análisis de ellos, observando su correspondencia con la planta de la catedral de Toledo. Varios investigadores los han aplicado a las plantas de edificios realizados por Rodrigo Gil, como la iglesia del monasterio de las Bernardas en Salamanca ${ }^{328}$, la desaparecida colegiata de Santa María en Valladolid ${ }^{329}$, la iglesia de San Sebastián en Villacastín (Segovia) o la de San Martín en Mota del Marqués (Valladolid) ${ }^{330}$. Algunos han llegado incluso a atribuirle edificios basándose entre otras cosas en la comprobación de dicho trazado, como es el caso de la iglesia de la Asunción de Nuestra Señora en Meco (Madrid) y de San Pedro Apóstol en Fuente el Saz de Jarama (Madrid) ${ }^{331}$. Por otro lado, algunos estudios han analizado el trazado en planta y sección de edificios en los que intervino Rodrigo Gil como la Catedral Nueva de Salamanca o la catedral de Segovia ${ }^{332}$, bajo presupuestos distintos a los recogidos en el Compendio. Finalmente, algunos han intentado aplicar sistemas de generación geométrica no a la planta sino a los alzados de edificios como el Colegio Mayor de San Ildefonso en Alcalá de Henares (Madrid) ${ }^{333}$ o el palacio de la Salina en Salamanca ${ }^{334}$.

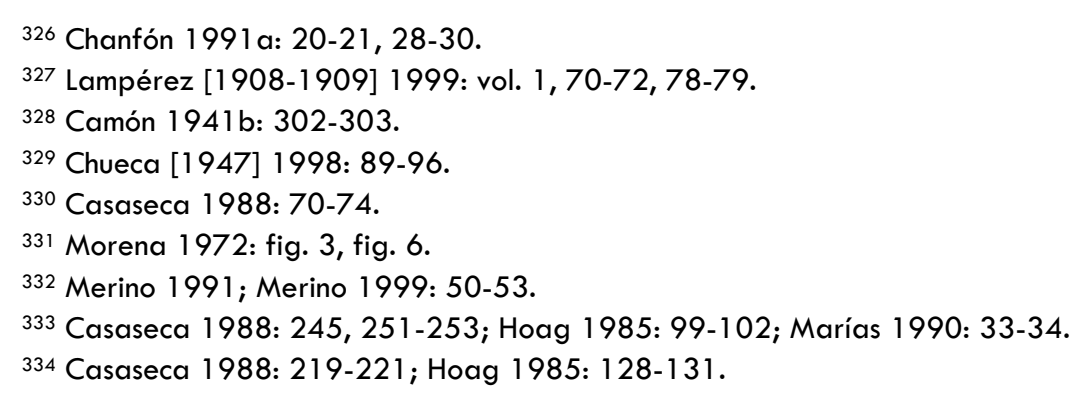


Estos métodos geométricos de trazado en planta, o "sistemas de trazos", como se refiere a ellos Chanfón, tendrían según este estudioso 335 un claro origen medieval, manifestado principalmente en el uso mecánico que las explicaciones del texto les asignan, y en que todos ellos tienen su inicio en un cuadrado con sus diagonales. Junto a ellos aparecen también en el Compendio reglas geométricas para el dimensionado en sección de estribos o contrafuertes, que, aunque también de tradición medieval, podrían tener su origen en la primera mitad del siglo $\mathrm{XVI}^{336} \circ$ incluso en el XVII ${ }^{337}$. En ese momento los métodos geométricos de trazado en planta no eran en absoluto considerados como algo anacrónico, sino como un instrumento de diseño perfectamente válido, mientras que los sistemas gráficos aplicados al cálculo estructural fueron utilizados incluso hasta finales del siglo XIX.

Teniendo en cuenta el conjunto de los procedimientos de diseño, e independientemente del tipo de formulación utilizado para definir cada uno de ellos, sea este aritmético, proporcional o geométrico, el contenido original del texto se podría dividir en tres partes fundamentales: métodos para el trazado arquitectónico, métodos para el dimensionado estructural, y dimensionado, construcción y montaje de una bóveda de crucería. El proyecto se inicia con la determinación de la superficie interior del edificio, que a continuación se reparte en una planta de las dimensiones adecuadas, eligiendo, de acuerdo con las necesidades, una determinada configuración en cuanto a número de naves y forma del crucero y cabecera. A partir del trazado en planta se puede diseñar la sección del edificio, decidiendo si las naves van al mismo o a distinto nivel y estableciendo las relaciones entre sus alturas. Una vez definido de este modo el espacio interior del edificio, se calculan de modo independiente sus elementos estructurales, culminando el proceso con el dimensionado, construcción y montaje de las bóvedas de crucería que lo cubren.

\subsubsection{Métodos para el trazado arquitectónico}

En la arquitectura gótica el espacio interior es siempre prioritario frente a la configuración exterior del edificio, y esta es sin duda la razón por la que las indicaciones que se dan en estos métodos de trazado corresponden siempre a dicho espacio. Una vez definido este, se materializará con una determinada envolvente, cuyos elementos estructurales de soporte y contrarresto se calculan de modo totalmente independiente, y cuyo alzado parece tener una importancia secundaria, dado que el manuscrito se refiere a él en pocas ocasiones y solo aparece definido en algunas ilustraciones $(8 v, 9 r$, parte izquierda 9v, 10r, 26r, 26v).

\subsubsection{Trazado de la planta}

\subsection{Dimensiones: superficie interior}

Se establece el tamaño preciso que ha de tener un edificio religioso a partir del cálculo de su superficie en planta, a fin de poder trasponer un trazado geométrico adimensional o un modelo con unas dimensiones concretas a los requerimientos de un determinado encargo. La regla es aritmética (cap. 2: 3v). Expresada algebraicamente:

\footnotetext{
335 Chanfón 1991 b: 32-34.

336 Chanfón 1991 b: 42.

337 Sanabria [1982] 1999: [285] 5 nota 12.
} 
$S=[(100+r) / 100]$ p $4 / 3(3 \times 7)$

Donde: S: superficie total interior del edificio (pies cuadrados); r: tasa de crecimiento demográfico (\%); p: población inicial. En el sistema de medidas castellano, una vara equivale a 0.835905 metros y se divide en tres pies de 0.278635 metros.

El cálculo de la superficie se realiza en función de la población total a la que debe servir el edificio, tomando la inicial y previendo un aumento futuro que, dependiendo del caso, puede oscilar entre el 10, el 20 o el $30 \%$ en 100 años. Se asigna en el interior a cada vecino una superficie de sepultura de $3 \times 7$ pies, aumentándola en una tercera parte necesaria para la disposición de los paseos y los recercados de las sepulturas.

Una vez obtenida la superficie total interior que habrá de tener el edificio, podremos distribuirla en una planta cuya forma se decide bajo otros parámetros: "Asi que por esta ReGla se podran haçer otros quales quier" (cap. 2: 3v). De modo revelador, se indica expresamente que en este cálculo no se debe tener en consideración el canon de proporciones humanas: "en esto no será menester mirar destos Rostros" (cap. 2: 3v); se trata de establecer, de modo objetivo y práctico, las necesidades de una comunidad.

\subsection{Tipología: modelos de aplicación proporcional}

Distintos ejemplos de templos se describen a lo largo del texto, proporcionando datos respecto al trazado de su planta, de su sección y de sus elementos estructurales. Prácticamente para todos ellos se dan dimensiones que podrían corresponder a las de edificios construidos, con la excepción del que se presenta en los folios 15v-16r (cap. 6), para el que se recogen unas medidas teóricas no realizables por su pequeño tamaño. La finalidad de todos ellos es la misma: no se trata solo de que el lector pueda repetir en un momento dado las dimensiones de alguno de los ejemplos, sino principalmente de que estos le permitan conocer las relaciones proporcionales entre los diferentes miembros a fin de aplicarlas a unas dimensiones concretas de acuerdo con las necesidades de cada caso práctico. De hecho, esto es lo que se dice explícitamente en el folio $3 r$ (cap. 2): "De aqui. y por estas medidas se pueden fabricar quales quier templos. Asi de vna nave como de 3. y 5. y 7. Y tomar de las dhas [dichas] medidas como mas hiçiere a el proposito de la disposiçion del tal templo Respecto del pueblo en que se haçe". De entre los distintos ejemplos de edificios, por tanto, el tracista podrá elegir en el proceso de diseño aquella configuración que más se adapte a sus necesidades ajustando su tamaño proporcionalmente. El hecho de que estas relaciones proporcionales procedan de una construcción geométrica medieval o de la aplicación de un canon de proporciones humanas renacentista es quizás un problema de índole meramente teórico; Sanabria ${ }^{338}$ incluso observó la práctica coincidencia en el resultado obtenido utilizando uno u otro procedimiento.

Las tipologías de edificios religiosos propuestas en el texto e ilustradas con sus plantas son reflejo de los modelos desarrollados desde finales del siglo XV por maestros como Juan Guas, utilizados en nuestro país a lo largo del XVI y XVII ${ }^{339}$. Describimos a continuación los distintos ejemplos, colocándolos por orden creciente de complejidad y no por el de aparición en el texto. En varios de ellos se proporcionan métodos de diseño referidos a la

\footnotetext{
338 Sanabria [1982] 1999: [281-284] 1-4.

339 Morena 2000: 39.
} 
sección (cálculo de las alturas generales del edificio) ○ a los elementos estructurales (dimensionado de los pilares y estribos de una iglesia cubierta por bóvedas de crucería, y de los muros y contrafuertes de una torre), que hemos separado de este apartado para explicarlos de modo independiente; igualmente aparecen reflejadas algunas reglas geométricas $\circ$ aritméticas que se dan en otros lugares del Compendio (relación entre anchura y longitud total de la planta).

- Modelo 1 (cap. 2: 3r): referido a cualquier iglesia de una, tres, cinco o siete naves (sin ilustración). Se dan las proporciones para los anchos de nave en planta, relacionando su tamaño con el del pecho, el brazo, el antebrazo, la mano y los dedos: mayor 24 , colaterales 19, hornacinas 17 , capillas particulares 12 , pared y estribos 6; la proporción entre nave mayor, colaterales y hornacinas es aproximadamente 4:3:3. Se vincula también la dimensión de los pilares o muros con la de las articulaciones del hombro, codo y muñeca: mayor 4 , colaterales 3 y hornacinas 2. La alusión a capillas hornacinas y capillas particulares, que deberían ser una misma cosa, y lo desmesurado del contrafuerte, parecen indicar un fallo del copista.

Este ejemplo podría relacionarse con el que aparece en la parte baja del folio siguiente, acompañado de un pequeño texto referido a la planta de una iglesia de tres naves (ilustración parte inferior $4 \mathrm{r}$ ). La anchura total en planta de las naves es de 60 pies; los anchos de la nave mayor y de cada una de las colaterales son respectivamente 24 y 18 , con lo que la proporción entre ellos es $4: 3$. Si suponemos que los tramos de la nave central son de planta cuadrada, estos tendrían $24 \times 24$ (1:1), mientras que los de las laterales serían de $18 \times 24$ (4:3). La altura se fija en 62 , sin precisar si se refiere a la de imposta o a la de la clave del arco perpiaño de la nave mayor. El pilar aislado entre ellas tiene 4 de diámetro y el estribo lateral es de 12 (incluyendo el medio pilar adosado, de 1.5; el grueso del muro, de 5.5; y el contrafuerte exterior, de 5); lo desmesurado de este ( $12 / 18$ de la luz) hace pensar en un fallo del copista.

Igualmente podría relacionarse con otro que aparece más adelante (cap. 6: 15v16r), referido a una iglesia de tres naves con capillas entre contrafuertes (sin ilustración). La anchura total en planta del crucero es de 30 y la de las naves 24 ; los anchos de la nave mayor y de cada una de las colaterales y hornacinas son respectivamente $6,4.5$ y 4.5 , con lo que la proporción entre ellos es 4:3:3.

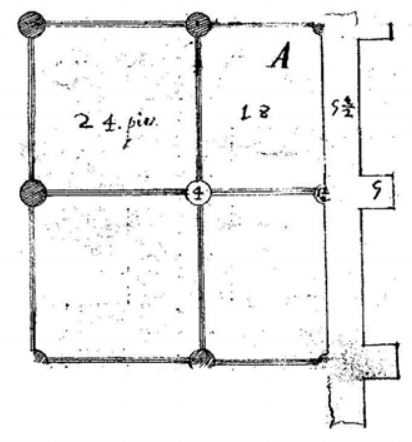

Figura 29. llustración parte inferior 4r (García 1681) 
- Modelo 2 (cap. 2: 3v-4r): referido a la planta de una iglesia de una nave con crucero saliente y cabecera cuadrangular (ilustración parte superior $4 \mathrm{r}$ ). La planta del conjunto se inscribe en un rectángulo de $60 \times 150$ pies (5:2). La anchura total en planta del crucero es de 60 y la de la nave es de 30 . Cada uno de los cuatro tramos de nave tiene en planta $30 \times 22.5(4: 3)$, los brazos del crucero $15 \times 30(2: 1)$ y tanto el tramo central de este como la cabecera $30 \times 30(1: 1)$, con lo que la cabecera y el crucero quedan inscritos en un cuadrado. La altura de la clave del arco perpiaño es de 60. El estribo necesario para los tramos de nave es de 11 (incluyendo el medio pilar adosado, el grueso del muro y el contrafuerte exterior) (11/30 de la luz). La torre es de planta cuadrada, de 25 aproximadamente de lado y 100 de fuste sin aguja, con lo que la proporción entre ambos es 4:1.

- Modelo 3 (cap. 2: 4v): referido a la planta de una iglesia de una nave con capillas entre contrafuertes, crucero saliente y cabecera cuadrangular (ilustración $4 \mathrm{v}$ ). Las medidas en planta que se ofrecen no permiten establecer fácilmente las proporciones del conjunto. La anchura total en planta del crucero es de 60 pies y la del cuerpo 45; los anchos de la nave y de cada una de las hornacinas son respectivamente 30 y 7.5 , con lo que la proporción entre ambos es $4: 1$. El dimensionado del contrafuerte necesario para los tramos de nave se encuentra interpolado en la descripción del ejemplo subsiguiente $(7.33 / 30$ de la luz, planta 2:1) (cap. 2: $5 \mathrm{r}-5 \mathrm{v}$ ), calculándose con una fórmula que explicamos separadamente. De este dimensionado se deduce que la altura de imposta es de 30.

- Modelo 4 (cap. 2: 5r-6r): referido a la planta de una iglesia de una nave con capillas entre contrafuertes, crucero saliente y cabecera cuadrangular (ilustración 6r). La anchura total en planta del crucero es de 100 pies y la del cuerpo sería quizás de 70; los anchos de la nave y de cada una de las hornacinas son respectivamente 40 y quizás 15 , con lo que la proporción entre ambos es quizás 8:3. Cada uno de los cuatro tramos de nave tiene en planta quizás $40 \times 30$ (4:3), las hornacinas quizás $15 \times 30(2: 1)$, los brazos del crucero $30 \times 40(4: 3)$ y el tramo central de este $40 \times 40(1: 1)$. Se describe la altura de la nave central y la del cimborrio, si bien existen contradicciones entre los datos del texto y los de la ilustración; se podría interpretar que la altura de imposta es 50 y la de la clave del arco perpiaño 75; la distancia desde la imposta hasta el cimborrio sería 42 36/85 (43). Se trata del único caso en el que se proporcionan datos sobre el rampante de las bóvedas, especificando que en el sentido longitudinal de la nave es "a ReGla" u horizontal, y en el transversal es curvado, con una curva de diámetro 100 pies; si consideramos cada tramo de $40 \times 30$, el diámetro que correspondería a un arco diagonal semicircular sería de 50 , la mitad de lo propuesto para el rampante. Se describen las dimensiones de un estribo (planta 2:1), si bien no resulta fácil determinar con qué elemento se corresponde; en el texto (cap. 2: $5 \mathrm{r}-5 \mathrm{v}$ ) se encuentra interpolado, a continuación, el dimensionado de los contrafuertes para el ejemplo precedente (cap. 2: 4v). Las torres son de planta cuadrada, de 30 de lado, 120 de fuste y 30 de remate superior, con lo que la proporción entre fuste y lado es $4: 1$; se incluye el dimensionado de sus muros y estribos, calculándose con fórmulas que explicamos separadamente. 

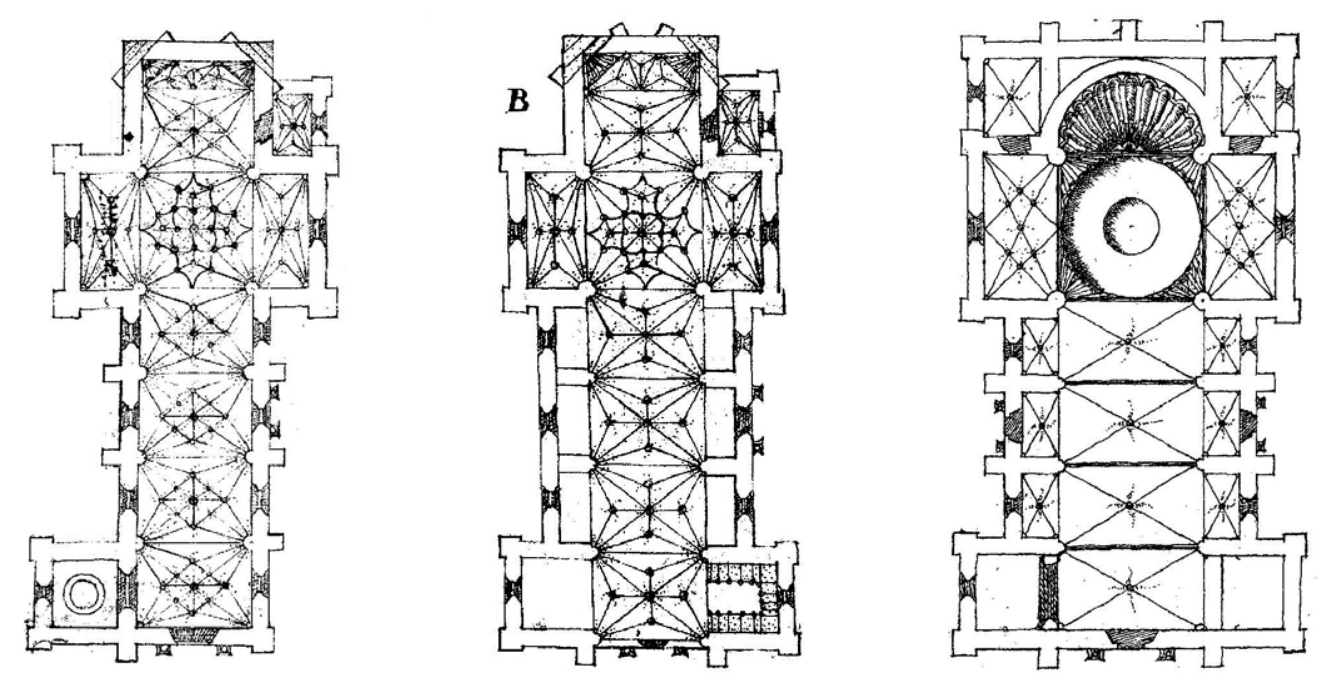

Figura 30. (a) llustración parte superior 4r. (b) llustración 4v. (c) Ilustración 6r (a-c: García 1681)

- Modelo 6 (cap. 2: 7v): referido a la planta de una iglesia de tres naves con crucero saliente y ábside semicircular (ilustración $7 \mathrm{v}$ ). La explicación es muy reducida, y únicamente se proporcionan datos relativos a la altura de distintos elementos del edificio (altura de la nave mayor (quizás referida a la de la clave del arco perpiaño) 66 pies, distancia desde la imposta hasta el cimborrio 37, altura de las hornacinas (quizás referida a la de la clave del arco perpiaño) 46, altura de las torres 120).

- Modelo 5 (cap. 2: 6r-7r): referido a la planta de una iglesia de cinco naves con capillas entre contrafuertes, crucero alineado y girola de siete capillas radiales (ilustración 7r). La planta del conjunto es de proporción dupla (2:1), inscribiéndose en un rectángulo de $205 \times 410$. Los tramos de la nave mayor y de cada una de las colaterales (interior y exterior) y hornacinas tienen en planta respectivamente $45 \times 30(3: 2), 30 \times 30(1: 1), 30 \times 30(1: 1)$ y $20 \times 30(3: 2)$; la proporción entre sus anchos es 9:6:6:4, indicándose que se relacionan según una proporción continua, en la que el ancho de las naves colaterales es la media proporcional o geométrica de los otros dos. La altura de la nave mayor (quizás referida a la de la clave del arco perpiaño) es de 133, y la distancia desde la imposta hasta el cimborrio 66. Se dice explícitamente que no está trazada con referencia al canon de proporciones humanas, sino por métodos geométricos. La torre es de planta cuadrada; aunque en la ilustración se dice que tiene $\mathbf{2 0 0}$ de altura, de acuerdo con el dibujo en planta solo le corresponderían 20 de lado, algo que no parece lógico; si lo consideramos un error del copista al realizar la ilustración a partir del texto y pensamos que la torre ocupa el ancho no solo de la capilla hornacina sino también de la nave lateral extrema, tendríamos una base de 50 , con lo que la proporción entre fuste y lado sería $4: 1$; sin embargo en este caso la longitud total del templo sobrepasaría los 410.

- Modelo 7 (cap. 6: 17r-18v): referido a la planta de una iglesia de tres naves con crucero alineado y cabecera ochavada (ilustración 18v). La planta del conjunto es de proporción dupla (2:1), inscribiéndose en un rectángulo de $80 \times 160$ pies; los 
anchos de la nave mayor y de cada una de las colaterales son respectivamente 40 y 20, indicándose que todos estos términos se relacionan según una proporción continua (160:80:40:20) (2:1). La longitud total se reparte en tres tramos de nave de 30 , crucero de 40 y cabecera de 30 . De este modo, cada uno de los tres tramos de la nave mayor tiene en planta $40 \times 30$ (4:3), como la cabecera; los de las colaterales $20 \times 30$ (3:2), los brazos del crucero $20 \times 40$ (2:1) y el tramo central de este $40 \times 40$ (1:1). La altura de imposta (quizás referida a la de la nave mayor) es de 40, y la de la clave del arco (quizás referida a la del arco perpiaño de la nave mayor) de 60, calculándose con fórmulas que explicamos separadamente. Se incluye el dimensionado de los pilares y contrafuertes (ilustración 18r), utilizando reglas que describimos igualmente de modo independiente.
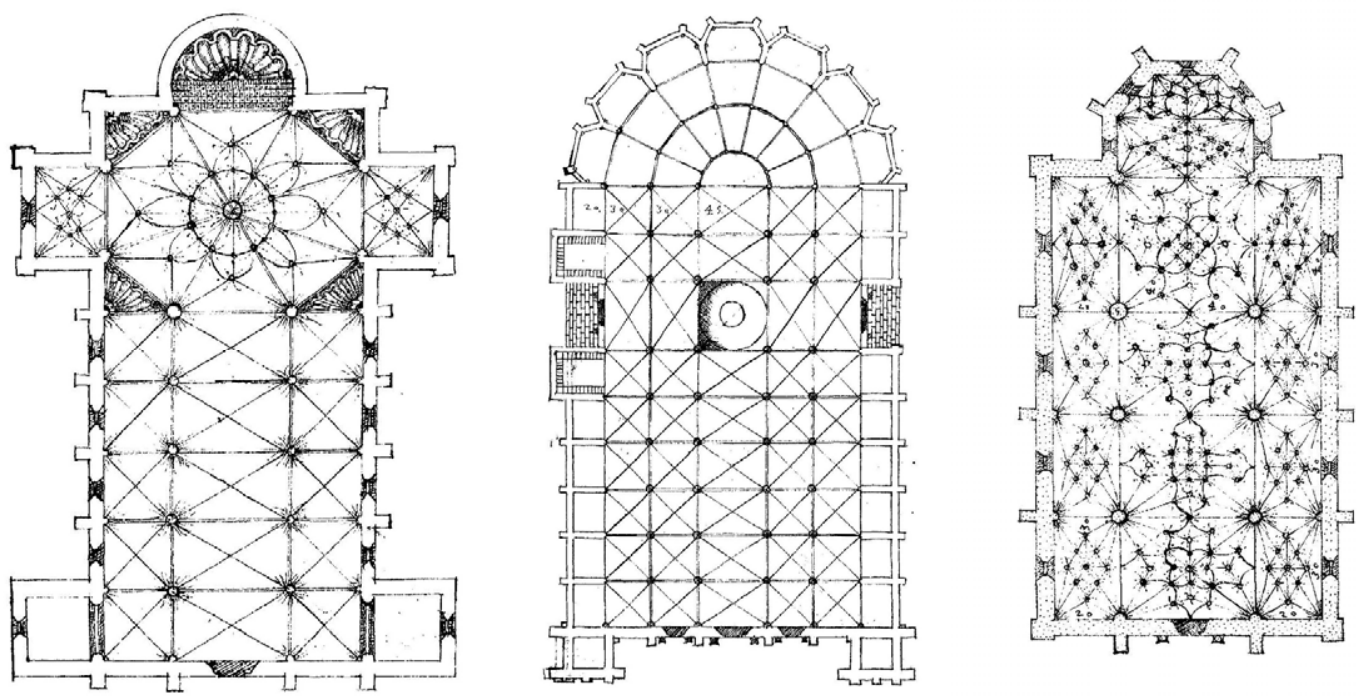

Figura 31. (a) llustración 7v. (b) Ilustración 7r. (c) Ilustración 18v (a-c: García 1681)

A partir de los modelos que se proponen en el texto podemos hacer las siguientes observaciones relativas al repartimiento en planta. En el modelo 2 la planta del conjunto se inscribe en un rectángulo de proporción 5:2, mientras que en los modelos 5 y 7 la proporción es dupla (2:1); por otro lado, en el modelo 2 la cabecera y el crucero quedan inscritos en un cuadrado. En los modelos 3 y 4 vemos utilizada una proporción 4:1 u 8:3 entre los anchos de la nave y de cada una de las hornacinas. En el modelo 1 y los dos ejemplos que hemos asociado con él se emplea una proporción 4:3 4 4:3:3 entre los anchos de la nave mayor y de cada una de las colaterales y hornacinas, mientras que en el modelo 5 los anchos se relacionan según una proporción continua, 9:6:6:4. En el modelo 7 se utiliza de nuevo una proporción continua, 8:4:2:1, pero esta se establece entre anchura y longitud total en planta del edificio y anchos de nave mayor y de cada una de las colaterales. Por lo que respecta a las proporciones de los tramos, no encontramos demasiada variedad, limitándose a emplear las relaciones $1: 1,2: 1,3: 2$ y $4: 3$.

Junto a estos modelos de edificios, aparecen también referencias a distintos elementos arquitectónicos parciales, como arcos, torres, puertas o escaleras, que se presentan seguidamente. 
- Arcos (cap. 4: 9r): por lo que respecta al trazado de los arcos formeros de las naves, se señala la proporción con la que se deben trazar y la de los huecos de iluminación que en ellos se abren: la relación entre anchura y altura es 6:5, prácticamente equivalente a la de un triángulo equilátero (6:5.196), correspondiendo un ancho de 3 a la ventana (ilustración 9r; podría corresponderse con la ilustración 26r). No se señala en cambio ningún criterio general para el trazado de los perpiaños de las naves.
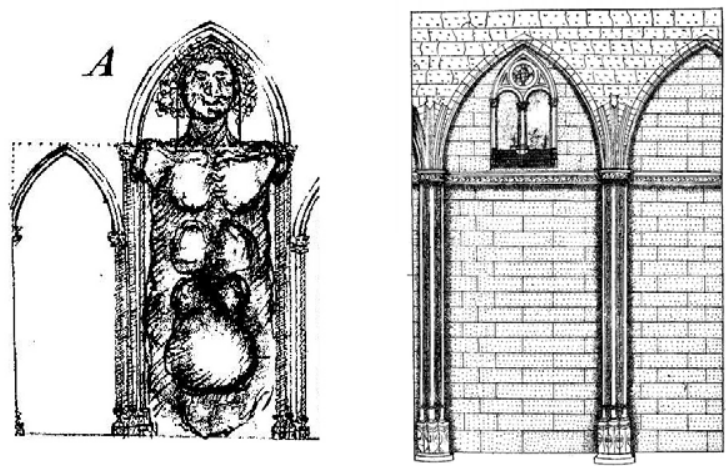

Figura 32. (a) Ilustración 9r. (b) Ilustración 26r (a, b: García 1681)

- Torres (cap. 4: 9r-9v): se dan las relaciones de altura que deben tener las distintas partes de una torre de planta cuadrada (ilustración parte izquierda 9v). Para un lado de la torre de 2, la cimentación tendría $1 / 3$, el fuste 8 y el remate superior $5 / 3$, con lo que la proporción entre fuste y lado es $4: 1$. Las proporciones entre lado, fuste y remate superior no se corresponden con las que se recogen en los folios 135r-137r (cap. 75) (lado 40, fuste 120, remate superior 40), mucho menos esbeltas.
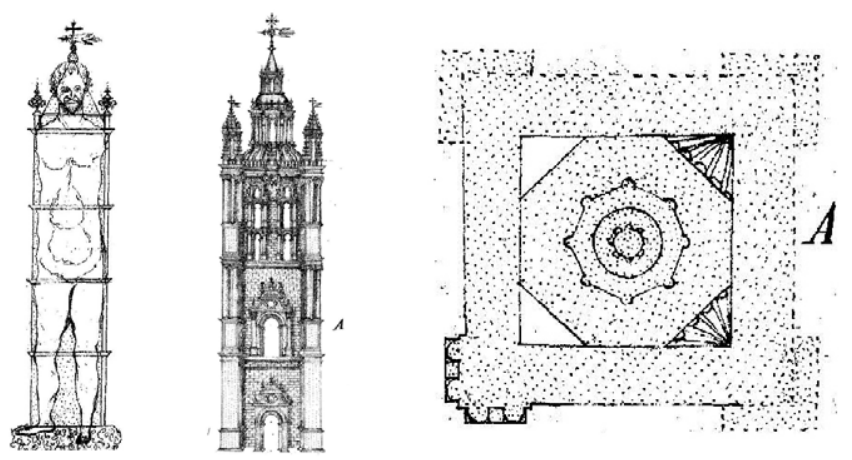

Figura 33. (a) Ilustración parte izquierda 9v. (b) Ilustración 10r. (c) llustración parte derecha 9v (a-c: García 1681)

- Torres (cap. 75: 135r-137r): se dan las distintas dimensiones de una torre de planta cuadrada de 40 pies de lado (ilustración parte derecha $9 \mathrm{v}$, ilustración 10r). Su fuste tiene una altura de 120, dividido en tres cuerpos de 40, al que se añade otro cuerpo superior de remate de 40, con lo que la proporción entre fuste y lado es 3:1. 
Los muros tienen 8 de grosor en la cimentación, 7 en el arranque, $61 / 3$ en el primer cuerpo, $52 / 3$ en el segundo y 5 en el tercero; los 8 contrafuertes que se sitúan en las esquinas tienen por ancho y grosor $11 \times 3.5$ en la cimentación, $10 \times 3$ en el arranque, $9 \times 2.7$ en el primer cuerpo, $8 \times 2.4$ en el segundo y $7 \times 2.1$ en el tercero. Se dan también indicaciones respecto a la configuración del cuerpo de remate, aunque no son de fácil interpretación. Las proporciones entre lado de la torre, altura del fuste y altura del remate superior no se corresponden con las que se recogen en los folios $9 \mathrm{r}-9 \mathrm{v}$ (cap. 4) (lado 2, fuste 8 , remate superior 5/3), mucho más esbeltas.

- Puertas (cap. 4: 10v): se describen las diferentes relaciones posibles entre la anchura y la altura de los "frontispiçios" o frontones, desde los triangulares hasta los de medio punto, entre las cuales el arquitecto debe elegir a criterio personal (ilustración 10v).

- Escaleras (cap. 4: 10v-11r): se describen las dimensiones de los distintos elementos de una escalera de caracol de ojo central (esto es, de las que se denominaban en la época "de Mallorca") (ilustración 11r). De la explicación, algo oscura, parece deducirse que, para un diámetro total del caracol de 10, incluyendo la porción de los peldaños que queda empotrada en el muro, el diámetro interior de la escalera sería 8 y el del ojo central 1; el empotramiento mediría 1 y el pasamanos central 1/3. No queda claro el valor del ancho de los peldaños; a la contrahuella se le asigna, en términos absolutos, una altura de una cuarta o una quinta de vara 0.209 $\circ 0.167 \mathrm{~m})$.
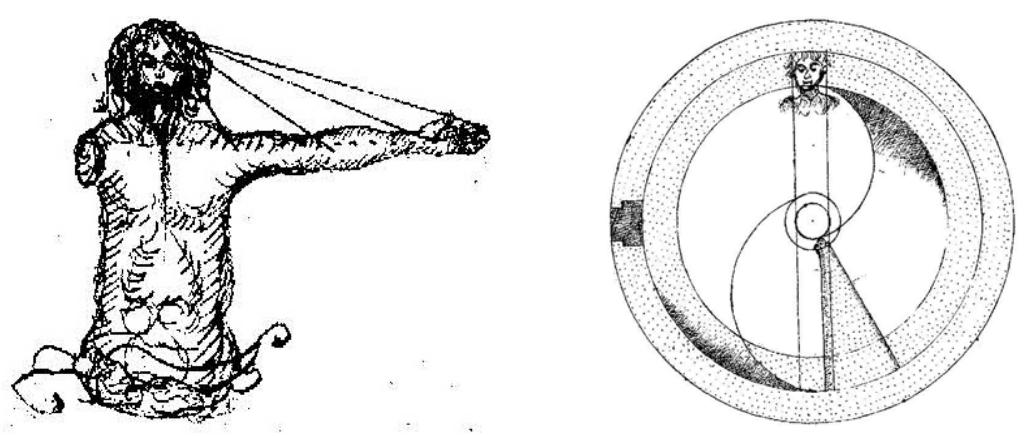

Figura 34. (a) Ilustración 10v. (b) Ilustración 11 r (a, b: García 1681)

\subsection{Tipología: trazados geométricos}

En el manuscrito se presentan cuatro métodos para el trazado de la planta, que parten siempre de un cuadrado inicial. Tres de ellos generan una planta cuya anchura y longitud total guardan una proporción dupla (2:1), algo que el autor considera recomendable (cap. 5: 14v). No desarrollamos aquí cada uno de estos métodos porque las indicaciones del manuscrito son suficientemente claras como para no ofrecer dudas al respecto; nos limitamos a describirlos brevemente, colocándolos por orden creciente de complejidad y no por el de aparición en el texto.

- Método 4 (cap. 5: 14v-15r): referido a la planta de una iglesia de una nave con capillas entre contrafuertes, crucero saliente y cabecera ochavada (ilustración 15r). El trazado, que parte de un cuadrado en el que se inscribe la cabecera y el crucero, 
da como resultado una planta que no es de proporción dupla (2:1). La proporción del tramo central del crucero es $1: 1$, y la de la cabecera y brazos del crucero $2: 1$; la proporción de los tramos de la nave es $\sqrt{ } 2$.

- Método 3 (cap. 5: 13v-14v): referido a la planta de una iglesia de tres naves con crucero alineado y cabecera ochavada (ilustración 14r). El trazado, que parte de un cuadrado en el que se inscribe la cabecera y el crucero, da como resultado una planta de proporción dupla (2:1). La proporción del tramo central del crucero es $1: 1$, y la de la cabecera y brazos del crucero $2: 1$; las proporciones de los tramos de las naves mayor y colaterales son respectivamente $3: 2$ y $4: 3$; la anchura y longitud total del edificio y los anchos de la nave mayor y de cada una de las colaterales se relacionan según una proporción continua $(8: 4: 2: 1)(2: 1)$.

- Método 2 (cap. 5: 12v-13r): referido a la planta de una iglesia de tres naves con crucero alineado y cabecera ochavada (ilustración 13r). El trazado, que parte de un cuadrado en el que se inscribe la cabecera, el crucero y el primer tramo de naves, da como resultado una planta de proporción dupla (2:1). La proporción del tramo central del crucero es $1: 1$, y la de la cabecera y brazos del crucero $4: 3$; las proporciones de los tramos de las naves mayor y colaterales son, en el primer tramo de naves, respectivamente $4: 3$ y $1: 1$, y en el resto de tramos, respectivamente $6: 5$ y 10:9; la relación entre sus anchos es 4:3.

- Método 1 (cap. 5: $11 \mathrm{v}-12 \mathrm{v}$ ): referido a la planta de una iglesia de cinco naves con crucero alineado y girola de cinco capillas radiales (ilustración 12r). El trazado, que parte de un cuadrado en el que se inscribe todo el conjunto, da como resultado una planta de proporción dupla (2:1). Las proporciones de los tramos de la nave mayor y de cada una de las colaterales (interior y exterior) son respectivamente 6:5, 1:1 y 5:4; la relación entre sus anchos es 6:5:4. Debemos observar que el procedimiento geométrico de reparto en longitud de los tramos del edificio no parece correcto, ya que parte de dicha longitud queda sin repartir (en la ilustración del Compendio se ha obviado este problema haciendo que los tres últimos tramos de la nave tengan una anchura diferente a la del cuarto, que es el que teóricamente debería guiar el trazado de todos ellos); la confusa explicación de este método de trazado parece indicar un error del copista. Por otro lado, el reparto de los tramos, tanto en longitud como en anchura, no coincide con el empleado en la Catedral Nueva de Salamanca y en la catedral de Segovia, únicos edificios en los que intervino Rodrigo Gil en los que se podría haber aplicado un trazado de este tipo.

A partir de los métodos que se proponen en el texto podemos hacer las siguientes observaciones relativas al repartimiento en planta. En los métodos 4 y 3 la cabecera y el crucero quedan inscritos en un cuadrado. En los métodos 2 y 1 vemos utilizada respectivamente una proporción $4: 3$ y 6:5:4 entre los anchos de la nave mayor y de cada una de las colaterales. En el método 3 se utiliza una proporción continua, 8:4:2:1, que se establece entre anchura y longitud total en planta del edificio y anchos de nave mayor y de cada una de las colaterales. Por lo que respecta a las proporciones de los tramos, encontramos una cierta variedad, empleándose las relaciones $1: 1,2: 1,3: 2,4: 3,5: 4,6: 5$, $10: 9$ y $\sqrt{ } 2$. 

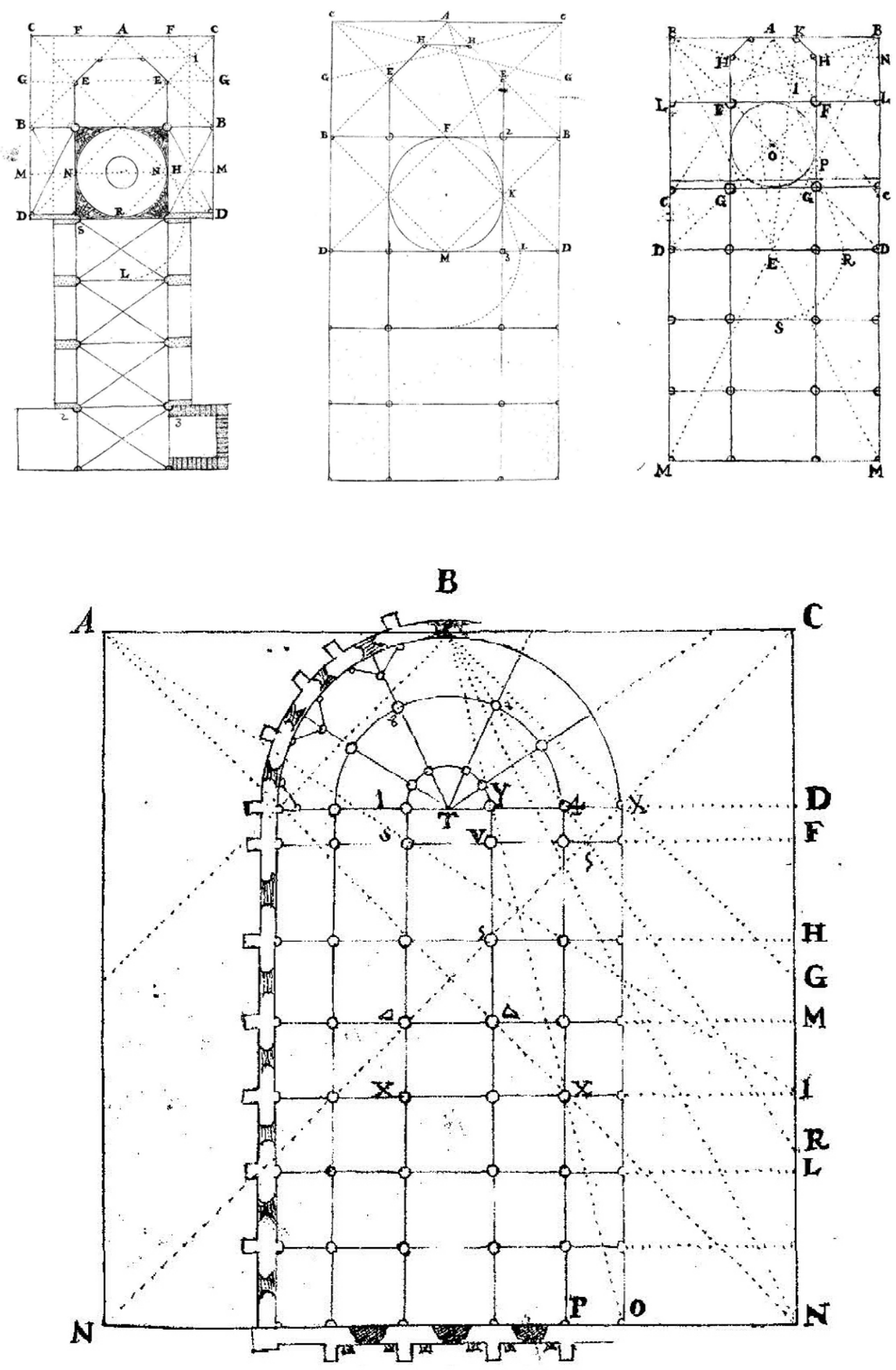

Figura 35. Métodos geométricos para el trazado de la planta: (a) llustración 15r. (b) llustración 14r. (c) llustración 13r. (d) Ilustración 12r (a-d: García 1681) 

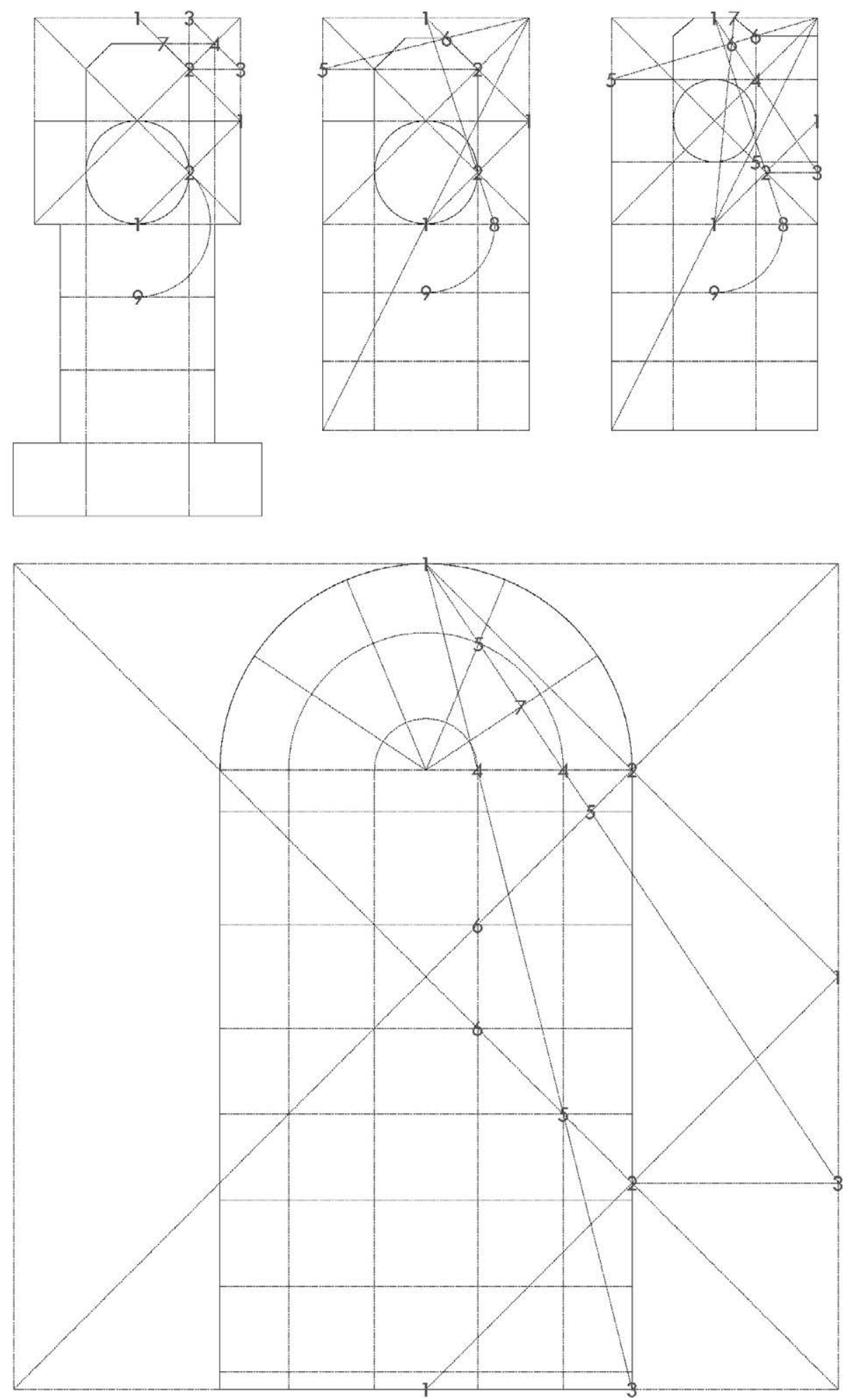

Figura 36. Métodos geométricos para el trazado de la planta: (a) Método 4. (b) Método 3. (c) Método 2. (d) Método 1 (a-d: P. Moreno) 


\subsubsection{Trazado de la sección}

\subsection{Relación entre las alturas de las naves}

Se indica que las naves colaterales suelen tener una altura inferior a la de la central, aunque es igualmente válido cubrir todas a la misma altura. Del mismo modo las capillas hornacinas pueden coincidir $o$ no en altura con las colaterales, señalándose que es preferible que su elevación sea menor, pero advirtiéndose también las ventajas de lo contrario. En definitiva, se observa la bondad de las dos soluciones para la sección del edificio: la escalonada, con sus naves cubiertas a distinta altura (ilustración 9r), que requiere la disposición de "arbotantes" (ilustración 26v) y la utilización de pilares de mayor tamaño, y la de la iglesia de salón, con sus naves a la misma altura, que ofrece ventajas estructurales pero permite una menor iluminación (ilustración 8v). Cuando la sección es escalonada, se explica la relación que debe existir entre las distintas alturas: la imposta de donde arrancan las bóvedas de la nave mayor debe quedar a la misma altura que la clave de los perpiaños de las colaterales (ilustración 9r); y la imposta de donde arrancan las bóvedas de las colaterales debe quedar a la misma altura que la clave de los perpiaños de las capillas hornacinas. Esta prescripción para la sección escalonada es matizada en otro lugar, observando que, en la práctica, la clave de los perpiaños de las colaterales ha de disponerse algo más baja de lo indicado, a fin de que las cubiertas de dichas naves no oculten el claristorio de la nave mayor (cap. 2: 4v; cap. 3: 8r-8v; cap. 4: 9r; cap. 6: $21 \mathrm{v}-$ $22 r, 23 r-23 v, 26 r-26 v)$.
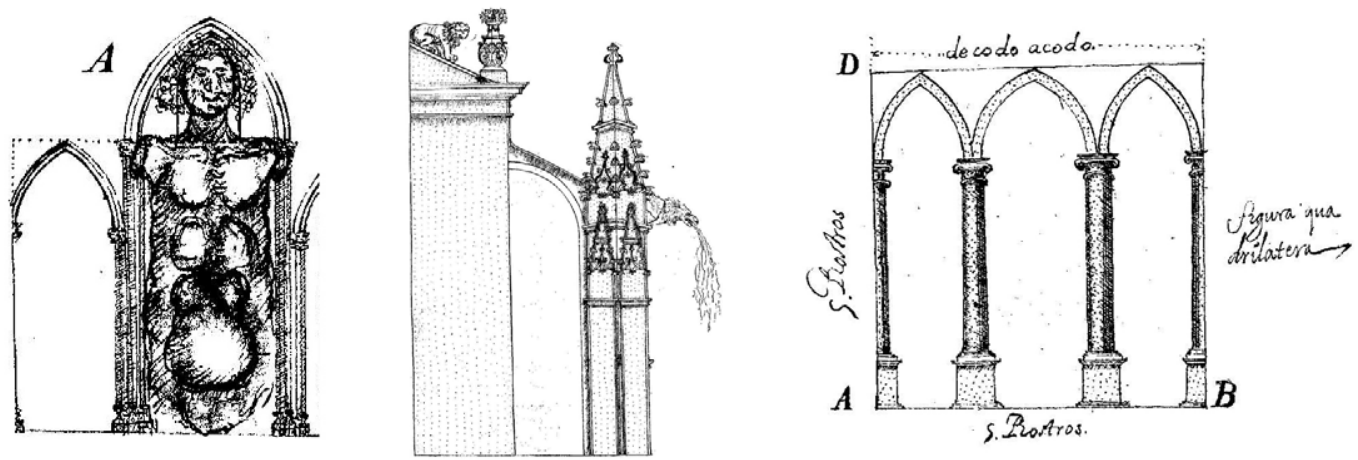

Figura 37. (a) llustración 9r. (b) llustración 26v. (c) llustración 8v (a-c: García 1681)

\subsection{Altura de la clave del arco perpiaño de la nave mayor}

Se establece como regla general que en las iglesias de una, tres, cinco o siete naves, con o sin capillas hornacinas, la altura de la clave del arco perpiaño de la nave mayor debe ser igual a la anchura total del edificio en planta, de modo que la sección del conjunto queda inscrita en un cuadrado (cap. 3: 8r-8v; cap. 4: 9r) (ilustración 8v). Expresada algebraicamente:

$$
\mathrm{H}=\mathrm{A}
$$

Donde: H: altura de la clave del arco perpiaño de la nave mayor; A: anchura total del edificio en planta. 


\subsection{Altura de la clave del arco perpiaño de la nave mayor para plantas duplas}

Se establece la altura de la clave del arco perpiaño (probablemente de la nave mayor) como la media aritmética de la anchura total del edificio en planta y la de la nave mayor. La regla es aritmética (cap. 6: 17r). Expresada algebraicamente:

$$
\mathrm{H}=(\mathrm{A}+\mathrm{a}) / 2
$$

Donde: $\mathrm{H}$ : altura de la clave del arco perpiaño (probablemente de la nave mayor); A: anchura total del edificio en planta; a: anchura de la nave mayor.

La regla se establece para edificios cuya anchura y longitud total en planta guardan una proporción dupla $(2: 1)$, y no se indica si puede extenderse a plantas de otras proporciones.

Como vemos, esta regla contradice la precedente.

\subsection{Altura de la línea de imposta de la nave mayor para plantas duplas}

Se establece la altura de la línea de imposta (probablemente de la nave mayor) como el tercero de una proporción continua en la que la anchura total del edificio en planta es la media proporcional o geométrica entre aquella y la longitud total. La regla es aritmética (cap. 6: 16r-16v), aunque también se ofrece de modo geométrico (ilustración 16v). Expresada algebraicamente:

$h=A A / 2 A$

Donde: h: altura de la línea de imposta (probablemente de la nave mayor); A: anchura total del edificio en planta; $2 \mathrm{~A}$ : longitud total del edificio en planta.

La regla se establece para edificios cuya anchura y longitud total en planta guardan una proporción dupla (2:1), y no se indica si puede extenderse a plantas de otras proporciones. En el texto el desarrollo matemático es torpe, ya que, tras prescribir la utilización de la media proporcional o geométrica, se describe una regla que solo es aplicable a plantas de proporción dupla $(2: 1)(\mathrm{h}=1 / 3[(\mathrm{~A}+2 \mathrm{~A}) / 2])$, cuya formulación sería en cualquier caso mucho más sencilla $(\mathrm{h}=\mathrm{A} / 2)$.

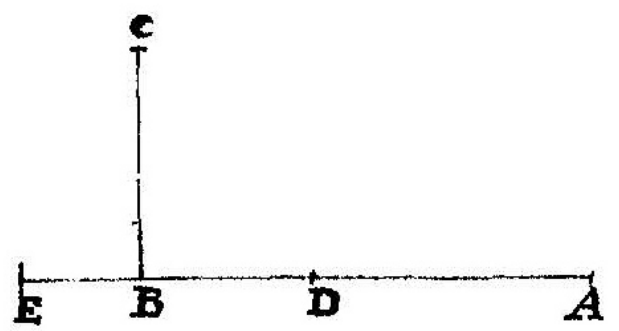

Figura 38. llustración 16v (García 1681) 


\subsubsection{Métodos para el dimensionado estructural}

Una vez determinada la superficie del edificio y establecido en planta y sección el tamaño y la forma del espacio interior, el siguiente paso en el proceso de proyecto consiste en el cálculo de los distintos elementos estructurales, como señala el propio texto: "Pues que se ha tratado del Repartimiento. y de todos sus interbalos sera bien tratar de la Groseza de los pilares. y salida de estrivos. para que todo quede medido. y proporçionado" (cap. 6: 17r). Este dimensionado se realiza de un modo totalmente independiente con respecto al trazado arquitectónico.

Las fórmulas de cálculo recogidas en el Compendio representan quizás el conjunto más completo de reglas estructurales góticas que se conserva ${ }^{340}$. Su naturaleza es tanto geométrica, de tradición altomedieval, como aritmética, resultado del desarrollo del vocabulario matemático en la baja Edad Media; a diferencia de lo que ocurría con el trazado de la planta y de la sección del edificio, no se plantea la analogía con el canon de proporciones humanas, salvo cuando esta es útil para generar alguna regla mnemotécnica (ilustración 25v). Estos métodos no estarían basados en un verdadero entendimiento de la mecánica teórica, sino en un conjunto de datos empíricos, recogidos probablemente por Rodrigo Gil y por su padre a lo largo de su carrera profesional, dando como resultado valores conservadores ${ }^{341}$.

La gran mayoría de las reglas medievales para estructuras de fábrica son proporcionales, esto es, suponen que una determinada forma geométrica es siempre válida independientemente de su tamaño. Este planteamiento fue refutado a mediados del siglo XVII por Galileo con el enunciado de su conocida ley del cuadrado-cubo; sin embargo, como ha puesto de relieve Heyman ${ }^{342}$, en las estructuras de fábrica la condición más restrictiva de diseño no es la resistencia del material, sino la estabilidad de la estructura, por lo que las fórmulas proporcionales, basadas en la forma geométrica, son esencialmente válidas si nos mantenemos en el rango de las dimensiones "reales" de un edificio, en el que las tensiones son bajas ${ }^{343}$. En este sentido, muchas de las reglas dadas en el manuscrito intentan superar la teoría gótica, estableciendo una relación no proporcional entre los distintos parámetros que intervienen, ya que, como ha observado Huerta ${ }^{344}$, se refieren efectivamente a problemas no proporcionales: tal es el caso del diseño de los pilares,

\footnotetext{
340 Huerta 2006: 24.

341 Huerta 2002: 580-581; Huerta 2006: 26-27; Sanabria [1982] 1999: [286-287] 6-7, [291-293] 11-13.

342 El análisis límite, también llamado plástico o a rotura, del comportamiento de las estructuras de fábrica ha sido desarrollado por Heyman desde finales de los sesenta del pasado siglo. La consecuencia más relevante de dicho análisis, deducida de su primer teorema ("teorema de la seguridad"), es que su estudio se puede llevar a cabo utilizando el denominado "enfoque del equilibrio": la estructura es segura si es posible encontrar una situación de equilibrio compatible con las cargas en la que el material trabaje a compresión, esto es, la estructura es estable si tiene la forma geométrica adecuada. De este modo, esta teoría de las estructuras confluye con los métodos tradicionales de trazado. La manera en que la estructura de fábrica se adapta a nuevas situaciones de equilibrio, originadas por cambios en las cargas o en las condiciones de contorno, es mediante la formación de grietas o articulaciones, que tienden a convertir una estructura hiperestática en isostática (Heyman 1999a: ix-x, 26, 30-31; Heyman 1999b: ix-xii, 234-235, 379-389). Sobre el diseño de estructuras de fábrica, véanse Fitchen 1986; Heyman 2001; Huerta 2004; Mark 2002; Mas-Guindal 2011; Sanabria 1988.

343 En líneas generales, la tensión media a que están sometidos los elementos más solicitados en cualquier estructura de fábrica no supera la décima parte de la resistencia de rotura a compresión del material, mientras que la de aquellos que solo soportan su propio peso está en torno a una centésima parte (Heyman 1999b: 229-231).

344 Huerta 2002: 581-583; Huerta 2006: 27-28.
} 
contrafuertes y claves de las bóvedas de crucería, o el de los muros y estribos de las torres. Las fórmulas propuestas, no lineales y deducidas empíricamente, representarían un acercamiento a los problemas estructurales más preciso que las tradicionales reglas medievales.

Las reglas han sido atribuidas a Rodrigo Gil por los distintos autores que se han ocupado del tema ${ }^{345}$, aunque Sanabria ${ }^{346}$ también plantea la posibilidad de que las fórmulas geométricas puedan corresponder al siglo XVII. Pasamos a continuación a describirlas utilizando para ello los estudios existentes; a fin de homogeneizar los enunciados de las fórmulas y de evitar confusiones, emplearemos para las expresiones algebraicas la notación dada por Huerta (2006).

\subsubsection{Pilares para bóvedas de crucería}

Se establece el diámetro de un pilar aislado de planta circular para una bóveda de crucería. La regla es aritmética (cap. 6: 17r). Expresada algebraicamente:

$$
\mathrm{d}=1 / 2 \sqrt{ }(\mathrm{h}+\mathrm{w}+\mathrm{s}) \text { (Huerta 2006) }
$$

Donde: d: diámetro de un pilar aislado de planta circular para una bóveda de crucería (pies); h: altura del pilar (pies); w, s: anchura y luz de un tramo de la nave central (pies) ${ }^{347}$.

Las unidades de la fórmula son incoherentes, lo cual se traduce en que el resultado cambia dependiendo de cuáles usemos; en el sistema de medidas castellano, en el que una vara equivale a 0.835905 metros y se divide en tres pies de 0.278635 metros, el resultado en varas aumentará respecto al resultado en pies por un factor de $\sqrt{ } 3$; en metros, por un factor de $\sqrt{ }(1 / 0.278635)$. Para obtener resultados adecuados los datos se deben introducir en pies, como se hace en el ejemplo con el que se ilustra la regla.

Como hemos indicado, la luz a introducir corresponde a la de la nave central y no a la de la lateral; como esta última suele ser menor, y de hecho lo es en el ejemplo presentado, permaneceremos del lado de la seguridad. Por otra parte, en el manuscrito no se especifica si este método de cálculo es válido cuando las naves se cubren a la misma altura o a distinta, aunque Hoag, Huerta y Sanabria ${ }^{348}$ indiquen que es aplicable a iglesias de salón; la planta del ejemplo utilizado de hecho sugiere dicha tipología. En este sentido, en los folios $21 v-22 r$ (cap. 6) se indica en dos ocasiones de modo general que si las naves van a distinta altura el pilar habrá de ser más grueso que si van a la misma, aunque sin concretar en qué medida.

La regla de cálculo es no proporcional, ya que, como ha observado Huerta ${ }^{349}$, se aplica a un problema de diseño que tampoco es proporcional. El grosor de la plementería de una bóveda gótica de la época es a menudo independiente del tamaño de esta, manteniéndose en valores en torno a $1 / 2$ y $2 / 3$ de pie $(0.14$ y $0.19 \mathrm{~m})$ por circunstancias prácticas de su construcción; por otro lado, el peso representado por los nervios es comparativamente mucho menor. El peso y por tanto el empuje de la bóveda aumenta con su superficie, pero el

\footnotetext{
345 Huerta 2002, Huerta 2006, Huerta 2013; Kubler 1944; Sanabria [1982] 1999.

346 Sanabria [1982] 1999: [285] 5 nota 12.

347 Hoag [1958] 1999: 427-429; Huerta 2002: 576; Huerta 2006: 25; Sanabria [1982] 1999: [286] 6.

348 Hoag [1958] 1999: 427-429; Huerta 2002: 576; Sanabria [1982] 1999: [286] 6.

349 Huerta 2002: 581-583; Huerta 2006: 27-28; Huerta 2013: 118.
} 
peso de los pilares crece con su volumen, con lo que un pilar más alto puede ser más esbelto.

\subsubsection{Estribos o contrafuertes}

\subsection{Regla general para arcos y bóvedas}

Se establecen las dimensiones del estribo o contrafuerte para un arco o bóveda. La regla es aritmética (cap. 2: 2v; cap. 6: 18v-19r). Expresada algebraicamente:

$$
\mathrm{c}=1 / 4 \mathrm{~s}
$$

Donde: c: grosor total del contrafuerte para un arco o bóveda (incluyendo el grueso de la "pared" o muro y la proyección exterior del contrafuerte); s: luz de ese tramo.

Según Sanabria ${ }^{350}$ debe considerarse como una regla tradicional de trazado, conservada entre los constructores por tradición oral a través de los siglos. Coincide con las reglas utilizadas habitualmente en los siglos XVII y XVIII, como la publicada por Blondel en 1675, muy difundida, que asigna un estribo de $1 / 4$ de la luz para un arco de medio punto, o la propuesta a principios del XVIII por Wren, que conduce de nuevo a la misma proporción ${ }^{351}$.

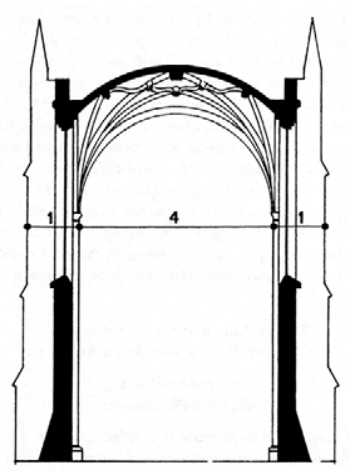

Figura 39. Estribos o contrafuertes: regla general para arcos y bóvedas, según Sanabria ([1982] 1999: [285] 5 fig. 7)

\subsection{Regla particular para bóvedas de crucería}

Se establecen las dimensiones del estribo o contrafuerte para una bóveda de crucería. Se considera como presupuesto de partida que la planta del contrafuerte tiene proporción 2:1. La regla es aritmética (cap. 2: 5r-5v; cap. 6: 17v-18r, ilustración 18r, 22r-22v). Expresada algebraicamente:

$$
c=2 / 3 \sqrt{ }\left(\mathrm{h}+2 / 3 \sum \mathrm{Ni}\right) \text { (Huerta 2006) }
$$

Donde: c: grosor total del contrafuerte a la altura del arranque de la bóveda de crucería (incluyendo el grueso del "medio pilar" o pilar adosado, el de la "pared" 。 muro y la proyección exterior del contrafuerte) (su ancho es $\mathrm{c} / 2$ ) (pies); h: altura del contrafuerte (pies); $\sum \mathrm{Ni}$ : suma de las longitudes de los nervios que arrancan del

\footnotetext{
350 Sanabria [1982] 1999: [285-286] 5-6, [291-293] 11-13.

351 Heyman 1999b: 273-275, 278.
} 
contrafuerte (arcos perpiaños, diagonales y terceletes), medidos desde el arranque hasta sus respectivas claves (pies) ${ }^{352}$.

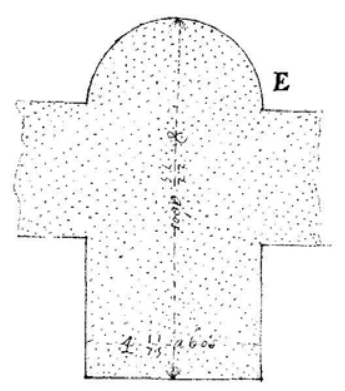

Figura 40. Estribos o contrafuertes: regla particular para bóvedas de crucería: ilustración 18r (García 1681)

Las unidades de la fórmula son incoherentes. Para obtener resultados adecuados los datos se deben introducir en pies, como se hace en el ejemplo con el que se ilustra la regla.

En el texto se explica que el motivo de tomar solo dos tercios de las longitudes de los nervios es que el tercio restante es el que corresponde normalmente a la piedra eliminada del nervio al tallar la correspondiente moldura, precisándose que si esta relación fuera distinta se debe aplicar proporcionalmente a la fórmula (cap. 6: 17v, 22v); como puede observarse, el factor $2 / 3$ se aplica dos veces, una dentro de la raíz cuadrada y otra fuera, sin que se ofrezca una explicación razonable para esta duplicidad. De modo lógico no se consideran para el cálculo las longitudes de los arcos formeros, ya que los empujes producidos por estos sobre el estribo quedan mutuamente contrarrestados. La planta del contrafuerte, calculada a la altura del arranque de la bóveda, irá aumentando progresivamente hacia el suelo por medio de "talus" y "chapados", esto es, taludes o inclinaciones y escalonamientos en la fábrica, si bien no se expresa en qué proporción se produce dicho crecimiento (cap. 6: 18r, 22v). En ningún caso se asigna al muro de cerramiento ningún cometido estructural en relación con las bóvedas, limitándose su función al soporte de su propio peso y el de las armaduras de cubierta.

Por otra parte, en el manuscrito no se especifica si este método de cálculo es válido cuando las naves se cubren a la misma altura $\circ$ a distinta, aunque Sanabria ${ }^{353}$ indique que es aplicable a iglesias de salón; la planta del ejemplo utilizado de hecho sugiere dicha tipología. No se considera la posibilidad de que sobre el estribo cargue un arbotante que transmita el empuje de las bóvedas de la nave central si las naves del edificio se cubren a distinta altura, ni tampoco el empleo de un pináculo para evitar un posible fallo por deslizamiento de la cabeza del contrafuerte ${ }^{354}$. Sin embargo, al final del capítulo 3 e interpolada al término del 6 aparecen dos pequeñas explicaciones que aluden tanto al uso de arbotantes como al de pináculos, aunque sin dar ningún criterio concreto de diseño (cap. 3: $8 \mathrm{v}$; cap. 6: 26r-26v, ilustración $26 \mathrm{v}$ ).

\footnotetext{
352 Hoag [1958] 1999: 429-430; Huerta 2002: 576-577; Huerta 2006: 25-26; Sanabria [1982] 1999: [286] 6.

353 Sanabria [1982] 1999: [286] 6.

354 Heyman 1999a: 103-105; Heyman 1999b: 230-231.
} 
La regla de cálculo es no proporcional, ya que, como ha observado Huerta ${ }^{355}$, se aplica a un problema de diseño que tampoco es proporcional, por las mismas razones que las ya explicadas en el cálculo de los pilares para bóvedas de crucería. El peso y por tanto el empuje de la bóveda aumenta con su superficie, pero el peso de los contrafuertes crece con su volumen, con lo que un contrafuerte más alto puede ser más esbelto.

Por otro lado, Sanabria ${ }^{356}$ ha indicado el interés de la temprana formulación teórica del concepto de un coeficiente de seguridad: "Y esto es lo que podra sustentar lo que embotan los arcos. Aqui podra el artifiçe añadirle vn poco mas porque mas bale que llebe de mas que de menos. pero esto es lo que podra sustentar como está đho [dicho]" (cap. 6: 18r).

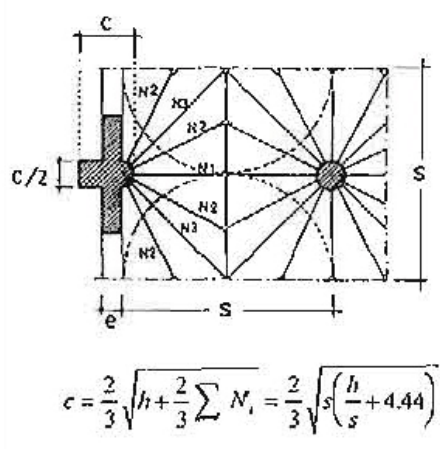

(a)

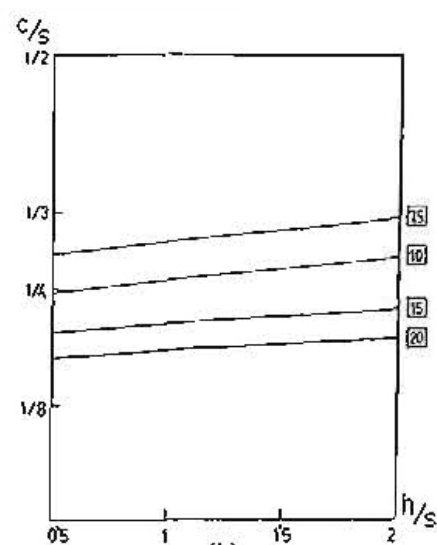

(b)

Figura 41. Estribos o contrafuertes: regla particular para bóvedas de crucería: aplicación al caso de bóvedas de planta cuadrada, según Huerta (2006: 26 fig. 7): (a) Expresión algebraica. (b) Gráfica mostrando la esbeltez de los estribos $\mathrm{c} / \mathrm{s}$, para diferentes proporciones altura/luz $\mathrm{h} / \mathrm{s}$, para luces entre 7.5 y $20 \mathrm{~m}$

\subsubsection{Estribos o contrafuertes para arcos semicirculares}

En el manuscrito se recogen, además de las anteriores, una serie de reglas, tanto aritméticas como geométricas, referidas al diseño de estribos o contrafuertes. No existe un acuerdo unánime entre los investigadores para determinar a qué tipo de elementos podrían servir de contrarresto. Al parecer Kubler 357 avanzó que la primera fórmula geométrica correspondería a una bóveda de cañón. Hoag ${ }^{358}$ argumenta que estas fórmulas estarían destinadas tanto para bóvedas de cañón como para arcos y arbotantes, y aclara que, en los dos primeros casos, se referirían a elementos que deben soportar, además de su propio peso, una determinada carga colocada sobre ellos. Para Sanabria ${ }^{359}$, que es el último investigador que las ha estudiado con detalle, permitirían dimensionar el contrafuerte necesario para un arco semicircular, que en el caso de las tres reglas geométricas soporta un muro plano de una altura determinada; estarían destinadas a un arco aislado, un conjunto de ellos a modo de arcada, o quizás una bóveda de cañón, sugiriendo un estilo

\footnotetext{
355 Huerta 2002: 581-583; Huerta 2006: 27-28.

356 Sanabria [1982] 1999: [289] 9.

357 Kubler 1944: 142, citado en Sanabria [1982] 1999: [287] 7 nota 19.

358 Hoag [1958] 1999: 426-427, 430-435.

359 Sanabria [1982] 1999: [286-291] 6-11.
} 
clásico más que gótico. Según Huerta ${ }^{360}$, se utilizarían para el cálculo de los contrafuertes de arcos simples y bóvedas de cañón clásicas, o simplemente para los de arcos sencillos y arcadas renacentistas; su naturaleza sería teórica e investigativa, frente al resto de las fórmulas de cálculo estructural recogidas en el texto, de carácter práctico.

Toda la arquitectura gótica se basa en el trazado de arcos simples, como pueden ser los arcos perpiaños que separan los tramos de un edificio religioso o los arcos torales que soportan un cimborrio; o de conjuntos de ellos, como los arcos que en una iglesia de naves desiguales en altura permiten el paso de la nave central a las laterales y de estas a las capillas hornacinas, y que soportan los claristorios; si bien se trata habitualmente de arcos apuntados y no de medio punto. Por otro lado, las bóvedas de cañón no eran desconocidas para Rodrigo Gil (encontramos cañones apuntados en la iglesia de la Asunción de Nuestra Señora en Villamor de los Escuderos (Zamora), en la del monasterio de las Bernardas en Salamanca, en la de Santa María de la Asunción en Guareña (Badajoz) y en la del Hospital de la Misericordia en Segovia); sin embargo, en el manuscrito únicamente se hace referencia explícita a arcos, y nunca a cañones, ni tampoco a arbotantes.

En nuestra opinión, un arco cargado con un muro plano es simplemente un arco enjutado, como es el caso de los que acabamos de presentar como ejemplos ${ }^{361}$. No obstante, se presentan numerosas incógnitas. Por una parte, este apartado ("Sobre los estribos") comienza con la siguiente aserción: "Probado he muchas veçes a sacar Raçon del estribo que abrá menester, vna qualquiera forma" (cap. 6: 18v); debemos recordar que en el manuscrito el término "forma" se reserva para el arco formero de una bóveda, aunque, en este caso, parece más bien referirse al trazado geométrico de un arco cualquiera. Por otra, las reglas contemplan siempre el apoyo del arco en dos contrafuertes, y no en un contrafuerte y un pilar, como ocurriría en el estribo occidental de la nave central de una iglesia de tres naves; en el texto se confiere importancia a este último elemento, explicándose que el edificio, "donde a menester mas estrivo, [es] en los pies, por que le encomendamos toda la furia de toda la obra" (cap. 6: 22r), pero no se proporciona ninguna regla concreta de cálculo. Para terminar, como ya hemos indicado más arriba, Sanabria ${ }^{362}$ no descarta que las fórmulas geométricas puedan corresponder al siglo XVII, comparando su relativa sofisticación con la simplicidad de la publicada por Derand en 1643. Por todas estas razones el destino y autoría de estas formulaciones continúa siendo poco claro.

\subsection{Reglas geométricas para arcos semicirculares}

Se establece el grosor del estribo o contrafuerte de un arco semicircular cargado con un muro plano, esto es, un arco de medio punto enjutado, proporcionándose para ello tres reglas geométricas.

\footnotetext{
360 Huerta 2002: 574, 580-581; Huerta 2006: 25-27.

361 En relación con las enjutas de los arcos perpiaños, su importancia en la estabilidad del conjunto del esqueleto pétreo ha sido señalada por Cassinello, defendiendo la relevancia que dichos elementos adquieren ante acciones dinámicas horizontales de viento y sismo, y demostrando la utilización histórica en nuestro país de estos elementos en zonas geográficas de alta sismicidad. Pese a aportar mayor peso y empuje que los arcos exentos, la presencia de enjutas sobre los arcos del perímetro de la bóveda de crucería proporciona en tales situaciones un marco rígido de borde que limita la deformación de aquella (Cassinello 2004: 11 -15, 29, 35, 37; Cassinello 2005: 252-253).
}

362 Sanabria [1982] 1999: [285] 5 nota 12. 
Las dos primeras toman como dato de partida únicamente la luz del arco, sin considerar la altura del contrafuerte $\circ$ el espesor de rosca del arco. La primera conduce según Sanabria ${ }^{363}$ a un estribo de 0.293 veces la luz, resultando una relación entre ambos de $1 / 3.414$, y pudiendo el arco soportar la carga de un muro de altura 1.041 veces la luz, medida desde la línea de imposta (regla 1, cap. 6: 19r-19v, ilustración 19v). La segunda conduce a un estribo de $0.301 \circ 0.311$ veces la luz, resultando una relación entre ambos de $1 / 3.25$ ○ 1/3.22, y pudiendo el arco soportar la carga de un muro de altura 1.447 veces la luz, medida de nuevo desde la línea de imposta (regla 2, cap. 6: 19v-20r, ilustración 20r). Esta última es por tanto más conservadora que la primera, aunque a cambio permite una mayor carga.

La regla más interesante y completa es, según este estudioso ${ }^{364}$, la tercera (regla 3, cap. 6: 20r-20v, ilustración 21 r; cap. 16: ilustración 59r), ya que constituye un intento de establecer un método general de cálculo, dividiéndose su explicación a su vez en tres partes. En las partes 1 y 2 se relacionan cinco parámetros: altura y grosor del contrafuerte; luz y espesor de rosca del arco; y altura del muro cargado sobre el trasdós del arco. En la parte 1, dado un arco de medio punto con un espesor de rosca de $1 / 6$ de su luz y un estribo de grosor $1 / 3$ de la misma, se obtiene la altura de este (que resulta ser $4 / 3$ ), y la altura máxima del muro (que resulta ser 1.236 medida desde la línea de imposta). En la parte 2, dado un arco de medio punto con un espesor de rosca de $1 / 5$ y un contrafuerte de altura $3 / 2$, se obtiene el grosor de este (que resulta ser 15/44, 0.341 ), y la altura máxima del muro (que resulta ser 1.3 medida desde la línea de imposta). Finalmente, en la parte 3 se hace un confuso intento, quizás debido a la poca precisión del copista, de generalizar aritméticamente para cualquier condición de partida la regla geométrica expuesta en las partes 1 y 2 ; el dibujo recogido en el folio 59r (cap. 16) representa la generalización del mismo trazado geométrico a distintos tipos de arco (rebajado, semicircular y apuntado), para una altura de contrafuerte y una luz de arco dadas, aunque sin tener en cuenta el espesor de rosca.
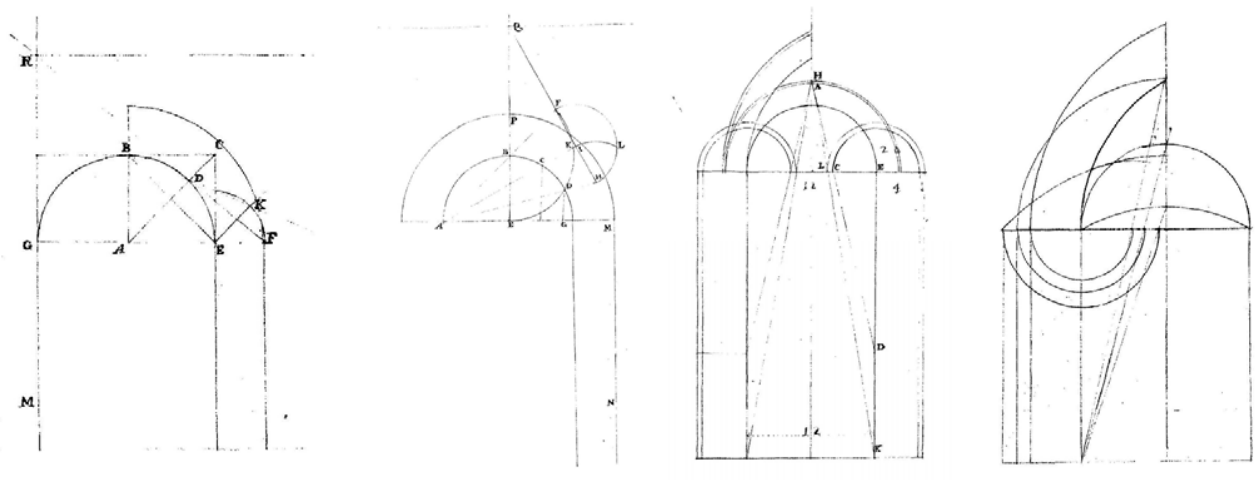

Figura 42. Estribos o contrafuertes para arcos semicirculares: reglas geométricas: (a) llustración 19v. (b) Ilustración 20r. (c) Ilustración 21 r. (d) Ilustración 59r (a-d: García 1681)

Estos tres métodos de cálculo toman en consideración la configuración del arco, intentando superar la fórmula inespecífica que asigna al estribo una proporción de 1/4 de la luz. Debemos observar que el empuje que un arco produce sobre los contrafuertes depende

363 Sanabria [1982] 1999: [287-292] 7-12.
364 Sanabria [1982] 1999: [287-292] 7-12. 
efectivamente de su forma, de modo que los arcos apuntados producen un menor empuje que los rebajados, algo que se observa de modo intuitivo, y que queda adecuadamente reflejado en la construcción geométrica publicada por Blondel en 1675. Esta, como ya hemos comentado, asigna un estribo de $1 / 4$ de la luz para un arco de medio punto, disminuyendo su valor para el caso de un arco apuntado, y aumentando hasta un valor límite de $1 / 3$ para un arco rebajado. Como ha observado Heyman ${ }^{365}$, no es posible extrapolar la primera regla geométrica dada por Rodrigo Gil al caso de arcos no semicirculares, ya que según esta los arcos peraltados requerirían estribos mayores, y los rebajados más pequeños, pero la generalización de la tercera regla geométrica, expuesta en la ilustración 59r, recoge correctamente la misma circunstancia que Blondel.

Sanabria ${ }^{366}$ ha puesto de relieve otros aspectos interesantes de estas reglas geométricas. En primer lugar, el problema teórico de la suficiencia estructural es formulado en época temprana: "y aquello se puede bien fiar, que ni será mucho travajar, ni tampoco olgar ni estará demas el estriuo" (cap. 6: 19v); "Y aquella carga podra sostener sin que aya menester mas estrivo ni este superfluo" (cap. 6: 20r). Por otro lado, este estudioso sugiere que en el planteamiento de estas fórmulas se habrían utilizado valores para la altura y el grosor del contrafuerte obtenidos a partir de pruebas experimentales, que constituirían en tal caso el ejemplo más antiguo de una investigación de este tipo del que se tiene noticia, opinión compartida por Huerta ${ }^{367}$.

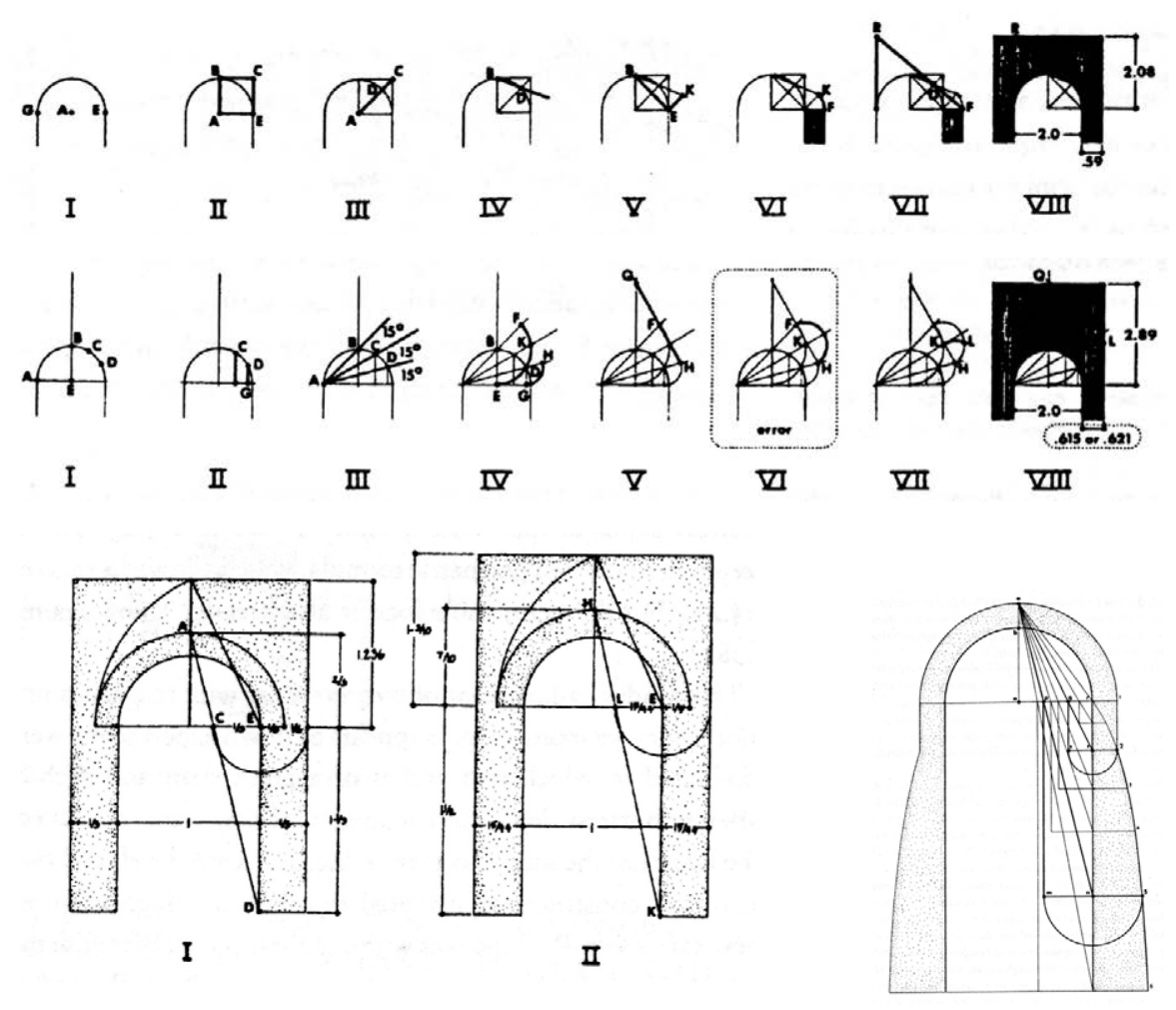

Figura 43. Estribos o contrafuertes para arcos semicirculares: reglas geométricas, según Sanabria ([1982] 1999: [288] 8 fig. 9, [288] 8 fig. 11, [290] 10 fig. 14, [291] 11 fig. 15): (a) Regla 1. (b) Regla 2. (c) Regla 3, partes 1 y 2. (d) Regla 3, parte 3 (generalización hiperbólica)

\footnotetext{
365 Heyman 1999b: 273-276.

366 Sanabria [1982] 1999: [287-292] 7-1 2.

367 Huerta 2002: 580-581; Huerta 2006: 26-27.
} 


\subsection{Regla aritmética para arcos semicirculares}

Se establece el grosor del estribo o contrafuerte de un arco semicircular. La regla es aritmética (cap. 6: 20v-21v). Expresada algebraicamente:

$$
c=\sqrt{ }(h+N)
$$

Donde: c: grosor del contrafuerte de un arco semicircular (pies); h: altura del contrafuerte (pies); $\mathrm{N}$ : longitud del arco que arranca del contrafuerte, medido en su intradós desde el arranque hasta la clave (pies) ${ }^{368}$.

Las unidades de la fórmula son incoherentes. Para obtener resultados adecuados los datos se deben introducir en pies, como se hace en el ejemplo con el que se ilustra la regla.

El planteamiento es análogo al que se propone para el dimensionado de los contrafuertes para bóvedas de crucería y para torres. No obstante, si comparamos la fórmula con la regla particular para bóvedas de crucería encontramos una matización importante: el factor $2 / 3$, aplicado en esta última para considerar la proporción de la sección transversal del nervio que queda habitualmente después de haber tallado las correspondientes molduras sobre un contorno inicialmente rectangular, no se incluye ahora, de lo que podríamos deducir que está destinada a arcos de sección transversal perfectamente rectangular. Al terminar la explicación de la fórmula se dice que el ancho del contrafuerte y el del arco deben coincidir, si bien la frase es equívoca ("Y que este estribo a de ser de la Groseça del mismo arco", cap. 6: 21 v).

\subsubsection{Torres}

Se establece el grosor del muro y los estribos o contrafuertes de una torre. Las reglas son aritméticas (cap. 2: 5v-6r). Expresadas algebraicamente:

$$
\begin{aligned}
& t=1 / 2 \sqrt{ } h \text { (Huerta 2006) } \\
& b=1 / 2 \sqrt{ }(h+a) \text { (Huerta 2006) }
\end{aligned}
$$

Donde: t: grosor del muro en la parte superior de la torre (pies); h: altura de la torre (pies); b: grosor del contrafuerte en la parte superior de la torre (pies); a: altura del elemento (aguja, remate, etc.) colocado en la parte superior de la torre (pies) ${ }^{369}$.

Se especifica que ambos cálculos se refieren a las dimensiones en la parte superior de la torre, y que estas deben ser aumentadas en razón de los "taluses" y "cornijamentos", esto es, taludes o inclinaciones y escalonamientos en la fábrica y cornisas a lo largo del fuste, del mismo modo que se indica para los contrafuertes para bóvedas de crucería. Para el cálculo del grosor del estribo se especifica además que, caso de que la torre se cierre interiormente en su parte superior con una cúpula de media naranja, se puede introducir la siguiente corrección, con un planteamiento análogo al que se propone para el dimensionado de los contrafuertes para bóvedas de crucería y los de arcos semicirculares (regla aritmética):

$$
b=1 / 2 \sqrt{ }(h+a+N)
$$

Donde: b: grosor del contrafuerte en la parte superior de la torre (pies); h: altura de la torre (pies); a: altura del elemento (aguja, remate, etc.) colocado en la parte superior de la torre (pies); N: longitud del cuarto de circunferencia de la cúpula que

\footnotetext{
368 Sanabria [1982] 1999: [286-287] 6-7.

369 Huerta 2002: 579-580; Huerta 2006: 26.
} 
cierra interiormente la parte superior de la torre, medida desde el arranque hasta la clave (pies).

Las unidades de las fórmulas son incoherentes. Para obtener resultados adecuados los datos se deben introducir en pies, como se hace en el ejemplo con el que se ilustran las reglas.

Ambas fórmulas de cálculo son no proporcionales, ya que, como ha observado Huerta ${ }^{370}$, se aplican a un problema de diseño que tampoco es proporcional. La acción principal a la que está sometida la torre es el viento. El empuje total de este aumenta con la superficie de la sección transversal de la torre, pero el peso de los muros crece con su volumen, con lo que una torre más alta puede tener unos muros más esbeltos.
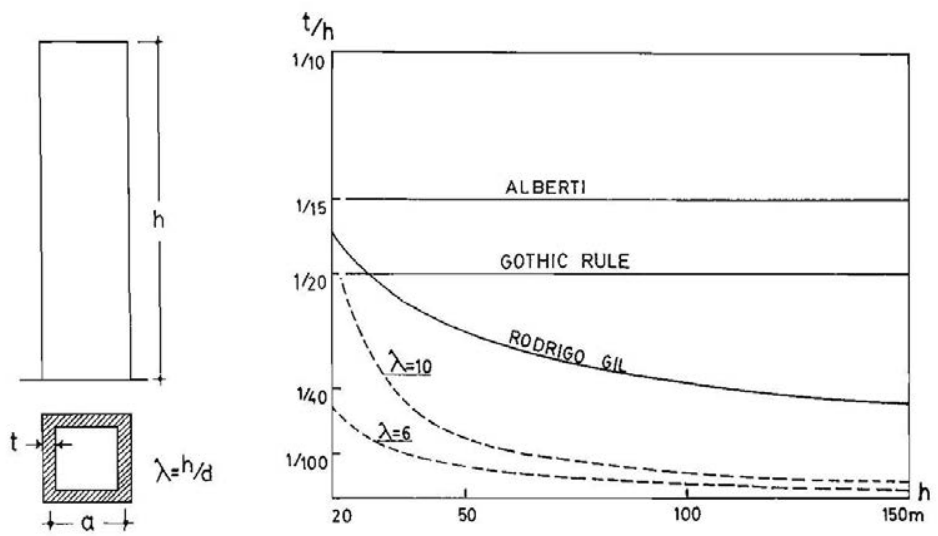

Figura 44. Torres: comparación entre las reglas tradicionales de diseño (línea continua), entre ellas la de Rodrigo Gil, y los resultados del cálculo científico de los valores típicos para fábrica y viento (línea discontinua), según Huerta (2006: 28 fig. 13)

\subsubsection{Dimensionado, construcción y montaje de una bóveda de crucería}

La sección del Compendio "De lo que le toca a cada miembro" (cap. 6: 22v-25v) es sin duda la más importante del manuscrito de Rodrigo Gil desde el punto de vista de nuestra investigación, ya que en ella no solo se recogen algunos procedimientos válidos para el dimensionado de los elementos estructurales de una bóveda de crucería, sino que se describe con cierto detalle el método a seguir para su construcción y montaje. De hecho se trata, junto con el tratado del cantero mallorquín Joseph Gelabert ${ }^{371}$, del único texto de tradición medieval conocido en Europa que explica el procedimiento de ejecución de una bóveda gótica, ilustrándolo además con un célebre dibujo de considerable interés (ilustración 25r), si bien debemos tener en cuenta la distorsión introducida tanto por García como por Gelabert en las técnicas góticas descritas debido a su carácter anacrónico en el siglo XVII, momento en que ambos redactan sus manuscritos ${ }^{372}$.

\footnotetext{
370 Huerta 2002: 581-583; Huerta 2006: 27-28.

371 Gelabert [1653] 1977, Gelabert [1653] 2011.

372 Huerta 2013: 108-109; Palacios 2006: 2420; Palacios 2009: 89; Rabasa 2007a: 748-749. Según Gómez Martínez (Gómez 1998: 36-37), el tratado de Rodrigo Gil y el de Joseph Gelabert representarían
} 
La importancia de esta sección ha sido destacada por los investigadores, como Kubler o Hoag, y más recientemente Huerta ${ }^{373}$. A continuación desarrollamos las dos partes en que se puede dividir su contenido.

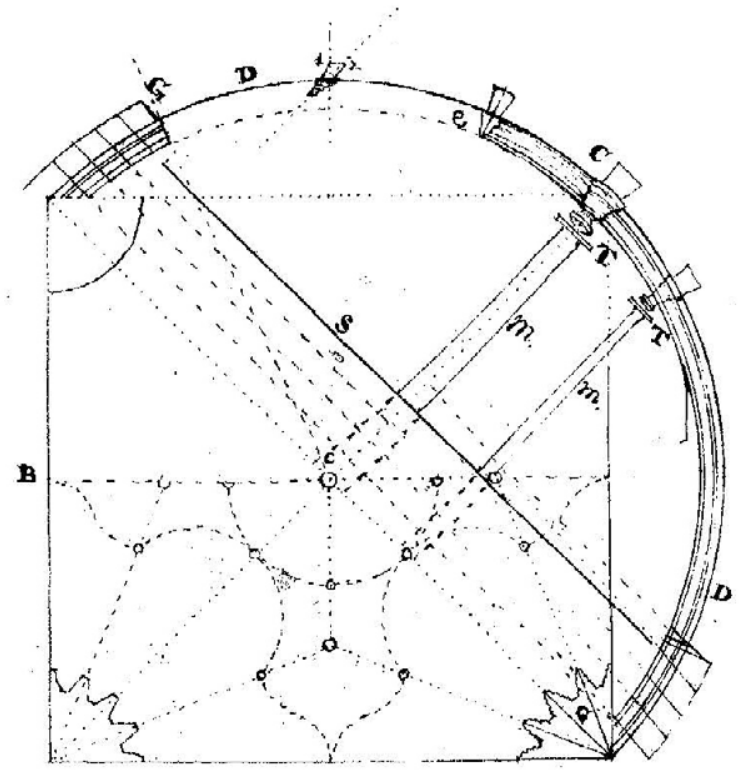

Figura 45. llustración 25r (García 1681)

\subsubsection{Elementos que componen la bóveda. Dimensionado de los elementos estructurales}

La primera parte de la sección se dedica a describir los dos elementos fundamentales de que se compone la "capilla" o bóveda de crucería: los "miembros" o nervios, y las "claues" 。 claves (cap. 6: 22v).

Se establece una distinción inicial entre dos tipos de nervios: "los miembros que sustentan y los que son sustentados"; los primeros son los que "naçen de los jarjamentos" o jarjas, esto es, los arcos ("cruçeros", "diagonales" o cruceros, y "terçeletes" o terceletes), mientras que los segundos son los que "naszen de las claues", esto es, los "combados" o nervios decorativos curvos y los "rampantes" o ligaduras (en el texto se designa con el término "rampante" tanto la línea que configura el espinazo de la bóveda como el nervio de ligadura que puede disponerse a lo largo de dicha línea) (cap. 6: 23v-24r). Se podría pensar en extender esta clasificación a los arcos del perímetro de la bóveda ("arcos", "arcos pripiaños" o perpiaños, y "formas" o formeros), pero no deja de ser curioso que en el texto se omita por dos veces consecutivas esta circunstancia. Tal vez tenga que ver con ello el hecho de que los arcos perpiaños puedan ser arcos enjutados, es decir, que sobre su trasdós cargue un muro, y de que los formeros se encuentran integrados en el cerramiento y no trabajan estructuralmente como arcos. Por ello el cálculo debería ser totalmente distinto.

respectivamente la scientia y el ars medievales, si bien el primero recogería una ciencia medieval renovada hasta el siglo XVI, y el segundo unas técnicas probablemente inalteradas desde el siglo XIII.

373 Hoag [1958] 1999: 439-443; Huerta 2013; Kubler 1944. 
La misma diferenciación se emplea para las claves, identificando "claves que sustentan, $Y$ otras que son sustentadas"; las primeras se encuentran en el extremo de las diagonales y terceletes, mientras que las segundas aparecen a lo largo del recorrido de estos arcos (cap. 6: $23 v-24 r)$.

Rodrigo Gil resalta la importancia de ambos elementos, nervios y claves, refiriéndose quizás no solo a su papel en la bóveda terminada, sino también, como ha señalado Huerta ${ }^{374}$, durante su montaje: las claves sirven, evidentemente, para resolver el problema constructivo de la conexión de diferentes nervios, pero también juegan un papel fundamental estabilizando el esqueleto pétreo durante la colocación de la plementería. Para nervios y claves da el texto unas reglas de dimensionado, que describimos a continuación. Sin embargo no recoge demasiadas indicaciones acerca de los otros dos elementos básicos que componen una bóveda de crucería: los "jarjamentos" o jarjas y la "plemeteria" o plementería. Intentaremos hacer también algunas observaciones sobre ellos, incluyendo finalmente algunas consideraciones relativas al trazado del rampante o línea de espinazo de la bóveda, que, aunque no es propiamente uno de los elementos que la componen, sí la caracteriza en gran medida.

\subsubsection{1. "Miembros" o nervios}

Para su dimensionado se proporcionan reglas aritméticas, en las que únicamente interviene el "largo o lado de la capilla" (el lado de la bóveda en planta). Establecido este, las fórmulas permiten calcular el "alto" de cada arco (cap. 6: 23v) ० "lo que a de colgar" (ilustración 25v), esto es, el canto relativo a la parte de la sección transversal que corresponde a la "moldura", que queda vista desde la parte inferior de la bóveda y que recibe el peso de la plementería durante el montaje; no incluye por tanto la parte del nervio que corresponde a la "cola", es decir, la porción superior cortada en forma de cuña que queda oculta por la plementería una vez construida esta (según parece deducirse de cap. 6: 24v I. 17-20). Existen algunas discrepancias, ya observadas por Hoag y Huerta ${ }^{375}$, en los valores de cálculo dados en distintos lugares, en dos ocasiones dentro del texto de la sección, y, por último, en el conocido dibujo en el que se establece una analogía antropomórfica entre los dedos de una mano y la dimensión de los nervios de una bóveda de crucería (cap. 6: 23r-23v, ilustración 25v); de acuerdo con la terminología empleada en esta sección el dimensionado de las nervaduras es el siguiente:

- "arco" ○ "arco pripiaño" (arco perpiaño o fajón): L/20 (cap. 6: 23r, 23v) ○ L/22 (ilustración 25v)

- "cruçero", "cruzero" o "diagonal" (arco crucero, diagonal u ojivo): L/24 (cap. 6: 23r, $23 \mathrm{v}$, ilustración $25 \mathrm{v}$ )

- "terçelete" (tercelete): L/28 (cap. 6: 23r, 23v, ilustración 25v)

- "rampante" (ligadura): L/28 (ilustración 25v)

- "forma" (arco formero): L/30 (cap. 6: 23v) ○ L/36 (cap. 6: 23r, ilustración 25v)

Donde: L: lado de la bóveda en planta.

\footnotetext{
374 Huerta 2002: 577-579; Huerta 2006: 26; Huerta 2013: 109.

375 Hoag [1958] 1999: 439-443 nota 31; Huerta 2013: $112-115$.
} 
Las fórmulas se refieren a un tipo de bóveda básico, de planta cuadrada, cuyo arranque o línea de imposta se encuentra a una altura equivalente a la longitud del lado $L$ de la bóveda, y cuyo arco diagonal es probablemente semicircular. Si no se cumplen estas condiciones, es necesario hacer algunos ajustes en el cálculo. De este modo, si la bóveda "fuere perlongada", esto es, de planta rectangular, se indica que debe tomarse la media aritmética de sus lados para el cálculo de los valores (cap. 6: 23v). La utilización de un valor promedio en lugar del mayor de los dos implica que las reglas están concebidas con un cierto margen de seguridad que permite esta aproximación. Por otro lado, si la altura de imposta es mayor o menor que la longitud del lado $L$ se especifica que los valores deben aumentar o disminuir respectivamente de modo proporcional (cap. 6: 23v). Como Hoag ${ }^{376}$, no entendemos qué relación puede existir entre la sección de los nervios de la bóveda y la altura de la que esta arranca. Finalmente se precisa que "si la montea fuere a paynel", esto es, si sus arcos son carpaneles, los valores se deben acrecentar en proporción al rebaje que tenga (cap. 6: 23v), entendemos que tomando como referencia un arco diagonal semicircular. Como ha observado Huerta ${ }^{377}$, aunque los arcos rebajados pueden tener un espesor inferior al de un arco de medio punto manteniendo la estabilidad, los posibles movimientos de los apoyos son en ellos más ostensibles, y un nervio más grueso tolerará mejor las deformaciones.

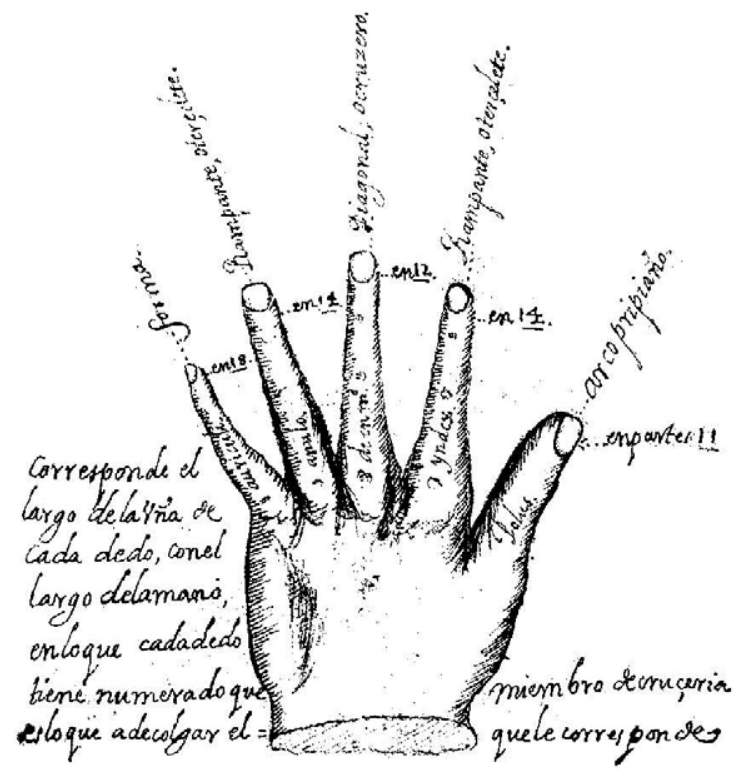

Figura 46. llustración 25v (García 1681)

Llama la atención la escasa diferencia en el canto asignado por estas reglas al arco perpiaño y al diagonal: en el primer caso L/20 ○ L/22, y en el segundo L/24. Si pensamos en una estructura real de tamaño convencional, por ejemplo una bóveda de planta cuadrada de 30 pies de lado $(8.36 \mathrm{~m})$, el perpiaño correspondiente tendría $0.418 \circ 0.380$ $\mathrm{m}$ de canto, y la diagonal $0.348 \mathrm{~m}$. Esta circunstancia resulta aún más chocante si acudimos a la obra construida de Rodrigo Gil, en la que los arcos perpiaños tienen siempre una gran

\footnotetext{
376 Hoag [1958] 1999: 439-443 nota 32.

377 Huerta 2013: $115-116$.
} 
presencia y articulan de hecho el espacio interior, como sucede en prácticamente toda la arquitectura gótica española. En el manuscrito encontramos un pasaje, relativo al empuje producido por una bóveda de crucería, que puede explicar en parte el dimensionado del perpiaño: "Lo que se a de procurar en vn templo es, que los arcos sean delgados. la Raçon de lo qual trataremos adelante con el fauor de Dios, $Y$ esto combiene que sean asi porque quien ofende a los estrivos es los arcos. la Raçon por ser Gruesos, y pujar derechos contra los estribos, lo qual no azen a los estrivos mal los cruçeros, ni terçeletes, asi por ser delgados, como por estriuar obliquamente" (cap. 6: $21 \mathrm{v}$ ).

Se trata en todo caso de reglas de cálculo proporcionales, expresadas como una fracción de la luz de la bóveda y por tanto correctamente planteadas, cuyo objetivo es definir el espesor para que cada arco sea estable respetando unos márgenes razonables de seguridad ${ }^{378}$. Sin embargo no están referidas, como hemos indicado, a la luz individual que corresponde a cada uno de los arcos, sino al lado de la bóveda en planta; tampoco lo están al canto total de cada nervio, sino que excluyen las colas entre las que se dispone el casco de la bóveda, para las que además no se da ninguna regla de dimensionado, asumiendo quizás que la plementería, y por tanto estas colas, tiene habitualmente un espesor más o menos constante independientemente de las dimensiones de la bóveda. No se ofrece ninguna regla para establecer la proporción entre ancho y canto de la sección transversal, y tampoco se dan prescripciones para el diseño de las nervaduras decorativas.

\subsection{Claves}

A continuación se establece el tamaño de las claves de una bóveda de crucería. La regla es aritmética (cap. 6: 23v-24r). Expresada algebraicamente:

$$
Q=P \sqrt{ }\left(\sum R i-\sum S i\right) \text { (Huerta 2006) }
$$

Donde: Q: peso de la clave que sustenta (quintales; en el sistema métrico castellano un quintal equivale a $46.00093 \mathrm{~kg}$, $\circ$ el peso de un pie cúbico de piedra convencional, de densidad en torno a $2100 \mathrm{~kg} / \mathrm{m}^{3}$ ); P: peso del nervio que sustenta - portante por unidad de longitud (quintales/pie); $\sum$ Ri: suma de las longitudes de los nervios que sustentan o portantes (pies); $\sum \mathrm{Si}$ : suma de las longitudes de los nervios sustentados (pies) $)^{379}$.

Las unidades de la fórmula son incoherentes. Para obtener resultados adecuados los datos se deben introducir en pies, como se hace en el ejemplo con el que se ilustra la regla.

Este ejemplo se refiere al cálculo del peso de la clave central de una bóveda, y como tal sería aplicable a las otras claves que sustentan, esto es, las que se encuentran en los extremos de los terceletes. El planteamiento implica que el peso de cada clave que sustenta aumenta con el del arco en el que se encuentra colocada, mientras que se reduce por la presencia de ligaduras y nervios decorativos, entendidos, al menos durante el proceso de montaje de la bóveda, como cargas permanentes aplicadas sobre la clave en cuestión. De esto se deduce que una bóveda en la que no aparezcan ligaduras o nervaduras decorativas necesitará de claves de mayor tamaño, aunque menos numerosas, mientras que una provista de estos nervios requerirá de claves más pequeñas y abundantes, lo cual parece lógico. La fórmula omite la circunstancia de que, muy a menudo, estos nervios

\footnotetext{
378 Huerta 2013: 114-115.

379 Huerta 2002: 577-579; Huerta 2006: 26; Huerta 2013: 116-118.
} 
decorativos tienen un espesor y por tanto un peso inferior al de los arcos. Por otro lado, no estamos seguros de cómo se realizaría el cálculo de una clave sustentada, situada a lo largo del recorrido de las nervaduras principales de la bóveda.

El dimensionado de las claves, como ha observado Huerta ${ }^{380}$, es fundamental para el equilibrio del esqueleto pétreo y la plementería. La colocación de esta se realizaría desde el perímetro hacia el centro de la bóveda, con lo que durante el montaje podría llegar el caso de que el esqueleto formado por nervios y claves, que está funcionando en ese momento como cimbra permanente para el casco, esté lo suficientemente cargado en sus hombros como para producir la deformación de alguno de los nervios, el movimiento de alguna de las claves centrales y finalmente el colapso, al menos parcial, de la estructura, algo que se podría evitar dando un peso adecuado a las claves. El cálculo de estas se lleva a cabo con una fórmula no proporcional, ya que, como ha señalado Huerta ${ }^{381}$, se trata de un problema que tampoco es proporcional. La estabilidad del conjunto depende de tres factores: el peso de los nervios, el de las claves y el de la superficie del casco de bóveda construido. El cálculo de los nervios, como hemos visto, se realiza proporcionalmente, pero estos representan en el conjunto un peso mucho menor que el del casco (Huerta lo estima en torno a la décima parte). El espesor de este es constante en las bóvedas tardogóticas españolas (en torno a $1 / 2$ y $2 / 3$ de pie, 00.14 y $0.19 \mathrm{~m}$ ), por lo que al aumentar el tamaño de la bóveda el peso de la plementería crece con la superficie. Si utilizáramos un cálculo proporcional para las claves, el peso de estas, como el de los nervios, aumentaría o disminuiría con el volumen, por lo que podría resultar una clave excesivamente pesada, o, por el contrario, demasiado ligera. La fórmula propuesta constituye una aproximación empírica a este problema de diseño.

\subsection{Jarjamentos o jarjas. Plementería}

En el texto no se proporciona ninguna información relativa al diseño de los "jarjamentos", esto es, las jarjas o, en francés, tas de charge. De la ilustración recogida en el folio $25 \mathrm{r}$ se pueden extraer algunas conclusiones al respecto, que veremos más adelante.

Tampoco se ofrece ninguna orientación sobre el dimensionado y la disposición de la "plemeteria" o plementería. Como hemos visto más arriba, el peso del casco de la bóveda no es contemplado explícitamente en las fórmulas para el cálculo de los nervios y claves, asumiendo quizás de manera implícita que su grosor es más o menos constante con independencia del tamaño de la bóveda, como efectivamente se demuestra en los edificios de la época (en torno a $1 / 2$ y $2 / 3$ de pie, 00.14 y 0.19 m) ) $^{382}$. La única alusión a ella pone de manifiesto la concepción básica de todo el sistema estructural gótico, esto es, la concentración de los empujes en los ángulos de la bóveda: "Porque a la pared no la puede el casco de la capilla apartar, por mala que sea la montea" (cap. 6: 22v). Efectivamente, el empuje que ejerce la plementería de una bóveda de crucería sobre los muros es mínimo, algo que queda demostrado por el hecho de que en muchos casos llega a formarse una grieta entre ambos ${ }^{383}$.

\footnotetext{
380 Huerta 2002: 581-583; Huerta 2006: 27-28; Huerta 2013: 109.

381 Huerta 2013: 116-118.

382 Huerta 2013: $116-118$.

383 Heyman 1999a: 61-64, 77-82; Huerta 2013: 110.
} 
No tenemos noticia de demasiados documentos en los que se recojan los criterios de diseño dados por Rodrigo Gil para la construcción de alguna de sus bóvedas. En este sentido, son excepcionales las condiciones para la ejecución de las bóvedas de las capillas hornacinas de la girola de la catedral de Segovia, dadas en 1591; algunos autores ${ }^{384}$ defienden que están basadas en otras previas redactadas por Rodrigo Gil, aunque Rodrigo del Solar era maestro de las obras desde 1590. En cualquier caso pueden ser ilustrativas de los modos de construcción de la época. Por lo que respecta a la plementería, en dichas condiciones se especifica que los cruceros o diagonales deben tener una cola de $1 / 2$ pie $(0.14 \mathrm{~m})$ para facilitar la colocación de la plementería, también de piedra. Las piezas utilizadas para la ejecución de esta deben tener un espesor de $3 / 4$ de pie $(0.21 \mathrm{~m})$ y un ancho entre $3 / 4$ y 1 pie $(0.21$ y $0.28 \mathrm{~m}$ respectivamente), estando dispuestas por "galgas" $\circ$ hiladas bien definidas. El relleno de los riñones de las bóvedas se ha de realizar con mampostería de cal y canto, elevándose hasta un tercio de la altura de la bóveda; dado que las jarjas ya habían sido previamente construidas, Huerta ${ }^{385}$ interpreta que dicho dato se refiere al tercio de la distancia entre el lecho superior del jarjamento y la clave central, lo que representaría según él un relleno algo inferior a la mitad de la altura total de la bóveda. Finalmente se señala que se deben colocar las cubiertas antes de comenzar la construcción de las bóvedas, a fin de evitar que la filtración del agua de lluvia las ensucie.

\subsection{Rampante}

Como hemos comentado, en el texto se designa con el término "rampante" tanto la línea que configura el espinazo de la bóveda (cap. 2: 5r; cap. 6: 21 v-22r) como el nervio de ligadura que puede disponerse a lo largo de dicha línea (cap. 6: 24r, ilustración 25v) ${ }^{386}$. Ya hemos presentado al tratar de los nervios la regla de dimensionado que se ofrece para este último (ilustración 25v). Vamos a referirnos ahora al rampante como línea de espinazo de la bóveda. Tomado en este sentido, el trazado del rampante es, junto al del arco diagonal o crucero, uno de los aspectos que en mayor medida condicionan la forma de una bóveda de crucería.

A pesar de su capital importancia, las alusiones al rampante en la parte del manuscrito atribuida a Rodrigo Gil son escasas. En los folios $21 \mathrm{v}-22 \mathrm{r}$ (cap. 6), aunque de modo algo confuso, se ofrecen algunas consideraciones de carácter general relativas al trazado del conjunto de las bóvedas de un templo, defendiendo la utilización de un rampante "a rreGla" u horizontal en el sentido longitudinal de la nave, y otro curvo en el transversal: "Quando vbiese de ser, a de ser debajo de 2. lineas, vna en largo Recta a nibel, (esto es bueno) $Y$ otra en el ancho curba. $Y$ que lo supremo de la colateral, sea el arco que topa con la maior, a manera de capialçada" (cap. 6: 22r). Del texto se deduce que este rampante curvo transversal está referido a una iglesia de tres naves levantadas a la misma altura, en la que la línea de espinazo forma una curva continua que abarca las tres bóvedas de cada tramo, resultando que las bóvedas laterales tienen un rampante asimétrico, capialzado o levantado en la parte que limita con la nave central y más bajo en la contraria. Curiosamente, en la obra construida por Rodrigo Gil encontramos utilizado de modo casi

\footnotetext{
384 Huerta 2013: 126-129; Ruiz 2003.

385 Huerta 2013: 126-129.

386 El término "ligadura" es un galicismo introducido en el siglo XIX para diferenciar la línea de espinazo del nervio que la materializa (Gómez 1998: 124-130).
} 
invariable un rampante transversal independiente para cada bóveda, y no uno común a las tres como se prescribe en este pasaje.

El único dato concreto relativo al trazado del rampante de las bóvedas se proporciona con relación a uno de los modelos de templo propuestos en el texto, una iglesia de una nave con capillas entre contrafuertes (cap. 2: $5 r-6 r$, ilustración $6 r$ ). Se especifica de nuevo que en el sentido longitudinal de la nave es "a ReGla" u horizontal, y en el transversal es curvado, con una curva de diámetro 100 pies (cap. 2: 5r); si consideramos cada tramo de 40×30, el diámetro que correspondería a un arco diagonal semicircular sería de 50, la mitad de lo propuesto para el rampante. Esta prescripción coincide con la dada por Hernán Ruiz "el Joven" en su tratado de hacia mediados del siglo XVI, que presenta un modelo de bóveda de crucería de cinco claves cuyo rampante tiene un diámetro que duplica al de la diagonal ${ }^{387}$; y con la relación encontrada en algunas bóvedas de la época, como la que, en la catedral de Sevilla, cubre el tramo del presbiterio contiguo al crucero, también de cinco claves, cuya montea, realizada entre 1499 y 1504, se conserva en las azoteas del templo ${ }^{388}$.

\subsubsection{Construcción y montaje de la bóveda}

La segunda parte de la sección (cap. 6: 24r-25v) se dedica a describir el método a seguir para la construcción y el montaje de una bóveda de crucería, ilustrándose con un dibujo o "demostracion" (ilustración 25r).

El texto advierte inicialmente de la dificultad que reviste para los legos la materia en cuestión, asumiendo que no resulta posible la transmisión de estos conocimientos sin que medie la experiencia práctica (cap. 6: 24r-24v). Se omite cualquier explicación referida a las fases iniciales de la construcción: no se recoge el procedimiento necesario para llevar a cabo la montea de la bóveda, esto es, la generación geométrica a escala natural del trazado general y el de cada una de sus piezas, tanto en planta como en alzado o sección. Consiguientemente, tampoco se describe el método que sería utilizado a continuación para la confección de plantillas, baiveles y saltarreglas o escuadras falsas, necesarias para el traslado de los datos geométricos de la montea a las piezas a tallar.

A continuación comienza la explicación de la ilustración citada, en la que aparece una bóveda de crucería dibujada en planta, constituida por arcos diagonales, terceletes sencillos en la dirección de ambos ejes y un cuadrifolio de hojas conopiales, en cuyo interior se dispone un círculo; debemos observar que el uso de círculos en torno al polo es poco habitual en las bóvedas de Rodrigo Gil, si bien encontramos excepciones relevantes, como las bóvedas de la nave central de la Catedral Nueva de Salamanca, o la del tramo cuadrado de la cabecera de la catedral de Ciudad Rodrigo (Salamanca). La sección de uno de los arcos diagonales se representa abatida sobre el propio arco, coincidiendo su trasdós con los vértices de la bóveda y asumiéndose su trazado como semicircular (ilustración 25r). Sobre el dibujo, que se relaciona con el texto por medio de letras y números, se realiza una descripción de algunos de los elementos constructivos que componen la bóveda de crucería y se explica el método a seguir en su montaje. A pesar de su carácter didáctico, el texto requiere para su comprensión de unos conocimientos previos de cantería por parte del lector, ya que omite muchas aclaraciones previas que seguramente estima innecesarias.

\footnotetext{
387 Palacios 2009: 91-93; Rabasa 1996: 427-429; Ruiz el Joven 1559: 46v.

388 Pinto y Jiménez 2016: 457, 463.
} 
Consideramos interesante indicar el significado de cada una de estas letras o números, recogiendo los términos procedentes del texto original junto con su equivalencia actual, a fin de ilustrar el vocabulario constructivo de la época. Los términos se enumeran de acuerdo al orden de aparición en el manuscrito.

\subsection{Terminología}

En el texto se describen los siguientes elementos constructivos, aunque no se precisan los procesos materiales de trazado y talla a través de los cuales se llega a su obtención:

- C (planta y sección): "claue maior" (clave central).

- G (planta y sección): "garjamentos" ○ "jarjamentos" (jarja o tas de charge), en los que se observan sus "abançamentos" (lechos horizontales dispuestos en vuelos sucesivos o "por abanço") y "salmeres" (porción del lecho superior de la jarja cortado en plano inclinado de donde arrancan propiamente las dovelas de los arcos de la bóveda).

- D (sección): "linea curba diagonal, que haçe el casco de la capilla" (línea curva que describe la superficie de la bóveda sobre su arco diagonal).

- ○_(sección): "orejillas" (ángulos sobresalientes) de que está provista la "moldura" (parte moldurada correspondiente a una dovela o clave que queda vista desde la parte inferior de la bóveda una vez terminada esta) del "cruçero", "cruzero" ○ "diagonal" (arco crucero, diagonal u ojivo). Por encima de la "curba diagonal" los "cruçeros" y "claues" están provistos de una "cola" (parte superior cortada en forma de cuña que queda oculta una vez construida la bóveda). Sobre las orejillas y entre las colas cargan las "losas" o "plemeteria" (plementería).

- 1, 2 (sección): "molde" (sección transversal) "jayrado" (asimétrico) de los "combados" (nervios decorativos curvos). La diferencia entre 1 (eje vertical) y 2 (eje radial) representa el "bulco", esto es, "lo que rrequiere bulcar" o "rrebirar" "para que su moldura cayga a plomo" (la deformación necesaria para que el plano de apoyo de la plementería se adapte a la pendiente de la superficie de la bóveda en cada punto manteniéndose vertical el plano medio del nervio). Se trata de una de las escasas alusiones concretas a la generación geométrica de los elementos de la bóveda que aparecen en el texto.

A continuación se expone en el manuscrito el proceso de montaje de la bóveda, en lo referente a la disposición de los andamios, el replanteo sobre ellos de la bóveda, la colocación de las cimbras para las claves y el montaje de estas. Los elementos auxiliares a los que se alude son los siguientes:

- m (sección): "maças", "mazas" o "pies đros. [diestros]" (mazas o pies derechos) "para asentar las claves" (para apear las claves durante el montaje de la bóveda).

- G (planta): "andamio" (para el montaje de la bóveda) (queda representado en sección por la diagonal en planta de la bóveda, línea común para ambos dibujos).

- S (sección): "segundo andamio" (para el montaje de la bóveda). 
- B-C (planta): "çercha" ○ "zercha" (cercha ○ patrón de madera de contorno curvo para replantear las claves que se encuentran en la línea del espinazo de la bóveda durante el montaje de esta).

- T (sección): "pedaçito de tablon" (trozo de tablón), "para que mejor asiente la tortera de la claue que es lo que cuelga de la moldura abajo" (para apoyar la base de la clave sobre la maza durante el montaje de la bóveda).

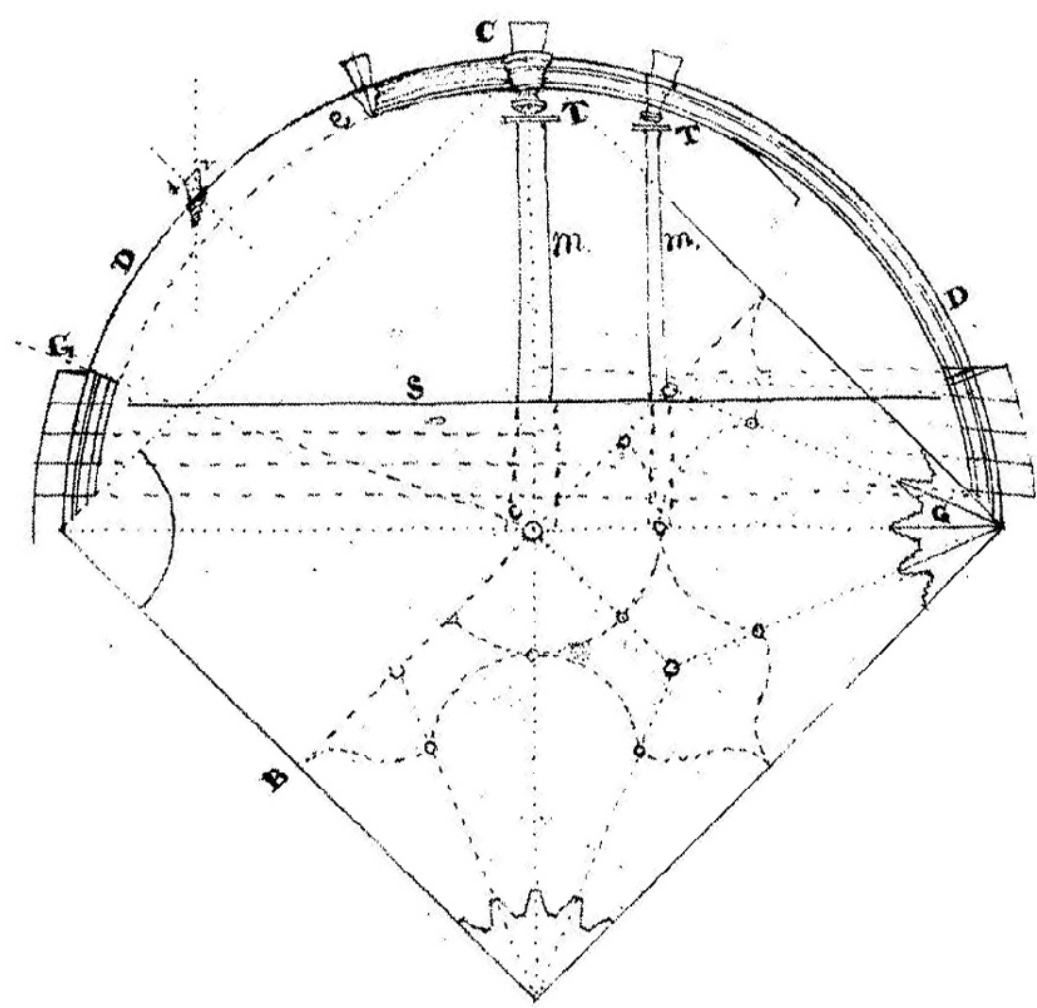

Figura 47. llustración 25r (García 1681). Se ha rotado $45^{\circ}$ con respecto a su disposición original en el manuscrito. Elementos constructivos: C: "claue maior" | G: "garjamentos" o "jarjamentos" con sus "abançamentos" y "salmeres" | D: "linea curba diagonal, que haçe el casco de la capilla" | o: "orejillas" de la "moldura" del "cruçero", "cruzero" o "diagonal"; "cola" de los "cruçeros" y "claues"; "losas" o "plemeteria" | 1, 2: "molde" "jayrado" de los "combados"; diferencia 1-2: "bulco" - Montaje: m: "maças", "mazas" o "pies đros. [diestros] para asentar las claves" | G: "andamio" | S: "segundo andamio" | B-C: "çercha" o "zercha" | T: "pedaçito de tablon", "para que mejor asiente la tortera de la clave"

\subsection{Descripción del proceso}

De acuerdo con la descripción dada por Rodrigo Gil el montaje de la bóveda se desarrollaría del siguiente modo. Se coloca un primer "andamio", "al nibel de donde comiençan a mober las bueltas" (cap. 6: 24v-25r), esto es, a la altura de la imposta de donde arranca la bóveda. Se trataría de una estructura de madera, que se levantaría directamente desde el suelo o quizás se apoyaría en algunos casos en los muros laterales, particular que ha sido investigado en el ámbito del gótico clásico francés por Fitchen ${ }^{389}$. 
Desde este andamio se montarían los "jarjamentos" o jarjas, sobre cuya disposición no se da ninguna información, tal vez por considerarse sencilla al estar formadas por hiladas horizontales. De la ilustración, sin embargo, pueden extraerse algunas informaciones relativas a su trazado y construcción. En primer lugar, en el dibujo en planta se representan tres fases consecutivas para la talla de una de sus piezas: una primera en la que se muestra el volumen del que se parte para la labra del conjunto, representado por una envolvente semicircular; una fase intermedia donde se ha individualizado ya el sólido capaz que corresponde a cada nervio; y otra final en la que se han ejecutado las molduras de cada uno de ellos. A pesar de la corrección del resto del dibujo, la proyección en planta y en sección de estas piezas no se corresponde, mostrándose en planta mucho más grande, quizás para ilustrar mejor el aspecto referido. Por otro lado, en la sección se pueden observar las distintas hiladas horizontales que componen la jarja, y el lecho superior de la más elevada de ellas, con su salmer cortado radialmente hacia el centro de la bóveda, circunstancia que se indica adecuadamente con una línea de puntos, y destinado a recibir la primera de las dovelas del arco diagonal. Debemos recordar que la función de las jarjas y de los rellenos de mampostería de los senos de la bóveda es reducir la luz efectiva de esta, convirtiendo en rebajados los arcos que la componen, que pueden mantener su estabilidad con un espesor mucho más bajo, produciéndose un importante ahorro de material ${ }^{390}$.

La colocación de la cimbra para la bóveda no se hace directamente sobre esta plataforma de trabajo, sino sobre un "segundo andamio", construido, según indica el dibujo, a la altura del lecho inferior de la última pieza que compone la jarja, esto es, el último que es horizontal en toda su superficie. La razón de no hacerlo desde el andamio principal es "porque alli estará vajo, por allarse los jarjamentos con sus abançamentos mas altos, Y no se alcançará a asentar los cruzeros sobre ellos" (cap. 6: 25r). Pensemos que las jarjas pueden ser elementos constructivos de considerable elevación; en la ilustración la altura a la que se coloca el segundo andamio equivale aproximadamente al $27 \%$ de la altura total de la clave central. Si tomamos una bóveda de planta cuadrada de 30 pies de lado $(8.36 \mathrm{~m}$ ) y diagonal semicircular, la jarja correspondiente tendría $1.60 \mathrm{~m}$ de altura, por lo que sus piezas podrían colocarse sin problema trabajando sobre el andamio principal situado en la línea de imposta.

El segundo andamio se concibe como una superficie totalmente entablada, a fin de poder realizar sobre ella el replanteo de la bóveda, esto es, el trazado de su dibujo en planta a escala natural. Una vez "señaladas todas las claues en su lugar sobre los tablones" (cap. 6: $25 r$ ), esto es, localizada la posición de las claves, se comienzan a colocar sus apeos, para lo cual, aunque no se especifique en el texto, será necesario conocer previamente la altura que corresponde a cada una de ellas, dato que se toma sin duda de la montea del alzado de la bóveda, realizado en la obra a escala natural, sobre el suelo o sobre una pared. En este sentido la explicación que se ofrece es algo fragmentaria, y puede ser interpretada a nuestro juicio del siguiente modo.

En el caso de los arcos cruceros o diagonales se especifica que, hecho el replanteo de sus claves, se deben colocar "las maças o pies đros. [diestros] para asentar las claues antes que cruzero alguno. Para cortarlas al alto que requieren" (cap. 6: 24v) es necesario tomar los datos del dibujo a escala real, para lo cual se debe "dejar caer perpendiculos, de la buelta a ellas [las claves en planta]" (cap. 6: 25r), lo que en otro lugar se define como "el tirar de los cordeles" (cap. 6: 24v). Las alturas se tomarían del dibujo por medio de un "cordel", si el 
trazado se ha realizado sobre un pavimento, o con un "perpendículo", "plomo" o plomada, si el dibujo se ha hecho sobre una pared. Una vez cortada cada maza con su tamaño correspondiente, se colocarían sobre su posición señalada en planta, utilizando este mismo perpendículo para comprobar su verticalidad. En ningún momento se alude a la utilización de ningún otro tipo de cimbra para estos nervios. Debemos señalar que la clave intermedia del arco diagonal, representada en sección sobre una de las mazas designadas como m, tiene su eje inclinado, es decir, orientado hacia el centro del arco; sin embargo, la práctica habitual observada en las bóvedas de crucería de Rodrigo Gil es que las claves tengan su eje vertical, siguiendo la tradición medieval.

El siguiente paso consiste en la construcción de una "çercha" o cercha, entendida con el sentido de un patrón de madera de contorno curvo, destinada a colocarse en la línea del espinazo de la bóveda, abarcando la distancia que va desde la clave central hasta la de cada uno de los arcos del perímetro. Esta cercha tiene como objetivo dar la forma adecuada a la ligadura que configura el rampante en la bóveda, especificándose que, una vez colocada, se debe "dejar caer plomos a las claves que estan señaladas en los tablones, y aquello será el largo de cada maça" (cap. 6: 25v). Parece sugerirse que la longitud de cada una de ellas se toma directamente en obra en lugar de acudir al dibujo, algo que también se podría interpretar al leer el pasaje previo referido a las mazas de las claves de los arcos diagonales.

Desde un punto de vista constructivo, si las alturas de las claves del arco crucero se replantean sin la ayuda de una cercha, no parece tener mucho sentido que esto sí se haga para las del rampante, habida cuenta de que el correcto trazado de uno y otro están asegurados siempre por los datos de la montea, sean estos trasladados individualmente para cada clave con un cordel $\circ$ un perpendículo $\circ$ en conjunto con una cercha. La convivencia de ambos sistemas en la construcción de la misma bóveda, en lugar de la utilización de uno solo de ellos, no resulta, a nuestro juicio, coherente.

Por lo que respecta a la forma de la cercha, esto es, la del rampante de la bóveda, se especifica que se debe trazar "con la buelta de la diaGonal" (cap. 6: 25r), es decir, con el mismo radio que el arco crucero. Esta circunstancia ha sido motivo de largas reflexiones por parte de los estudiosos ${ }^{391}$, ya que la bóveda resultante sería baída, esto es, un hemisferio cortado por cuatro planos verticales paralelos entre sí dos a dos. Palacios ${ }^{392}$, al analizar la ilustración de esta sección (ilustración 25r), ha indicado que los elementos designados como 1, 2 y como o _representarían las claves del arco formero y del tercelete, dibujadas en alzado a lo largo del recorrido del arco diagonal, coincidente con el trazado del rampante, si bien en el texto se dice expresamente que dichos elementos corresponden, respectivamente, al molde revirado de los combados y al del arco crucero, como hemos indicado con anterioridad. Por su parte, Huerta ${ }^{393}$ ha visto en la utilización de este rampante la descripción de un método simplificado por parte de Rodrigo Gil, a fin de evitar explicaciones ulteriores sobre el trazado de aquel a personas legas; sin embargo, si la bóveda de crucería tiene la forma de un casquete esférico, los arcos diagonales, terceletes, perpiaños y formeros serán lógicamente circulares, pero sus radios serán todos distintos, lo cual aumenta la dificultad de su construcción; por el contrario, si todos los arcos de la bóveda se trazan con el mismo radio, el de la diagonal, la talla de las piezas se

\footnotetext{
391 Gómez 1998: 124-130.

392 Palacios 2006: 2420; Palacios 2009: 90.

393 Huerta 2013: $118-123$.
} 
facilitará en gran medida, resultando un rampante llano; finalmente, antes señalábamos el hecho de que el texto, a pesar de su carácter didáctico, asume unos determinados conocimientos de cantería en el lector, que sin duda deben incluir una cuestión tan básica como esta.

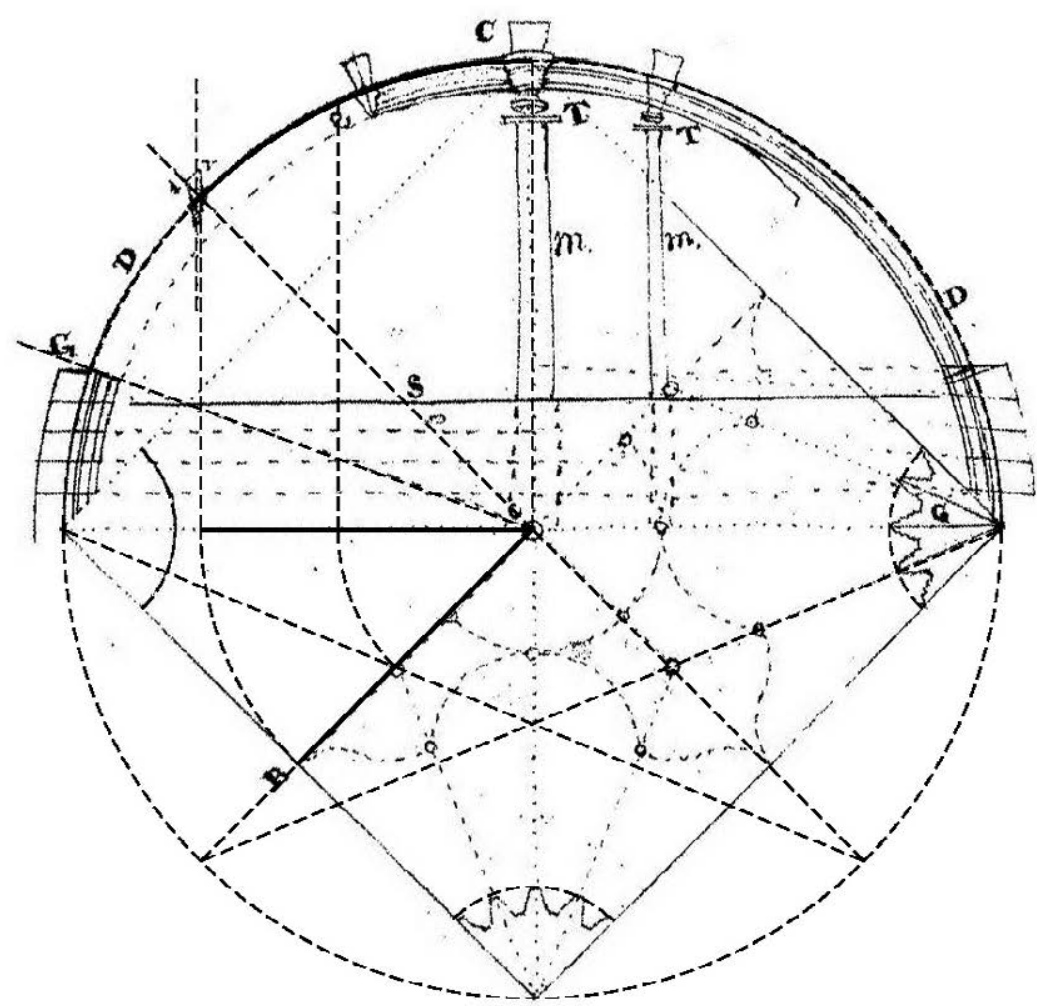

Figura 48. llustración 25r (García 1681). Se ha rotado $45^{\circ}$ con respecto a su disposición original en el manuscrito. Se puede comprobar sobre el dibujo que los terceletes se sitúan en la bisectriz del ángulo formado por los arcos del perímetro y las diagonales. Se ha dibujado sobre la planta la proyección del rampante de la bóveda, así como el abatimiento de este sobre la diagonal en planta y sección, comprobándose que el nervio designado como 1, 2 correspondería por su posición a la clave de los arcos perpiaños y formeros (P. Moreno)

Como ya hemos comentado, el único dato concreto recogido en el Compendio para el trazado del rampante le asigna un diámetro doble que el de la diagonal semicircular, coincidiendo en este sentido con la bóveda de crucería incluida en el tratado de Hernán Ruiz "el Joven" 394 , así como con la citada montea de la bóveda que cubre el tramo del presbiterio contiguo al crucero de la catedral de Sevilla ${ }^{395}$, de mediados y principios del siglo XVI respectivamente. Si examinamos la obra construida por Rodrigo Gil, ninguna de las bóvedas de crucería que conocemos tiene forma esférica: el rampante de sus bóvedas tiene habitualmente un radio bastante mayor que el de la diagonal, y en muy pocas ocasiones todos los arcos del perímetro de la bóveda son semicirculares.

Todo ello podría indicarnos que la identificación como baída de la bóveda recogida en el manuscrito constituye una interpolación realizada por Simón García, planteándose incógnitas con respecto a la cantidad de información añadida o alterada en la copia del

394 Palacios 2009: 91-93; Rabasa 1996: 427-429; Ruiz el Joven 1559: 46v.

395 Pinto y Jiménez 2016: 457, 463. 
manuscrito original, tanto en lo referido al texto como a la ilustración. En este sentido, es interesante analizar la bóveda que cubre la capilla central de la girola de la Catedral Nueva de Salamanca, denominada del Cristo de las Batallas y construida en algún momento entre 1658 y 1713. Como ha observado Palacios ${ }^{396}$, la bóveda tiene un diseño en planta cercano al del Compendio, forma esférica y claves de eje inclinado. Debemos recordar que Simón García trabajó en la fábrica de la Catedral Nueva aproximadamente entre 1661 y 1679, por lo que hay ciertas posibilidades de que la bóveda estuviera en construcción durante ese periodo.

En cualquier caso, y para recapitular, sobre el segundo andamio se replantea la posición de las claves que corresponden a los arcos diagonales, a los del perímetro y a las ligaduras de la bóveda, disponiendo en posición vertical sus correspondientes mazas. No se recoge ninguna indicación respecto a la colocación de las claves secundarias situadas en los terceletes, quizás entendiendo que, como en el caso de los arcos diagonales, se resuelve de nuevo con mazas verticales y no con cerchas. Hecho esto se especifica que cada maza, "a la caveza alta llevará un pedaçito de tablon, bien clauado, y Grueso, para que mejor asiente la tortera de la clave que es lo que cuelga de la moldura abajo" (cap. 6: 25v), es decir, que cada maza va rematada en su parte superior por un tablón que facilita el apoyo de la tortera, esto es, la base de la clave, en forma de disco normalmente decorado con relieves tallados, e independiente de la moldura que en ocasiones circunda el cilindro central. En la ilustración se aprecia con claridad que dichos tablones se colocan en posición horizontal en cada maza, sin indicarse en el texto la circunstancia de que las torteras se disponen con frecuencia inclinadas, paralelas a la superficie de la bóveda en cada punto, algo que observamos de modo casi invariable en las construidas por Rodrigo Gil. Por esta razón, y si tomamos en consideración el tamaño real que puede tener cada una de estas claves, sería necesario un cuidadoso acuñado de cada una de ellas, a fin de asegurar su posición y evitar su movimiento o giro durante la colocación de las dovelas de los arcos. De hecho, al examinar toda esta estructura auxiliar de pies derechos debemos tener en cuenta su entidad. Si tomamos de nuevo una bóveda de planta cuadrada de 30 pies de lado (8.36 $\mathrm{m})$ y diagonal semicircular, desde el segundo andamio, dispuesto a $1.60 \mathrm{~m}$ de altura de su arranque, todavía quedará una altura de $4.31 \mathrm{~m}$ hasta la clave central, por lo que será necesaria la utilización de caballetes y escaleras que permitan la disposición de todas las piezas, si bien la precaución de disponer ese segundo andamio evita que dicha altura sea de $5.91 \mathrm{~m}$. Este sistema de doble andamiada sería probablemente habitual en la época, confirmándose su utilización en los documentos ${ }^{397}$, y su lógica queda demostrada por el hecho de que ha sido empleado en ámbitos geográficos y temporales totalmente distintos, como por ejemplo en la reconstrucción de bóvedas góticas en Alemania tras la Segunda Guerra Mundial ${ }^{398}$.

Sobre las mazas, rematadas con sus correspondientes tablones, se irían colocando las claves. Para la disposición del resto de las piezas de la bóveda, esto es, por un lado las dovelas que conforman los arcos, las ligaduras y los nervios decorativos curvos, y por otro la plementería, no se da la menor información. Por lo que respecta a la terminología, se define como "pie de Gallo" al remate, de planta conopial, de los combados en las zonas cercanas a las claves de los arcos del perímetro.

\footnotetext{
396 Palacios 2009: 90-91, 188-190.

397 Rokiski 1980.

398 Huerta 2013: 11 8-123; Huerta y Ruiz 2006: 1625.
} 
Finalmente, y a colación de las claves, se hace en el texto una última observación, señalándose que "abarrenanse algunas claves por $\mathrm{m}^{\circ}$ [medio] de abajo a Riva y estos agujeros sirben para limpiar la capilla, o para colgar lamparas, o para deshaçer los andamios de tha [dicha] capilla" (cap. 6: 25v). El montaje de la plataforma principal de trabajo y del segundo andamio se habría realizado quizás disponiendo la maquinaria necesaria (tornos, polipastos) sobre las armaduras de cubierta, elevando desde allí tanto la madera necesaria para las cimbras como las distintas piezas que componen la bóveda de crucería, ya terminadas y dispuestas para su colocación en obra. También existe la posibilidad de que el izado de materiales se realizara desde el segundo andamio ${ }^{399}$. Una vez terminada la bóveda, el texto apunta la posibilidad de mantener en el trasdós de la bóveda esta maquinaria para el desmontaje de la andamiada, pasando las cuerdas a través de dichos agujeros, que pueden además emplearse posteriormente para ejecutar labores de mantenimiento, limpieza y pintura, o para armar el monumento el día de Jueves Santo, elevando de nuevo otra plataforma, de mayor o menor entidad. Debemos señalar que en las bóvedas realizadas por Rodrigo Gil las claves nunca se barrenan, encontrándonos como únicas excepciones las de las bóvedas de la iglesia de San Pedro Apóstol en Fuente el Saz de Jarama (Madrid) ${ }^{400}$.

\footnotetext{
399 Huerta 2013: 118-123; 126-129.

400 También encontramos taladros practicados en las claves de las bóvedas de la cabecera de la iglesia de San Juan de Puerta Nueva en Zamora y en las del crucero y la cabecera de la iglesia de Santa Ana en Peñaranda de Duero (Burgos), pero en ambos casos parece tratarse de perforaciones parciales, que no atraviesan la totalidad de las piezas, realizadas para sujetar elementos decorativos en la parte inferior de estas. Por otro lado, Rabasa (1996: 426, 426 fig. 4) indica que algunas claves de la catedral de Segovia presentan una perforación; aunque no especifica cuáles, se trata probablemente de las que corresponden a los polos de las bóvedas de algunas de las capillas hornacinas de la girola, ajenas a nuestro estudio (el resto de las bóvedas de este edificio no presentan aparentemente taladros).
} 
2.2. APLICACIÓN PRÁCTICA DE LAS REGLAS 

Una vez identificados los distintos procedimientos de diseño, tanto arquitectónico como estructural, recogidos en la parte del Compendio atribuida a Rodrigo Gil, hemos procedido a investigar su aplicación práctica en algunos edificios trazados por este maestro. Para ello hemos analizado las condiciones geométricas que definen sus "tramos-tipo", entendiendo como tales al conjunto formado por nave central, laterales y capillas hornacinas entre contrafuertes (cuando estas existen), considerado entre dos pilares o contrafuertes contiguos. Hemos limitado dicho estudio a algunos ejemplos representativos, tomando como criterio discriminatorio su claridad tipológica: todos ellos son tramos intermedios de nave, cubiertos por bóvedas de planta cuadrangular, ya sea cuadrada o perlongada. Los edificios considerados son los siguientes:

- Becerril de Campos (Palencia) - Iglesia de Santa Eugenia.

- Fuenteguinaldo (Salamanca) · Iglesia de San Juan Bautista.

- Guareña (Badajoz) · Iglesia de Santa María de la Asunción.

- Meco (Madrid) - Iglesia de la Asunción de Nuestra Señora.

- Medina de Rioseco (Valladolid) - Iglesia de Santiago de los Caballeros.

- Mota del Marqués (Valladolid) - Iglesia de San Martín.

- Nava del Rey (Valladolid) - Iglesia de los Santos Juanes.

- Salamanca Catedral Nueva.

- Salamanca $\cdot$ Iglesia del monasterio de las Bernardas.

- Segovia $\cdot$ Catedral.

- Tendilla (Guadalajara) • Iglesia de la Asunción de Nuestra Señora.

- Valladolid · Iglesia de Santa María Magdalena.

- Vegas de Matute (Segovia) - Iglesia de Santo Tomás.

- Villacastín (Segovia) · Iglesia de San Sebastián.

- Villamor de los Escuderos (Zamora) - Iglesia de la Asunción de Nuestra Señora.

El análisis de los tramos-tipo utilizados en estos quince edificios religiosos afecta, en primer lugar, a las condiciones geométricas del espacio arquitectónico generado, en lo que se refiere a trazado de la planta (proporciones del conjunto, proporciones de cada tramo cubierto por una bóveda, relación entre las anchuras de las naves) y trazado de la sección (altura de la línea de imposta, relación entre las alturas de las naves, altura de la clave del arco perpiaño de la nave mayor). En segundo lugar, concierne a las dimensiones en planta de los elementos de apoyo y contrarresto (diámetro del pilar; grosor total y ancho del contrafuerte y proporción entre ambos parámetros), deducidas a partir de las condiciones establecidas durante el proceso de trazado arquitectónico previo.

Ambos aspectos son fundamentales para el examen de las bóvedas de crucería, que desarrollamos en otros apartados de este estudio. En efecto, estas cubriciones pétreas no solo condicionan la configuración y dimensiones de los elementos estructurales, como se ha observado habitualmente: el establecimiento de reglas que relacionan la altura de imposta y la de clave con otros parámetros arquitectónicos del edificio supone que las bóvedas son modeladas geométricamente para la consecución de un determinado espacio interior, guardando por tanto relación con este. 

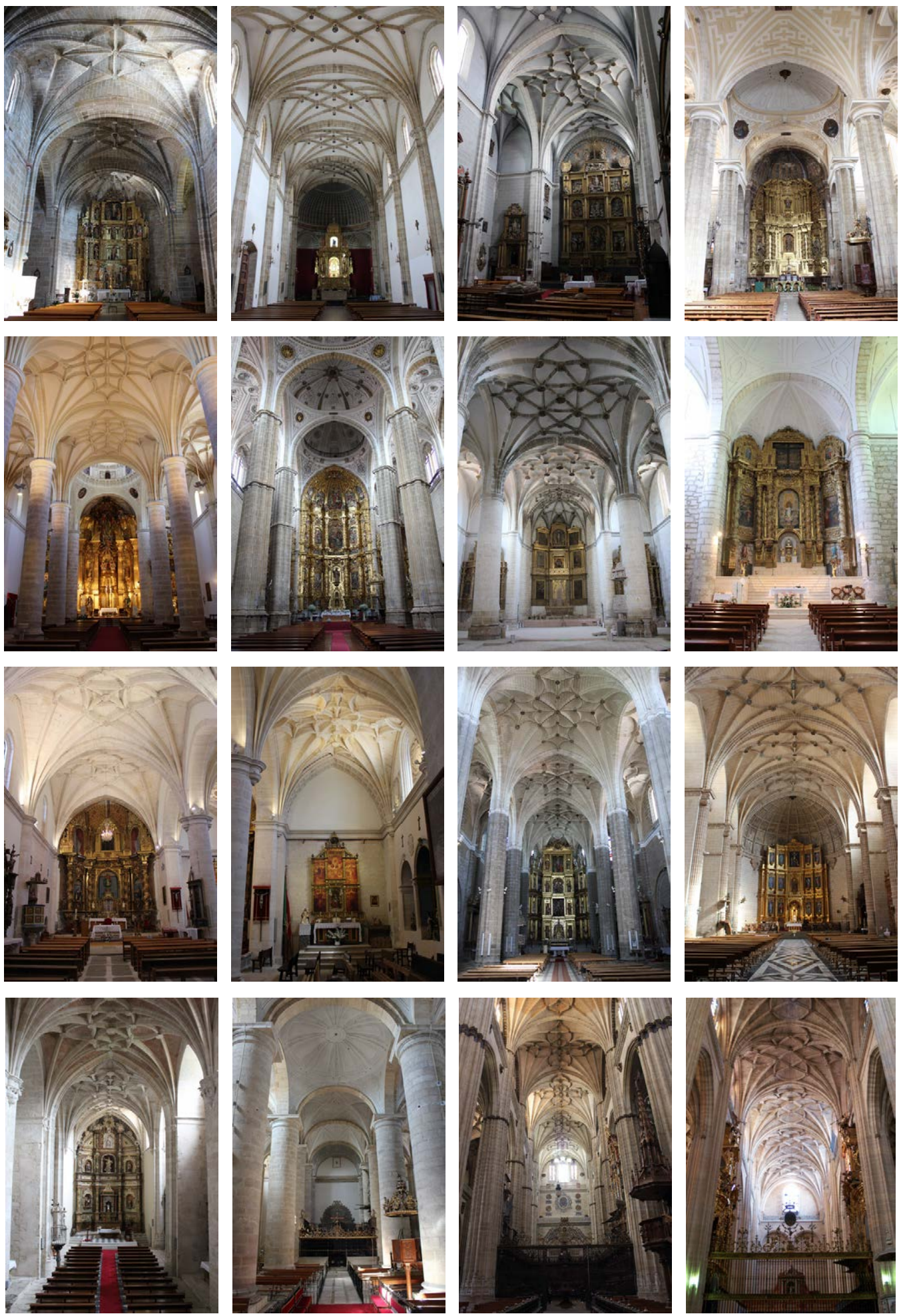

Figura 49. Edificios seleccionados: iglesias de una y tres naves, sin capillas hornacinas entre contrafuertes (a-k) y con capillas hornacinas entre contrafuertes (l-o): (a) Iglesia de San Juan Bautista, Fuenteguinaldo (Salamanca). (b) Iglesia del monasterio de las Bernardas, Salamanca. (c) Iglesia de Santa María Magdalena, Valladolid. (d) Iglesia de Santa Eugenia, Becerril de Campos (Palencia). (e) Iglesia de la Asunción de Nuestra Señora, Meco (Madrid). (f) Iglesia de Santiago de los Caballeros, Medina de Rioseco (Valladolid). (g) Iglesia de San Martín, Mota del Marqués (Valladolid). (h) Iglesia de la Asunción de Nuestra Señora, Tendilla (Guadalajara). (i, i) Iglesia de Santo Tomás, Vegas de Matute (Segovia). (k) Iglesia de San Sebastián, Villacastín (Segovia). (I) Iglesia de Santa María de la Asunción, Guareña (Badajoz). (m) Iglesia de la Asunción de Nuestra Señora, Villamor de los Escuderos (Zamora). (n) Iglesia de los Santos Juanes, Nava del Rey (Valladolid). (ñ) Catedral Nueva de Salamanca. (o) Catedral de Segovia (o: commons.wikimedia.org) 

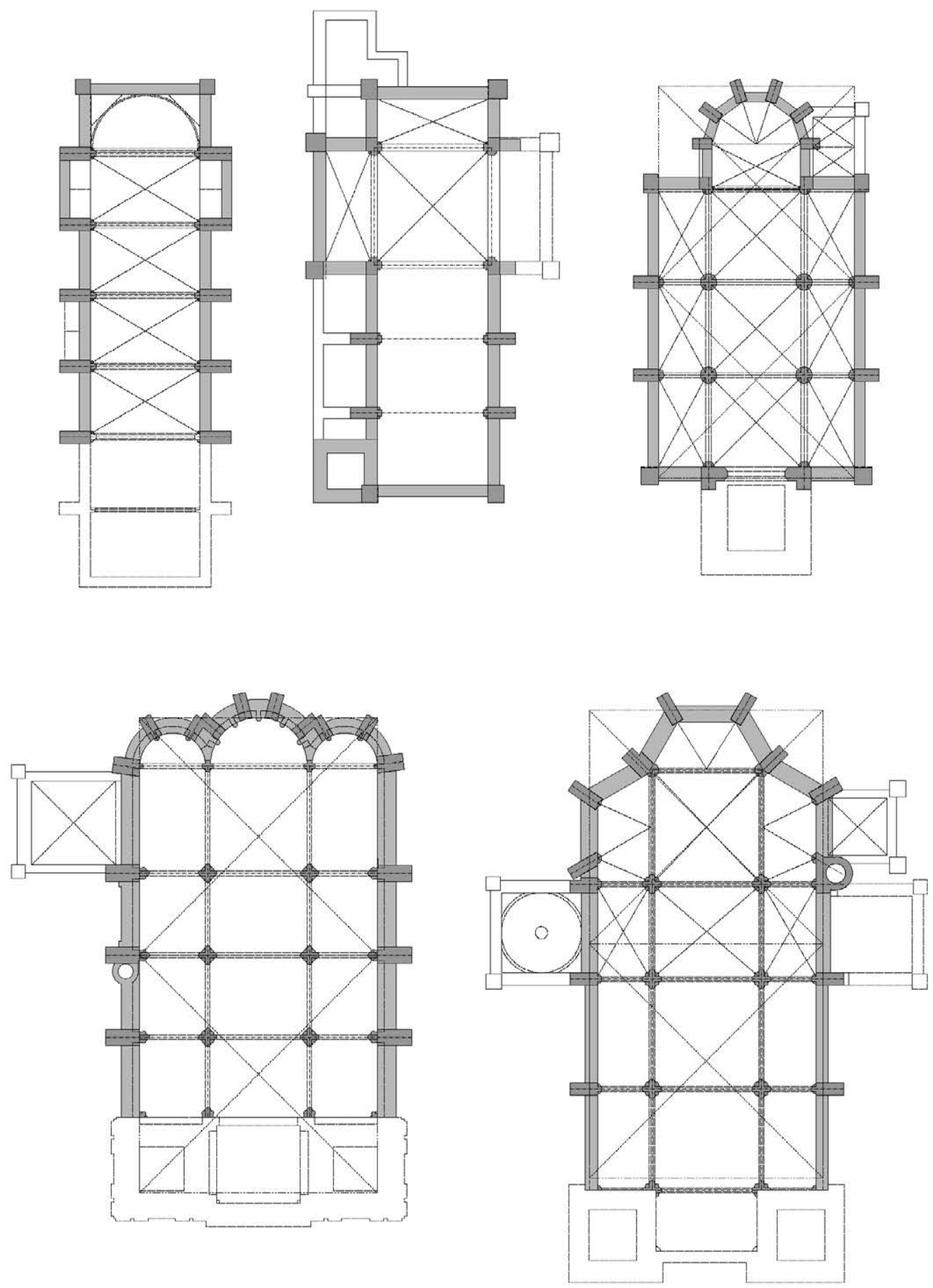

$012345 \mathrm{~m}$

$\sqrt{311014} *$

Figura 50. Configuración en planta de cinco de los quince edificios seleccionados: (a) Iglesia del monasterio de las Bernardas, Salamanca. (b) Iglesia de Santa María Magdalena, Valladolid. (c) Iglesia de San Martín, Mota del Marqués (Valladolid). (d) Iglesia de Santiago de los Caballeros, Medina de Rioseco (Valladolid). (e) Iglesia de San Sebastián, Villacastín (Segovia) (a-e: P. Moreno) 

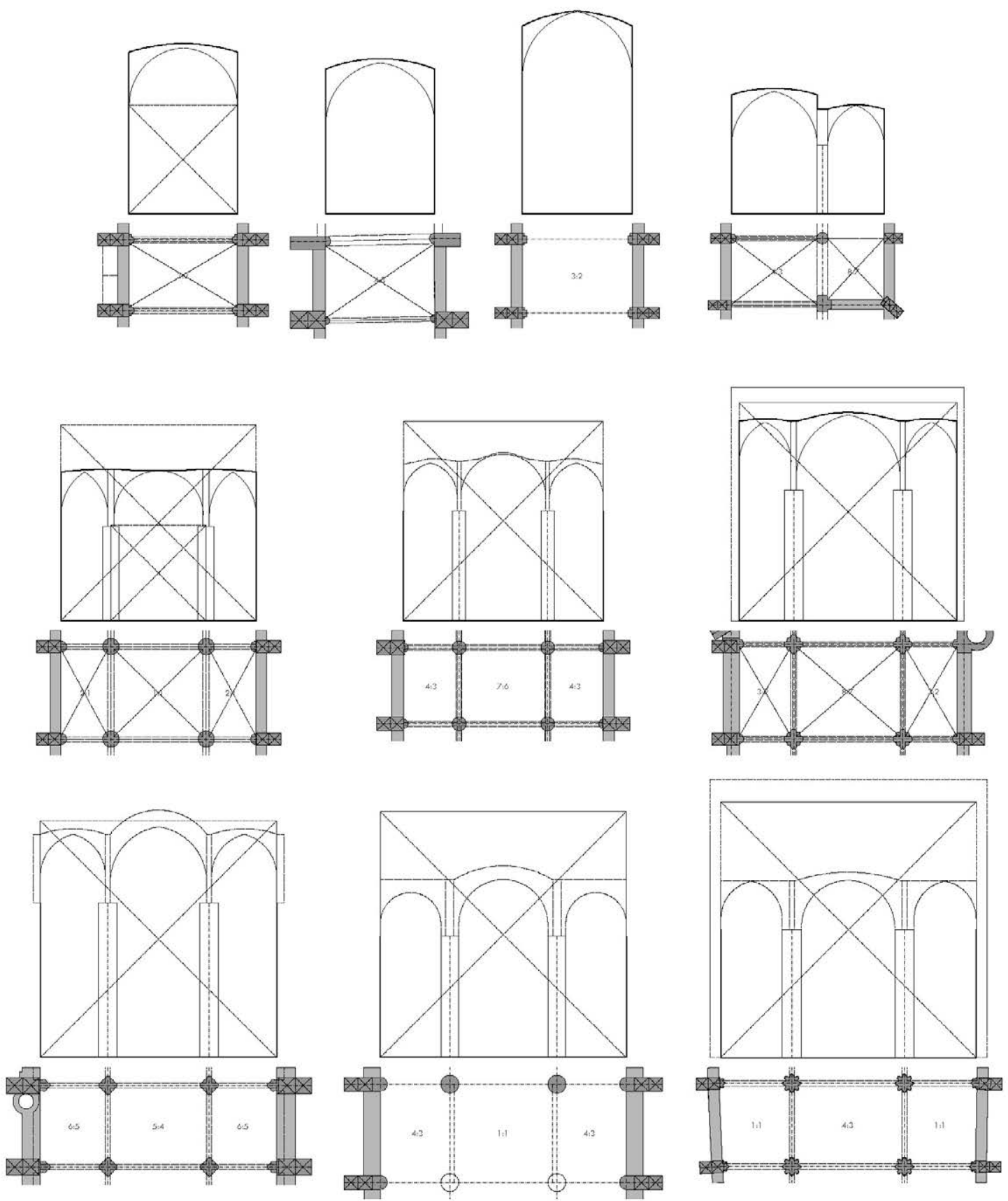

$012345 \mathrm{~m}$

111014

Figura 51. Configuración en planta y sección de los tramos-tipo seleccionados: iglesias de una y tres naves sin capillas hornacinas entre contrafuertes: (a) Iglesia del monasterio de las Bernardas, Salamanca. (b) Iglesia de San Juan Bautista, Fuenteguinaldo (Salamanca). (c) Iglesia de Santa María Magdalena, Valladolid. (d) Iglesia de Santo Tomás, Vegas de Matute (Segovia). (e) Iglesia de San Martín, Mota del Marqués (Valladolid). (f)

Iglesia de la Asunción de Nuestra Señora, Meco (Madrid). (g) Iglesia de San Sebastián, Villacastín (Segovia). (h) Iglesia de Santiago de los Caballeros, Medina de Rioseco (Valladolid). (i) Iglesia de la Asunción de Nuestra Señora, Tendilla (Guadalajara). (i) Iglesia de Santa Eugenia, Becerril de Campos (Palencia) (a-j: P. Moreno) 

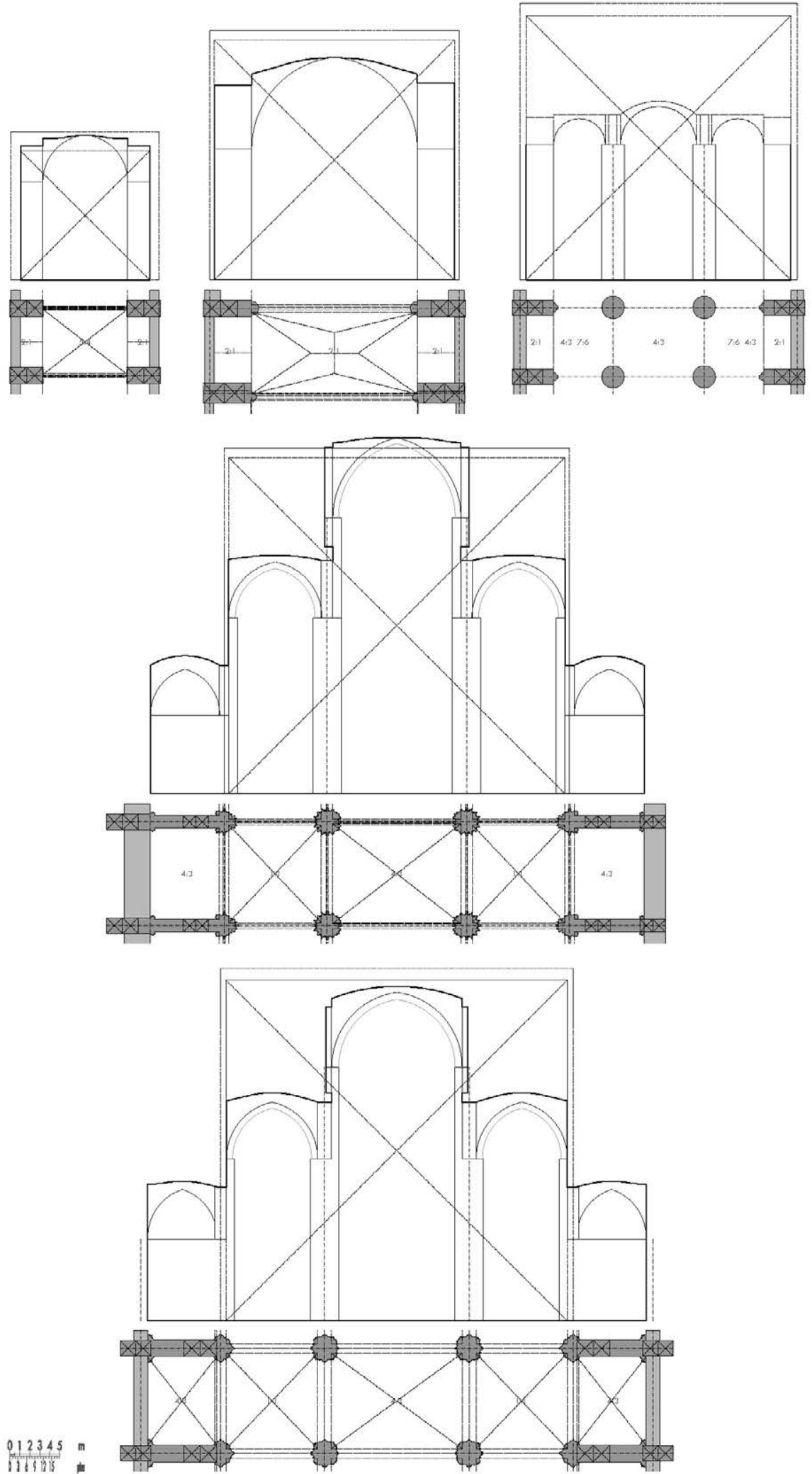

Figura 52. Configuración en planta y sección de los tramos-tipo seleccionados: iglesias de una y tres naves con capillas hornacinas entre contrafuertes: (a) Iglesia de la Asunción de Nuestra Señora, Villamor de los Escuderos (Zamora). (b) Iglesia de Santa María de la Asunción, Guareña (Badajoz). (c) Iglesia de los Santos Juanes, Nava del Rey (Valladolid). (d) Catedral Nueva de Salamanca. (e) Catedral de Segovia (a-e: P. Moreno) 
dada la escasa diferencia entre ellas. Por otro lado, las anchuras interiores parciales de nave y capilla (31.2 y 20.6 respectivamente) y sus luces $(33.1$ y 22.5 respectivamente), indicadas tanto en esta tabla como más abajo, difieren debido a que las primeras están medidas al contorno interior del muro central de separación entre ambos espacios, mientras que las segundas lo hacen al eje del pilar central.

** En la iglesia de San Sebastián en Villacastín (Segovia) existe una pequeña diferencia entre la altura de imposta de los pilares centrales y la de los muros perimetrales (47.6 y 48.8 pies respectivamente), habiéndose consignado la primera de ellas dado que fue fijada con posterioridad a la segunda.

\subsubsection{Trazado de la planta}

Analizamos primero los procedimientos empleados para el trazado en planta de los tramostipo seleccionados, en lo que se refiere a proporciones del conjunto del edificio, proporciones entre las dimensiones de cada tramo cubierto por una bóveda y relación entre las anchuras de las naves.

\subsection{Proporciones del conjunto}

No podemos estudiar las condiciones geométricas de los tramos-tipo sin analizar previamente las proporciones en planta del conjunto del edificio, ya que, como observaremos en el siguiente apartado, en el Compendio se establecen relaciones entre unas y otras que condicionan el trazado de la sección. En el citado texto se presentan cuatro métodos geométricos para el trazado de la planta; tres de ellos se refieren a iglesias de tres y cinco naves, y generan una planta cuya anchura y longitud total guardan una proporción dupla $(2: 1)^{401}$, algo que el autor del manuscrito considera recomendable ${ }^{402}$; el cuarto se refiere a una iglesia de una nave con capillas hornacinas entre contrafuertes, quedando la cabecera y el crucero inscritos en un cuadrado, como ocurre también en uno de los métodos anteriores ${ }^{403}$, y dando como resultado una planta que no es de proporción dupla $(2: 1)^{404}$. Por otro lado, en el Compendio se describen aritméticamente dos modelos de templos, de cinco naves con capillas entre contrafuertes y de tres naves, que presentan igualmente una proporción dupla $(2: 1)^{405}$; y un tercer modelo, de una nave, con una relación $5: 2$, en el que, además, la cabecera y el crucero quedan inscritos en un cuadrado ${ }^{406}$.

Si examinamos los edificios seleccionados, observamos que las iglesias de una nave, con y sin capillas entre contrafuertes, no guardan una relación dupla $(2: 1)$ en planta, sino que presentan proporciones más alargadas: iglesias del monasterio de las Bernardas en Salamanca, de San Juan Bautista en Fuenteguinaldo (Salamanca), de Santa María Magdalena en Valladolid, de Santo Tomás en Vegas de Matute (Segovia), de la Asunción de Nuestra Señora en Villamor de los Escuderos (Zamora) y de Santa María de la Asunción

\footnotetext{
401 García 1681: cap. 5: $11 v-12 v$, ilustración 12r (método 1); cap. 5: 12v-13r, ilustración 13r (método 2); cap. 5: $13 \mathrm{v}-14 \mathrm{v}$, ilustración $14 \mathrm{r}$ (método 3).

402 García 1681: cap. 5: 14v.

403 García 1681: cap. 5: 13v-14v, ilustración 14r (método 3).

${ }^{404}$ García 1681: cap. 5: 14v-15r, ilustración 15r (método 4).

405 García 1681: cap. 2: 6r-7r, ilustración 7r (modelo 5); cap. 6: 17r-18v, ilustración 18v (modelo 7).

406 García 1681: cap. 2: 3v-4r, ilustración parte superior $4 r$ (modelo 2).
} 
en Guareña (Badajoz). En el caso de Villamor de los Escuderos la cabecera y el crucero quedan efectivamente inscritos en un cuadrado.

Por otro lado, si tomamos las iglesias de tres naves sin capillas hornacinas entre contrafuertes, vemos que todas ellas, excepto la de Santa Eugenia en Becerril de Campos (Palencia), guardan una relación dupla $(2: 1)$, si bien los términos que adoptan dicha proporción varían de un caso a otro: en la iglesia de San Sebastián en Villacastín (Segovia) y en la de San Martín en Mota del Marqués (Valladolid) la longitud del templo parece incluir ábside y cuerpo de naves, pero no coro y torre ${ }^{407}$, mientras que en la de Santiago de los Caballeros en Medina de Rioseco (Valladolid) coro y torre quedan incluidos. En los dos últimos casos las dimensiones relacionadas se refieren al contorno interior de los muros, siguiendo el criterio utilizado en las descripciones del Compendio, pero en Villacastín lo hacen al eje de aquellos; por su parte, en las iglesias de la Asunción de Nuestra Señora en Meco (Madrid) y Tendilla (Guadalajara) la proporción dupla (2:1) parece aplicarse al contorno exterior de los muros de ábside, naves y torre, lo cual introduce nuevas dudas acerca de la atribución de dichos edificios a Rodrigo Gil.

Por último, si examinamos las iglesias de tres naves con capillas hornacinas entre contrafuertes, vemos que los tres casos guardan una proporción dupla (2:1) en planta, aunque los términos que se relacionan varían nuevamente de un ejemplo a otro: en la iglesia de los Santos Juanes en Nava del Rey (Valladolid) la longitud interior del edificio no incluye ábside semihexagonal, coro y torre, y la anchura interior tampoco considera las capillas hornacinas entre contrafuertes; por el contrario en la Catedral Nueva de Salamanca y en la catedral de Segovia la proporción dupla $(2: 1)$ considera el conjunto del edificio, incluyendo ábside, naves y capillas hornacinas, y presentando la particularidad de que las dimensiones relacionadas son aparentemente la longitud interior y la anchura al eje del muro.

\subsection{Proporciones de cada tramo cubierto por una bóveda}

Por lo que respecta a las proporciones entre las dimensiones en planta de cada tramo cubierto por una bóveda, en los distintos modelos de templos que se describen aritméticamente en el Compendio las relaciones empleadas se limitan a 1:1, 2:1, 3:2 y 4:3408; de los métodos geométricos para el trazado de la planta descritos en el manuscrito resultan, además de las anteriores, las relaciones $5: 4,6: 5,10: 9$ y $\sqrt{ } 2^{409}$. Si examinamos los edificios seleccionados encontramos una variedad similar: 1:1, 2:1, 3:2, 4:3, 5:4, 6:5, 7:6 y 8:7.

En los ejemplos de una y tres naves sin capillas hornacinas entre contrafuertes observamos que dichas proporciones de los tramos se refieren siempre a las dimensiones definidas por los ejes de los pilares y por los contornos interiores de muros. Como excepciones tenemos la iglesia de San Sebastián en Villacastín (Segovia), donde el trazado de las naves laterales

\footnotetext{
407 Debemos considerar que durante la construcción de la iglesia de Mota del Marqués se alargó el presbiterio a petición del promotor, añadiendo un tramo rectangular no previsto originalmente (Vasallo y Pérez 201 1: 42; este hecho había sido ya intuido por Hoag 1985: 80-83). Por esta razón, las proporciones del conjunto pudieron quedar alteradas.

408 García 1681: cap. 2: 3r, ilustración parte inferior 4r; cap. 6: 15v-16r (modelo 1); cap. 2: 3v-4r, ilustración parte superior $4 \mathrm{r}$ (modelo 2); cap. 2: $5 \mathrm{r}$-6r, ilustración $6 \mathrm{r}$ (modelo 4); cap. 2: 6r-7r, ilustración $7 \mathrm{r}$ (modelo 5); cap. 6: 17r-18v, ilustración 18v (modelo 7).

409 García 1681: cap. 5: $11 v-12 v$, ilustración 12r (método 1); cap. 5: 12v-13r, ilustración 13r (método 2); cap. 5: $13 \mathrm{v}-14 \mathrm{v}$, ilustración 14r (método 3); cap. 5: 14v-15r, ilustración 15r (método 4).
} 
se refiere al eje del muro, y la de Santa Eugenia en Becerril de Campos (Palencia), donde se refiere al contorno exterior del muro; esta anomalía hace que las proporciones con las que parecen haberse trazado las colaterales $y$ las que efectivamente presentan sus bóvedas puedan no coincidir (la proporción entre las dimensiones a ejes del tramo, a ejes de los arcos del perímetro de la bóveda y contorno interior del muro, y a contorno interior de arcos y muro, son respectivamente, para el caso de Villacastín, 1.540 (3:2), 1.742 y 1.720, y para el de Becerril de Campos, 1.007 (1:1), 1.161 y 1.132).

En las iglesias de una y tres naves con capillas hornacinas entre contrafuertes encontramos diferencias en el trazado de los ejes que delimitan dichas capillas. En las iglesias de la Asunción de Nuestra Señora en Villamor de los Escuderos (Zamora), de Santa María de la Asunción en Guareña (Badajoz) y de los Santos Juanes en Nava del Rey (Valladolid) parece haberse considerado para el diseño el contorno interior del muro de la nave, pero, por otro lado, mientras que en el primer caso se ha tomado el contorno exterior del muro de cierre de la capilla, en los otros dos se ha considerado el eje del muro; esta diferencia no tiene mayor repercusión sobre las bóvedas que cubren las hornacinas, ya que en los tres casos son de cañón. Por el contrario, en la Catedral Nueva de Salamanca y en la catedral de Segovia se ha tomado el eje del muro de la nave y, respectivamente, el contorno interior o el eje del muro de cierre de la capilla; estas anomalías provocan de nuevo que las proporciones con las que parecen haberse trazado las colaterales y las que efectivamente presentan sus bóvedas puedan no coincidir (la proporción entre las dimensiones a ejes del tramo, a ejes de los arcos del perímetro de la bóveda y contorno interior del muro, y a contorno interior de arcos y muro, son respectivamente, para el caso de Salamanca, 1.005 (1:1), 1.051 y 1.054 , y para el de Segovia, 1.011 (1:1), 1.071 y 1.046), ocurriendo lo mismo con las hornacinas.

\subsection{Relación entre las anchuras de las naves}

En los modelos de iglesias de una nave con capillas hornacinas entre contrafuertes que se describen aritméticamente en el Compendio vemos utilizadas las proporciones 4:1 y 8:3410. Por lo que respecta a las iglesias de tres naves $\sin y$ con capillas hornacinas entre contrafuertes, en los modelos descritos aritméticamente en el manuscrito las relaciones empleadas se limitan a 2:1, 4:3 y 4:3:3411, mientras que de los métodos geométricos para el trazado de la planta resultan las dos primeras relaciones indicadas ${ }^{412}$.

Si tomamos las iglesias seleccionadas con una nave y capillas hornacinas entre contrafuertes, observamos que la de Santa María de la Asunción en Guareña (Badajoz) presenta una relación 4:1 entre los anchos de la nave y de cada una de las hornacinas, coincidiendo con uno de los dos valores recogidos en el Compendio, mientras que en la de la Asunción de Nuestra Señora en Villamor de los Escuderos (Zamora) la proporción es 5:2.

Las iglesias de tres naves, en cambio, ofrecen una mayor variedad. En los ejemplos de tres naves sin capillas hornacinas entre contrafuertes observamos las siguientes relaciones entre los anchos de la nave mayor y de cada una de las colaterales: 14:9 (iglesia de la Asunción de Nuestra Señora en Meco (Madrid)), 12:7 (iglesia de San Sebastián en Villacastín

\footnotetext{
410 García 1681 : cap. 2: 4v, ilustración 4v (modelo 3); cap. 2: 5r-6r, ilustración 6r (modelo 4).

411 García 1681: cap. 2: 3r, ilustración parte inferior 4r; cap. 6: 15v-16r (modelo 1); cap. 6: 17r-18v, ilustración 18v (modelo 7).

412 García 1681: cap. 5: 12v-13r, ilustración 13r (método 2); cap. 5: 13v-14v, ilustración 14r (método 3).
} 
(Segovia)), 4:3 (iglesias de la Asunción de Nuestra Señora en Tendilla (Guadalajara) y de Santa Eugenia en Becerril de Campos (Palencia)), 3:2 (iglesia de Santiago de los Caballeros en Medina de Rioseco (Valladolid)) y 2:1 (iglesia de San Martín en Mota del Marqués (Valladolid)).

En las iglesias de tres naves con capillas hornacinas entre contrafuertes observamos las siguientes relaciones entre los anchos de la nave mayor y de cada una de las colaterales y hornacinas: 56:36:21 (iglesia de los Santos Juanes en Nava del Rey (Valladolid)) y 16:1 2:9 (Catedral Nueva de Salamanca y catedral de Segovia). Si en estos tres casos consideramos únicamente la relación entre nave central y laterales, en el primero tenemos 14:9, y en los otros dos 4:3.

Por otro lado, tanto uno de los modelos descritos aritméticamente en el Compendio como uno de los métodos geométricos de trazado de la planta, ambos referidos a iglesias de tres naves, presentan un procedimiento de diseño que relaciona mediante una proporción continua, en concreto $8: 4: 2: 1$, anchura y longitud total en planta del edificio y anchos de nave mayor y de cada una de las colaterales ${ }^{413}$. Si examinamos las iglesias de tres naves seleccionadas, únicamente apreciamos este método en la iglesia de San Martín en Mota del Marqués (Valladolid), en la que los términos anteriores guardan la misma relación 8:4:2:1, esto es, sus dimensiones se encuentran vinculadas por una proporción continua $2: 1$; sin embargo, el número de tramos no coincide en el modelo del Compendio y en Mota del Marqués: mientras que en el modelo teórico la nave está formada por cuatro tramos, en el caso práctico está formada por tres, lo cual nos indica de nuevo la infinita variedad de estos sistemas de trazado. En el resto de edificios no observamos la utilización de ninguna proporción continua, ya sea entre los anchos de las naves, ya entre estos y la anchura y longitud totales.

\subsubsection{Trazado de la sección}

En los tramos-tipo estudiados observamos varios procedimientos de diseño relativos al trazado de la sección del edificio, que establecen la altura de la línea de imposta, la relación entre las alturas de las naves y la altura de la clave del arco perpiaño de la nave mayor. Tanto una como otra varían en los edificios de Rodrigo Gil, en función de distintos parámetros ${ }^{414}$.

\footnotetext{
413 García 1681: cap. 6: 17r-18v, ilustración 18v (modelo 7); cap. 5: 13v-14v, ilustración 14r (método 3).

414 Como orientación respecto a los rangos dimensionales en los que se mueven estas estructuras, si examinamos los 36 edificios en los que se localizan las 104 bóvedas analizadas en los apartados anteriores, la altura de imposta a partir de la que arrancan se encuentra en la mayor parte de los casos entre los 20 y los 50 pies (520 pies: 14 bóvedas; $20-30$ pies: $26 ; 30-40$ pies: $27 ; 40-50$ pies: 23 ; $>50$ pies: 14 ). Entre las bóvedas cuyo arranque se produce a mayor altura (>50 pies) encontramos las de las naves de la catedral de Segovia (laterales 58.3 pies, central 91.3 pies) y de la Catedral Nueva de Salamanca (laterales 63.4, central 99.3); las de la cabecera y los brazos del crucero de la iglesia del convento de San Esteban en Salamanca (65.3); y las de los cimborrios que cubren el tramo central del crucero de la capilla del Colegio Mayor del Arzobispo Fonseca en Salamanca (61.3), de la iglesia de Santa Ana en Peñaranda de Duero (Burgos) (83.8) y de la iglesia del convento de San Esteban en Salamanca (105.5). La bóveda de mayor altura trazada por Rodrigo Gil es esta última, con su imposta situada a 105.5 pies $(29.38 \mathrm{~m})$, las claves de los formeros a 145.2 pies $(40.45 \mathrm{~m})$ y la clave central a 147.8 pies $(41.17 \mathrm{~m})$, las dos últimas medidas al intradós de la plementería.
} 


\subsection{Altura de la línea de imposta. Relación entre las alturas de las naves}

En algunos edificios seleccionados se establecen relaciones entre la anchura interior total del edificio y la altura de la línea de imposta.

En concreto, en las iglesias de una nave sin capillas hornacinas entre contrafuertes se hace coincidir la anchura interior total con la altura de imposta $(h=A)$. Esta relación es la misma que se recoge en las fórmulas del Compendio para el dimensionado de los nervios de una bóveda de crucería, propuestas para un tipo de bóveda básico, de planta cuadrada, cuyo arranque o línea de imposta se encuentra a una altura equivalente a la longitud de su lado415. Se trata del método aplicado con exactitud en la iglesia del monasterio de las Bernardas en Salamanca (anchura 39.5 pies, altura 39.4 pies), y con poca aproximación en las iglesias de San Juan Bautista en Fuenteguinaldo (Salamanca) (anchura 39.6, altura 32.4), de Santa María Magdalena en Valladolid (anchura 39.9, altura 44.9) y de Santo Tomás en Vegas de Matute (Segovia) (anchura 31.2 y 20.6 para la nave principal y la capilla de Santo Tomás (o de los Segovia) respectivamente, altura 24.6). Debemos puntualizar que todas ellas tienen bóvedas de planta rectangular y no cuadrada.

En algunas de las iglesias de tres naves, con y sin capillas hornacinas entre contrafuertes, encontramos aplicado uno de los métodos dados en el Compendio para edificios de planta dupla (2:1), según el cual se establece la altura de la línea de imposta (sin que quede claro si se refiere a la de la nave mayor o a la de las naves laterales) como el tercero de una proporción continua en la que la anchura total del edificio en planta es la media proporcional o geométrica entre aquella y la longitud total 416 (h $=A A / 2 A, 0$, más sencillamente, $h=A / 2)$ :

- En algunas de las iglesias de tres naves de igual altura sin capillas hornacinas entre contrafuertes se hace coincidir la mitad de la anchura interior total con la altura de imposta. Este es el método aplicado en las iglesias de San Martín en Mota del Marqués (Valladolid) (anchura 71.1, altura 34.3), de la Asunción de Nuestra Señora en Meco (Madrid) (anchura 72.7, altura 40.0), de la Asunción de Nuestra Señora en Tendilla (Guadalajara) (anchura 89.5, altura 44.2) y de Santa Eugenia en Becerril de Campos (Palencia) (anchura 93.1, altura 46.5). En el caso de Mota del Marqués la relación 1:2:1 entre las anchuras de los tramos hace que el ancho de la nave central y la altura de imposta también coincidan (anchura 34.7, altura 34.3).

- En las iglesias de tres naves de igual altura con capillas hornacinas entre contrafuertes se hace coincidir la mitad de la anchura interior total, incluyendo capillas hornacinas, con la altura de imposta. Este es el método aplicado en la iglesia de los Santos Juanes en Nava del Rey (Valladolid) (anchura 95.2, altura 48.8).

- En las iglesias de tres naves de distinta altura con capillas hornacinas entre contrafuertes se hace coincidir la mitad de la anchura interior total, sin incluir capillas hornacinas, con la altura de imposta de las naves laterales. Este es el método aplicado aproximadamente en la Catedral Nueva de Salamanca (anchura 121.1, altura 63.4) y en la catedral de Segovia (anchura 122.7, altura 58.3).

\footnotetext{
415 García 1681: cap. 6: 23v.

416 García 1681: cap. 6: 16r-16v, ilustración 16v.
} 
En la práctica lo vemos en efecto aplicado a iglesias de tres naves de planta aproximadamente dupla (2:1), excepto en el caso de Becerril de Campos. Cuando la sección es escalonada, caso de las catedrales de Salamanca y Segovia, la altura de imposta calculada corresponde, como hemos visto, a la de las naves laterales, y no a la de la central. Por otro lado, en estos dos edificios, los únicos en los que intervino activamente Rodrigo Gil que tienen sus naves a distinta altura, observamos que la altura de imposta de las capillas hornacinas es a su vez la mitad de la de imposta de las naves laterales (Salamanca: capilla $\sim 28.3$, nave lateral 63.4; Segovia: capilla 29.4, nave lateral 58.3). Sin embargo, no encontramos aplicado en ellos otro método dado en el Compendio relativo a la relación que debe existir entre las alturas de las naves cuando la sección es escalonada, y según el cual la imposta de donde arrancan las bóvedas de la nave mayor debe quedar a la misma altura que la clave de los perpiaños de las colaterales; y la imposta de donde arrancan las bóvedas de las colaterales debe quedar a la misma altura que la clave de los perpiaños de las capillas hornacinas ${ }^{417}$; ninguna de estas dos condiciones se cumple ni en Salamanca ni en Segovia, donde la aplicación de esta regla requeriría la disposición de unos peraltes desmesurados para elevar las bóvedas desde la línea de imposta, limitando las posibilidades para disponer tanto el ándito como el claristorio de la nave mayor (este último quedaría parcialmente oculto por la cubierta de la nave lateral, circunstancia que de hecho es apuntada en otro lugar del manuscrito ${ }^{418}$ ).

\subsection{Altura de la clave del arco perpiaño de la nave mayor}

En algunos edificios seleccionados encontramos, por otra parte, una relación entre la anchura interior total del edificio y la altura de la clave del arco perpiaño de la nave central o mayor. El procedimiento se corresponde con uno de los métodos dados en el Compendio, según el cual se establece como regla general que en las iglesias de una, tres, cinco o siete naves, con o sin capillas hornacinas, la altura de la clave del arco perpiaño de la nave mayor debe ser igual a la anchura total del edificio en planta, de modo que la sección del conjunto queda inscrita en un cuadrado ${ }^{419}(H=A)$ :

- En las iglesias de una nave con capillas hornacinas entre contrafuertes se hace coincidir la anchura interior total, incluyendo capillas hornacinas, con la altura de la clave de la nave. Este es el método aplicado aproximadamente en las iglesias de la Asunción de Nuestra Señora en Villamor de los Escuderos (Zamora) (anchura 46.4 pies, altura 52.1 pies) y de Santa María de la Asunción en Guareña (Badajoz) (anchura 86.4, altura 80.1).

- En algunas de las iglesias de tres naves de igual altura sin capillas hornacinas entre contrafuertes se hace coincidir la anchura interior total con la altura de la clave de la nave central. Este es el método aplicado aproximadamente en las iglesias de San Sebastián en Villacastín (Segovia) (anchura 79.3, altura 74.9) y de Santiago de los Caballeros en Medina de Rioseco (Valladolid) (anchura 86.1, altura $81.9^{\lrcorner}$).

- En las iglesias de tres naves de distinta altura con capillas hornacinas entre contrafuertes se hace coincidir la anchura interior total, sin incluir capillas hornacinas, con la altura de la clave de la nave central. Este es el método aplicado

\footnotetext{
417 García 1681: cap. 4: 9r, ilustración 9r.

418 García 1681: cap. 6: 23r-23v.

419 García 1681: cap. 3: 8r-8v, ilustración 8v; cap. 4: 9r.
} 
aproximadamente en la Catedral Nueva de Salamanca (anchura 121.1, altura 128.1 ) y en la catedral de Segovia (anchura 122.7, altura 118.2).

En la práctica lo vemos aplicado a iglesias tanto de una como de tres naves, estas últimas, por otro lado, de planta aproximadamente dupla (2:1). A excepción de las catedrales de Salamanca y Segovia, los edificios en los que observamos este tipo de relación son precisamente aquellos en los que no se aprecia la vinculación entre anchura interior total y altura de imposta mencionada en el apartado anterior. El hecho de utilizar como altura de referencia la de la clave del arco perpiaño y no la de la diagonal tiene que ver, quizás, con el hecho de que la altura de la clave central de la bóveda varía dependiendo de la proporción del tramo, ya que esta última condiciona la luz de la diagonal, mientras que la altura de la clave del arco perpiaño puede ser fija.

Por otro lado, en el Compendio se ofrece igualmente otro método que relaciona de un modo menos directo la anchura interior y la altura de clave. Esta regla, referida a edificios de planta dupla (2:1), establece la altura de la clave del arco perpiaño (probablemente de la nave mayor) como la media aritmética de la anchura total del edificio en planta y la de la nave mayor ${ }^{420}(H=(A+a) / 2)$. Presentamos a continuación los resultados obtenidos al aplicar esta regla a las iglesias de tres naves, con y sin capillas entre contrafuertes, todas ellas de planta aproximadamente dupla (2:1) excepto la de Santa Eugenia en Becerril de Campos (Palencia):

\begin{tabular}{|c|c|c|c|c|}
\hline & $\begin{array}{c}\text { Anchura interior } \\
\text { total (1) } \\
\text { A }\end{array}$ & $\begin{array}{c}\text { Anchura de la } \\
\text { nave central (1) } \\
\text { a }\end{array}$ & $\begin{array}{c}\text { Media } \\
\text { aritmética } \\
(A+a) / 2\end{array}$ & $\begin{array}{c}\text { Altura clave } \\
\text { perpiaño (2) } \\
\text { H }\end{array}$ \\
\hline \multicolumn{5}{|c|}{ Iglesias de tres naves sin capillas hornacinas entre contrafuertes } \\
\hline Becerril de Campos & 93.1 & 41.0 & 67.1 & $64.5\lrcorner$ \\
\hline Meco & 72.7 & 32.2 & 52.5 & 60.6 \\
\hline Medina de Rioseco & 86.1 & 36.9 & 61.5 & $81.9+$ \\
\hline Mota del Marqués & 71.1 & 34.7 & 52.9 & 54.5 \\
\hline Tendilla & 89.5 & 38.9 & 64.2 & $64.8\lrcorner$ \\
\hline Villacastín & 79.3 & 39.7 & 59.5 & 74.9 \\
\hline \multicolumn{5}{|c|}{ Iglesias de tres naves con capillas hornacinas entre contrafuertes } \\
\hline Nava del Rey & {$[75.6] / 95.2$} & 32.8 & {$[54.2] / 64.0$} & $\sim 62.5$ \\
\hline Salamanca $\cdot$ Catedral Nueva & {$[121.1] / 177.7$} & 50.1 & {$[85.6] / 113.9$} & 128.1 \\
\hline Segovia $\cdot$ Catedral & {$[122.7] / 179.5$} & 52.0 & {$[87.4] / 115.8$} & 118.2 \\
\hline \multicolumn{5}{|c|}{ [ ] Valor sin computar las capillas hornacinas. } \\
\hline \multicolumn{5}{|c|}{ Datos en pies castellanos ( 1 pie $=0.278635$ metros). } \\
\hline
\end{tabular}

Tabla 4. Métodos para el trazado arquitectónico: datos geométricos en planta de diez de los quince tramostipo seleccionados, resultados del cálculo de la altura de la clave del arco perpiaño de la nave mayor por el método 2 y comparación con los valores reales (P. Moreno)

\section{Observaciones:}

(1) La anchura interior total (A) se ha considerado a contorno interior de muros, y la anchura de la nave central (a) a ejes de pilares.

420 García 1681: cap. 6: 17r. 
(2) La altura de clave del arco perpiaño $(H)$ se ha medido a la línea de contacto del nervio con el intradós de la plementería (las indicadas como ${ }^{-}$se refieren a la línea de intradós del arco).

- Como vemos, este método parece ser el aplicado en algunas de las iglesias de tres naves de igual altura sin capillas hornacinas entre contrafuertes, como la de San Martín en Mota del Marqués (Valladolid) (media 52.9, altura 54.5), la de la Asunción de Nuestra Señora en Tendilla (Guadalajara) (media 64.2, altura 64.8$\lrcorner$ ) y la de Santa Eugenia en Becerril de Campos (Palencia) (media 67.1, altura 64.5 \lrcorner ). Por el contrario, tanto la iglesia de San Sebastián en Villacastín (Segovia) (media 59.5, altura 74.9) como la de Santiago de los Caballeros en Medina de Rioseco (Valladolid) (media 61.5, altura 81.9$\lrcorner$ ) presentan valores muy alejados, habiéndose aplicado probablemente en ambos casos, como hemos dicho, el método ya descrito que hace coincidir la anchura interior total con la altura de la clave de la nave central (los valores son, respectivamente: anchura 79.3, altura 74.9; anchura 86.1, altura 81.9$\lrcorner$ ).

- En las iglesias de tres naves de igual o distinta altura con capillas hornacinas entre contrafuertes se presenta el problema de si computar o no dichas capillas para el cálculo de la anchura total del edificio. Si lo hacemos, encontramos que la regla se cumple aproximadamente en la iglesia de los Santos Juanes en Nava del Rey (Valladolid) (media 64.0, altura 62.5) y en la catedral de Segovia (media 115.8, altura 1 18.2). Ambos edificios tienen una proporción en planta aproximadamente dupla (2:1), pero debemos tener en cuenta que en Nava del Rey dicha proporción no incluye las capillas hornacinas, mientras que en Segovia sí lo hace, lo que introduce nuevas peculiaridades en los trazados de cada edificio. Por otro lado, ya hemos observado cómo en Segovia podría haberse aplicado el método ya descrito que hace coincidir la anchura interior total, en este caso sin incluir capillas hornacinas, con la altura de la clave de la nave central (anchura 122.7, altura 1 18.2).

\subsubsection{Métodos para el dimensionado estructural}

En el Compendio se proporcionan diez reglas para el dimensionado de distintos elementos estructurales del edificio gótico. Entre ellas aparecen siete métodos aritméticos, destinados al cálculo de los pilares, de los estribos o contrafuertes y de las torres; y tres métodos geométricos, orientados al cálculo de los contrafuertes. En este apartado vamos a comprobar la aplicación práctica de cuatro de las reglas aritméticas, concretamente la que permite el cálculo de los pilares para bóvedas de crucería y las tres que sirven para el dimensionado de los contrafuertes en circunstancias distintas (regla general para arcos y bóvedas; regla particular para bóvedas de crucería; regla para arcos semicirculares). No analizaremos las tres fórmulas geométricas, ni tampoco las tres fórmulas para el cálculo de torres por carecer de los datos oportunos (en el caso de la torre de la Catedral-Magistral de Alcalá de Henares (Madrid) desconocemos la altura proyectada, mientras que en el de la catedral de Segovia carecemos de los datos geométricos tanto en planta como en altura). 
Como ya hicimos en el análisis teórico de cada uno de los métodos de cálculo, utilizaremos para las expresiones algebraicas la notación dada por Huerta (2006), a fin de homogeneizar los enunciados de las fórmulas y de evitar confusiones. Por otro lado, debemos recordar que tres de las fórmulas estudiadas, en concreto aquellas que presentan una raíz cuadrada en su enunciado, tienen la peculiaridad de que sus unidades son incoherentes, lo cual se traduce en que el resultado cambia dependiendo de cuáles usemos; en el sistema de medidas castellano, en el que una vara equivale a 0.835905 metros y se divide en tres pies de 0.278635 metros, el resultado en varas aumentará respecto al resultado en pies por un factor de $\sqrt{ } 3$; en metros, por un factor de $\sqrt{ }(1 / 0.278635)$. Para obtener resultados adecuados los datos se deben introducir en pies, siendo esta la práctica observada en los ejemplos del Compendio con los que se ilustran las reglas, y el pie ha sido por tanto la unidad de medida empleada en todos los casos.

\subsubsection{Datos geométricos}

Los datos geométricos para el análisis de los tramos-tipo seleccionados se presentan a continuación:

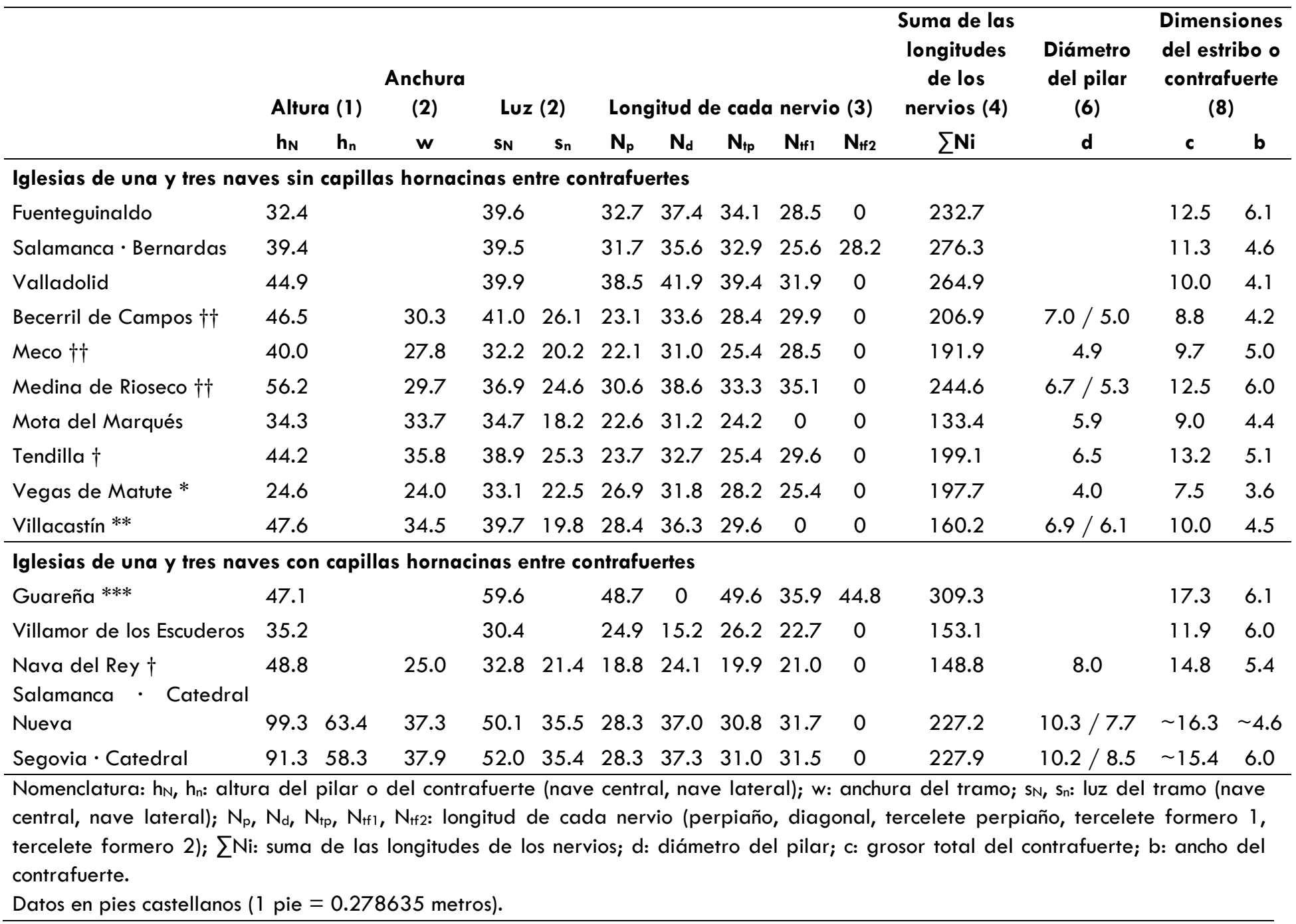

Tabla 5. Métodos para el dimensionado estructural: datos geométricos en planta y sección de los quince tramos-tipo seleccionados (P. Moreno) 
Observaciones:

(1) La altura del pilar o del contrafuerte $\left(h_{i}\right)$ coincide con la altura de imposta.

(2) La anchura $(w)$ y la luz $\left(\mathrm{s}_{\mathrm{i}}\right)$ del tramo se han considerado a ejes de pilares y a contorno interior de muros.

(3) La longitud de cada nervio $\left(\mathrm{N}_{\mathrm{i}}\right)$, correspondiente a las bóvedas de las naves laterales cuando estas existen, se ha medido en la línea de contacto del nervio con el intradós de la plementería, computando el peralte caso de presentarse este.

(4) La suma de las longitudes de los nervios ( $\sum \mathrm{Ni}$ ) se ha calculado computando todos los nervios soportados por el contrafuerte, duplicando por tanto las correspondientes a diagonal y terceletes para considerar dos tramos contiguos de bóveda $\left(\sum \mathrm{Ni}=\mathrm{N}_{\mathrm{p}}+2\right.$ * $\left.\left(N_{d}+N_{t p}+N_{t f 1}+N_{t f 2}\right)\right)$.

(6) Cuando el soporte es una columna agrupada o una columna fasciculada se dan dos valores reales del diámetro (d), de los cuales el primero corresponde a la envolvente exterior del pilar, y el segundo a la sección más restrictiva, esto es, medida hasta los ángulos $o$ acanaladuras más interiores.

(8) El valor real del grosor total del contrafuerte (c) reflejado incluye el grueso del muro y la proyección exterior del contrafuerte, pero no el del pilar adosado.

* En la iglesia de Santo Tomás en Vegas de Matute (Segovia) existe una pequeña diferencia entre la altura de imposta de la nave principal y la de la capilla de Santo Tomás (o de los Segovia) (24.9 y 24.3 pies respectivamente), debido a su ejecución en dos fases constructivas distintas, habiéndose consignado la media aritmética de ambas dada la escasa diferencia entre ellas. Por otro lado, las anchuras interiores parciales de nave y capilla (31.2 y 20.6 respectivamente) y sus luces $(33.1$ y 22.5 respectivamente), indicadas tanto en esta tabla como más arriba, difieren debido a que las primeras están medidas al contorno interior del muro central de separación entre ambos espacios, mientras que las segundas lo hacen al eje del pilar central. Finalmente, se han consignado los valores del contrafuerte de la nave principal (norte) del tramo considerado, presentando el que corresponde a la capilla de Santo Tomás (o de los Segovia) (sur) unos valores $c=6.8, b=3.5, c / b=1.9$.

** En la iglesia de San Sebastián en Villacastín (Segovia) existe una pequeña diferencia entre la altura de imposta de los pilares centrales y la de los muros perimetrales (47.6 y 48.8 pies respectivamente), habiéndose consignado la primera de ellas dado que fue fijada con posterioridad a la segunda.

*** En la iglesia de Santa María de la Asunción en Guareña (Badajoz) se han consignado los valores del contrafuerte este del tramo considerado, presentando el oeste unos valores $c=17.3, b=7.4, c / b=2.3$ ).

† Las bóvedas de crucería no llegaron a construirse, por lo que se han tomado unas longitudes hipotéticas para perpiaño, diagonales y terceletes, considerando que la diagonal es semicircular y que todos los nervios tienen el mismo radio y ningún peralte.

†† Solo se construyeron los arcos perpiaños y formeros, por lo que para el perpiaño se ha tomado su longitud y peralte reales, y para diagonales y terceletes unas longitudes hipotéticas, considerando que la diagonal es semicircular, que diagonal y terceletes tienen el mismo radio y que ambos tienen el mismo peralte que el perpiaño. 


\subsubsection{Resultados del cálculo}

Los resultados de aplicar las cuatro reglas de dimensionado estructural que son objeto de estudio a los tramos-tipo anteriores, junto con los valores reales medidos en los edificios seleccionados, se presentan a continuación de modo conjunto, a fin de proporcionar una visión comparada de todos ellos:

\begin{tabular}{|c|c|c|c|c|c|c|c|c|}
\hline & \multicolumn{2}{|c|}{ Diámetro del pilar } & \multicolumn{6}{|c|}{ Dimensiones del estribo o contrafuerte } \\
\hline & \multirow{3}{*}{$\begin{array}{l}\text { Valores de } \\
\text { cálculo (5) } \\
1 / 2 \sqrt{ }(h+w+s) \\
\end{array}$} & \multirow{3}{*}{$\begin{array}{l}\text { Valores } \\
\text { reales (6) } \\
\text { d }\end{array}$} & \multirow{2}{*}{\multicolumn{3}{|c|}{ Valores de cálculo (7) }} & \multirow{2}{*}{\multicolumn{3}{|c|}{$\begin{array}{c}\text { Valores reales } \\
\text { (8) }\end{array}$}} \\
\hline & & & & & & & & \\
\hline & & & $1 / 4 \mathrm{~s}$ & $2 / 3 \sqrt{ }\left(h+2 / 3 \sum N i\right)$ & $\sqrt{ }\left(\mathbf{h}+\mathbf{N}_{\mathbf{p}}\right)$ & c & b & $\mathbf{c} / \mathbf{b}$ \\
\hline \multicolumn{9}{|c|}{ Iglesias de una y tres naves sin capillas hornacinas entre contrafuertes } \\
\hline Fuenteguinaldo & & & 9.9 & 9.1 & 8.1 & 12.5 & 6.1 & 2.0 \\
\hline Salamanca $\cdot$ Bernardas & & & 9.9 & 10.0 & 8.4 & 11.3 & 4.6 & 2.5 \\
\hline Valladolid & & & 10.0 & 9.9 & 9.1 & 10.0 & 4.1 & 2.4 \\
\hline Becerril de Campos $\dagger \dagger$ & 5.4 & $7.0 / 5.0$ & 6.5 & 9.1 & 8.3 & 8.8 & 4.2 & 2.1 \\
\hline Meco †† & 5.0 & 4.9 & 5.1 & 8.6 & 7.9 & 9.7 & 5.0 & 1.9 \\
\hline Medina de Rioseco $† \dagger$ & 5.5 & $6.7 / 5.3$ & 6.2 & 9.9 & 9.3 & 12.5 & 6.0 & 2.1 \\
\hline Mota del Marqués & 5.1 & 5.9 & 4.6 & 7.4 & 7.5 & 9.0 & 4.4 & 2.0 \\
\hline Tendilla $\dagger$ & 5.5 & 6.5 & 6.3 & 8.9 & 8.2 & 13.2 & 5.1 & 2.6 \\
\hline Vegas de Matute * & 4.5 & 4.0 & 8.3 & 8.3 & 7.2 & 7.5 & 3.6 & 2.1 \\
\hline Villacastín ** & 5.5 & $6.9 / 6.1$ & 5.0 & 8.3 & 8.7 & 10.0 & 4.5 & 2.2 \\
\hline \multicolumn{9}{|c|}{ Iglesias de una y tres naves con capillas hornacinas entre contrafuertes } \\
\hline Guareña *** & & & 14.9 & 10.6 & 9.8 & 17.3 & 6.1 & 2.8 \\
\hline Villamor de los Escuderos & & & 7.6 & 7.8 & 7.8 & 11.9 & 6.0 & 2.0 \\
\hline Nava del Rey $\dagger$ & 5.2 & 8.0 & 5.4 & 8.1 & 8.2 & 14.8 & 5.4 & 2.7 \\
\hline Salamanca - Catedral & & & & & & & & \\
\hline Nueva & 6.8 & $10.3 / 7.7$ & 8.9 & 9.8 & 9.6 & $\sim 16.3$ & $\sim 4.6$ & 3.5 \\
\hline Segovia $\cdot$ Catedral & 6.7 & 10.2 / 8.5 & 8.9 & 9.7 & 9.3 & $\sim 15.4$ & 6.0 & 2.6 \\
\hline \multicolumn{9}{|c|}{ Nomenclatura: d: diámetro del pilar; c: grosor total del contrafuerte; b: ancho del contrafuerte. } \\
\hline \multicolumn{9}{|c|}{$\begin{array}{l}\text { Métodos para el dimensionado estructural: } 1 / 2 \sqrt{ }(\mathrm{h}+\mathrm{w}+\mathrm{s}) \text { : pilares para bóvedas de crucería; } 1 / 4 \mathrm{~s} \text { : estribos o } \\
\text { contrafuertes, regla general para arcos y bóvedas; } 2 / 3 \sqrt{ }\left(\mathrm{h}+2 / 3 \sum N \mathrm{~N}\right) \text { : estribos o contrafuertes, regla } \\
\text { particular para bóvedas de crucería; } \sqrt{ }(\mathrm{h}+\mathrm{Np}) \text { : estribos o contrafuertes, regla aritmética para arcos } \\
\text { semicirculares. }\end{array}$} \\
\hline \multicolumn{9}{|c|}{ Datos en pies castellanos ( 1 pie $=0.278635$ metros). } \\
\hline
\end{tabular}

Tabla 6. Métodos para el dimensionado estructural: resultados del cálculo de las dimensiones de pilares y contrafuertes y comparación con los valores reales (P. Moreno)

\section{Observaciones:}

(5) El cálculo del diámetro del pilar (d) toma en consideración los datos geométricos de las bóvedas de la nave central ( $h, w, s)$. Los valores de cálculo serían mayores si consideráramos, en lugar de un tramo intermedio de nave, aquellos de mayor anchura que configuran en ocasiones el crucero 0 se colocan contiguos a la cabecera ochavada $^{421}$. Sin embargo, la naturaleza de la fórmula es tal que las diferencias

\footnotetext{
421 Los valores para la anchura del tramo (w) serían, en tal caso, los siguientes: iglesia de Santo Tomás en Vegas de Matute (Segovia) 28.6 pies, iglesia de la Asunción de Nuestra Señora en Meco (Madrid) 32.1, iglesia
} 
encontradas entre utilizar uno u otro valor de la anchura del tramo son pequeñas, oscilando entre los 0 y los 0.2 pies, por lo que se ha preferido continuar utilizando los datos correspondientes a tramos intermedios de nave para mayor claridad de la exposición.

(6): ver tabla precedente.

(7) El cálculo del grosor total del contrafuerte (c) toma en consideración los datos geométricos de las bóvedas de las naves laterales cuando estas existen (s, $\left.h, \sum N i, N_{p}\right)$. Los valores de cálculo obtenidos con la regla particular para bóvedas de crucería (c $=$ $\left.2 / 3 \sqrt{ }\left(\mathrm{h}+2 / 3 \sum \mathrm{Ni}\right)\right)$ serían mayores si consideráramos, en lugar de un tramo intermedio de nave, aquellos de mayor anchura que configuran en ocasiones el crucero - se colocan contiguos a la cabecera ochavada, y cuyos nervios suman por tanto una mayor longitud. Hemos realizado la misma simplificación que en el cálculo del diámetro del pilar, utilizando los datos correspondientes a tramos intermedios de nave para mayor claridad de la exposición.

(8): ver tabla precedente.

$*, * *, * *, \dagger, \dagger \dagger:$ ver tabla precedente.

Pasamos seguidamente a discutir los resultados anteriores de modo pormenorizado.
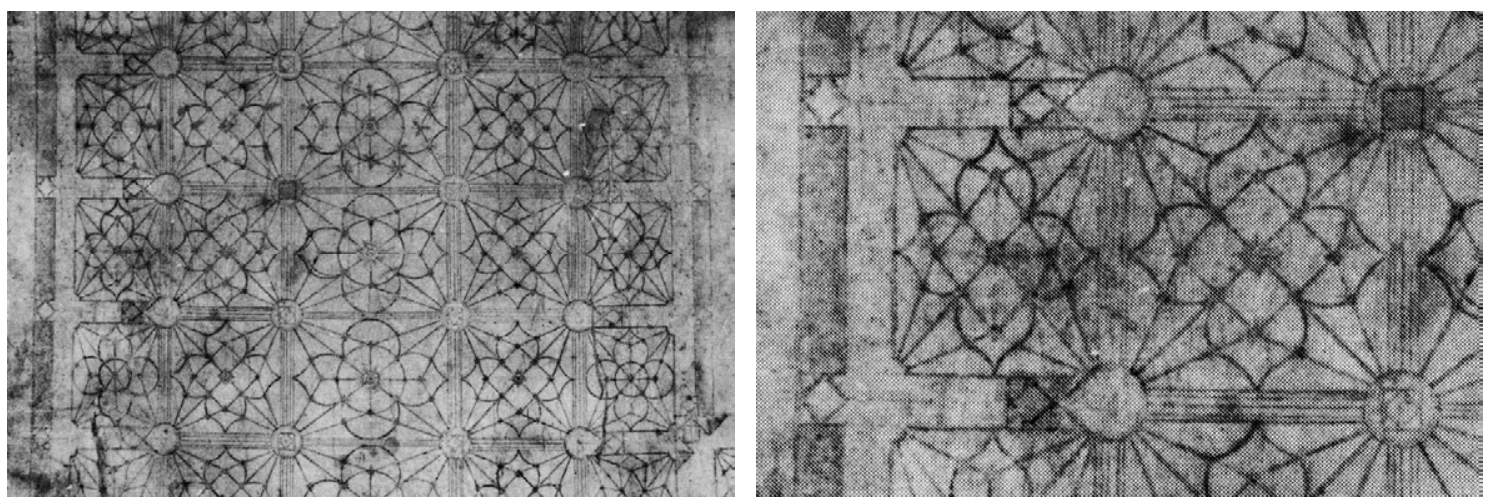

Figura 53. Trazas para la construcción de la catedral de Segovia: (a, b) Detalles de una de las plantas de conjunto, atribuible a Rodrigo Gil, mostrando la posición y dimensiones de pilares, estribos y pináculos

(Casaseca 1988: 349 fig. 24. Archivo de la catedral de Segovia)

\subsubsection{Pilares para bóvedas de crucería}

La primera de las reglas aritméticas examinadas establece el diámetro de un pilar aislado de planta circular para una bóveda de crucería ${ }^{422}$. Recordamos el enunciado de esta fórmula, ya analizada en su momento:

$$
d=1 / 2 \sqrt{ }(h+w+s) \text { (Huerta 2006) }
$$

de San Sebastián en Villacastín (Segovia) 41.3, iglesia de Santiago de los Caballeros en Medina de Rioseco (Valladolid) 38.9, iglesia de la Asunción de Nuestra Señora en Tendilla (Guadalajara) 38.0, iglesia de Santa Eugenia en Becerril de Campos (Palencia) 32.2, iglesia de los Santos Juanes en Nava del Rey (Valladolid) 35.3. 422 García 1681: cap. 6: 17r. 
Donde: d: diámetro de un pilar aislado de planta circular para una bóveda de crucería (pies); h: altura del pilar (pies); w, s: anchura y luz de un tramo de la nave central (pies) ${ }^{423}$.

Si tomamos las iglesias de tres naves de igual altura sin capillas hornacinas entre contrafuertes y comparamos los valores de cálculo y los reales (considerando entre estos últimos, cuando se presentan dos, los más restrictivos), observamos una cierta coincidencia, encontrando diferencias por encima o por debajo que oscilan entre los 0.1 y 1.0 pies $(2.0$ y $19.2 \%)$.

La misma apreciación es válida para el caso particular de la iglesia de Santo Tomás en Vegas de Matute (Segovia) y para la Catedral Nueva de Salamanca.

Únicamente en dos ejemplos, la catedral de Segovia y la iglesia de los Santos Juanes en Nava del Rey (Valladolid), la diferencia es mayor (1.8 y 2.8 pies, o 26.3 y $55.0 \%$, respectivamente), siendo superior en ambos casos el valor real al de cálculo. En el primero de ellos, podemos comparar los valores observados con los que corresponden a su edificio homólogo, la Catedral Nueva de Salamanca; para unas condiciones geométricas similares para las naves, los valores del diámetro interior del pilar difieren, pero los del diámetro exterior coinciden: la explicación puede ser que Rodrigo Gil tomara para el replanteo de Segovia el valor exterior ya determinado en Salamanca, o bien que el cálculo se realizara por procedimientos distintos. En Nava del Rey, sin embargo, no parece existir una razón que explique dicha diferencia de tamaño, habida cuenta de que al parecer los segundos pilares de las naves se llegaron a levantar antes de la muerte de Rodrigo Gil, con lo que su trazado no debería haber sido realizado por sus aparejadores.

Como ya hemos comentado, la obtención de resultados satisfactorios con esta fórmula implica la utilización obligatoria del pie castellano como unidad para la introducción de los datos, tal y como se hace en el ejemplo del Compendio con el que se ilustra la regla. Si introdujéramos los datos en varas, observaríamos diferencias bastante mayores entre el valor de cálculo y el real, que oscilarían entre los 2.9 y los 4.4 pies, siendo siempre superiores los de cálculo a los reales, resultado ilógico desde el punto de vista del diseño estructural. Curiosamente, en la iglesia de los Santos Juanes en Nava del Rey (Valladolid) la diferencia sería de solo 0.9 pies, encontrándose el valor de cálculo igualmente por encima del valor real: este hecho podría indicar que se produjo un error en la utilización de la fórmula, lo cual explicaría el gran tamaño de los pilares en este edificio.

En el manuscrito no se especifica si este método de cálculo es válido cuando las naves se cubren a la misma altura $\circ$ a distinta, y únicamente se indica en dos ocasiones de modo general que si las naves van a distinta altura el pilar habrá de ser más grueso que si van a la misma, aunque sin concretar en qué medida ${ }^{424}$. A la vista de los ejemplos examinados se podría aventurar, con las matizaciones observadas, que la fórmula sería aplicable en ambos casos.

\footnotetext{
423 Hoag [1958] 1999: 427-429; Huerta 2002: 576; Huerta 2006: 25; Sanabria [1982] 1999: [286] 6.

${ }^{424}$ García 1681: cap. 6: 21 v-22r.
} 

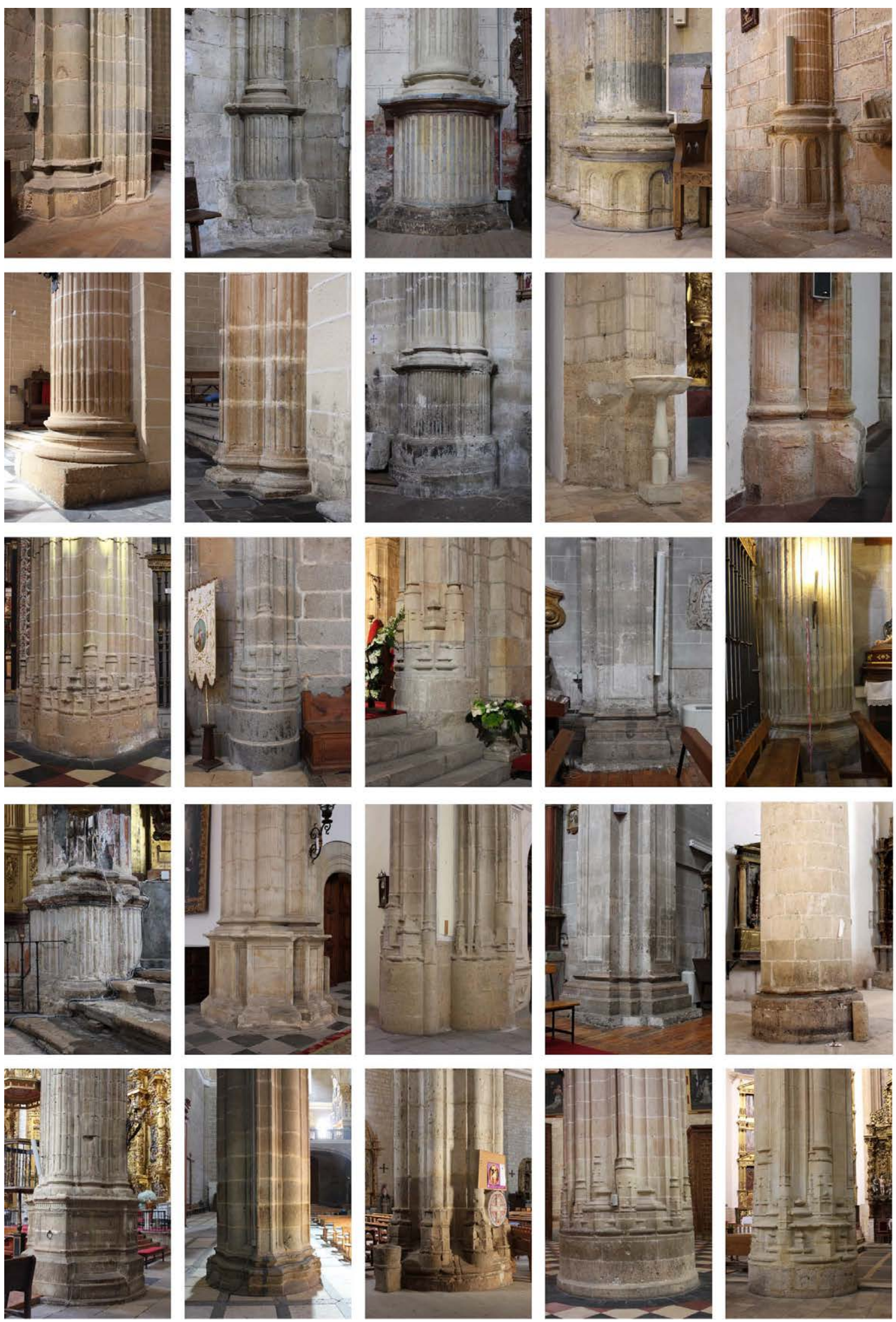

Figura 54. Distintos modelos de pilares, en rincón (a, b), adosados (medios pilares) (c-n), en esquina (caberos)

(ñ-r) y aislados (s-x): (a) Catedral de Astorga (León) (capilla de San Juan Bautista (costado sur del falso crucero)). (b) Iglesia de Santiago de los Caballeros, Medina de Rioseco (Valladolid) (nave lateral). (c) Iglesia de Santiago Apóstol, Cigales (Valladolid) (nave lateral). (d) Catedral de Ciudad Rodrigo (Salamanca) (cabecera). (e) Iglesia de San Juan Bautista, Fuenteguinaldo (Salamanca) (nave). (f, g) Iglesia de Santa María de la Asunción, Guareña (Badajoz) (nave; nave). (h) Iglesia de Santiago de los Caballeros, Medina de Rioseco 
(Valladolid) (nave lateral). (i) Iglesia de los Santos Juanes, Nava del Rey (Valladolid) (nave lateral). (i) Iglesia del monasterio de las Bernardas, Salamanca (nave). (k) Catedral de Segovia (nave lateral). (I) Iglesia de San Sebastián, Villacastín (Segovia) (nave lateral). (m) Iglesia de San Juan de Puerta Nueva, Zamora (cabecera). (n) Iglesia de Santa María Magdalena, Valladolid (nave). (ñ) Iglesia de Santiago de los Caballeros, Cáceres (cabecera). (o) Iglesia de Santiago Apóstol, Cigales (Valladolid) (cabecera). (p) Capilla del Colegio Mayor del Arzobispo Fonseca, Salamanca (crucero). (q) Iglesia del Salvador, Segovia (crucero). (r) Iglesia de Santa María Magdalena, Valladolid (crucero). (s) Iglesia de San Martín, Mota del Marqués (Valladolid) (nave central). ( $t$ ) Iglesia de Santiago de los Caballeros, Medina de Rioseco (Valladolid) (nave central). (u) Iglesia de San Sebastián, Villacastín (Segovia) (nave central). (v) Iglesia de Santa Eugenia, Becerril de Campos (Palencia) (nave central). (w) Catedral de Segovia (nave central). (x) Iglesia de San Julián de los Caballeros, Toro

(Zamora) (nave central)

\subsubsection{Estribos o contrafuertes}

Las otras tres reglas aritméticas estudiadas se refieren al cálculo de los estribos o contrafuertes. La primera de ellas debe considerarse como una regla medieval de trazado, y coincide con las utilizadas habitualmente en los siglos XVII y XVIII; la segunda está destinada específicamente a bóvedas de crucería; la tercera, aunque no existe un acuerdo unánime entre los investigadores, parece estar indicada únicamente para arcos semicirculares. Recordamos el enunciado de cada una de estas fórmulas, ya analizadas en su momento:

- Regla general para arcos y bóvedas: Se establecen las dimensiones del estribo o contrafuerte para un arco o bóveda ${ }^{425}$ :

$c=1 / 4 \mathrm{~s}$

Donde: c: grosor total del contrafuerte para un arco o bóveda (incluyendo el grueso de la "pared" o muro y la proyección exterior del contrafuerte); s: luz de ese tramo.

- Regla particular para bóvedas de crucería: Se establecen las dimensiones del estribo o contrafuerte para una bóveda de crucería. Se considera como presupuesto de partida que la planta del contrafuerte tiene proporción 2:1426:

$c=2 / 3 \sqrt{ }\left(\mathrm{h}+2 / 3 \sum \mathrm{Ni}\right)($ Huerta 2006)

Donde: c: grosor total del contrafuerte a la altura del arranque de la bóveda de crucería (incluyendo el grueso del "medio pilar" o pilar adosado, el de la "pared" 。 muro y la proyección exterior del contrafuerte) (su ancho es $\mathrm{c} / 2$ ) (pies); h: altura del contrafuerte (pies); $\sum \mathrm{Ni}$ : suma de las longitudes de los nervios que arrancan del contrafuerte (arcos perpiaños, diagonales y terceletes), medidos desde el arranque hasta sus respectivas claves (pies) ${ }^{427}$.

- Regla aritmética para arcos semicirculares: Se establece el grosor del estribo ○ contrafuerte de un arco semicircular ${ }^{428}$ :

$c=\sqrt{ }(h+N)$

\footnotetext{
425 García 1681: cap. 2: 2v; cap. 6: 18v-19r.

426 García 1681 : cap. 2: 5r-5v; cap. 6: 17v-18r, ilustración 18r, 22r-22v.

427 Hoag [1958] 1999: 429-430; Huerta 2002: 576-577; Huerta 2006: 25-26; Sanabria [1982] 1999: [286] 6.

428 García 1681: cap. 6: 20v-21v.
} 
Donde: c: grosor del contrafuerte de un arco semicircular (pies); h: altura del contrafuerte (pies); N: longitud del arco que arranca del contrafuerte, medido en su intradós desde el arranque hasta la clave (pies) ${ }^{429}$.

\subsection{Comparación entre las tres reglas}

Si tomamos las iglesias de una nave, con o sin capillas hornacinas entre contrafuertes, y comparamos los valores obtenidos con la regla general para arcos y bóvedas ( $c=1 / 4 \mathrm{~s}$ ) y la regla particular para bóvedas de crucería $\left(c=2 / 3 \sqrt{ }\left(\mathrm{h}+2 / 3 \sum \mathrm{Ni}\right)\right)$, observamos una cierta coincidencia, encontrando diferencias que oscilan entre los 0.1 y 0.8 pies por encima - por debajo; un caso excepcional es el representado por la iglesia de Santa María de la Asunción en Guareña (Badajoz), cuya luz, inusualmente amplia, provoca que el valor obtenido con la regla general sea muy superior al resultado de la regla particular (4.3 pies de diferencia). En las iglesias de tres naves de igual altura, con $\circ$ sin capillas hornacinas entre contrafuertes, observamos diferencias apreciables, que oscilan entre los 2.5 y los 3.7 pies, siendo siempre superiores los valores obtenidos por medio de la regla particular; la razón de estas mayores diferencias se encuentra fundamentalmente en que los resultados de la regla general se ven reducidos de modo importante al considerar como valor de cálculo la luz de las naves laterales. En las iglesias de tres naves de distinta altura con capillas hornacinas entre contrafuertes (Catedral Nueva de Salamanca y catedral de Segovia) observamos, por el contrario, una cierta coincidencia, encontrando diferencias que oscilan entre los 0.8 y 0.9 pies, siendo siempre superiores los valores obtenidos por medio de la regla particular; sin embargo, la diferencia con los de la regla general es moderada debido a que en los dos casos estudiados la luz de cálculo tiene un valor importante.

El planteamiento de la regla particular para bóvedas de crucería (c $=2 / 3 \sqrt{ }$ (h $+2 / 3$ $\left.\sum \mathrm{Ni}\right)$ ) y la regla aritmética para arcos semicirculares $(c=\sqrt{ }(\mathrm{h}+\mathrm{N}))$ es análogo, si bien ambas presentan matizaciones importantes. Una de ellas consiste en que la primera fórmula considera la suma de las longitudes del conjunto de los nervios de la bóveda de crucería que arrancan del contrafuerte (arcos perpiaños, diagonales y terceletes) ( $\sum \mathrm{Ni}$ ), mientras que la segunda tiene en cuenta la longitud de un solo arco (N). Por otro lado la primera fórmula introduce un factor de corrección $2 / 3$ que, según se explica en el Compendio, representa la proporción de la sección transversal del nervio que queda habitualmente después de haber tallado las correspondientes molduras sobre un contorno inicialmente rectangular, precisándose que si esta relación fuera distinta se debe aplicar proporcionalmente a la fórmula ${ }^{430}$; la segunda regla, por el contrario, no aplica dicho factor de corrección, de lo que podríamos deducir que está destinada a arcos de sección transversal perfectamente rectangular. Ambas razones indican que la segunda regla no sería aplicable a bóvedas de crucería. Sin embargo, dados los problemas de autoría que presenta el texto del Compendio y la posible corrupción de su contenido debido a la reelaboración llevada a cabo por su copista, hemos comparado los valores obtenidos de la aplicación de ambas reglas a los edificios seleccionados, a fin de despejar posibles dudas. Las diferencias encontradas entre unos y otros valores no son importantes, oscilando en la mayor parte de los casos entre los 0.1 y 0.8 pies por encima o por debajo (en tres de los quince casos la

\footnotetext{
429 Sanabria [1982] 1999: [286-287] 6-7.

430 García 1681: cap. 6: 17v, 22v.
} 
diferencia es superior, pudiendo alcanzar los 1.5 pies), siendo habitualmente superiores los valores obtenidos por medio de la regla particular para bóvedas de crucería.

\subsection{Comparación entre los valores de cálculo y los reales}

Si comparamos los valores obtenidos con la regla general para arcos y bóvedas ( $c=1 / 4 \mathrm{~s}$ ) y los valores reales, observamos diferencias apreciables, que oscilan entre los 1.4 y los 9.5 pies (14.4 y 176.6\%), siendo siempre superiores los reales a los de cálculo. Como excepción, en la iglesia de Santo Tomás en Vegas de Matute (Segovia) el valor real se encuentra 0.8 pies por debajo del de cálculo $(9.4 \%)$, y en la iglesia de Santa María Magdalena en Valladolid existe plena coincidencia entre ambos.

Si comparamos los valores obtenidos con la regla particular para bóvedas de crucería $(\mathrm{c}=$ $\left.2 / 3 \sqrt{ }\left(\mathrm{h}+2 / 3 \sum \mathrm{Ni}\right)\right)$ y los valores reales, observamos de nuevo diferencias apreciables, que oscilan entre los 1.1 y 6.7 pies (12.3 y $82.5 \%)$, siendo siempre superiores los reales a los de cálculo. Como excepción, en Vegas de Matute el valor real se encuentra nuevamente 0.8 pies por debajo del de cálculo (10.0\%), y en la iglesia de Santa Eugenia en Becerril de Campos (Palencia) 0.3 pies por debajo (2.8\%). Tanto en Valladolid como en Becerril de Campos prácticamente existe coincidencia entre el valor de cálculo y el real $(0.1$ y 0.3 pies de diferencia, 00.8 y $2.8 \%$, respectivamente). Si comparamos los valores obtenidos con la regla aritmética para arcos semicirculares $(c=\sqrt{ }(h+N))$ y los valores reales, observamos de nuevo valores reales por encima de los de cálculo, sin otras conclusiones relevantes.

Podemos observar que las mayores diferencias entre los valores de cálculo y los reales se producen precisamente en las iglesias de una y tres naves con capillas hornacinas entre contrafuertes; cuando las naves se elevan a la misma altura podríamos deducir que el grosor o canto del contrafuerte se ve condicionado por la proporción en planta ( $y$, consecuentemente, la profundidad) que se da a estas capillas en la fase de trazado arquitectónico; cuando, por el contrario, las naves se elevan a distinta altura, aunque el canto del contrafuerte no toma toda la profundidad de la capilla conserva un valor importante, a fin de contrarrestar el empuje de las bóvedas de la nave central, transmitido por encima de la nave lateral por un arbotante.

Como ya hemos comentado, la obtención de resultados satisfactorios con la regla particular para bóvedas de crucería ( $c=2 / 3 \sqrt{ }\left(\mathrm{h}+2 / 3 \sum \mathrm{Ni}\right)$ ) implica la utilización obligatoria del pie castellano como unidad para la introducción de los datos, tal y como se hace en el ejemplo del Compendio con el que se ilustra la regla. Si introdujéramos los datos en varas, observaríamos diferencias bastante mayores entre el valor de cálculo y el real, que oscilarían entre los 1.1 y los 7.2 pies, siendo siempre superiores los de cálculo a los reales, resultado ilógico desde el punto de vista del diseño estructural. Excepcionalmente, en la Catedral Nueva de Salamanca la diferencia sería de solo 0.6 pies, y en la iglesia de los Santos Juanes en Nava del Rey (Valladolid) de 0.8, encontrándose en este último caso el valor de cálculo por debajo del valor real: este hecho podría indicar que en ambos casos los datos fueron introducidos en varas. Así lo ha defendido Sanabria ${ }^{431}$ en relación con la iglesia de la Asunción de Nuestra Señora en Villamor de los Escuderos (Zamora) (1.6 pies de diferencia), y lo mismo podría aplicarse a la iglesia de Santa María de la Asunción en Guareña (Badajoz) y a la catedral de Segovia $(1.1$ y 1.3 pies de diferencia

431 Sanabria 2003: 1797-1799. 
respectivamente), si bien, como ya hemos dicho, en los tres casos el valor de cálculo es superior al real, algo no razonable desde el punto de vista del diseño estructural.

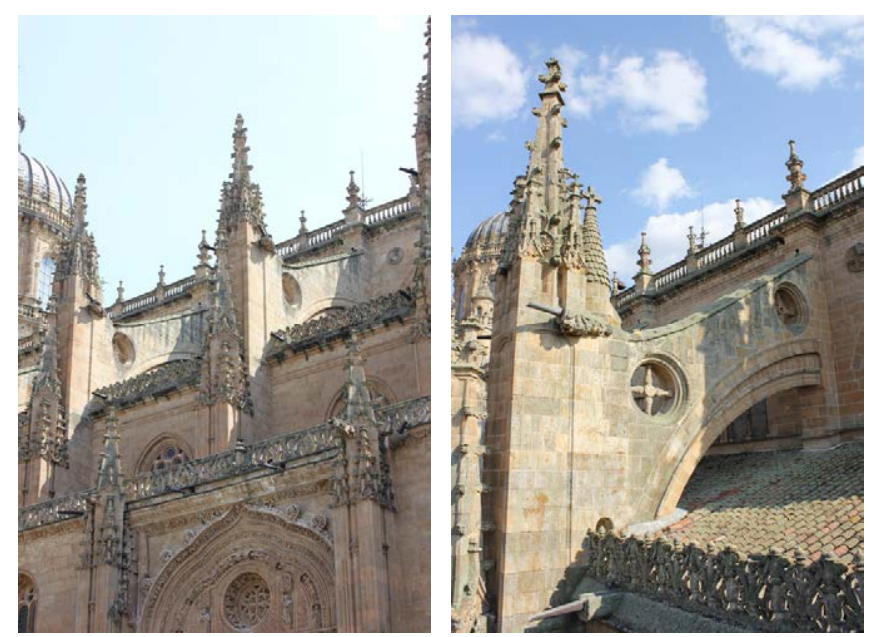

Figura 55. $(a, b)$ Catedral Nueva de Salamanca: contrafuertes y arbotantes de las naves
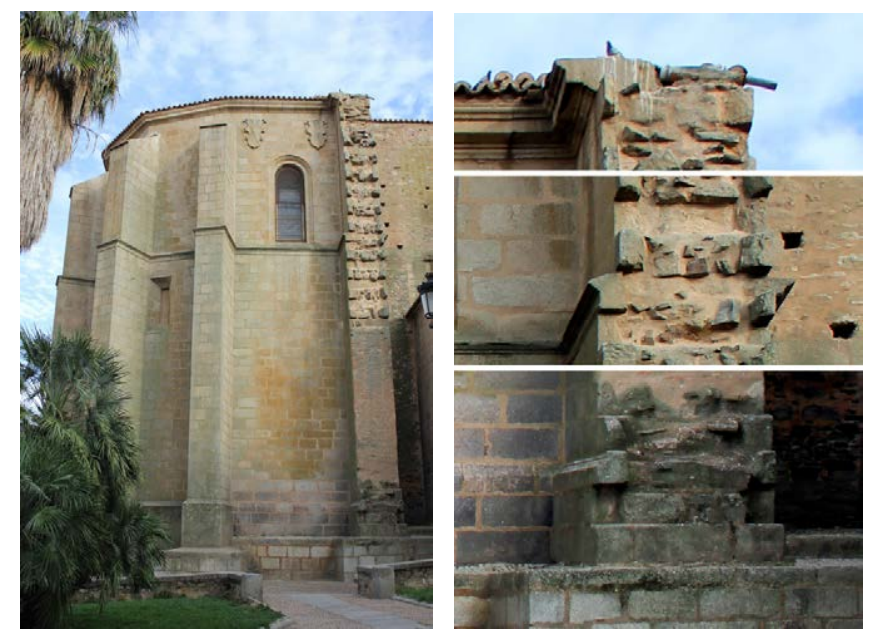

Figura 56. (a, b) Iglesia de Santiago de los Caballeros, Cáceres: escalonamientos sucesivos en la cara exterior del muro de cierre del crucero (inconcluso), a la altura de la imposta de arranque de las bóvedas, del zócalo inferior y de la cimentación (la cara interior mantiene un plano vertical uniforme)

\subsection{Proporción entre las dimensiones en planta del contrafuerte}

Al describir la regla particular para bóvedas de crucería $\left(c=2 / 3 \sqrt{ }\left(\mathrm{h}+2 / 3 \sum \mathrm{Ni}\right)\right.$ ) se establece como presupuesto de partida que la planta del contrafuerte tiene proporción 2:1, como ya hemos comentado, de modo que, si el grosor o canto del contrafuerte es c, su ancho es $c / 2$. Por ello hemos procedido a examinar la relación que se establece entre las dimensiones en planta del contrafuerte en los ejemplos seleccionados. Las relaciones encontradas oscilan entre 1.9 y 2.8, con la única excepción de la Catedral Nueva de Salamanca donde aumenta hasta $3.5^{432}$, observando por tanto que, a grandes rasgos, se cumple la regla establecida en el Compendio (relación 2.0). Es necesario, sin embargo, que hagamos algunas matizaciones a esta afirmación.

432 Los estribos de las naves laterales ya estaban construidos cuando Rodrigo Gil accedió a la maestría, debiéndose su trazado a Juan de Álava o a otro de los maestros que intervinieron en la fábrica. 
Debemos considerar que los valores de cálculo se refieren, según se especifica en el manuscrito, a la planta del contrafuerte a la altura del arranque de la bóveda de crucería, y que dichas dimensiones deben ir aumentando progresivamente hacia el suelo por medio de escalonamientos sucesivos en la fábrica, si bien en el texto no se expresa en qué proporción se produce dicho crecimiento ${ }^{433}$. Los valores reales medidos en cada uno de los edificios seleccionados corresponden, en cambio, a los que presenta el contrafuerte a una altura aproximada de cinco pies del suelo, por encima del habitual zócalo de arranque, aunque únicamente 4 de los 15 ejemplos seleccionados ${ }^{434}$ presentan un escalonamiento entre la altura del arranque de la bóveda y aquella a la que se han tomado las mediciones, cuya dimensión podemos estimar en torno a 0.5 pies. La diferencia no es por tanto demasiado relevante, y consideramos que los valores consignados siguen siendo válidos para ofrecer una orientación respecto a la aplicación práctica de estas reglas de cálculo.
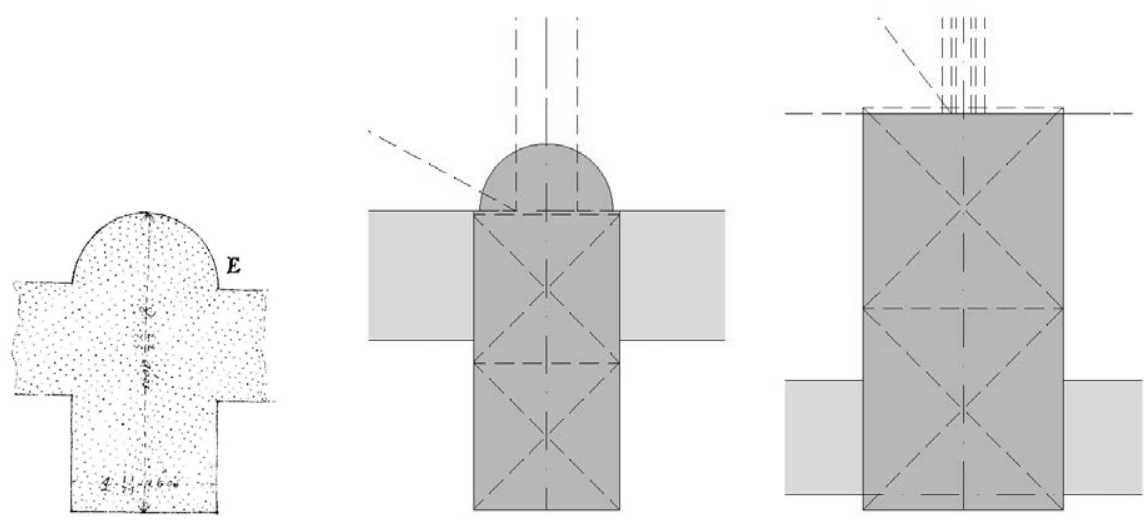

Figura 57. Proporción entre las dimensiones en planta del contrafuerte: (a) Figura que ilustra la regla particular para bóvedas de crucería en el Compendio (García 1681: ilustración 18r). (b) Iglesia de San Martín, Mota del Marqués (Valladolid) (contrafuerte de la nave). (c) Iglesia de la Asunción de Nuestra Señora, Villamor de los

Escuderos (Zamora) (contrafuerte de la nave) (b, c dibujados a la misma escala: P. Moreno)

Por otro lado, el grosor total calculado para el contrafuerte incluye, según el Compendio, el grueso del pilar adosado, el del muro y la proyección exterior del contrafuerte. A diferencia de lo anterior, los valores reales no incluyen el grueso del pilar adosado. Sin embargo, en muchos de los casos estudiados hemos encontrado que la proporción 2:1 entre canto $y$ ancho del contrafuerte se cumple con gran aproximación si no incluimos dicho grueso: en concreto 10 de los 15 ejemplos presentan una relación entre ambos que oscila entre 1.9 y 2.5 , mientras que si computáramos como canto del contrafuerte el grosor del pilar adosado dicha proporción aumentaría sensiblemente. En tres de dichos casos, la iglesia de San Juan Bautista en Fuenteguinaldo (Salamanca), la iglesia de San Martín en Mota del Marqués (Valladolid) y la iglesia de la Asunción de Nuestra Señora en Villamor de los Escuderos (Zamora), la regla se cumple con absoluta precisión, presentando una relación

\footnotetext{
${ }^{433}$ García 1681: cap. 6: 18r, 22v.

${ }^{434}$ Se trata de las iglesias del monasterio de las Bernardas en Salamanca, de la Asunción de Nuestra Señora en Meco (Madrid), de San Sebastián en Villacastín (Segovia) y de la Asunción de Nuestra Señora en Tendilla (Guadalajara).
} 
entre canto y ancho del contrafuerte de 2.0, pero mientras que en Fuenteguinaldo y Mota del Marqués existe efectivamente un pilar adosado en el interior del edificio sobre el que se produce el apoyo de los nervios, en Villamor de los Escuderos el apoyo de las bóvedas de la nave se resuelve con ménsulas: en conclusión, la práctica observada en el dimensionado de estos edificios parece no computar como canto del contrafuerte el grosor del pilar adosado, contradiciendo lo que se indica en el Compendio al describir la regla particular para bóvedas de crucería. 
3. LAS BÓVEDAS DE CRUCERÍA DE RODRIGO GIL 

3.1. ANÁLISIS INDIVIDUAL DE LAS BÓVEDAS 

Now professional men are so commonly entrusted with the repairs or restoration of these old structures, that ... a few years would suffice to bring together a body of examples from which general rules might be deduced. It is only by comparing many examples that this can be done, for general rules deduced from single instances are commonly worthless. (R. Willis, On the Construction of the Vaults of the Middle Ages ${ }^{435}$ ).

La bóveda de crucería ha sido siempre considerada el elemento más característico del gótico, y quizás su mayor logro arquitectónico. Como tal, ha sido objeto de innumerables reflexiones, de las cuales las más extensas son sin duda las que afectan a la función de sus principales elementos constitutivos, los nervios ${ }^{436}$. Dejando aparte su evidente carácter estilístico, se podrían señalar las siguientes funciones constructivas y estáticas. En primer lugar, permiten resolver la arista que resulta de la intersección de los dos cañones perpendiculares que forman una bóveda cuatripartita, facilitando en gran medida la ejecución al sustituir las piezas de dichas aristas, de complicada estereotomía, por arcos simples (el corte de estas piezas es complejo, ya que difieren en cada hilada, y aún más dificultoso si la planta no es cuadrada sino rectangular, ya que la línea de encuentro resultante no es una elipse plana sino una curva alabeada). En segundo lugar, reducen la entidad de las cimbras necesarias para la construcción, ya que parte del peso de la plementería es recogido por los propios nervios durante el montaje, por lo que, hasta que se produzca el cierre de la bóveda, presentan una función estructural temporal ${ }^{437}$.

El gótico fue evolucionando, desde esta bóveda clásica en cruce de ojivas, hacia una estructura caracterizada por la proliferación de los nervios, algo que modifica notablemente el sistema de ejecución. Por un lado, los arcos requieren disponer un mayor número de cimbras curvas, de costosa ejecución, si bien su importancia disminuye debido a que el peso de la plementería, recogido durante el montaje en parte por los nervios, se encuentra más distribuido. Por otro, la presencia de nervaduras decorativas, que unen los arcos generando claves en los puntos de encuentro, obliga a la utilización de cimbras para su montaje, si bien la entidad de estas es limitada o incluso pueden llegar a desaparecer

\footnotetext{
435 Willis 1842: 3.

436 El debate sobre la función de los nervios ha ocupado a gran número de estudiosos en los últimos ciento cincuenta años. Durante la segunda mitad del siglo XVIII la historiografía interpretaba los usos decorativo, constructivo y estructural como aspectos conciliables (Gómez 1998: 11-12). Willis (2012: 5), ya en el XIX, tampoco daba especial relevancia al papel estructural de los nervios ("La bóveda nervada de la Edad Media ... Consiste, como es sabido, en un entramado de nervios o arcos de piedra, sobre los cuales descansan las auténticas bóvedas"). Sin embargo, a mediados de esa centuria Viollet-le-Duc (1854-1868: vol. IX, 501, 502, 505, 513, 524, 537 ("Voûte")) planteó su visión constructiva de la arquitectura gótica, defendiendo la existencia de elementos pasivos y activos, estructuralmente hablando, y considerando los nervios como cintres permanents (cimbras permanentes). Su planteamiento tuvo multitud de seguidores, como su discípulo Choisy (1899), aunque no tardaron en aparecer en las décadas siguientes posiciones críticas con esta postura, como las de Sabouret (1928) y Abraham (Abraham 1934, Abraham 1939), que defendían la función simplemente decorativa de los nervios, apoyándose en parte en el comportamiento de muchas bóvedas francesas dañadas durante la Primera Guerra Mundial, que se mantenían en pie a pesar de que sus nervios habían desaparecido total o parcialmente. Desde los años cuarenta surgieron visiones más eclécticas, pudiendo citar en nuestro país las de Torres Balbás (Torres 1939, Torres 1945) ○ Bassegoda (1944), que defendían de nuevo la función doble, estética y constructiva o estructural, de los nervios. El debate continuaría, con estudiosos como Frankl (2002: 83-84) apoyando la postura formalista, y otros como Mark (Mark 1977, Mark [1977] 1997) defendiendo la funcionalista.

437 Bassegoda 1944: 128-132; Fitchen 1960: 287-289; Heyman 1999a: 61-64; Torres 1945: 228-231.
} 
dada la cercanía entre las claves. Finalmente, la proximidad de los nervios simplifica la colocación del plemento, reduciendo o eliminando de igual manera el cimbrado, algo de gran importancia, ya que el casco supone la mayor parte de la superficie total de la bóveda, frente a los nervios que, comparativamente, representan una menor proporción.

Por último, debemos señalar que los nervios pueden en ocasiones conservar una función estructural en la bóveda terminada. Aunque los plementos en que se divide la cáscara de la bóveda están sometidos a niveles tensionales muy bajos, las intersecciones donde se produce un cambio de curvatura, esto es, los pliegues de la cáscara, presentan una importante concentración de tensiones: los nervios situados en dichos pliegues absorben parte de esas tensiones que, de otro modo, tendrían que ser asumidas por la cáscara. Este sería el caso de una bóveda cuatripartita del gótico clásico, que presenta discontinuidades bruscas en la curvatura, crecientes desde la clave central hacia los ángulos de la bóveda. Por el contrario, cuando los nervios se disponen en una cáscara de curvatura continua perderán en gran medida dicha función estructural: esto es lo que ocurre con muchos de los nervios de una bóveda del gótico tardío, cuyos terceletes y nervios decorativos generan pliegues poco acusados. En ambos casos los arcos formeros, empotrados en los muros de cerramiento, tendrán escaso cometido en el sostén de la bóveda, y lo mismo ocurrirá con los perpiaños que separan los tramos si el espinazo es aproximadamente horizontal, esto es, si no existe una discontinuidad brusca en ellos ${ }^{438}$.

\subsubsection{Metodología}

Después de estudiar las obras realizadas por Rodrigo Gil a lo largo de su trayectoria profesional, se ha seleccionado para su análisis un conjunto de 104 bóvedas de crucería, presentes en 36 edificios de 27 localidades distintas. Los edificios, todos ellos de carácter religioso 439 , se ordenan alfabéticamente por localización. Dentro de cada uno de ellos, las bóvedas se presentan procediendo desde la cabecera hacia los pies del edificio, y desde la nave central hacia las laterales; una vez estudiado el espacio principal del templo, se investigan las bóvedas que corresponden a las dependencias secundarias, como sacristías, capillas particulares y otras. Las bóvedas se describen y representan gráficamente considerando sus plantas orientadas hacia la cabecera del conjunto, situada habitualmente hacia el este.

El análisis individual de las bóvedas tiene como finalidad la formulación de una serie de hipótesis relativas al trazado geométrico teórico con el que pudieron ser concebidas, así como de algunas observaciones referidas a su configuración constructiva. Los resultados de este análisis se han organizado, para cada una de las bóvedas, en una serie de apartados, divididos en características geométricas (modulación y rangos dimensionales, sistemas de composición, arcos, rampante) y características constructivas (nervios, jarjas, claves, plementería), acerca de los cuales hacemos a continuación algunas precisiones. Estos apartados han sido igualmente utilizados en la parte de este estudio que se refiere al

\footnotetext{
438 Heyman 1999a: 61-64; Heyman 1999b: 222-226; Huerta 2007: 526 nota 36.

439 Tanto el Colegio Mayor del Arzobispo Fonseca como el Colegio Menor de San Pelayo, ambos en Salamanca, son edificios de carácter civil, aunque las bóvedas analizadas se localizan en sus respectivas capillas.
} 
análisis comparativo de la totalidad de las bóvedas, por lo que cualquier explicación ulterior puede encontrarse en la citada parte.

\subsubsection{Modulación y rangos dimensionales}

Se plantean siempre como principales las dimensiones de la bóveda a ejes de los arcos del perímetro. Dichos ejes corresponden a los de los perpiaños que limitan cada uno de los tramos en un edificio abovedado y separan entre sí sus bóvedas de crucería, estén dispuestas las bóvedas a la misma altura a ambos lados del arco, o a alturas distintas; y a los de los formeros, que coinciden con el contorno interior de los muros que limitan cada espacio del edificio. En cualquier caso, cuando las dimensiones a ejes de los arcos del perímetro y las interiores no coinciden, se proporcionan también estas últimas, por ser igualmente esenciales para el trazado de la bóveda.

Por lo que respecta a la proporción entre los lados de las bóvedas de planta cuadrada o rectangular, hemos indicado el valor real encontrado (con tres decimales) y la proporción teórica a la que este se aproxima en mayor medida (entre paréntesis). Únicamente hemos tenido en consideración, de las infinitas posibilidades que pueden presentarse, el siguiente conjunto de proporciones: $1: 1=1.000 ; 2: 1=2.000 ; 3: 2=1.500 ; 4: 3=1.333 ; 5: 4=1.250$; $6: 5=1.200 ; 7: 6=1.167 ; 8: 7=1.143 ;$ phi $\approx 1.618 ; \sqrt{ } 2=1.414$.

\subsubsection{Sistemas de composición}

El número de terceletes indicado toma en consideración, en las bóvedas de planta cuadrangular, un cuarto de la bóveda en planta, limitado por sus ejes de simetría y los arcos del perímetro; $y$, en el de las bóvedas de planta poligonal, la mitad de cada uno de los sectores triangulares en que se dividen.

Por otra parte, el número de claves interiores indicado omite, como era habitual en la época, las claves centrales de los arcos del perímetro, por lo que, si queremos tomarlas en consideración, es necesario añadir cuatro para las bóvedas de planta cuadrangular, o un número equivalente al de lados para las de planta poligonal. Sin embargo, sí incluye las claves secundarias que, en algunos casos poco frecuentes, se presentan en puntos intermedios del recorrido de los arcos del perímetro.

\subsubsection{Arcos}

Los resultados geométricos del análisis se han recogido en tablas, organizadas en cuatro columnas: nervio, tipo, radio y peralte. Estas recogen, respectivamente, la denominación del arco según su posición en la bóveda, su clasificación en cuanto a número de centros y posición de estos, y los valores numéricos relativos a sus curvaturas de trazado y peraltes.

\subsection{Nervio}

Como hemos comentado, las bóvedas, que pertenecen siempre a edificios de carácter religioso, se describen y representan gráficamente considerando sus plantas orientadas hacia la cabecera del conjunto, situada usualmente hacia el este; con esta disposición, los arcos dispuestos en dicha dirección (eje y) reciben en las tablas el nombre de formeros, mientras que los arcos perpendiculares a los anteriores (eje $\mathrm{x}$ ) son denominados perpiaños, 
con independencia de su relación con los tramos contiguos y con el cerramiento. En puridad, los arcos formeros serían aquellos que reciben la intersección de la bóveda con el muro de cerramiento, mientras que arcos perpiaños serían los que separan tramos contiguos, independientemente de su orientación con respecto a la nave del templo, y en este sentido se emplean dichos términos en el resto del presente texto; sin embargo, hemos considerado que la reducción terminológica indicada es útil en la confección de las tablas, a fin de poder identificar, en cada bóveda, los datos de cada uno de los arcos, eliminando posibles confusiones.

Siguiendo esta misma convención, los terceletes más cercanos a los arcos formeros, esto es, cuyas claves se sitúan sobre el eje $\mathrm{x}$ de la bóveda, se han denominado terceletes formeros, mientras que los más cercanos a los arcos perpiaños, esto es, cuyas claves se sitúan sobre el eje y de la bóveda, se han denominado terceletes perpiaños. Ambos se han identificado respectivamente con las abreviaturas tercelete for. $y$ tercelete per.

Caso de haber dos nervios, ya sean perpiaños, formeros, terceletes perpiaños o terceletes formeros, que coinciden en denominación pero cuyas características geométricas difieren, se identifica cada uno de ellos como N, S, E u O (norte, sur, este u oeste), en función de su posición con respecto al conjunto; caso de haber más de dos nervios que coinciden en denominación, se identifica cada uno de ellos como 1, 2, 3, 4, siendo, en las bóvedas de planta cuadrada o rectangular, 1 el nervio más cercano al perímetro de la bóveda y 4 el más cercano a su centro, $y$, en las bóvedas de planta poligonal, 1 el más cercano a la embocadura y 4 el más cercano al interior.
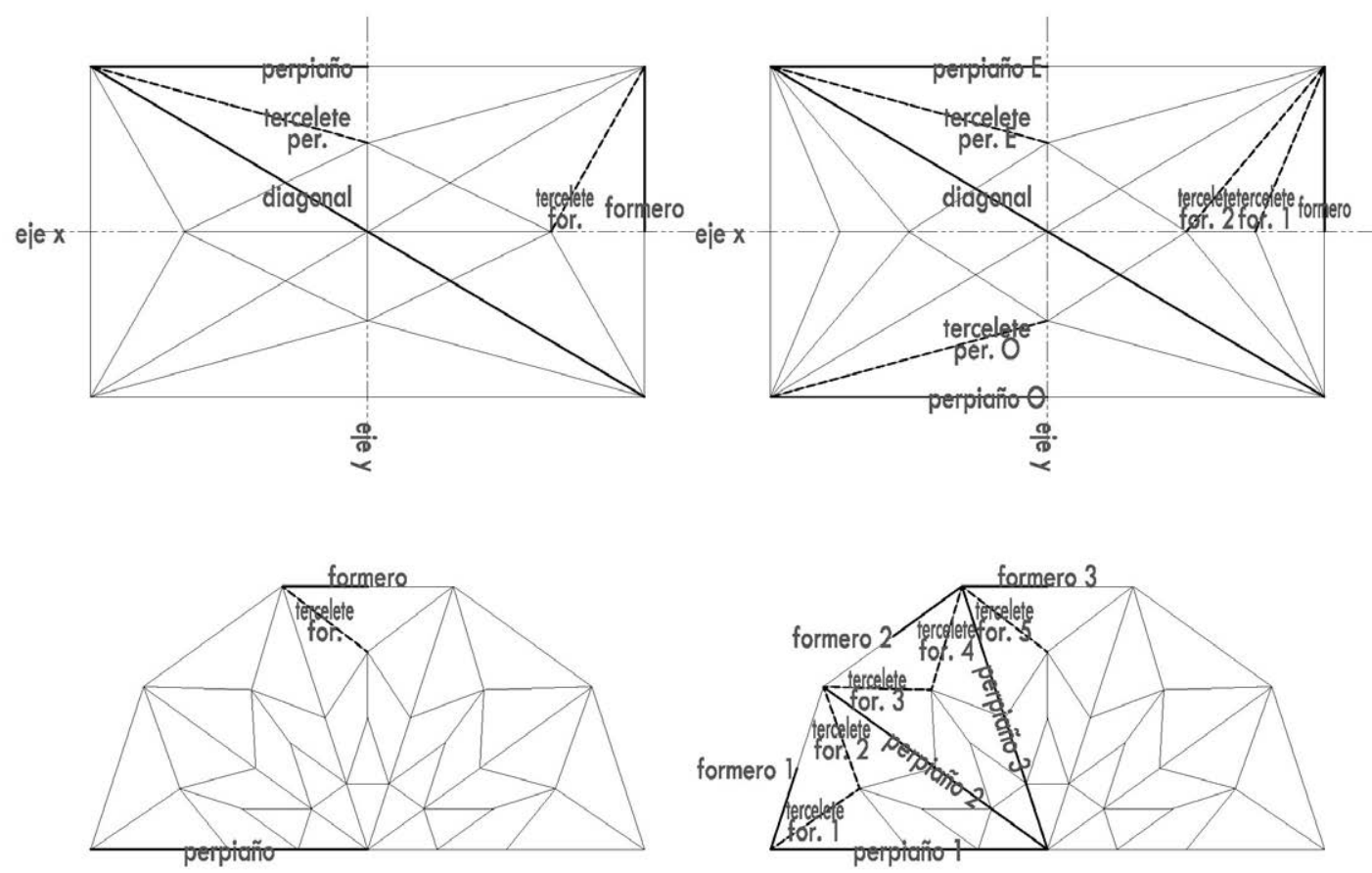

Figura 58. Criterios para la denominación de los arcos en las tablas: (a) Bóvedas de planta cuadrada o rectangular: caso general. (b) Bóvedas de planta cuadrada o rectangular: presencia de nervios que coinciden en denominación pero no en geometría. (c) Bóvedas de planta poligonal: caso general. (d) Bóvedas de planta poligonal: presencia de nervios que coinciden en denominación pero no en geometría (a-d: P. Moreno) 


\subsection{Tipo}

Dependiendo del número de centros de trazado que presente el arco y de la posición de estos se han utilizado las siguientes categorías y abreviaturas:

- Sc: semicircular; ap: apuntado (con uno o dos centros respectivamente, situados en el plano de arranque de los arcos).

- sc.rb: semicircular rebajado o escarzano; ap.in: apuntado inclinado (con uno o dos centros respectivamente, situados por debajo del plano de arranque de los arcos).

- car: carpanel; tu: Tudor (con tres o cuatro centros respectivamente, situados dos en el plano de arranque de los arcos y otro $u$ otros dos por debajo de él).

Al indicar el tipo al que pertenece el tercelete, ha de considerarse que este representa solo la mitad del arco correspondiente, por lo que si es apuntado, apuntado inclinado o Tudor tendrá, respectivamente, uno, uno o dos centros.

Como hemos señalado en la introducción de nuestra investigación, aunque una rigurosa toma de datos realizada in situ sobre cada una de las bóvedas permita acometer con ciertas garantías su restitución geométrica, la forma de los arcos está sometida a variaciones introducidas por distintos factores, como el mayor o menor nivel de precisión alcanzado en cada caso en el trazado y la construcción de las piezas y de las cimbras, o las deformaciones introducidas por la puesta en carga de las bóvedas o por los asientos de los apoyos en el terreno. Todas estas razones hacen que las geometrías encontradas rara vez respondan con absoluta exactitud a un modelo teórico, y que haya que tomar determinados criterios aproximativos que permitan su análisis y estudio. Esta circunstancia es especialmente delicada en el caso del arco diagonal, cuyo trazado es fundamental en la definición geométrica del conjunto de la bóveda. Efectivamente, en ocasiones puede ser difícil determinar si su forma es semicircular o rebajada, ya que el valor de este rebaje puede ser poco importante. A fin de resolver este problema hemos tomado para nuestro análisis unos valores límite de referencia, basados en la relación $d / I$, siendo d la distancia vertical entre la clave de la diagonal real y la que correspondería a una diagonal semicircular, y I la luz de la diagonal. Dichos valores son los siguientes:

- El arco se considera semicircular o de medio punto si $d / l \leq 0.010(1 \%)$, partiendo en su arranque tangente a la vertical (su centro se encuentra a la altura de sus arranques). Los valores límite encontrados son $d / l=0.010(1 \%)$ y $d=0.13 \mathrm{~m}$.

- El arco se considera rebajado si d/I>0.010 (1\%). Dentro de los arcos rebajados, el arco carpanel parte tangente a la vertical en sus arranques (los centros de las porciones inferiores del arco se encuentran a la altura de sus arranques), mientras que el arco semicircular rebajado o escarzano parte en su arranque inclinado respecto a la vertical (su centro se encuentra por debajo de la altura de sus arranques); los valores límite encontrados son $d / l=0.011(1.1 \%)$ y $d=0.13 \mathrm{~m}^{440}$.

\footnotetext{
440 La diagonal de la bóveda del tramo lateral norte del pórtico del Paraíso de la catedral de Ourense ha sido considerada carpanel, y la de la bóveda del tramo lateral sur de la cabecera de la iglesia de San Juan de Puerta Nueva en Zamora ha sido clasificada como escarzana, aunque presentan respectivamente unos valores $\mathrm{d}=0.08 \mathrm{~m}$ y $\mathrm{d}=0.11 \mathrm{~m}$, en aras de no complicar innecesariamente el estudio y dado el escaso interés de ambos ejemplares.
} 
- En los arcos apuntados el cambio de curvatura en la clave central entre las dos porciones que los componen se percibe con claridad, por lo que no es necesario tomar ningún criterio aproximativo. No obstante los valores límite encontrados son $d / I=0.011(1.1 \%)$ y $d=0.14 \mathrm{~m}$.

Un problema similar se nos presenta para determinar si el arco diagonal está peraltado o no. Para resolverlo hemos tomado igualmente unos valores límite, obtenidos a partir de la relación $\mathrm{p} / \mathrm{I}$, siendo $\mathrm{p}$ el peralte de la diagonal, y I su luz. De acuerdo con ello, el arco se considera no peraltado si $\mathrm{p} / \mathrm{I} \leq 0.010(1 \%)$, siendo los valores límite encontrados $p / I=0.010$ $(1 \%)$ y $p=0.08 \mathrm{~m}$. Por el contrario el arco se considera peraltado si $\mathrm{p} / \mathrm{l}>0.010(1 \%)$, apareciendo unos valores límite $p / l=0.013(1.3 \%)$ y $p=0.13 \mathrm{~m}$.

\subsection{Radio}

Por un lado, debemos señalar que los datos relativos al radio de cada uno de los arcos se refieren siempre a la línea de trasdós de la zona moldurada de los nervios, situada en contacto con la superficie inferior de la plementería. Por otro, al comparar los radios de curvatura de los distintos arcos nos encontramos con el problema de que rara vez coinciden con absoluta exactitud, ya sea por irregularidades geométricas producidas durante la ejecución o por deformaciones en el descimbrado o a lo largo de la vida del edificio. Por esta razón se hace imprescindible establecer un margen de tolerancia que nos permita determinar los intervalos de valores que corresponden a un mismo radio. Hemos fijado dicha tolerancia en un valor absoluto de 1 pie $(0.278635 \mathrm{~m})$, y de acuerdo con él hemos analizado la posible existencia de coincidencias entre los radios de trazado en cada una de las bóvedas. En la parte de este estudio dedicada al análisis comparativo del conjunto de estas estructuras se incluyen una serie de tablas que toman en consideración no solo el valor citado, sino también uno inferior y otro superior $(0.5$ pies $(0.139318 \mathrm{~m})$ y 1.5 pies $(0.417953 \mathrm{~m})$ ), indicando las razones por las que se ha asumido como más acertado el rango central, esto es, el margen de tolerancia de 1 pie. En este sentido, el interés de las hipótesis de diseño formuladas no se encuentra, de modo fundamental, en el planteamiento de unos determinados valores numéricos, ya que, pese a la rigurosidad con que la toma de datos pueda haber sido llevada a cabo, los resultados del análisis quedan siempre del lado de la hipótesis. Por el contrario, la importancia estriba, a nuestro juicio, en el estudio de las estrategias generales de trazado y construcción.

\subsubsection{Rampante}

Los rampantes o líneas de espinazo de la bóveda se clasifican, según la forma general que presenten, en cuatro categorías distintas: horizontal, convexo, llano y redondo. El rampante horizontal corresponde a una línea de espinazo totalmente recta cuyos puntos se encuentran siempre al mismo nivel. El rampante convexo tiene la singularidad de que la clave central se encuentra más baja que la de los arcos del perímetro de la bóveda. El rampante llano y el redondo presentan una forma general cóncava, habiendo establecido las siguientes convenciones, meramente metodológicas, para diferenciarlos en nuestro estudio: el rampante llano será considerado como el que se genera en una bóveda de planta cuadrada y diagonal semicircular cuyos arcos comparten el mismo radio, resultando una línea levemente curvada, mientras que el rampante redondo corresponderá a una línea de espinazo que 
coincide en radio con el de la diagonal semicircular, y por tanto equivale al de una bóveda baída.

\subsubsection{Unidades utilizadas}

Los datos correspondientes a cada una de las bóvedas analizadas se recogen, como hemos indicado al comienzo de nuestra investigación, utilizando como unidad común el pie castellano. En el caso de las magnitudes más importantes, los valores en pies se acompañan de su equivalencia en metros: tal es el caso de las dimensiones de la bóveda en planta, las alturas del plano de imposta y de la clave central, y la diferencia de altura entre la clave central y las claves de los arcos del perímetro. Por su parte, los datos relativos a la geometría de los nervios (radio y peralte de los arcos) se ofrecen solo en pies castellanos. La equivalencia utilizada en la conversión de medidas es la ya señalada, esto es, una vara castellana equivale a 0.835905 metros y se divide en tres pies de 0.278635 metros.

\subsubsection{Convenciones gráficas}

Una vez planteadas las distintas hipótesis de diseño, la geometría de cada una de las bóvedas se ha plasmado en un dibujo realizado en sistema diédrico, en el que se emplean las siguientes convenciones:

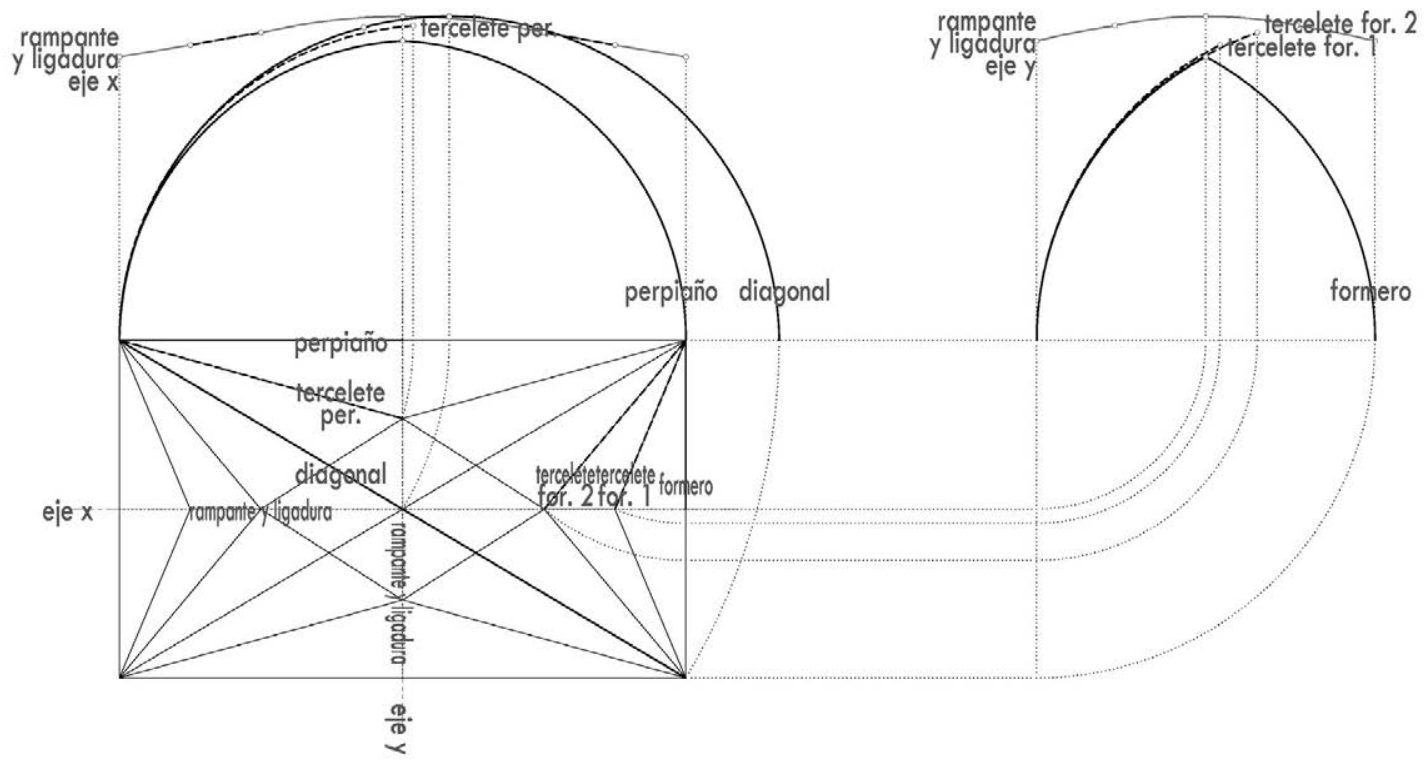

Figura 59. Convenciones gráficas para la representación en sistema diédrico de las bóvedas de crucería estudiadas (P. Moreno)

- La planta se representa orientada hacia la cabecera del conjunto. Esta disposición coincide con la de la planta del edificio al que corresponde la bóveda.

- La línea de imposta de la que arranca la bóveda y la línea de tierra del dibujo coinciden. 
- En el alzado se representan las proyecciones de los arcos del perímetro de la bóveda que se disponen en la dirección del eje $x, y$ por tanto paralelos en planta a la línea de tierra (denominados en las tablas como perpiaños). También aparecen en él los abatimientos de los terceletes más cercanos a dichos arcos, esto es, cuyas claves se sitúan sobre el eje y de la bóveda (denominados en las tablas como terceletes perpiaños). Por último, en el alzado se dibuja también la proyección del rampante según el eje $x$ de la bóveda (junto con su ligadura, caso de existir), y el abatimiento del arco diagonal.

- En la vista lateral se representan los abatimientos de los arcos del perímetro de la bóveda que se disponen en la dirección del eje $y, y$ por tanto perpendiculares en planta a la línea de tierra (denominados en las tablas como formeros). También aparecen en ella los abatimientos de los terceletes más cercanos a dichos arcos, esto es, cuyas claves se sitúan sobre el eje $\mathrm{x}$ de la bóveda (denominados en las tablas como terceletes formeros). Por último, en la vista lateral se dibuja también el abatimiento del rampante según el eje y de la bóveda (junto con su ligadura, caso de existir).

- Los arcos perpiaños, formeros y diagonales y los rampantes se representan en línea continua, que en el caso de estos últimos es de color gris. Los terceletes y ligaduras lo hacen en línea discontinua. La geometría de perpiaños, formeros y diagonales se representa en su totalidad, es decir, abarcando su desarrollo entre apoyos. De modo análogo, los rampantes se dibujan en su recorrido completo entre las claves de los arcos del perímetro de la bóveda. Los terceletes se representan en su desarrollo entre apoyo y clave.

Finalmente, este dibujo se ha acompañado de un modelo tridimensional que facilita la comprensión del trazado. 


\subsubsection{Astorga (León) - Catedral de Santa María}

Datos históricos del edificio: véase página 770 y siguientes

Datos de medición de las bóvedas: véase página 846 y siguientes
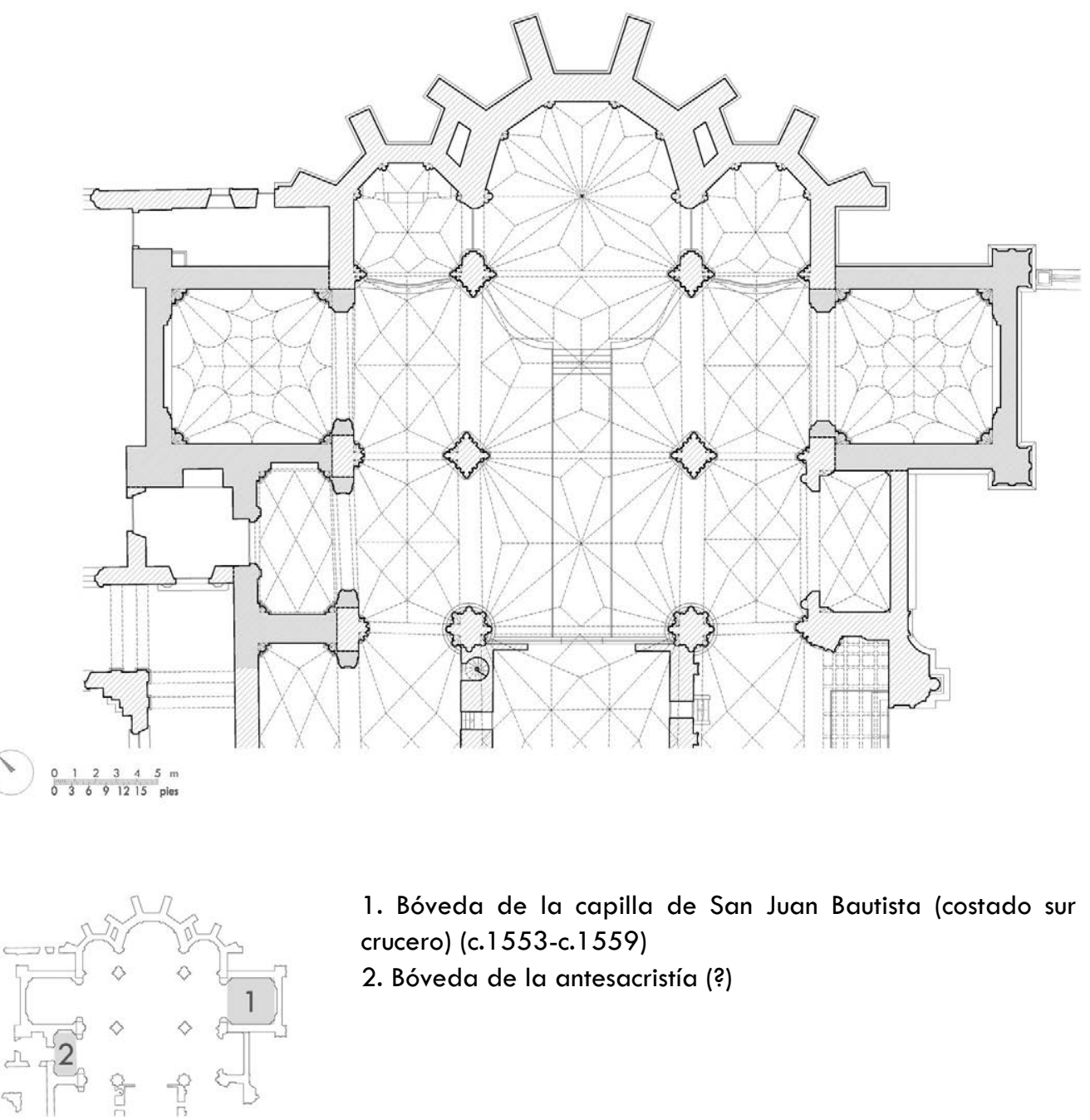

1. Bóveda de la capilla de San Juan Bautista (costado sur del falso crucero) (c.1553-c.1559)

2. Bóveda de la antesacristía (?)

Figura 60. Catedral de Astorga (León): (a) Planta de la cabecera, primer y segundo tramo de naves (García y Pérez 1995). (b) Indicación de las bóvedas analizadas, con su fecha de ejecución (P. Moreno) 


\subsubsection{Bóveda de la capilla de San Juan Bautista (costado sur del falso crucero) ${ }^{441}$}

Modulación y rangos dimensionales: La bóveda tiene una planta cuadrada de dimensiones $27.0 \times 27.0$ pies $(7.53 \times 7.53 \mathrm{~m})$ y proporción entre los lados $1.000(1: 1)$, ambas consideradas a ejes de los arcos del perímetro (coinciden con las interiores). Todos los nervios tienen un punto de arranque común en cada apoyo.

Sistemas de composición: La crucería principal está formada por los dos arcos diagonales y terceletes sencillos en la dirección de ambos ejes. Las nervaduras decorativas forman un cuadrifolio de hojas cóncavas, en cuyo interior se dispone otro cuadrifolio de hojas convexas y tangentes al primero. En conjunto se obtiene un diseño con 21 claves interiores. - Las claves de los terceletes se sitúan en la bisectriz del ángulo formado por la diagonal y los arcos del perímetro. Las claves secundarias sobre los terceletes quedan aproximadamente alineadas sobre un paralelogramo que une los puntos medios de los lados de la bóveda; las dieciséis claves secundarias se sitúan en los puntos de corte de los nervios con una retícula de $3 \times 3$ aplicada a la planta (esta queda dividida en nueve sectores de 9.0×9.0 pies); los centros principales del cuadrifolio exterior se disponen sobre la diagonal, y los de sus remates o pies de gallo sobre el perímetro de la bóveda; los centros del cuadrifolio interior (uno por cada hoja) se disponen en el punto medio de los segmentos limitados por las cinco claves de las diagonales.

Arcos: El plano de imposta se sitúa a una altura de 40.5 pies ( $11.29 \mathrm{~m}$ ) del suelo, y la clave central a 17.6 pies $(4.91 \mathrm{~m})$ de dicho plano. Todos los arcos parten tangentes a la vertical en el arranque, presentando algunos peraltes, aunque no la diagonal. La clave central se encuentra 1.5 pies $(0.41 \mathrm{~m})$ por debajo de la posición que correspondería a la de un arco ojivo semicircular. Un examen visual de la geometría de la diagonal y la comprobación de la posición que ocupan las claves secundarias dispuestas a lo largo de este arco nos hace concluir que su trazado teórico es carpanel, partiendo sin peralte en su arranque. Los arcos se trazarían aparentemente con 4 radios distintos, siendo sus datos geométricos en pies los siguientes:

\begin{tabular}{lccc} 
nervio & tipo & radio & peralte \\
\hline diagonal & car & $16.7 \cdot 20.3$ & 22 \\
perpiaño & ap & 14.7 & 2.9 \\
formero & ap & 14.7 & 2.9 \\
tercelete per. & ap & 17.9 & \\
tercelete for. & ap & 17.9 &
\end{tabular}

Rampante: Las claves de los arcos del perímetro se sitúan, en la dirección de ambos ejes, a la misma altura que la clave central. El rampante se puede considerar horizontal en la dirección de ambos ejes.

Características constructivas: Los nervios que forman la crucería interior presentan 3 tipos distintos de sección en cuanto a molduraje y canto (grande para la diagonal; mediano para el tercelete y la ligadura; pequeño para el nervio decorativo). - Las jarjas se componen de 5 y 6 hiladas, dependiendo del nervio considerado. - Las claves tienen su eje central vertical (y su cara inferior paralela a la superficie de la bóveda en cada punto). - La plementería es probablemente de ladrillo; asienta directamente sobre el trasdós del formero 442.

\footnotetext{
${ }^{441}$ La bóveda que cubre la capilla del costado norte del falso crucero difiere ligeramente de la analizada, en cuanto a trazado en planta del cuadrifolio interior (dos centros por cada hoja en lugar de uno) y características geométricas de los distintos nervios.

442 Otro análisis de esta bóveda aparece en Palacios 2009: 125-127. Según este autor, el trazado de las claves secundarias partiría de dividir en cuatro partes iguales los ejes; los arcos principales del cuadrifolio exterior y los del cuadrifolio interior coincidirían en radio; la diagonal sería semicircular ligeramente peraltada y todos los arcos tendrían el mismo radio.
} 

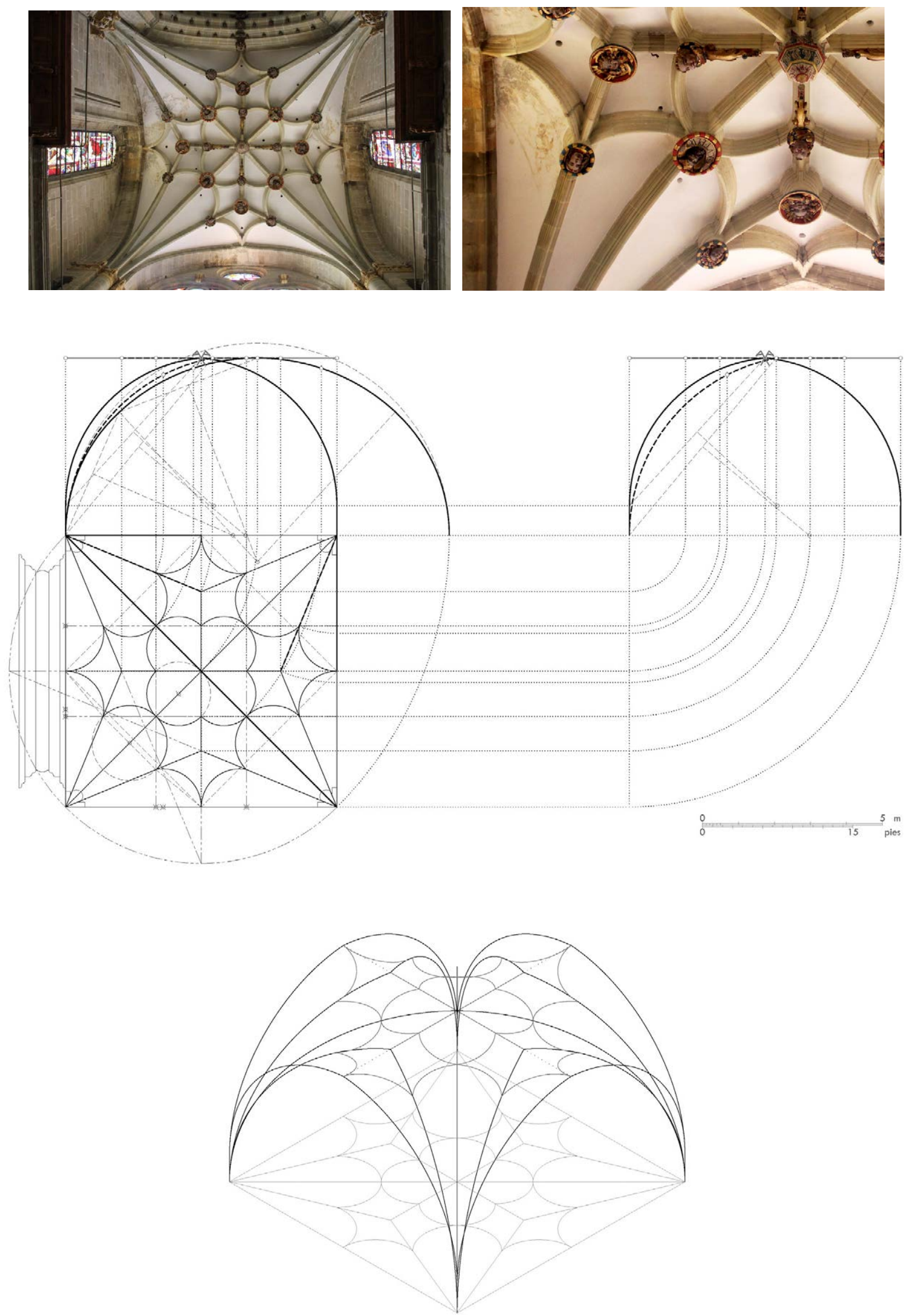

Figura 61. Catedral de Astorga (León): bóveda de la capilla de San Juan Bautista (costado sur del falso crucero): (a) Vista en planta. (b) Detalle de los nervios, claves y plementería. (c) Hipótesis de trazado de los nervios. (d) Modelizado de los nervios (c, d: P. Moreno) 


\subsubsection{Bóveda de la antesacristía}

Modulación y rangos dimensionales: La bóveda tiene una planta rectangular de dimensiones $11.1 \times 23.0$ pies $(3.09 \times 6.42 \mathrm{~m})$ y proporción entre los lados $2.072(2: 1)$, ambas consideradas a ejes de los arcos del perímetro (coinciden con las interiores). Todos los nervios tienen un punto de arranque común en cada apoyo.

Sistemas de composición: La crucería principal está formada por los dos arcos diagonales, careciendo de terceletes. Las nervaduras decorativas forman un rombo de lados rectos. En conjunto se obtiene un diseño con 5 claves interiores. - Las claves sobre las diagonales son generadas automáticamente uniendo las claves de los arcos del perímetro.

Arcos: El plano de imposta se sitúa a una altura de 45.8 pies (12.75 m) del suelo, y la clave central a 13.4 pies $(3.73 \mathrm{~m})$ de dicho plano. Todos los arcos parten tangentes a la vertical en el arranque, presentando todos peraltes. La clave central se encuentra 0.6 pies $(0.17 \mathrm{~m})$ por encima de la posición que correspondería a la de un arco ojivo semicircular. Un examen visual de la geometría de la diagonal y la comprobación de la posición que ocupan las claves secundarias dispuestas a lo largo de este arco nos hace concluir que su trazado teórico es efectivamente semicircular, partiendo con un peralte de 0.6 pies $(0.17 \mathrm{~m})$ en su arranque. Los arcos se trazarían aparentemente con 3 radios distintos, siendo sus datos geométricos en pies los siguientes:

\begin{tabular}{lccc} 
nervio & tipo & radio & peralte \\
\hline diagonal & sc & 12.8 & 0.6 \\
perpiaño & ap & 9.1 & 0.6 \\
formero & ap & 11.7 & 0.6
\end{tabular}

Rampante: Las claves de los arcos del perímetro se sitúan, en la dirección del eje $\mathrm{x}$ (menor), a 1.0 pies $(0.29 \mathrm{~m}$ ) por debajo de la clave central; en la dirección del eje y (mayor), a 4.4 pies (1.22 m) por debajo de la clave central. El rampante se puede considerar llano en la dirección del eje $x$ (menor) y redondo en la del eje y (mayor).

Características constructivas: Los nervios que forman la crucería interior presentan 2 tipos distintos de sección en cuanto a molduraje y canto (grande para la diagonal; pequeño para el nervio decorativo). - Carece de jarjas, ya que los nervios son independientes desde el arranque. • Las claves tienen su eje central vertical (y su cara inferior paralela a la superficie de la bóveda en cada punto). - La plementería es probablemente de ladrillo; asienta directamente sobre el trasdós del formero. 

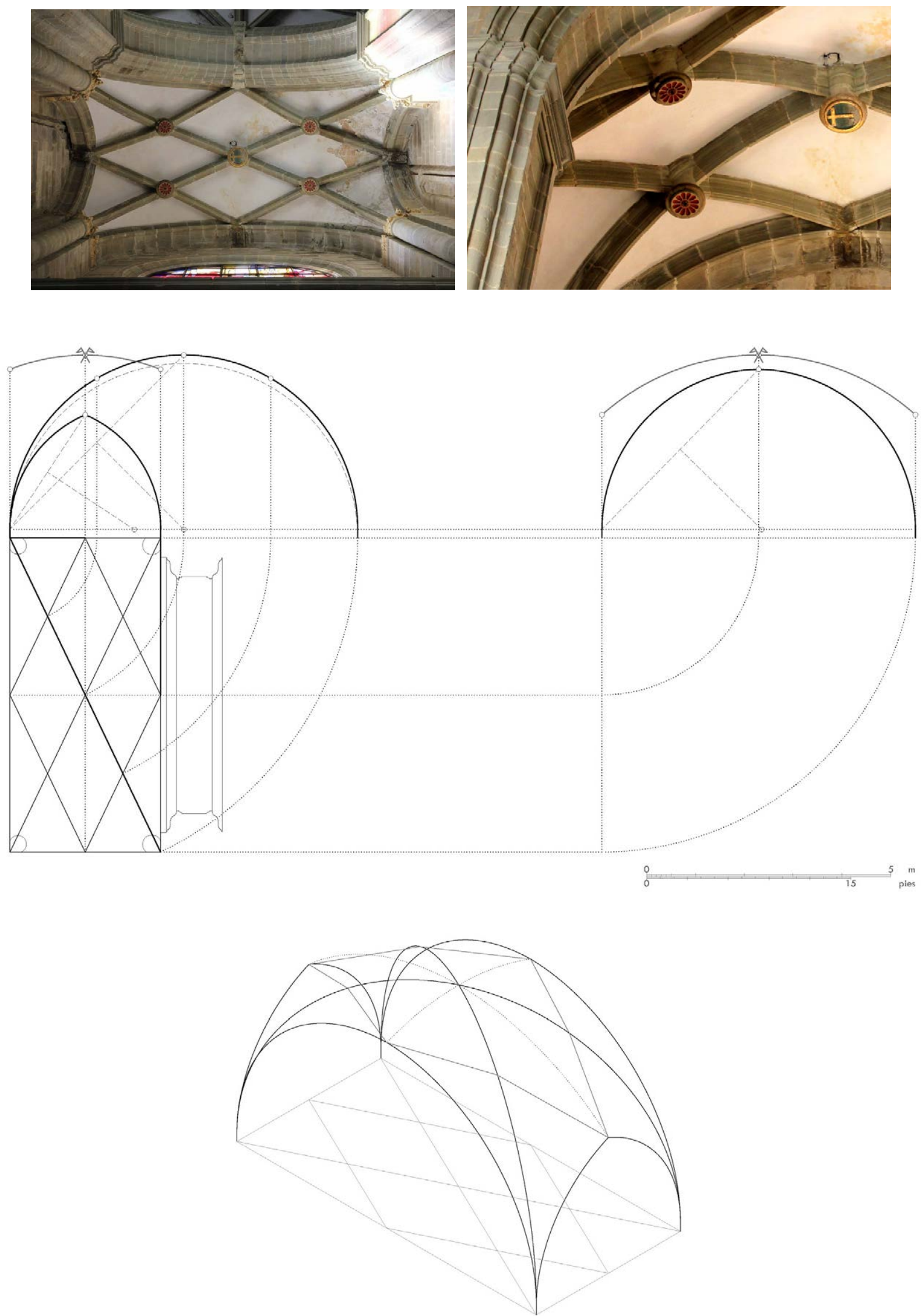

Figura 62. Catedral de Astorga (León): bóveda de la antesacristía: (a) Vista en planta. (b) Detalle de los nervios, claves y plementería. (c) Hipótesis de trazado de los nervios. (d) Modelizado de los nervios (c, d: P. Moreno) 


\subsubsection{Cáceres - Iglesia de San Mateo}

Datos históricos del edificio: véase página 785

Datos de medición de las bóvedas: véase página 848
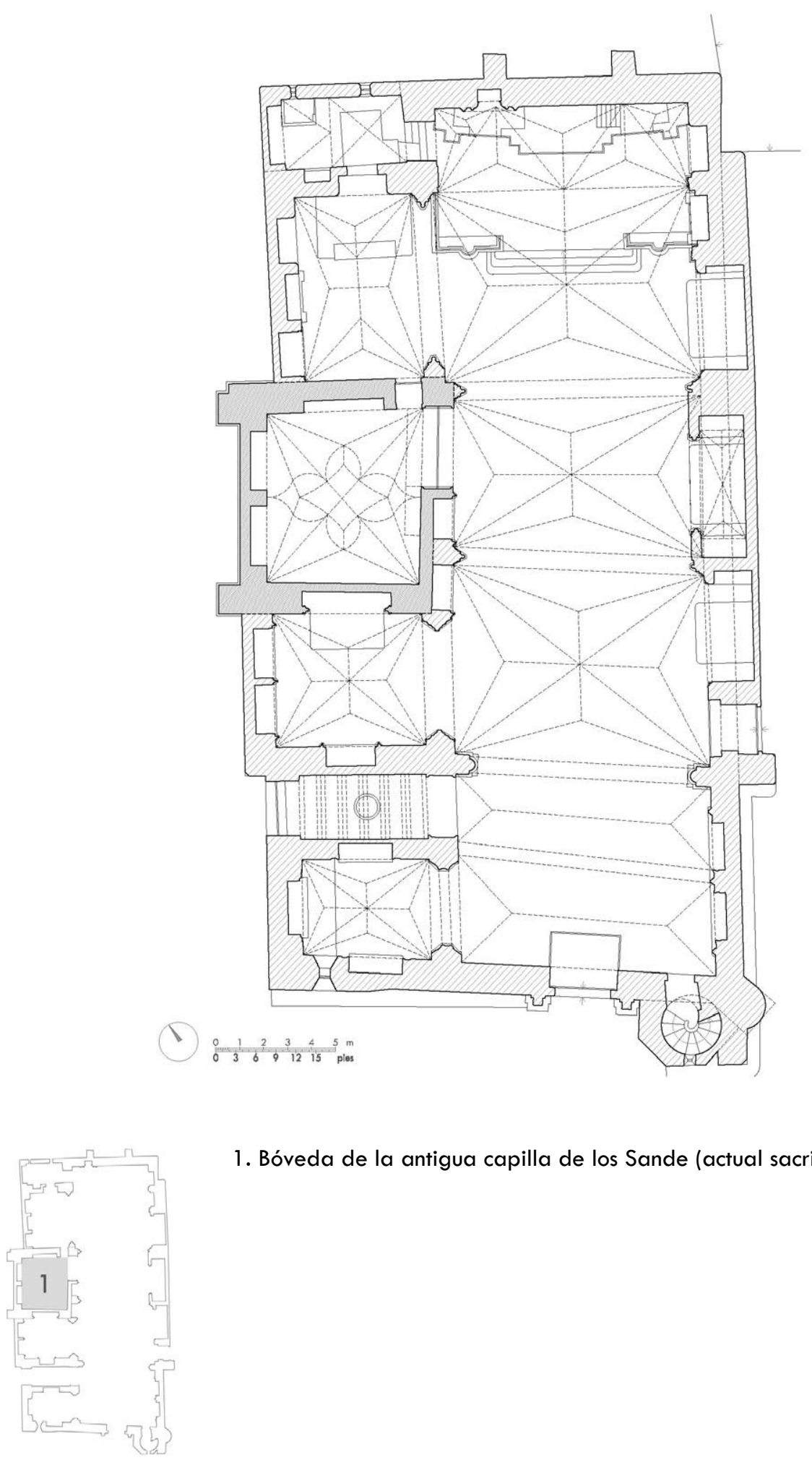

1. Bóveda de la antigua capilla de los Sande (actual sacristía) (c.1550-1551)

Figura 63. Iglesia de San Mateo, Cáceres: (a) Planta (P. Moreno, basado parcialmente en Redondo 1996). (b) Indicación de las bóvedas analizadas, con su fecha de ejecución (P. Moreno) 


\subsubsection{Bóveda de la antigua capilla de los Sande (actual sacristía)}

Modulación y rangos dimensionales: La bóveda tiene una planta rectangular de dimensiones $23.1 \times 25.8$ pies $(6.43 \times 7.20 \mathrm{~m})$ y proporción entre los lados $1.117(8: 7)$, ambas consideradas a ejes de los arcos del perímetro (coinciden con las interiores). Todos los nervios tienen un punto de arranque común en cada apoyo.

Sistemas de composición: La crucería principal está formada por los dos arcos diagonales y terceletes sencillos en la dirección de ambos ejes. Las nervaduras decorativas forman un cuadrifolio con dos hojas convexas y dos conopiales, en cuyo interior se dispone una figura de lados cóncavos. En conjunto se obtiene un diseño con 15 claves interiores. - Las claves de los terceletes se sitúan en la bisectriz del ángulo formado por la diagonal y los arcos del perímetro. Las claves secundarias sobre los terceletes se sitúan en los puntos de corte con un paralelogramo que une los extremos del cuadrifolio; las claves sobre las diagonales y sobre la ligadura del eje mayor se sitúan aproximadamente en los puntos de corte con un arco que tiene por centro el vértice de la bóveda y por radio la distancia hasta las claves de los terceletes situados sobre el eje menor; los centros de las hojas (dos por cada hoja) se disponen en puntos cuyo trazado geométrico no hemos logrado determinar, y los de sus remates o pies de gallo aproximadamente sobre el perímetro de la bóveda; la figura central se compone de cuatro arcos.

Arcos: El plano de imposta se sitúa a una altura de 23.0 pies $(6.41 \mathrm{~m})$ del suelo, y la clave central a 19.6 pies $(5.47 \mathrm{~m})$ de dicho plano. Todos los arcos parten tangentes a la vertical en el arranque, presentando todos peraltes. La clave central se encuentra 2.3 pies $(0.65 \mathrm{~m})$ por encima de la posición que correspondería a la de un arco ojivo semicircular. Un examen visual de la geometría de la diagonal y la comprobación de la posición que ocupan las claves secundarias dispuestas a lo largo de este arco nos hace concluir que su trazado teórico es efectivamente semicircular, partiendo con un peralte de 2.3 pies $(0.65 \mathrm{~m})$ en su arranque. Los arcos se trazarían aparentemente con 2 radios distintos, siendo sus datos geométricos en pies los siguientes:

\begin{tabular}{lccc} 
nervio & tipo & radio & peralte \\
\hline diagonal & sc & 17.3 & 2.3 \\
perpiaño & ap & 16.2 & 2.3 \\
formero & ap & 15.3 & 2.3 \\
tercelete per. & ap & 16.8 & 2.3 \\
tercelete for. & ap & 17.0 & 2.3
\end{tabular}

Rampante: Las claves de los arcos del perímetro se sitúan, en la dirección del eje x (menor), a 2.2 pies $(0.61 \mathrm{~m})$ por debajo de la clave central; en la dirección del eje y (mayor), a 1.8 pies $(0.51 \mathrm{~m})$ por debajo de la clave central. El rampante se puede considerar llano en la dirección de ambos ejes.

Características constructivas: Los nervios que forman la crucería interior presentan 3 tipos distintos de sección en cuanto a molduraje y canto (grande para la diagonal; mediano para el tercelete y la ligadura; pequeño para el nervio decorativo). - Las jarjas se componen de 6 y 7 hiladas, dependiendo del nervio considerado. - Las claves tienen su eje central vertical (y su cara inferior paralela a la superficie de la bóveda en cada punto). - La plementería es de ladrillo; queda ligeramente separada del trasdós del formero. 

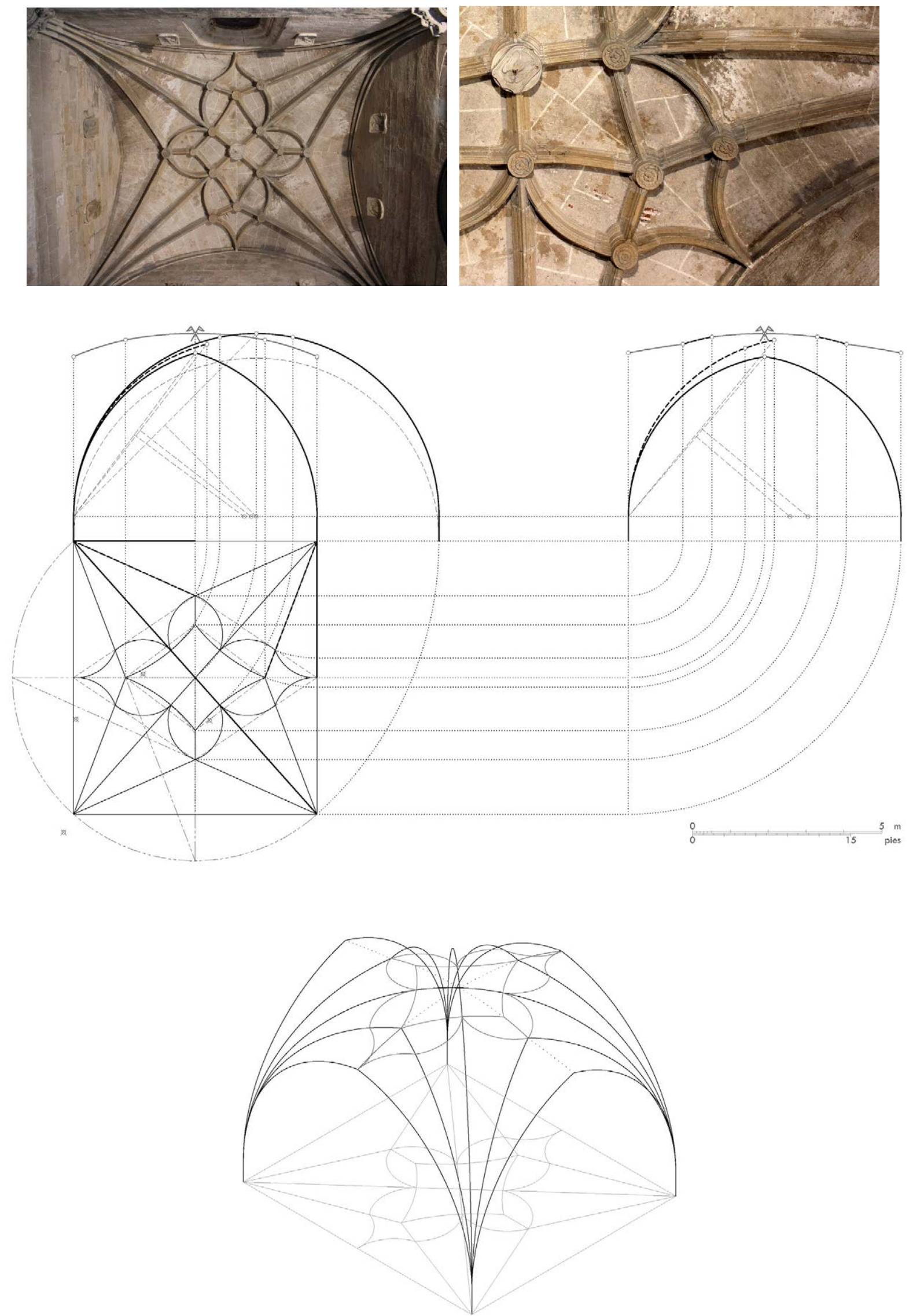

Figura 64. Iglesia de San Mateo, Cáceres: bóveda de la antigua capilla de los Sande (actual sacristía): (a) Vista en planta. (b) Detalle de los nervios, claves y plementería. (c) Hipótesis de trazado de los nervios. (d) Modelizado de los nervios (c, d: P. Moreno) 


\subsubsection{Cáceres - Iglesia de Santiago de los Caballeros}

Datos históricos del edificio: véase página 782 y siguientes

Datos de medición de las bóvedas: véase página 849 y siguientes

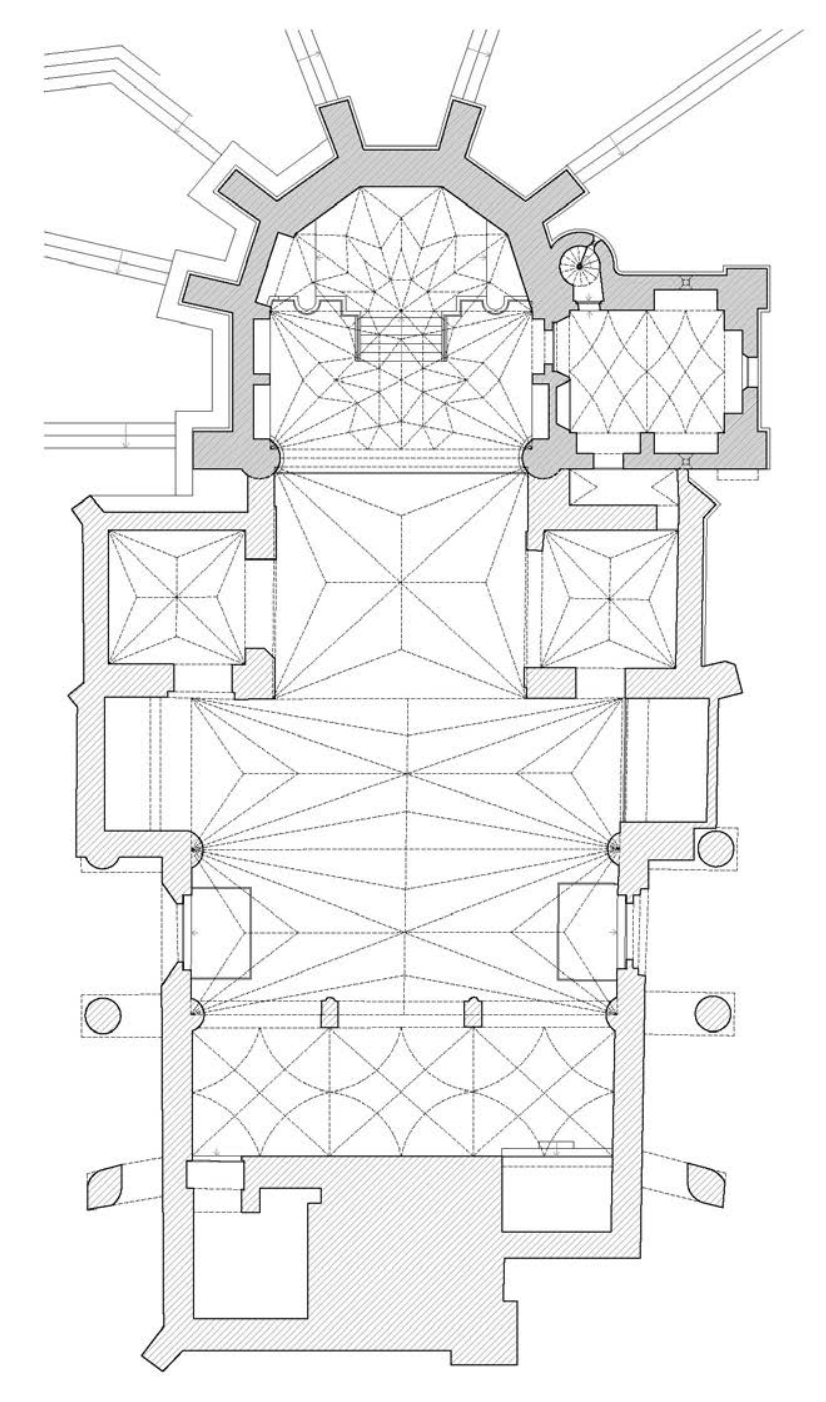

\section{$\frac{012345 m}{0.3691215 \text { plas }}$}

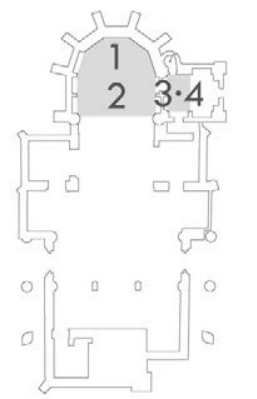

1. Bóveda de la cabecera (ábside) (c.1549-1553)

2. Bóveda de la cabecera (presbiterio) (c.1549-1553)

3. Bóveda de la sacristía (c.1549-1553)

4. Bóveda de la tribuna (c.1549-1553)

Figura 65. Iglesia de Santiago de los Caballeros, Cáceres: (a) Planta (P. Moreno, basado parcialmente en Jiménez 2012 y Rodríguez 2010). (b) Indicación de las bóvedas analizadas, con su fecha de ejecución (P. Moreno) 


\subsubsection{Bóveda de la cabecera (ábside)}

Modulación y rangos dimensionales: La bóveda tiene una planta poligonal basada en un decágono regular de lado 11.7 pies $(3.26 \mathrm{~m})$ y radio 18.9 pies $(5.28 \mathrm{~m})$, y una embocadura de 37.9 pies $(10.55 \mathrm{~m})$. Todos los nervios tienen un punto de arranque común en cada apoyo.

Sistemas de composición: La crucería principal está formada por los arcos perpiaños radiales y terceletes sencillos. Las nervaduras decorativas forman un quinquefolio de hojas convexas, en cuyo interior se dispone otro quinquefolio de hojas convexas y medio decágono regular. En conjunto se obtiene un diseño con 22 claves interiores. - La clave principal se sitúa en el centro del polígono generador, y coincide con la del arco perpiaño de la embocadura; las claves de los terceletes se sitúan en los puntos que resultan de dividir las apotemas en cuatro partes iguales (a 1/4 del perímetro). Las puntas del quinquefolio interior se sitúan en los puntos medios de las apotemas; las claves de los quinquefolios sobre los perpiaños radiales se sitúan en los puntos que resultan de dividir los perpiaños en cuatro partes iguales (a $1 / 4$ y 2/4 de la clave principal); obtenidas estas claves, es posible trazar el medio decágono central.

Arcos: El plano de imposta se sitúa a una altura de 42.1 pies $(11.74 \mathrm{~m})$ del suelo, y la clave principal a 23.1 pies $(6.43 \mathrm{~m})$ de dicho plano. Todos los arcos parten tangentes a la vertical en el arranque, presentando algunos peraltes. El arco perpiaño de la embocadura es apuntado, encontrándose su clave 4.1 pies $(1.16 \mathrm{~m})$ por encima de la posición que correspondería a la de un arco perpiaño semicircular y partiendo sin peralte en su arranque. Los arcos se trazarían aparentemente con 3 radios distintos, siendo sus datos geométricos en pies los siguientes:

\begin{tabular}{lccc} 
nervio & tipo & radio & peralte \\
\hline perpiaño & ap & 23.5 & \\
formero & ap & 11.1 & 9.8 \\
tercelete for. & ap & 17.3 & 6.0
\end{tabular}

Rampante: -

Características constructivas: Los nervios que forman la crucería interior presentan 1 único tipo de sección en cuanto a molduraje y canto (perpiaño radial, tercelete, ligadura y nervio decorativo). • Las jarjas se componen de 8 hiladas. - Las claves tienen su eje central vertical (y su cara inferior paralela a la superficie de la bóveda en cada punto); no están provistas de un cilindro central, sino que se resuelven como un cruce de nervios, presentando las que corresponden a las intersecciones del quinquefolio exterior con los arcos perpiaños radiales únicamente una moldura cilíndrica limitada a la zona superior de contacto con la plementería. - La plementería es de cantería, dispuesta a la francesa; sus hiladas se componen de entre 1 y 2 piezas; asienta directamente sobre el trasdós del formero. 

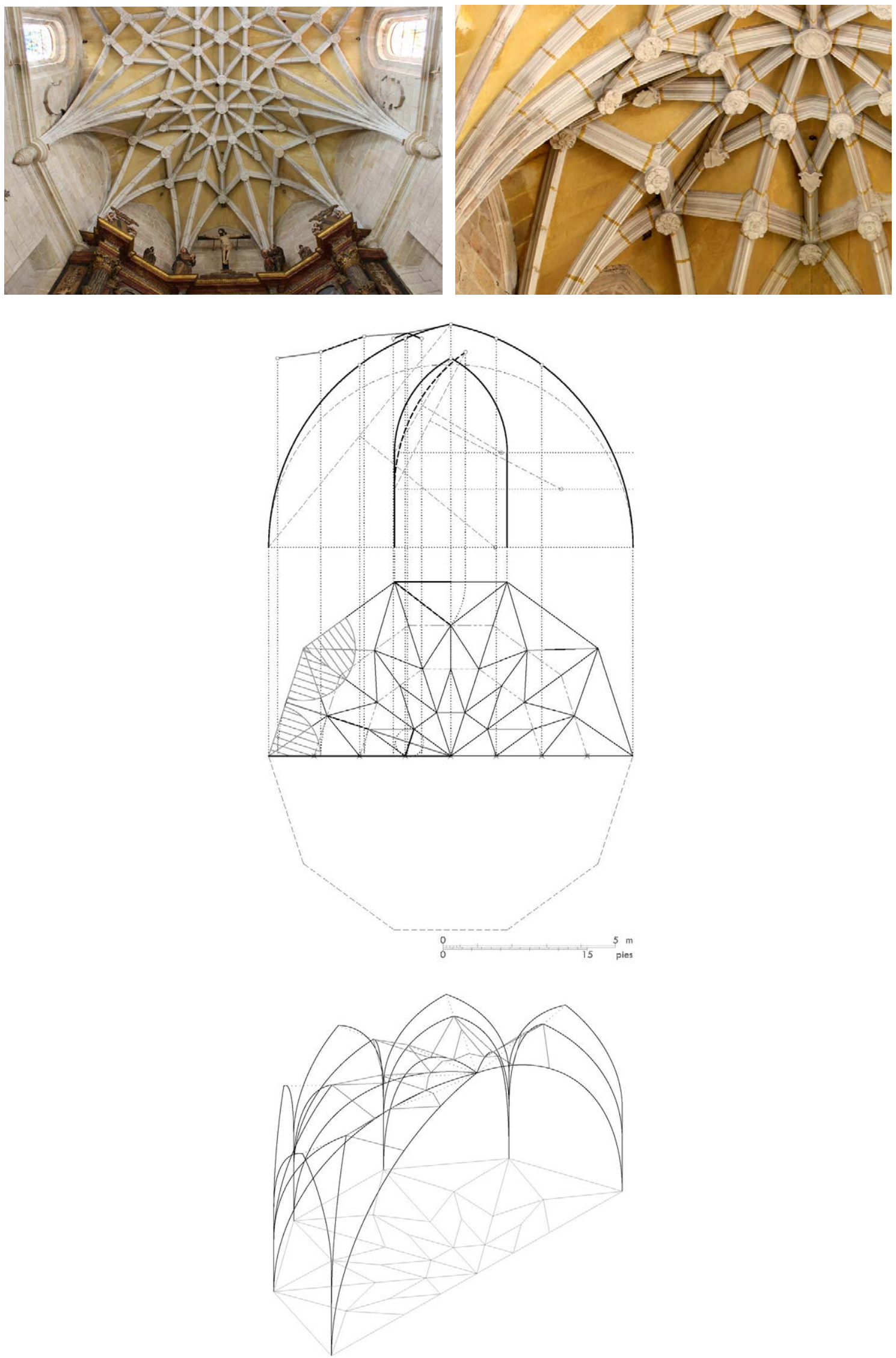

Figura 66. Iglesia de Santiago de los Caballeros, Cáceres: bóveda de la cabecera (ábside): (a) Vista en planta. (b) Detalle de los nervios, claves y plementería. (c) Hipótesis de trazado de los nervios. (d) Modelizado de los nervios (c, d: P. Moreno) 


\subsubsection{Bóveda de la cabecera (presbiterio)}

Modulación y rangos dimensionales: La bóveda tiene una planta rectangular de dimensiones $37.9 \times 21.2$ pies ( $10.55 \times 5.90 \mathrm{~m}$ ) y proporción entre los lados 1.788 (phi), ambas consideradas a ejes de los arcos del perímetro (las interiores son $37.9 \times 19.9$ pies $(10.55 \times 5.55 \mathrm{~m})$ y $1.905(2: 1)$, respectivamente). Los perpiaños tienen un punto de arranque distinto al del resto de los nervios en cada apoyo.

Sistemas de composición: La crucería principal está formada por los dos arcos diagonales, terceletes dobles en la dirección del eje mayor y sencillos en la dirección del eje menor. Las nervaduras decorativas forman un cuadrifolio de hojas convexas, en cuyo interior se dispone un rombo de lados rectos y otro rombo de lados quebrados. En conjunto se obtiene un diseño con 33 claves interiores. - Las claves de los terceletes se sitúan, sobre el eje mayor, en los puntos que resultan de dividir dicho eje en ocho partes iguales (a $1 / 8$ y $2 / 8$ del perímetro); sobre el eje menor, en los puntos que resultan de dividir dicho eje en cinco partes iguales (a $1 / 5$ del perímetro). El rombo de lados rectos, que se obtiene prolongando los terceletes interiores situados sobre el eje mayor, genera cuatro claves sobre las diagonales y otras cuatro sobre los terceletes situados sobre el eje menor; uniendo estas últimas dos a dos en dirección paralela al eje menor se obtienen sobre las diagonales las claves del rombo central de lados quebrados; las cuatro claves secundarias del perímetro de la bóveda se sitúan en los puntos que resultan de dividir el lado mayor de la bóveda en ocho partes iguales (a 1/8 de los ejes); las claves secundarias del cuadrifolio sobre los terceletes se sitúan en puntos cuyo trazado geométrico no hemos logrado determinar.

Arcos: El plano de imposta se sitúa a una altura de 42.1 pies $(11.74 \mathrm{~m}$ ) del suelo, y la clave central a 23.1 pies $(6.43 \mathrm{~m})$ de dicho plano. Todos los arcos parten tangentes a la vertical en el arranque, excepto el formero que parte inclinado, presentando algunos peraltes, entre ellos la diagonal. La clave central se encuentra 1.7 pies $(0.47 \mathrm{~m})$ por encima de la posición que correspondería a la de un arco ojivo semicircular. Un examen visual de la geometría de la diagonal y la comprobación de la posición que ocupan las claves secundarias dispuestas a lo largo de este arco nos hace concluir que su trazado teórico es efectivamente semicircular, partiendo con un peralte de 1.7 pies $(0.47 \mathrm{~m})$ en su arranque. Los arcos se trazarían aparentemente con 3 radios distintos, siendo sus datos geométricos en pies los siguientes:

\begin{tabular}{lccc} 
nervio & tipo & radio & peralte \\
\hline diagonal & sc & 21.4 & 1.7 \\
perpiaño & ap & 23.5 & \\
formero & ap.in & 19.3 & 14.3 \\
tercelete per. & ap & 23.4 & \\
tercelete for. 1 & ap & 23.6 & \\
tercelete for. 2 & ap & 23.7 &
\end{tabular}

Rampante: Las claves de los arcos del perímetro se sitúan, en la dirección del eje x (mayor), a 4.0 pies $(1.11 \mathrm{~m}$ ) por debajo de la clave central; en la dirección del eje y (menor), a la misma altura que la clave central. El rampante se puede considerar llano en la dirección del eje $x$ (mayor) y horizontal en la del eje y (menor).

Características constructivas: Los nervios que forman la crucería interior presentan 2 tipos distintos de sección en cuanto a molduraje y canto (grande para la diagonal; pequeño para el tercelete, la ligadura y el nervio decorativo). - Las jarjas se componen de 6, 7 y 8 hiladas, dependiendo del soporte y del nervio considerado. - Las claves tienen su eje central vertical (y su cara inferior paralela a la superficie de la bóveda en cada punto); no están provistas de un cilindro central, sino que se resuelven como un cruce de nervios, presentando algunas de las que corresponden al cuadrifolio únicamente una moldura cilíndrica limitada a la zona superior de contacto con la plementería. - La plementería es de cantería, dispuesta a la francesa; sus hiladas se componen de entre 1 y 2 piezas; asienta directamente sobre el trasdós del formero. 

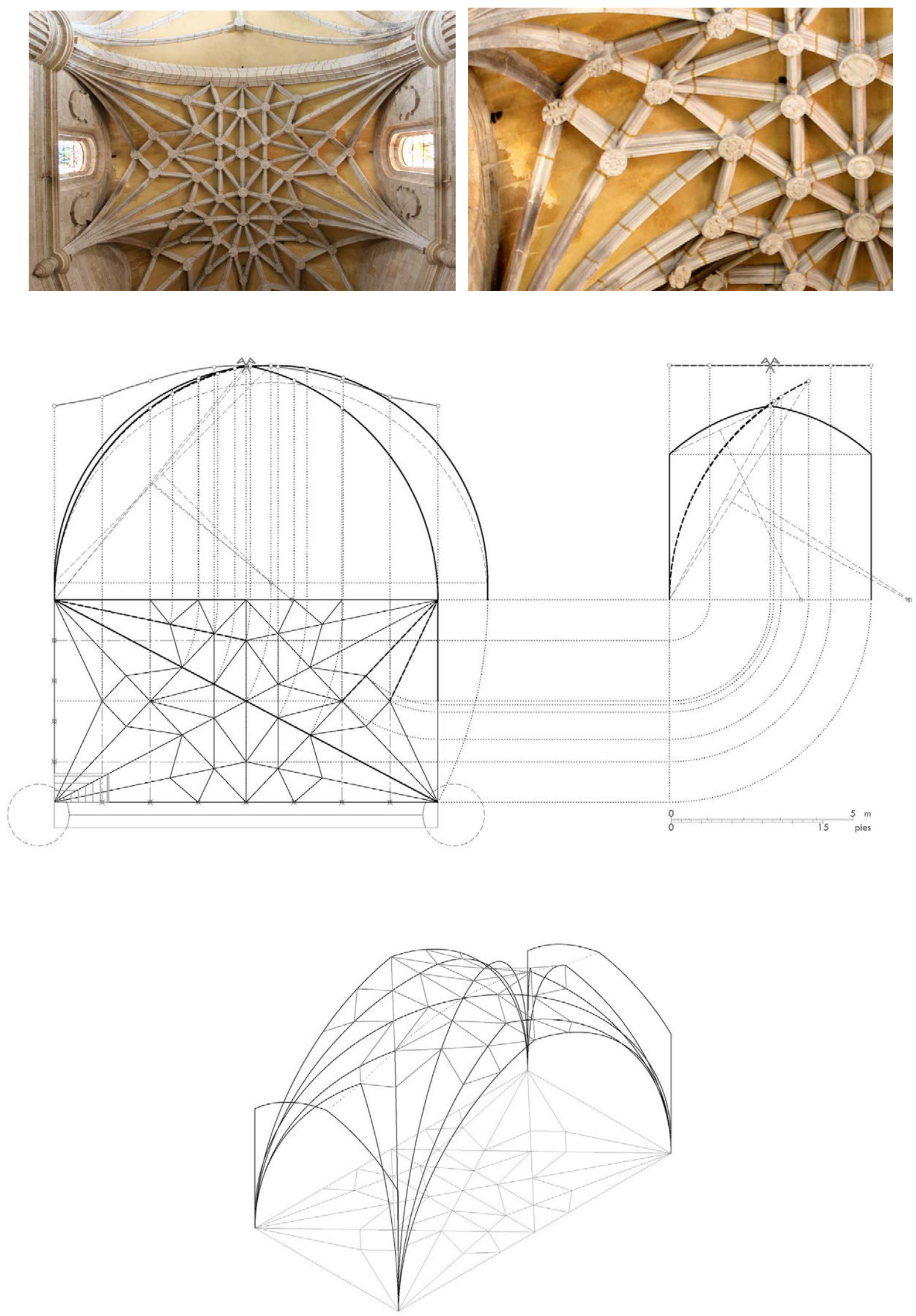

Figura 67. Iglesia de Santiago de los Caballeros, Cáceres: bóveda de la cabecera (presbiterio): (a) Vista en planta. (b) Detalle de los nervios, claves y plementería. (c) Hipótesis de trazado de los nervios. (d) Modelizado de los nervios (c, d: P. Moreno) 


\subsubsection{Bóveda de la sacristía}

Modulación y rangos dimensionales: La bóveda tiene una planta rectangular de dimensiones $11.2 \times 17.7$ pies $(3.12 \times 4.92 \mathrm{~m}$ ) y proporción entre los lados 1.580 (phi), ambas consideradas a ejes de los arcos del perímetro (coinciden con las interiores). Todos los nervios tienen un punto de arranque común en cada apoyo.

Sistemas de composición: La crucería principal está formada por los dos arcos diagonales, careciendo de terceletes. Las nervaduras decorativas forman una figura de lados cóncavos. En conjunto se obtiene un diseño con 5 claves interiores. - Las claves sobre las diagonales se sitúan aproximadamente en los puntos de corte con una circunferencia que tiene por centro el polo de la bóveda y por radio la mitad del semieje mayor; la figura se compone de cuatro arcos.

Arcos: El plano de imposta se sitúa a una altura de 11.3 pies $(3.14 \mathrm{~m})$ del suelo, y la clave central a 8.8 pies $(2.46 \mathrm{~m})$ de dicho plano. Los arcos del perímetro parten tangentes a la vertical en el arranque, y la diagonal parte inclinada, no presentando ninguno peraltes. La clave central se encuentra 1.6 pies $(0.45 \mathrm{~m})$ por debajo de la posición que correspondería a la de un arco ojivo semicircular. Un examen visual de la geometría de la diagonal y la comprobación de la posición que ocupan las claves secundarias dispuestas a lo largo de este arco nos hace concluir que su trazado teórico es semicircular rebajado o escarzano, partiendo sin peralte en su arranque. Los arcos se trazarían aparentemente con 3 radios distintos, siendo sus datos geométricos en pies los siguientes:

\begin{tabular}{lccc} 
nervio & tipo & radio & peralte \\
\hline diagonal & sc.rb & 10.6 & \\
perpiaño & ap & 6.8 & \\
formero & sc & 8.8 &
\end{tabular}

Rampante: Las claves de los arcos del perímetro se sitúan, en la dirección del eje $\mathrm{x}$ (menor), a la misma altura que la clave central; en la dirección del eje y (mayor), a 2.2 pies (0.60 m) por debajo de la clave central. El rampante se puede considerar horizontal en la dirección del eje $x$ (menor) y redondo en la del eje y (mayor).

Características constructivas: Los nervios que forman la crucería interior presentan 1 único tipo de sección en cuanto a molduraje y canto (diagonal y nervio decorativo). • Las jarjas se componen de 3 hiladas. - Las claves tienen su eje central vertical (y su cara inferior paralela a la superficie de la bóveda en cada punto). - La plementería es de cantería, dispuesta a la francesa; sus hiladas se componen de entre 1 y 3 piezas; asienta directamente sobre el trasdós del formero. 

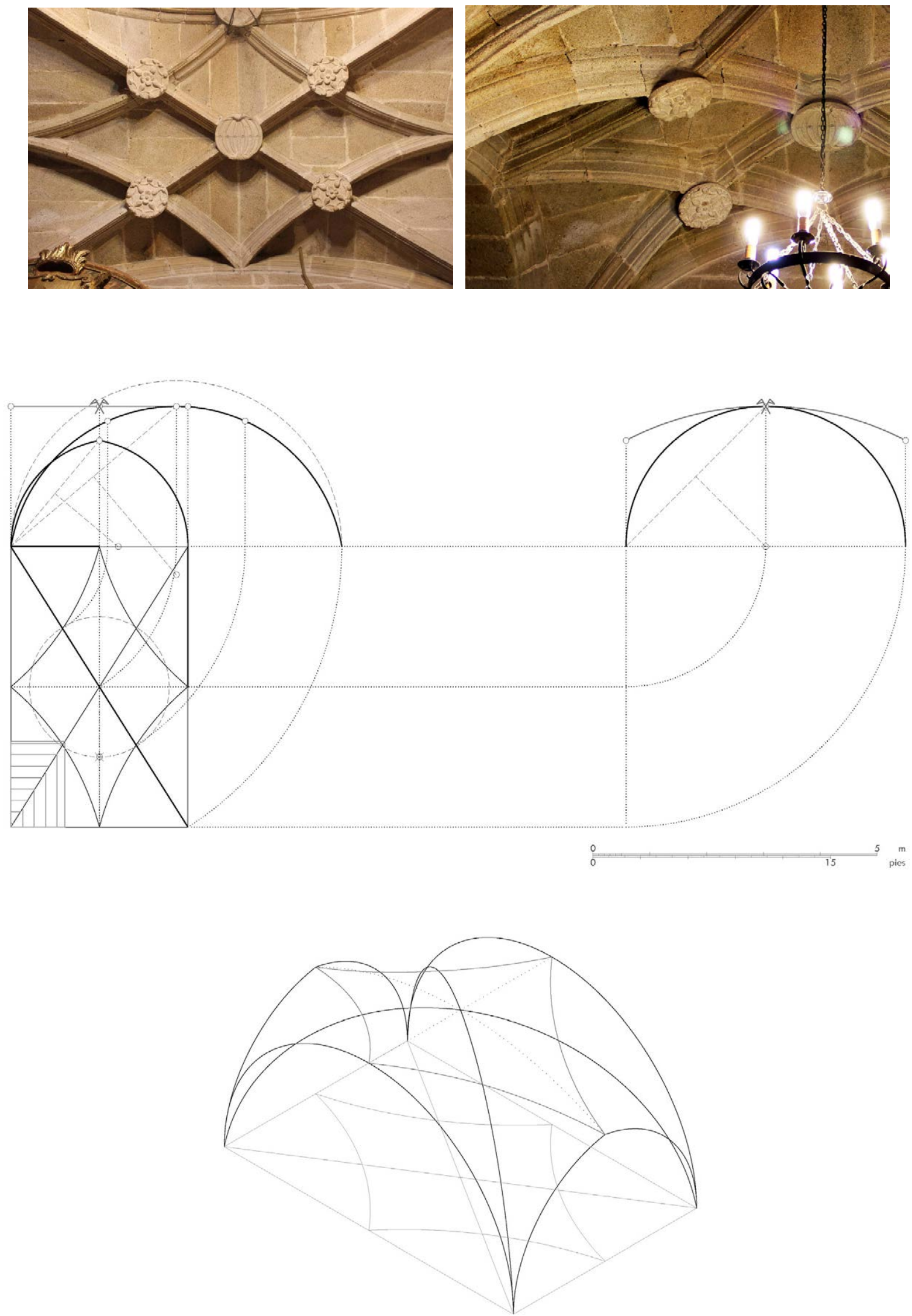

Figura 68. Iglesia de Santiago de los Caballeros, Cáceres: bóveda de la sacristía: (a) Vista en planta. (b) Detalle de los nervios, claves y plementería. (c) Hipótesis de trazado de los nervios. (d) Modelizado de los nervios (c, d: P. Moreno) 


\subsubsection{Bóveda de la tribuna}

Modulación y rangos dimensionales: La bóveda tiene una planta rectangular de dimensiones $11.2 \times 17.7$ pies $(3.13 \times 4.92 \mathrm{~m}$ ) y proporción entre los lados 1.580 (phi), ambas consideradas a ejes de los arcos del perímetro (coinciden con las interiores). Todos los nervios tienen un punto de arranque común en cada apoyo.

Sistemas de composición: La crucería principal está formada por los dos arcos diagonales, careciendo de terceletes. Carece de nervaduras decorativas. En conjunto se obtiene un diseño con 1 clave interior.

Arcos: El plano de imposta se sitúa a una altura de 9.1 pies $(2.54 \mathrm{~m})$ del suelo, y la clave central a 8.7 pies $(2.42 \mathrm{~m})$ de dicho plano. Los arcos del perímetro parten tangentes a la vertical en el arranque, y la diagonal parte inclinada, no presentando ninguno peraltes. La clave central se encuentra 1.8 pies $(0.49 \mathrm{~m})$ por debajo de la posición que correspondería a la de un arco ojivo semicircular. Un examen visual de la geometría de la diagonal nos hace concluir que su trazado teórico es semicircular rebajado o escarzano, partiendo sin peralte en su arranque. Los arcos se trazarían aparentemente con 3 radios distintos, siendo sus datos geométricos en pies los siguientes:

\begin{tabular}{lccc} 
nervio & tipo & radio & peralte \\
\hline diagonal & sc.rb & 10.6 & \\
perpiaño & ap & 7.0 & \\
formero & sc & 8.8 &
\end{tabular}

Rampante: Las claves de los arcos del perímetro se sitúan, en la dirección del eje x (menor), a la misma altura que la clave central; en la dirección del eje y (mayor), a 1.8 pies (0.50 m) por debajo de la clave central. El rampante se puede considerar horizontal en la dirección del eje $x$ (menor) y llano en la del eje y (mayor).

Características constructivas: Los nervios que forman la crucería interior presentan 1 único tipo de sección en cuanto a molduraje y canto (diagonal). • Las jarjas se componen de 3 hiladas. • Las claves tienen su eje central vertical (y su cara inferior paralela a la superficie de la bóveda en cada punto). - La plementería es de cantería, dispuesta a la francesa; sus hiladas se componen de entre 1 y 3 piezas; asienta directamente sobre el trasdós del formero. 

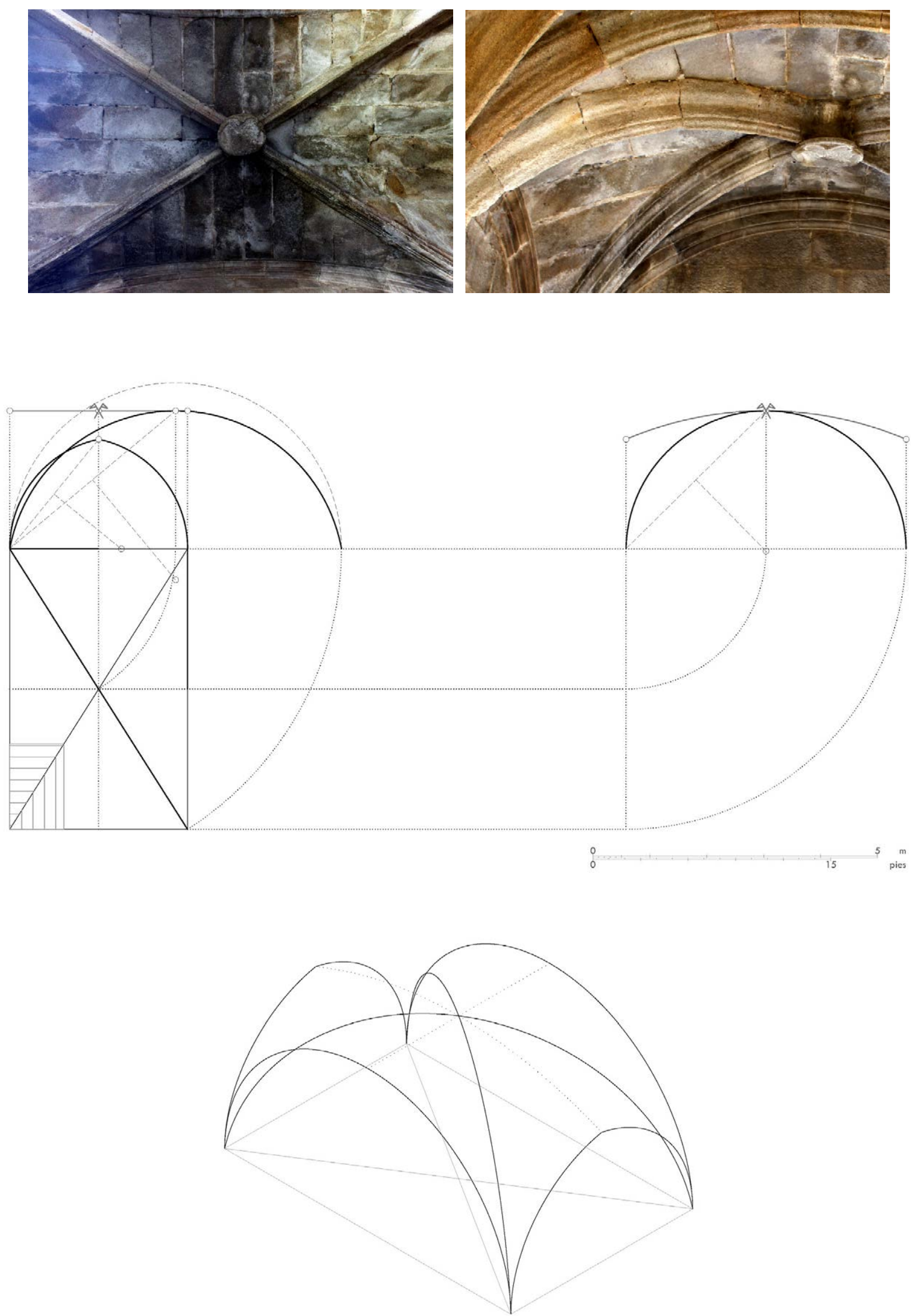

Figura 69. Iglesia de Santiago de los Caballeros, Cáceres: bóveda de la tribuna: (a) Vista en planta. (b) Detalle de los nervios, claves y plementería. (c) Hipótesis de trazado de los nervios. (d) Modelizado de los nervios (c, d: P. Moreno) 


\subsubsection{Castellanos de Villiquera (Salamanca) - Iglesia de San Juan Bautista}

Datos históricos del edificio: véase página 776

Datos de medición de las bóvedas: véase página 853

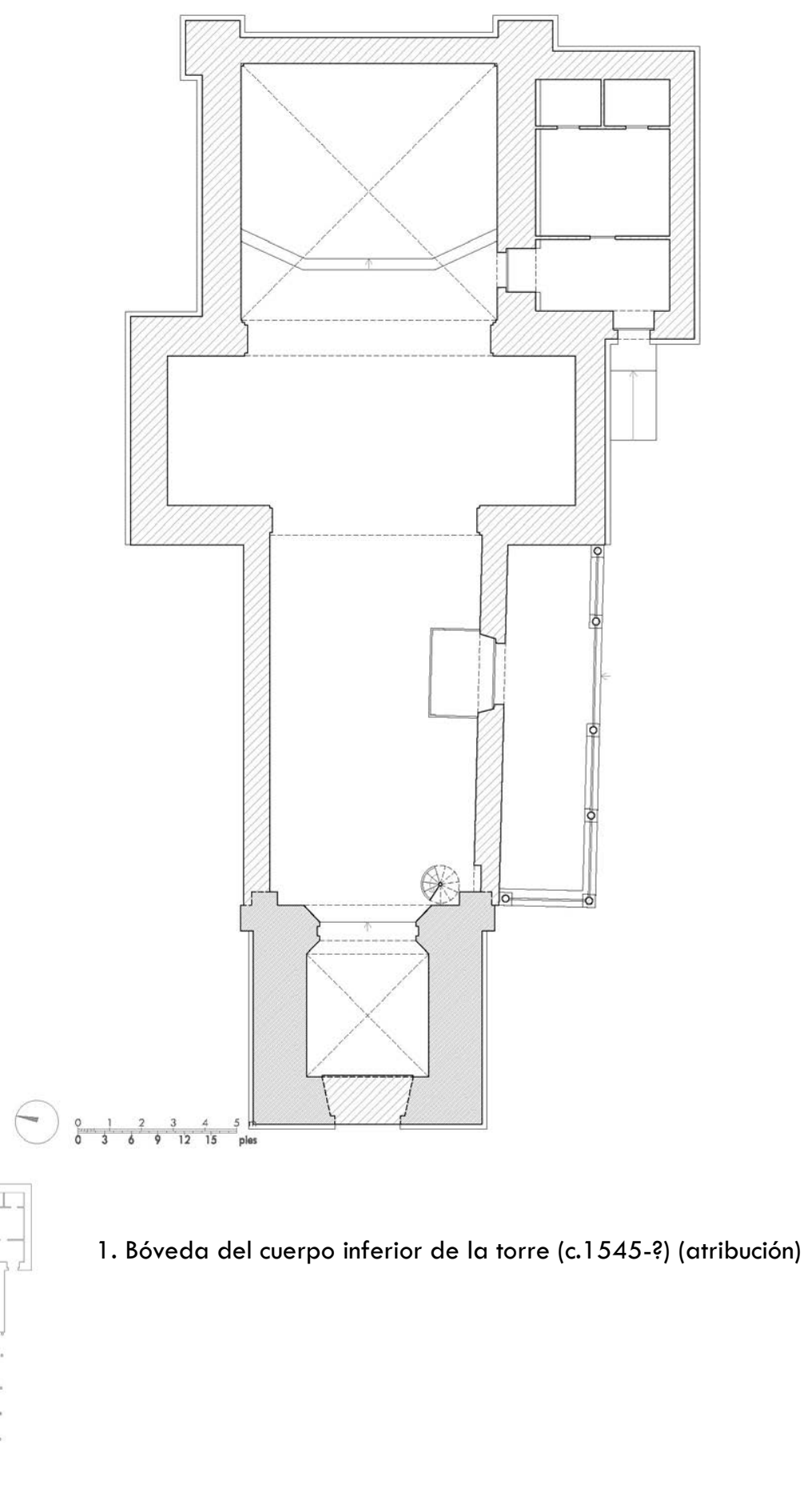

Figura 70. Iglesia de San Juan Bautista, Castellanos de Villiquera (Salamanca): (a) Planta (P. Moreno). (b) Indicación de las bóvedas analizadas, con su fecha de ejecución (P. Moreno) 


\subsubsection{Bóveda del cuerpo inferior de la torre}

Modulación y rangos dimensionales: La bóveda tiene una planta aproximadamente cuadrada de dimensiones $13.8 \times 13.9$ pies $(3.85 \times 3.87 \mathrm{~m})$ y proporción entre los lados $1.007(1: 1)$, ambas consideradas a ejes de los arcos del perímetro (coinciden con las interiores). Todos los nervios tienen un punto de arranque común en cada apoyo.

Sistemas de composición: La crucería principal está formada por los dos arcos diagonales, careciendo de terceletes. Carece de nervaduras decorativas. En conjunto se obtiene un diseño con 1 clave interior.

Arcos: El plano de imposta se sitúa a una altura de 12.1 pies $(3.38 \mathrm{~m}$ ) del suelo, y la clave central a 8.1 pies $(2.25 \mathrm{~m})$ de dicho plano. Los arcos del perímetro parten tangentes a la vertical en el arranque, y la diagonal parte inclinada, presentando algunos peraltes, aunque no la diagonal. La clave central se encuentra 1.7 pies $(0.48 \mathrm{~m})$ por debajo de la posición que correspondería a la de un arco ojivo semicircular. Un examen visual de la geometría de la diagonal nos hace concluir que su trazado teórico es semicircular rebajado o escarzano, partiendo sin peralte en su arranque. Los arcos se trazarían aparentemente con 3 radios distintos, siendo sus datos geométricos en pies los siguientes:

\begin{tabular}{lccc} 
nervio & tipo & radio & peralte \\
\hline diagonal & sc.rb & 10.0 & \\
perpiaño E & sc & 6.9 & 1.3 \\
perpiaño O & tu & $6.9 \cdot 8.3$ & 2.5 \\
formero & ap & 8.8 &
\end{tabular}

Rampante: Las claves de los arcos del perímetro se sitúan, en la dirección del eje x, a 0.5 pies (0.14 $\mathrm{m}$ ) por encima de la clave central; en la dirección del eje y, a 0.2 pies $(0.05 \mathrm{~m})$ por encima de la clave central. El rampante se puede considerar convexo en la dirección de ambos ejes.

Características constructivas: Los nervios que forman la crucería interior presentan 1 único tipo de sección en cuanto a molduraje y canto (diagonal). - Las jarjas se componen de 2, 3 y 4 hiladas, dependiendo del soporte y del nervio considerado. - Las claves tienen su eje central vertical (y su cara inferior paralela a la superficie de la bóveda en cada punto). - La plementería es de cantería, dispuesta a la francesa; sus hiladas se componen de entre 1 y 3 piezas; asienta directamente sobre el trasdós del formero. 

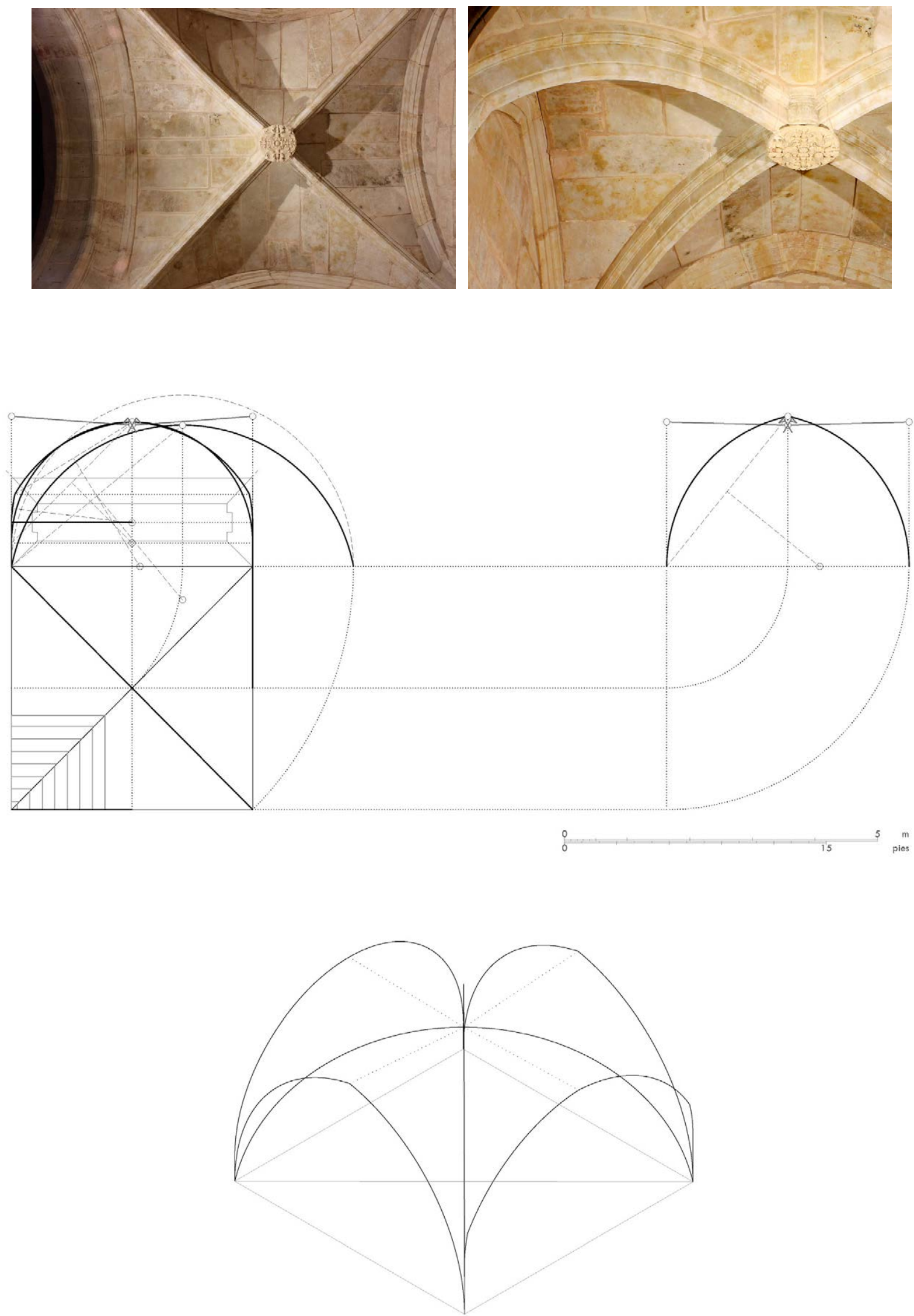

Figura 71. Iglesia de San Juan Bautista, Castellanos de Villiquera (Salamanca): bóveda del cuerpo inferior de la torre: (a) Vista en planta. (b) Detalle de los nervios, claves y plementería. (c) Hipótesis de trazado de los nervios. (d) Modelizado de los nervios (c, d: P. Moreno) 


\subsubsection{Ciudad Rodrigo (Salamanca) - Catedral de Santa María}

Datos históricos del edificio: véase página 759 y siguientes

Datos de medición de las bóvedas: véase página 854 y siguientes

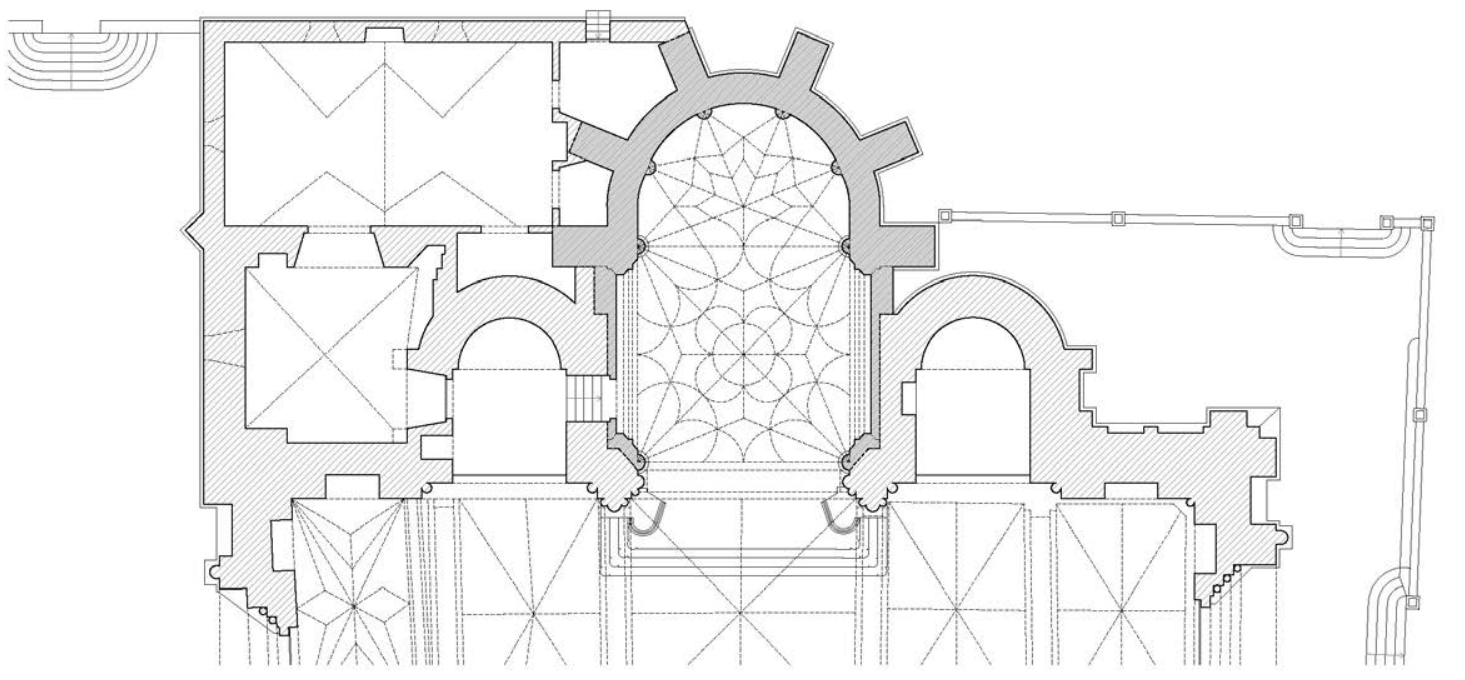

$\frac{0.12345 \mathrm{~m}}{0.0691215 \text { ples }}$

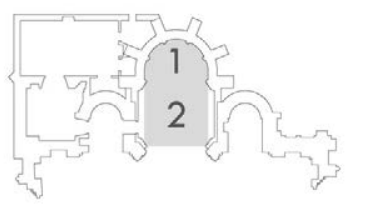

1. Bóveda de la cabecera (ábside) (c.1547-1549)

2. Bóveda de la cabecera (presbiterio) (c.1547-1549)

Figura 72. Catedral de Ciudad Rodrigo (Salamanca): (a) Planta de la cabecera (P. Moreno). (b) Indicación de las bóvedas analizadas, con su fecha de ejecución (P. Moreno) 


\subsubsection{Bóveda de la cabecera (ábside)}

Modulación y rangos dimensionales: La bóveda tiene una planta aproximadamente semicircular basada en un octógono regular de lado 11.4 pies $(3.18 \mathrm{~m})$ y radio 14.9 pies $(4.16 \mathrm{~m})$, y una embocadura de 30.6 pies $(8.53 \mathrm{~m})$. Todos los nervios tienen un punto de arranque común en cada apoyo.

Sistemas de composición: La crucería principal está formada por los arcos perpiaños radiales y terceletes sencillos. Las nervaduras decorativas forman un quinquefolio de hojas convexas, en cuyo interior se dispone otro quinquefolio de hojas convexas. En conjunto se obtiene un diseño con 25 claves interiores. - La clave principal se sitúa en el centro del polígono generador, y no coincide con la del arco perpiaño de la embocadura; las claves de los terceletes se sitúan en la bisectriz del ángulo formado por los perpiaños radiales y los arcos del perímetro. Las claves del quinquefolio exterior sobre los perpiaños radiales se sitúan en los puntos de corte con un arco que tiene por centro el vértice del polígono generador y por radio la distancia hasta las claves de los terceletes; las puntas del quinquefolio interior se sitúan en los puntos medios de las apotemas; las claves del quinquefolio interior sobre los perpiaños radiales se sitúan en los puntos de corte con una circunferencia que tiene por centro la clave principal y por radio 4.5 pies, coincidente con el del círculo central de la bóveda contigua.

Arcos: El plano de imposta se sitúa a una altura de 50.8 pies $(14.14 \mathrm{~m}$ ) del suelo, y la clave principal a 22.8 pies $(6.35 \mathrm{~m})$ de dicho plano. Todos los arcos parten tangentes a la vertical en el arranque, presentando todos peraltes. El arco perpiaño de la embocadura es apuntado, encontrándose su clave 7.7 pies $(2.14 \mathrm{~m})$ por encima de la posición que correspondería a la de un arco perpiaño semicircular y partiendo con un peralte de 2.6 pies $(0.73 \mathrm{~m})$ en su arranque. Los arcos se trazarían aparentemente con 4 radios distintos, siendo sus datos geométricos en pies los siguientes:

\begin{tabular}{lccc} 
nervio & tipo & radio & peralte \\
\hline perpiaño 1 & ap & 21.2 & 2.6 \\
perpiaño 2 & sc & 16.2 & 6.6 \\
perpiaño 3 & sc & 16.2 & 6.6 \\
formero 1 & ap & 8.3 & 9.2 \\
formero 2 & ap & 8.3 & 9.2 \\
tercelete for. 1 & ap & 12.7 & 7.9 \\
tercelete for. 2 & ap & 13.5 & 7.9
\end{tabular}

\section{Rampante: -}

Características constructivas: Los nervios que forman la crucería interior presentan 2 tipos distintos de sección en cuanto a molduraje y canto (grande para el perpiaño radial 2 y 3; pequeño para el tercelete, la ligadura y el nervio decorativo). - Las jarjas se componen de 9 y 10 hiladas, dependiendo del soporte considerado. - Las claves tienen su eje central vertical (y su cara inferior paralela a la superficie de la bóveda en cada punto); las que corresponden al quinquefolio exterior no están provistas de un cilindro central, sino que se resuelven como un cruce de nervios. - La plementería es de cantería, dispuesta a la inglesa en los arranques y a la francesa en la zona central, encerrada por las nervaduras decorativas; sus hiladas se componen de entre 1 y 3 piezas; queda ligeramente separada del trasdós del formero. 

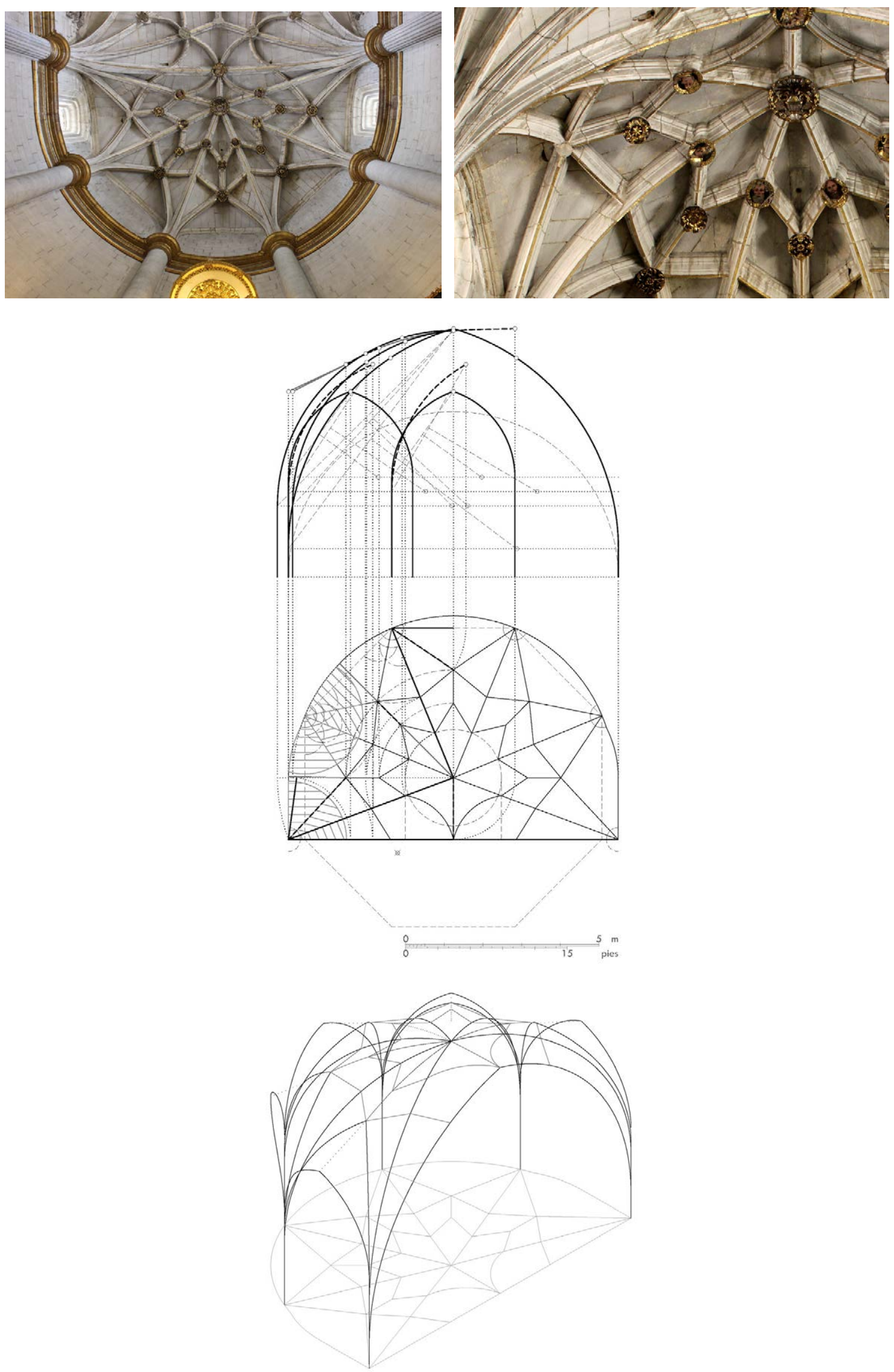

Figura 73. Catedral de Ciudad Rodrigo (Salamanca): bóveda de la cabecera (ábside): (a) Vista en planta. (b) Detalle de los nervios, claves y plementería. (c) Hipótesis de trazado de los nervios. (d) Modelizado de los nervios (c, d: P. Moreno) 


\subsubsection{Bóveda de la cabecera (presbiterio)}

Modulación y rangos dimensionales: La bóveda tiene una planta aproximadamente cuadrada de dimensiones $30.6 \times 31.2$ pies $(8.53 \times 8.69 \mathrm{~m})$ y proporción entre los lados $1.020(1: 1)$, ambas consideradas a ejes de los arcos del perímetro (coinciden con las interiores). Todos los nervios tienen un punto de arranque común en cada apoyo.

Sistemas de composición: La crucería principal está formada por los dos arcos diagonales y terceletes sencillos en la dirección de ambos ejes. Las nervaduras decorativas forman un cuadrifolio de hojas cóncavas, en cuyo interior se dispone otro cuadrifolio de hojas convexas y tangentes al primero y un círculo, y en cuyo exterior se dispone una serie de figuras de lados cóncavos unidas a los vértices del cuadrifolio. En conjunto se obtiene un diseño con 37 claves interiores. - Las claves de los terceletes se sitúan en la bisectriz del ángulo formado por la diagonal y los arcos del perímetro. Los centros principales del cuadrifolio exterior se disponen sobre la diagonal, aproximadamente en los puntos de corte con una circunferencia que tiene por centro el polo de la bóveda y por radio la distancia hasta las claves de los arcos del perímetro; los arcos principales del cuadrifolio exterior tienen por radio la distancia hasta el vértice de la bóveda, obteniéndose las claves intermedias sobre las diagonales y los terceletes; las ocho claves secundarias del perímetro de la bóveda quedan alineadas con las obtenidas sobre las diagonales, y las ocho claves secundarias obtenidas sobre los terceletes quedan alineadas con los centros anteriores; los centros de los remates o pies de gallo se disponen fuera del perímetro de la bóveda; las claves sobre las ligaduras se sitúan en los puntos medios de los segmentos limitados por las claves de los terceletes y la central; los centros del cuadrifolio interior (uno por cada hoja) se disponen sobre las diagonales; obtenidas estas claves, es posible trazar el círculo central, generando las claves interiores sobre las diagonales; las claves exteriores sobre los diagonales se desplazan ligeramente con respecto a los centros principales del cuadrifolio exterior; las claves secundarias sobre los terceletes resultan aproximadamente alineadas sobre un paralelogramo que une los puntos medios de los lados de la bóveda.

Arcos: El plano de imposta se sitúa a una altura de 50.8 pies (14.14 m) del suelo, y la clave central a 23.0 pies $(6.40 \mathrm{~m})$ de dicho plano. Todos los arcos parten tangentes a la vertical en el arranque, presentando todos peraltes. La clave central se encuentra 1.1 pies $(0.31 \mathrm{~m})$ por encima de la posición que correspondería a la de un arco ojivo semicircular. Un examen visual de la geometría de la diagonal y la comprobación de la posición que ocupan las claves secundarias dispuestas a lo largo de este arco nos hace concluir que su trazado teórico es efectivamente semicircular, partiendo con un peralte de 1.3 pies $(0.36 \mathrm{~m})$ en su arranque. Los arcos se trazarían aparentemente con 3 radios distintos, siendo sus datos geométricos en pies los siguientes:

\begin{tabular}{lccc} 
nervio & tipo & radio & peralte \\
\hline diagonal & sc & 21.9 & 1.3 \\
perpiaño & ap & 21.2 & 2.6 \\
formero & ap & 20.1 & 1.3 \\
tercelete per. & ap & 22.4 & 1.3 \\
tercelete for. & ap & 20.9 & 1.3
\end{tabular}

Rampante: Las claves de los arcos del perímetro se sitúan, en la dirección del eje x, a 2.0 pies (0.57 m) por debajo de la clave central; en la dirección del eje y, a la misma altura que la clave central. El rampante se puede considerar llano en la dirección del eje $x$ y horizontal en la del eje y.

Características constructivas: Los nervios que forman la crucería interior presentan 2 tipos distintos de sección en cuanto a molduraje y canto (grande para la diagonal, el tercelete y la ligadura; pequeño para el nervio decorativo). • Las jarjas se componen de 9 hiladas. • Las claves tienen su eje central vertical (y su cara inferior paralela a la superficie de la bóveda en cada punto). • La plementería es de cantería, dispuesta a la francesa; sus hiladas se componen de entre 1 y 2 piezas; queda ligeramente separada del trasdós del formero. 

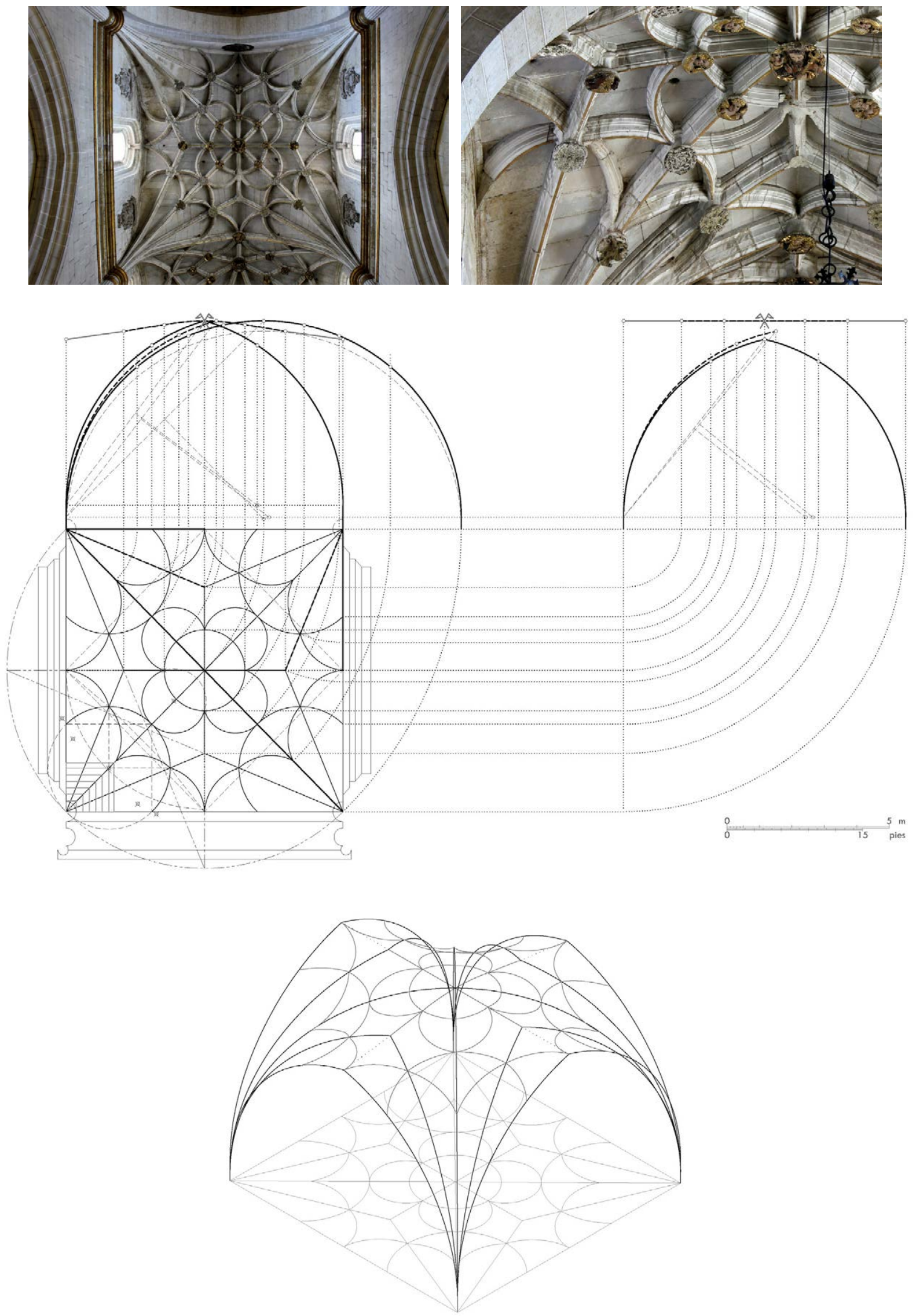

Figura 74. Catedral de Ciudad Rodrigo (Salamanca): bóveda de la cabecera (presbiterio): (a) Vista en planta.

(b) Detalle de los nervios, claves y plementería. (c) Hipótesis de trazado de los nervios. (d) Modelizado de los nervios (c, d: P. Moreno) 


\subsubsection{Fontiveros (Ávila) - Iglesia de San Cipriano}

Datos históricos del edificio: véase página 803 y siguientes

Datos de medición de las bóvedas: véase página 856 y siguientes

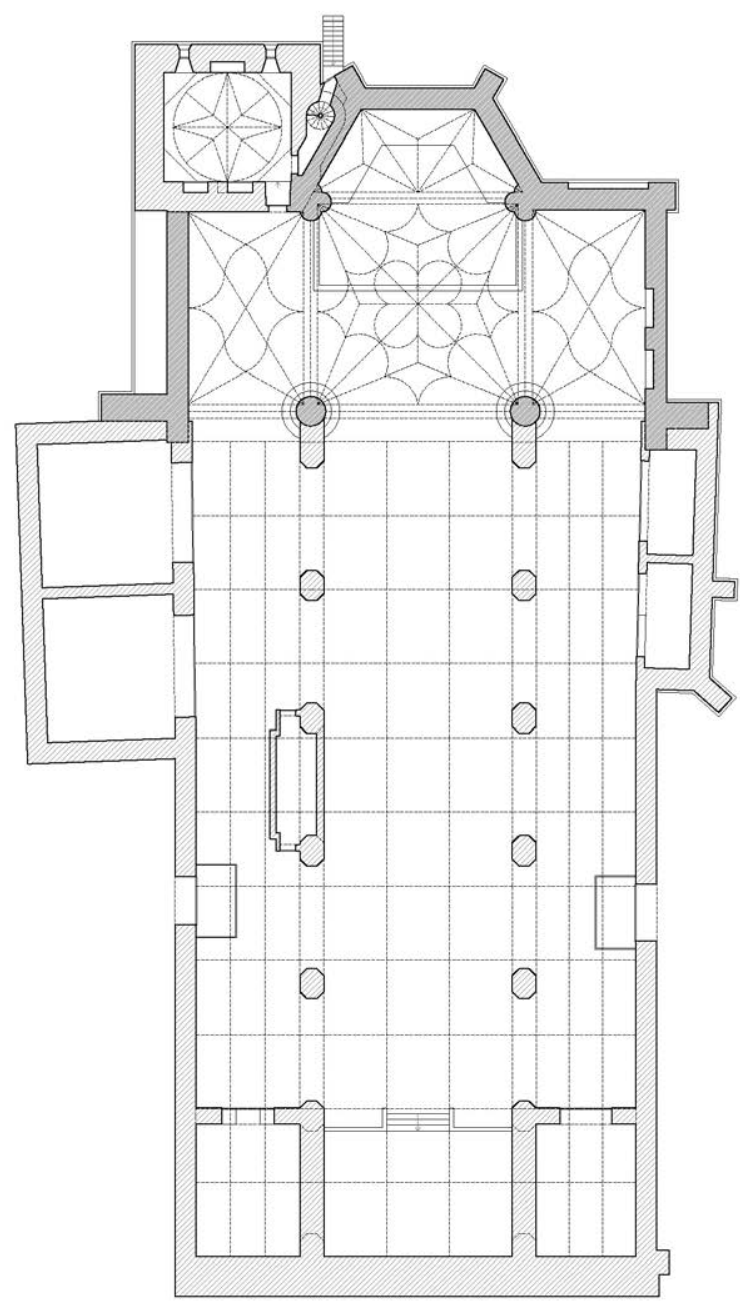

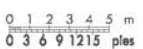

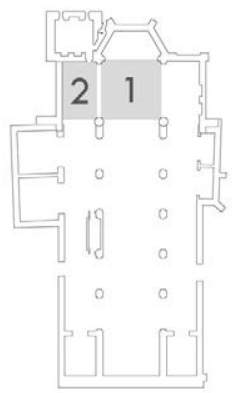

1. Bóveda del crucero (tramo central) (c.1558-1563)

2. Bóveda del crucero (tramo lateral norte) (c.1558-1563)

Figura 75. Iglesia de San Cipriano, Fontiveros (Ávila): (a) Planta (P. Moreno). (b) Indicación de las bóvedas analizadas, con su fecha de ejecución (P. Moreno) 


\subsubsection{Bóveda del crucero (tramo central)}

Modulación y rangos dimensionales: La bóveda tiene una planta aproximadamente cuadrada de dimensiones $38.7 \times 38.5$ pies $(10.79 \times 10.72 \mathrm{~m})$ y proporción entre los lados $1.005(1: 1)$, ambas consideradas a ejes de los arcos del perímetro (las interiores son $36.2 \times 36.2$ pies $(10.08 \times 10.08 \mathrm{~m}$ ) y $1.000(1: 1)$, respectivamente). Los perpiaños tienen un punto de arranque distinto al del resto de los nervios en cada apoyo.

Sistemas de composición: La crucería principal está formada por los dos arcos diagonales y terceletes sencillos en la dirección de ambos ejes. Las nervaduras decorativas forman un cuadrifolio de hojas cóncavas, en cuyo interior se dispone otro cuadrifolio de hojas convexas y tangentes al primero. En conjunto se obtiene un diseño con 21 claves interiores. - Las claves de los terceletes se sitúan en la bisectriz del ángulo formado por la diagonal y los arcos del perímetro. Las claves secundarias sobre los terceletes quedan aproximadamente alineadas sobre un paralelogramo que une los puntos medios de los lados de la bóveda; los centros principales del cuadrifolio exterior se disponen sobre la diagonal y alineados con las claves de los terceletes, y los de sus remates o pies de gallo fuera del perímetro de la bóveda; obtenidas las claves sobre las diagonales, las claves sobre las ligaduras se sitúan en los puntos medios de los segmentos limitados por las claves de los terceletes y la central; los centros del cuadrifolio interior (uno por cada hoja) se disponen sobre las diagonales.

Arcos: El plano de imposta se sitúa a una altura de 33.9 pies $(9.45 \mathrm{~m}$ ) del suelo, y la clave central a 24.4 pies $(6.81 \mathrm{~m})$ de dicho plano. Todos los arcos parten tangentes a la vertical en el arranque, presentando algunos peraltes, aunque no la diagonal. La clave central se encuentra 1.2 pies (0.32 m) por debajo de la posición que correspondería a la de un arco ojivo semicircular. Un examen visual de la geometría de la diagonal y la comprobación de la posición que ocupan las claves secundarias dispuestas a lo largo de este arco nos hace concluir que su trazado teórico es carpanel, partiendo sin peralte en su arranque. Los arcos se trazarían aparentemente con 3 radios distintos, siendo sus datos geométricos en pies los siguientes:

\begin{tabular}{lccc} 
nervio & tipo & radio & peralte \\
\hline diagonal & car & $30.1 \cdot 24.3$ & \\
perpiaño & ap & 25.6 & \\
formero & ap & 24.3 & 1.7 \\
tercelete per. & ap & 25.0 & \\
tercelete for. & ap & 25.0 &
\end{tabular}

Rampante: Las claves de los arcos del perímetro se sitúan, en la dirección de ambos ejes, a la misma altura que la clave central (la diferencia de altura es despreciable). El rampante se puede considerar horizontal en la dirección de ambos ejes.

Características constructivas: Los nervios que forman la crucería interior presentan 3 tipos distintos de sección en cuanto a molduraje y canto (grande para la diagonal; mediano para el tercelete y la ligadura; pequeño para el nervio decorativo). - Las jarjas se componen de 3,6 y 8 hiladas, dependiendo del soporte y del nervio considerado. - Las claves tienen su eje central vertical (y su cara inferior paralela a la superficie de la bóveda en cada punto). - La plementería es probablemente de ladrillo. 

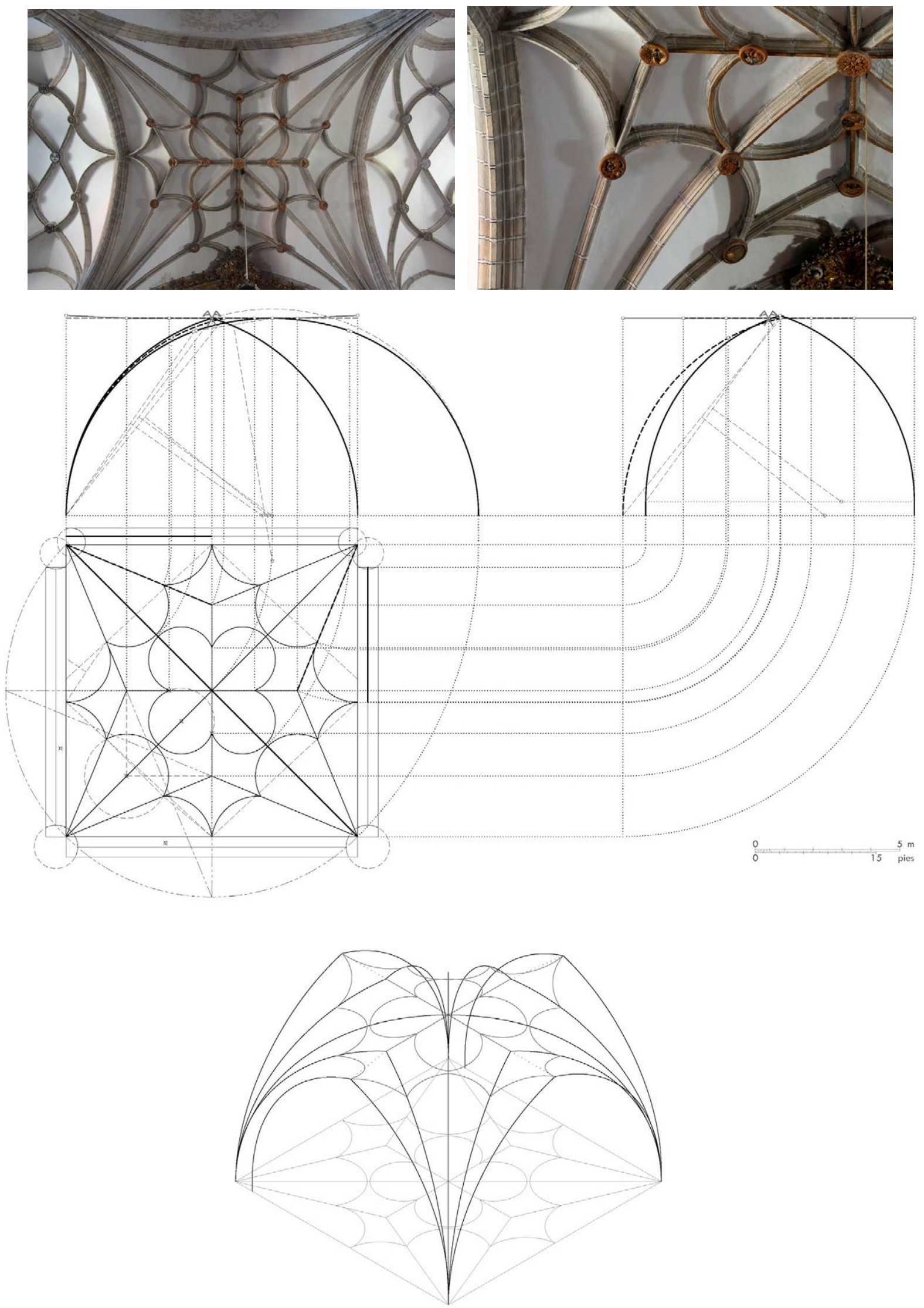

Figura 76. Iglesia de San Cipriano, Fontiveros (Ávila): bóveda del crucero (tramo central): (a) Vista en planta. (b) Detalle de los nervios, claves y plementería. (c) Hipótesis de trazado de los nervios. (d) Modelizado de los nervios (c, d: P. Moreno) 


\subsubsection{Bóveda del crucero (tramo lateral norte)}

Modulación y rangos dimensionales: La bóveda tiene una planta rectangular de dimensiones $22.1 \times 36.0$ pies $(6.17 \times 10.03 \mathrm{~m})$ y proporción entre los lados 1.629 (phi), ambas consideradas a ejes de los arcos del perímetro (las interiores son $20.9 \times 34.7$ pies $(5.82 \times 9.67 \mathrm{~m}$ ) y 1.660 (phi), respectivamente). Los perpiaños tienen un punto de arranque distinto al del resto de los nervios en cada apoyo.

Sistemas de composición: La crucería principal está formada por los dos arcos diagonales y terceletes sencillos en la dirección del eje mayor. Las nervaduras decorativas forman una figura de lados cóncavos y convexos. En conjunto se obtiene un diseño con 7 claves interiores. $\cdot$ Las claves de los terceletes se sitúan en la bisectriz del ángulo formado por la diagonal y los arcos del perímetro. Las claves sobre las diagonales se sitúan en los puntos de corte con la bisectriz del ángulo formado por la diagonal y el lado mayor de la bóveda; la figura se compone de ocho arcos, disponiéndose los centros de los lados cóncavos sobre el perímetro de la bóveda.

Arcos: El plano de imposta se sitúa a una altura de 33.9 pies $(9.45 \mathrm{~m}$ ) del suelo, y la clave central a 25.6 pies $(7.13 \mathrm{~m})$ de dicho plano. Todos los arcos parten tangentes a la vertical en el arranque, presentando algunos peraltes, entre ellos la diagonal. La clave central se encuentra 5.3 pies (1.49 m) por encima de la posición que correspondería a la de un arco ojivo semicircular. Un examen visual de la geometría de la diagonal y la comprobación de la posición que ocupan las claves secundarias dispuestas a lo largo de este arco nos hace concluir que su trazado teórico es carpanel, partiendo con un peralte de 7.7 pies $(2.14 \mathrm{~m}$ ) en su arranque. Los arcos se trazarían aparentemente con 5 radios distintos, siendo sus datos geométricos en pies los siguientes:

\begin{tabular}{lccc} 
nervio & tipo & radio & peralte \\
\hline diagonal & car & $22.2 \cdot 16.5$ & 7.7 \\
perpiaño & ap & 14.3 & 7.7 \\
formero $N$ & ap & 26.4 & \\
formero S & ap & 24.3 & 1.7 \\
tercelete per. & ap & 15.6 & 7.7
\end{tabular}

Rampante: Las claves de los arcos del perímetro se sitúan, en la dirección del eje $\mathrm{x}$ (menor), a 0.8 pies $(0.22 \mathrm{~m}$ ) por debajo de la clave central; en la dirección del eje y (mayor), a 4.2 pies (1.16 m) por debajo de la clave central. El rampante se puede considerar llano en la dirección del eje $x$ (menor) y redondo en la del eje y (mayor).

Características constructivas: Los nervios que forman la crucería interior presentan 2 tipos distintos de sección en cuanto a molduraje y canto (grande para la diagonal y el tercelete; pequeño para el nervio decorativo). - Las jarjas se componen de 3, 5, 7, 8 y 9 hiladas, dependiendo del soporte y del nervio considerado. - Las claves tienen su eje central vertical (y su cara inferior paralela a la superficie de la bóveda en cada punto). - La plementería es probablemente de ladrillo; asienta directamente sobre el trasdós del formero. 

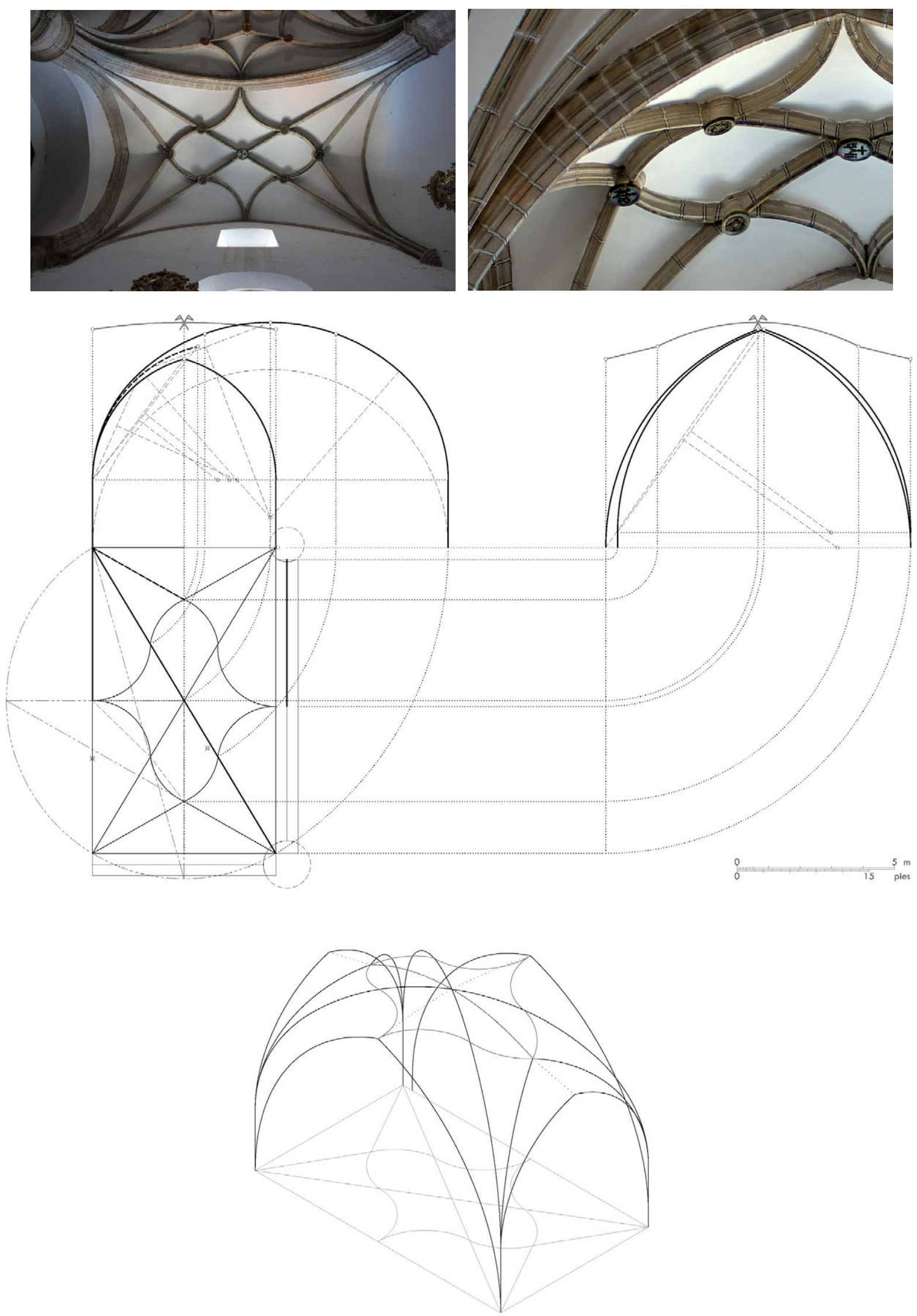

Figura 77. Iglesia de San Cipriano, Fontiveros (Ávila): bóveda del crucero (tramo lateral norte): (a) Vista en planta. (b) Detalle de los nervios, claves y plementería. (c) Hipótesis de trazado de los nervios. (d) Modelizado de los nervios (c, d: P. Moreno) 


\subsubsection{Fuente el Saz de Jarama (Madrid) - Iglesia de San Pedro Apóstol}

Datos históricos del edificio: véase página 764 y siguientes

Datos de medición de las bóvedas: véase página 858 y siguientes

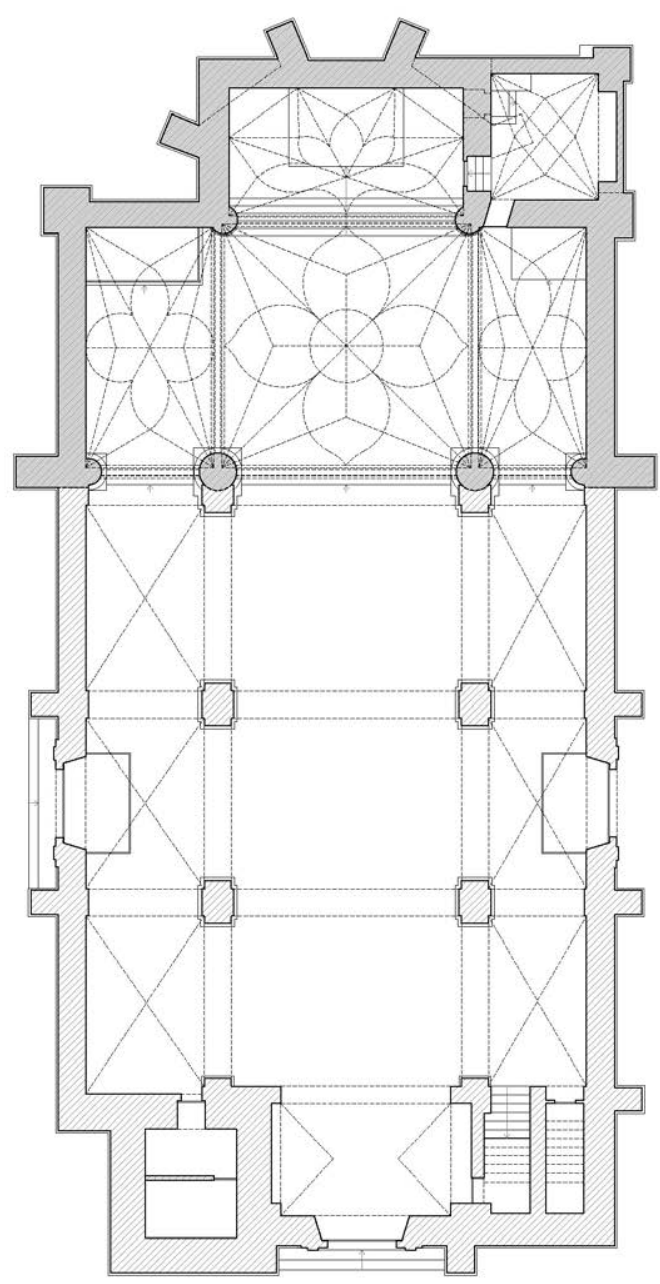

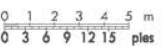

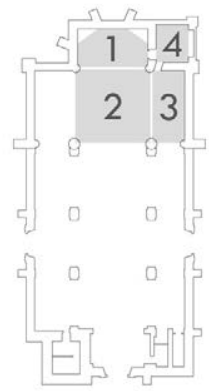

1. Bóveda de la cabecera (c.1540-1568) (atribución)

2. Bóveda del crucero (tramo central) (c.1540-1568) (atribución)

3. Bóveda del crucero (tramo lateral sur) (c.1540-1568) (atribución)

4. Bóveda de la sacristía (c.1540-1568) (atribución)

Figura 78. Iglesia de San Pedro Apóstol, Fuente el Saz de Jarama (Madrid): (a) Planta (P. Moreno). (b) Indicación de las bóvedas analizadas, con su fecha de ejecución (P. Moreno) 


\subsubsection{Bóveda de la cabecera}

Modulación y rangos dimensionales: La bóveda tiene una planta poligonal basada en un octógono irregular de lados 11.9, 12.2, 14.0, 12.2 y 11.9 pies $(3.30,3.41,3.91,3.41$ y $3.30 \mathrm{~m})$, y una embocadura de 33.8 pies $(9.43 \mathrm{~m}$ ) (quedaría inscrita en un rectángulo que tuviera por base la embocadura y por altura 19.0 pies $(5.30 \mathrm{~m})$ ). El arco perpiaño de la embocadura tiene un punto de arranque distinto al del resto de los nervios en cada apoyo.

Sistemas de composición: La crucería principal está formada por los arcos perpiaños radiales y terceletes sencillos. Las nervaduras decorativas forman un quinquefolio de hojas convexas. En conjunto se obtiene un diseño con 12 claves interiores. - La clave principal se sitúa en el centro del polígono generador, y no coincide con la del arco perpiaño de la embocadura; las claves de los terceletes correspondientes a los dos sectores triangulares más cercanos a la embocadura se sitúan en la bisectriz del ángulo formado por los perpiaños radiales y los arcos del perímetro; las correspondientes a los otros tres sectores se sitúan aproximadamente en los puntos de corte de sus medianas con una circunferencia que tiene por centro la clave principal y por radio la mitad de la mediana correspondiente a los dos sectores más cercanos a la embocadura. Las claves del quinquefolio sobre los perpiaños radiales se sitúan en puntos cuyo trazado geométrico no hemos logrado determinar; sus hojas no comparten el mismo trazado.

Arcos: El plano de imposta se sitúa a una altura de 39.2 pies $(10.91 \mathrm{~m})$ del suelo, y la clave principal a 23.3 pies $(6.48 \mathrm{~m})$ de dicho plano. Todos los arcos parten tangentes a la vertical en el arranque, presentando todos peraltes. El arco perpiaño de la embocadura es apuntado, encontrándose su clave 4.9 pies $(1.37 \mathrm{~m}$ ) por encima de la posición que correspondería a la de un arco perpiaño semicircular y partiendo con un peralte de 4.5 pies $(1.26 \mathrm{~m}$ ) en su arranque. Los arcos se trazarían aparentemente con 3 radios distintos, siendo sus datos geométricos en pies los siguientes:

$\begin{array}{lccc}\text { nervio } & \text { tipo } & \text { radio } & \text { peralte } \\ \text { perpiaño 1 } & \text { ap } & 18.4 & 4.5 \\ \text { perpiaño 2 } & \text { ap } & 18.8 & 4.5 \\ \text { perpiaño 3 } & \text { ap } & 19.3 & 4.5 \\ \text { formero 1 } & \text { ap } & 9.1 & 12.1 \\ \text { formero 2 } & \text { ap } & 8.9 & 12.1 \\ \text { formero 3 } & \text { ap } & 8.6 & 12.1 \\ \text { tercelete for. 1 } & \text { ap } & 8.7 & 12.1 \\ \text { tercelete for. 2 } & \text { ap } & 9.6 & 12.1 \\ \text { tercelete for. 3 } & \text { ap } & 10.1 & 12.1 \\ \text { tercelete for. 4 } & \text { ap } & 9.8 & 12.1\end{array}$

\section{Rampante: -}

Características constructivas: Los nervios que forman la crucería interior presentan 2 tipos distintos de sección en cuanto a molduraje y canto (grande para el perpiaño radial 2 y 3; pequeño para el tercelete, la ligadura y el nervio decorativo). • Las jarjas se componen de 9 hiladas. • Las claves tienen su eje central vertical (y su cara inferior paralela a la superficie de la bóveda en cada punto). - La plementería es probablemente de ladrillo; asienta directamente sobre el trasdós del formero. 

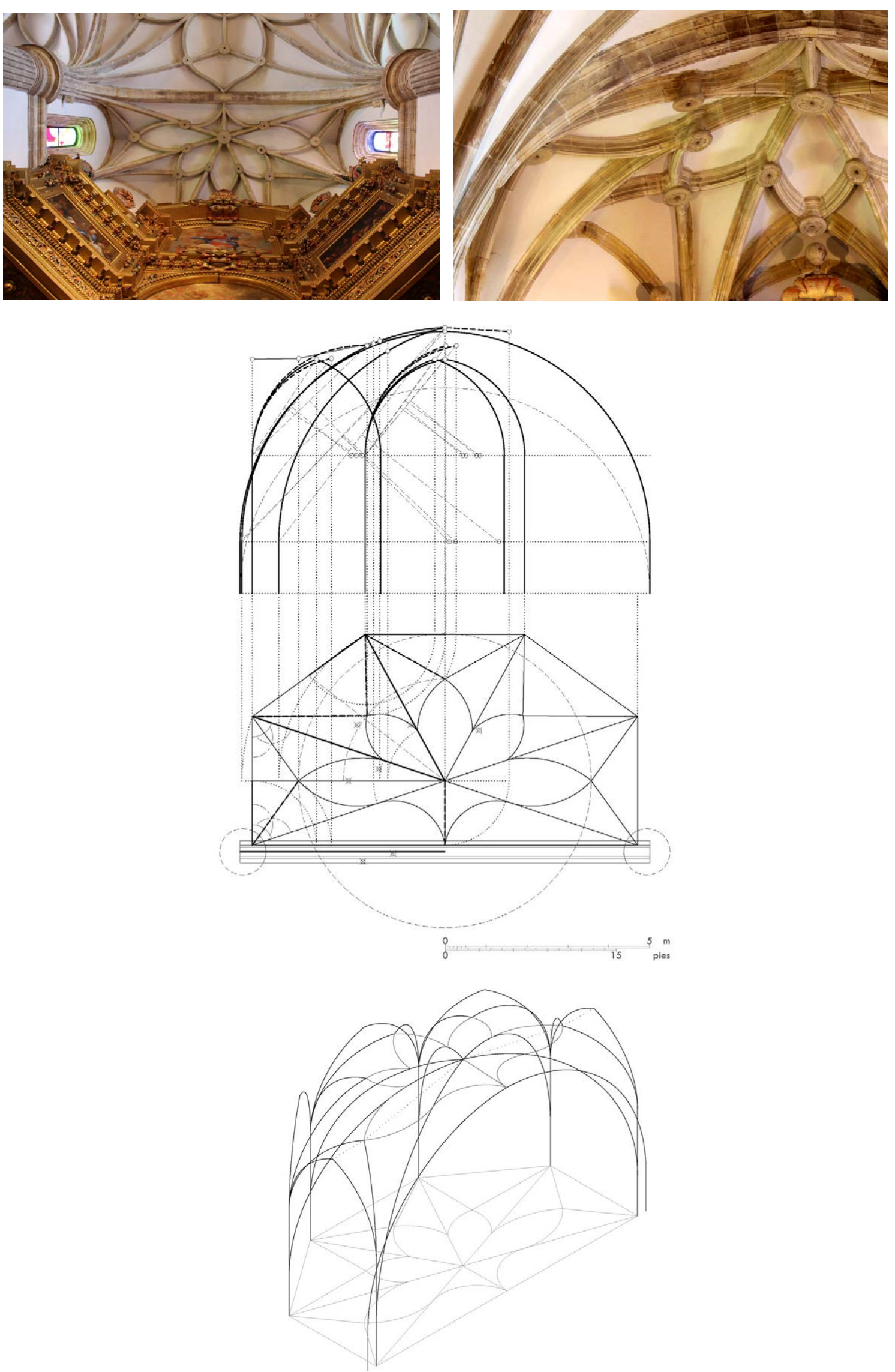

Figura 79. Iglesia de San Pedro Apóstol, Fuente el Saz de Jarama (Madrid): bóveda de la cabecera: (a) Vista en planta. (b) Detalle de los nervios, claves y plementería. (c) Hipótesis de trazado de los nervios. (d) Modelizado de los nervios (c, d: P. Moreno) 


\subsubsection{Bóveda del crucero (tramo central)}

Modulación y rangos dimensionales: La bóveda tiene una planta aproximadamente cuadrada de dimensiones $37.2 \times 36.3$ pies $(10.35 \times 10.12 \mathrm{~m})$ y proporción entre los lados $1.025(1: 1)$, ambas consideradas a ejes de los arcos del perímetro (las interiores son $36.0 \times 35.2$ pies $(10.03 \times 9.80 \mathrm{~m}$ ) y $1.023(1: 1)$, respectivamente). Los perpiaños tienen un punto de arranque distinto al del resto de los nervios en cada apoyo.

Sistemas de composición: La crucería principal está formada por los dos arcos diagonales y terceletes sencillos en la dirección de ambos ejes. Las nervaduras decorativas forman un cuadrifolio de hojas conopiales, en cuyo interior se dispone un círculo. En conjunto se obtiene un diseño con 21 claves interiores. - Las claves de los terceletes se sitúan en la bisectriz del ángulo formado por la diagonal y los arcos del perímetro. Las claves secundarias sobre los terceletes quedan alineadas sobre un paralelogramo que une los extremos del cuadrifolio; las claves sobre las ligaduras se sitúan en los puntos medios de los segmentos limitados por las claves de los terceletes y la central; obtenidas estas claves, es posible trazar el círculo central, generando las claves sobre las diagonales; los centros principales del cuadrifolio (dos por cada hoja) se disponen aproximadamente en las mediatrices de los semiejes, y los de sus remates o pies de gallo fuera del perímetro de la bóveda.

Arcos: El plano de imposta se sitúa a una altura de 39.2 pies $(10.91 \mathrm{~m})$ del suelo, y la clave central a 23.5 pies $(6.56 \mathrm{~m})$ de dicho plano. Todos los arcos parten tangentes a la vertical en el arranque, presentando todos peraltes. La clave central se encuentra 1.6 pies $(0.45 \mathrm{~m})$ por debajo de la posición que correspondería a la de un arco ojivo semicircular. Un examen visual de la geometría de la diagonal y la comprobación de la posición que ocupan las claves secundarias dispuestas a lo largo de este arco nos hace concluir que su trazado teórico es carpanel, partiendo con un peralte de 1.5 pies $(0.42 \mathrm{~m})$ en su arranque. Los arcos se trazarían aparentemente con 5 radios distintos, siendo sus datos geométricos en pies los siguientes:

\begin{tabular}{lccc} 
nervio & tipo & radio & peralte \\
\hline diagonal & car & $21.8 \cdot 39.3$ & 1.5 \\
perpiaño & ap & 18.4 & 4.5 \\
formero (mitad E) & sc & 16.1 & 4.5 \\
formero (mitad O) & sc & 17.6 & 3.0 \\
tercelete per. & ap & 20.4 & 3.0 \\
tercelete for. & ap & 19.8 & 3.0
\end{tabular}

Rampante: Las claves de los arcos del perímetro se sitúan, en la dirección del eje x, a 2.9 pies (0.82 $\mathrm{m})$ por debajo de la clave central; en la dirección del eje y, a 0.6 pies $(0.18 \mathrm{~m})$ por debajo de la clave central. El rampante se puede considerar llano en la dirección de ambos ejes.

Características constructivas: Los nervios que forman la crucería interior presentan 2 tipos distintos de sección en cuanto a molduraje y canto (grande para la diagonal; pequeño para el tercelete, la ligadura y el nervio decorativo). - Las jarjas se componen de 7, 8 y 9 hiladas, dependiendo del soporte y del nervio considerado. - Las claves tienen su eje central vertical (y su cara inferior paralela a la superficie de la bóveda en cada punto); las que corresponden a las intersecciones del círculo central con las ligaduras no están provistas de un cilindro central, sino que se resuelven como un cruce de nervios. - La plementería es probablemente de ladrillo. 

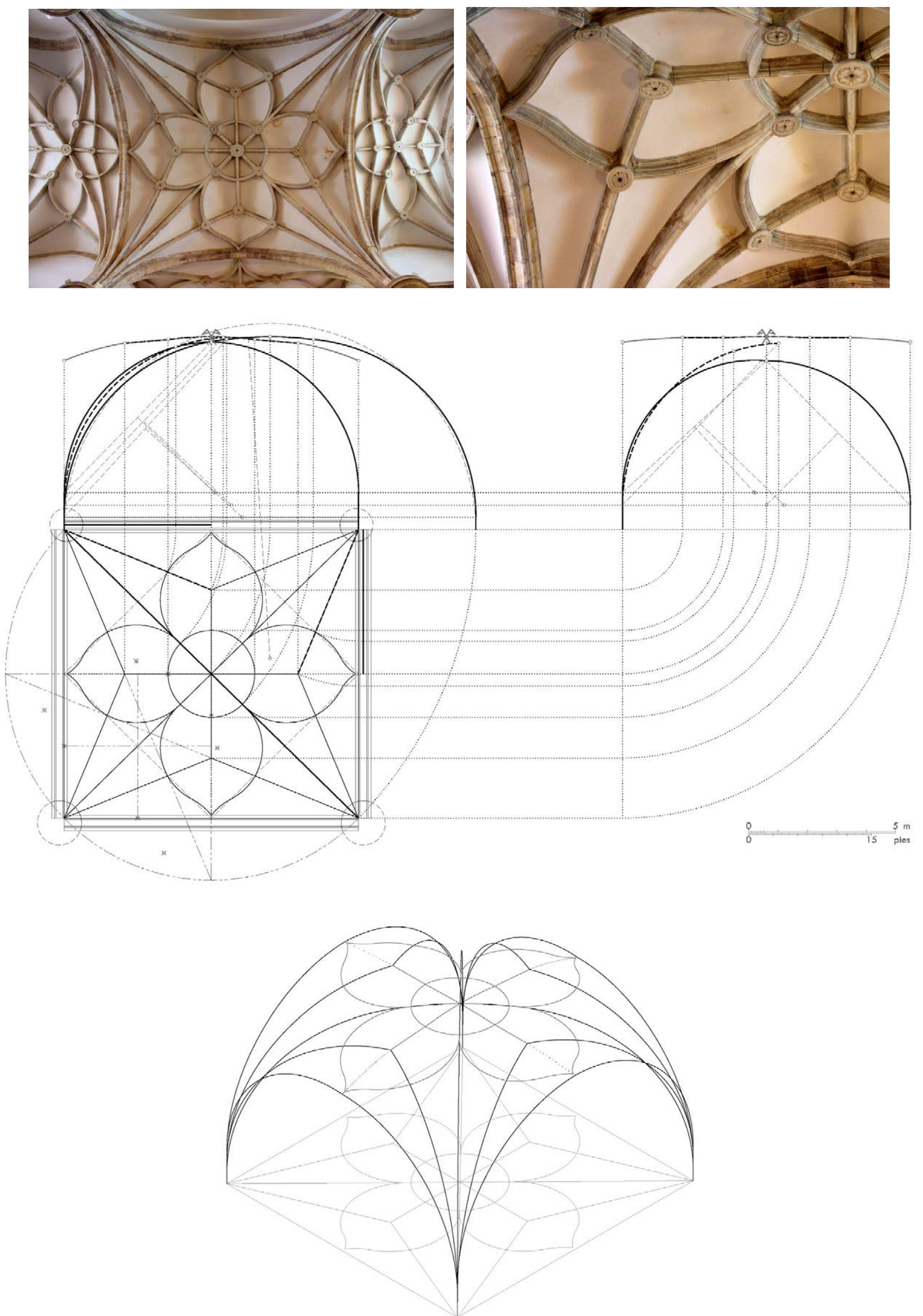

Figura 80. Iglesia de San Pedro Apóstol, Fuente el Saz de Jarama (Madrid): bóveda del crucero (tramo central): (a) Vista en planta. (b) Detalle de los nervios, claves y plementería. (c) Hipótesis de trazado de los nervios. (d) Modelizado de los nervios (c, d: P. Moreno) 


\subsubsection{Bóveda del crucero (tramo lateral sur)}

Modulación y rangos dimensionales: La bóveda tiene una planta rectangular de dimensiones $16.1 \times 35.2$ pies $(4.50 \times 9.82 \mathrm{~m})$ y proporción entre los lados $2.186(>2: 1)$, ambas consideradas a ejes de los arcos del perímetro (las interiores son $15.6 \times 34.7$ pies $(4.33 \times 9.66 \mathrm{~m})$ y $2.224(>2: 1)$, respectivamente). Los perpiaños tienen un punto de arranque distinto al del resto de los nervios en cada apoyo.

Sistemas de composición: La crucería principal está formada por los dos arcos diagonales y terceletes sencillos en la dirección de ambos ejes. Las nervaduras decorativas forman un cuadrifolio de hojas convexas. En conjunto se obtiene un diseño con 13 claves interiores. - Las claves de los terceletes se sitúan en la bisectriz del ángulo formado por la diagonal y los arcos del perímetro. Las claves secundarias sobre los terceletes se sitúan en los puntos de corte con un paralelogramo que une los extremos del cuadrifolio; los centros de las hojas del eje menor (uno por cada hoja) se disponen sobre dicho eje, generando las claves sobre las diagonales; los centros de las hojas del eje mayor (dos por cada hoja) se disponen en puntos cuyo trazado geométrico no hemos logrado determinar.

Arcos: El plano de imposta se sitúa a una altura de 39.2 pies $(10.91 \mathrm{~m})$ del suelo, y la clave central a 21.5 pies $(6.00 \mathrm{~m})$ de dicho plano. Todos los arcos parten tangentes a la vertical en el arranque, presentando todos peraltes. La clave central se encuentra 2.5 pies $(0.71 \mathrm{~m})$ por encima de la posición que correspondería a la de un arco ojivo semicircular. Un examen visual de la geometría de la diagonal y la comprobación de la posición que ocupan las claves secundarias dispuestas a lo largo de este arco nos hace concluir que su trazado teórico es carpanel, partiendo con un peralte de 3.0 pies $(0.84 \mathrm{~m})$ en su arranque. Los arcos se trazarían aparentemente con 4 radios distintos, siendo sus datos geométricos en pies los siguientes:

\begin{tabular}{lccc} 
nervio & tipo & radio & peralte \\
\hline diagonal & car & $18.0 \cdot 13.5$ & 3.0 \\
perpiaño & ap & 10.3 & 10.0 \\
formero N (mitad E) & sc & 16.1 & 4.5 \\
formero N (mitad O) & sc & 17.6 & 3.0 \\
formero S & ap & 17.6 & 3.0 \\
tercelete per. & ap & 10.3 & 10.0 \\
tercelete for. & ap & 18.1 & 3.0
\end{tabular}

Rampante: Las claves de los arcos del perímetro se sitúan, en la dirección del eje x (menor), a 0.9 pies $(0.26 \mathrm{~m}$ ) por debajo de la clave central; en la dirección del eje y (mayor), a 1.5 pies (0.42 m) por debajo de la clave central. El rampante se puede considerar llano en la dirección de ambos ejes.

Características constructivas: Los nervios que forman la crucería interior presentan 2 tipos distintos de sección en cuanto a molduraje y canto (grande para la diagonal; pequeño para el tercelete, la ligadura y el nervio decorativo). - Las jarjas se componen de 7, 8, 9, 10 y 11 hiladas, dependiendo del soporte y del nervio considerado. - Las claves tienen su eje central vertical (y su cara inferior paralela a la superficie de la bóveda en cada punto); las que corresponden a las intersecciones del cuadrifolio con los terceletes situados sobre el eje menor no están provistas de un cilindro central, sino que se resuelven como un cruce de nervios. - La plementería es probablemente de ladrillo; asienta directamente sobre el trasdós del formero. 

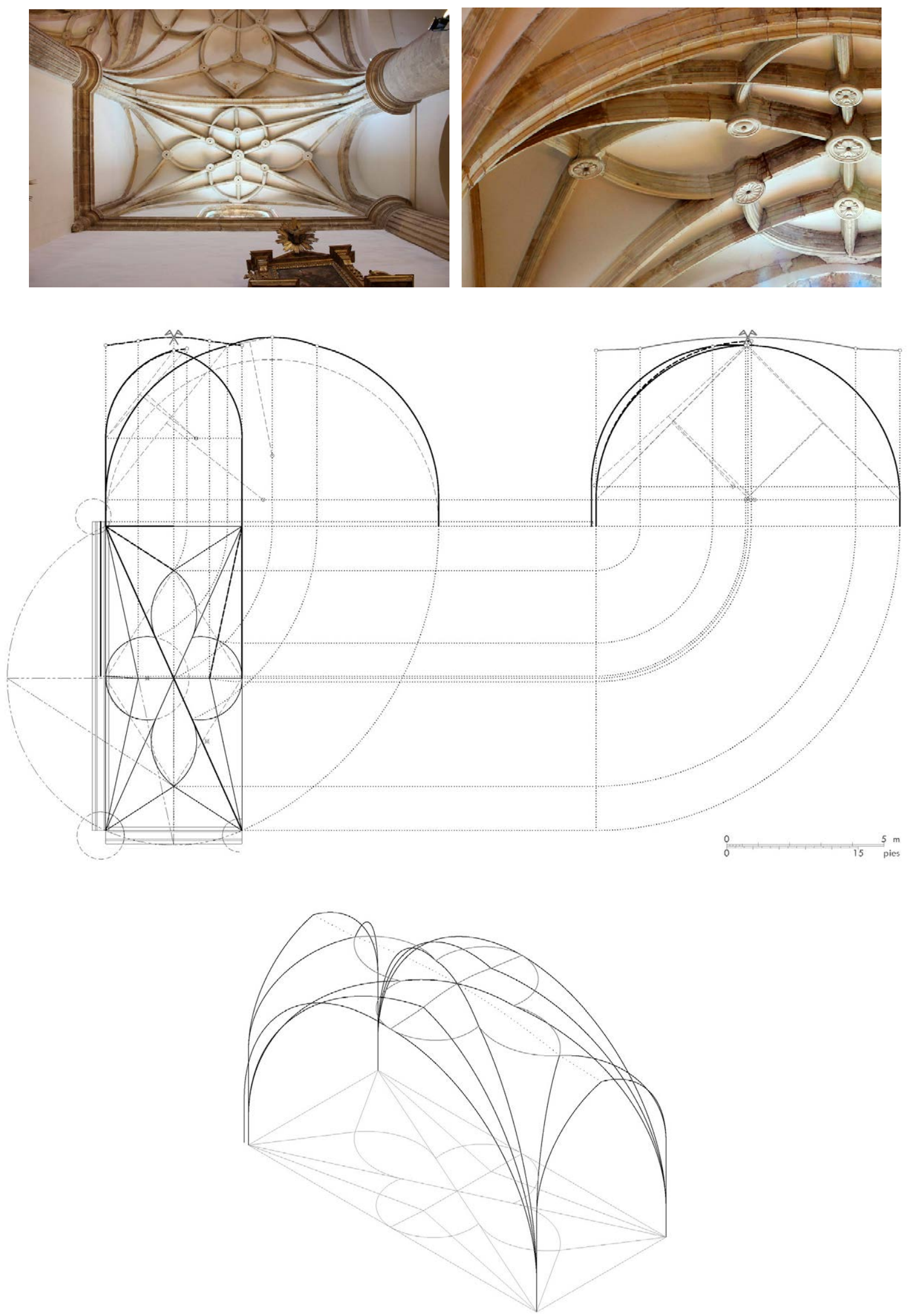

Figura 81. Iglesia de San Pedro Apóstol, Fuente el Saz de Jarama (Madrid): bóveda del crucero (tramo lateral sur): (a) Vista en planta. (b) Detalle de los nervios, claves y plementería. (c) Hipótesis de trazado de los nervios.

(d) Modelizado de los nervios (c, d: P. Moreno) 


\subsubsection{Bóveda de la sacristía}

Modulación y rangos dimensionales: La bóveda tiene una planta rectangular de dimensiones $15.5 \times 18.2$ pies $(4.32 \times 5.07 \mathrm{~m})$ y proporción entre los lados $1.174(7: 6)$, ambas consideradas a ejes de los arcos del perímetro (coinciden con las interiores). Todos los nervios tienen un punto de arranque común en cada apoyo.

Sistemas de composición: La crucería principal está formada por los dos arcos diagonales y terceletes sencillos en la dirección de ambos ejes. Las nervaduras decorativas forman un rombo de lados rectos. En conjunto se obtiene un diseño con 9 claves interiores. - Las claves de los terceletes se sitúan en la bisectriz del ángulo formado por la diagonal y los arcos del perímetro. Las claves sobre las diagonales son generadas automáticamente uniendo las claves de los terceletes.

Arcos: El plano de imposta se sitúa a una altura de 10.6 pies $(2.94 \mathrm{~m}$ ) del suelo, y la clave central a 11.9 pies $(3.32 \mathrm{~m}$ ) de dicho plano. Todos los arcos parten tangentes a la vertical en el arranque, no presentando ninguno peraltes. La clave central coincide con la posición que correspondería a la de un arco ojivo semicircular. Un examen visual de la geometría de la diagonal y la comprobación de la posición que ocupan las claves secundarias dispuestas a lo largo de este arco nos hace concluir que su trazado teórico es efectivamente semicircular, partiendo sin peralte en su arranque. Los arcos se trazarían aparentemente con 2 radios distintos, siendo sus datos geométricos en pies los siguientes:

$\begin{array}{lccc}\text { nervio } & \text { tipo } & \text { radio } & \text { peralte } \\ \text { diagonal } & \text { sc } & 12.0 & \\ \text { perpiaño } & \text { ap } & 10.5 & \\ \text { formero } & \text { ap } & 10.6 \\ \text { tercelete per. } & \text { ap } & 11.4 \\ \text { tercelete for. } & \text { ap } & 11.6\end{array}$

Rampante: Las claves de los arcos del perímetro se sitúan, en la dirección del eje x (menor), a 1.4 pies $(0.39 \mathrm{~m}$ ) por debajo de la clave central; en la dirección del eje y (mayor), a 1.8 pies (0.49 m) por debajo de la clave central. El rampante se puede considerar llano en la dirección de ambos ejes.

Características constructivas: Los nervios que forman la crucería interior presentan 2 tipos distintos de sección en cuanto a molduraje y canto (grande para la diagonal; pequeño para el tercelete y el nervio decorativo). - Las jarjas se componen de 3 y 4 hiladas, dependiendo del nervio considerado. • Las claves tienen su eje central vertical (y su cara inferior paralela a la superficie de la bóveda en cada punto). - La plementería es probablemente de ladrillo; asienta directamente sobre el trasdós del formero. 

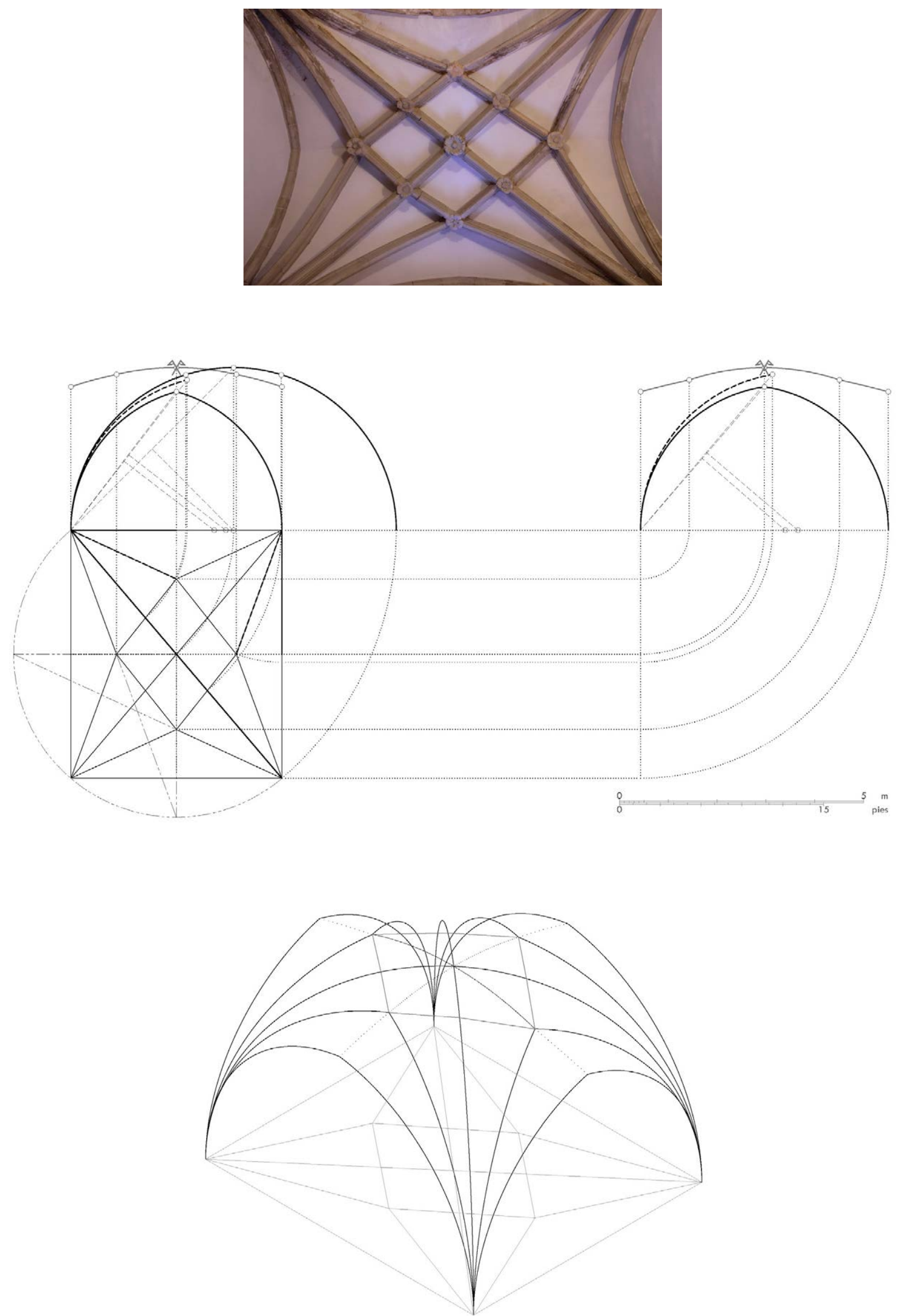

Figura 82. Iglesia de San Pedro Apóstol, Fuente el Saz de Jarama (Madrid): bóveda de la sacristía: (a) Vista en planta. (b) Hipótesis de trazado de los nervios. (c) Modelizado de los nervios (b, c: P. Moreno) 


\subsubsection{Fuenteguinaldo (Salamanca) - Iglesia de San Juan Bautista}

Datos históricos del edificio: véase página 777

Datos de medición de las bóvedas: véase página 862
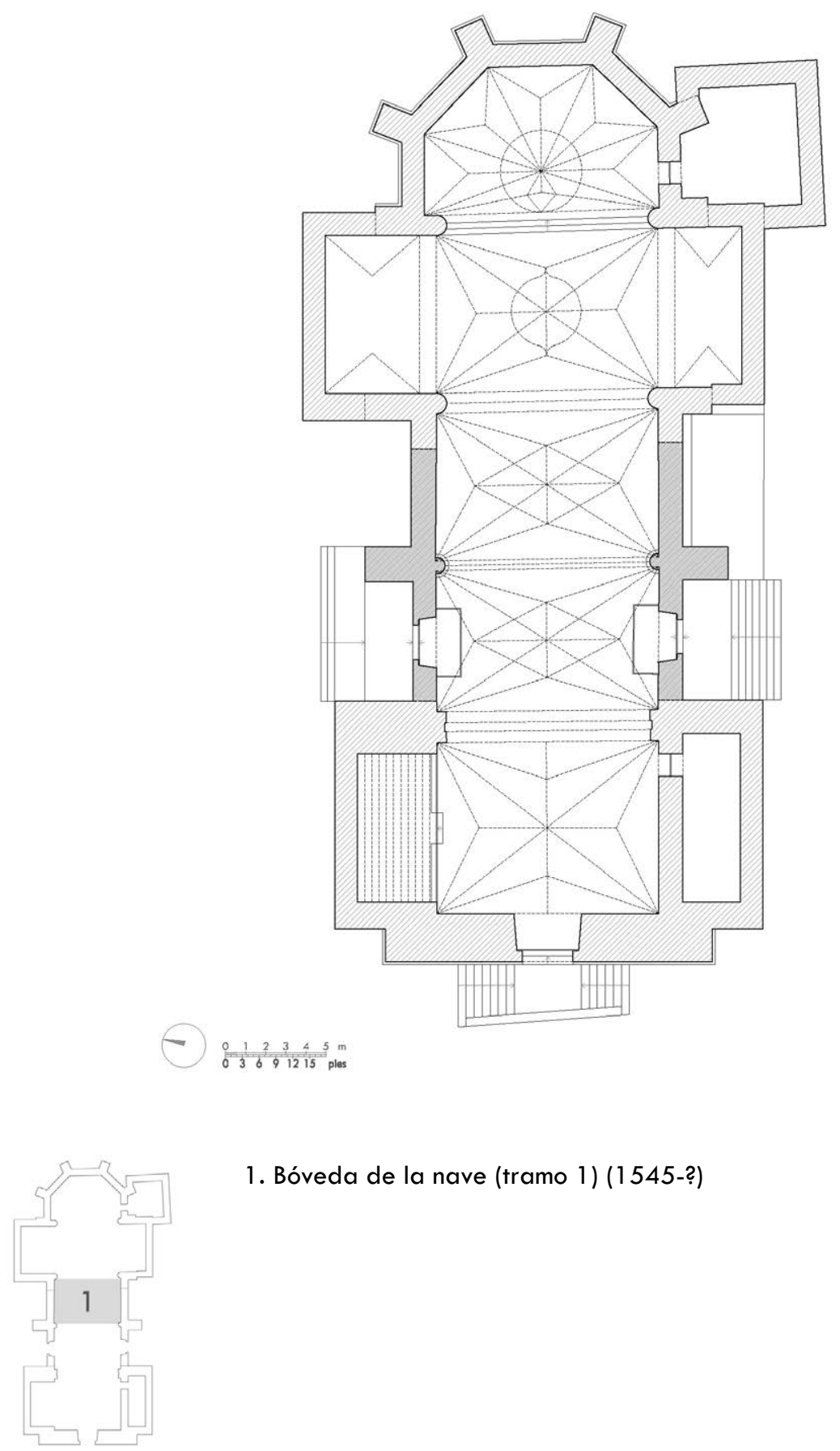

1. Bóveda de la nave (tramo 1) (1545-?)

Figura 83. Iglesia de San Juan Bautista, Fuenteguinaldo (Salamanca): (a) Planta (P. Moreno). (b) Indicación de las bóvedas analizadas, con su fecha de ejecución (P. Moreno) 


\subsubsection{Bóveda de la nave (tramo 1) $)^{443}$}

Modulación y rangos dimensionales: La bóveda tiene una planta rectangular de dimensiones $39.6 \times 29.0$ pies ( $11.04 \times 8.08 \mathrm{~m}$ ) y proporción entre los lados $1.366(4: 3)$, ambas consideradas a ejes de los arcos del perímetro (las interiores son $39.6 \times 26.4$ pies (11.04x7.34 m) y 1.500 (3:2), respectivamente). Los perpiaños tienen un punto de arranque distinto al del resto de los nervios en cada apoyo.

Sistemas de composición: La crucería principal está formada por los dos arcos diagonales y terceletes sencillos en la dirección de ambos ejes. Las nervaduras decorativas forman un rombo de lados rectos. En conjunto se obtiene un diseño con 9 claves interiores. - Las claves de los terceletes se sitúan en la bisectriz del ángulo formado por la diagonal y los arcos del perímetro. Las claves sobre las diagonales son generadas automáticamente uniendo las claves de los terceletes.

Arcos: El plano de imposta se sitúa a una altura de 32.4 pies $(9.04 \mathrm{~m}$ ) del suelo, y la clave central a 23.8 pies $(6.63 \mathrm{~m})$ de dicho plano. Todos los arcos parten tangentes a la vertical en el arranque, no presentando ninguno peraltes. La clave central coincide con la posición que correspondería a la de un arco ojivo semicircular. Un examen visual de la geometría de la diagonal y la comprobación de la posición que ocupan las claves secundarias dispuestas a lo largo de este arco nos hace concluir que su trazado teórico es efectivamente semicircular, partiendo sin peralte en su arranque. Los arcos se trazarían aparentemente con 2 radios distintos, siendo sus datos geométricos en pies los siguientes:

\begin{tabular}{lccc} 
nervio & tipo & radio & peralte \\
\hline diagonal & sc & 23.8 & \\
perpiaño E & ap & 21.9 & \\
perpiaño $O$ & ap & 22.5 & \\
formero & ap & 21.8 \\
tercelete per. & ap & 23.5 & \\
tercelete for. & ap & 24.2
\end{tabular}

Rampante: Las claves de los arcos del perímetro se sitúan, en la dirección del eje x (mayor), a 3.8 pies $(1.05 \mathrm{~m}$ ) por debajo de la clave central; en la dirección del eje y (menor), a 1.7 pies $(0.48 \mathrm{~m})$ (valor promedio) por debajo de la clave central. El rampante se puede considerar llano en la dirección de ambos ejes.

Características constructivas: Los nervios que forman la crucería interior presentan 1 único tipo de sección en cuanto a molduraje y canto (diagonal, tercelete, ligadura y nervio decorativo). - Las jarjas se componen de 6 y 7 hiladas, dependiendo del soporte considerado. - Las claves tienen su eje central vertical (y su cara inferior paralela a la superficie de la bóveda en cada punto). • La plementería es de cantería, dispuesta a la francesa; sus hiladas se componen de entre 1 y 4 piezas; queda ligeramente separada del trasdós del formero.

\footnotetext{
${ }^{443}$ La bóveda que limita con el coro difiere de la analizada, en cuanto a disposición de las claves (eje central inclinado en lugar de vertical) y de la plementería.
} 

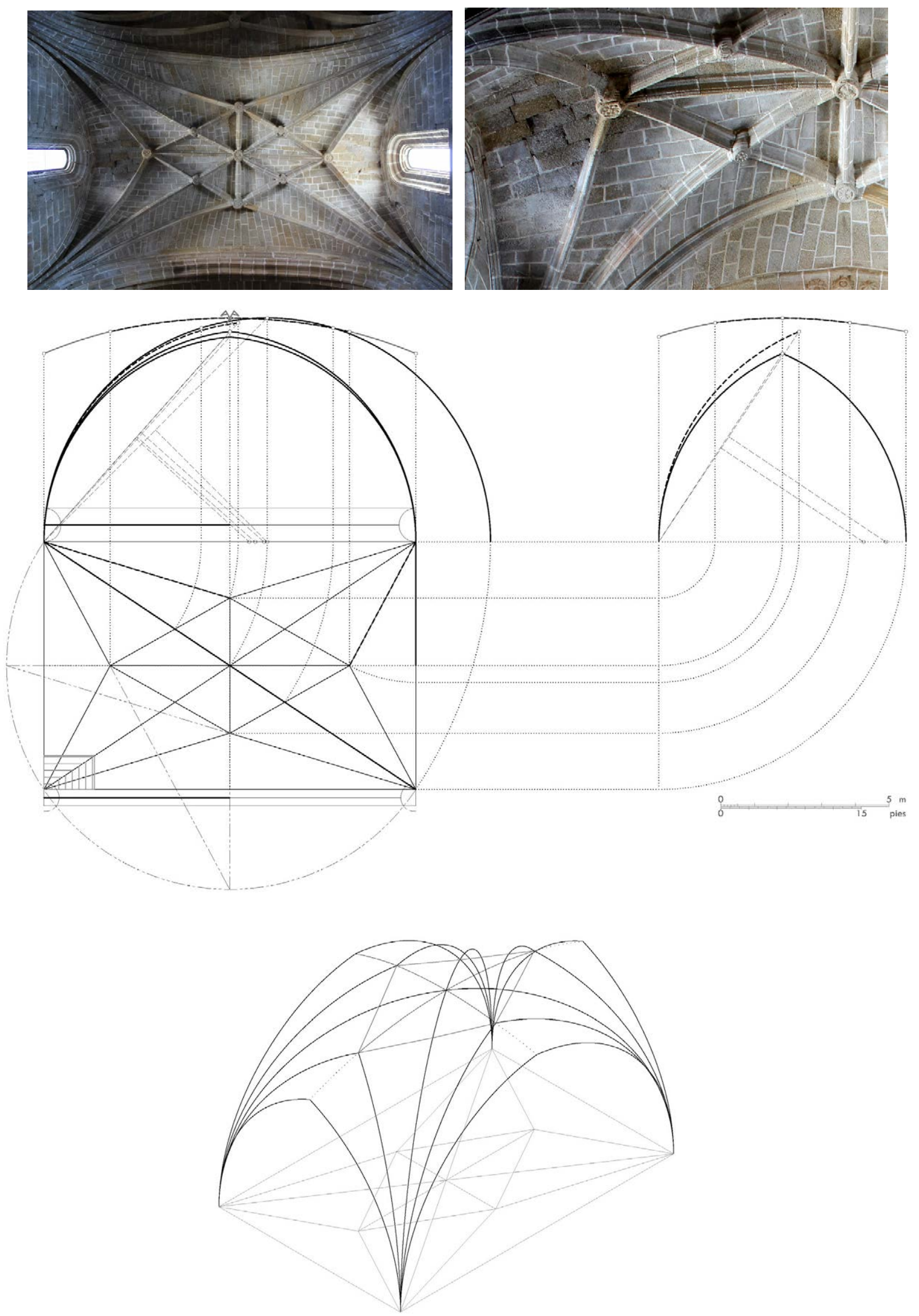

Figura 84. Iglesia de San Juan Bautista, Fuenteguinaldo (Salamanca): bóveda de la nave (tramo 1): (a) Vista en planta. (b) Detalle de los nervios, claves y plementería. (c) Hipótesis de trazado de los nervios. (d) Modelizado de los nervios (c, d: P. Moreno) 


\subsubsection{Guareña (Badajoz) - Iglesia de Santa María de la Asunción}

Datos históricos del edificio: véase página 806 y siguientes

Datos de medición de las bóvedas: véase página 863
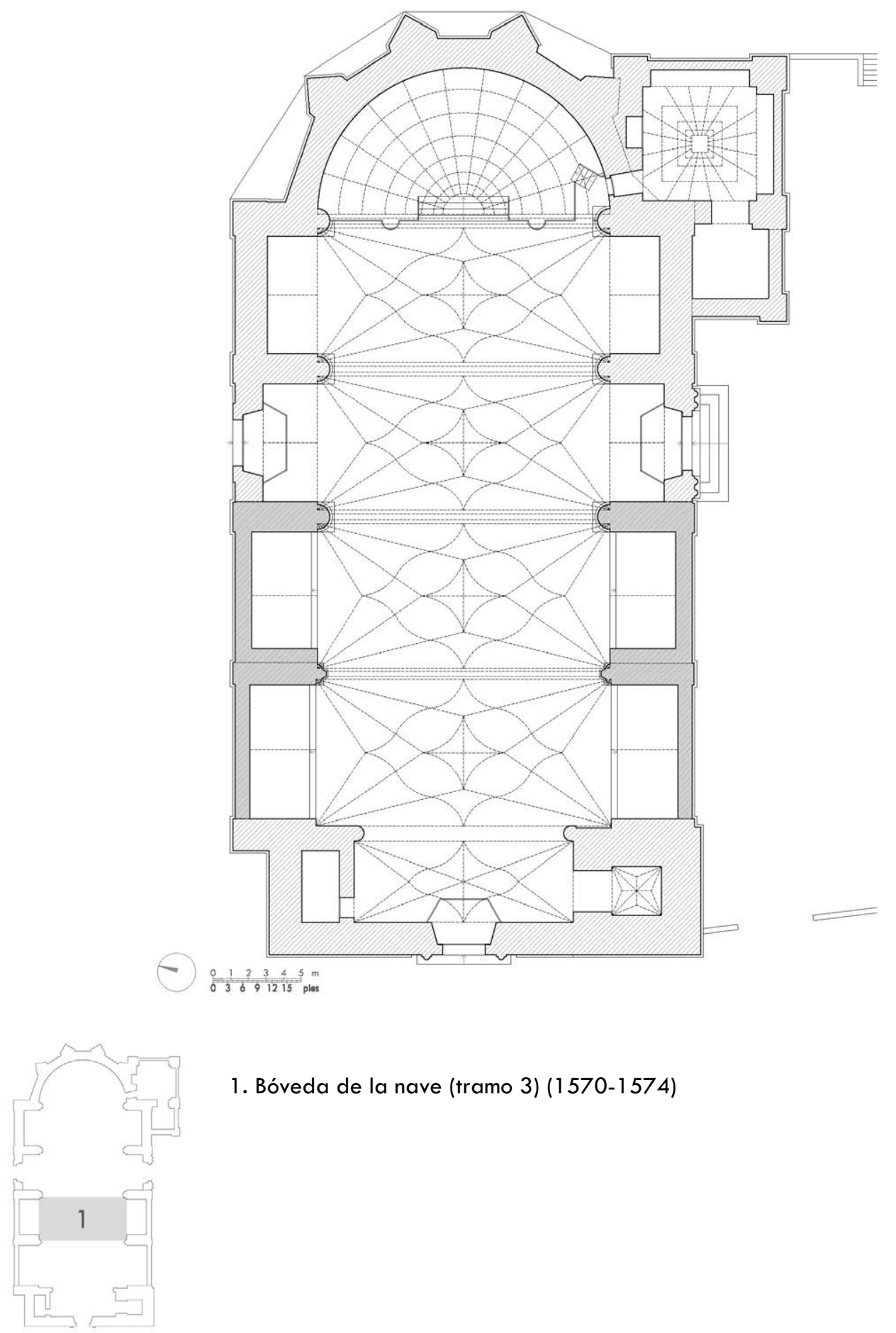

1. Bóveda de la nave (tramo 3) (1570-1574)

Figura 85. Iglesia de Santa María de la Asunción, Guareña (Badajoz): (a) Planta (P. Moreno). (b) Indicación de las bóvedas analizadas, con su fecha de ejecución (P. Moreno) 


\subsubsection{Bóveda de la nave (tramo 3)}

Modulación y rangos dimensionales: La bóveda tiene una planta rectangular de dimensiones $59.6 \times 32.0$ pies ( $16.60 \times 8.90 \mathrm{~m})$ y proporción entre los lados $1.863(2: 1)$, ambas consideradas a ejes de los arcos del perímetro (las interiores son $59.6 \times 29.4$ pies $(16.60 \times 8.19 \mathrm{~m})$ y $2.027(2: 1)$, respectivamente). Los perpiaños tienen un punto de arranque distinto al del resto de los nervios en cada apoyo.

Sistemas de composición: La crucería principal está formada por terceletes dobles en la dirección del eje mayor y sencillos en la dirección del eje menor, careciendo de arcos diagonales. Las nervaduras decorativas forman una figura de lados cóncavos y convexos, en cuyo interior se dispone otra figura de lados cóncavos. En conjunto se obtiene un diseño con 15 claves interiores. • Las claves de los terceletes se sitúan, sobre el eje mayor, en la bisectriz del ángulo formado por la diagonal y los arcos del perímetro, y en otros dos puntos cuyo trazado geométrico no hemos logrado determinar; sobre el eje menor, en los puntos que resultan de dividir dicho eje en cuatro partes iguales (a 1/4 del perímetro). Las claves secundarias sobre los terceletes se sitúan aproximadamente en los puntos de corte con un paralelogramo que une los extremos de la figura exterior; esta se compone de doce arcos, y la interior de cuatro.

Arcos: El plano de imposta se sitúa a una altura de 47.1 pies $(13.12 \mathrm{~m}$ ) del suelo, y la clave central a 33.0 pies $(9.19 \mathrm{~m}$ ) de dicho plano. Todos los arcos parten tangentes a la vertical en el arranque, presentando algunos peraltes. La clave central se encuentra 0.2 pies $(0.07 \mathrm{~m})$ por debajo de la posición que correspondería a la de un arco ojivo semicircular. Aunque no existe diagonal, la posición de dicha clave central parece haber sido fijada como si realmente la hubiera y fuera semicircular. Los arcos se trazarían aparentemente con 3 radios distintos, siendo sus datos geométricos en pies los siguientes:

\begin{tabular}{lccc} 
nervio & tipo & radio & peralte \\
\hline perpiaño E & ap & 33.2 & \\
perpiaño $O$ & sc & 30.1 & 3.9 \\
formero & ap & 23.8 & 5.0 \\
tercelete per. & ap & 33.1 & \\
tercelete for. 1 & ap & 33.9 & \\
tercelete for. 2 & ap & 33.2 &
\end{tabular}

Rampante: Las claves de los arcos del perímetro se sitúan, en la dirección del eje x (mayor), a 6.0 pies $(1.66 \mathrm{~m}$ ) por debajo de la clave central; en la dirección del eje y (menor), a la misma altura que la clave central (la diferencia de altura es despreciable). El rampante se puede considerar llano en la dirección del eje $x$ (mayor) y horizontal en la del eje y (menor).

Características constructivas: Los nervios que forman la crucería interior presentan 1 único tipo de sección en cuanto a molduraje y canto (tercelete, ligadura y nervio decorativo). - Las jarjas se componen de 13 y 15 hiladas, dependiendo del soporte y del nervio considerado. - Las claves tienen su eje central vertical (y su cara inferior paralela a la superficie de la bóveda en cada punto). • La plementería es probablemente de ladrillo; asienta directamente sobre el trasdós del formero. 

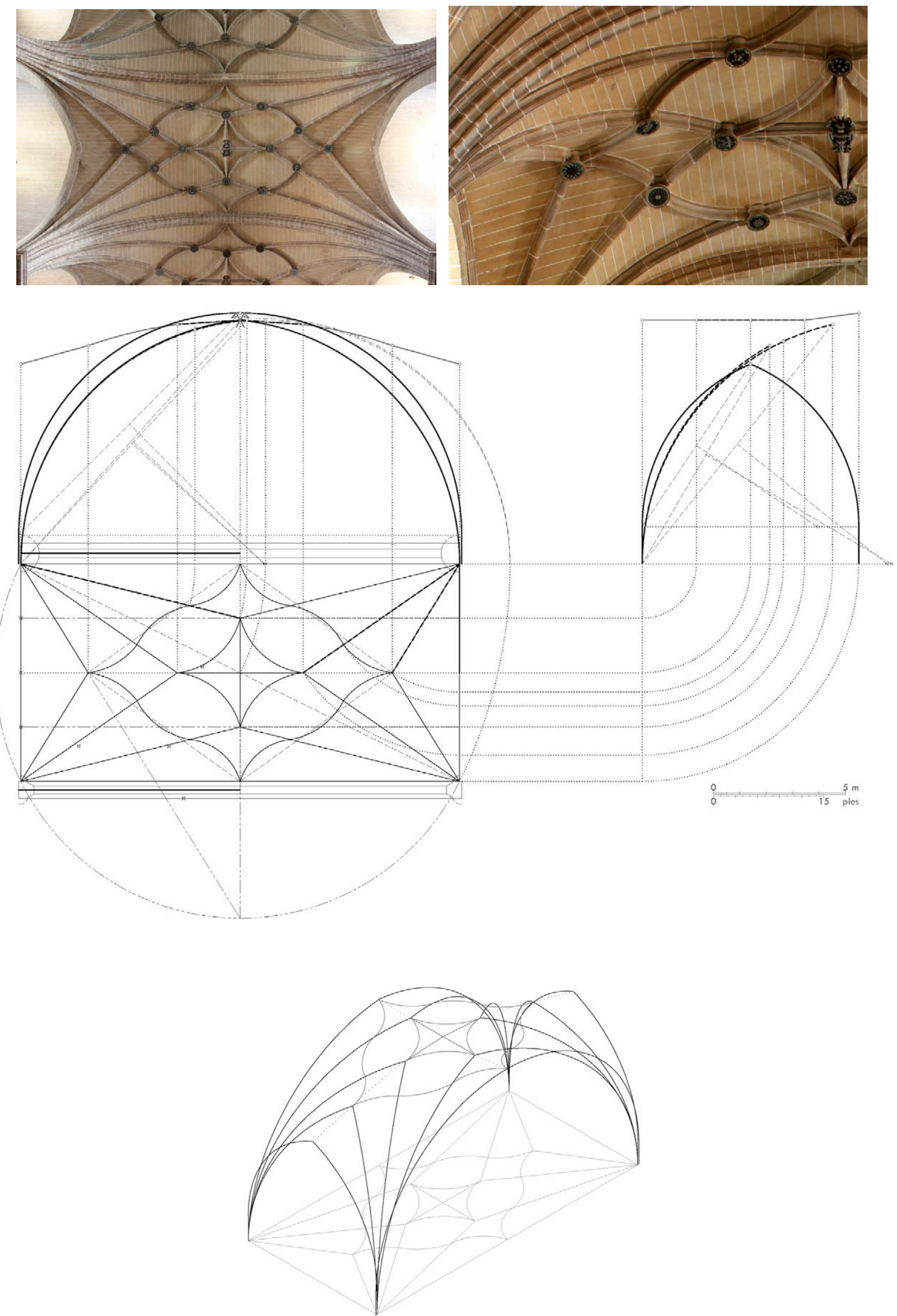

Figura 86. Iglesia de Santa María de la Asunción, Guareña (Badajoz): bóveda de la nave (tramo 3): (a) Vista en planta. (b) Detalle de los nervios, claves y plementería. (c) Hipótesis de trazado de los nervios. (d) Modelizado de los nervios (c, d: P. Moreno) 


\subsubsection{Laguna de Duero (Valladolid) - Iglesia de la Asunción de Nuestra Señora}

Datos históricos del edificio: véase página 743 y siguientes

Datos de medición de las bóvedas: véase página 864 y siguientes

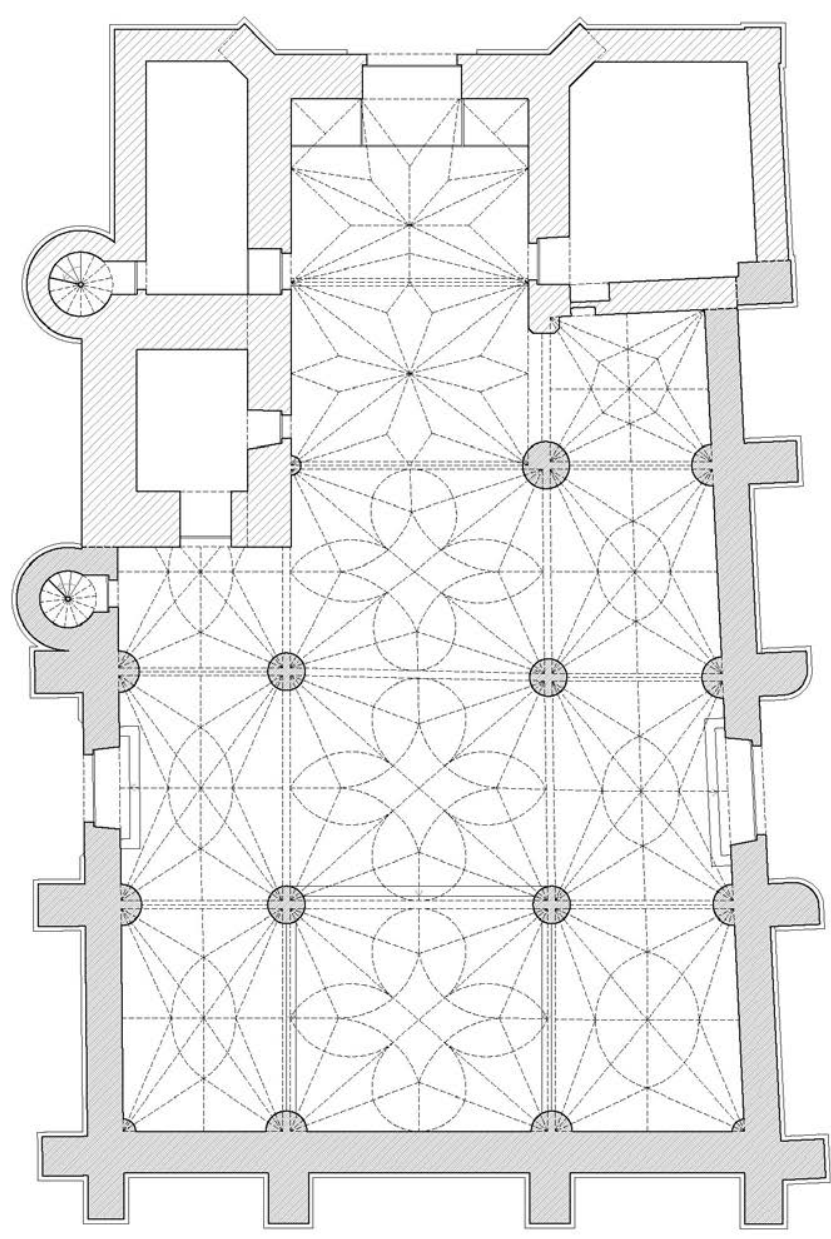

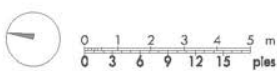

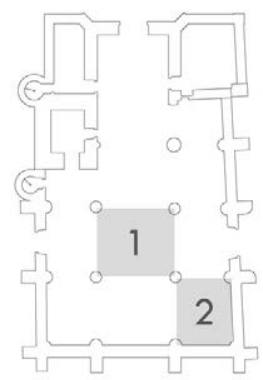

1. Bóveda de la nave central (tramo 3) (c.1544-1568)

2. Bóveda de la nave lateral (tramo 4 sur) (c.1544-1568)

Figura 87. Iglesia de la Asunción de Nuestra Señora, Laguna de Duero (Valladolid): (a) Planta (P. Moreno). (b) Indicación de las bóvedas analizadas, con su fecha de ejecución (P. Moreno) 


\subsection{Bóveda de la nave central (tramo 3)}

Modulación y rangos dimensionales: La bóveda tiene una planta rectangular de dimensiones $28.7 \times 25.2$ pies $(8.01 \times 7.03 \mathrm{~m})$ y proporción entre los lados 1.139 (8:7), ambas consideradas a ejes de los arcos del perímetro (las interiores son $27.9 \times 24.4$ pies $(7.78 \times 6.80 \mathrm{~m})$ y 1.143 (8:7), respectivamente). Los perpiaños tienen un punto de arranque distinto al del resto de los nervios en cada apoyo.

Sistemas de composición: La crucería principal está formada por los dos arcos diagonales y terceletes sencillos en la dirección de ambos ejes. Las nervaduras decorativas forman un cuadrifolio de hojas convexas, en cuyo interior se dispone una figura de lados cóncavos. En conjunto se obtiene un diseño con 17 claves interiores. - Las claves de los terceletes se sitúan en la bisectriz del ángulo formado por la diagonal y los arcos del perímetro. Las claves secundarias sobre los terceletes del eje mayor se sitúan en los puntos de corte con un paralelogramo que une los extremos del cuadrifolio; los centros de las hojas del eje menor (uno por cada hoja) se disponen en las claves de los terceletes de dicho eje, generando las claves secundarias sobre estos y sobre las diagonales; obtenidas estas, es posible trazar las hojas del eje mayor, cuyos centros (dos por cada hoja) se disponen en puntos cuyo trazado geométrico no hemos logrado determinar, y la figura central, que se compone de cuatro arcos.

Arcos: El plano de imposta se sitúa a una altura de 26.8 pies $(7.47 \mathrm{~m})$ del suelo, y la clave central a 17.8 pies $(4.96 \mathrm{~m})$ de dicho plano. Todos los arcos parten tangentes a la vertical en el arranque, excepto la diagonal que parte inclinada, presentando algunos peraltes, aunque no la diagonal. La clave central se encuentra 0.7 pies $(0.21 \mathrm{~m})$ por debajo de la posición que correspondería a la de un arco ojivo semicircular. Un examen visual de la geometría de la diagonal y la comprobación de la posición que ocupan las claves secundarias dispuestas a lo largo de este arco nos hace concluir que su trazado teórico es semicircular rebajado o escarzano, partiendo sin peralte en su arranque. Los arcos se trazarían aparentemente con 4 radios distintos, siendo sus datos geométricos en pies los siguientes:

\begin{tabular}{lccc} 
nervio & tipo & radio & peralte \\
\hline diagonal & sc.rb & 18.6 & \\
perpiaño & sc & 14.0 & 0.6 \\
formero & sc & 12.2 & 1.5 \\
tercelete per. & ap & 16.4 & \\
tercelete for. & ap & 16.1 &
\end{tabular}

Rampante: Las claves de los arcos del perímetro se sitúan, en la dirección del eje x (mayor), a 4.1 pies $(1.14 \mathrm{~m}$ ) por debajo de la clave central; en la dirección del eje y (menor), a 3.3 pies $(0.91 \mathrm{~m})$ por debajo de la clave central. El rampante se puede considerar redondo en la dirección de ambos ejes.

Características constructivas: Los nervios que forman la crucería interior presentan 3 tipos distintos de sección en cuanto a molduraje y canto (grande para la diagonal; mediano para el tercelete y la ligadura; pequeño para el nervio decorativo). - Las jarjas se componen de 4, 5, 6 y 7 hiladas, dependiendo del soporte y del nervio considerado. • Las claves tienen su eje central inclinado. • La plementería es de ladrillo. 

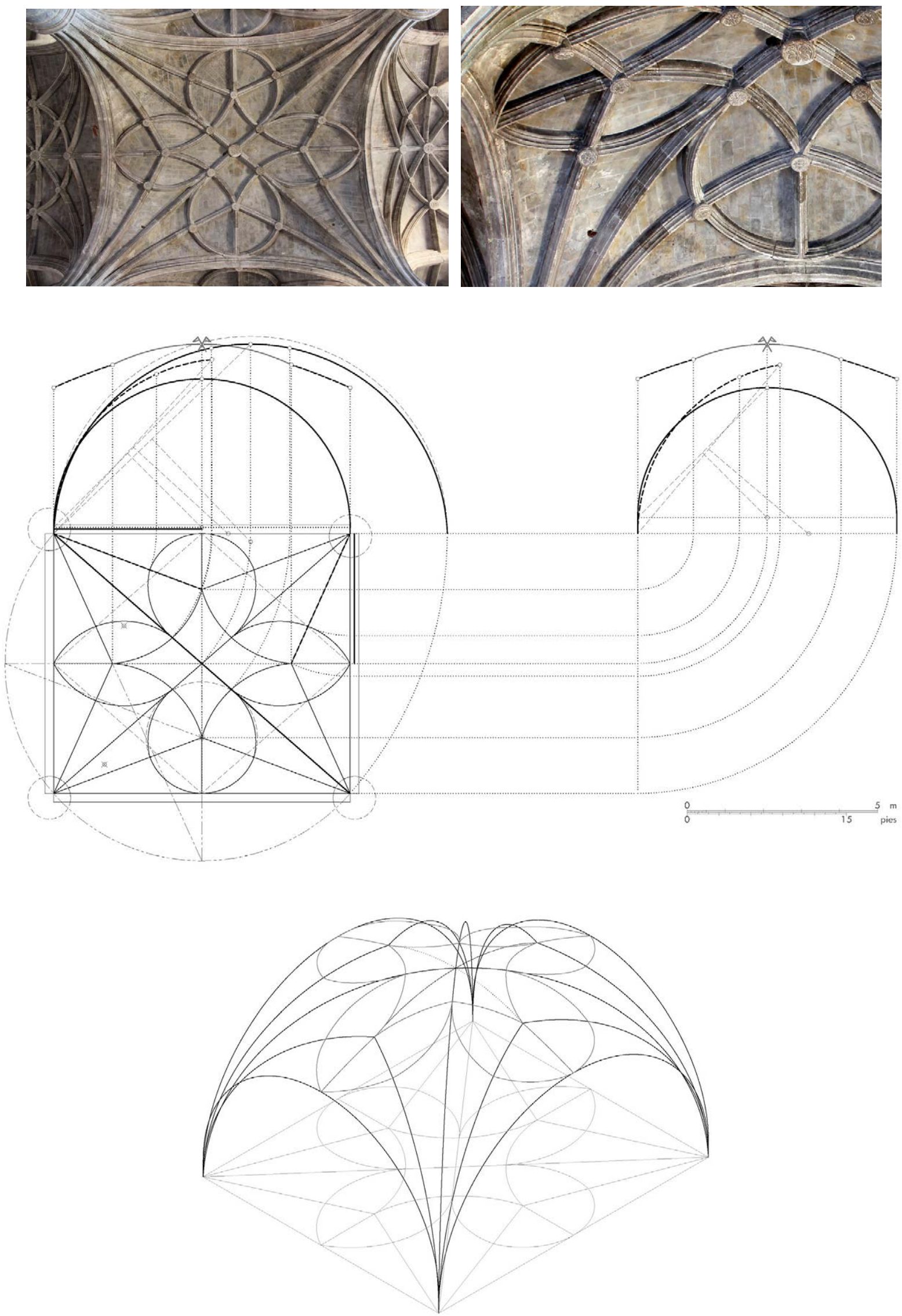

Figura 88. Iglesia de la Asunción de Nuestra Señora, Laguna de Duero (Valladolid): bóveda de la nave central (tramo 3): (a) Vista en planta. (b) Detalle de los nervios, claves y plementería. (c) Hipótesis de trazado de los nervios. (d) Modelizado de los nervios (c, d: P. Moreno) 


\subsection{Bóveda de la nave lateral (tramo 4 sur)}

Modulación y rangos dimensionales: La bóveda tiene una planta rectangular de dimensiones $20.3 \times 24.5$ pies $(5.66 \times 6.84 \mathrm{~m})$ y proporción entre los lados 1.207 (6:5), ambas consideradas a ejes de los arcos del perímetro (las interiores son $19.9 \times 24.1$ pies $(5.54 \times 6.72 \mathrm{~m})$ y 1.211 (6:5), respectivamente). Los perpiaños tienen un punto de arranque distinto al del resto de los nervios en cada apoyo.

Sistemas de composición: La crucería principal está formada por los dos arcos diagonales y terceletes sencillos en la dirección de ambos ejes. Las nervaduras decorativas forman una figura de lados convexos. En conjunto se obtiene un diseño con 9 claves interiores. - Las claves de los terceletes se sitúan en la bisectriz del ángulo formado por la diagonal y los arcos del perímetro. La figura se compone de dos arcos cuyos centros se sitúan sobre el eje menor, obteniéndose las claves sobre las diagonales.

Arcos: El plano de imposta se sitúa a una altura de 26.8 pies $(7.47 \mathrm{~m})$ del suelo, y la clave central a 15.1 pies $(4.21 \mathrm{~m})$ de dicho plano. Todos los arcos parten tangentes a la vertical en el arranque, excepto la diagonal que parte inclinada, presentando algunos peraltes, aunque no la diagonal. La clave central se encuentra 0.5 pies $(0.15 \mathrm{~m})$ por debajo de la posición que correspondería a la de un arco ojivo semicircular. Un examen visual de la geometría de la diagonal y la comprobación de la posición que ocupan las claves secundarias dispuestas a lo largo de este arco nos hace concluir que su trazado teórico es semicircular rebajado o escarzano, partiendo sin peralte en su arranque. Los arcos se trazarían aparentemente con 4 radios distintos, siendo sus datos geométricos en pies los siguientes:

\begin{tabular}{lccc} 
nervio & tipo & radio & peralte \\
\hline diagonal & sc.rb & 15.6 & \\
perpiaño E & sc & 9.9 & 3.5 \\
perpiaño O & ap & 14.0 & \\
formero N & sc & 12.1 & 0.9 \\
formero S & ap & 13.6 & \\
tercelete per. & ap & 14.8 & \\
tercelete for. & ap & 14.3 &
\end{tabular}

Rampante: Las claves de los arcos del perímetro se sitúan, en la dirección del eje x (menor), a 1.9 pies $(0.53 \mathrm{~m}$ ) (valor promedio) por debajo de la clave central; en la dirección del eje y (mayor), a 1.7 pies $(0.47 \mathrm{~m})$ por debajo de la clave central. El rampante se puede considerar llano en la dirección de ambos ejes.

Características constructivas: Los nervios que forman la crucería interior presentan 2 tipos distintos de sección en cuanto a molduraje y canto (grande para la diagonal; pequeño para el tercelete, la ligadura y el nervio decorativo). - Las jarjas se componen de 3, 4, 5 y 6 hiladas, dependiendo del soporte y del nervio considerado. - Las claves tienen su eje central inclinado. - La plementería es de ladrillo; asienta directamente sobre el trasdós del formero. 

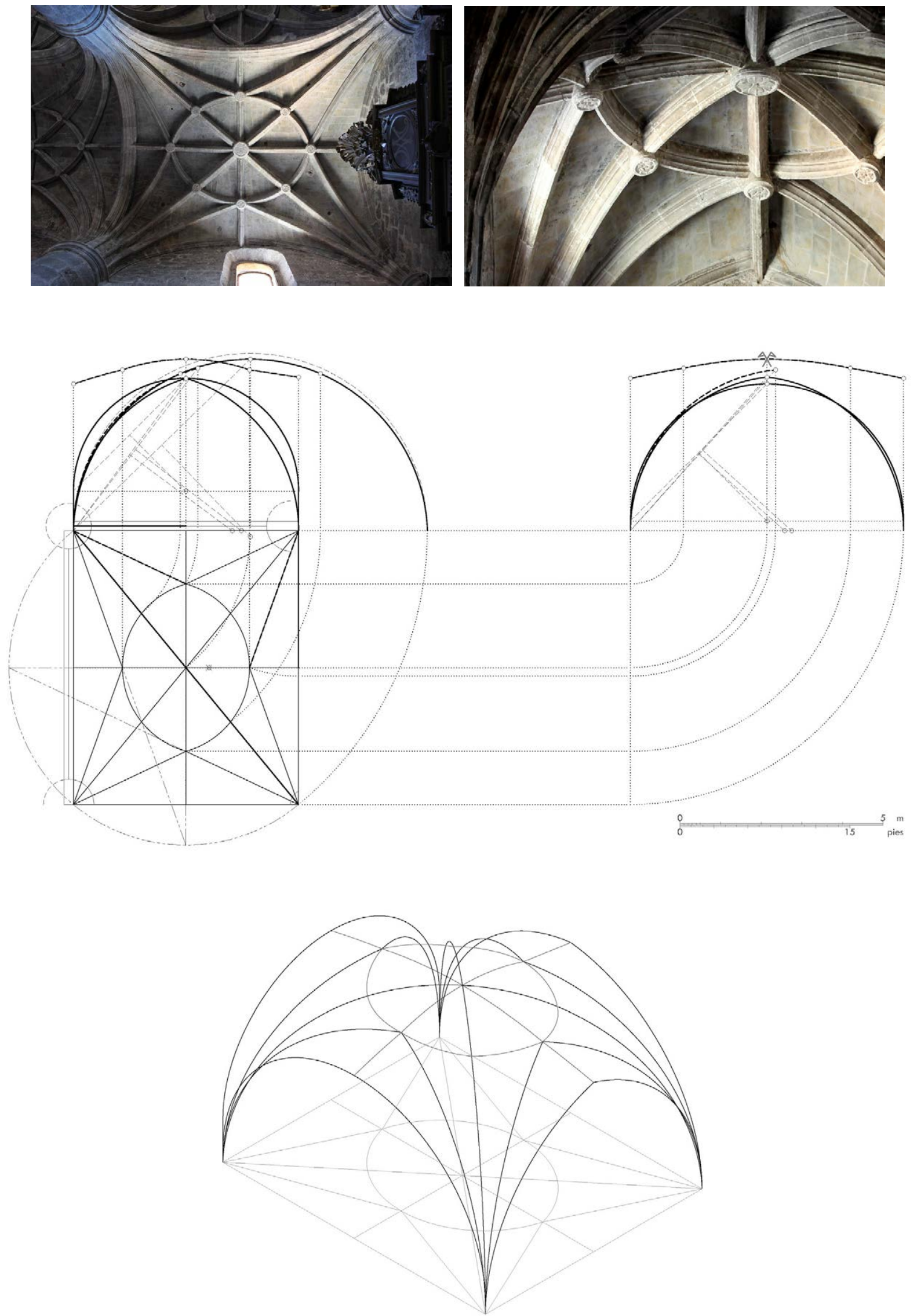

Figura 89. Iglesia de la Asunción de Nuestra Señora, Laguna de Duero (Valladolid): bóveda de la nave lateral (tramo 4 sur): (a) Vista en planta. (b) Detalle de los nervios, claves y plementería. (c) Hipótesis de trazado de los nervios. (d) Modelizado de los nervios (c, d: P. Moreno) 


\subsubsection{Medina de Rioseco (Valladolid) - Iglesia de Santiago de los Caballeros}

Datos históricos del edificio: véase página 736 y siguientes

Datos de medición de las bóvedas: véase página 866

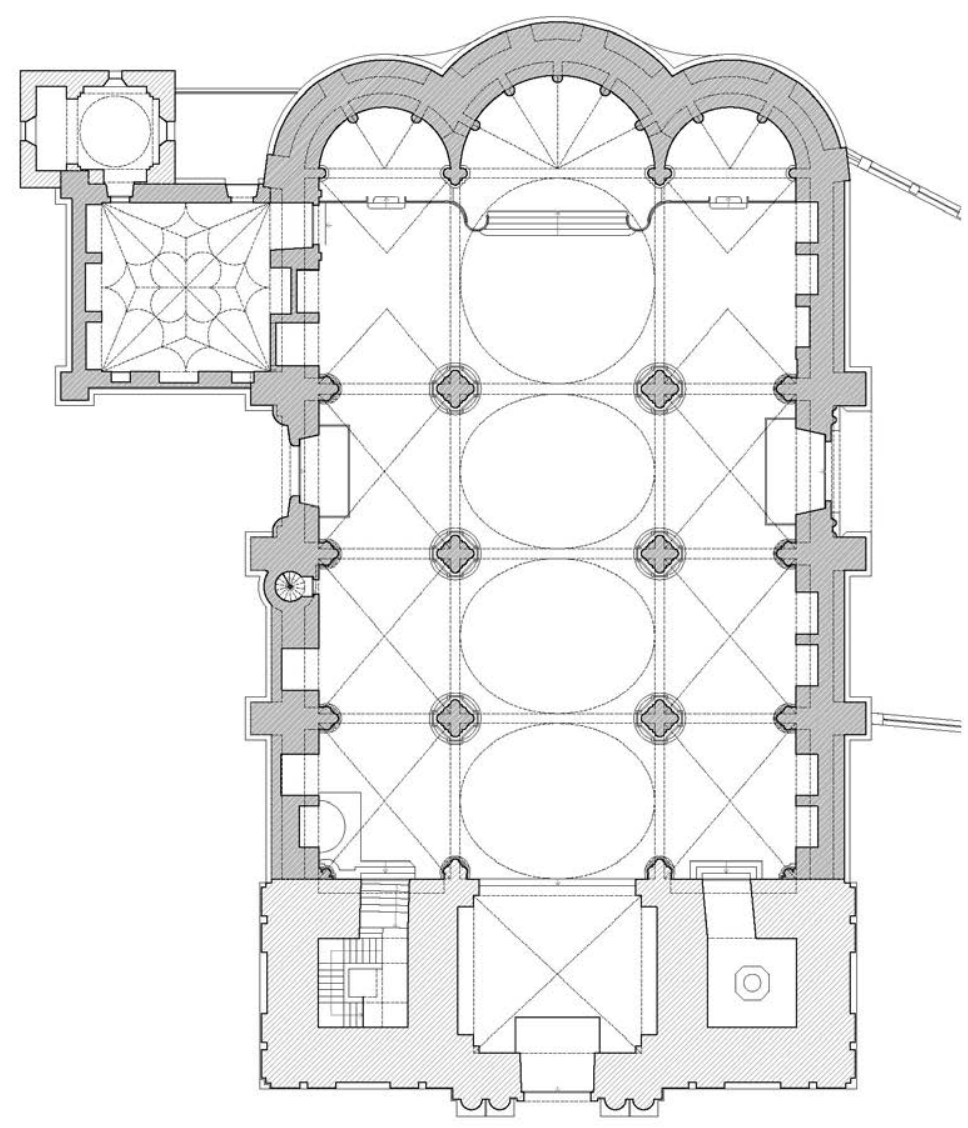

\section{$\frac{122345 \mathrm{~m}}{0.12691215 \text { ples }}$}

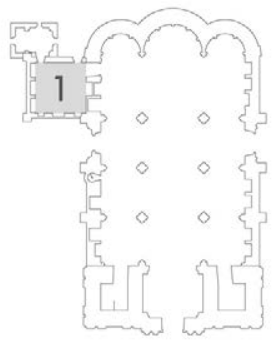

1. Bóveda de la sacristía (c.1556-c.1571)

Figura 90. Iglesia de Santiago de los Caballeros, Medina de Rioseco (Valladolid): (a) Planta (P. Moreno). (b) Indicación de las bóvedas analizadas, con su fecha de ejecución (P. Moreno) 


\subsubsection{Bóveda de la sacristía}

Modulación y rangos dimensionales: La bóveda tiene una planta cuadrada de dimensiones $30.4 \times 30.4$ pies $(8.48 \times 8.48 \mathrm{~m})$ y proporción entre los lados $1.000(1: 1)$, ambas consideradas a ejes de los arcos del perímetro (coinciden con las interiores). Todos los nervios tienen un punto de arranque común en cada apoyo.

Sistemas de composición: La crucería principal está formada por los dos arcos diagonales y terceletes sencillos en la dirección de ambos ejes. Las nervaduras decorativas forman un cuadrifolio de hojas cóncavas, en cuyo interior se dispone otro cuadrifolio de hojas convexas y tangentes al primero. En conjunto se obtiene un diseño con 21 claves interiores. - Las claves de los terceletes se sitúan en la bisectriz del ángulo formado por la diagonal y los arcos del perímetro. Las claves secundarias sobre los terceletes quedan alineadas sobre un paralelogramo que une los puntos medios de los lados de la bóveda; los centros principales del cuadrifolio exterior se disponen sobre la diagonal y aproximadamente alineados con las claves de los terceletes, y los de sus remates 0 pies de gallo sobre el perímetro de la bóveda; obtenidas las claves sobre las diagonales, las claves sobre las ligaduras se sitúan en los puntos medios de los segmentos limitados por las claves de los terceletes y la central, resultando alineadas con las claves y los centros de los pies de gallo; los centros del cuadrifolio interior (uno por cada hoja) se disponen sobre las diagonales.

Arcos: El plano de imposta se sitúa a una altura de 27.7 pies $(7.72 \mathrm{~m}$ ) del suelo, y la clave central a 21.1 pies $(5.87 \mathrm{~m})$ de dicho plano. Todos los arcos parten tangentes a la vertical en el arranque, excepto la diagonal que parte inclinada, no presentando ninguno peraltes. La clave central se encuentra 0.5 pies $(0.13 \mathrm{~m})$ por debajo de la posición que correspondería a la de un arco ojivo semicircular. Un examen visual de la geometría de la diagonal y la comprobación de la posición que ocupan las claves secundarias dispuestas a lo largo de este arco nos hace concluir que su trazado teórico es semicircular rebajado o escarzano, partiendo sin peralte en su arranque. Los arcos se trazarían aparentemente con 3 radios distintos, siendo sus datos geométricos en pies los siguientes:

$\begin{array}{lccc}\text { nervio } & \text { tipo } & \text { radio } & \text { peralte } \\ \text { diagonal } & \text { sc.rb } & 21.5 & \\ \text { perpiaño } & \text { ap } & 18.8 & \\ \text { formero } & \text { ap } & 18.8 & \\ \text { tercelete per. } & \text { ap } & 20.4 & \\ \text { tercelete for. } & \text { ap } & 20.4 & \end{array}$

Rampante: Las claves de los arcos del perímetro se sitúan, en la dirección de ambos ejes, a 2.6 pies $(0.72 \mathrm{~m}$ ) por debajo de la clave central. El rampante se puede considerar llano en la dirección de ambos ejes.

Características constructivas: Los nervios que forman la crucería interior presentan 3 tipos distintos de sección en cuanto a molduraje y canto (grande para la diagonal; mediano para el tercelete y la ligadura; pequeño para el nervio decorativo). - Las jarjas se componen de 5 y 6 hiladas, dependiendo del nervio considerado. - Las claves tienen su eje central vertical (y su cara inferior paralela a la superficie de la bóveda en cada punto). - La plementería es de ladrillo; asienta directamente sobre el trasdós del formero. 

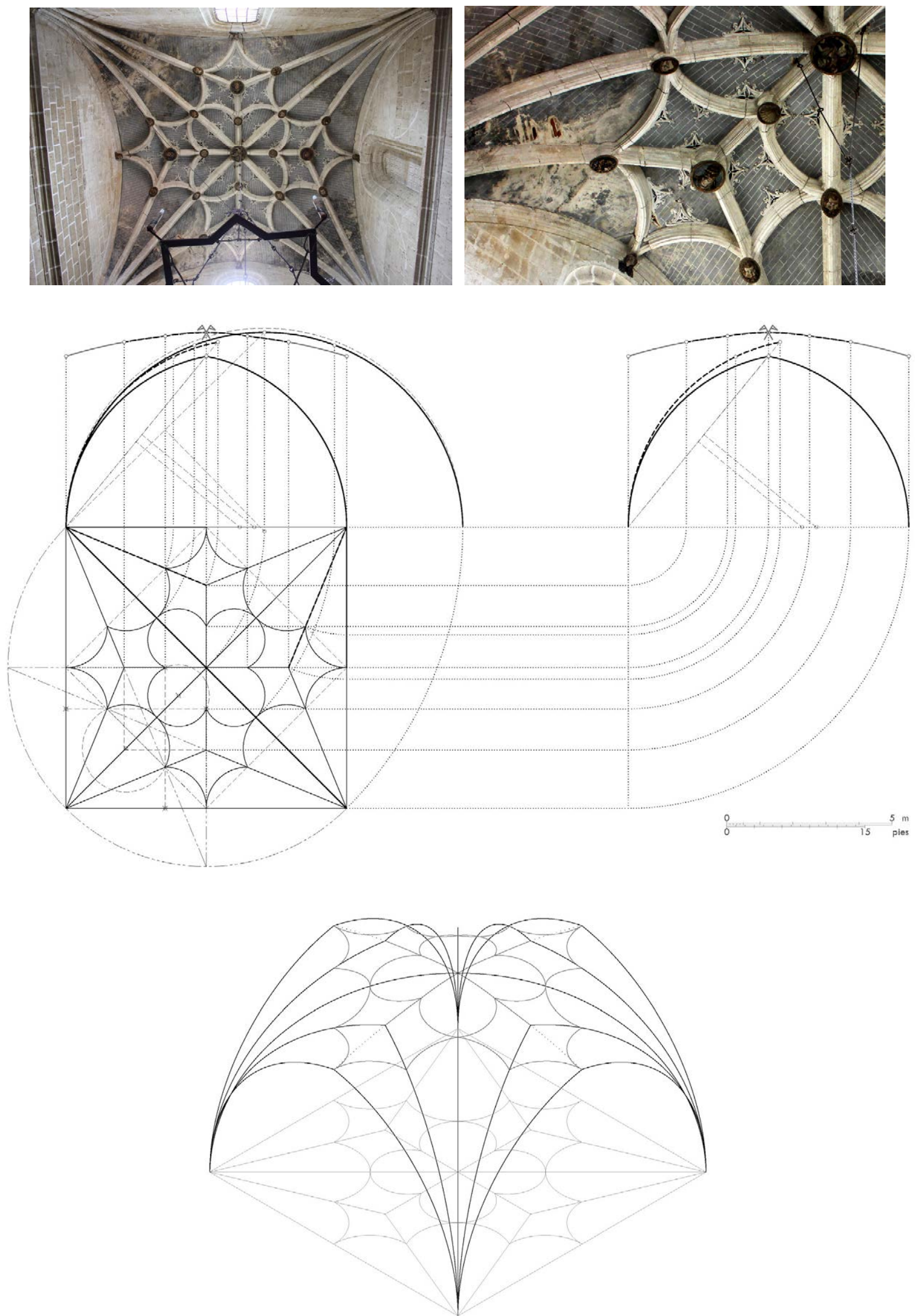

Figura 91. Iglesia de Santiago de los Caballeros, Medina de Rioseco (Valladolid): bóveda de la sacristía: (a) Vista en planta. (b) Detalle de los nervios, claves y plementería. (c) Hipótesis de trazado de los nervios. (d) Modelizado de los nervios (c, d: P. Moreno) 


\subsubsection{Medina del Campo (Valladolid) - Colegiata de San Antolín}

Datos históricos del edificio: véase página 721

Datos de medición de las bóvedas: véase página 867 y siguientes

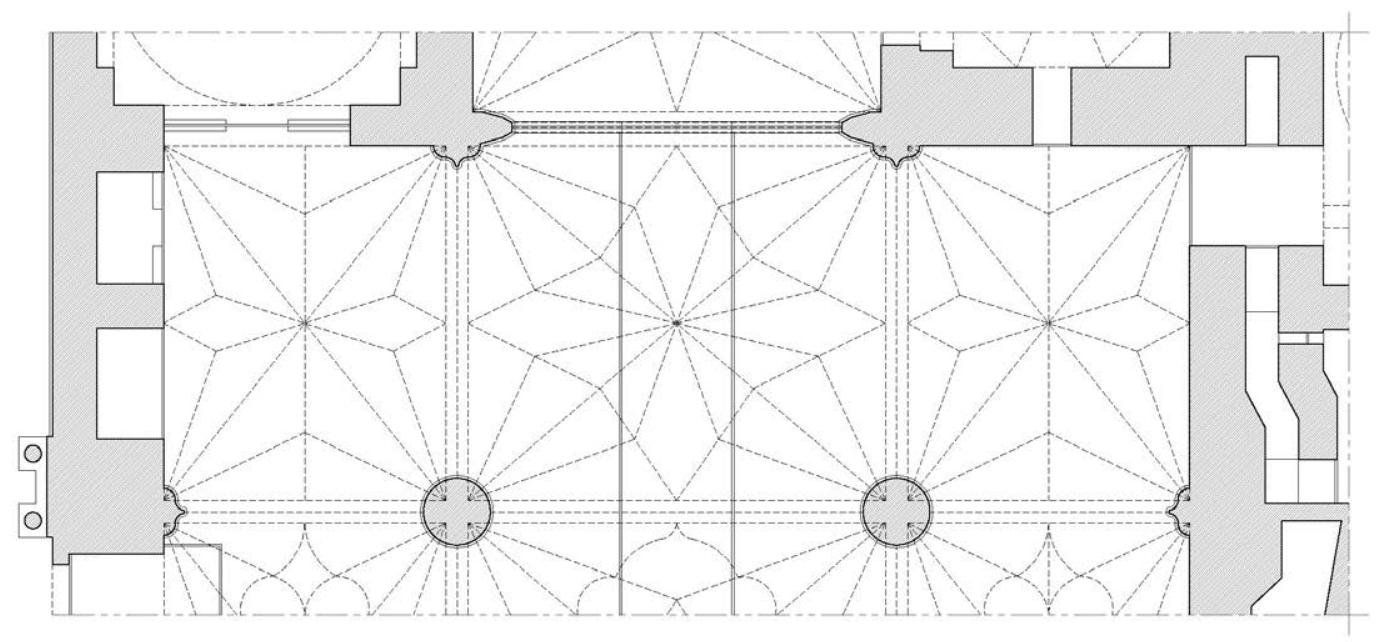

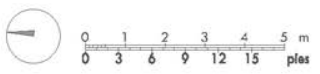

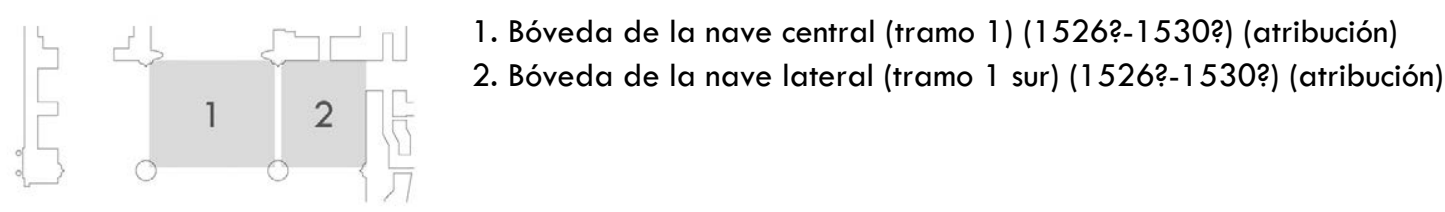

Figura 92. Colegiata de San Antolín, Medina del Campo (Valladolid): (a) Planta del primer tramo de naves (P. Moreno). (b) Indicación de las bóvedas analizadas, con su fecha de ejecución (P. Moreno) 


\subsubsection{Bóveda de la nave central (tramo 1)}

Modulación y rangos dimensionales: La bóveda tiene una planta rectangular de dimensiones $39.6 \times 34.5$ pies ( $11.04 \times 9.62 \mathrm{~m}$ ) y proporción entre los lados 1.148 (8:7), ambas consideradas a ejes de los arcos del perímetro (las interiores son $37.6 \times 32.0$ pies $(10.48 \times 8.92 \mathrm{~m})$ y $1.175(7: 6)$, respectivamente). Los perpiaños tienen un punto de arranque distinto al del resto de los nervios en cada apoyo.

Sistemas de composición: La crucería principal está formada por los dos arcos diagonales y terceletes sencillos en la dirección de ambos ejes, que no llegan a unirse dos a dos en ninguno de los dos ejes. Las nervaduras decorativas forman un rombo de lados quebrados. En conjunto se obtiene un diseño con 13 claves interiores. - Las claves de los terceletes se sitúan en la bisectriz del ángulo formado por la diagonal y los arcos del perímetro. Tanto estas como las claves sobre las diagonales podrían ser generadas automáticamente uniendo las claves de los arcos del perímetro con los puntos de corte de las bisectrices y los ejes de la bóveda.

Arcos: El plano de imposta se sitúa a una altura de 45.2 pies (12.59 m) del suelo, y la clave central a 25.7 pies $(7.15 \mathrm{~m})$ de dicho plano. Todos los arcos parten tangentes a la vertical en el arranque, no presentando ninguno peraltes. La clave central se encuentra 1.0 pies $(0.27 \mathrm{~m})$ por encima de la posición que correspondería a la de un arco ojivo semicircular. Un examen visual de la geometría de la diagonal y la comprobación de la posición que ocupan las claves secundarias dispuestas a lo largo de este arco nos hace concluir que su trazado teórico es apuntado, partiendo sin peralte en su arranque. Los arcos se trazarían aparentemente con 3 radios distintos, siendo sus datos geométricos en pies los siguientes:

$\begin{array}{llll}\text { nervio } & \text { tipo } & \text { radio } & \text { peralte } \\ \text { diagonal } & \text { ap } & 25.7 & \\ \text { perpiaño } & \text { ap } & 23.1 & \\ \text { formero } & \text { ap } & 23.8 & \\ \text { tercelete per. } & \text { ap } & 25.5 & \\ \text { tercelete for. } & \text { ap } & 26.7 & \end{array}$

Rampante: Las claves de los arcos del perímetro se sitúan, en la dirección del eje x (mayor), a 3.2 pies $(0.88 \mathrm{~m}$ ) por debajo de la clave central; en la dirección del eje y (menor), a 3.0 pies $(0.83 \mathrm{~m})$ por debajo de la clave central. El rampante se puede considerar llano en la dirección de ambos ejes.

Características constructivas: Los nervios que forman la crucería interior presentan 2 tipos distintos de sección en cuanto a molduraje y canto (grande para la diagonal; pequeño para el tercelete y el nervio decorativo). - Las jarjas se componen de $2+2$ y $2+3$ hiladas, dependiendo del soporte y del nervio considerado. - Las claves tienen su eje central vertical (las claves de los terceletes tienen su cara inferior horizontal; el resto tienen su cara inferior paralela a la superficie de la bóveda en cada punto). - La plementería es probablemente de ladrillo; queda ligeramente separada del trasdós del formero. 

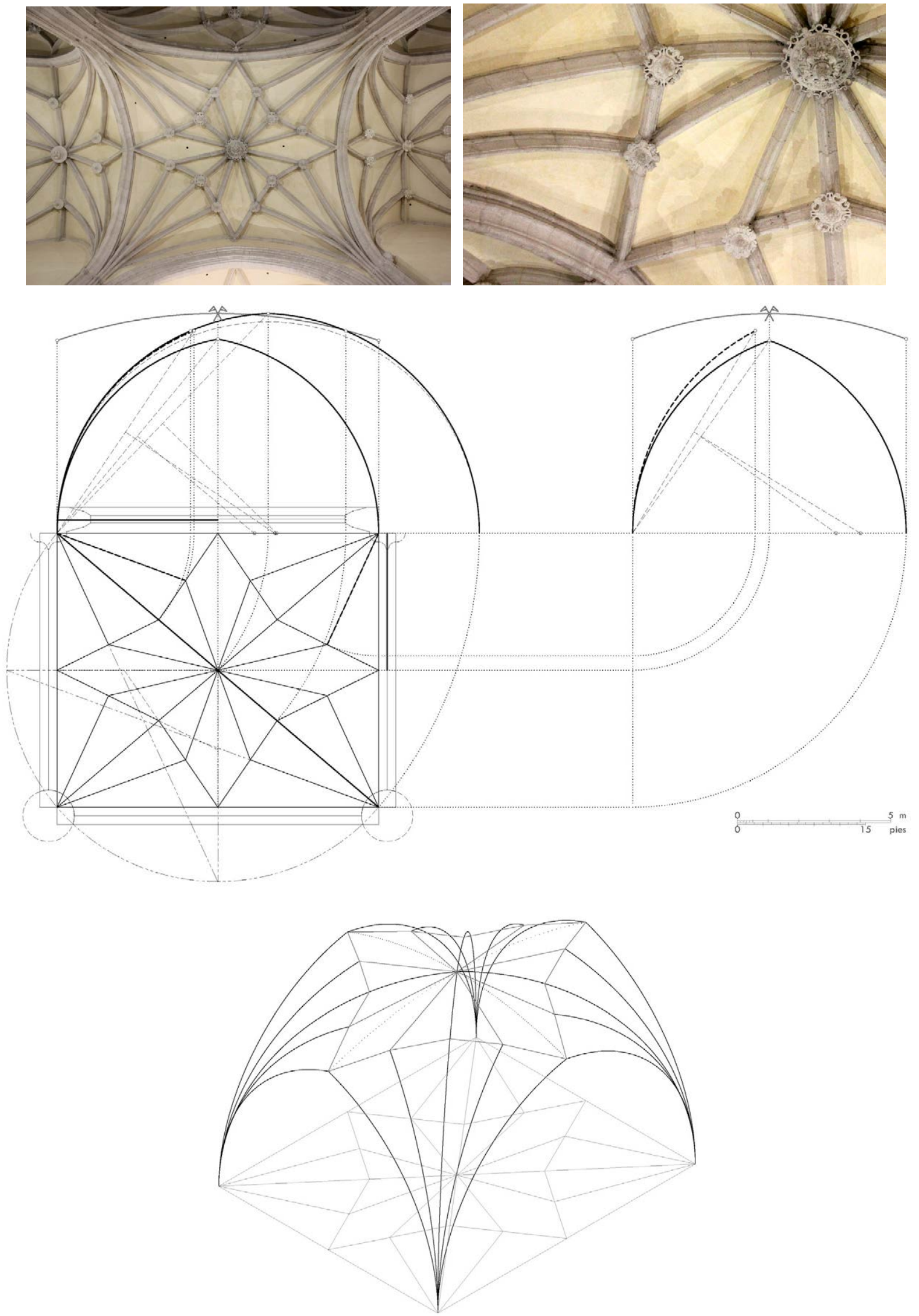

Figura 93. Colegiata de San Antolín, Medina del Campo (Valladolid): bóveda de la nave central (tramo 1): (a) Vista en planta. (b) Detalle de los nervios, claves y plementería. (c) Hipótesis de trazado de los nervios. (d) Modelizado de los nervios (c, d: P. Moreno) 


\subsubsection{Bóveda de la nave lateral (tramo 1 sur)}

Modulación y rangos dimensionales: La bóveda tiene una planta rectangular de dimensiones $26.4 \times 33.0$ pies $(7.36 \times 9.20 \mathrm{~m})$ y proporción entre los lados $1.250(5: 4)$, ambas consideradas a ejes de los arcos del perímetro (las interiores son $25.4 \times 32.0$ pies $(7.08 \times 8.92 \mathrm{~m})$ y $1.260(5: 4)$, respectivamente). Los perpiaños tienen un punto de arranque distinto al del resto de los nervios en cada apoyo.

Sistemas de composición: La crucería principal está formada por los dos arcos diagonales y terceletes sencillos en la dirección de ambos ejes, que no llegan a unirse dos a dos en el eje menor. Carece de nervaduras decorativas. En conjunto se obtiene un diseño con 7 claves interiores. - Las claves de los terceletes se sitúan en la bisectriz del ángulo formado por la diagonal y los arcos del perímetro. Podrían ser generadas automáticamente uniendo las claves de los arcos del perímetro con los vértices opuestos de la bóveda.

Arcos: El plano de imposta se sitúa a una altura de 48.5 pies $(13.51 \mathrm{~m})$ del suelo, y la clave central a 21.5 pies $(6.00 \mathrm{~m}$ ) de dicho plano (el arco que limita con la nave central parte de un plano de imposta más bajo, situado a una altura de 45.2 pies (12.59 m), por lo que se le ha asignado un peralte negativo de -3.3 pies $(-0.92 \mathrm{~m})$ ). Todos los arcos parten tangentes a la vertical en el arranque, presentando algunos peraltes, aunque no la diagonal. La clave central se encuentra 1.1 pies $(0.30 \mathrm{~m})$ por encima de la posición que correspondería a la de un arco ojivo semicircular. Un examen visual de la geometría de la diagonal nos hace concluir que su trazado teórico es apuntado, partiendo sin peralte en su arranque. Los arcos se trazarían aparentemente con 3 radios distintos, siendo sus datos geométricos en pies los siguientes:

\begin{tabular}{lccc} 
nervio & tipo & radio & peralte \\
\hline diagonal & ap & 21.6 & \\
perpiaño & ap & 21.7 & \\
formero $N$ & ap & 23.8 & -3.3 \\
formero S & ap & 20.8 & \\
tercelete per. & ap & 21.7 & \\
tercelete for. & ap & 21.9 &
\end{tabular}

Rampante: Las claves de los arcos del perímetro se sitúan, en la dirección de ambos ejes, a 1.8 pies (0.50 m) (valor promedio) por debajo de la clave central. El rampante se puede considerar llano en la dirección de ambos ejes.

Características constructivas: Los nervios que forman la crucería interior presentan 2 tipos distintos de sección en cuanto a molduraje y canto (grande para la diagonal; pequeño para el tercelete y la ligadura). - Las jarjas se componen de $2+2,2+3,2+4$ y $2+5$ hiladas, dependiendo del soporte y del nervio considerado. - Las claves tienen su eje central vertical (y su cara inferior horizontal). • La plementería es probablemente de ladrillo; queda ligeramente separada del trasdós del formero. 

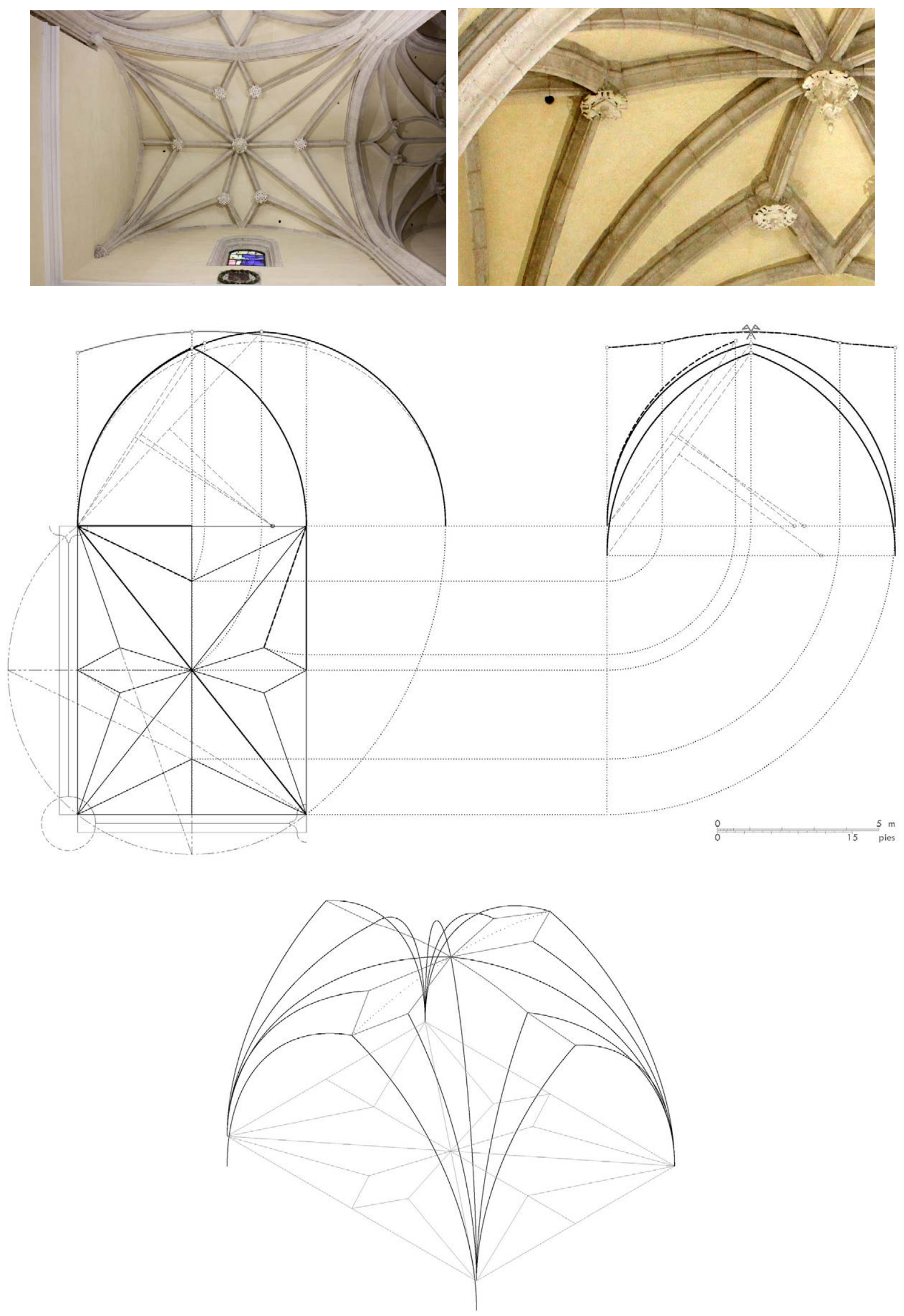

Figura 94. Colegiata de San Antolín, Medina del Campo (Valladolid): bóveda de la nave lateral (tramo 1 sur): (a) Vista en planta. (b) Detalle de los nervios, claves y plementería. (c) Hipótesis de trazado de los nervios. (d) Modelizado de los nervios (c, d: P. Moreno) 


\subsubsection{Miraflores de la Sierra (Madrid) - Iglesia de la Asunción de Nuestra Señora}

Datos históricos del edificio: véase página 723 y siguientes

Datos de medición de las bóvedas: véase página 869 y siguientes

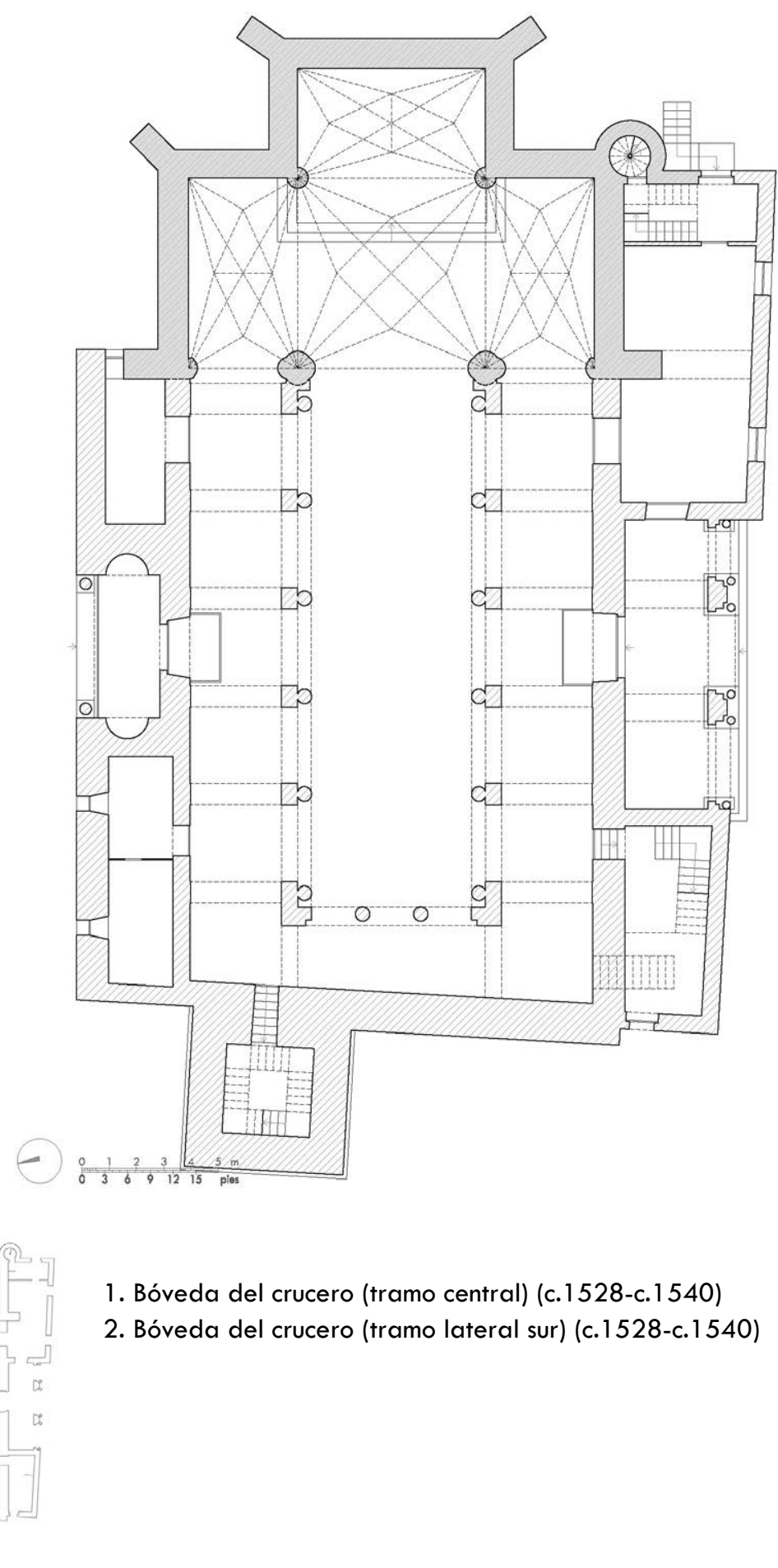

Figura 95. Iglesia de la Asunción de Nuestra Señora, Miraflores de la Sierra (Madrid): (a) Planta (P. Moreno). (b) Indicación de las bóvedas analizadas, con su fecha de ejecución (P. Moreno) 


\subsubsection{Bóveda del crucero (tramo central)}

Modulación y rangos dimensionales: La bóveda tiene una planta aproximadamente cuadrada de dimensiones $24.7 \times 25.0$ pies $(6.89 \times 6.97 \mathrm{~m})$ y proporción entre los lados $1.012(1: 1)$, ambas consideradas a ejes de los arcos del perímetro (coinciden con las interiores). Todos los nervios tienen un punto de arranque común en cada apoyo.

Sistemas de composición: La crucería principal está formada por los dos arcos diagonales y terceletes sencillos en la dirección de ambos ejes. Las nervaduras decorativas forman un rombo de lados rectos. En conjunto se obtiene un diseño con 9 claves interiores. - Las claves de los terceletes se sitúan en la bisectriz del ángulo formado por la diagonal y los arcos del perímetro. Las claves sobre las diagonales son generadas automáticamente uniendo las claves de los terceletes.

Arcos: El plano de imposta se sitúa a una altura de 26.1 pies $(7.28 \mathrm{~m})$ del suelo, y la clave central a 17.0 pies $(4.75 \mathrm{~m})$ de dicho plano. Todos los arcos parten tangentes a la vertical en el arranque, no presentando ninguno peraltes. La clave central se encuentra 0.5 pies $(0.15 \mathrm{~m})$ por debajo de la posición que correspondería a la de un arco ojivo semicircular. Un examen visual de la geometría de la diagonal y la comprobación de la posición que ocupan las claves secundarias dispuestas a lo largo de este arco nos hace concluir que su trazado teórico es carpanel, partiendo sin peralte en su arranque. Los arcos se trazarían aparentemente con 3 radios distintos, siendo sus datos geométricos en pies los siguientes:

\begin{tabular}{|c|c|c|}
\hline nervio & tipo & radio \\
\hline diagonal & car & $17.0 \cdot 20.9$ \\
\hline perpiaño & ap & 15.3 \\
\hline formero & ap & 15.3 \\
\hline tercelete per. & ap & 16.5 \\
\hline tercelete for. & ap & 16.4 \\
\hline
\end{tabular}

Rampante: Las claves de los arcos del perímetro se sitúan, en la dirección de ambos ejes, a 2.0 pies $(0.57 \mathrm{~m})$ por debajo de la clave central. El rampante se puede considerar llano en la dirección de ambos ejes.

Características constructivas: Los nervios que forman la crucería interior presentan 2 tipos distintos de sección en cuanto a molduraje y canto (grande para la diagonal; pequeño para el tercelete y el nervio decorativo). - Las jarjas se componen de 4, 5 y 6 hiladas, dependiendo del soporte y del nervio considerado. - Las claves tienen su eje central vertical (y su cara inferior paralela a la superficie de la bóveda en cada punto). - La plementería es probablemente de ladrillo; queda ligeramente separada del trasdós del formero. 

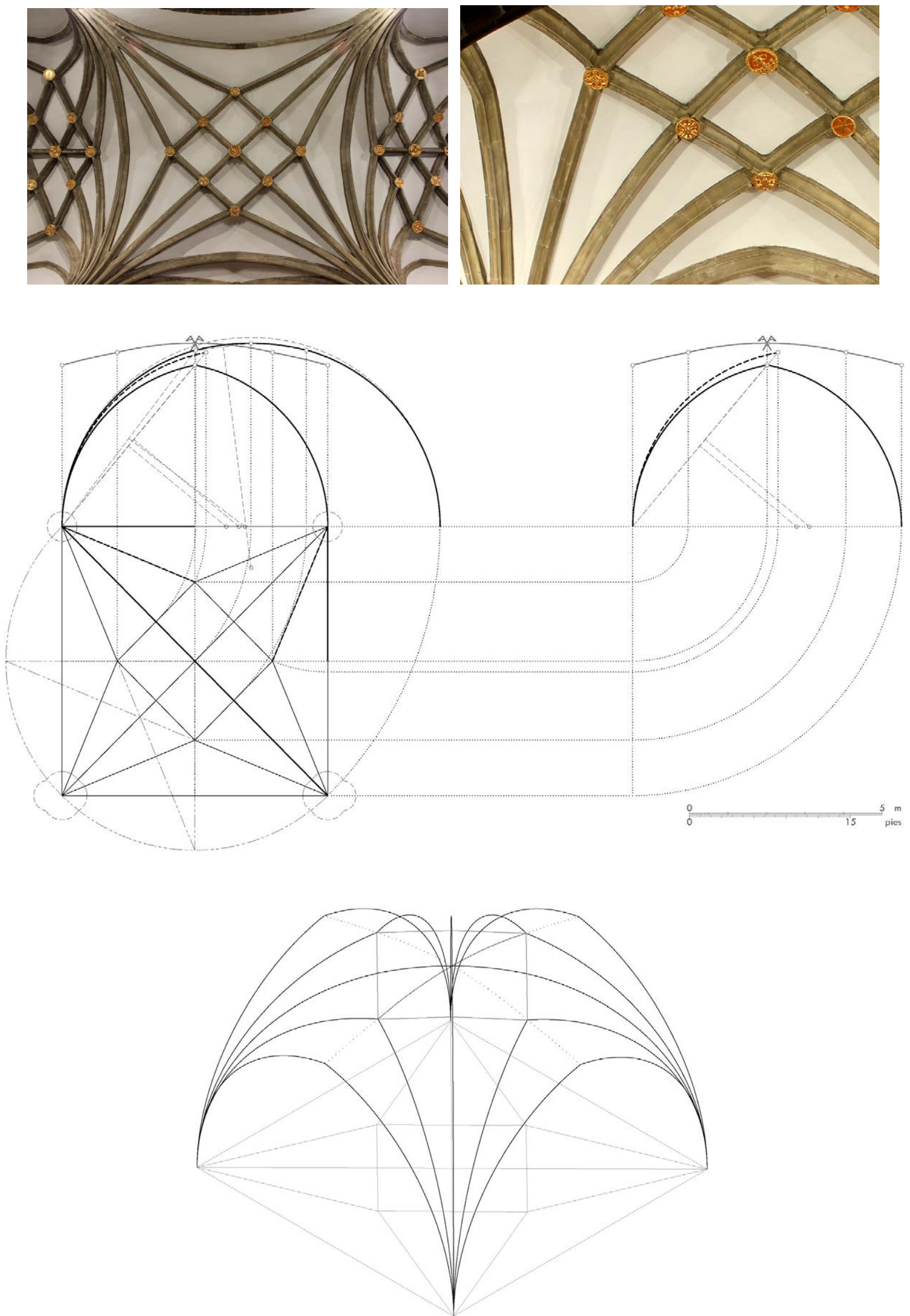

Figura 96. Iglesia de la Asunción de Nuestra Señora, Miraflores de la Sierra (Madrid): bóveda del crucero (tramo central): (a) Vista en planta. (b) Detalle de los nervios, claves y plementería. (c) Hipótesis de trazado de los nervios. (d) Modelizado de los nervios (c, d: P. Moreno) 


\subsection{Bóveda del crucero (tramo lateral sur)}

Modulación y rangos dimensionales: La bóveda tiene una planta rectangular de dimensiones $14.4 \times 25.0$ pies $(4.00 \times 6.97 \mathrm{~m})$ y proporción entre los lados 1.736 (phi), ambas consideradas a ejes de los arcos del perímetro (coinciden con las interiores). Todos los nervios tienen un punto de arranque común en cada apoyo.

Sistemas de composición: La crucería principal está formada por los dos arcos diagonales y terceletes sencillos en la dirección de ambos ejes. Las nervaduras decorativas forman un rombo de lados rectos. En conjunto se obtiene un diseño con 9 claves interiores. - Las claves de los terceletes se sitúan en la bisectriz del ángulo formado por la diagonal y los arcos del perímetro. Las claves sobre las diagonales son generadas automáticamente uniendo las claves de los terceletes.

Arcos: El plano de imposta se sitúa a una altura de 26.1 pies $(7.28 \mathrm{~m})$ del suelo, y la clave central a 13.7 pies $(3.82 \mathrm{~m}$ ) de dicho plano. Todos los arcos parten tangentes a la vertical en el arranque, no presentando ninguno peraltes. La clave central se encuentra 0.7 pies $(0.20 \mathrm{~m})$ por debajo de la posición que correspondería a la de un arco ojivo semicircular. Un examen visual de la geometría de la diagonal y la comprobación de la posición que ocupan las claves secundarias dispuestas a lo largo de este arco nos hace concluir que su trazado teórico es carpanel, partiendo sin peralte en su arranque. Los arcos se trazarían aparentemente con 3 radios distintos, siendo sus datos geométricos en pies los siguientes:

\begin{tabular}{|c|c|c|}
\hline nervio & tipo & radio \\
\hline diagonal & car & $13.5 \cdot 14.5$ \\
\hline perpiaño & ap & 12.5 \\
\hline formero $\mathrm{N}$ & ap & 15.3 \\
\hline formero $\mathrm{S}$ & sc & 12.5 \\
\hline tercelete per. & ap & 13.7 \\
\hline tercelete for. $\mathrm{N}$ & $a p$ & 14.4 \\
\hline tercelete for. S & ap & 13.3 \\
\hline
\end{tabular}

Rampante: Las claves de los arcos del perímetro se sitúan, en la dirección del eje $x$ (menor), a 1.1 pies $(0.32 \mathrm{~m})$ por debajo y 1.3 pies $(0.36 \mathrm{~m}$ ) por encima de la clave central (se trata excepcionalmente de un rampante de diseño asimétrico); en la dirección del eje y (mayor), a 2.4 pies $(0.67 \mathrm{~m})$ por debajo de la clave central. El rampante se puede considerar llano en la dirección de ambos ejes.

Características constructivas: Los nervios que forman la crucería interior presentan 3 tipos distintos de sección en cuanto a molduraje y canto (grande para la diagonal; mediano para el tercelete; pequeño para la ligadura y el nervio decorativo). - Las jarjas se componen de 3, 4, 5 y 6 hiladas, dependiendo del soporte y del nervio considerado. - Las claves tienen su eje central vertical (y su cara inferior paralela a la superficie de la bóveda en cada punto). - La plementería es probablemente de ladrillo; queda ligeramente separada del trasdós del formero. 

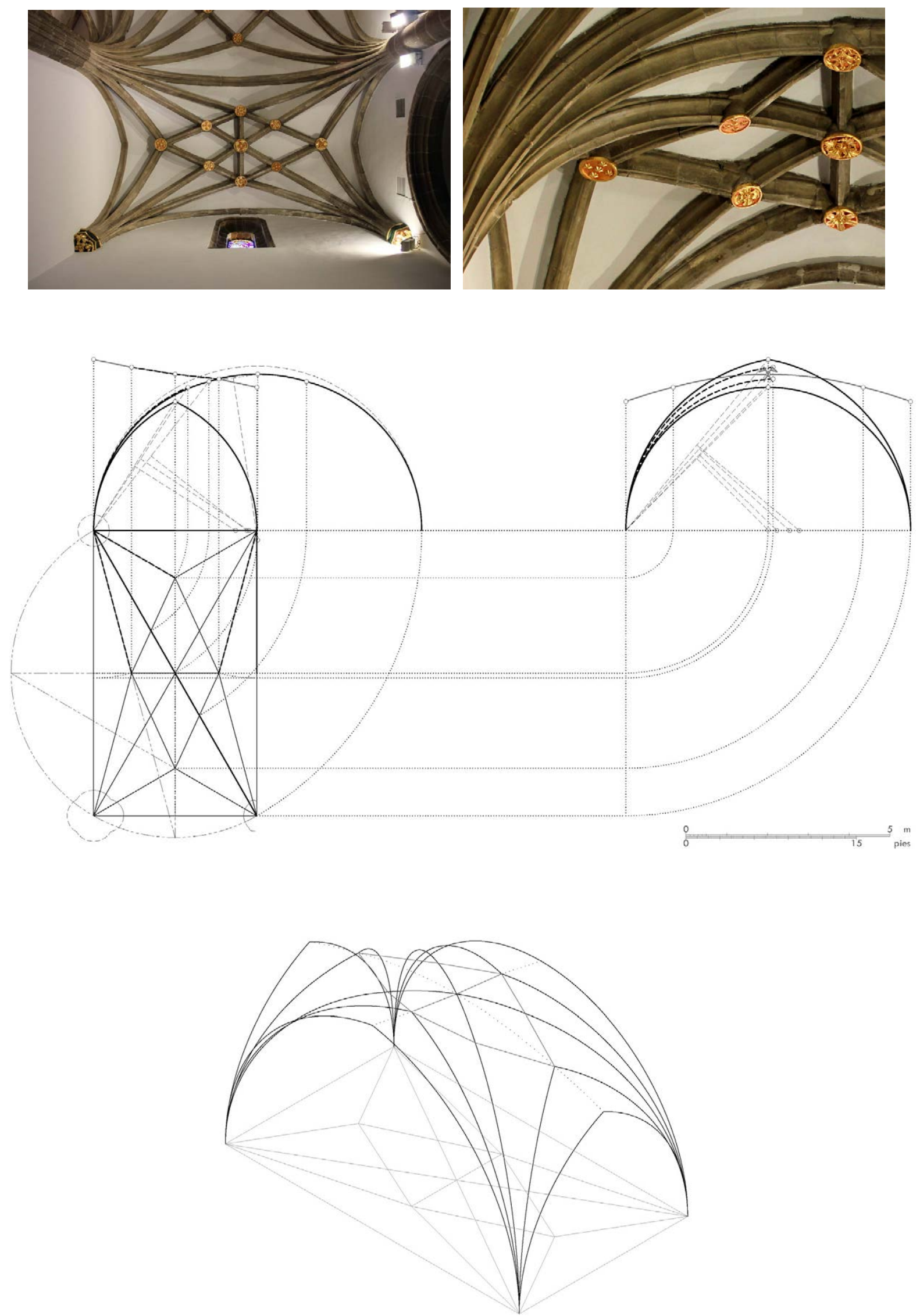

Figura 97. Iglesia de la Asunción de Nuestra Señora, Miraflores de la Sierra (Madrid): bóveda del crucero (tramo lateral sur): (a) Vista en planta. (b) Detalle de los nervios, claves y plementería. (c) Hipótesis de trazado de los nervios. (d) Modelizado de los nervios (c, d: P. Moreno) 


\subsubsection{Mota del Marqués (Valladolid) - Iglesia de San Martín}

Datos históricos del edificio: véase página 756 y siguientes

Datos de medición de las bóvedas: véase página 871 y siguientes

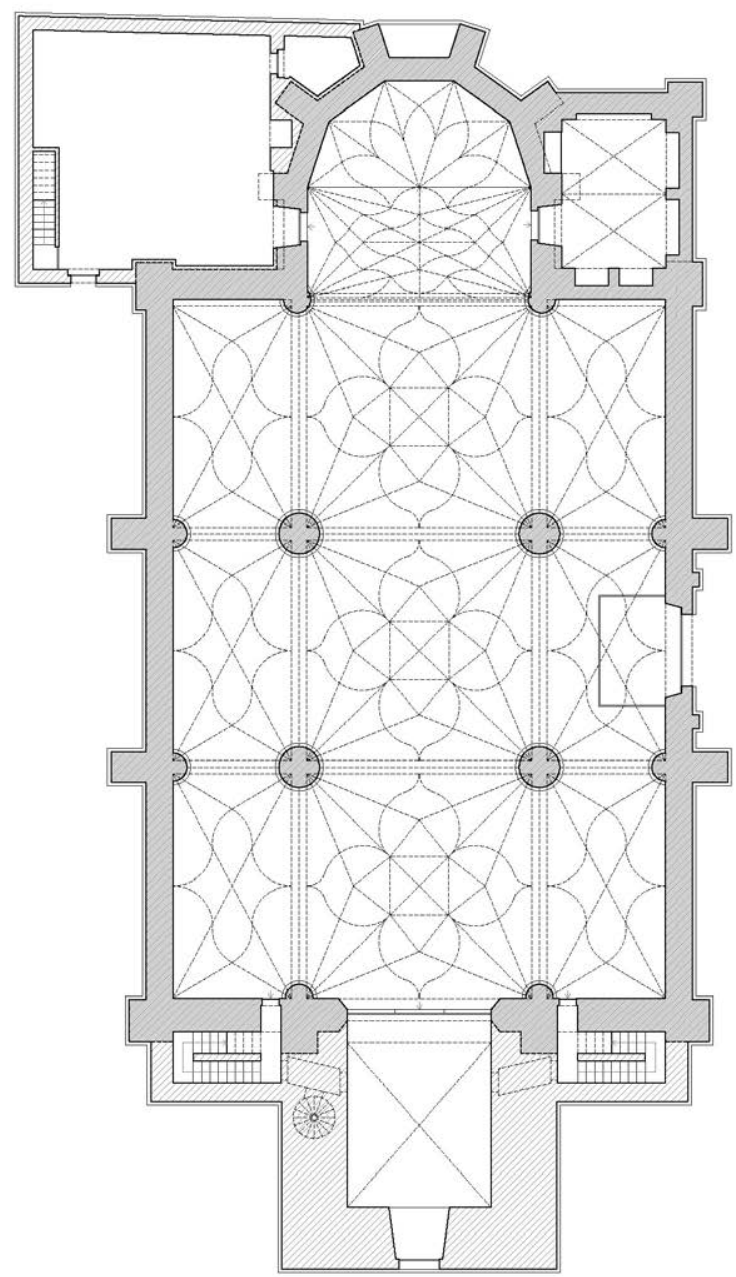

\section{$012345 \mathrm{~m}$}

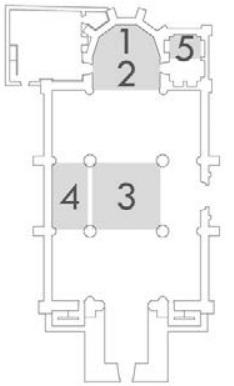

1. Bóveda de la cabecera (ábside) (1554-1558)

2. Bóveda de la cabecera (presbiterio) (1554-1558)

3. Bóveda de la nave central (tramo 2) (1554-1558)

4. Bóveda de la nave lateral (tramo 2 norte) (1554-1558)

5. Bóveda de la sacristía (1554-1558)

Figura 98. Iglesia de San Martín, Mota del Marqués (Valladolid): (a) Planta (P. Moreno). (b) Indicación de las bóvedas analizadas, con su fecha de ejecución (P. Moreno) 


\subsubsection{Bóveda de la cabecera (ábside)}

Modulación y rangos dimensionales: La bóveda tiene una planta poligonal basada en un decágono regular de lado 10.0 pies $(2.78 \mathrm{~m})$ y radio 16.1 pies $(4.50 \mathrm{~m})$, y una embocadura de 32.3 pies $(8.99 \mathrm{~m})$. Todos los nervios tienen un punto de arranque común en cada apoyo.

Sistemas de composición: La crucería principal está formada por los arcos perpiaños radiales y terceletes sencillos. Las nervaduras decorativas forman un quinquefolio de hojas convexas. En conjunto se obtiene un diseño con 11 claves interiores. - La clave principal se sitúa en el centro del polígono generador, y coincide con la del arco perpiaño de la embocadura; las claves de los terceletes se sitúan en la bisectriz del ángulo formado por los perpiaños radiales y los arcos del perímetro. Las claves del quinquefolio sobre los perpiaños radiales se sitúan en puntos cuyo trazado geométrico no hemos logrado determinar; sus hojas comparten el mismo trazado.

Arcos: El plano de imposta se sitúa a una altura de 34.3 pies $(9.55 \mathrm{~m}$ ) del suelo, y la clave principal a 22.0 pies $(6.12 \mathrm{~m})$ de dicho plano. Todos los arcos parten tangentes a la vertical en el arranque, presentando todos peraltes. El arco perpiaño de la embocadura es apuntado, encontrándose su clave 5.8 pies $(1.63 \mathrm{~m}$ ) por encima de la posición que correspondería a la de un arco perpiaño semicircular y partiendo con un peralte de 3.9 pies $(1.10 \mathrm{~m})$ en su arranque. Los arcos se trazarían aparentemente con 3 radios distintos, siendo sus datos geométricos en pies los siguientes:

\begin{tabular}{lccc} 
nervio & tipo & radio & peralte \\
\hline perpiaño & ap & 18.1 & 3.9 \\
formero & ap & 15.5 & 7.3 \\
tercelete for. & ap & 14.4 & 7.3
\end{tabular}

Rampante: -

Características constructivas: Los nervios que forman la crucería interior presentan 2 tipos distintos de sección en cuanto a molduraje y canto (grande para el perpiaño radial y el tercelete; pequeño para el nervio decorativo). - Las jarjas se componen de 11 hiladas. - Las claves tienen su eje central vertical (y su cara inferior paralela a la superficie de la bóveda en cada punto). • La plementería es probablemente de ladrillo; queda ligeramente separada del trasdós del formero. 

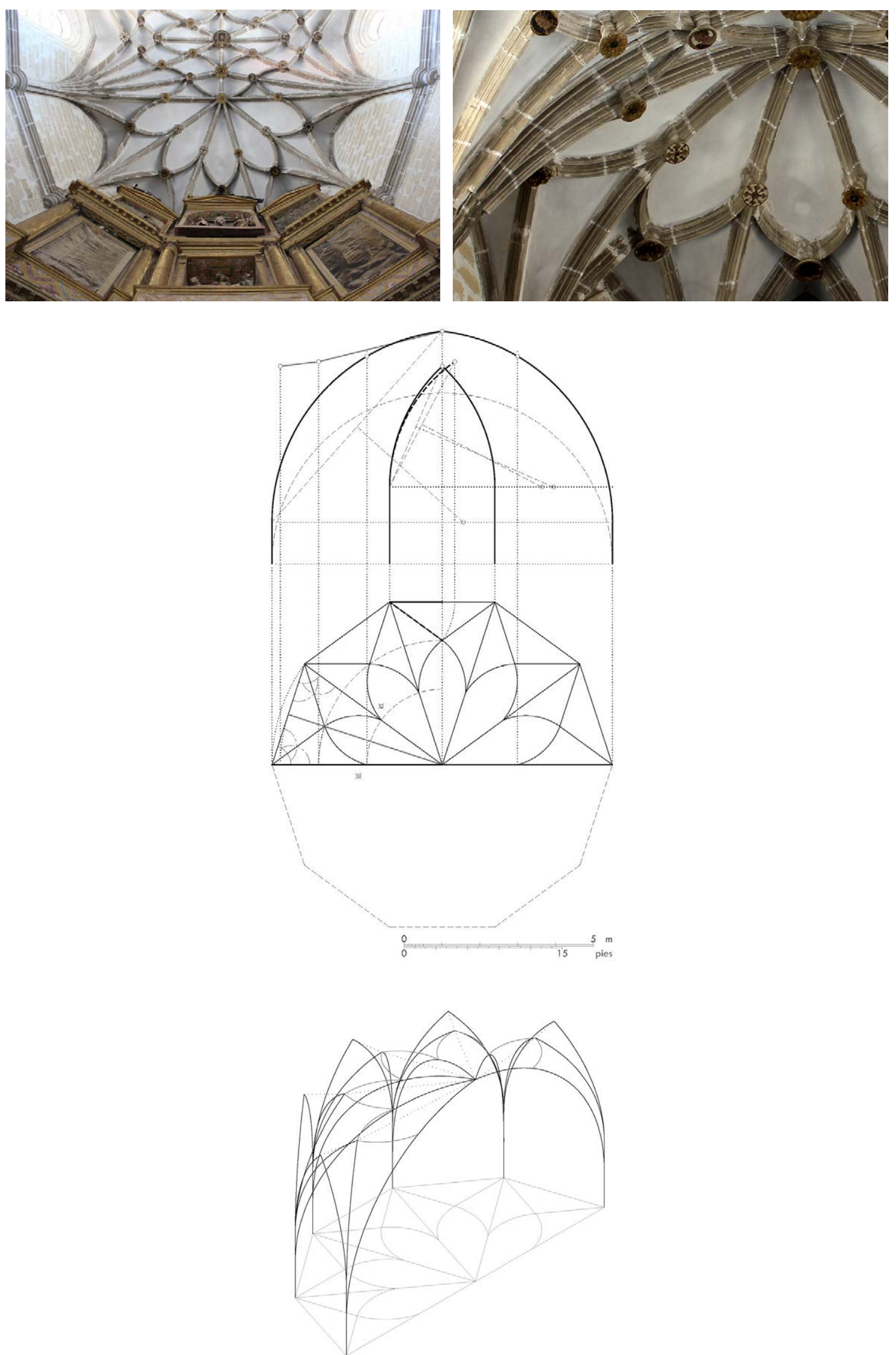

Figura 99. Iglesia de San Martín, Mota del Marqués (Valladolid): bóveda de la cabecera (ábside): (a) Vista en planta. (b) Detalle de los nervios, claves y plementería. (c) Hipótesis de trazado de los nervios. (d) Modelizado de los nervios (c, d: P. Moreno) 


\subsubsection{Bóveda de la cabecera (presbiterio)}

Modulación y rangos dimensionales: La bóveda tiene una planta rectangular de dimensiones $32.3 \times 16.2$ pies $(8.99 \times 4.52 \mathrm{~m})$ y proporción entre los lados $1.994(2: 1)$, ambas consideradas a ejes de los arcos del perímetro (las interiores son $32.3 \times 15.9$ pies $(8.99 \times 4.43 \mathrm{~m})$ y $2.032(2: 1)$, respectivamente). Los perpiaños tienen un punto de arranque distinto al del resto de los nervios en cada apoyo.

Sistemas de composición: La crucería principal está formada por los dos arcos diagonales, terceletes dobles en la dirección del eje mayor y sencillos en la dirección del eje menor. Las nervaduras decorativas forman una figura de lados cóncavos y convexos, en cuyo interior se dispone otra figura de lados cóncavos y convexos. En conjunto se obtiene un diseño con 27 claves interiores. • Las claves de los terceletes se sitúan, sobre el eje mayor, en los puntos que resultan de dividir dicho eje en ocho partes iguales (a $1 / 8$ y $2 / 8$ del perímetro); sobre el eje menor, en los puntos que resultan de dividir dicho eje en cuatro partes iguales (a 1/4 del perímetro). Las claves secundarias se sitúan en los puntos de corte de los nervios con una retícula de $8 \times 4$ aplicada a la planta (esta queda dividida en treinta y dos sectores de $4.0 \times 4.0$ pies); las que corresponden a los terceletes interiores del eje mayor se disponen en los puntos de corte con una línea que une las dos claves contiguas; la figura exterior se compone de catorce arcos, y la interior de ocho.

Arcos: El plano de imposta se sitúa a una altura de 34.3 pies $(9.55 \mathrm{~m}$ ) del suelo, y la clave central a 21.7 pies $(6.04 \mathrm{~m})$ de dicho plano. Todos los arcos parten tangentes a la vertical en el arranque, presentando todos peraltes. La clave central se encuentra 3.7 pies $(1.03 \mathrm{~m})$ por encima de la posición que correspondería a la de un arco ojivo semicircular. Un examen visual de la geometría de la diagonal y la comprobación de la posición que ocupan las claves secundarias dispuestas a lo largo de este arco nos hace concluir que su trazado teórico es efectivamente semicircular, partiendo con un peralte de 3.9 pies $(1.10 \mathrm{~m})$ en su arranque. Los arcos se trazarían aparentemente con 2 radios distintos, siendo sus datos geométricos en pies los siguientes:

\begin{tabular}{lccc} 
nervio & tipo & radio & peralte \\
\hline diagonal & sc & 18.8 & 3.9 \\
perpiaño E & ap & 18.1 & 3.9 \\
perpiaño O & ap & 17.8 & 3.9 \\
formero & ap & 19.5 & 3.9 \\
tercelete per. & ap & 17.8 & 3.9 \\
tercelete for. 1 & ap & 18.9 & 3.9 \\
tercelete for. 2 & tu & $18.7 \cdot 17.5$ & 3.9
\end{tabular}

Rampante: Las claves de los arcos del perímetro se sitúan, en la dirección del eje x (mayor), a 2.0 pies $(0.56 \mathrm{~m}$ ) por debajo de la clave central; en la dirección del eje y (menor), a la misma altura que la clave central (la diferencia de altura es despreciable). El rampante se puede considerar llano en la dirección del eje $x$ (mayor) y horizontal en la del eje y (menor).

Características constructivas: Los nervios que forman la crucería interior presentan 2 tipos distintos de sección en cuanto a molduraje y canto (grande para la diagonal y el tercelete; pequeño para la ligadura y el nervio decorativo). - Las jarjas se componen de 11 hiladas. - Las claves tienen su eje central vertical (y su cara inferior paralela a la superficie de la bóveda en cada punto). • La plementería es probablemente de ladrillo; queda ligeramente separada del trasdós del formero. 

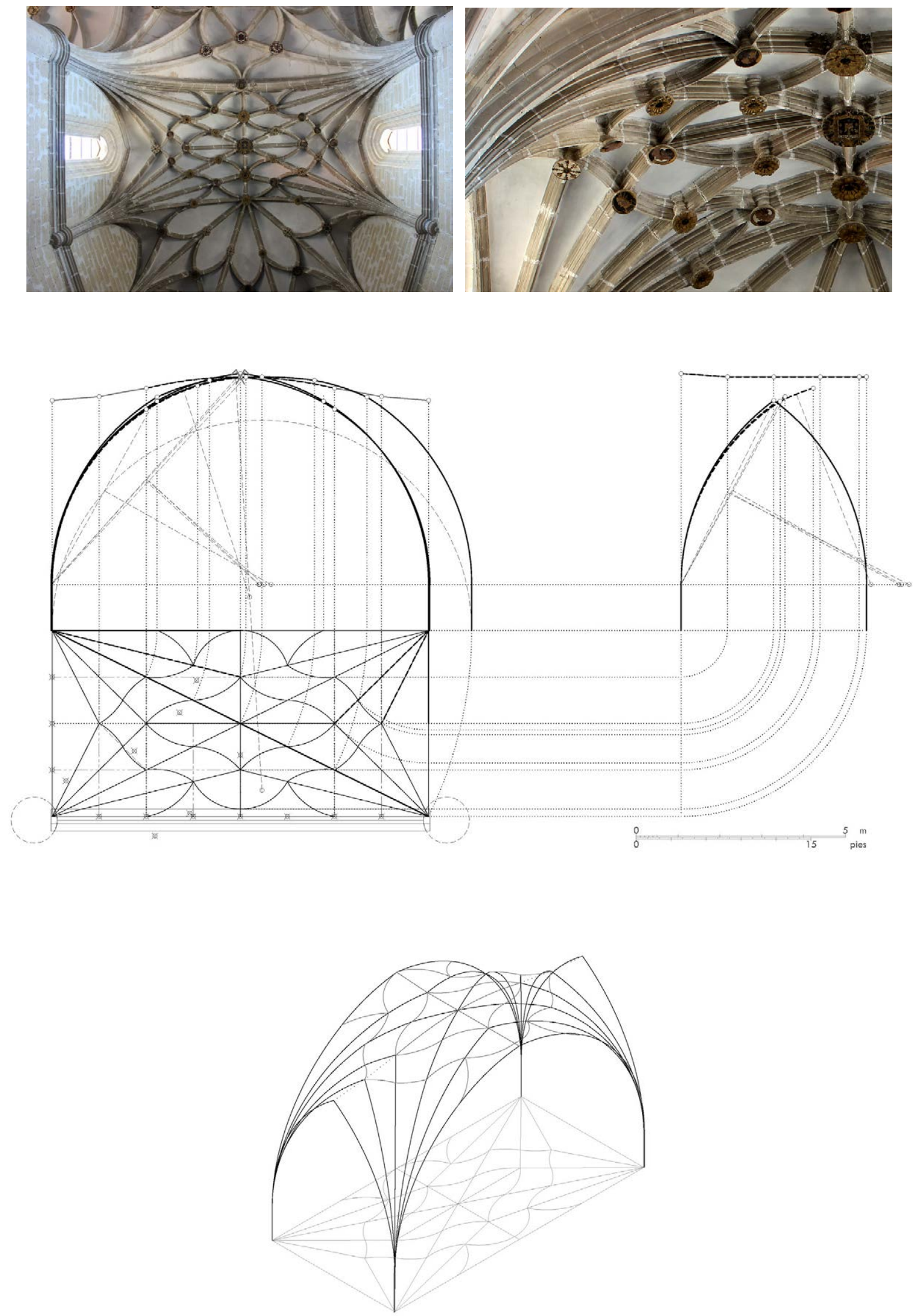

Figura 100. Iglesia de San Martín, Mota del Marqués (Valladolid): bóveda de la cabecera (presbiterio): (a) Vista en planta. (b) Detalle de los nervios, claves y plementería. (c) Hipótesis de trazado de los nervios. (d) Modelizado de los nervios (c, d: P. Moreno) 


\subsubsection{Bóveda de la nave central (tramo 2)}

Modulación y rangos dimensionales: La bóveda tiene una planta aproximadamente cuadrada de dimensiones $34.7 \times 33.7$ pies $(9.67 \times 9.38 \mathrm{~m})$ y proporción entre los lados $1.030(1: 1)$, ambas consideradas a ejes de los arcos del perímetro (las interiores son $32.5 \times 31.8$ pies $(9.04 \times 8.86 \mathrm{~m}$ ) y $1.022(1: 1)$, respectivamente). Los perpiaños tienen un punto de arranque distinto al del resto de los nervios en cada apoyo.

Sistemas de composición: La crucería principal está formada por los dos arcos diagonales y terceletes sencillos en la dirección de ambos ejes. Las nervaduras decorativas forman un cuadrifolio de hojas conopiales, en cuyo interior se dispone un rombo de lados quebrados y un rectángulo de lados paralelos al perímetro. En conjunto se obtiene un diseño con 17 claves interiores. • Las claves de los terceletes se sitúan en la bisectriz del ángulo formado por la diagonal y los arcos del perímetro. Las claves secundarias sobre los terceletes quedan alineadas sobre un paralelogramo que une los extremos del cuadrifolio; las claves sobre las diagonales se sitúan en los puntos de corte con un paralelogramo que une las claves de los terceletes, resultando alineadas con las anteriores; los centros principales del cuadrifolio (uno por cada hoja) se disponen en los puntos medios de los semiejes, y los de sus remates o pies de gallo sobre el perímetro de la bóveda; obtenidas las claves sobre las diagonales, los vértices del rectángulo central se desplazan ligeramente para generar el quiebro del rombo, situándose en los puntos de corte con una circunferencia que tiene por centro el polo de la bóveda y por radio el mismo que las hojas del cuadrifolio.

Arcos: El plano de imposta se sitúa a una altura de 34.3 pies $(9.55 \mathrm{~m}$ ) del suelo, y la clave central a 20.3 pies $(5.66 \mathrm{~m})$ de dicho plano. Todos los arcos parten tangentes a la vertical en el arranque, presentando algunos peraltes, aunque no la diagonal. La clave central se encuentra 2.4 pies $(0.67 \mathrm{~m})$ por debajo de la posición que correspondería a la de un arco ojivo semicircular. Un examen visual de la geometría de la diagonal y la comprobación de la posición que ocupan las claves secundarias dispuestas a lo largo de este arco nos hace concluir que su trazado teórico es carpanel, partiendo sin peralte en su arranque. Los arcos se trazarían aparentemente con 3 radios distintos, siendo sus datos geométricos en pies los siguientes:

\begin{tabular}{lccc} 
nervio & tipo & radio & peralte \\
\hline diagonal & car & $20.3 \cdot 50.0$ & \\
perpiaño & sc & 16.2 & 3.9 \\
formero & sc & 15.9 & 5.0 \\
tercelete per. & ap & 15.7 & 3.9 \\
tercelete for. & ap & 16.0 & 3.9
\end{tabular}

Rampante: Las claves de los arcos del perímetro se sitúan, en la dirección del eje $x$, a 0.6 pies (0.16 m) por encima de la clave central; en la dirección del eje y, a la misma altura que la clave central (la diferencia de altura es despreciable). El rampante se puede considerar convexo en la dirección del eje $x$ y horizontal en la del eje $y$.

Características constructivas: Los nervios que forman la crucería interior presentan 2 tipos distintos de sección en cuanto a molduraje y canto (grande para la diagonal y el tercelete; pequeño para el nervio decorativo). • Las jarjas se componen de 4 y 9 hiladas, dependiendo del nervio considerado. • Las claves tienen su eje central vertical (y su cara inferior paralela a la superficie de la bóveda en cada punto). $\bullet$ La plementería es de ladrillo 444.

\footnotetext{
444 Otro análisis de esta bóveda aparece en Palacios 2006: 2427-2429 y Palacios 2009: 229-232. Según este autor, todos los arcos serían ovales, esto es, estarían trazados con dos o tres centros.
} 

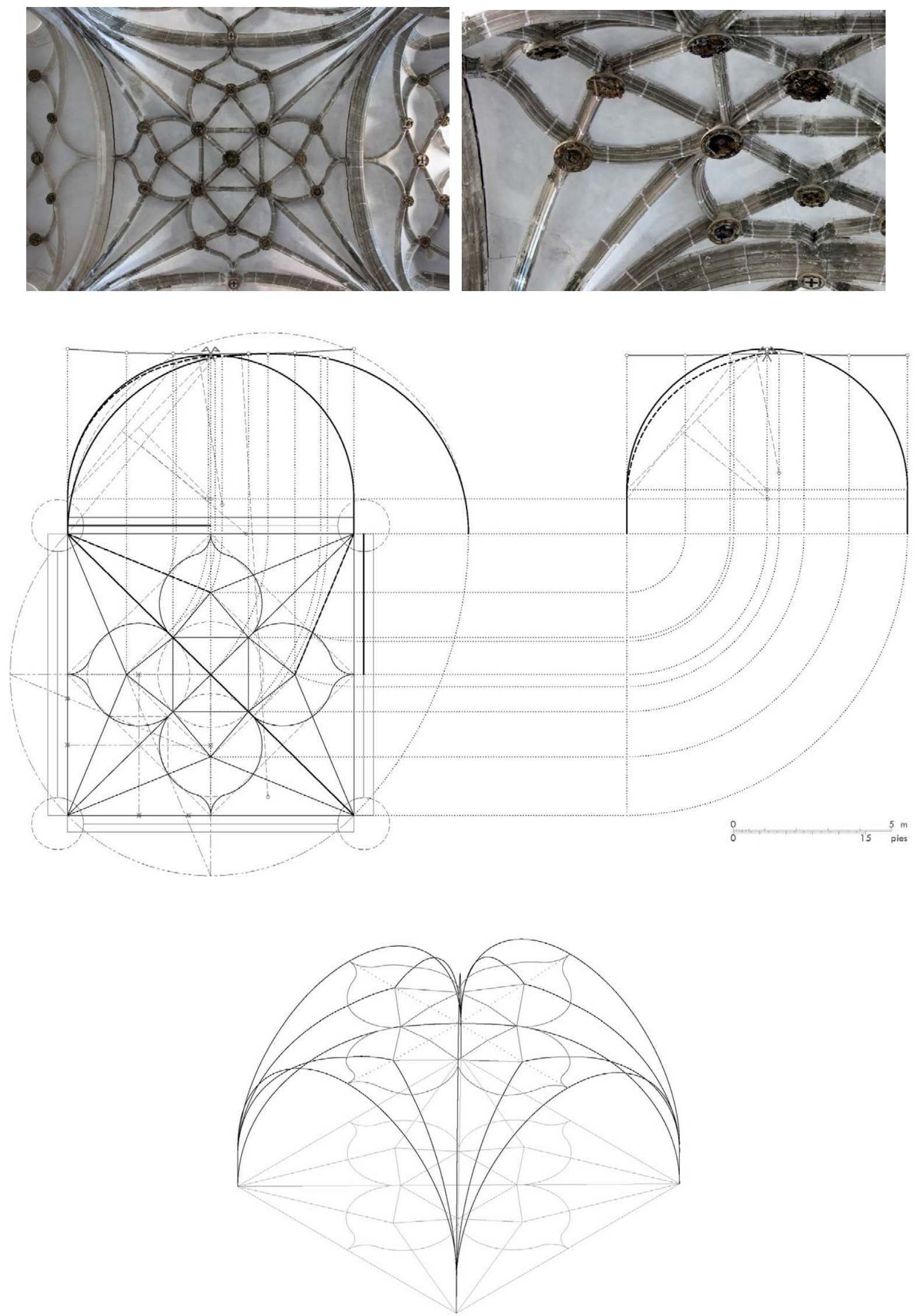

Figura 101. Iglesia de San Martín, Mota del Marqués (Valladolid): bóveda de la nave central (tramo 2): (a) Vista en planta. (b) Detalle de los nervios, claves y plementería. (c) Hipótesis de trazado de los nervios. (d) Modelizado de los nervios (c, d: P. Moreno) 


\subsubsection{Bóveda de la nave lateral (tramo 2 norte)}

Modulación y rangos dimensionales: La bóveda tiene una planta rectangular de dimensiones $18.2 \times 33.7$ pies $(5.08 \times 9.38 \mathrm{~m})$ y proporción entre los lados $1.852(2: 1)$, ambas consideradas a ejes de los arcos del perímetro (las interiores son $17.1 \times 31.8$ pies $(4.76 \times 8.86 \mathrm{~m})$ y $1.860(2: 1)$, respectivamente). Los perpiaños tienen un punto de arranque distinto al del resto de los nervios en cada apoyo.

Sistemas de composición: La crucería principal está formada por los dos arcos diagonales y terceletes sencillos en la dirección del eje mayor. Las nervaduras decorativas forman una figura de lados cóncavos y convexos. En conjunto se obtiene un diseño con 7 claves interiores. $\cdot$ Las claves de los terceletes se sitúan en la bisectriz del ángulo formado por la diagonal y los arcos del perímetro. Las claves sobre las diagonales se sitúan aproximadamente en los puntos de corte con la bisectriz del ángulo formado por la diagonal y el lado mayor de la bóveda; la figura se compone de ocho arcos, disponiéndose los centros de los lados cóncavos sobre el perímetro de la bóveda, y los de los lados convexos alineados con ellos según el eje menor.

Arcos: El plano de imposta se sitúa a una altura de 34.3 pies $(9.55 \mathrm{~m}$ ) del suelo, y la clave central a 20.6 pies $(5.74 \mathrm{~m})$ de dicho plano. Todos los arcos parten tangentes a la vertical en el arranque, presentando todos peraltes. La clave central se encuentra 2.5 pies $(0.71 \mathrm{~m})$ por encima de la posición que correspondería a la de un arco ojivo semicircular. Un examen visual de la geometría de la diagonal y la comprobación de la posición que ocupan las claves secundarias dispuestas a lo largo de este arco nos hace concluir que su trazado teórico es carpanel, partiendo con un peralte de 3.9 pies $(1.10 \mathrm{~m})$ en su arranque. Los arcos se trazarían aparentemente con 3 radios distintos, siendo sus datos geométricos en pies los siguientes:

\begin{tabular}{lccc} 
nervio & tipo & radio & peralte \\
\hline diagonal & car & $16.2 \cdot 17.9$ & 3.9 \\
perpiaño & ap & 18.8 & 3.9 \\
formero N & sc & 15.9 & 3.9 \\
formero S & sc & 15.9 & 5.0 \\
tercelete per. & ap & 14.8 & 5.9
\end{tabular}

Rampante: Las claves de los arcos del perímetro se sitúan, en la dirección del eje $\mathrm{x}$ (menor), a 0.2 pies $(0.06 \mathrm{~m}$ ) (valor promedio) por debajo de la clave central; en la dirección del eje y (mayor), a 0.9 pies $(0.25 \mathrm{~m})$ por debajo de la clave central. El rampante se puede considerar llano en la dirección de ambos ejes.

Características constructivas: Los nervios que forman la crucería interior presentan 2 tipos distintos de sección en cuanto a molduraje y canto (grande para la diagonal y el tercelete; pequeño para el nervio decorativo). - Las jarjas se componen de 6, 7 y 9 hiladas, dependiendo del soporte y del nervio considerado. - Las claves tienen su eje central vertical (y su cara inferior paralela a la superficie de la bóveda en cada punto). - La plementería es de ladrillo; queda ligeramente separada del trasdós del formero. 

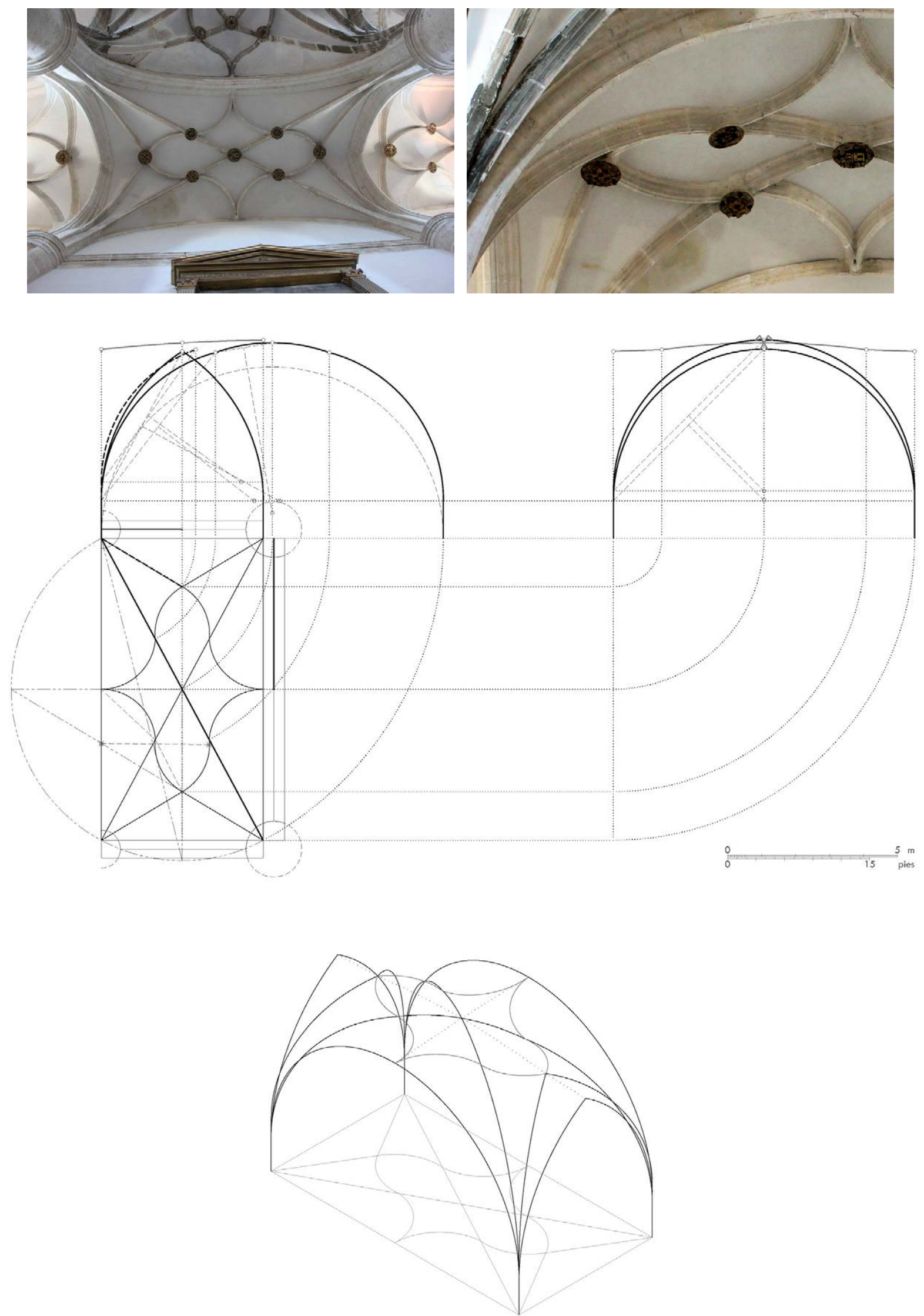

Figura 102. Iglesia de San Martín, Mota del Marqués (Valladolid): bóveda de la nave lateral (tramo 2 norte): (a) Vista en planta. (b) Detalle de los nervios, claves y plementería. (c) Hipótesis de trazado de los nervios. (d) Modelizado de los nervios (c, d: P. Moreno) 


\subsubsection{Bóveda de la sacristía}

Modulación y rangos dimensionales: La bóveda tiene una planta rectangular de dimensiones $15.1 \times 10.8$ pies $(4.20 \times 3.00 \mathrm{~m})$ y proporción entre los lados $1.398(\sqrt{ } 2)$, ambas consideradas a ejes de los arcos del perímetro (coinciden con las interiores). Todos los nervios tienen un punto de arranque común en cada apoyo.

Sistemas de composición: La crucería principal está formada por los dos arcos diagonales, careciendo de terceletes. Carece de nervaduras decorativas. En conjunto se obtiene un diseño con 1 clave interior.

Arcos: El plano de imposta se sitúa a una altura de 14.7 pies $(4.09 \mathrm{~m}$ ) del suelo, y la clave central a 9.2 pies $(2.55 \mathrm{~m})$ de dicho plano. Todos los arcos parten tangentes a la vertical en el arranque, no presentando ninguno peraltes. La clave central se encuentra 0.1 pies $(0.03 \mathrm{~m})$ por debajo de la posición que correspondería a la de un arco ojivo semicircular. Un examen visual de la geometría de la diagonal nos hace concluir que su trazado teórico es efectivamente semicircular, partiendo sin peralte en su arranque. Los arcos se trazarían aparentemente con 1 único radio, siendo sus datos geométricos en pies los siguientes:

\begin{tabular}{lccc} 
nervio & tipo & radio & peralte \\
\hline diagonal & sc & 9.3 & \\
perpiaño & ap & 9.3 & \\
formero & ap & 9.4 &
\end{tabular}

Rampante: Las claves de los arcos del perímetro se sitúan, en la dirección del eje x (mayor), a 0.7 pies $(0.19 \mathrm{~m}$ ) por debajo de la clave central; en la dirección del eje y (menor), a la misma altura que la clave central. El rampante se puede considerar llano en la dirección del eje $x$ (mayor) y horizontal en la del eje y (menor).

Características constructivas: Los nervios que forman la crucería interior presentan 1 único tipo de sección en cuanto a molduraje y canto (diagonal). • Las jarjas se componen de 4 hiladas. • Las claves tienen su eje central vertical (y su cara inferior paralela a la superficie de la bóveda en cada punto). - La plementería es probablemente de ladrillo; queda ligeramente separada del trasdós del formero. 

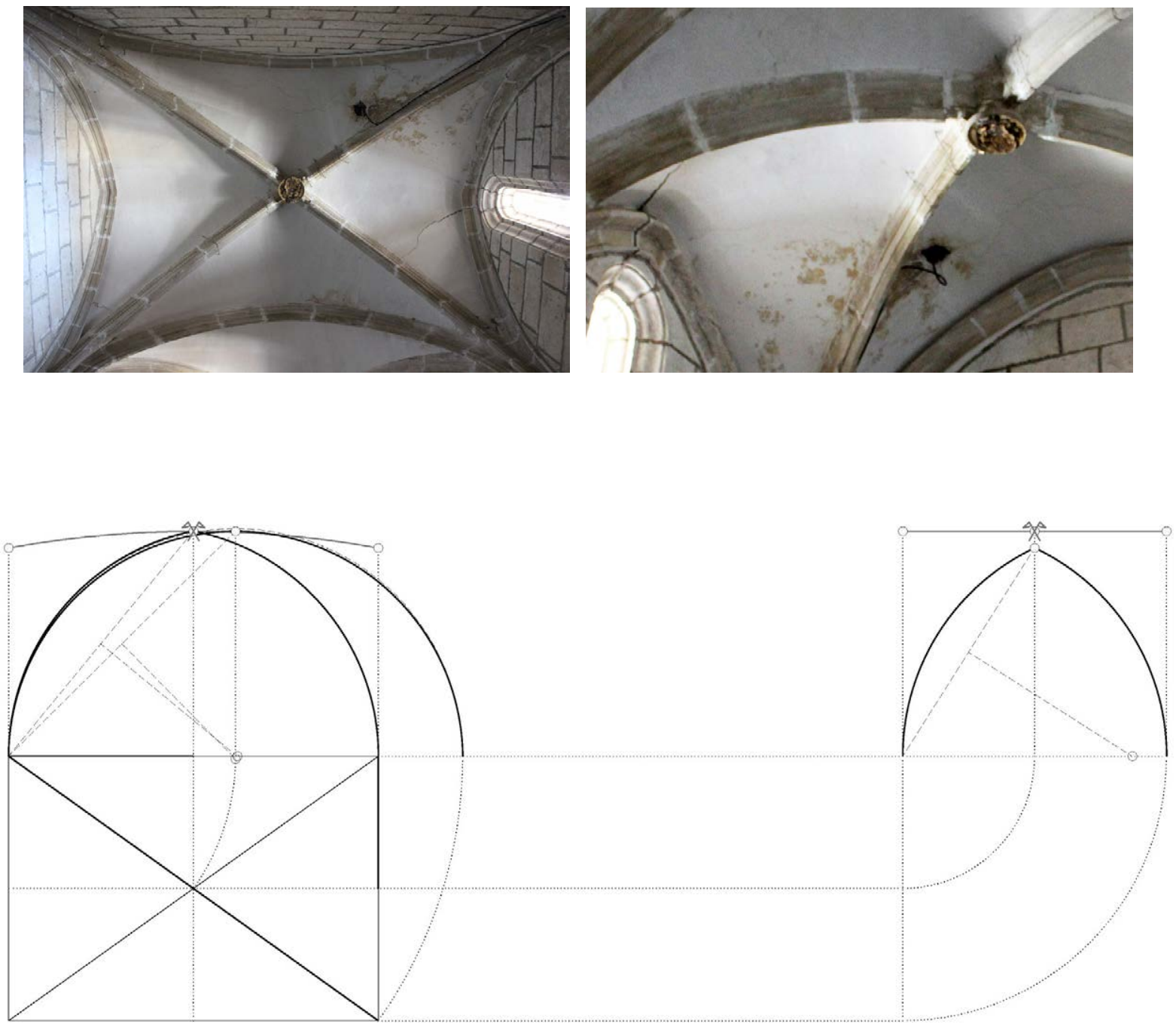

$\stackrel{0}{0}$

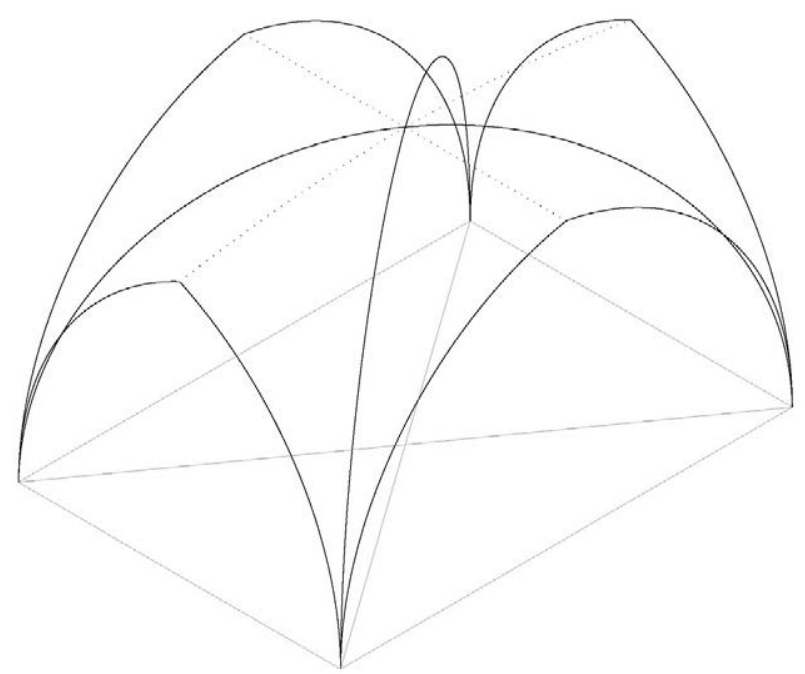

Figura 103. Iglesia de San Martín, Mota del Marqués (Valladolid): bóveda de la sacristía: (a) Vista en planta. (b) Detalle de los nervios, claves y plementería. (c) Hipótesis de trazado de los nervios. (d) Modelizado de los nervios (c, d: P. Moreno) 


\subsubsection{Nava del Rey (Valladolid) - Iglesia de los Santos Juanes}

Datos históricos del edificio: véase página 793 y siguientes

Datos de medición de las bóvedas: véase página 876 y siguientes
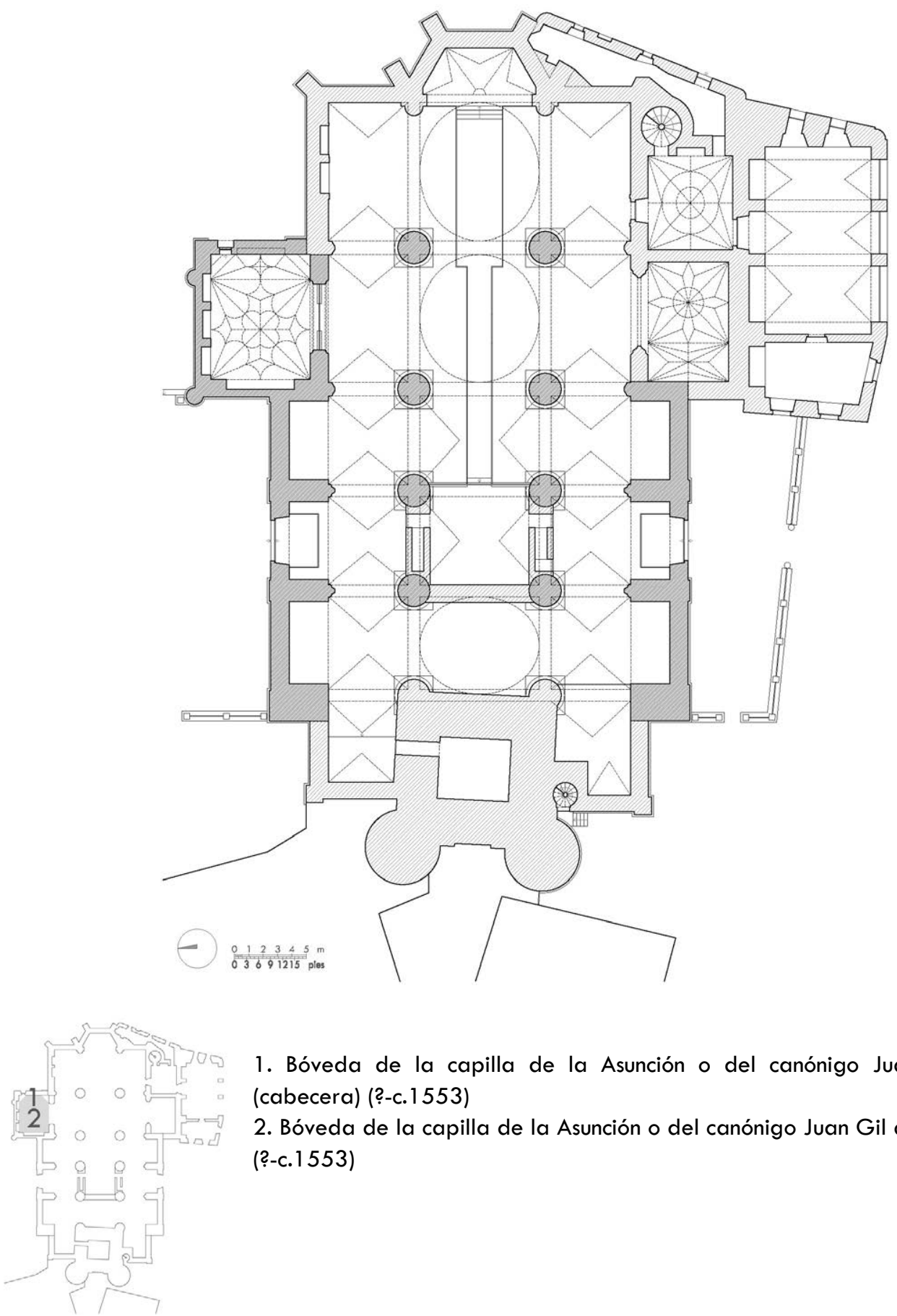

1. Bóveda de la capilla de la Asunción o del canónigo Juan Gil de Nava (cabecera) (?-c.1553)

2. Bóveda de la capilla de la Asunción o del canónigo Juan Gil de Nava (cuerpo) (?-c.1553)

Figura 104. Iglesia de los Santos Juanes, Nava del Rey (Valladolid): (a) Planta (P. Moreno). (b) Indicación de las bóvedas analizadas, con su fecha de ejecución (P. Moreno) 


\subsubsection{Bóveda de la capilla de la Asunción o del canónigo Juan Gil de Nava (cabecera)}

Modulación y rangos dimensionales: La bóveda tiene una planta poligonal basada en un octógono irregular de lados 8.9, 12.3 y 8.9 pies $(2.49,3.42$ y 2.49 m), y una embocadura de 24.9 pies (6.94 $\mathrm{m}$ ) (quedaría inscrita en un rectángulo que tuviera por base la embocadura y por altura 6.3 pies $(1.76 \mathrm{~m})$ ). Todos los nervios tienen un punto de arranque común en cada apoyo.

Sistemas de composición: La crucería principal está formada por terceletes sencillos, careciendo de arcos perpiaños radiales salvo el de embocadura. Las nervaduras decorativas forman una figura de lados cóncavos. En conjunto se obtiene un diseño con 3 claves interiores. • La clave principal se sitúa en el punto medio del eje central de simetría de la bóveda, y no coincide con la del arco perpiaño de la embocadura; las claves de los terceletes se sitúan alineadas con dicha clave y con las claves secundarias que forman el remate o pie de gallo del cuadrifolio de la bóveda contigua. Las claves de la figura central sobre la ligadura se desplazan ligeramente, situándose en los puntos de corte con una circunferencia que tiene por centro la clave principal y por radio el semieje.

Arcos: El plano de imposta se sitúa a una altura de 25.7 pies $(7.15 \mathrm{~m})$ del suelo, y la clave principal a 16.3 pies $(4.55 \mathrm{~m})$ de dicho plano. Todos los arcos parten tangentes a la vertical en el arranque, presentando algunos peraltes. El arco perpiaño de la embocadura es apuntado, encontrándose su clave 4.5 pies $(1.24 \mathrm{~m}$ ) por encima de la posición que correspondería a la de un arco perpiaño semicircular y partiendo sin peralte en su arranque. Los arcos se trazarían aparentemente con 4 radios distintos, siendo sus datos geométricos en pies los siguientes:

$\begin{array}{lccc}\text { nervio } & \text { tipo } & \text { radio } & \text { peralte } \\ \text { perpiaño } & \text { ap } & 17.7 & \\ \text { formero 1 } & \text { ap } & 7.5 & 9.6 \\ \text { formero 2 } & \text { sc } & 6.1 & 9.6 \\ \text { tercelete for. 1 } & \text { ap } & 11.3 & 4.8 \\ \text { tercelete for. 2 } & \text { ap } & 7.0 & 9.6\end{array}$

Rampante: -

Características constructivas: Los nervios que forman la crucería interior presentan 2 tipos distintos de sección en cuanto a molduraje y canto (grande para el tercelete; pequeño para la ligadura y el nervio decorativo). • Las jarjas se componen de 5 y 8 hiladas, dependiendo del nervio considerado. • Las claves tienen su eje central vertical (y su cara inferior paralela a la superficie de la bóveda en cada punto). - La plementería es de ladrillo; queda ligeramente separada del trasdós del formero. 

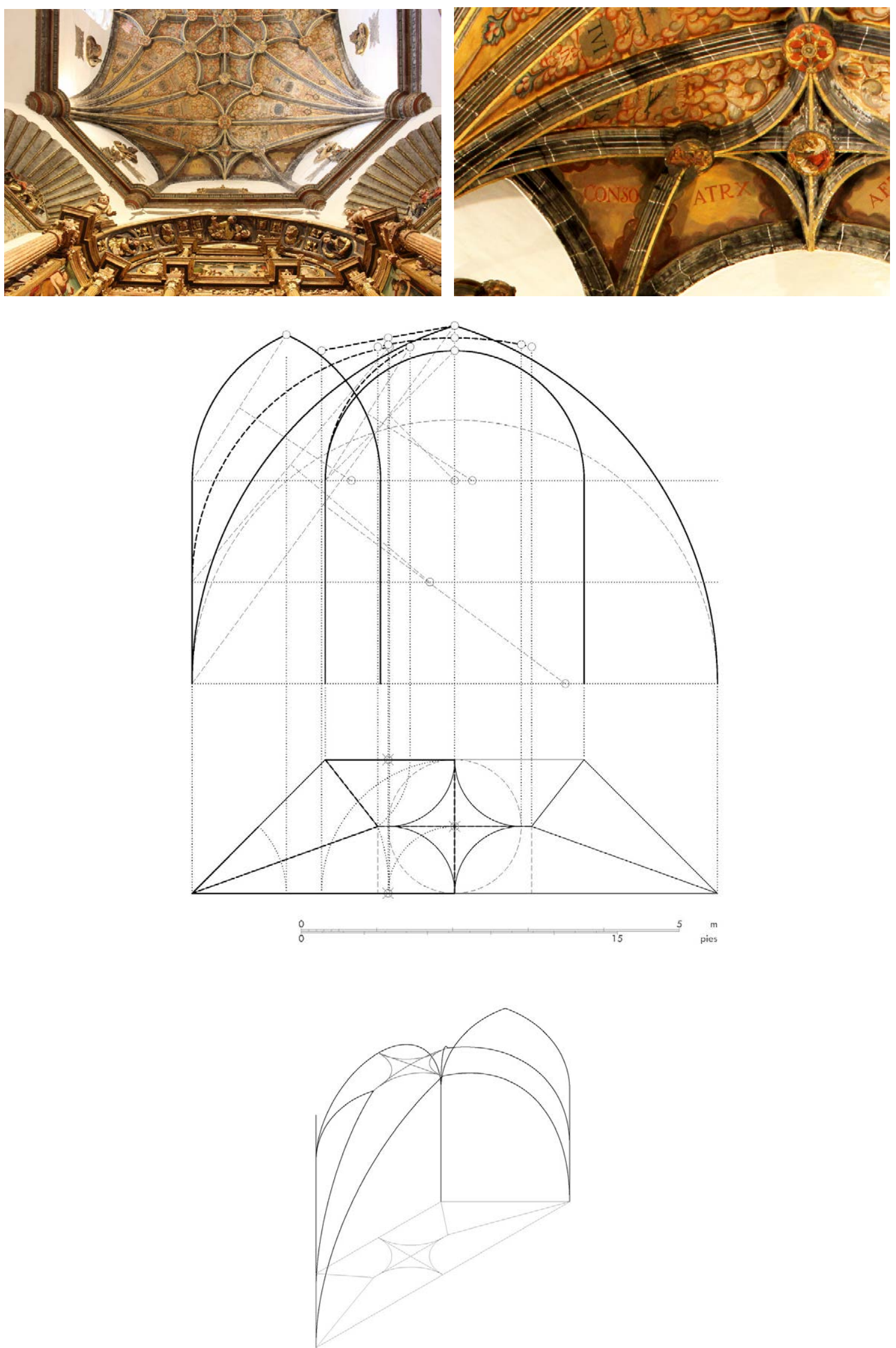

Figura 105. Iglesia de los Santos Juanes, Nava del Rey (Valladolid): bóveda de la capilla de la Asunción o del canónigo Juan Gil de Nava (cabecera): (a) Vista en planta. (b) Detalle de los nervios, claves y plementería. (c) Hipótesis de trazado de los nervios. (d) Modelizado de los nervios (c, d: P. Moreno) 


\subsubsection{Bóveda de la capilla de la Asunción o del canónigo Juan Gil de Nava (cuerpo)}

Modulación y rangos dimensionales: La bóveda tiene una planta cuadrada de dimensiones $24.9 \times 24.9$ pies $(6.94 \times 6.94 \mathrm{~m})$ y proporción entre los lados $1.000(1: 1)$, ambas consideradas a ejes de los arcos del perímetro (coinciden con las interiores). Todos los nervios tienen un punto de arranque común en cada apoyo.

Sistemas de composición: La crucería principal está formada por los dos arcos diagonales y terceletes sencillos en la dirección de ambos ejes. Las nervaduras decorativas forman un cuadrifolio de hojas cóncavas, en cuyo interior se dispone otro cuadrifolio de hojas convexas y tangentes al primero. En conjunto se obtiene un diseño con 21 claves interiores. - Las claves de los terceletes se sitúan en la bisectriz del ángulo formado por la diagonal y los arcos del perímetro. Las claves secundarias sobre los terceletes quedan alineadas sobre un paralelogramo que une los puntos medios de los lados de la bóveda; los centros principales del cuadrifolio exterior se disponen aproximadamente en los puntos de corte de dicho paralelogramo con las diagonales, y los de sus remates o pies de gallo sobre el perímetro de la bóveda; obtenidas las claves sobre las diagonales, las claves sobre las ligaduras se sitúan en los puntos medios de los segmentos limitados por las claves de los terceletes y la central, resultando alineadas con las claves y los centros de los pies de gallo; los centros del cuadrifolio interior (uno por cada hoja) se disponen sobre las diagonales.

Arcos: El plano de imposta se sitúa a una altura de 25.7 pies $(7.15 \mathrm{~m})$ del suelo, y la clave central a 17.6 pies $(4.91 \mathrm{~m})$ de dicho plano. Todos los arcos parten tangentes a la vertical en el arranque, no presentando ninguno peraltes. La clave central coincide con la posición que correspondería a la de un arco ojivo semicircular. Un examen visual de la geometría de la diagonal y la comprobación de la posición que ocupan las claves secundarias dispuestas a lo largo de este arco nos hace concluir que su trazado teórico es efectivamente semicircular, partiendo sin peralte en su arranque. Los arcos se trazarían aparentemente con 2 radios distintos, siendo sus datos geométricos en pies los siguientes:

\begin{tabular}{lccc} 
nervio & tipo & radio & peralte \\
\hline diagonal & sc & 17.6 \\
perpiaño E & ap & 17.7 \\
perpiaño O & ap & 16.2 \\
formero & ap & 16.2 \\
tercelete per. E & ap & 17.8 \\
tercelete per. $O$ & ap & 17.3 \\
tercelete for. & ap & 17.3
\end{tabular}

Rampante: Las claves de los arcos del perímetro se sitúan, en la dirección del eje x, a 1.8 pies (0.51 $\mathrm{m}$ ) por debajo de la clave central; en la dirección del eje y, a 1.3 pies $(0.36 \mathrm{~m}$ ) (valor promedio) por debajo de la clave central. El rampante se puede considerar llano en la dirección de ambos ejes.

Características constructivas: Los nervios que forman la crucería interior presentan 2 tipos distintos de sección en cuanto a molduraje y canto (grande para la diagonal, el tercelete y la ligadura; pequeño para el nervio decorativo). - Las jarjas se componen de 5 hiladas. - Las claves tienen su eje central vertical (y su cara inferior paralela a la superficie de la bóveda en cada punto). • La plementería es de ladrillo; queda ligeramente separada del trasdós del formero. 

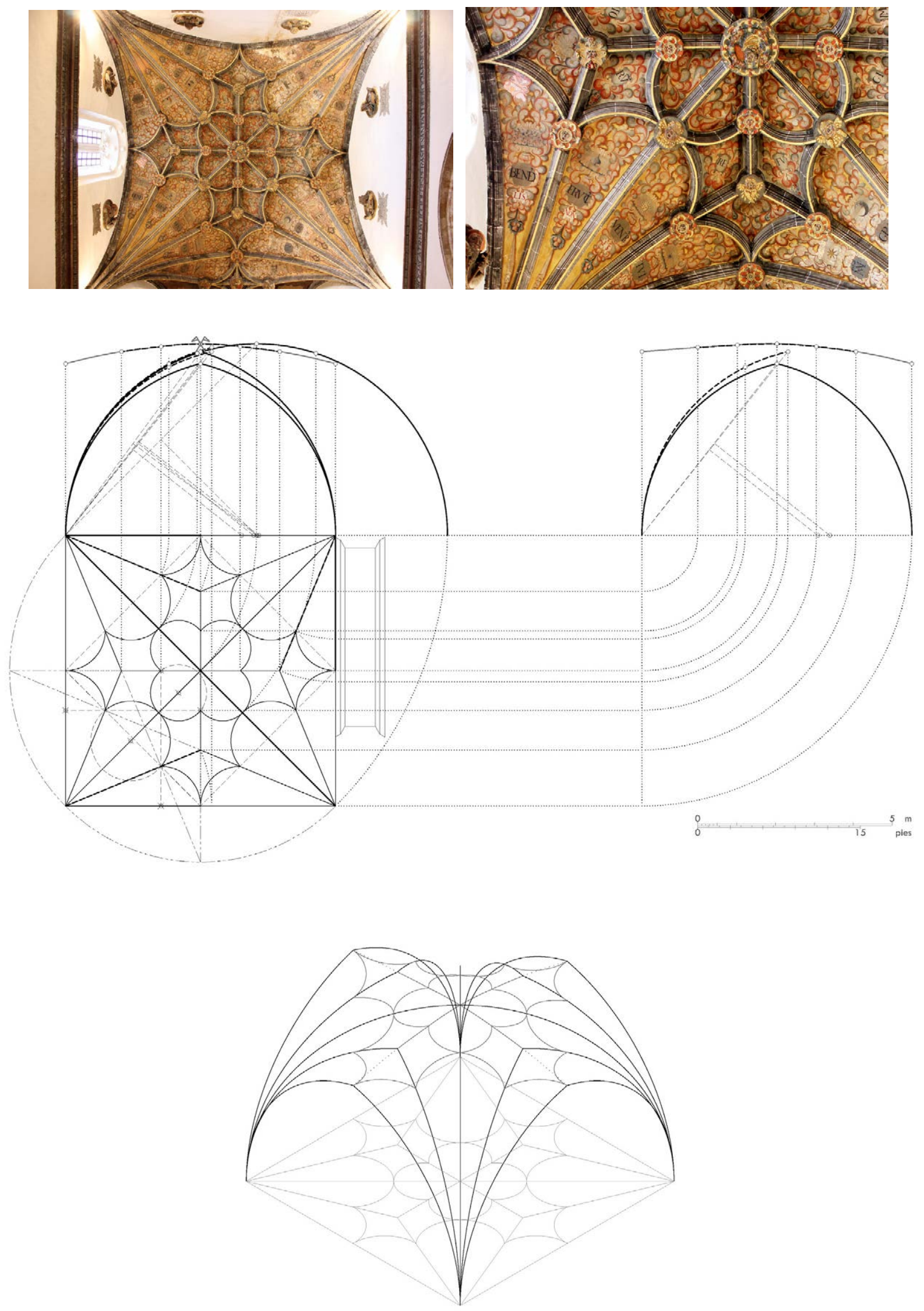

Figura 106. Iglesia de los Santos Juanes, Nava del Rey (Valladolid): bóveda de la capilla de la Asunción o del canónigo Juan Gil de Nava (cuerpo): (a) Vista en planta. (b) Detalle de los nervios, claves y plementería. (c) Hipótesis de trazado de los nervios. (d) Modelizado de los nervios (c, d: P. Moreno) 


\subsubsection{Ourense - Catedral de San Martín}

Datos históricos del edificio: véase página 773 y siguientes

Datos de medición de las bóvedas: véase página 878 y siguientes

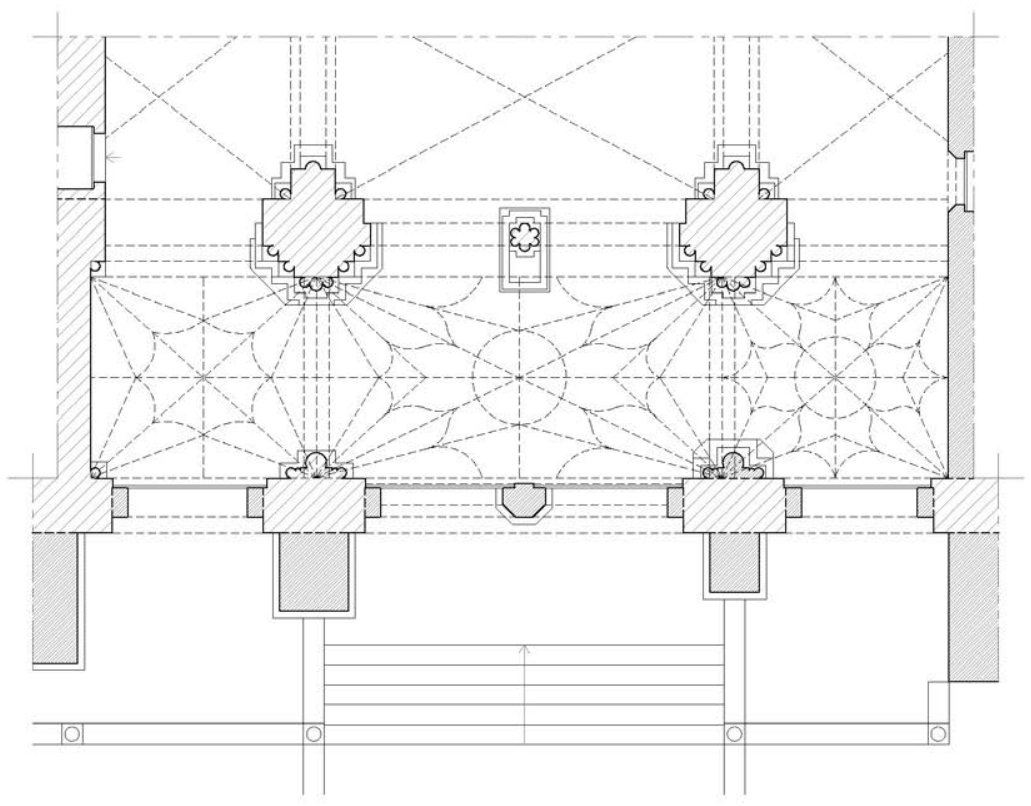

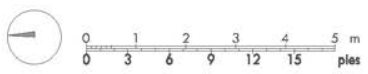

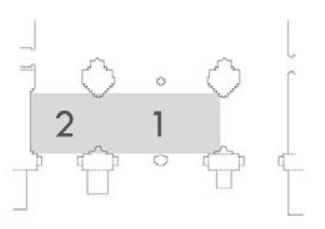

1. Bóveda del pórtico del Paraíso (tramo central) (c.1544-1551)

2. Bóveda del pórtico del Paraíso (tramo lateral norte) (c.1544-1551)

Figura 107. Catedral de Ourense: (a) Planta del pórtico del Paraíso (P. Moreno). (b) Indicación de las bóvedas analizadas, con su fecha de ejecución (P. Moreno) 


\subsubsection{Bóveda del pórtico del Paraíso (tramo central)}

Modulación y rangos dimensionales: La bóveda tiene una planta rectangular de dimensiones $29.3 \times 14.5$ pies $(8.16 \times 4.04 \mathrm{~m})$ y proporción entre los lados 2.021 (2:1), ambas consideradas a ejes de los arcos del perímetro (coinciden con las interiores). Todos los nervios tienen un punto de arranque común en cada apoyo.

Sistemas de composición: La crucería principal está formada por los dos arcos diagonales, terceletes dobles en la dirección del eje mayor y sencillos en la dirección del eje menor. Las nervaduras decorativas forman una figura de lados cóncavos, en cuyo interior se dispone un círculo. En conjunto se obtiene un diseño con 29 claves interiores. - Las claves de los terceletes se sitúan, sobre el eje mayor, en la bisectriz del ángulo formado por la diagonal y los arcos del perímetro, y en otros dos puntos que resultan de dividir la distancia entre la clave central y las claves obtenidas anteriormente en tres partes iguales (a 2/3 de la clave central); sobre el eje menor, en los puntos de corte de dicho eje con una circunferencia que tiene por centro la clave central y por radio una de las partes resultantes de la división anterior. La figura se compone de veinticuatro arcos.

Arcos: El plano de imposta se sitúa a una altura de 30.0 pies $(8.35 \mathrm{~m}$ ) del suelo, y la clave central a 11.6 pies $(3.23 \mathrm{~m}$ ) de dicho plano. Todos los arcos parten tangentes a la vertical en el arranque, no presentando ninguno peraltes. La clave central se encuentra 4.7 pies $(1.32 \mathrm{~m})$ por debajo de la posición que correspondería a la de un arco ojivo semicircular. Un examen visual de la geometría de la diagonal y la comprobación de la posición que ocupan las claves secundarias dispuestas a lo largo de este arco nos hace concluir que su trazado teórico es carpanel, partiendo sin peralte en su arranque. Los arcos se trazarían aparentemente con 4 radios distintos, siendo sus datos geométricos en pies los siguientes:

\begin{tabular}{|c|c|c|}
\hline nervio & tipo & radio \\
\hline diagonal & car & $11.1 \cdot 37.4$ \\
\hline perpiaño & car & $11.1 \cdot 22.2$ \\
\hline formero & ap & 11.2 \\
\hline tercelete per. & tu & $11.1 \cdot 28.6$ \\
\hline tercelete for. 1 & ap & 11.1 \\
\hline tercelete for. 2 & ap & 11.1 \\
\hline
\end{tabular}

Rampante: Las claves de los arcos del perímetro se sitúan, en la dirección del eje x (mayor), a 1.1 pies $(0.32 \mathrm{~m}$ ) por debajo de la clave central; en la dirección del eje y (menor), a la misma altura que la clave central. El rampante se puede considerar llano en la dirección del eje $x$ (mayor) y horizontal en la del eje y (menor).

Características constructivas: Los nervios que forman la crucería interior presentan 2 tipos distintos de sección en cuanto a molduraje y canto (grande para la diagonal, el tercelete y la ligadura; pequeño para el nervio decorativo). - Las jarjas se componen de 4 y 5 hiladas, dependiendo del soporte considerado. - Las claves tienen su eje central vertical (y su cara inferior paralela a la superficie de la bóveda en cada punto). - La plementería es de cantería, dispuesta a la francesa; sus hiladas se componen de entre 1 y 2 piezas; asienta directamente sobre el trasdós del formero. 

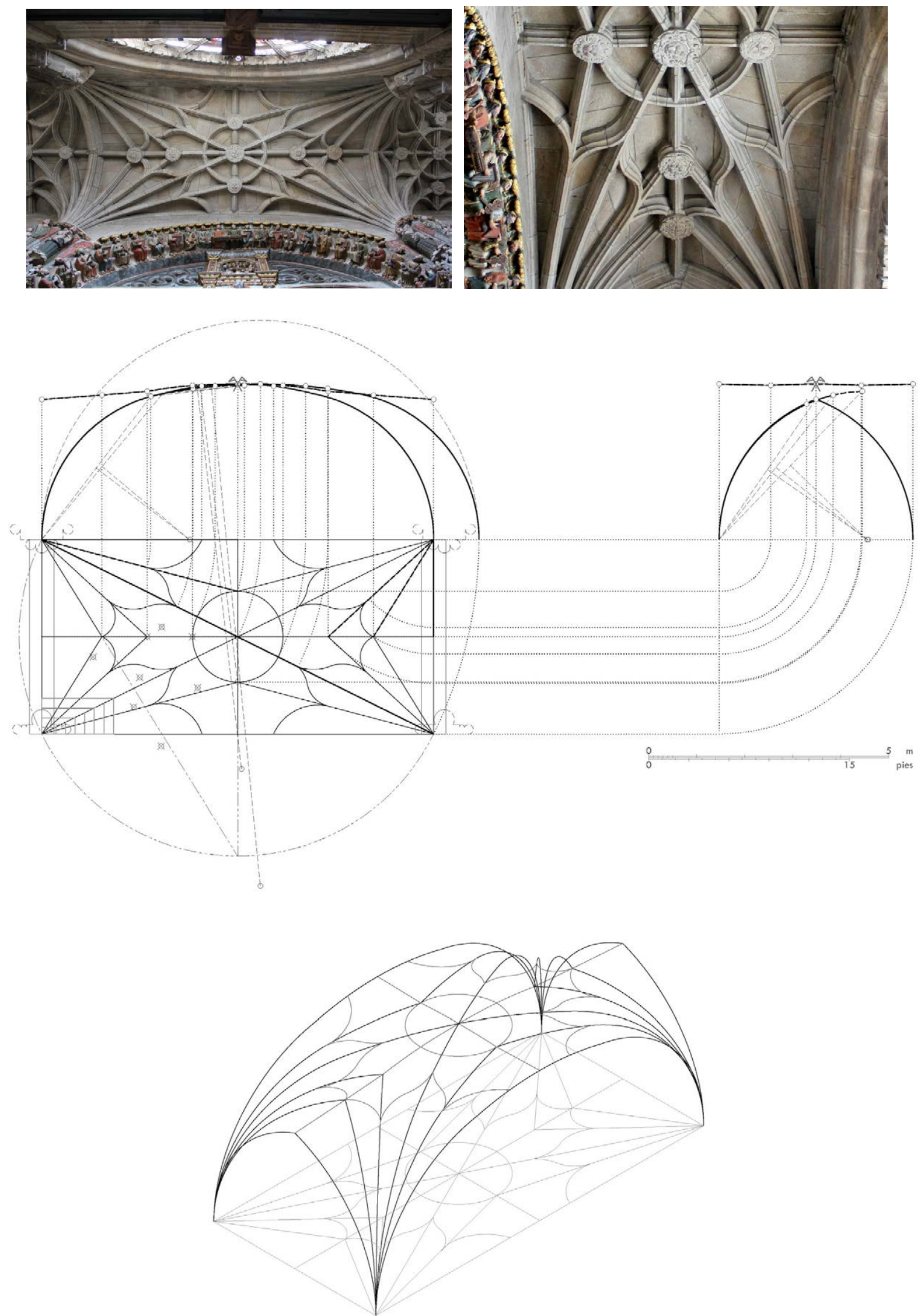

Figura 108. Catedral de Ourense: bóveda del pórtico del Paraíso (tramo central): (a) Vista en planta. (b) Detalle de los nervios, claves y plementería. (c) Hipótesis de trazado de los nervios. (d) Modelizado de los nervios (c, d: P. Moreno) 


\subsubsection{Bóveda del pórtico del Paraíso (tramo lateral norte)}

Modulación y rangos dimensionales: La bóveda tiene una planta rectangular de dimensiones $16.3 \times 14.5$ pies $(4.54 \times 4.04 \mathrm{~m})$ y proporción entre los lados 1.124 (8:7), ambas consideradas a ejes de los arcos del perímetro (coinciden con las interiores). Todos los nervios tienen un punto de arranque común en cada apoyo.

Sistemas de composición: La crucería principal está formada por los dos arcos diagonales y terceletes sencillos en la dirección de ambos ejes. Las nervaduras decorativas forman una figura de lados cóncavos. En conjunto se obtiene un diseño con 9 claves interiores. - Las claves de los terceletes se sitúan en la bisectriz del ángulo formado por la diagonal y los arcos del perímetro. Las claves sobre las diagonales se sitúan en los puntos de corte con una circunferencia que tiene por centro el polo de la bóveda y por radio la distancia hasta las claves de los terceletes situados sobre el eje mayor; la figura se compone de ocho arcos.

Arcos: El plano de imposta se sitúa a una altura de 30.0 pies $(8.35 \mathrm{~m})$ del suelo, y la clave central a 10.6 pies $(2.96 \mathrm{~m})$ de dicho plano. Todos los arcos parten tangentes a la vertical en el arranque, no presentando ninguno peraltes. La clave central se encuentra 0.3 pies $(0.08 \mathrm{~m})$ por debajo de la posición que correspondería a la de un arco ojivo semicircular. Un examen visual de la geometría de la diagonal y la comprobación de la posición que ocupan las claves secundarias dispuestas a lo largo de este arco nos hace concluir que su trazado teórico es carpanel, partiendo sin peralte en su arranque. Los arcos se trazarían aparentemente con 2 radios distintos, siendo sus datos geométricos en pies los siguientes:

\begin{tabular}{|c|c|c|}
\hline nervio & tipo & radio \\
\hline diagonal & car & $10.9 \cdot 13.9$ \\
\hline perpiaño & ap & 10.8 \\
\hline formero & ap & 11.2 \\
\hline tercelete per. & ap & 10.6 \\
\hline tercelete for. & ap & 10.8 \\
\hline
\end{tabular}

Rampante: Las claves de los arcos del perímetro se sitúan, en la dirección de ambos ejes, a la misma altura que la clave central (la diferencia de altura es despreciable). El rampante se puede considerar horizontal en la dirección de ambos ejes.

Características constructivas: Los nervios que forman la crucería interior presentan 2 tipos distintos de sección en cuanto a molduraje y canto (grande para la diagonal, el tercelete y la ligadura; pequeño para el nervio decorativo). • Las jarjas se componen de 5 hiladas. - Las claves tienen su eje central vertical (y su cara inferior paralela a la superficie de la bóveda en cada punto). • La plementería es de cantería, dispuesta a la francesa; sus hiladas se componen de 1 única pieza; asienta directamente sobre el trasdós del formero. 

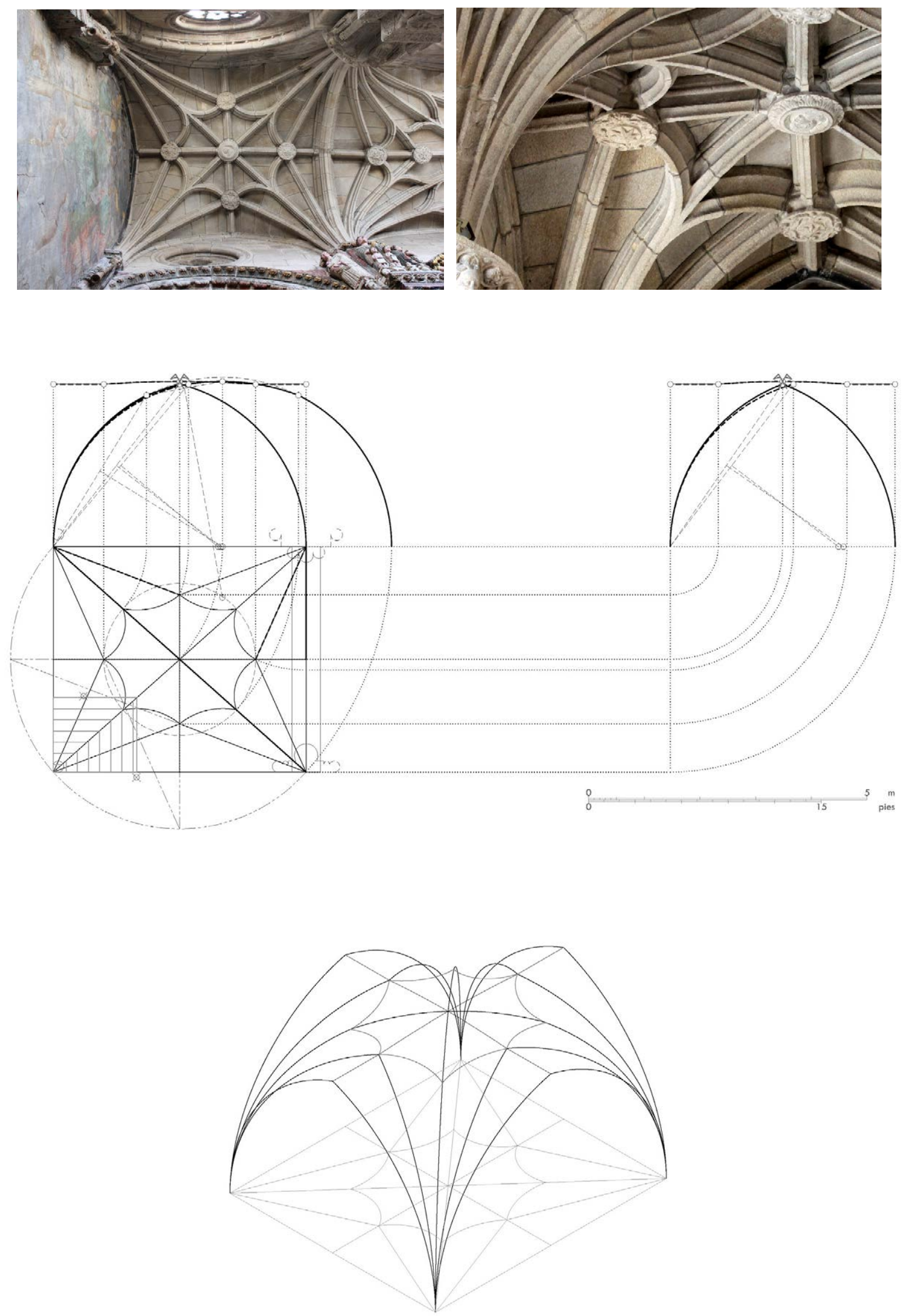

Figura 109. Catedral de Ourense: bóveda del pórtico del Paraíso (tramo lateral norte): (a) Vista en planta. (b) Detalle de los nervios, claves y plementería. (c) Hipótesis de trazado de los nervios. (d) Modelizado de los nervios (c, d: P. Moreno) 


\subsubsection{Ourense - Iglesia de la Santísima Trinidad}

Datos históricos del edificio: véase página 796

Datos de medición de las bóvedas: véase página 880 y siguientes
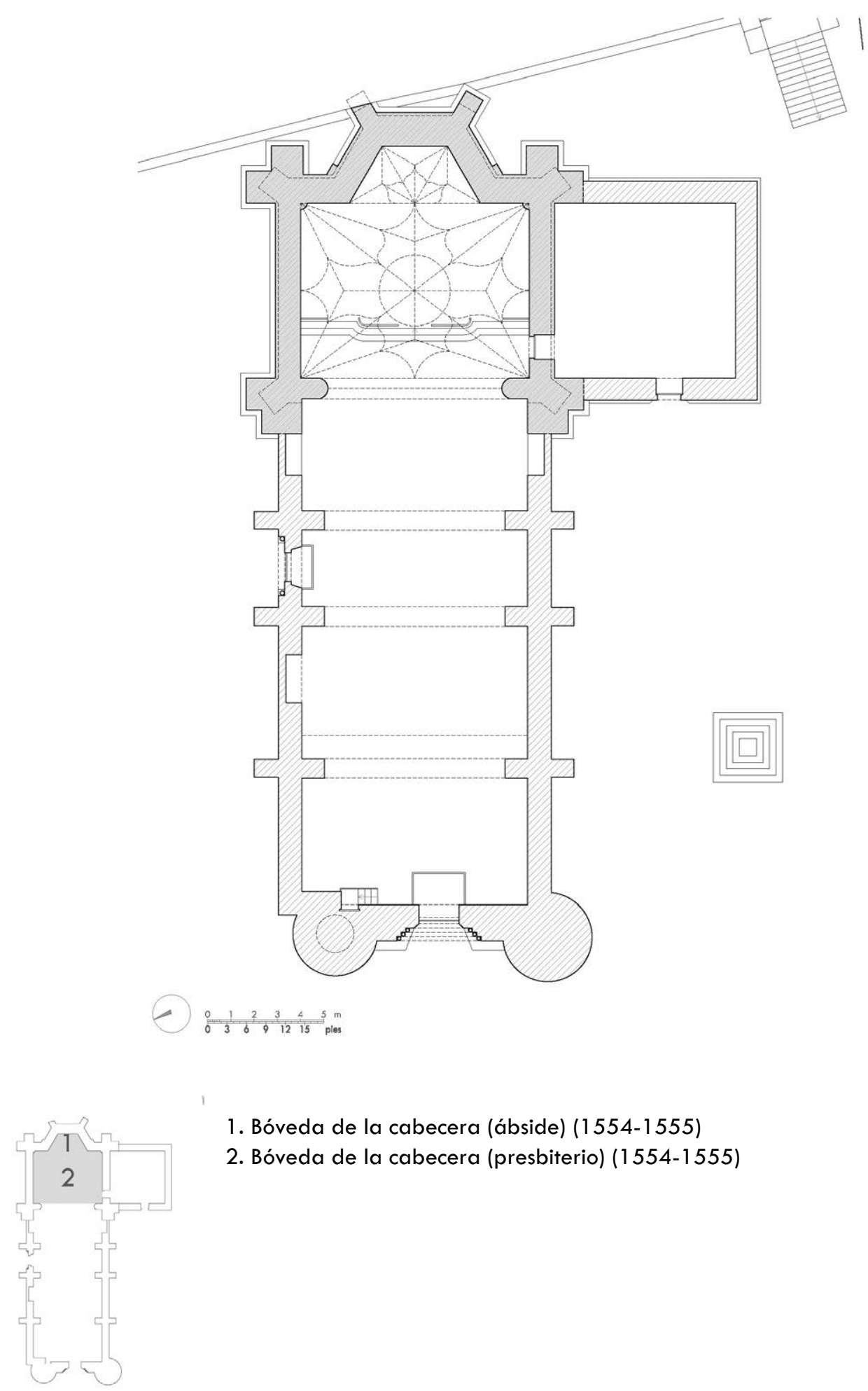

1. Bóveda de la cabecera (ábside) (1554-1555)

2. Bóveda de la cabecera (presbiterio) (1554-1555)

Figura 1 10. Iglesia de la Santísima Trinidad, Ourense: (a) Planta (P. Moreno). (b) Indicación de las bóvedas analizadas, con su fecha de ejecución (P. Moreno) 


\subsubsection{Bóveda de la cabecera (ábside)}

Modulación y rangos dimensionales: La bóveda tiene una planta poligonal basada en un hexágono regular de lado 10.1 pies $(2.82 \mathrm{~m})$ y el mismo radio, y una embocadura de 20.2 pies $(5.63 \mathrm{~m})$. Todos los nervios tienen un punto de arranque común en cada apoyo.

Sistemas de composición: La crucería principal está formada por los arcos perpiaños radiales y terceletes sencillos. Las nervaduras decorativas forman un trifolio de hojas conopiales. En conjunto se obtiene un diseño con 7 claves interiores. - La clave principal se sitúa en el centro del polígono generador, y coincide con la del arco perpiaño de la embocadura; las claves de los terceletes se sitúan en la bisectriz del ángulo formado por los perpiaños radiales y los arcos del perímetro. Las claves del trifolio sobre los perpiaños radiales se sitúan en puntos cuyo trazado geométrico no hemos logrado determinar; sus hojas comparten el mismo trazado.

Arcos: El plano de imposta se sitúa a una altura de 40.9 pies $(11.38 \mathrm{~m})$ del suelo, y la clave principal a 9.4 pies $(2.61 \mathrm{~m}$ ) de dicho plano (el arco que limita con el tramo adyacente, y que constituye la embocadura, parte de un plano de imposta más bajo, situado a una altura de 30.7 pies (8.55 m), por lo que se le ha asignado un peralte negativo de -10.2 pies $(-2.83 \mathrm{~m})$ ). Todos los arcos parten tangentes a la vertical en el arranque, excepto el tercelete formero 1 que parte inclinado, presentando algunos peraltes. El arco perpiaño de la embocadura es apuntado, encontrándose su clave 1.8 pies $(0.51 \mathrm{~m})$ por encima de la posición que correspondería a la de un arco perpiaño semicircular (apoyado en el plano de imposta inferior) y partiendo con un peralte de - 10.2 pies ($2.83 \mathrm{~m}$ ) en su arranque. Los arcos se trazarían aparentemente con 2 radios distintos, siendo sus datos geométricos en pies los siguientes:

\begin{tabular}{lccc} 
nervio & tipo & radio & peralte \\
\hline perpiaño 1 & ap & 19.6 & -10.2 \\
perpiaño 2 & sc & 9.4 & \\
formero 1 & ap & 9.6 & \\
formero 2 & ap & 9.6 & \\
tercelete for. 1 & ap.in & 9.4 & \\
tercelete for. 2 & ap & 9.4 &
\end{tabular}

\section{Rampante: -}

Características constructivas: Los nervios que forman la crucería interior presentan 2 tipos distintos de sección en cuanto a molduraje y canto (grande para el perpiaño radial, el tercelete y la ligadura; pequeño para el nervio decorativo). • Las jarjas se componen de 4 hiladas. • Las claves tienen su eje central vertical (y su cara inferior horizontal). • La plementería es probablemente de ladrillo; asienta directamente sobre el trasdós del formero. 

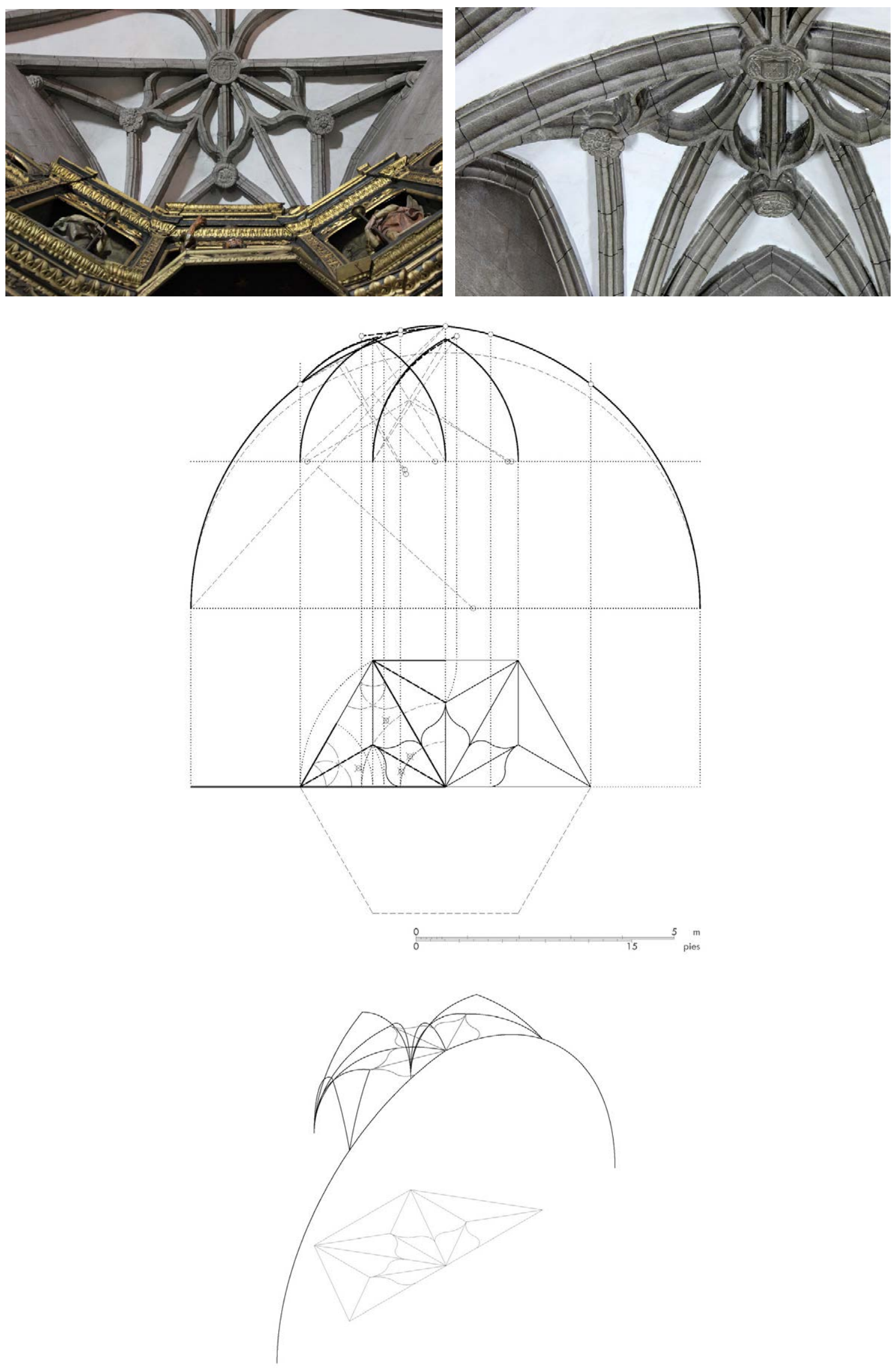

Figura 111. Iglesia de la Santísima Trinidad, Ourense: bóveda de la cabecera (ábside): (a) Vista en planta. (b) Detalle de los nervios, claves y plementería. (c) Hipótesis de trazado de los nervios. (d) Modelizado de los nervios (c, d: P. Moreno) 


\subsubsection{Bóveda de la cabecera (presbiterio)}

Modulación y rangos dimensionales: La bóveda tiene una planta rectangular de dimensiones $35.4 \times 27.1$ pies $(9.86 \times 7.55 \mathrm{~m})$ y proporción entre los lados $1.306(4: 3)$, ambas consideradas a ejes de los arcos del perímetro (coinciden con las interiores). Todos los nervios tienen un punto de arranque común en cada apoyo.

Sistemas de composición: La crucería principal está formada por los dos arcos diagonales y terceletes sencillos en la dirección de ambos ejes. Las nervaduras decorativas forman un cuadrifolio de hojas cóncavas, en cuyo interior se dispone un círculo. En conjunto se obtiene un diseño con 21 claves interiores. - Las claves de los terceletes se sitúan en la bisectriz del ángulo formado por la diagonal y los arcos del perímetro. Las claves secundarias sobre los terceletes del eje menor se sitúan en los puntos de corte con un paralelogramo que une los extremos del cuadrifolio, y sobre los terceletes del eje mayor en puntos cuyo trazado geométrico no hemos logrado determinar; las claves sobre la ligadura del eje mayor se sitúan en los puntos medios de los segmentos limitados por las claves de los terceletes y la central; obtenidas estas claves, es posible trazar el círculo central, generando las claves sobre las diagonales y sobre la ligadura del eje menor; los centros del cuadrifolio se disponen libremente.

Arcos: El plano de imposta se sitúa a una altura de 30.7 pies del suelo $(8.55 \mathrm{~m})$, y la clave central a 20.9 pies $(5.81 \mathrm{~m})$ de dicho plano. Todos los arcos parten tangentes a la vertical en el arranque, no presentando ninguno peraltes. La clave central se encuentra 1.4 pies $(0.40 \mathrm{~m})$ por debajo de la posición que correspondería a la de un arco ojivo semicircular. Un examen visual de la geometría de la diagonal y la comprobación de la posición que ocupan las claves secundarias dispuestas a lo largo de este arco nos hace concluir que su trazado teórico es carpanel, partiendo sin peralte en su arranque. Los arcos se trazarían aparentemente con 3 radios distintos, siendo sus datos geométricos en pies los siguientes:

\begin{tabular}{|c|c|c|}
\hline nervio & tipo & radio \\
\hline diagonal & car & $20.7 \cdot 29.9$ \\
\hline perpiaño $E$ & ap & 19.6 \\
\hline perpiaño $\bigcirc$ & ap & 18.7 \\
\hline formero & ap & 18.9 \\
\hline tercelete per. & ap & 20.3 \\
\hline tercelete for. & ap & 20.9 \\
\hline
\end{tabular}

Rampante: Las claves de los arcos del perímetro se sitúan, en la dirección del eje x (mayor), a 2.7 pies $(0.75 \mathrm{~m}$ ) por debajo de la clave central; en la dirección del eje y (menor), a 1.8 pies $(0.50 \mathrm{~m})$ (valor promedio) por debajo de la clave central. El rampante se puede considerar llano en la dirección de ambos ejes.

Características constructivas: Los nervios que forman la crucería interior presentan 2 tipos distintos de sección en cuanto a molduraje y canto (grande para la diagonal, el tercelete y la ligadura; pequeño para el nervio decorativo). - Las jarjas se componen de 6 hiladas. - Las claves superiores de los terceletes tienen su eje central vertical (y su cara inferior horizontal); las que corresponden a las intersecciones del círculo central con las diagonales tienen su eje central inclinado; las que corresponden a las intersecciones del círculo central con las ligaduras y del cuadrifolio con los terceletes no están provistas de un cilindro central, sino que se resuelven como un cruce de nervios. • La plementería es probablemente de ladrillo; asienta directamente sobre el trasdós del formero. 

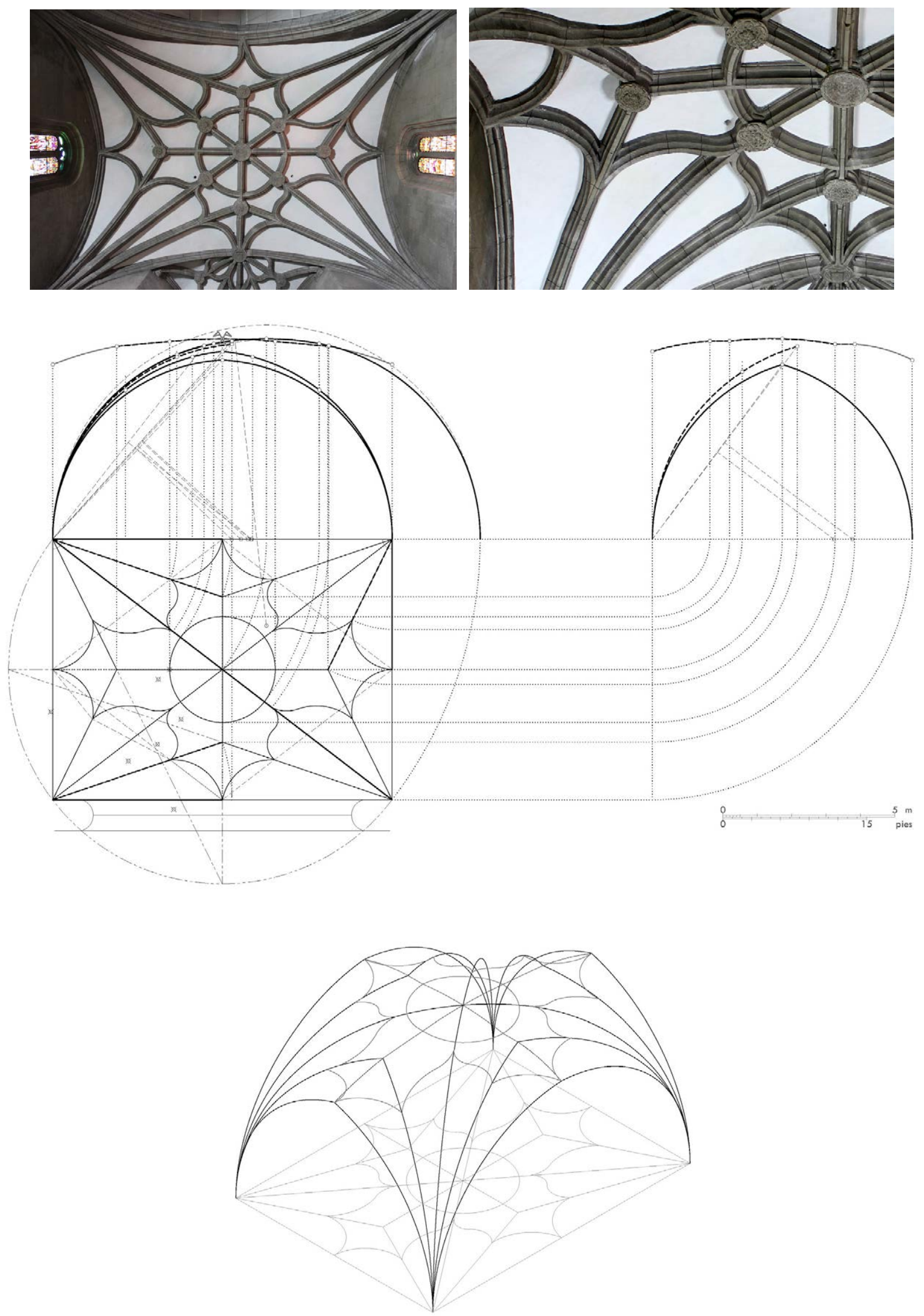

Figura 1 12. Iglesia de la Santísima Trinidad, Ourense: bóveda de la cabecera (presbiterio): (a) Vista en planta.

(b) Detalle de los nervios, claves y plementería. (c) Hipótesis de trazado de los nervios. (d) Modelizado de los nervios (c, d: P. Moreno) 


\subsubsection{Peñaranda de Duero (Burgos) - Iglesia (excolegiata) de Santa Ana}

Datos históricos del edificio: véase página 786 y siguientes

Datos de medición de las bóvedas: véase página 882 y siguientes

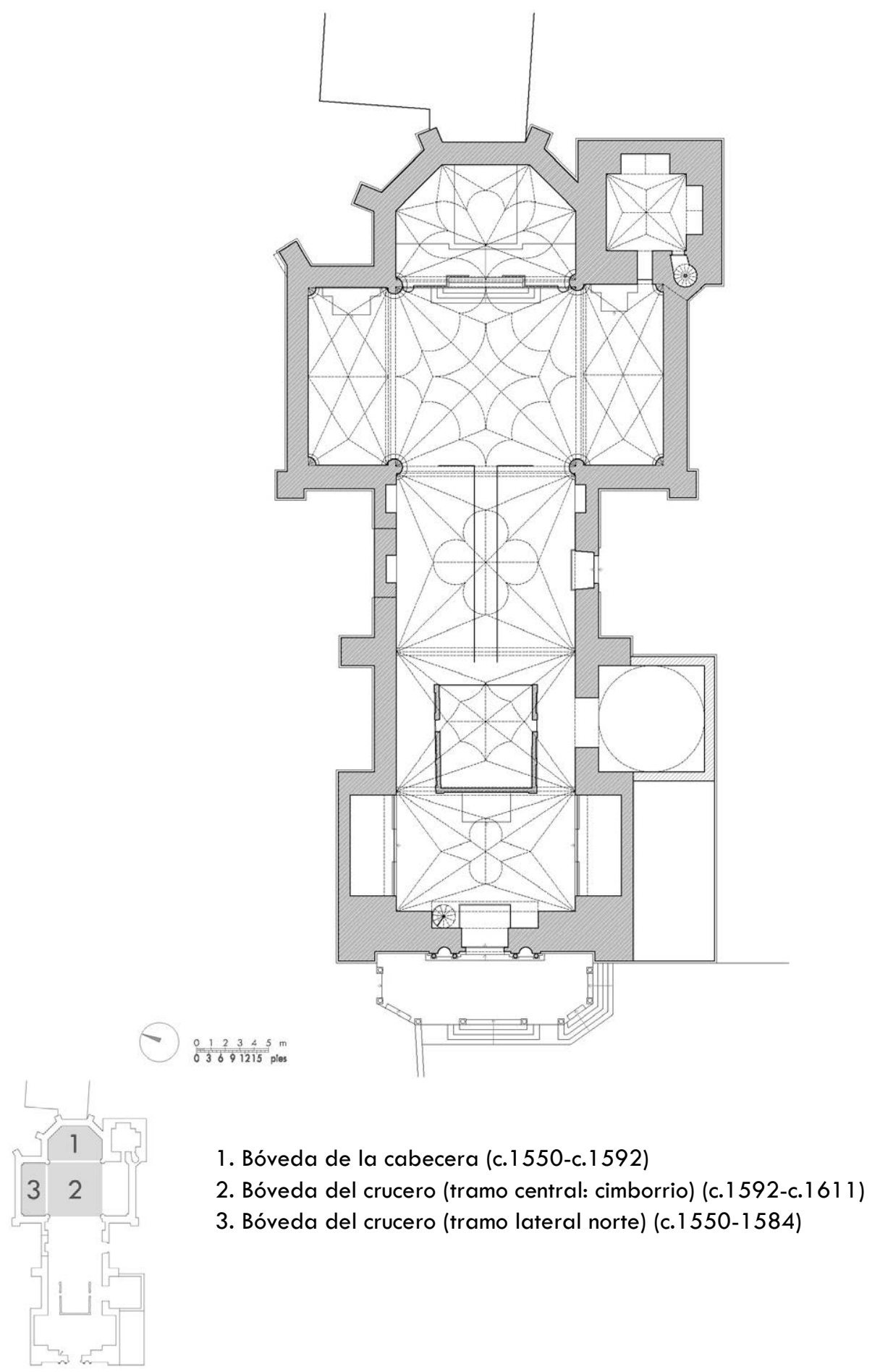

Figura 113. Iglesia de Santa Ana, Peñaranda de Duero (Burgos): (a) Planta (P. Moreno). (b) Indicación de las bóvedas analizadas, con su fecha de ejecución (P. Moreno) 


\subsubsection{Bóveda de la cabecera}

Modulación y rangos dimensionales: La bóveda tiene una planta poligonal basada en un octógono irregular de lados $17.7,16.3,21.8,16.3$ y 17.7 pies $(4.94,4.53,6.08,4.53$ y $4.94 \mathrm{~m})$, y una embocadura de 44.8 pies $(12.49 \mathrm{~m}$ ) (quedaría inscrita en un rectángulo que tuviera por base la embocadura y por altura 29.2 pies $(8.14 \mathrm{~m})$ ). El arco perpiaño de la embocadura tiene un punto de arranque distinto al del resto de los nervios en cada apoyo.

Sistemas de composición: La crucería principal está formada por los arcos perpiaños radiales y terceletes sencillos. Las nervaduras decorativas forman un quinquefolio de hojas convexas. En conjunto se obtiene un diseño con 12 claves interiores. - La clave principal se sitúa en el centro del polígono generador, y no coincide con la del arco perpiaño de la embocadura; las claves de los terceletes se sitúan en la bisectriz del ángulo formado por los perpiaños radiales y los arcos del perímetro. Las claves del quinquefolio sobre los perpiaños radiales se sitúan aproximadamente en los puntos de corte con una circunferencia que tiene por centro la clave principal y por radio la mitad de la distancia hasta el perímetro de la bóveda en el sector central; sus hojas no comparten el mismo trazado.

Arcos: El plano de imposta se sitúa a una altura de 44.9 pies $(12.50 \mathrm{~m})$ del suelo, y la clave principal a 30.8 pies $(8.58 \mathrm{~m})$ de dicho plano. Todos los arcos parten tangentes a la vertical en el arranque, presentando todos peraltes. El arco perpiaño de la embocadura es apuntado, encontrándose su clave 7.1 pies $(1.97 \mathrm{~m})$ por encima de la posición que correspondería a la de un arco perpiaño semicircular y partiendo con un peralte de 1.3 pies $(0.36 \mathrm{~m})$ en su arranque. Los arcos se trazarían aparentemente con 6 radios distintos, siendo sus datos geométricos en pies los siguientes:

\begin{tabular}{lccc} 
nervio & tipo & radio & peralte \\
\hline perpiaño 1 & ap & 29.0 & 1.3 \\
perpiaño 2 & sc & 23.4 & 7.4 \\
perpiaño 3 & sc & 23.4 & 7.4 \\
formero 1 & ap & 21.8 & 8.7 \\
formero 2 & ap & 22.6 & 8.7 \\
formero 3 & ap & 19.2 & 8.7 \\
tercelete for. 1 & ap & 24.9 & 7.4 \\
tercelete for. 2 & ap & 25.0 & 7.4 \\
tercelete for. 3 & ap & 26.5 & 7.4 \\
tercelete for. 4 & ap & 22.5 & 7.4
\end{tabular}

Rampante: -

Características constructivas: Los nervios que forman la crucería interior presentan 3 tipos distintos de sección en cuanto a molduraje y canto (grande para el perpiaño radial; mediano para el tercelete; pequeño para el nervio decorativo). - Las jarjas se componen de 9, 10, 11 y 12 hiladas, dependiendo del soporte y del nervio considerado. - Las claves de los terceletes y las que reciben el remate o pie de gallo del quinquefolio tienen su eje central vertical (y su cara inferior paralela a la superficie de la bóveda en cada punto); las que corresponden a los arcos perpiaños radiales, a excepción de las dos indicadas, tienen su eje central inclinado. - La plementería es de cantería, dispuesta a la inglesa en los arranques y por otros procedimientos en la zona central, encerrada por las nervaduras decorativas (cada témpano de esta zona se cierra con un aparejo independiente, respetándose la misma disposición en témpanos simétricos); sus hiladas se componen de entre 1 y 4 piezas; asienta directamente sobre el trasdós del formero. 

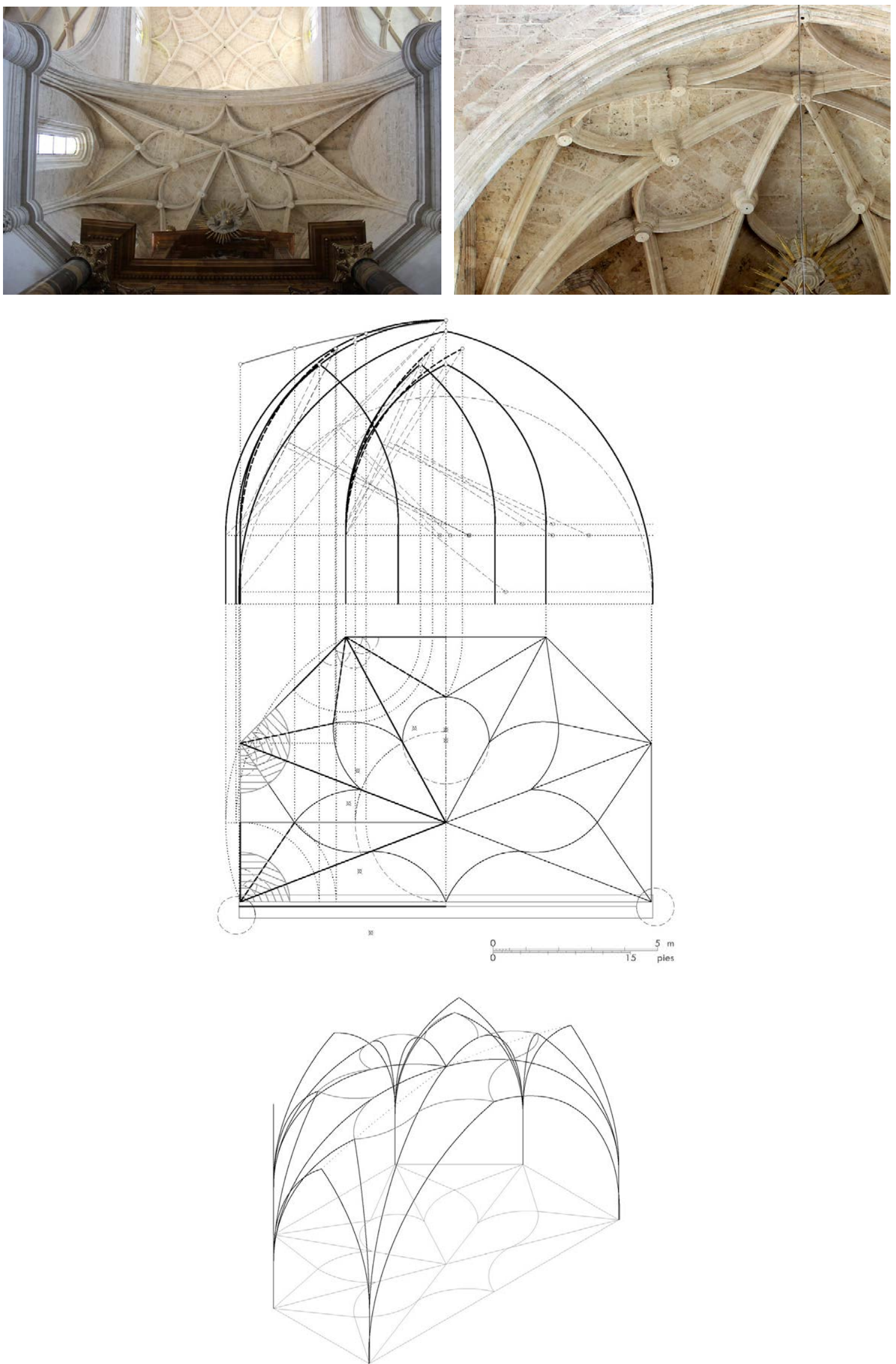

Figura 1 14. Iglesia de Santa Ana, Peñaranda de Duero (Burgos): bóveda de la cabecera: (a) Vista en planta. (b) Detalle de los nervios, claves y plementería. (c) Hipótesis de trazado de los nervios. (d) Modelizado de los nervios (c, d: P. Moreno) 


\subsubsection{Bóveda del crucero (tramo central: cimborrio)}

Modulación y rangos dimensionales: La bóveda tiene una planta aproximadamente cuadrada de dimensiones $47.6 \times 47.2$ pies $(13.26 \times 13.14 \mathrm{~m})$ y proporción entre los lados $1.009(1: 1)$, ambas consideradas a ejes de los arcos del perímetro (las interiores son $45.1 \times 44.6$ pies (12.56x $12.44 \mathrm{~m}$ ) y $1.011(1: 1)$, respectivamente). Todos los nervios tienen un punto de arranque común en cada apoyo.

Sistemas de composición: La crucería principal está formada por los dos arcos diagonales y terceletes sencillos en la dirección de ambos ejes. Las nervaduras decorativas forman un cuadrifolio de hojas cóncavas, en cuyo interior se dispone una figura de lados cóncavos y aproximadamente paralelos al anterior. En conjunto se obtiene un diseño con 21 claves interiores. - Las claves de los terceletes se sitúan en la bisectriz del ángulo formado por la diagonal y los arcos del perímetro. Las claves secundarias sobre los terceletes quedan alineadas sobre un paralelogramo que une los extremos del cuadrifolio; los centros principales del cuadrifolio, que no coinciden con los de la figura interior, se disponen sobre la diagonal y aproximadamente alineados con los de sus remates o pies de gallo, que se sitúan sobre el perímetro de la bóveda; los centros de la figura interior se disponen sobre la diagonal y alineados con las claves de los terceletes.

Arcos: El plano de imposta se sitúa a una altura de 83.8 pies $(23.36 \mathrm{~m})$ del suelo, y la clave central a 31.7 pies $(8.83 \mathrm{~m})$ de dicho plano. Todos los arcos parten tangentes a la vertical en el arranque, no presentando ninguno peraltes. La clave central coincide con la posición que correspondería a la de un arco ojivo semicircular. Un examen visual de la geometría de la diagonal y la comprobación de la posición que ocupan las claves secundarias dispuestas a lo largo de este arco nos hace concluir que su trazado teórico es efectivamente semicircular, partiendo sin peralte en su arranque. Los arcos se trazarían aparentemente con 3 radios distintos, siendo sus datos geométricos en pies los siguientes:

\begin{tabular}{lccc} 
nervio & tipo & radio & peralte \\
\hline diagonal & sc & 31.7 \\
perpiaño & ap & 27.7 \\
formero & ap & 27.8 \\
tercelete per. & ap & 30.4 \\
tercelete for. & ap & 30.5
\end{tabular}

Rampante: Las claves de los arcos del perímetro se sitúan, en la dirección de ambos ejes, a 4.5 pies (1.24 m) por debajo de la clave central. El rampante se puede considerar llano en la dirección de ambos ejes.

Características constructivas: Los nervios que forman la crucería interior presentan 3 tipos distintos de sección en cuanto a molduraje y canto (grande para la diagonal; mediano para el tercelete; pequeño para el nervio decorativo). • Las jarjas se componen de 7 hiladas. - Las claves tienen su eje central vertical (y su cara inferior paralela a la superficie de la bóveda en cada punto). • La plementería es de cantería, dispuesta a la inglesa en los arranques y superficie intermedia, y por otros procedimientos en el espacio central, encerrado por los combados más interiores (las hiladas se disponen en esta última zona paralelas al perímetro de la bóveda pero uniendo las diagonales, esto es, formando cuadrados concéntricos al perímetro); sus hiladas se componen de entre 1 y 6 piezas; asienta directamente sobre el trasdós del formero. 

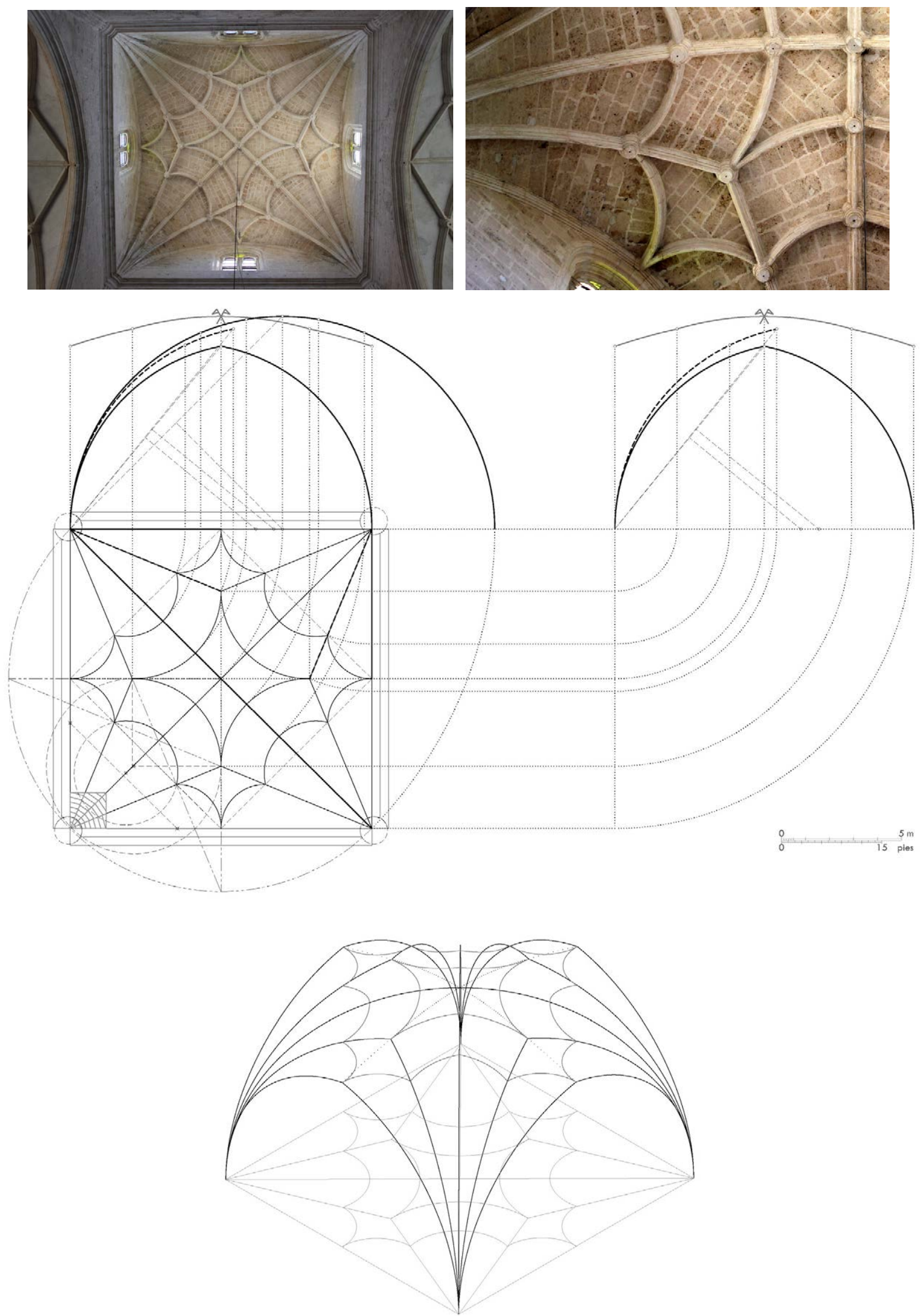

Figura 1 15. Iglesia de Santa Ana, Peñaranda de Duero (Burgos): bóveda del crucero (tramo central: cimborrio): (a) Vista en planta. (b) Detalle de los nervios, claves y plementería. (c) Hipótesis de trazado de los nervios. (d) Modelizado de los nervios (c, d: P. Moreno) 


\subsubsection{Bóveda del crucero (tramo lateral norte)}

Modulación y rangos dimensionales: La bóveda tiene una planta rectangular de dimensiones $20.5 \times 44.1$ pies $(5.71 \times 12.30 \mathrm{~m})$ y proporción entre los lados 2.151 (>2:1), ambas consideradas a ejes de los arcos del perímetro (las interiores son $20.0 \times 44.1$ pies $(5.57 \times 12.30 \mathrm{~m}$ ) y $2.205(>2: 1)$, respectivamente). Los perpiaños tienen un punto de arranque distinto al del resto de los nervios en cada apoyo.

Sistemas de composición: La crucería principal está formada por los dos arcos diagonales y terceletes sencillos en la dirección del eje mayor. Las nervaduras decorativas forman un rombo de lados rectos. En conjunto se obtiene un diseño con 7 claves interiores. - Las claves de los terceletes se sitúan en la bisectriz del ángulo formado por la diagonal y los arcos del perímetro. Las claves sobre las diagonales son generadas automáticamente uniendo las claves de los arcos del perímetro y las de los terceletes.

Arcos: El plano de imposta se sitúa a una altura de 44.9 pies ( $12.50 \mathrm{~m}$ ) del suelo, y la clave central a 30.8 pies $(8.57 \mathrm{~m})$ de dicho plano. Todos los arcos parten tangentes a la vertical en el arranque, presentando todos peraltes. La clave central se encuentra 6.5 pies $(1.82 \mathrm{~m})$ por encima de la posición que correspondería a la de un arco ojivo semicircular. Un examen visual de la geometría de la diagonal y la comprobación de la posición que ocupan las claves secundarias dispuestas a lo largo de este arco nos hace concluir que su trazado teórico es efectivamente semicircular, partiendo con un peralte de 6.5 pies $(1.82 \mathrm{~m})$ en su arranque. Los arcos se trazarían aparentemente con 4 radios distintos, siendo sus datos geométricos en pies los siguientes:

\begin{tabular}{lccc} 
nervio & tipo & radio & peralte \\
\hline diagonal & sc & 24.2 & 6.5 \\
perpiaño & ap & 19.3 & 8.2 \\
formero N & ap & 22.4 & 6.5 \\
formero S & ap & 29.0 & 1.3 \\
tercelete per. & ap & 25.0 & 6.5
\end{tabular}

Rampante: Las claves de los arcos del perímetro se sitúan, en la dirección del eje x (menor), a 1.6 pies $(0.43 \mathrm{~m}$ ) (valor promedio) por debajo de la clave central; en la dirección del eje y (mayor), a 5.7 pies $(1.58 \mathrm{~m})$ por debajo de la clave central. El rampante se puede considerar llano en la dirección del eje $x$ (menor) y redondo en la del eje y (mayor).

Características constructivas: Los nervios que forman la crucería interior presentan 3 tipos distintos de sección en cuanto a molduraje y canto (grande para la diagonal; mediano para el tercelete; pequeño para la ligadura y el nervio decorativo). - Las jarjas se componen de 10 y 12 hiladas, dependiendo del soporte y del nervio considerado. - Las claves tienen su eje central vertical (y su cara inferior paralela a la superficie de la bóveda en cada punto). - La plementería es probablemente de ladrillo; asienta directamente sobre el trasdós del formero. 

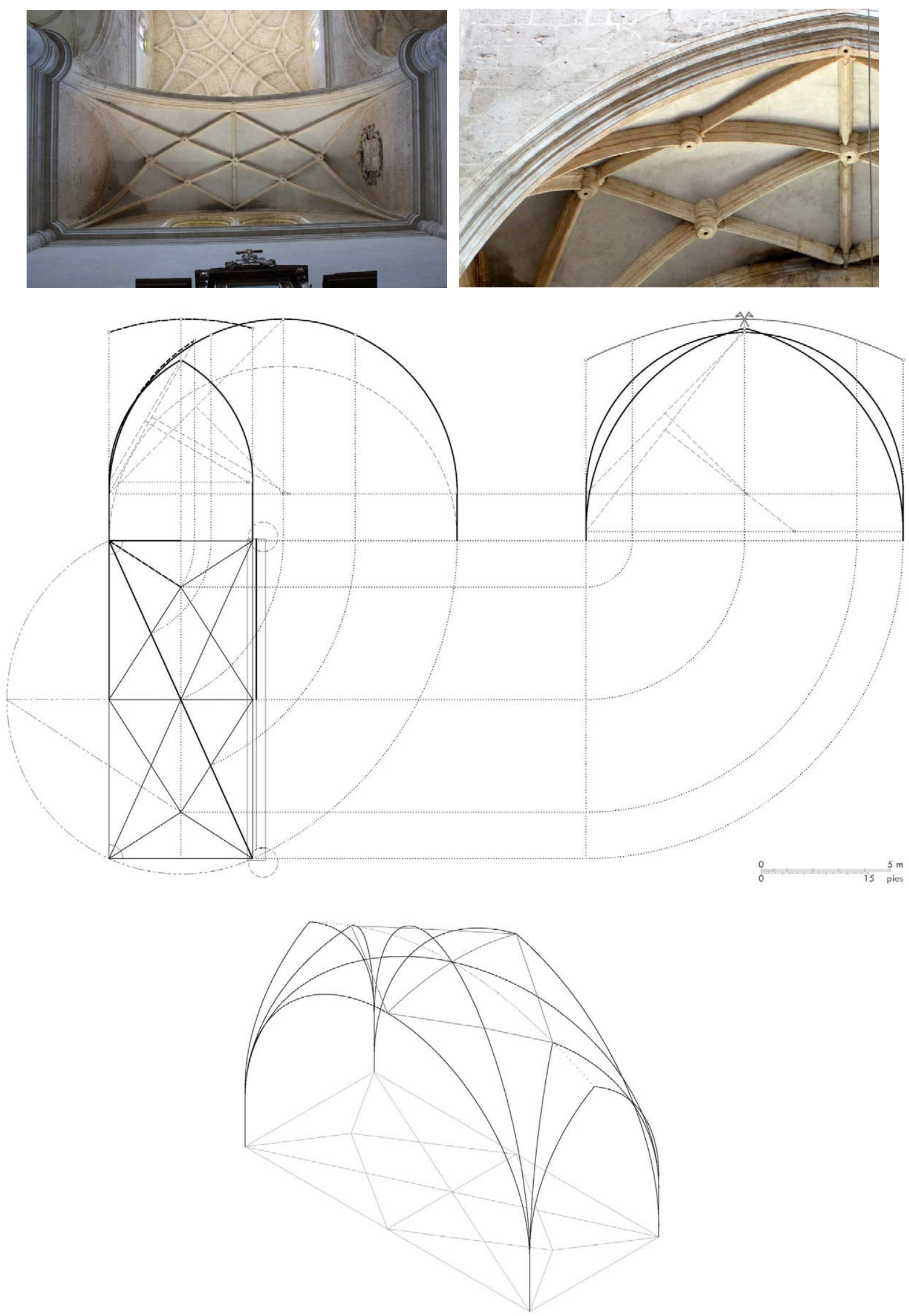

Figura 116 . Iglesia de Santa Ana, Peñaranda de Duero (Burgos): bóveda del crucero (tramo lateral norte): (a) Vista en planta. (b) Detalle de los nervios, claves y plementería. (c) Hipótesis de trazado de los nervios. (d) Modelizado de los nervios (c, d: P. Moreno) 


\subsubsection{Plasencia (Cáceres) - Catedral Nueva de Santa María de la Asunción}

Datos históricos del edificio: véase página 750 y siguientes

Datos de medición de las bóvedas: véase página 885

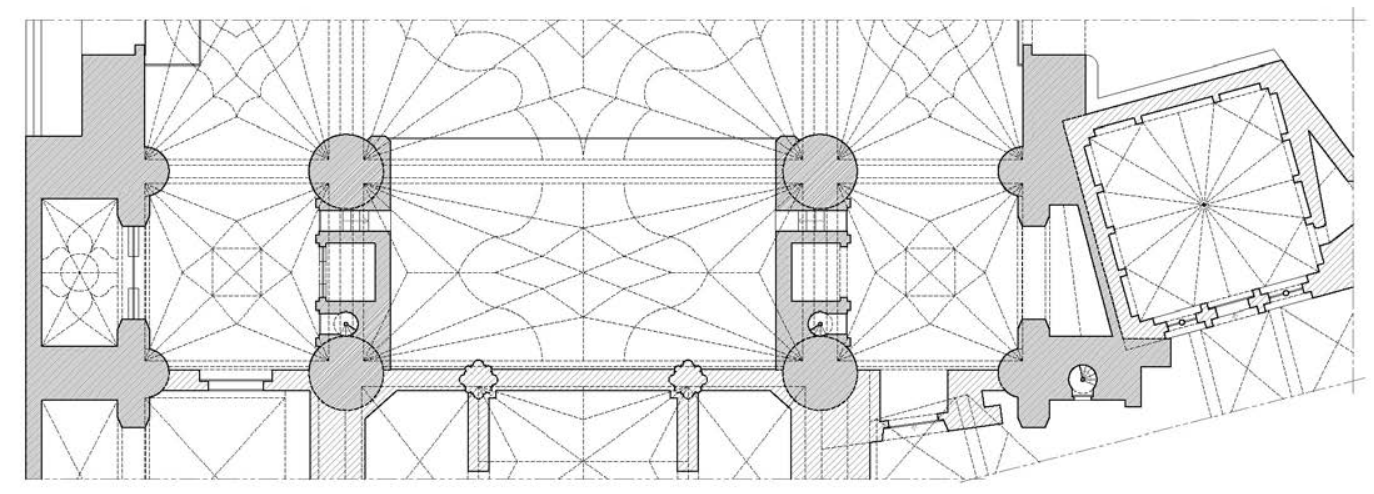

- $\frac{0.2345}{0.1291215}$ ples

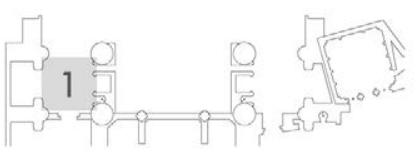

1. Bóveda de la nave lateral (tramo 1 norte) (c.1547-c.1554)

Figura 117. Catedral Nueva de Plasencia (Cáceres): (a) Planta del primer tramo de naves (P. Moreno). (b) Indicación de las bóvedas analizadas, con su fecha de ejecución (P. Moreno) 


\subsubsection{Bóveda de la nave lateral (tramo 1 norte)}

Modulación y rangos dimensionales: La bóveda tiene una planta cuadrada de dimensiones $29.1 \times 29.1$ pies $(8.11 \times 8.11 \mathrm{~m})$ y proporción entre los lados $1.000(1: 1)$, ambas consideradas a ejes de los arcos del perímetro (las interiores son $26.6 \times 25.6$ pies $(7.41 \times 7.13 \mathrm{~m})$ y $1.039(1: 1)$, respectivamente). Los perpiaños tienen un punto de arranque distinto al del resto de los nervios en cada apoyo.

Sistemas de composición: La crucería principal está formada por los dos arcos diagonales y terceletes sencillos en la dirección de ambos ejes. Las nervaduras decorativas forman un rombo de lados quebrados, en cuyo interior se dispone un rectángulo de lados paralelos al perímetro. En conjunto se obtiene un diseño con 9 claves interiores. - Las claves de los terceletes se sitúan en la bisectriz del ángulo formado por la diagonal y los arcos del perímetro. Las claves sobre las diagonales se sitúan cercanas a los puntos de corte con un paralelogramo que une las claves de los terceletes, desplazándose ligeramente para generar el quiebro del rombo.

Arcos: El plano de imposta se sitúa a una altura de 57.3 pies $(15.97 \mathrm{~m}$ ) del suelo, y la clave central a 32.0 pies $(8.92 \mathrm{~m}$ ) de dicho plano. Todos los arcos parten tangentes a la vertical en el arranque, presentando todos peraltes. La clave central se encuentra 13.6 pies $(3.78 \mathrm{~m})$ por encima de la posición que correspondería a la de un arco ojivo semicircular. Un examen visual de la geometría de la diagonal y la comprobación de la posición que ocupan las claves secundarias dispuestas a lo largo de este arco nos hace concluir que su trazado teórico es efectivamente semicircular, partiendo con un peralte de 13.6 pies $(3.78 \mathrm{~m})$ en su arranque. Los arcos se trazarían aparentemente con 1 único radio, siendo sus datos geométricos en pies los siguientes:

\begin{tabular}{lccc} 
nervio & tipo & radio & peralte \\
\hline diagonal & sc & 18.5 & 13.6 \\
perpiaño & ap & 18.3 & 13.6 \\
formero & ap & 18.5 & 13.6 \\
tercelete per. & ap & 18.4 & 13.6 \\
tercelete for. & ap & 18.5 & 13.6
\end{tabular}

Rampante: Las claves de los arcos del perímetro se sitúan, en la dirección de ambos ejes, a 0.9 pies $(0.24 \mathrm{~m})$ por debajo de la clave central. El rampante se puede considerar llano en la dirección de ambos ejes.

Características constructivas: Los nervios que forman la crucería interior presentan 2 tipos distintos de sección en cuanto a molduraje y canto (grande para la diagonal y el tercelete; pequeño para el nervio decorativo). - Las jarjas se componen de 18 hiladas. - Las claves tienen su eje central vertical (y su cara inferior paralela a la superficie de la bóveda en cada punto). - La plementería es de cantería, dispuesta a la francesa; sus hiladas se componen de 1 única pieza; asienta directamente sobre el trasdós del formero. 

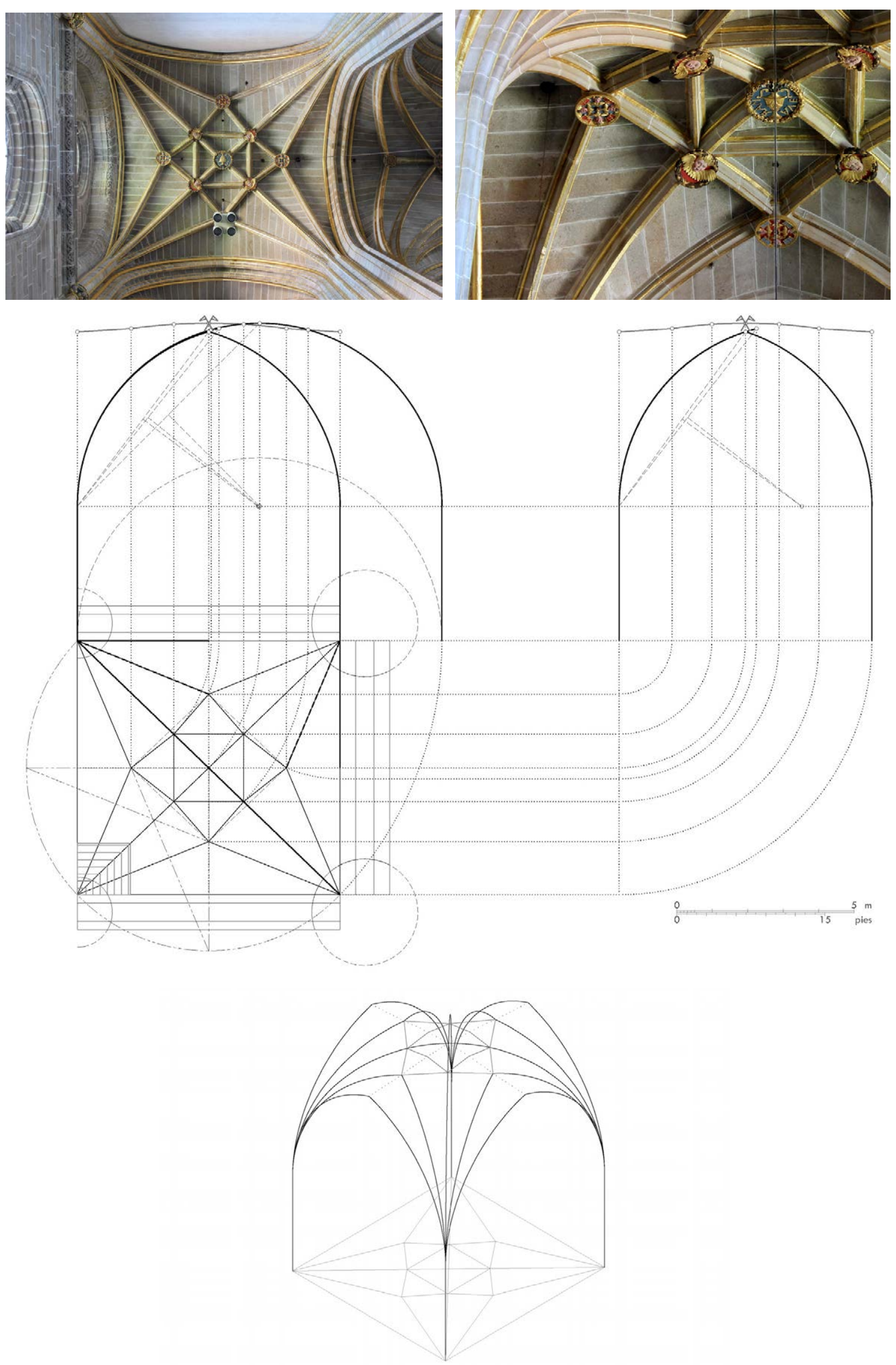

Figura 1 18. Catedral Nueva de Plasencia (Cáceres): bóveda de la nave lateral (tramo 1 norte): (a) Vista en planta. (b) Detalle de los nervios, claves y plementería. (c) Hipótesis de trazado de los nervios. (d) Modelizado de los nervios (c, d: P. Moreno) 


\subsubsection{Salamanca - Capilla del Colegio Mayor del Arzobispo Fonseca, de Santiago el Zebedeo o de los Irlandeses}

Datos históricos del edificio: véase página 760 y siguientes

Datos de medición de las bóvedas: véase página 886 y siguientes

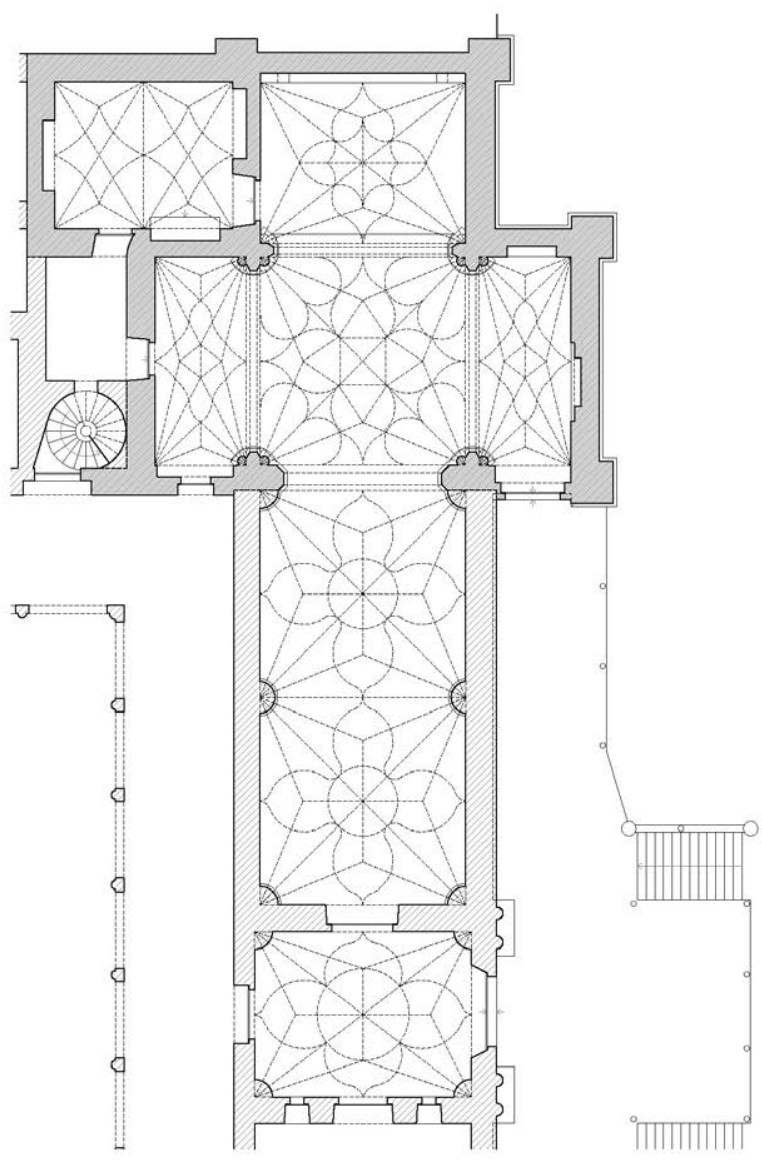

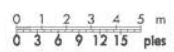

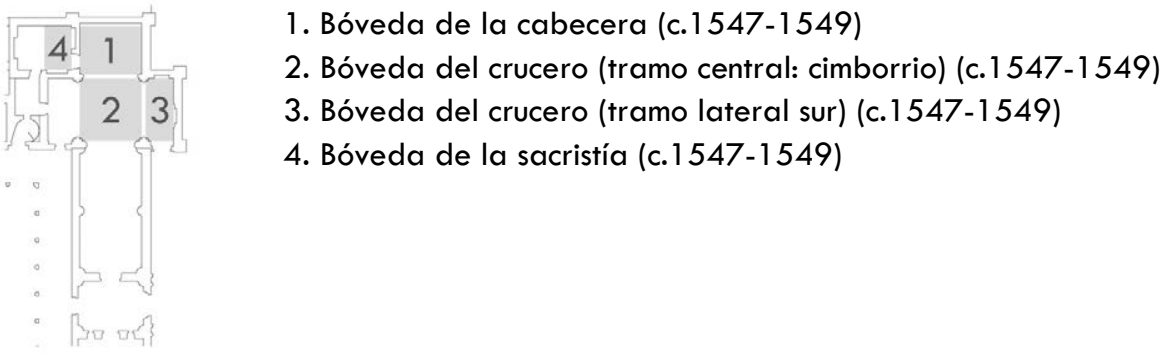

Figura 1 19. Capilla del Colegio Mayor del Arzobispo Fonseca, Salamanca: (a) Planta (P. Moreno). (b) Indicación de las bóvedas analizadas, con su fecha de ejecución (P. Moreno) 


\subsubsection{Bóveda de la cabecera}

Modulación y rangos dimensionales: La bóveda tiene una planta rectangular de dimensiones $29.6 \times 24.2$ pies $(8.25 \times 6.74 \mathrm{~m})$ y proporción entre los lados $1.223(6: 5)$, ambas consideradas a ejes de los arcos del perímetro (las interiores son $29.6 \times 23.2$ pies $(8.25 \times 6.46 \mathrm{~m})$ y $1.276(5: 4)$, respectivamente). Los perpiaños tienen un punto de arranque distinto al del resto de los nervios en cada apoyo.

Sistemas de composición: La crucería principal está formada por los dos arcos diagonales y terceletes sencillos en la dirección de ambos ejes. Las nervaduras decorativas forman un cuadrifolio con dos hojas convexas y dos conopiales, en cuyo interior se dispone una figura de lados cóncavos. En conjunto se obtiene un diseño con 15 claves interiores. - Las claves de los terceletes se sitúan en la bisectriz del ángulo formado por la diagonal y los arcos del perímetro. Las claves secundarias sobre los terceletes se sitúan en los puntos de corte con un paralelogramo que une los extremos del cuadrifolio; las claves sobre la ligadura del eje mayor se sitúan aproximadamente en los puntos medios de los segmentos limitados por las claves de los terceletes y la central; obtenidas estas claves, es posible trazar una circunferencia que tiene por centro el polo de la bóveda y por radio la distancia hasta ellas, generando las claves sobre las diagonales; los centros de las hojas del eje mayor (dos por cada hoja) se disponen en las mediatrices de los segmentos limitados por las claves de los terceletes y la central; los centros principales de las hojas del eje menor (dos por cada hoja) se disponen en puntos cuyo trazado geométrico no hemos logrado determinar, y los de sus remates o pies de gallo fuera del perímetro de la bóveda; obtenidas las claves sobre las diagonales y sobre la ligadura del eje mayor, es posible trazar la figura central, que se compone de ocho arcos.

Arcos: El plano de imposta se sitúa a una altura de 34.2 pies $(9.54 \mathrm{~m}$ ) del suelo, y la clave central a 20.0 pies $(5.58 \mathrm{~m})$ de dicho plano. Todos los arcos parten tangentes a la vertical en el arranque, no presentando ninguno peraltes. La clave central se encuentra 1.2 pies $(0.34 \mathrm{~m})$ por encima de la posición que correspondería a la de un arco ojivo semicircular. Un examen visual de la geometría de la diagonal y la comprobación de la posición que ocupan las claves secundarias dispuestas a lo largo de este arco nos hace concluir que su trazado teórico es apuntado, partiendo sin peralte en su arranque. Los arcos se trazarían aparentemente con 2 radios distintos, siendo sus datos geométricos en pies los siguientes:

\begin{tabular}{|c|c|c|}
\hline nervio & tipo & radio \\
\hline diagonal & ap & 20.1 \\
\hline perpiaño & ap & 20.9 \\
\hline formero & ap & 18.4 \\
\hline tercelete per. & ap & 20.6 \\
\hline tercelete for. & ap & 20.2 \\
\hline
\end{tabular}

Rampante: Las claves de los arcos del perímetro se sitúan, en la dirección del eje x (mayor), a 2.9 pies $(0.81 \mathrm{~m}$ ) por debajo de la clave central; en la dirección del eje y (menor), a la misma altura que la clave central. El rampante se puede considerar llano en la dirección del eje $x$ (mayor) y horizontal en la del eje y (menor).

Características constructivas: Los nervios que forman la crucería interior presentan 2 tipos distintos de sección en cuanto a molduraje y canto (grande para la diagonal y el tercelete; pequeño para la ligadura y el nervio decorativo). - Las jarjas se componen de 5 y 6 hiladas, dependiendo del soporte considerado. - Las claves tienen su eje central vertical (y su cara inferior paralela a la superficie de la bóveda en cada punto); las que corresponden a las intersecciones de la figura de lados cóncavos central con la ligadura situada sobre el eje mayor tienen su eje central inclinado. • La plementería es de cantería, dispuesta a la francesa; sus hiladas se componen de entre 1 y 2 piezas; queda ligeramente separada del trasdós del formero. 

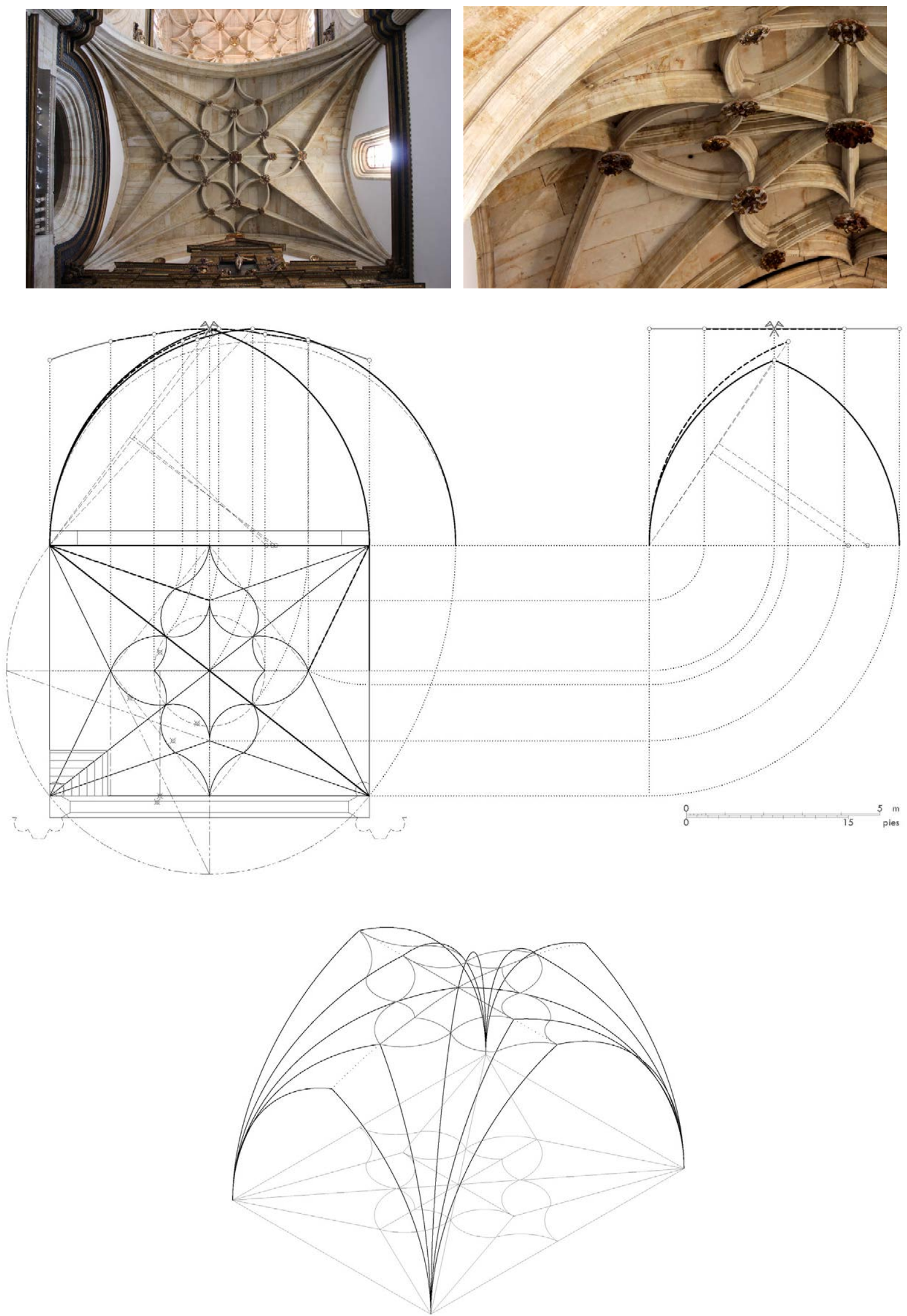

Figura 120. Capilla del Colegio Mayor del Arzobispo Fonseca, Salamanca: bóveda de la cabecera: (a) Vista en planta. (b) Detalle de los nervios, claves y plementería. (c) Hipótesis de trazado de los nervios. (d) Modelizado de los nervios (c, d: P. Moreno) 


\subsubsection{Bóveda del crucero (tramo central: cimborrio)}

Modulación y rangos dimensionales: La bóveda tiene una planta aproximadamente cuadrada de dimensiones $31.6 \times 32.8$ pies $(8.81 \times 9.15 \mathrm{~m})$ y proporción entre los lados $1.038(1: 1)$, ambas consideradas a ejes de los arcos del perímetro (las interiores son $29.6 \times 30.0$ pies $(8.25 \times 8.37 \mathrm{~m})$ y $1.014(1: 1)$, respectivamente). Todos los nervios tienen un punto de arranque común en cada apoyo.

Sistemas de composición: La crucería principal está formada por los dos arcos diagonales y terceletes sencillos en la dirección de ambos ejes. Las nervaduras decorativas forman un cuadrifolio de hojas conopiales, en cuyo interior se dispone un rombo de lados quebrados y un rectángulo de lados paralelos al perímetro, y en cuyo exterior se dispone una serie de figuras de lados cóncavos y tangentes al cuadrifolio. En conjunto se obtiene un diseño con 29 claves interiores. $\cdot$ Las claves de los terceletes se sitúan en la bisectriz del ángulo formado por la diagonal y los arcos del perímetro. Las claves interiores sobre las diagonales se sitúan en los puntos de corte con un arco que tiene por centro el vértice de la bóveda y por radio la distancia hasta las claves de los terceletes; las claves secundarias sobre los terceletes se sitúan aproximadamente alineadas con las anteriores; la proyección de dichas claves sobre los lados de la bóveda genera dos puntos que, unidos en diagonal, permiten obtener sobre los terceletes aproximadamente los centros de las figuras exteriores; estos centros quedan alineados con los centros principales del cuadrifolio (uno por cada hoja) y con las ocho claves secundarias del perímetro de la bóveda; las claves exteriores sobre las diagonales quedan alineadas con las de los terceletes; los centros de los remates o pies de gallo se disponen sobre el perímetro de la bóveda; obtenidas las claves interiores sobre las diagonales, es posible trazar el rombo; los vértices del rectángulo central se desplazan ligeramente, situándose en los puntos de corte con una circunferencia que tiene por centro el polo de la bóveda y por radio el mismo que las hojas del cuadrifolio; las claves secundarias sobre los terceletes no resultan alineadas sobre un paralelogramo que une los extremos del cuadrifolio.

Arcos: El plano de imposta se sitúa a una altura de 61.3 pies $(17.09 \mathrm{~m})$ del suelo, y la clave central a 21.9 pies $(6.11 \mathrm{~m}$ ) de dicho plano. Todos los arcos parten tangentes a la vertical en el arranque, presentando todos peraltes. La clave central se encuentra 0.8 pies $(0.24 \mathrm{~m})$ por encima de la posición que correspondería a la de un arco ojivo semicircular. Un examen visual de la geometría de la diagonal y la comprobación de la posición que ocupan las claves secundarias dispuestas a lo largo de este arco nos hace concluir que su trazado teórico es efectivamente semicircular, partiendo con un peralte de 0.8 pies $(0.24 \mathrm{~m})$ en su arranque. Los arcos se trazarían aparentemente con 2 radios distintos, siendo sus datos geométricos en pies los siguientes:

\begin{tabular}{lccc} 
nervio & tipo & radio & peralte \\
\hline diagonal & sc & 21.1 & 0.8 \\
perpiaño & ap & 19.6 & 0.8 \\
formero & ap & 19.6 & 0.8 \\
tercelete per. & ap & 20.9 & 0.8 \\
tercelete for. & ap & 20.9 & 0.8
\end{tabular}

Rampante: Las claves de los arcos del perímetro se sitúan, en la dirección de ambos ejes, a 2.0 pies $(0.57 \mathrm{~m})$ por debajo de la clave central. El rampante se puede considerar llano en la dirección de ambos ejes.

Características constructivas: Los nervios que forman la crucería interior presentan 2 tipos distintos de sección en cuanto a molduraje y canto (grande para la diagonal y el tercelete; pequeño para el nervio decorativo). - Las jarjas se componen de 8 hiladas. - Las claves tienen su eje central vertical (y su cara inferior paralela a la superficie de la bóveda en cada punto); las que corresponden al rombo de lados quebrados y al rectángulo central no están provistas de un cilindro central, sino que se resuelven como un cruce de nervios. - La plementería es de cantería, dispuesta a la francesa; sus hiladas se componen de entre 1 y 2 piezas; queda ligeramente separada del trasdós del formero. 

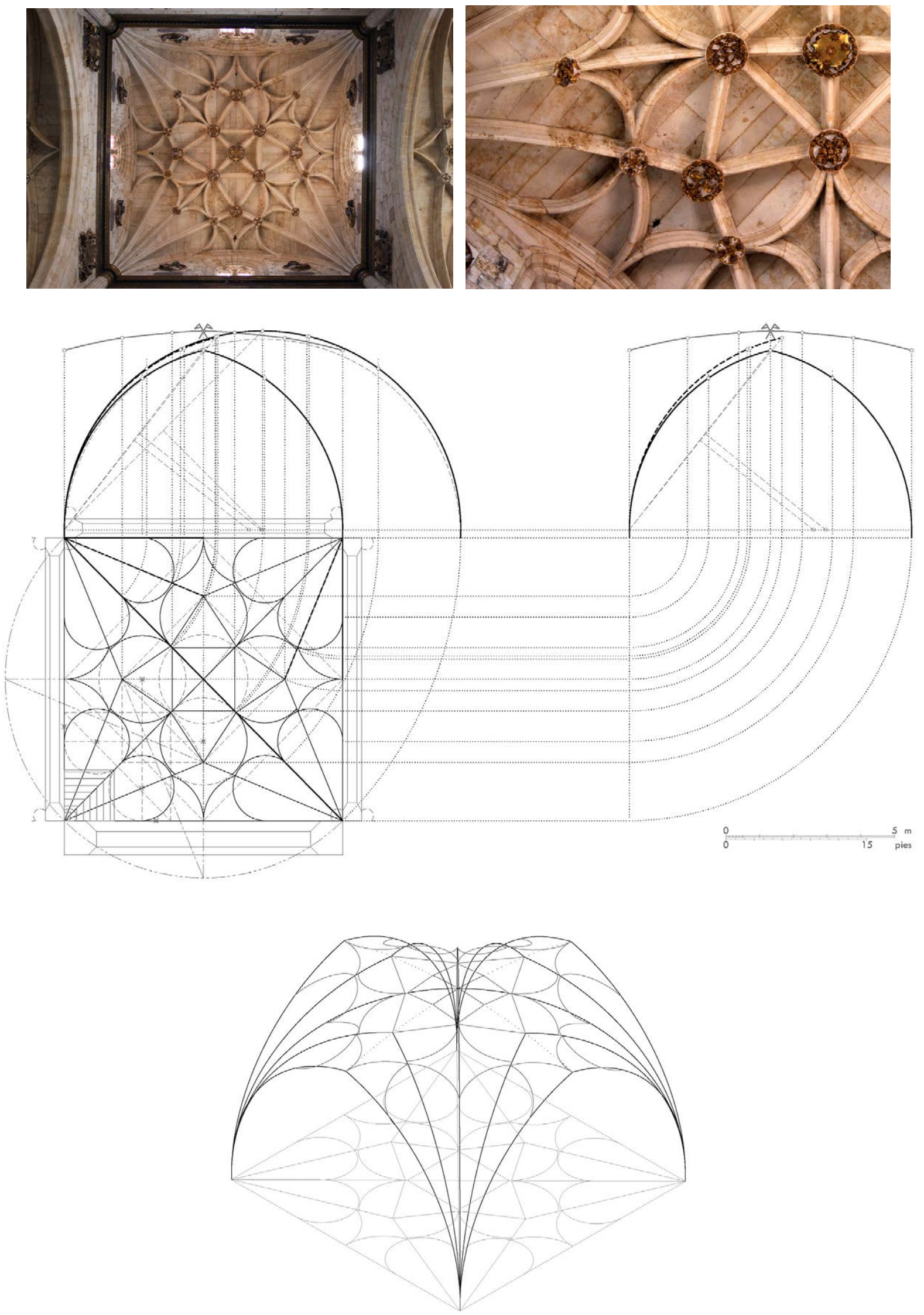

Figura 121. Capilla del Colegio Mayor del Arzobispo Fonseca, Salamanca: bóveda del crucero (tramo central: cimborrio): (a) Vista en planta. (b) Detalle de los nervios, claves y plementería. (c) Hipótesis de trazado de los nervios. (d) Modelizado de los nervios (c, d: P. Moreno) 


\subsubsection{Bóveda del crucero (tramo lateral sur)}

Modulación y rangos dimensionales: La bóveda tiene una planta rectangular de dimensiones $14.2 \times 30.2$ pies $(3.97 \times 8.41 \mathrm{~m})$ y proporción entre los lados $2.127(>2: 1)$, ambas consideradas a ejes de los arcos del perímetro (las interiores son $13.2 \times 30.2$ pies $(3.69 \times 8.41 \mathrm{~m})$ y $2.288(>2: 1)$, respectivamente). Los perpiaños tienen un punto de arranque distinto al del resto de los nervios en cada apoyo.

Sistemas de composición: La crucería principal está formada por terceletes triples en la dirección del eje mayor y sencillos en la dirección del eje menor, careciendo de arcos diagonales. Las nervaduras decorativas forman una figura de lados cóncavos y convexos, en cuyo interior se dispone un rombo de lados rectos. En conjunto se obtiene un diseño con 16 claves interiores. $•$ Las claves de los terceletes se sitúan en puntos cuyo trazado geométrico no hemos logrado determinar. El rombo central es generado automáticamente; las claves secundarias sobre los terceletes se sitúan en puntos cuyo trazado geométrico no hemos logrado determinar; la figura se compone de doce arcos.

Arcos: El plano de imposta se sitúa a una altura de 34.2 pies $(9.54 \mathrm{~m}$ ) del suelo, y la clave central a 20.3 pies $(5.65 \mathrm{~m})$ de dicho plano. Todos los arcos parten tangentes a la vertical en el arranque, presentando todos peraltes. La clave central se encuentra 3.8 pies $(1.06 \mathrm{~m})$ por encima de la posición que correspondería a la de un arco ojivo semicircular. Los arcos se trazarían aparentemente con 2 radios distintos, siendo sus datos geométricos en pies los siguientes:

\begin{tabular}{lccc} 
nervio & tipo & radio & peralte \\
\hline perpiaño & ap & 14.1 & 5.5 \\
formero & ap & 16.2 & 4.1 \\
tercelete per. 1 & ap & 14.4 & 5.5 \\
tercelete per. 2 & ap & 14.0 & 5.5 \\
tercelete per. 3 & ap & 16.2 & 4.1 \\
tercelete for. & ap & 16.2 & 4.1
\end{tabular}

Rampante: Las claves de los arcos del perímetro se sitúan, en la dirección del eje $\mathrm{x}$ (menor), a la misma altura que la clave central; en la dirección del eje y (mayor), a 2.8 pies (0.78 m) por debajo de la clave central. El rampante se puede considerar horizontal en la dirección del eje $x$ (menor) y llano en la del eje y (mayor).

Características constructivas: Los nervios que forman la crucería interior presentan 2 tipos distintos de sección en cuanto a molduraje y canto (grande para el tercelete, la ligadura y el nervio decorativo recto; pequeño para el nervio decorativo curvo). - Las jarjas se componen de 8 y 9 hiladas, dependiendo del soporte y del nervio considerado. - Las claves tienen su eje central vertical (y su cara inferior paralela a la superficie de la bóveda en cada punto). - La plementería es de cantería, dispuesta a la francesa; sus hiladas se componen de 1 única pieza; queda ligeramente separada del trasdós del formero. 

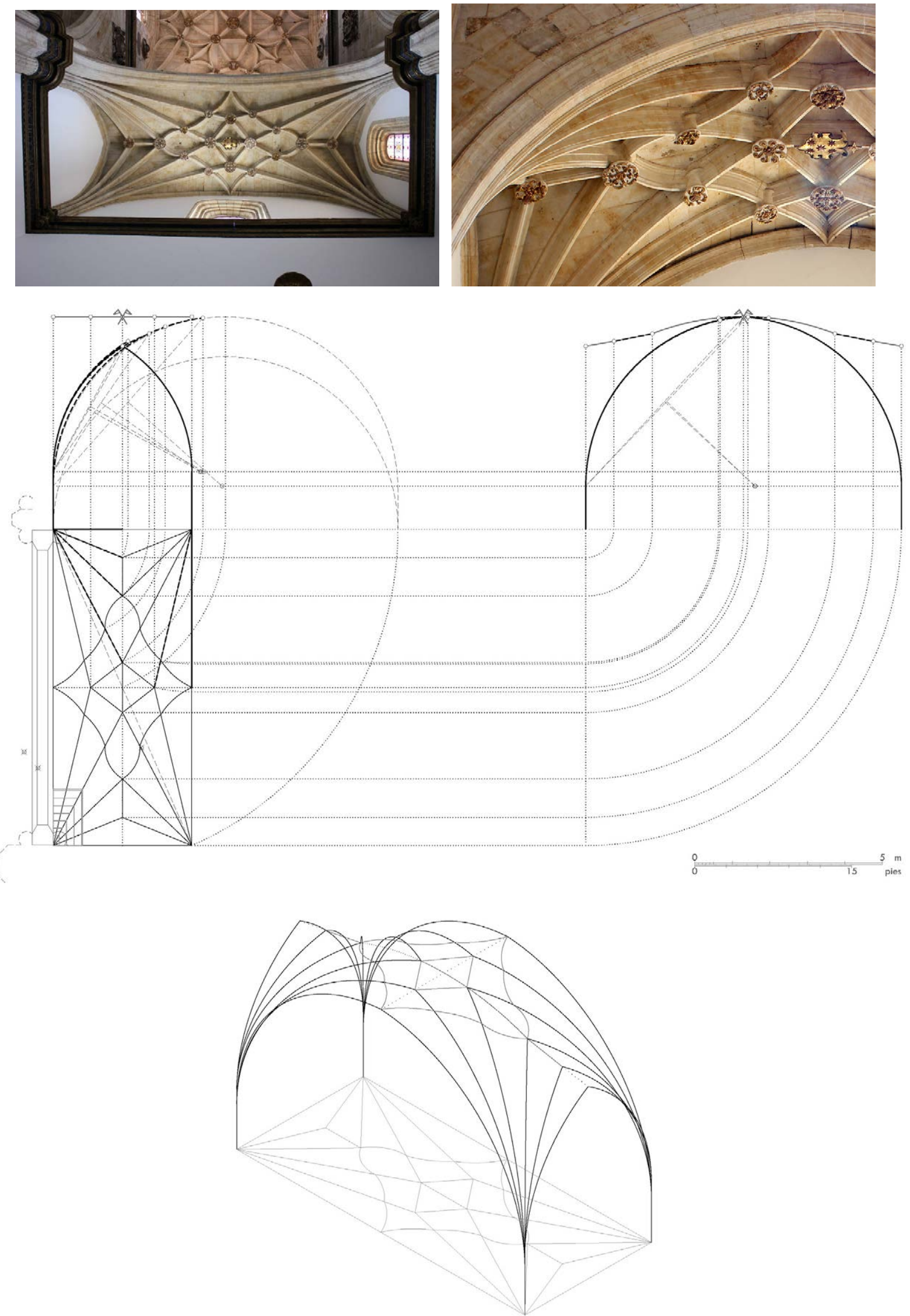

Figura 122. Capilla del Colegio Mayor del Arzobispo Fonseca, Salamanca: bóveda del crucero (tramo lateral sur): (a) Vista en planta. (b) Detalle de los nervios, claves y plementería. (c) Hipótesis de trazado de los nervios. (d) Modelizado de los nervios (c, d: P. Moreno) 


\subsubsection{Bóveda de la sacristía}

Modulación y rangos dimensionales: La bóveda tiene una planta rectangular de dimensiones $12.9 \times 21.2$ pies $(3.59 \times 5.92 \mathrm{~m})$ y proporción entre los lados 1.643 (phi), ambas consideradas a ejes de los arcos del perímetro (coinciden con las interiores). Todos los nervios tienen un punto de arranque común en cada apoyo.

Sistemas de composición: La crucería principal está formada por los dos arcos diagonales y terceletes sencillos en la dirección del eje mayor. Las nervaduras decorativas forman una figura de lados cóncavos. En conjunto se obtiene un diseño con 7 claves interiores. - Las claves de los terceletes se sitúan en la bisectriz del ángulo formado por la diagonal y los arcos del perímetro. Las claves sobre las diagonales se sitúan en puntos cuyo trazado geométrico no hemos logrado determinar; la figura se compone de cuatro arcos.

Arcos: El plano de imposta se sitúa a una altura de 15.3 pies $(4.25 \mathrm{~m})$ del suelo, y la clave central a 12.3 pies $(3.44 \mathrm{~m}$ ) de dicho plano. Todos los arcos parten tangentes a la vertical en el arranque, no presentando ninguno peraltes. La clave central se encuentra 0.1 pies $(0.02 \mathrm{~m})$ por debajo de la posición que correspondería a la de un arco ojivo semicircular. Un examen visual de la geometría de la diagonal y la comprobación de la posición que ocupan las claves secundarias dispuestas a lo largo de este arco nos hace concluir que su trazado teórico es efectivamente semicircular, partiendo sin peralte en su arranque. Los arcos se trazarían aparentemente con 2 radios distintos, siendo sus datos geométricos en pies los siguientes:

\begin{tabular}{lccc} 
nervio & tipo & radio & peralte \\
\hline diagonal & sc & 12.4 & \\
perpiaño & ap & 11.3 & \\
formero & ap & 12.5 & \\
tercelete per. & ap & 12.1
\end{tabular}

Rampante: Las claves de los arcos del perímetro se sitúan, en la dirección del eje x (menor), a la misma altura que la clave central; en la dirección del eje y (mayor), a 2.2 pies (0.60 m) por debajo de la clave central. El rampante se puede considerar horizontal en la dirección del eje $x$ (menor) y llano en la del eje y (mayor).

Características constructivas: Los nervios que forman la crucería interior presentan 2 tipos distintos de sección en cuanto a molduraje y canto (grande para la diagonal y el tercelete; pequeño para el nervio decorativo). - Las jarjas se componen de 4 y 5 hiladas, dependiendo del soporte y del nervio considerado. - Las claves tienen su eje central vertical (y su cara inferior horizontal). • La plementería es de cantería, dispuesta a la francesa; sus hiladas se componen de entre 1 y 2 piezas; queda ligeramente separada del trasdós del formero. 

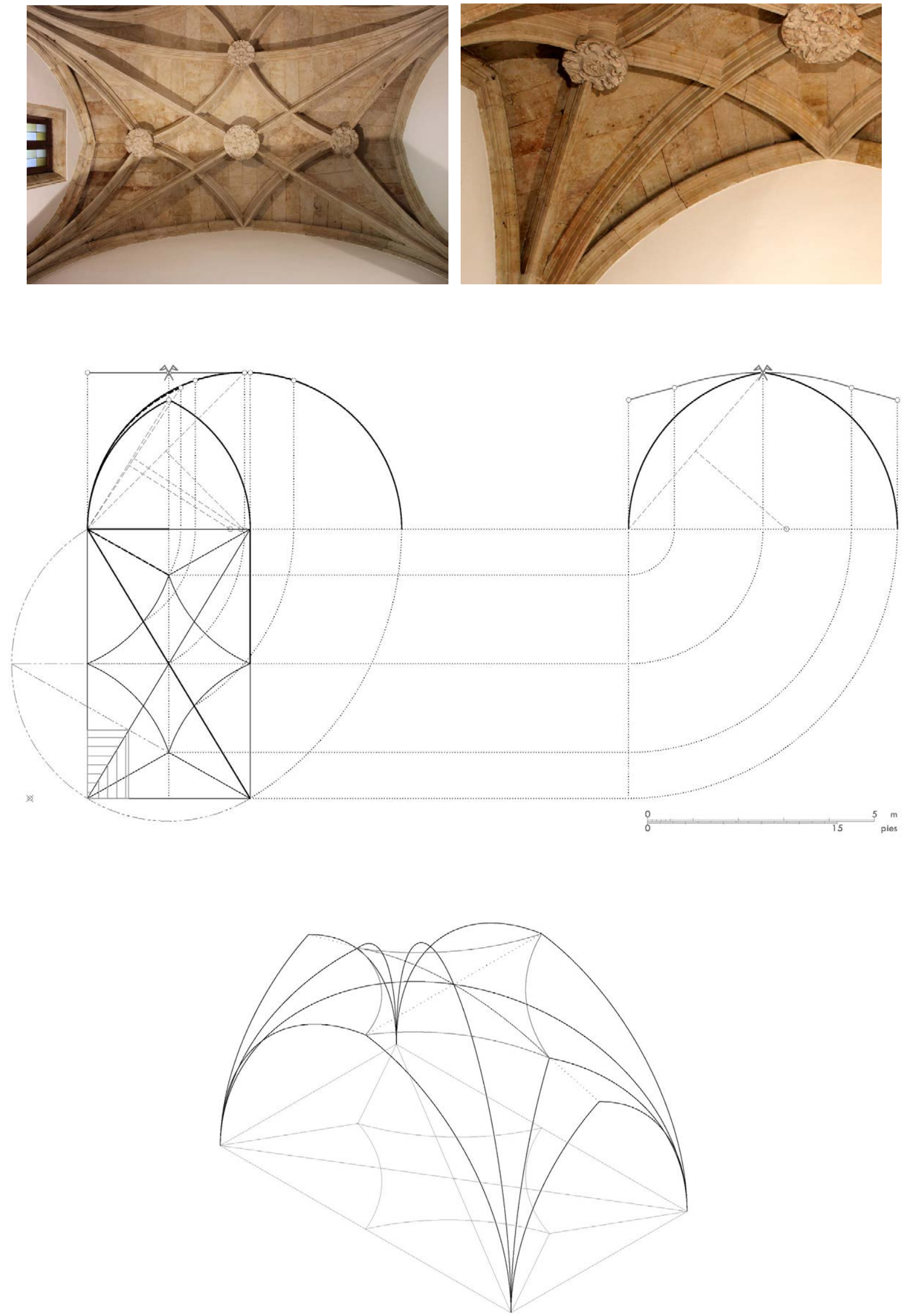

Figura 123. Capilla del Colegio Mayor del Arzobispo Fonseca, Salamanca: bóveda de la sacristía: (a) Vista en planta. (b) Detalle de los nervios, claves y plementería. (c) Hipótesis de trazado de los nervios. (d) Modelizado de los nervios (c, d: P. Moreno) 


\subsubsection{Salamanca - Catedral Nueva de la Asunción de la Virgen}

Datos históricos del edificio: véase página 746 y siguientes

Datos de medición de las bóvedas: véase página 890 y siguientes
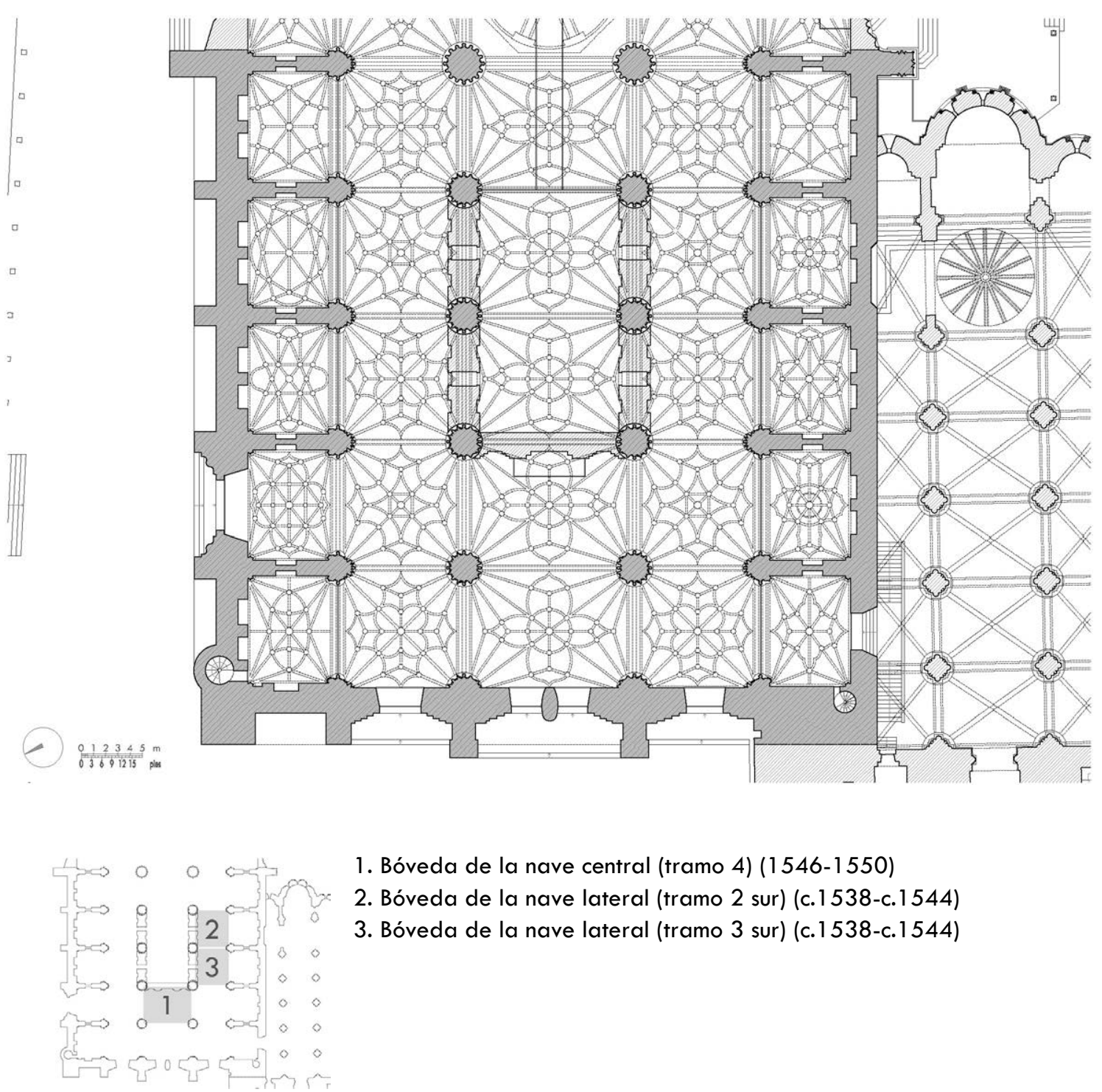

1. Bóveda de la nave central (tramo 4) (1546-1550)

2. Bóveda de la nave lateral (tramo 2 sur) (c.1538-c.1544)

3. Bóveda de la nave lateral (tramo 3 sur) (c.1538-c.1544)

Figura 124. Catedral Nueva de Salamanca: (a) Planta del cuerpo de naves (Berriochoa 1996). (b) Indicación de las bóvedas analizadas, con su fecha de ejecución (P. Moreno) 


\subsubsection{Bóveda de la nave central (tramo 4)}

Modulación y rangos dimensionales: La bóveda tiene una planta rectangular de dimensiones $50.1 \times 37.3$ pies $(13.97 \times 10.40 \mathrm{~m})$ y proporción entre los lados $1.343(4: 3)$, ambas consideradas a ejes de los arcos del perímetro (las interiores son $46.1 \times 35.9$ pies (12.85x10.02 m) y $1.284(5: 4)$, respectivamente). Los perpiaños tienen un punto de arranque distinto al del resto de los nervios en cada apoyo.

Sistemas de composición: La crucería principal está formada por los dos arcos diagonales, terceletes dobles en la dirección del eje mayor y sencillos en la dirección del eje menor. Las nervaduras decorativas forman un cuadrifolio de hojas conopiales, en cuyo interior se dispone un círculo. En conjunto se obtiene un diseño con 23 claves interiores. - Las claves de los terceletes se sitúan, sobre el eje mayor, en los puntos que resultan de dividir dicho eje en ocho partes iguales (a $1 / 8$ y $2 / 8$ del perímetro); sobre el eje menor, en la bisectriz del ángulo formado por la diagonal y los arcos del perímetro. Las claves sobre la ligadura del eje mayor se sitúan en los puntos medios de los segmentos limitados por las claves de los terceletes interiores y la central (a 1/8 del centro); obtenidas estas claves, es posible trazar el círculo central, generando las claves sobre las diagonales y sobre la ligadura del eje menor; las claves secundarias sobre los terceletes interiores del eje mayor se sitúan alineadas con las de las diagonales; los centros principales de las hojas del cuadrifolio (dos por cada hoja en el eje mayor y uno en el menor) se disponen aproximadamente en las mediatrices de los segmentos limitados por sus extremos y la clave central; las claves secundarias sobre los terceletes resultan aproximadamente alineadas sobre un paralelogramo que une dichos extremos.

Arcos: El plano de imposta se sitúa a una altura de 99.3 pies $(27.66 \mathrm{~m})$ del suelo, y la clave central a 28.8 pies $(8.02 \mathrm{~m})$ de dicho plano. Todos los arcos parten tangentes a la vertical en el arranque, presentando algunos peraltes, aunque no la diagonal. La clave central se encuentra 0.5 pies $(0.13 \mathrm{~m})$ por debajo de la posición que correspondería a la de un arco ojivo semicircular. Un examen visual de la geometría de la diagonal y la comprobación de la posición que ocupan las claves secundarias dispuestas a lo largo de este arco nos hace concluir que su trazado teórico es efectivamente semicircular, partiendo sin peralte en su arranque. Los arcos se trazarían aparentemente con 2 radios distintos, siendo sus datos geométricos en pies los siguientes:

\begin{tabular}{lccc} 
nervio & tipo & radio & peralte \\
\hline diagonal & sc & 29.2 & \\
perpiaño & ap & 29.5 & \\
formero & ap & 23.0 & 4.5 \\
tercelete per. & ap & 29.2 & \\
tercelete for. 1 & ap & 29.7 & \\
tercelete for. 2 & ap & 29.6 &
\end{tabular}

Rampante: Las claves de los arcos del perímetro se sitúan, en la dirección del eje x (mayor), a 1.9 pies $(0.52 \mathrm{~m}$ ) por debajo de la clave central; en la dirección del eje y (menor), a la misma altura que la clave central. El rampante se puede considerar llano en la dirección del eje $x$ (mayor) y horizontal en la del eje y (menor).

Características constructivas: Los nervios que forman la crucería interior presentan 2 tipos distintos de sección en cuanto a molduraje y canto (grande para la diagonal y el tercelete; pequeño para la ligadura y el nervio decorativo). - Las jarjas se componen de 8 y 9 hiladas, dependiendo del soporte y del nervio considerado. - Las claves tienen su eje central vertical (y su cara inferior paralela a la superficie de la bóveda en cada punto); las que corresponden a las intersecciones del círculo central con la ligadura situada sobre el eje mayor no están provistas de un cilindro central, sino que se resuelven como un cruce de nervios. - La plementería es de cantería, dispuesta a la francesa; sus hiladas se componen de entre 1 y 3 piezas; queda ligeramente separada del trasdós del formero 445 .

445 Otro análisis de esta bóveda aparece en Palacios 2006: 2416-2418 y Palacios 2009: 122-125. Según este autor, el tercelete del eje menor se situaría en el punto medio del semieje; la diagonal, el perpiaño y el tercelete del eje menor tendrían un mismo radio, mientras que el formero y los terceletes del eje mayor tendrían otro distinto. 

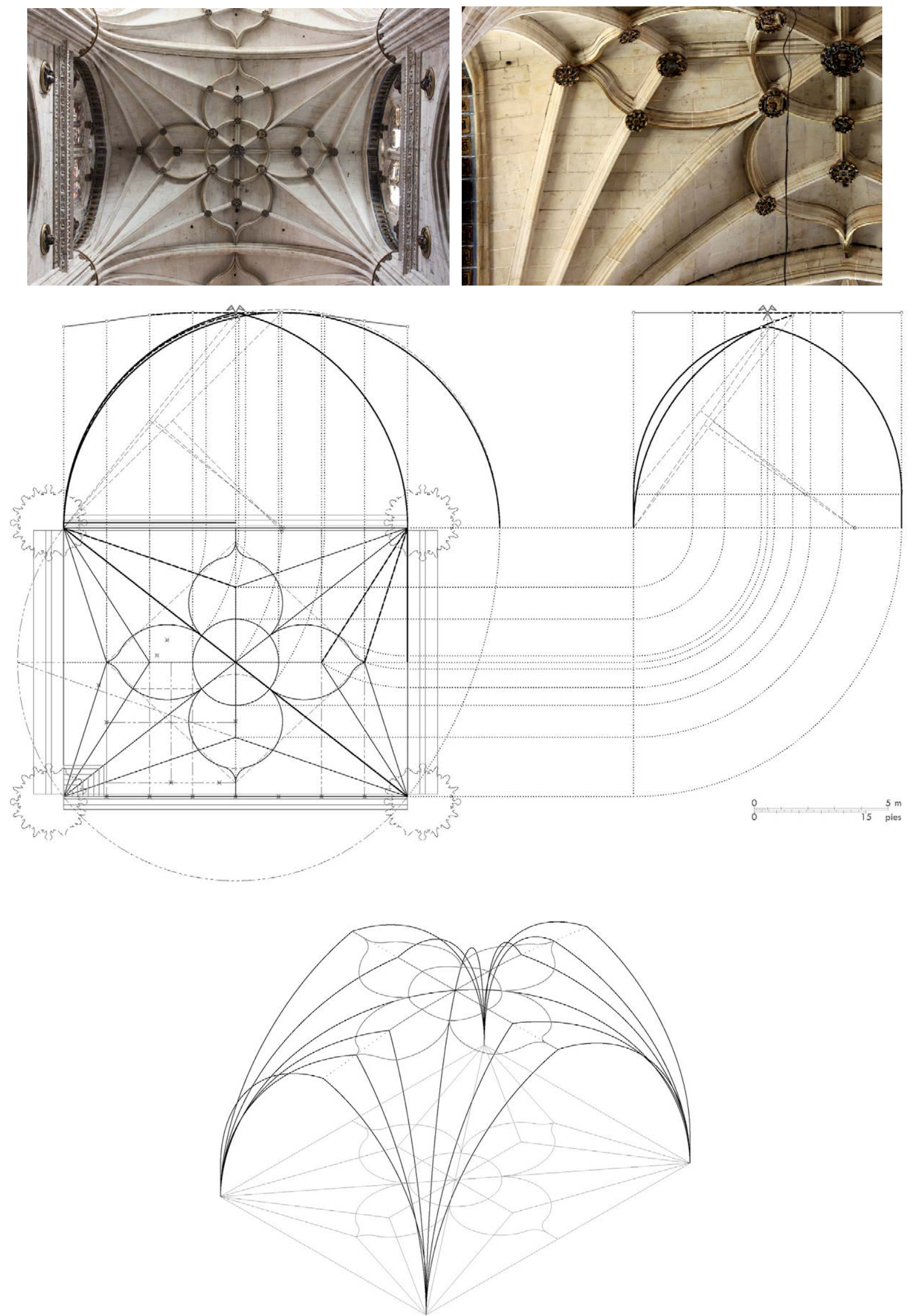

Figura 125. Catedral Nueva de Salamanca: bóveda de la nave central (tramo 4): (a) Vista en planta. (b) Detalle de los nervios, claves y plementería. (c) Hipótesis de trazado de los nervios. (d) Modelizado de los nervios (c, d: P. Moreno) 


\subsubsection{Bóveda de la nave lateral (tramo 2 sur)}

Modulación y rangos dimensionales: La bóveda tiene una planta aproximadamente cuadrada de dimensiones $35.5 \times 37.3$ pies $(9.88 \times 10.40 \mathrm{~m})$ y proporción entre los lados 1.051 (1:1), ambas consideradas a ejes de los arcos del perímetro (las interiores son $33.5 \times 35.3$ pies $(9.32 \times 9.84 \mathrm{~m})$ y $1.054(1: 1)$, respectivamente). Los perpiaños tienen un punto de arranque distinto al del resto de los nervios en cada apoyo 446 .

Sistemas de composición: La crucería principal está formada por los dos arcos diagonales y terceletes sencillos en la dirección de ambos ejes. Las nervaduras decorativas forman un cuadrifolio de hojas cóncavas, en cuyo interior se dispone una figura de lados cóncavos y paralelos al anterior y un rectángulo de lados paralelos al perímetro. En conjunto se obtiene un diseño con 21 claves interiores. - Las claves de los terceletes se sitúan en la bisectriz del ángulo formado por la diagonal y los arcos del perímetro. Las claves secundarias sobre los terceletes quedan aproximadamente alineadas sobre un paralelogramo que une los extremos del cuadrifolio; las claves sobre las diagonales se sitúan en los puntos de corte con dos circunferencias que tienen por centro el polo de la bóveda y por radios la distancia hasta las claves de los terceletes del eje menor y la mitad de dicha distancia; los centros principales del cuadrifolio, que coinciden con los de la figura interior, se disponen aproximadamente sobre la diagonal, alineados con las claves sobre los terceletes de los remates o pies de gallo, y los centros de estos últimos se sitúan sobre el perímetro de la bóveda; obtenidas las claves sobre las diagonales, es posible trazar el rectángulo central.

Arcos: El plano de imposta se sitúa a una altura de 63.4 pies $(17.65 \mathrm{~m})$ del suelo, y la clave central a 22.6 pies $(6.31 \mathrm{~m})$ de dicho plano. Todos los arcos parten tangentes a la vertical en el arranque, no presentando ninguno peraltes. La clave central se encuentra 1.7 pies $(0.47 \mathrm{~m})$ por debajo de la posición que correspondería a la de un arco ojivo semicircular. Un examen visual de la geometría de la diagonal y la comprobación de la posición que ocupan las claves secundarias dispuestas a lo largo de este arco nos hace concluir que su trazado teórico es carpanel, partiendo sin peralte en su arranque. Los arcos se trazarían aparentemente con 2 radios distintos, siendo sus datos geométricos en pies los siguientes:

\begin{tabular}{|c|c|c|}
\hline nervio & tipo & radio \\
\hline diagonal & car & $22.3 \cdot 22.1$ \\
\hline perpiaño & ap & 20.4 \\
\hline formero $\mathrm{N}$ & ap & 21.2 \\
\hline formero S & ap & 21.5 \\
\hline tercelete per. & ap & 22.2 \\
\hline tercelete for. & ap & 22.3 \\
\hline
\end{tabular}

Rampante: Las claves de los arcos del perímetro se sitúan, en la dirección del eje x, a 1.6 pies $(0.45$ m) (valor promedio) por debajo de la clave central; en la dirección del eje y, a 2.6 pies (0.73 m) por debajo de la clave central. El rampante se puede considerar llano en la dirección de ambos ejes.

Características constructivas: Los nervios que forman la crucería interior presentan 2 tipos distintos de sección en cuanto a molduraje y canto (grande para la diagonal y el tercelete; pequeño para el nervio decorativo). - Las jarjas se componen de 6, 10 y 11 hiladas, dependiendo del soporte y del nervio considerado. - Las claves tienen su eje central vertical (y su cara inferior paralela a la superficie de la bóveda en cada punto). - La plementería es de cantería, dispuesta a la francesa; sus hiladas se componen de entre 1 y 2 piezas; queda ligeramente separada del trasdós del formero 447 .

\footnotetext{
446 Como analizamos en otro apartado de este estudio, el trazado de las naves laterales de la Catedral Nueva de Salamanca parece haberse realizado tomando como referencia, junto a los ejes de los pilares centrales, el eje del muro de cierre de las naves laterales, en lugar del contorno interior de dicho muro, en cuyo caso las dimensiones y proporción serían $37.1 \times 37.3$ pies $(10.34 \times 10.40 \mathrm{~m})$ y $1.005(1: 1)$ respectivamente. Sin embargo, hemos mantenido los datos referidos al contorno interior para no modificar el criterio general utilizado en el análisis de todas las bóvedas.

447 Otro análisis de esta bóveda aparece en Palacios 2009: 167-168. Según este autor, el trazado de las claves secundarias partiría de dividir en cuatro partes iguales la distancia entre las claves de los terceletes del eje mayor; la diagonal sería semicircular.
} 

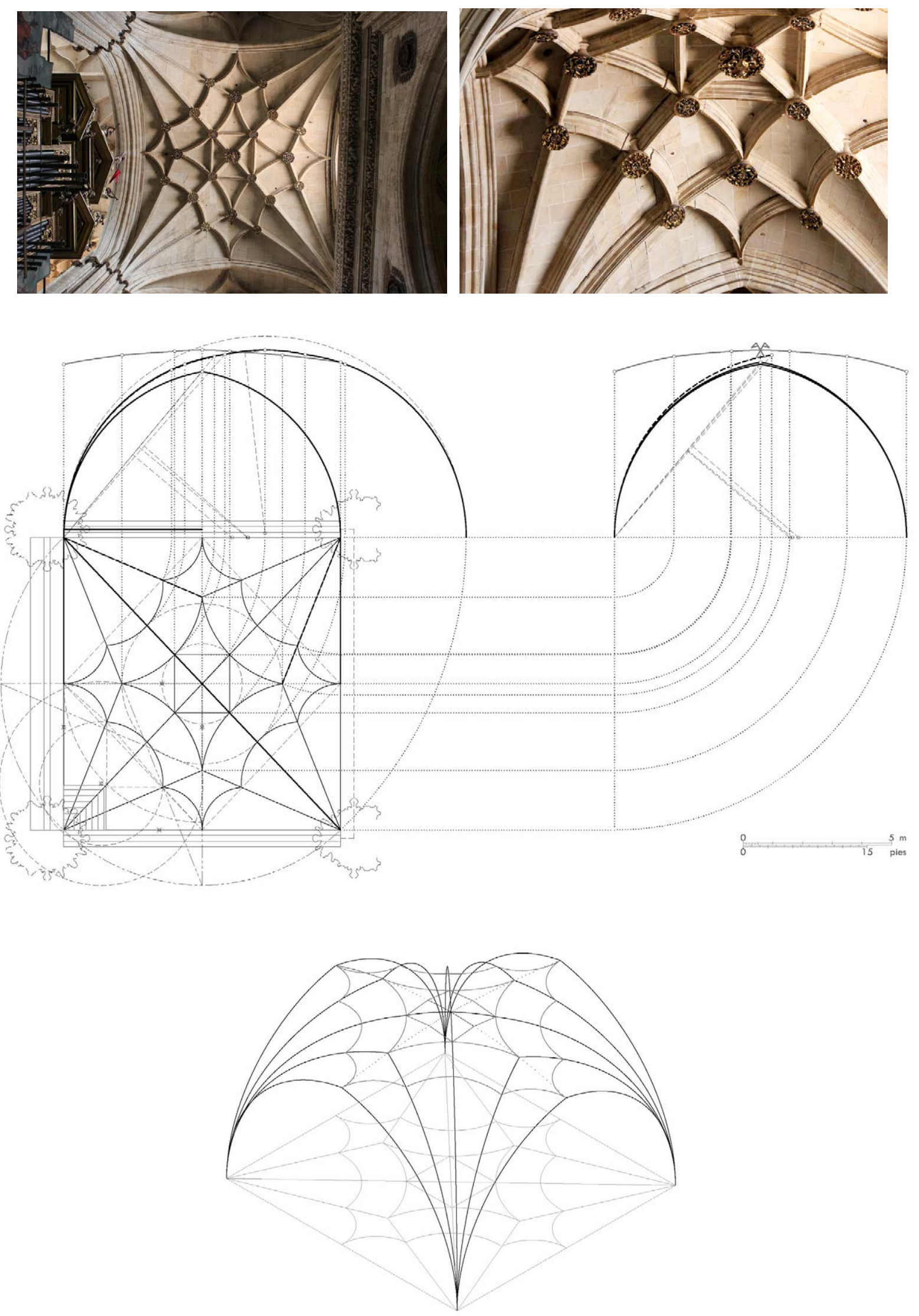

Figura 126. Catedral Nueva de Salamanca: bóveda de la nave lateral (tramo 2 sur): (a) Vista en planta. (b) Detalle de los nervios, claves y plementería. (c) Hipótesis de trazado de los nervios. (d) Modelizado de los nervios (c, d: P. Moreno) 


\subsubsection{Bóveda de la nave lateral (tramo 3 sur)}

Modulación y rangos dimensionales: La bóveda tiene una planta aproximadamente cuadrada de dimensiones $35.5 \times 37.3$ pies $(9.88 \times 10.40 \mathrm{~m})$ y proporción entre los lados 1.051 (1:1), ambas consideradas a ejes de los arcos del perímetro (las interiores son $33.5 \times 35.3$ pies $(9.32 \times 9.84 \mathrm{~m})$ y $1.054(1: 1)$, respectivamente). Los perpiaños tienen un punto de arranque distinto al del resto de los nervios en cada apoyo 448 .

Sistemas de composición: La crucería principal está formada por los dos arcos diagonales y terceletes sencillos en la dirección de ambos ejes. Las nervaduras decorativas forman un cuadrifolio de hojas cóncavas, en cuyo interior se dispone otro cuadrifolio de hojas convexas y tangentes al primero. En conjunto se obtiene un diseño con 21 claves interiores. - Las claves de los terceletes se sitúan en la bisectriz del ángulo formado por la diagonal y los arcos del perímetro. Las claves secundarias sobre los terceletes quedan aproximadamente alineadas sobre un paralelogramo que une los puntos medios de los lados de la bóveda; los centros principales del cuadrifolio exterior se disponen aproximadamente sobre la diagonal y alineados con las claves de los terceletes, y los de sus remates o pies de gallo sobre el perímetro de la bóveda; obtenidas las claves sobre las diagonales, las claves sobre las ligaduras se sitúan en los puntos medios de los segmentos limitados por las claves de los terceletes y la central; los centros del cuadrifolio interior (uno por cada hoja) se disponen sobre las diagonales.

Arcos: El plano de imposta se sitúa a una altura de 63.4 pies $(17.65 \mathrm{~m})$ del suelo, y la clave central a 22.4 pies $(6.23 \mathrm{~m})$ de dicho plano. Todos los arcos parten tangentes a la vertical en el arranque, no presentando ninguno peraltes. La clave central se encuentra 2.0 pies $(0.55 \mathrm{~m})$ por debajo de la posición que correspondería a la de un arco ojivo semicircular. Un examen visual de la geometría de la diagonal y la comprobación de la posición que ocupan las claves secundarias dispuestas a lo largo de este arco nos hace concluir que su trazado teórico es carpanel, partiendo sin peralte en su arranque. Los arcos se trazarían aparentemente con 3 radios distintos, siendo sus datos geométricos en pies los siguientes:

\begin{tabular}{|c|c|c|}
\hline nervio & tipo & radio \\
\hline diagonal & car & $21.7 \cdot 25.1$ \\
\hline perpiaño & ap & 20.4 \\
\hline formero $\mathrm{N}$ & ap & 20.9 \\
\hline formero S & ap & 21.4 \\
\hline tercelete per. & ap & 21.9 \\
\hline tercelete for. & ap & 22.1 \\
\hline
\end{tabular}

Rampante: Las claves de los arcos del perímetro se sitúan, en la dirección del eje x, a 1.5 pies $(0.42$ $\mathrm{m}$ ) (valor promedio) por debajo de la clave central; en la dirección del eje y, a 2.3 pies (0.65 m) por debajo de la clave central. El rampante se puede considerar llano en la dirección de ambos ejes.

Características constructivas: Los nervios que forman la crucería interior presentan 2 tipos distintos de sección en cuanto a molduraje y canto (grande para la diagonal y el tercelete; pequeño para la ligadura y el nervio decorativo). - Las jarjas se componen de 6, 10 y 11 hiladas, dependiendo del soporte y del nervio considerado. - Las claves tienen su eje central vertical (y su cara inferior paralela a la superficie de la bóveda en cada punto). - La plementería es de cantería, dispuesta a la francesa; sus hiladas se componen de entre 1 y 2 piezas; queda ligeramente separada del trasdós del formero.

\footnotetext{
${ }^{448}$ Como analizamos en otro apartado de este estudio, el trazado de las naves laterales de la Catedral Nueva de Salamanca parece haberse realizado tomando como referencia, junto a los ejes de los pilares centrales, el eje del muro de cierre de las naves laterales, en lugar del contorno interior de dicho muro, en cuyo caso las dimensiones y proporción serían $37.1 \times 37.3$ pies $(10.34 \times 10.40 \mathrm{~m})$ y $1.005(1: 1)$ respectivamente. Sin embargo, hemos mantenido los datos referidos al contorno interior para no modificar el criterio general utilizado en el análisis de todas las bóvedas.
} 

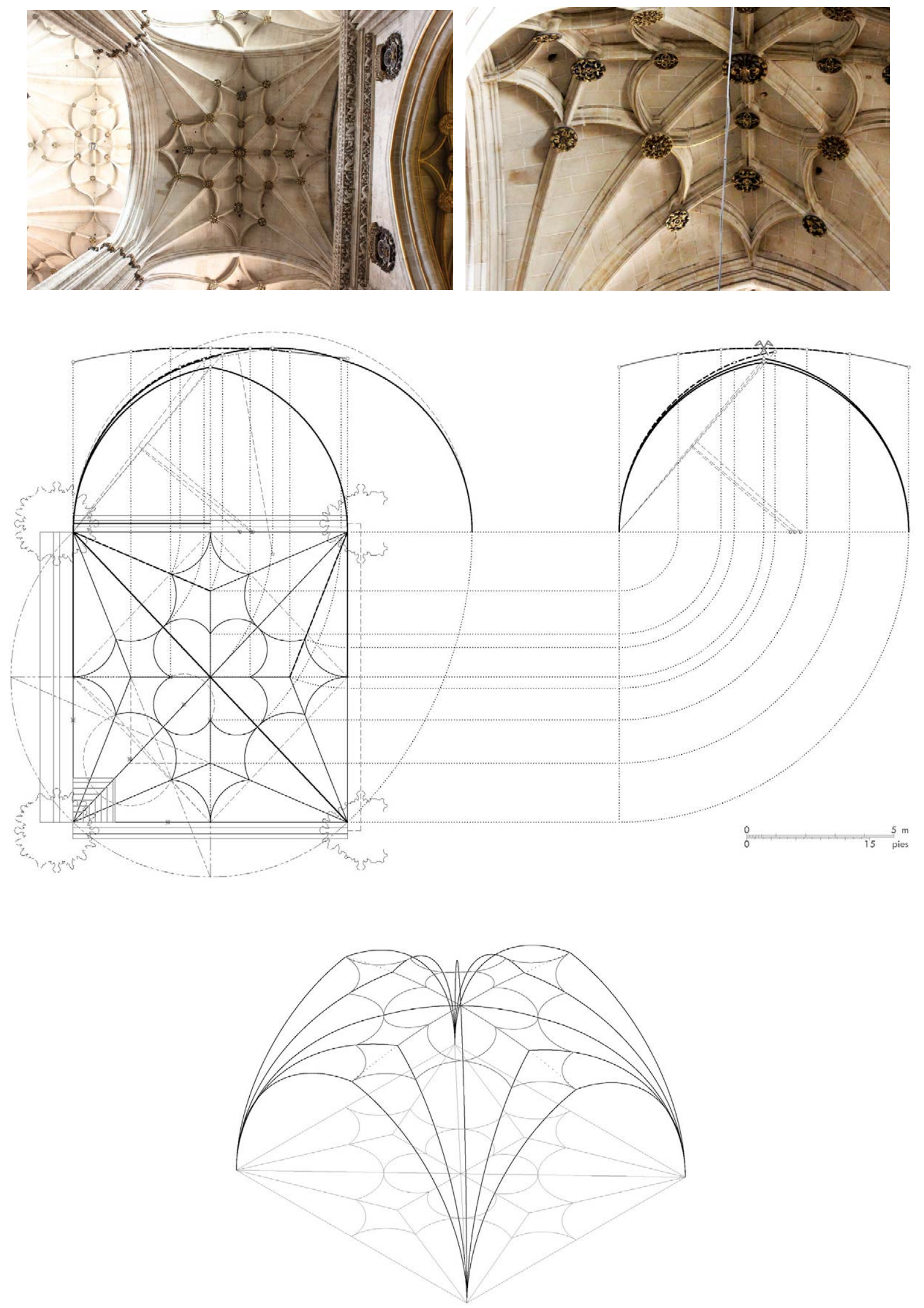

Figura 127. Catedral Nueva de Salamanca: bóveda de la nave lateral (tramo 3 sur): (a) Vista en planta. (b) Detalle de los nervios, claves y plementería. (c) Hipótesis de trazado de los nervios. (d) Modelizado de los nervios (c, d: P. Moreno) 


\subsubsection{Salamanca - Colegio Menor de San Pelayo}

Datos históricos del edificio: véase página 828 y siguientes

Datos de medición de las bóvedas: véase página 893

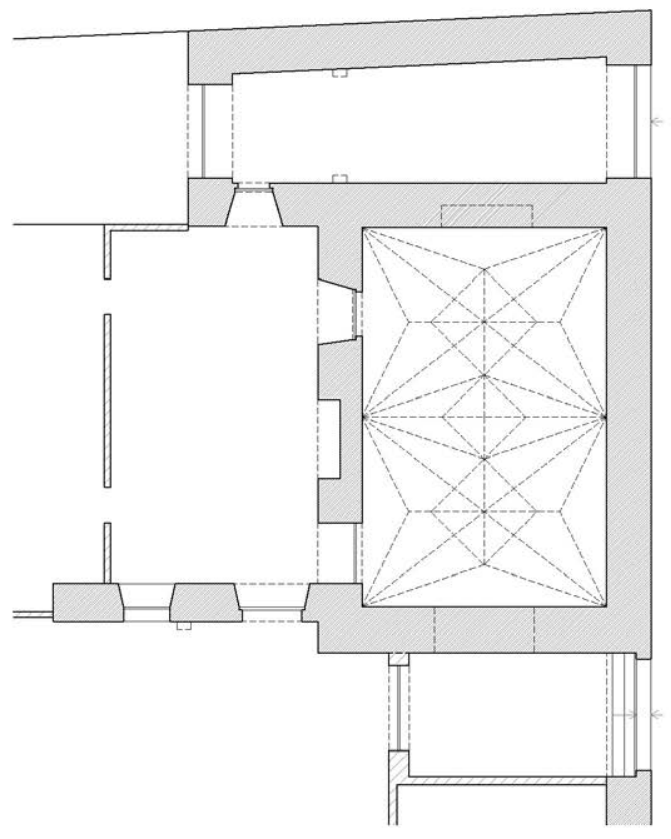

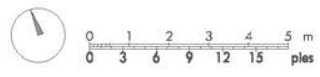

1. Bóveda de la capilla (c.1577-c.1585)

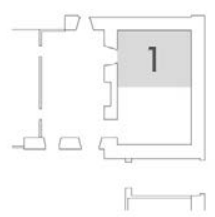

Figura 128. Colegio Menor de San Pelayo, Salamanca: (a) Planta de la capilla (P. Moreno). (b) Indicación de las bóvedas analizadas, con su fecha de ejecución (P. Moreno) 


\subsubsection{Bóveda de la capilla}

Modulación y rangos dimensionales: La bóveda tiene una planta rectangular de dimensiones $22.1 \times 17.1$ pies $(6.15 \times 4.77 \mathrm{~m})$ y proporción entre los lados $1.292(5: 4)$, ambas consideradas a ejes de los arcos del perímetro (coinciden con las interiores). Todos los nervios tienen un punto de arranque común en cada apoyo.

Sistemas de composición: La crucería principal está formada por los dos arcos diagonales y terceletes sencillos en la dirección de ambos ejes. Las nervaduras decorativas forman un rombo de lados rectos. En conjunto se obtiene un diseño con 13 claves interiores. • Las claves de los terceletes se sitúan en la bisectriz del ángulo formado por la diagonal y los arcos del perímetro. Los nervios decorativos constituyen un cuadrado central y otro medio cuadrado que enlaza con el tramo contiguo, ambos girados $45^{\circ}$ con respecto a los ejes; el primero tiene su centro en el polo de la bóveda y el segundo en la clave del arco de separación con el tramo contiguo; quedan inscritos en sendas circunferencias que tienen por radio la distancia hasta la clave de los terceletes situados sobre el eje menor, obteniéndose las claves restantes.

Arcos: El plano de imposta se sitúa a una altura de 19.8 pies $(5.51 \mathrm{~m})$ del suelo, y la clave central a 14.0 pies $(3.89 \mathrm{~m}$ ) de dicho plano. Todos los arcos parten tangentes a la vertical en el arranque, no presentando ninguno peraltes. La clave central coincide con la posición que correspondería a la de un arco ojivo semicircular. Un examen visual de la geometría de la diagonal y la comprobación de la posición que ocupan las claves secundarias dispuestas a lo largo de este arco nos hace concluir que su trazado teórico es efectivamente semicircular, partiendo sin peralte en su arranque. Los arcos se trazarían aparentemente con 2 radios distintos, siendo sus datos geométricos en pies los siguientes:

$\begin{array}{lccc}\text { nervio } & \text { tipo } & \text { radio } & \text { peralte } \\ \text { diagonal } & \text { sc } & 14.0 & \\ \text { perpiaño } & \text { ap } & 14.4 & \\ \text { formero } & \text { ap } & 12.7 \\ \text { tercelete per. } & \text { ap } & 14.2 & \\ \text { tercelete for. } & \text { ap } & 14.2\end{array}$

Rampante: Las claves de los arcos del perímetro se sitúan, en la dirección del eje x (mayor), a 2.0 pies $(0.55 \mathrm{~m}$ ) por debajo de la clave central; en la dirección del eje y (menor), a la misma altura que la clave central. El rampante se puede considerar llano en la dirección del eje $x$ (mayor) y horizontal en la del eje y (menor).

Características constructivas: Los nervios que forman la crucería interior presentan 2 tipos distintos de sección en cuanto a molduraje y canto (grande para la diagonal, el tercelete y la ligadura; pequeño para el nervio decorativo). • Las jarjas se componen de 7 hiladas. • Las claves tienen su eje central vertical (y su cara inferior paralela a la superficie de la bóveda en cada punto). • La plementería es de ladrillo; asienta directamente sobre el trasdós del formero. 

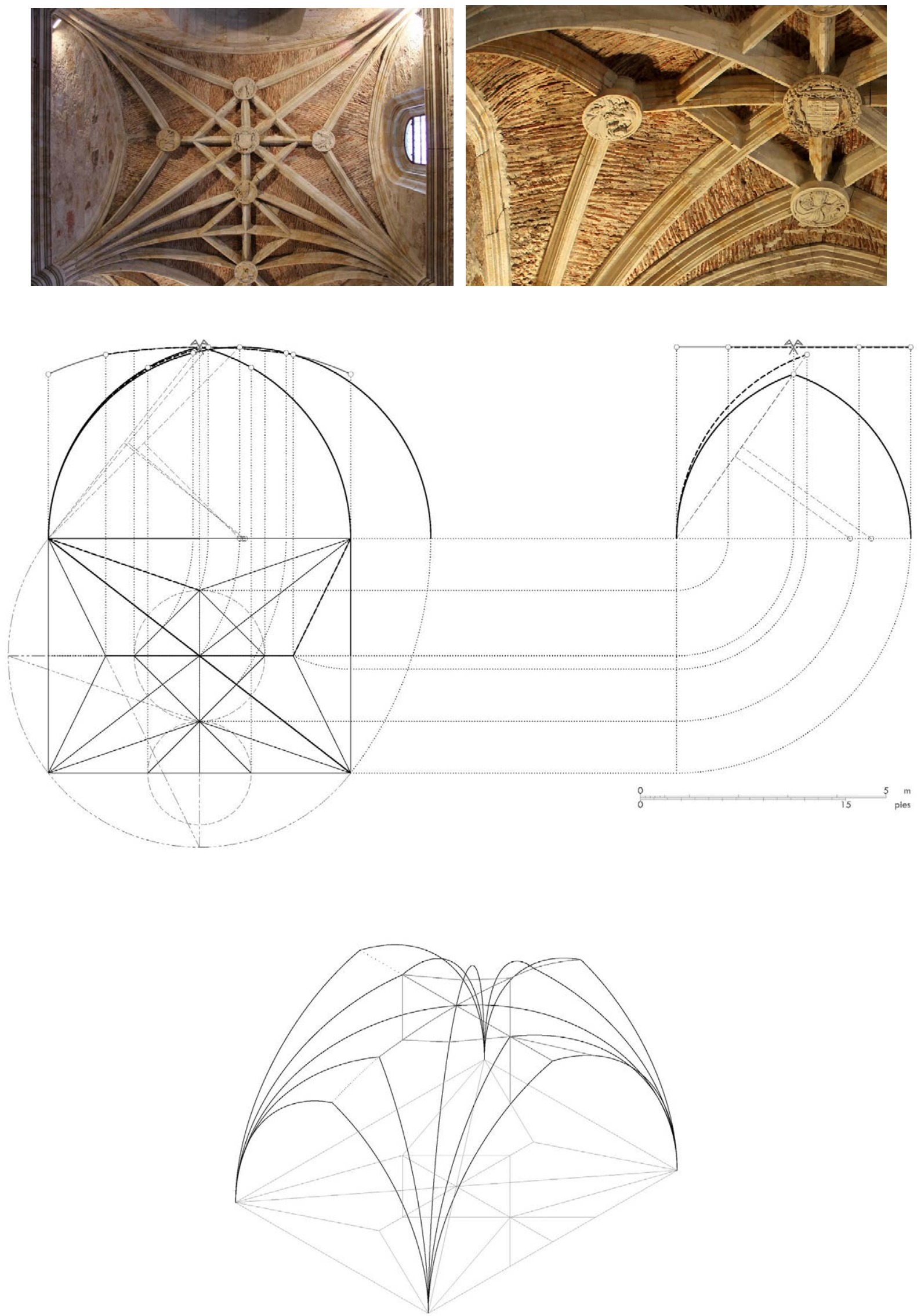

Figura 129. Colegio Menor de San Pelayo, Salamanca: bóveda de la capilla: (a) Vista en planta. (b) Detalle de los nervios, claves y plementería. (c) Hipótesis de trazado de los nervios. (d) Modelizado de los nervios (c, d: P. Moreno) 


\subsubsection{Salamanca - Iglesia del convento de San Esteban}

Datos históricos del edificio: véase página 799 y siguientes

Datos de medición de las bóvedas: véase página 894 y siguientes
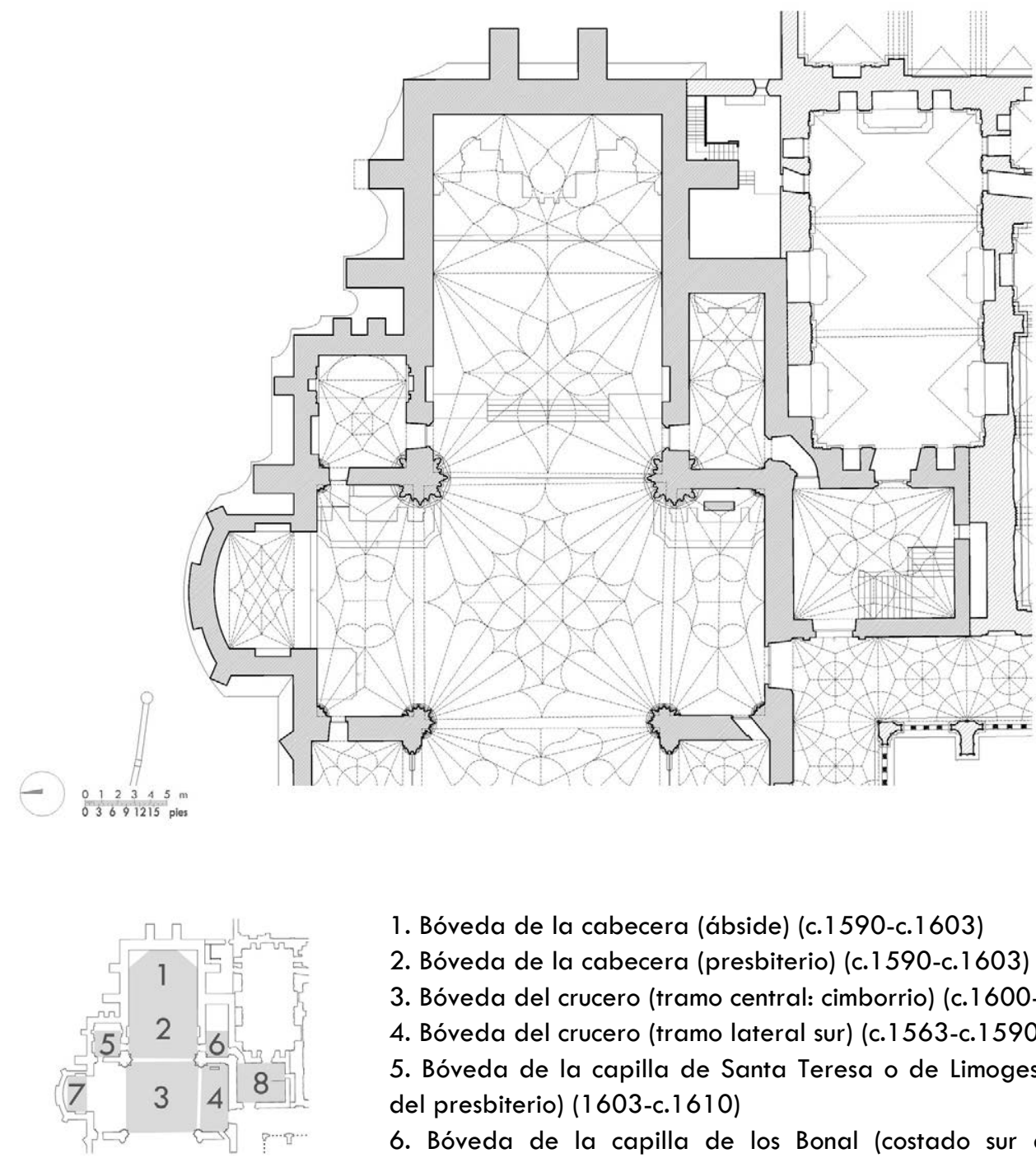

1. Bóveda de la cabecera (ábside) (c.1590-c.1603)

2. Bóveda de la cabecera (presbiterio) (c.1590-c.1603)

3. Bóveda del crucero (tramo central: cimborrio) (c.1600-c.1610)

4. Bóveda del crucero (tramo lateral sur) (c.1563-c.1590)

5. Bóveda de la capilla de Santa Teresa o de Limoges (costado norte del presbiterio) (1603-c.1610)

6. Bóveda de la capilla de los Bonal (costado sur del presbiterio) (1603-c.1610)

7. Bóveda de la capilla del Rosario o de los Anaya (costado norte del crucero) (c.1590-c.1603)

8. Bóveda de la escalera de Soto (1556)

Figura 130. Iglesia del convento de San Esteban, Salamanca: (a) Planta del crucero y cabecera, con la escalera de Soto (Manzano 2000). (b) Indicación de las bóvedas analizadas, con su fecha de ejecución (P. Moreno) 


\subsubsection{Bóveda de la cabecera (ábside)}

Modulación y rangos dimensionales: La bóveda tiene una planta poligonal basada en un octógono regular de lado 20.8 pies $(5.79 \mathrm{~m})$ y radio 27.1 pies $(7.56 \mathrm{~m})$, y una embocadura de 50.1 pies (13.97 m). Todos los nervios tienen un punto de arranque común en cada apoyo.

Sistemas de composición: La crucería principal está formada por los arcos perpiaños radiales y terceletes sencillos. Las nervaduras decorativas forman un quinquefolio de hojas conopiales, en cuyo interior se dispone una figura de lados cóncavos. En conjunto se obtiene un diseño con 12 claves interiores. - La clave principal se sitúa en el centro del polígono generador, y no coincide con la del arco perpiaño de la embocadura; las claves de los terceletes se sitúan en la bisectriz del ángulo formado por los perpiaños radiales y los arcos del perímetro. Las claves del quinquefolio sobre los perpiaños radiales se sitúan en los puntos de corte con una circunferencia que tiene por centro la clave principal y por radio la distancia hasta la clave del arco perpiaño de la embocadura; sus hojas, que comparten el mismo trazado, tienen sus centros sobre la circunferencia anterior, y generan al mismo tiempo la figura central, cuyas claves se desplazan ligeramente.

Arcos: El plano de imposta se sitúa a una altura de 65.3 pies $(18.19 \mathrm{~m})$ del suelo, y la clave principal a 27.1 pies $(7.54 \mathrm{~m})$ de dicho plano. Todos los arcos parten tangentes a la vertical en el arranque, presentando todos peraltes. El arco perpiaño de la embocadura es carpanel, encontrándose su clave 2.0 pies $(0.56 \mathrm{~m})$ por encima de la posición que correspondería a la de un arco perpiaño semicircular y partiendo con un peralte de 2.6 pies $(0.74 \mathrm{~m})$ en su arranque. Los arcos se trazarían aparentemente con 4 radios distintos, siendo sus datos geométricos en pies los siguientes:

\begin{tabular}{lccc} 
nervio & tipo & radio & peralte \\
\hline perpiaño 1 & car & $22.7 \cdot 29.3$ & 2.6 \\
perpiaño 2 & car & $22.7 \cdot 29.3$ & 2.6 \\
formero & ap & 17.4 & 5.3 \\
tercelete for. & ap & 19.7 & 5.3
\end{tabular}

Rampante: -

Características constructivas: Los nervios que forman la crucería interior presentan 2 tipos distintos de sección en cuanto a molduraje y canto (grande para el perpiaño radial y el tercelete; pequeño para la ligadura y el nervio decorativo). - Las jarjas se componen de 10+10 hiladas. - Las claves tienen su eje central vertical (y su cara inferior paralela a la superficie de la bóveda en cada punto). - La plementería es de cantería, dispuesta a la francesa; sus hiladas se componen de entre 1 y 2 piezas; queda ligeramente separada del trasdós del formero. 

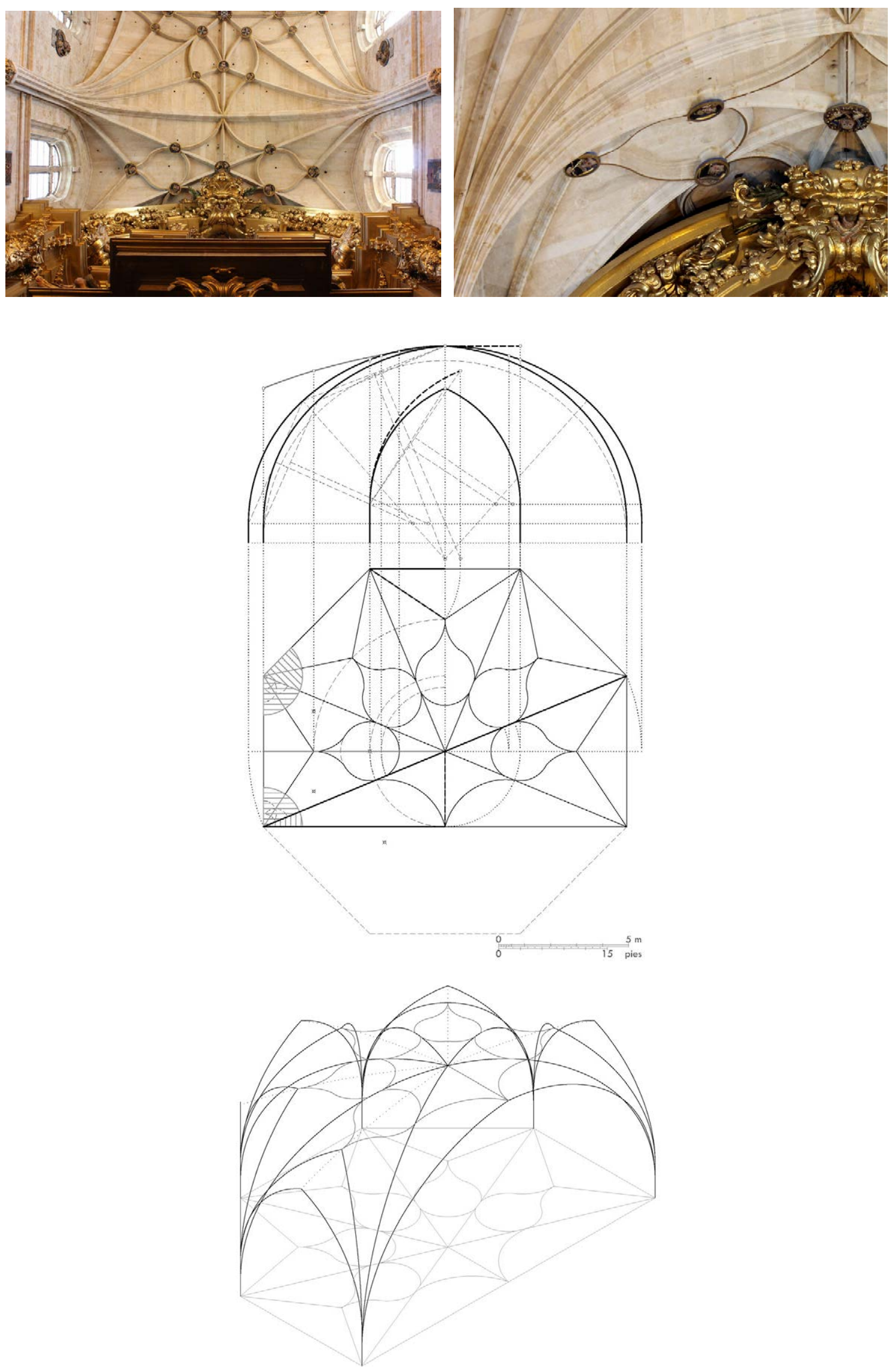

Figura 131. Iglesia del Convento de San Esteban, Salamanca: bóveda de la cabecera (ábside): (a) Vista en planta. (b) Detalle de los nervios, claves y plementería. (c) Hipótesis de trazado de los nervios. (d) Modelizado de los nervios (c, d: P. Moreno) 


\subsubsection{Bóveda de la cabecera (presbiterio)}

Modulación y rangos dimensionales: La bóveda tiene una planta rectangular de dimensiones $50.1 \times 45.3$ pies $(13.97 \times 12.61 \mathrm{~m})$ y proporción entre los lados $1.106(8: 7)$, ambas consideradas a ejes de los arcos del perímetro (las interiores son $50.1 \times 44.1$ pies $(13.97 \times 12.28 \mathrm{~m})$ y $1.136(8: 7)$, respectivamente). Los perpiaños tienen un punto de arranque distinto al del resto de los nervios en cada apoyo.

Sistemas de composición: La crucería principal está formada por los dos arcos diagonales, terceletes dobles en la dirección del eje mayor y sencillos en la dirección del eje menor. Las nervaduras decorativas forman un cuadrifolio de hojas conopiales, en cuyo interior se dispone una figura de lados cóncavos. En conjunto se obtiene un diseño con 19 claves interiores. $•$ Las claves de los terceletes se sitúan, sobre el eje menor, en los puntos que resultan de dividir dicho eje en cuatro partes iguales (a 1/4 del perímetro); sobre el eje mayor, en los puntos de corte de dicho eje con una circunferencia que tiene por centro la clave central y por radio una de las partes resultantes de la división anterior, y en otros dos puntos cuyo trazado geométrico no hemos logrado determinar. Las claves sobre las diagonales se sitúan en los puntos de corte con una circunferencia que tiene por centro el polo de la bóveda y por radio la mitad de la distancia hasta las claves de los terceletes del eje menor (la mitad de una de las partes anteriores); las claves secundarias sobre los terceletes interiores del eje mayor se sitúan alineadas con las de las diagonales; los centros principales de las hojas del cuadrifolio (dos por cada hoja en el eje mayor y uno en el menor) se disponen aproximadamente en las mediatrices de los segmentos limitados por sus extremos y la clave central; las claves secundarias sobre los terceletes no resultan alineadas sobre un paralelogramo que une dichos extremos.

Arcos: El plano de imposta se sitúa a una altura de 65.3 pies $(18.19 \mathrm{~m}$ ) del suelo, y la clave central a 29.4 pies $(8.19 \mathrm{~m}$ ) de dicho plano. Todos los arcos parten tangentes a la vertical en el arranque, presentando todos peraltes. La clave central se encuentra 4.0 pies $(1.11 \mathrm{~m})$ por debajo de la posición que correspondería a la de un arco ojivo semicircular. Un examen visual de la geometría de la diagonal y la comprobación de la posición que ocupan las claves secundarias dispuestas a lo largo de este arco nos hace concluir que su trazado teórico es carpanel, partiendo con un peralte de 2.6 pies $(0.74 \mathrm{~m})$ en su arranque. Los arcos se trazarían aparentemente con 6 radios distintos, siendo sus datos geométricos en pies los siguientes:

\begin{tabular}{lccc} 
nervio & tipo & radio & peralte \\
\hline diagonal & car & $23.2 \cdot 39.5$ & 2.6 \\
perpiaño E & car & $22.7 \cdot 29.3$ & 2.6 \\
perpiaño O & ap & 26.5 & 1.3 \\
formero & car & $18.0 \cdot 24.1$ & 2.6 \\
tercelete per. & tu & $23.2 \cdot 39.5$ & 2.6 \\
tercelete for. 1 & ap & 22.7 & 2.6 \\
tercelete for. 2 & tu & $23.2 \cdot 39.5$ & 2.6
\end{tabular}

Rampante: Las claves de los arcos del perímetro se sitúan, en la dirección del eje x (mayor), a 7.2 pies $(2.01 \mathrm{~m}$ ) por debajo de la clave central; en la dirección del eje y (menor), a 2.0 pies (0.55 m) (valor promedio) por debajo de la clave central. El rampante se puede considerar redondo en la dirección del eje $x$ (mayor) y llano en la del eje y (menor).

Características constructivas: Los nervios que forman la crucería interior presentan 2 tipos distintos de sección en cuanto a molduraje y canto (grande para la diagonal y el tercelete; pequeño para la ligadura y el nervio decorativo). - Las jarjas se componen de 8, 9, 10 y 10+10 hiladas, dependiendo del soporte y del nervio considerado. - Las claves tienen su eje central vertical (y su cara inferior paralela a la superficie de la bóveda en cada punto). - La plementería es de cantería, dispuesta a la francesa; sus hiladas se componen de entre 1 y 2 piezas; queda ligeramente separada del trasdós del formero. 

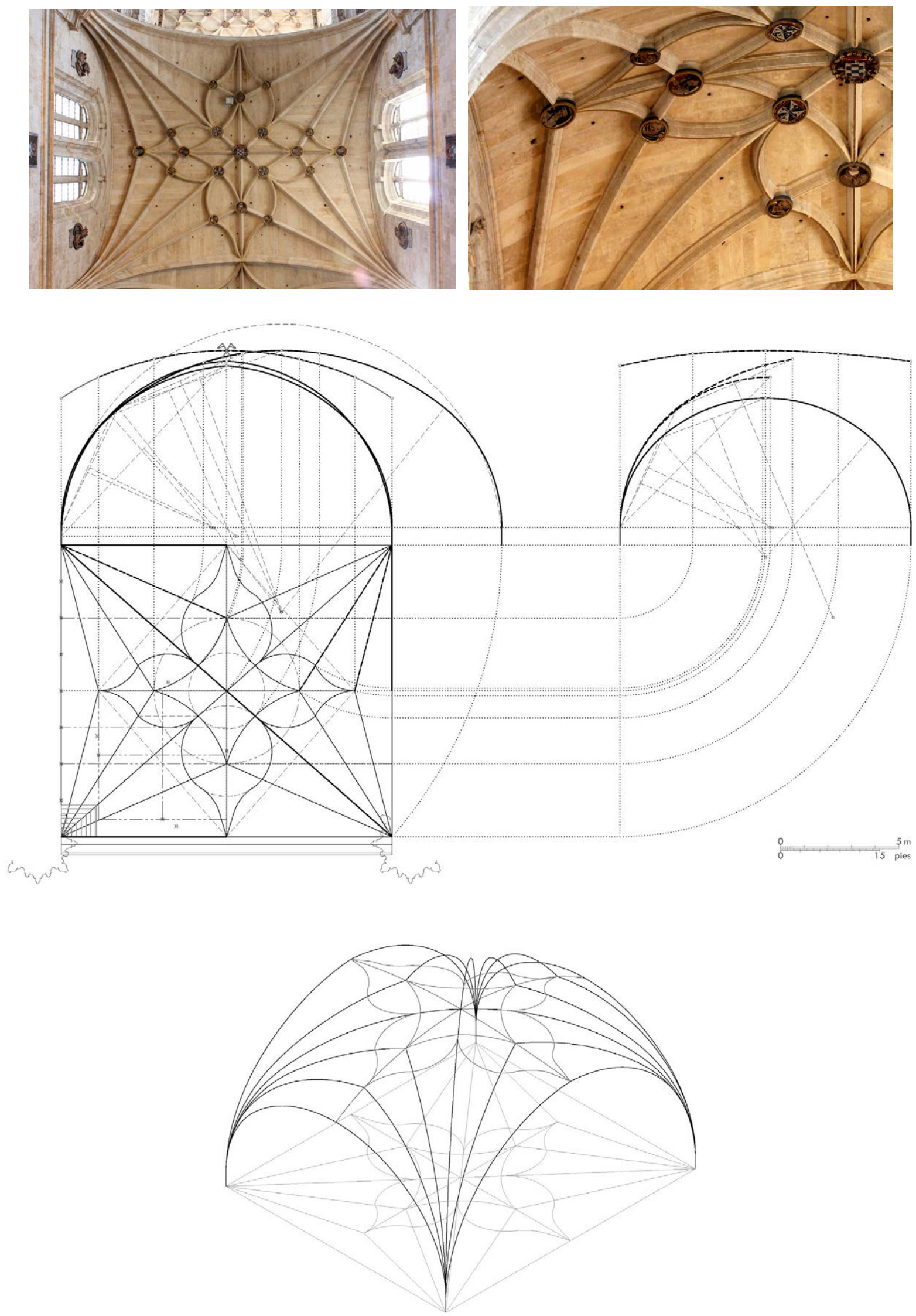

Figura 132. Iglesia del Convento de San Esteban, Salamanca: bóveda de la cabecera (presbiterio): (a) Vista en planta. (b) Detalle de los nervios, claves y plementería. (c) Hipótesis de trazado de los nervios. (d) Modelizado de los nervios (c, d: P. Moreno) 


\subsubsection{Bóveda del crucero (tramo central: cimborrio)}

Modulación y rangos dimensionales: La bóveda tiene una planta aproximadamente cuadrada de dimensiones $55.0 \times 53.9$ pies $(15.33 \times 15.02 \mathrm{~m})$ y proporción entre los lados $1.020(1: 1)$, ambas consideradas a ejes de los arcos del perímetro (las interiores son $51.9 \times 51.1$ pies $(14.45 \times 14.24 \mathrm{~m})$ y $1.016(1: 1)$, respectivamente) ${ }^{449}$. Todos los nervios tienen un punto de arranque común en cada apoyo.

Sistemas de composición: La crucería principal está formada por los dos arcos diagonales y terceletes dobles en la dirección de ambos ejes. Las nervaduras decorativas forman un cuadrifolio de hojas cóncavas, en cuyo interior se dispone otro cuadrifolio de hojas conopiales y tangentes al primero, una figura de lados cóncavos y un rectángulo de lados paralelos al perímetro. En conjunto se obtiene un diseño con 33 claves interiores. - Las claves de los terceletes exteriores se sitúan, sobre ambos ejes, en los puntos que resultan de dividir dichos ejes en ocho partes iguales (a $1 / 8$ del perímetro); una de dichas partes (sobre el eje mayor) sirve como radio de una circunferencia que, con centro en la clave central, genera sobre las diagonales las cuatro claves del rectángulo central; cuatro arcos con centros en cada uno de los vértices de la bóveda y radio la distancia hasta dichas claves permiten obtener sobre los ejes las claves de los terceletes restantes. Las hojas del cuadrifolio interior tienen el mismo radio que la circunferencia que genera el rectángulo central, y sus centros principales (uno por cada hoja) se disponen aproximadamente en los puntos medios de los segmentos limitados por los extremos de dicho cuadrifolio y la clave central; los centros principales del cuadrifolio exterior se disponen alineados con los anteriores, y los de sus remates o pies de gallo fuera del perímetro de la bóveda. Obtenidas las claves secundarias sobre los terceletes interiores, las claves secundarias sobre los terceletes exteriores quedan alineadas con ellas; las primeras no resultan alineadas sobre un paralelogramo que une los extremos del cuadrifolio interior; las segundas resultan aproximadamente alineadas sobre un paralelogramo que une los extremos del cuadrifolio exterior. Las claves exteriores sobre las diagonales se sitúan aproximadamente en los puntos de corte con una circunferencia que tiene por centro el polo de la bóveda y que circunscribe las circunferencias que generan las hojas del cuadrifolio interior.

Arcos: El plano de imposta se sitúa a una altura de 105.5 pies $(29.38 \mathrm{~m}$ ) del suelo, y la clave central a 42.3 pies $(11.79 \mathrm{~m}$ ) de dicho plano. Todos los arcos parten tangentes a la vertical en el arranque, presentando todos peraltes. La clave central se encuentra 5.9 pies $(1.65 \mathrm{~m})$ por encima de la posición que correspondería a la de un arco ojivo semicircular. Un examen visual de la geometría de la diagonal y la comprobación de la posición que ocupan las claves secundarias dispuestas a lo largo de este arco nos hace concluir que su trazado teórico es efectivamente semicircular, partiendo con un peralte de 5.9 pies $(1.65 \mathrm{~m})$ en su arranque. Los arcos se trazarían aparentemente con 2 radios distintos, siendo sus datos geométricos en pies los siguientes:

\begin{tabular}{lccc} 
nervio & tipo & radio & peralte \\
\hline diagonal & sc & 36.4 & 5.9 \\
perpiaño & ap & 35.0 & 5.9 \\
formero & ap & 35.2 & 5.9 \\
tercelete per. 1 & ap & 35.9 & 5.9 \\
tercelete per. 2 & ap & 36.1 & 5.9 \\
tercelete for. 1 & ap & 36.0 & 5.9 \\
tercelete for. 2 & ap & 36.1 & 5.9
\end{tabular}

Rampante: Las claves de los arcos del perímetro se sitúan, en la dirección de ambos ejes, a 2.6 pies $(0.72 \mathrm{~m})$ por debajo de la clave central. El rampante se puede considerar llano en la dirección de ambos ejes.

Características constructivas: Los nervios que forman la crucería interior presentan 2 tipos distintos de sección en cuanto a molduraje y canto (grande para la diagonal y el tercelete; pequeño para la ligadura y el nervio decorativo). - Las jarjas se componen de 11 y 14 hiladas, dependiendo del nervio considerado. - Las claves tienen su eje central vertical (y su cara inferior paralela a la superficie de la bóveda en cada punto). - La plementería es de cantería, dispuesta a la francesa; sus hiladas se componen de 1 única pieza; asienta directamente sobre el trasdós del formero. 

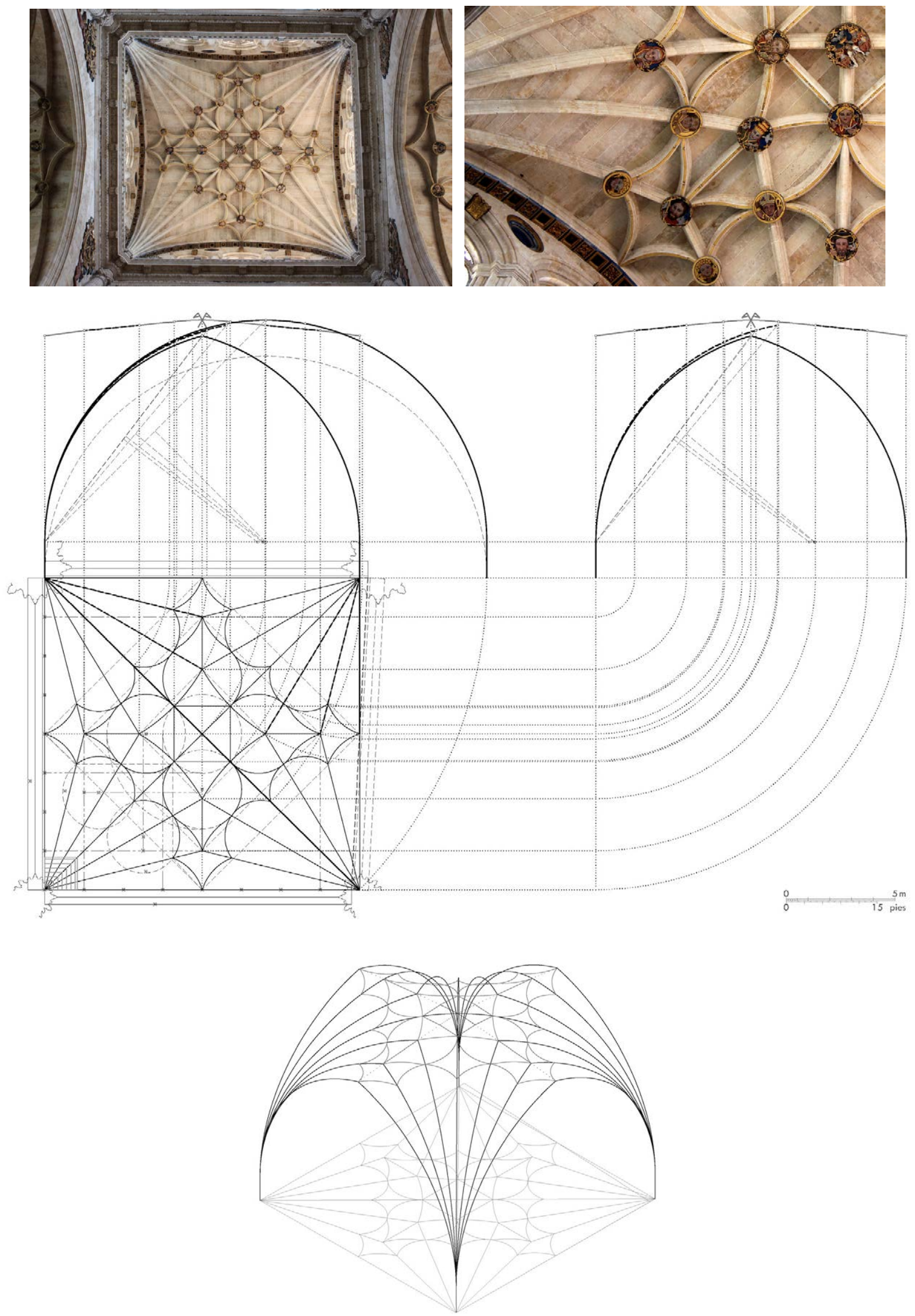

Figura 133. Iglesia del Convento de San Esteban, Salamanca: bóveda del crucero (tramo central: cimborrio): (a) Vista en planta. (b) Detalle de los nervios, claves y plementería. (c) Hipótesis de trazado de los nervios. (d) Modelizado de los nervios (c, d: P. Moreno) 


\subsubsection{Bóveda del crucero (tramo lateral sur)}

Modulación y rangos dimensionales: La bóveda tiene una planta aproximadamente rectangular de dimensiones $20.6 \times 50.5$ pies $(5.75 \times 14.07 \mathrm{~m})$ y proporción entre los lados $2.452(>2: 1)$, ambas consideradas a ejes de los arcos del perímetro (las interiores son $19.4 \times 50.5$ pies $(5.41 \times 14.07 \mathrm{~m})$ y $2.603(>2: 1)$, respectivamente $)^{449}$. Los perpiaños tienen un punto de arranque distinto al del resto de los nervios en cada apoyo.

Sistemas de composición: La crucería principal está formada por terceletes dobles en la dirección del eje mayor y sencillos en la dirección del eje menor, careciendo de arcos diagonales. Las nervaduras decorativas forman una figura de lados cóncavos y convexos. En conjunto se obtiene un diseño con 13 claves interiores. - Las claves de los terceletes se sitúan, sobre el eje mayor, en los puntos que resultan de dividir dicho eje en ocho partes iguales (a 1/8 del perímetro), y en otros dos puntos cuyo trazado geométrico no hemos logrado determinar; sobre el eje menor, en los puntos que resultan de dividir dicho eje en cuatro partes iguales (a 1/4 del perímetro). Las claves secundarias sobre los terceletes del eje menor se sitúan en los puntos de corte con las líneas que resultan de dividir el lado mayor de la bóveda en ocho partes iguales (a 1/8 de los ejes); las claves sobre las ligaduras del eje mayor se sitúan en puntos cuyo trazado geométrico no hemos logrado determinar; la figura se compone de diez arcos.

Arcos: El plano de imposta se sitúa a una altura de 65.3 pies $(18.19 \mathrm{~m}$ ) del suelo, y la clave central a 27.6 pies $(7.70 \mathrm{~m}$ ) de dicho plano. Todos los arcos parten tangentes a la vertical en el arranque, presentando algunos peraltes. La clave central se encuentra 0.6 pies $(0.16 \mathrm{~m})$ por encima de la posición que correspondería a la de un arco ojivo semicircular. Los arcos se trazarían aparentemente con 3 radios distintos, siendo sus datos geométricos en pies los siguientes:

$\begin{array}{lccc}\text { nervio } & \text { tipo } & \text { radio } & \text { peralte } \\ \text { perpiaño } & \text { ap } & 28.0 & \\ \text { formero N } & \text { ap } & 26.3 & 1.3 \\ \text { formero S } & \text { sc } & 25.3 & 2.4 \\ \text { tercelete per. 1 } & \text { ap } & 29.9 & \\ \text { tercelete per. 2 } & \text { ap } & 28.4 & \\ \text { tercelete for. } & \text { ap } & 27.7 & \end{array}$

Rampante: Las claves de los arcos del perímetro se sitúan, en la dirección del eje $x$ (menor), a la misma altura que la clave central; en la dirección del eje y (mayor), a 6.4 pies (1.79 m) por debajo de la clave central. El rampante se puede considerar horizontal en la dirección del eje $x$ (menor) y redondo en la del eje y (mayor).

Características constructivas: Los nervios que forman la crucería interior presentan 2 tipos distintos de sección en cuanto a molduraje y canto (grande para el tercelete; pequeño para la ligadura y el nervio decorativo). - Las jarjas se componen de 8 y 9 hiladas, dependiendo del soporte y del nervio considerado. - Las claves tienen su eje central vertical (y su cara inferior paralela a la superficie de la bóveda en cada punto). - La plementería es de cantería, dispuesta a la francesa; sus hiladas se componen de entre 1 y 2 piezas; asienta directamente sobre el trasdós del formero.

\footnotetext{
449 Las plantas de esta bóveda y de la contigua toman, en realidad, la forma aproximada de un trapecio rectángulo, cuyas dimensiones se han consignado en los apartados en los que se recogen los datos de medición de las bóvedas (Anexo B). Sin embargo, a la hora de llevar a cabo el análisis dichas plantas trapeciales han sido asumidas como rectangulares, por dos razones: en primer lugar, la forma trapecial es resultado de un error producido durante el replanteo de la cimentación en obra, siendo rectangular el trazado teórico en ambos casos; en segundo lugar, esta aproximación no introduce errores importantes ni en el trazado en planta ni en el de las elevaciones de los arcos, y permite acometer el análisis de ambas estructuras del mismo modo que para el resto de bóvedas de planta rectangular, mayoritarias entre las estudiadas. Las dimensiones teóricas consideradas para el análisis son la altura y la mediana del trapecio.
} 

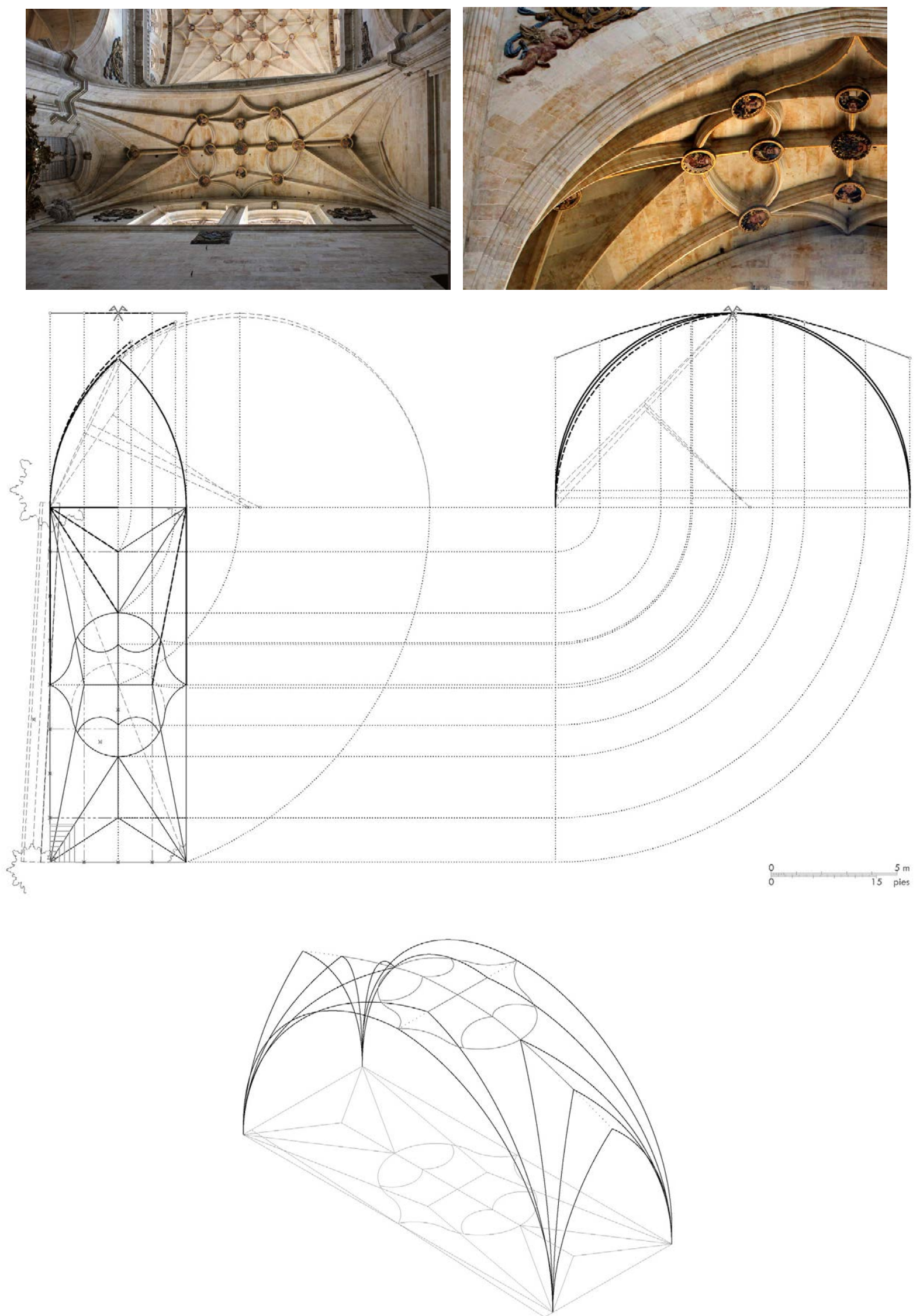

Figura 134. Iglesia del Convento de San Esteban, Salamanca: bóveda del crucero (tramo lateral sur): (a) Vista en planta. (b) Detalle de los nervios, claves y plementería. (c) Hipótesis de trazado de los nervios. (d) Modelizado de los nervios (c, d: P. Moreno) 


\subsubsection{Bóveda de la capilla de Santa Teresa o de Limoges (costado norte del presbiterio)}

Modulación y rangos dimensionales: La bóveda tiene una planta cuadrada de dimensiones $19.2 \times 19.2$ pies $(5.34 \times 5.34 \mathrm{~m}$ ) y proporción entre los lados 1.000 (1:1), ambas consideradas a ejes de los arcos del perímetro (coinciden con las interiores). Todos los nervios tienen un punto de arranque común en cada apoyo.

Sistemas de composición: La crucería principal está formada por los dos arcos diagonales y terceletes sencillos en la dirección de ambos ejes. Las nervaduras decorativas forman una figura de lados cóncavos, en cuyo interior se dispone un rectángulo de lados paralelos al perímetro. En conjunto se obtiene un diseño con 9 claves interiores. - Las claves de los terceletes se sitúan en la bisectriz del ángulo formado por la diagonal y los arcos del perímetro. Las claves sobre las diagonales se sitúan en los puntos de corte con un arco que tiene por centro el vértice de la bóveda y por radio la distancia hasta las claves de los terceletes; la figura se compone de cuatro arcos; obtenidas las claves sobre las diagonales, es posible trazar el rectángulo central.

Arcos: El plano de imposta se sitúa a una altura de 35.3 pies $(9.84 \mathrm{~m}$ ) del suelo, y la clave central a 12.5 pies $(3.49 \mathrm{~m})$ de dicho plano. Todos los arcos parten inclinados, no presentando ninguno peraltes. La clave central se encuentra 1.0 pies $(0.29 \mathrm{~m})$ por debajo de la posición que correspondería a la de un arco ojivo semicircular. Un examen visual de la geometría de la diagonal y la comprobación de la posición que ocupan las claves secundarias dispuestas a lo largo de este arco nos hace concluir que su trazado teórico es semicircular rebajado o escarzano, partiendo sin peralte en su arranque. Los arcos se trazarían aparentemente con 1 único radio, siendo sus datos geométricos en pies los siguientes:

\begin{tabular}{llll} 
nervio & tipo & radio & peralte \\
\hline diagonal & sc.rb & 13.6 \\
perpiaño & ap.in & 13.6 \\
formero & ap.in & 13.6 \\
tercelete per. & ap.in & 13.6 \\
tercelete for. & ap.in & 13.6
\end{tabular}

Rampante: Las claves de los arcos del perímetro se sitúan, en la dirección del eje x, a 1.1 pies (0.31 $\mathrm{m}$ ) por debajo de la clave central; en la dirección del eje y, a 0.5 pies $(0.13 \mathrm{~m})$ por debajo de la clave central. El rampante se puede considerar llano en la dirección de ambos ejes.

Características constructivas: Los nervios que forman la crucería interior presentan 2 tipos distintos de sección en cuanto a molduraje y canto (grande para la diagonal y el tercelete; pequeño para el nervio decorativo). - Las jarjas se componen de 4 y 5 hiladas, dependiendo del soporte considerado. - Las claves tienen su eje central vertical (y su cara inferior paralela a la superficie de la bóveda en cada punto). - La plementería es de cantería, dispuesta a la francesa; sus hiladas se componen de 1 única pieza; asienta directamente sobre el trasdós del formero. 

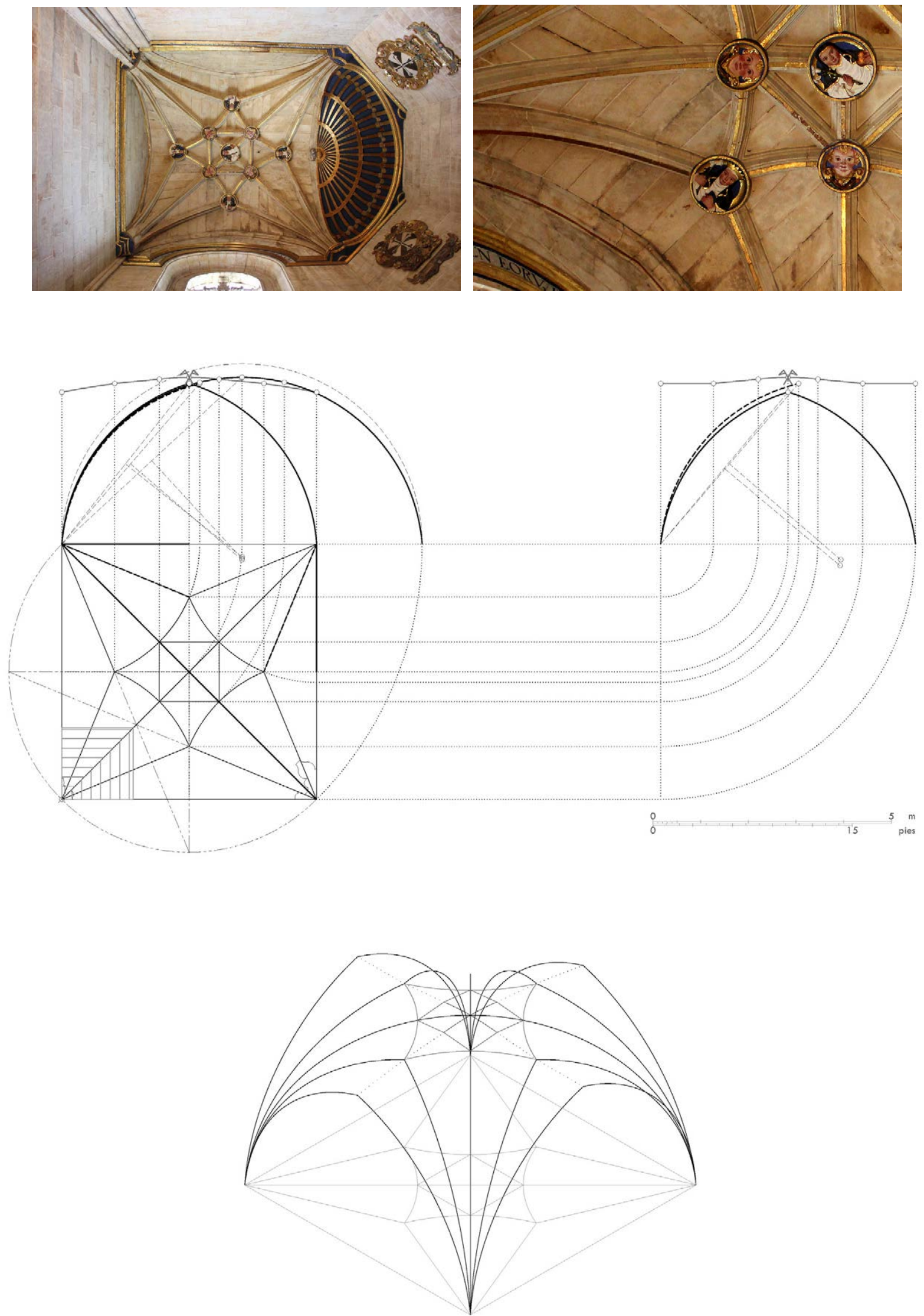

Figura 135. Iglesia del Convento de San Esteban, Salamanca: bóveda de la capilla de Santa Teresa o de Limoges (costado norte del presbiterio): (a) Vista en planta. (b) Detalle de los nervios, claves y plementería. (c) Hipótesis de trazado de los nervios. (d) Modelizado de los nervios (c, d: P. Moreno) 


\subsubsection{Bóveda de la capilla de los Bonal (costado sur del presbiterio)}

Modulación y rangos dimensionales: La bóveda tiene una planta rectangular de dimensiones $16.6 \times 19.4$ pies $(4.63 \times 5.40 \mathrm{~m})$ y proporción entre los lados $1.169(7: 6)$, ambas consideradas a ejes de los arcos del perímetro (coinciden con las interiores). Todos los nervios tienen un punto de arranque común en cada apoyo.

Sistemas de composición: La crucería principal está formada por los dos arcos diagonales y terceletes sencillos en la dirección de ambos ejes. Las nervaduras decorativas forman una figura de lados cóncavos. En conjunto se obtiene un diseño con 11 claves interiores. - Las claves de los terceletes se sitúan en la bisectriz del ángulo formado por la diagonal y los arcos del perímetro. Las claves sobre las diagonales se sitúan en los puntos de corte con una circunferencia que tiene por centro el polo de la bóveda y por radio la mitad de la distancia hasta las claves de los terceletes situados sobre el eje mayor; la figura se compone de cuatro arcos.

Arcos: El plano de imposta se sitúa a una altura de 35.0 pies $(9.75 \mathrm{~m}$ ) del suelo, y la clave central a 12.9 pies $(3.59 \mathrm{~m})$ de dicho plano. Todos los arcos parten tangentes a la vertical en el arranque, excepto el formero (eje y) que parte inclinado, presentando todos peraltes. La clave central se encuentra 0.1 pies $(0.04 \mathrm{~m})$ por encima de la posición que correspondería a la de un arco ojivo semicircular. Un examen visual de la geometría de la diagonal y la comprobación de la posición que ocupan las claves secundarias dispuestas a lo largo de este arco nos hace concluir que su trazado teórico es efectivamente semicircular, partiendo con un peralte despreciable en su arranque. Los arcos se trazarían aparentemente con 2 radios distintos, siendo sus datos geométricos en pies los siguientes:

\begin{tabular}{lccc} 
nervio & tipo & radio & peralte \\
\hline diagonal & sc & 12.8 & 0.1 \\
perpiaño $E$ & ap & 15.7 & 0.1 \\
perpiaño $O$ & ap & 12.7 & 0.1 \\
formero & ap.in & 12.8 & 0.1 \\
tercelete per. & ap & 13.2 & 0.1 \\
tercelete for. & ap & 12.8 & 0.1
\end{tabular}

Rampante: Las claves de los arcos del perímetro se sitúan, en la dirección de ambos ejes, a 0.9 pies $(0.24 \mathrm{~m})$ por debajo de la clave central. El rampante se puede considerar llano en la dirección de ambos ejes.

Características constructivas: Los nervios que forman la crucería interior presentan 2 tipos distintos de sección en cuanto a molduraje y canto (grande para la diagonal y el tercelete; pequeño para el nervio decorativo). - Las jarjas se componen de 4 y 5 hiladas, dependiendo del soporte considerado. - Las claves tienen su eje central vertical (y su cara inferior paralela a la superficie de la bóveda en cada punto). - La plementería es de cantería, dispuesta a la francesa; sus hiladas se componen de 1 única pieza; asienta directamente sobre el trasdós del formero. 

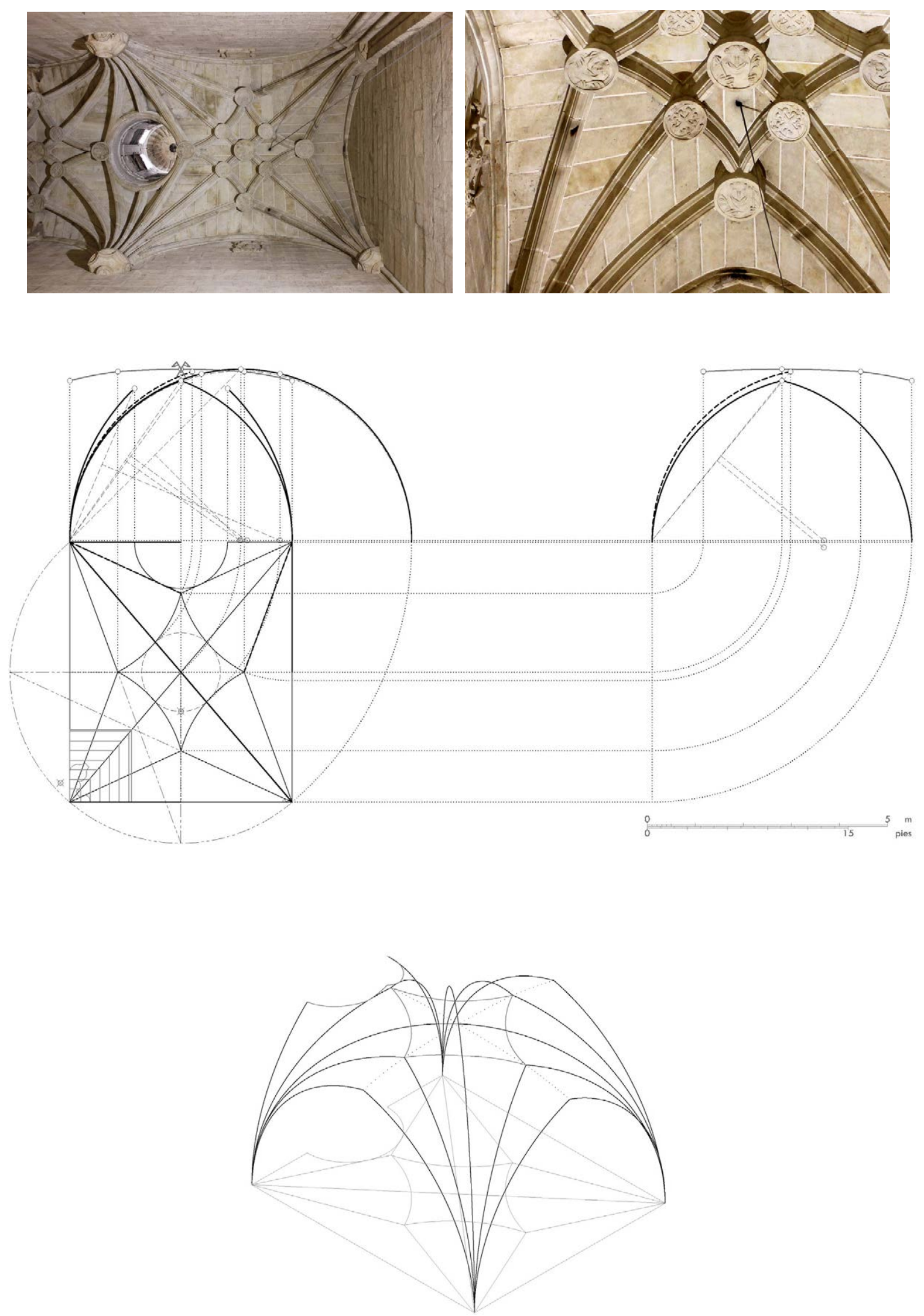

Figura 136. Iglesia del Convento de San Esteban, Salamanca: bóveda de la capilla de los Bonal (costado sur del presbiterio): (a) Vista en planta. (b) Detalle de los nervios, claves y plementería. (c) Hipótesis de trazado de los nervios. (d) Modelizado de los nervios (c, d: P. Moreno) 


\subsubsection{Bóveda de la capilla del Rosario o de los Anaya (costado norte del crucero)}

Modulación y rangos dimensionales: La bóveda tiene una planta rectangular de dimensiones $14.5 \times 25.8$ pies $(4.04 \times 7.20 \mathrm{~m})$ y proporción entre los lados 1.779 (phi), ambas consideradas a ejes de los arcos del perímetro (coinciden con las interiores). Todos los nervios tienen un punto de arranque común en cada apoyo.

Sistemas de composición: La crucería principal está formada por los dos arcos diagonales, terceletes dobles en la dirección del eje mayor y sencillos en la dirección del eje menor. Las nervaduras decorativas forman una figura de lados cóncavos, en cuyo interior se dispone otra figura de lados cóncavos. En conjunto se obtiene un diseño con 23 claves interiores. - Las claves de los terceletes se sitúan, sobre el eje mayor, en los puntos que resultan de dividir dicho eje en ocho partes iguales (a 1/8 del perímetro), y en otros dos puntos que resultan de dividir la distancia entre la clave central y las claves obtenidas anteriormente en dos partes iguales (a 1/2 de la clave central); sobre el eje menor, en los puntos que resultan de dividir dicho eje en cuatro partes iguales (a 1/4 del perímetro). Las claves de la figura exterior sobre las diagonales y sobre los terceletes interiores del eje mayor se sitúan en los puntos de corte con un paralelogramo que une los extremos de dicha figura; las claves sobre los terceletes del eje menor y las de la figura interior sobre las diagonales se sitúan en puntos cuyo trazado geométrico no hemos logrado determinar; la figura exterior se compone de dieciséis arcos, y la interior de ocho.

Arcos: El plano de imposta se sitúa a una altura de 35.8 pies $(9.96 \mathrm{~m}$ ) del suelo, y la clave central a 14.3 pies $(3.98 \mathrm{~m})$ de dicho plano. Todos los arcos parten tangentes a la vertical en el arranque, excepto la diagonal y el formero (eje y) que parten inclinados, no presentando ninguno peraltes. La clave central se encuentra 0.5 pies $(0.15 \mathrm{~m}$ ) por debajo de la posición que correspondería a la de un arco ojivo semicircular. Un examen visual de la geometría de la diagonal y la comprobación de la posición que ocupan las claves secundarias dispuestas a lo largo de este arco nos hace concluir que su trazado teórico es semicircular rebajado o escarzano, partiendo sin peralte en su arranque. Los arcos se trazarían aparentemente con 2 radios distintos, siendo sus datos geométricos en pies los siguientes:

\begin{tabular}{lccr} 
nervio & tipo & radio & peralte \\
\hline diagonal & sc.rb & 14.8 \\
perpiaño & ap & 12.7 \\
formero & sc.rb & 12.9 \\
tercelete per. 1 & ap & 13.9 \\
tercelete per. 2 & ap & 13.7 \\
tercelete for. & ap & 13.8
\end{tabular}

Rampante: Las claves de los arcos del perímetro se sitúan, en la dirección del eje x (menor), a 1.7 pies $(0.48 \mathrm{~m}$ ) por debajo de la clave central; en la dirección del eje y (mayor), a 2.8 pies (0.79 m) por debajo de la clave central. El rampante se puede considerar llano en la dirección de ambos ejes.

Características constructivas: Los nervios que forman la crucería interior presentan 2 tipos distintos de sección en cuanto a molduraje y canto (grande para la diagonal; pequeño para el tercelete, la ligadura y el nervio decorativo). - Las jarjas se componen de 5 hiladas. - Las claves tienen su eje central vertical (y su cara inferior paralela a la superficie de la bóveda en cada punto). • La plementería es de cantería, dispuesta a la francesa; sus hiladas se componen de 1 única pieza; asienta directamente sobre el trasdós del formero. 

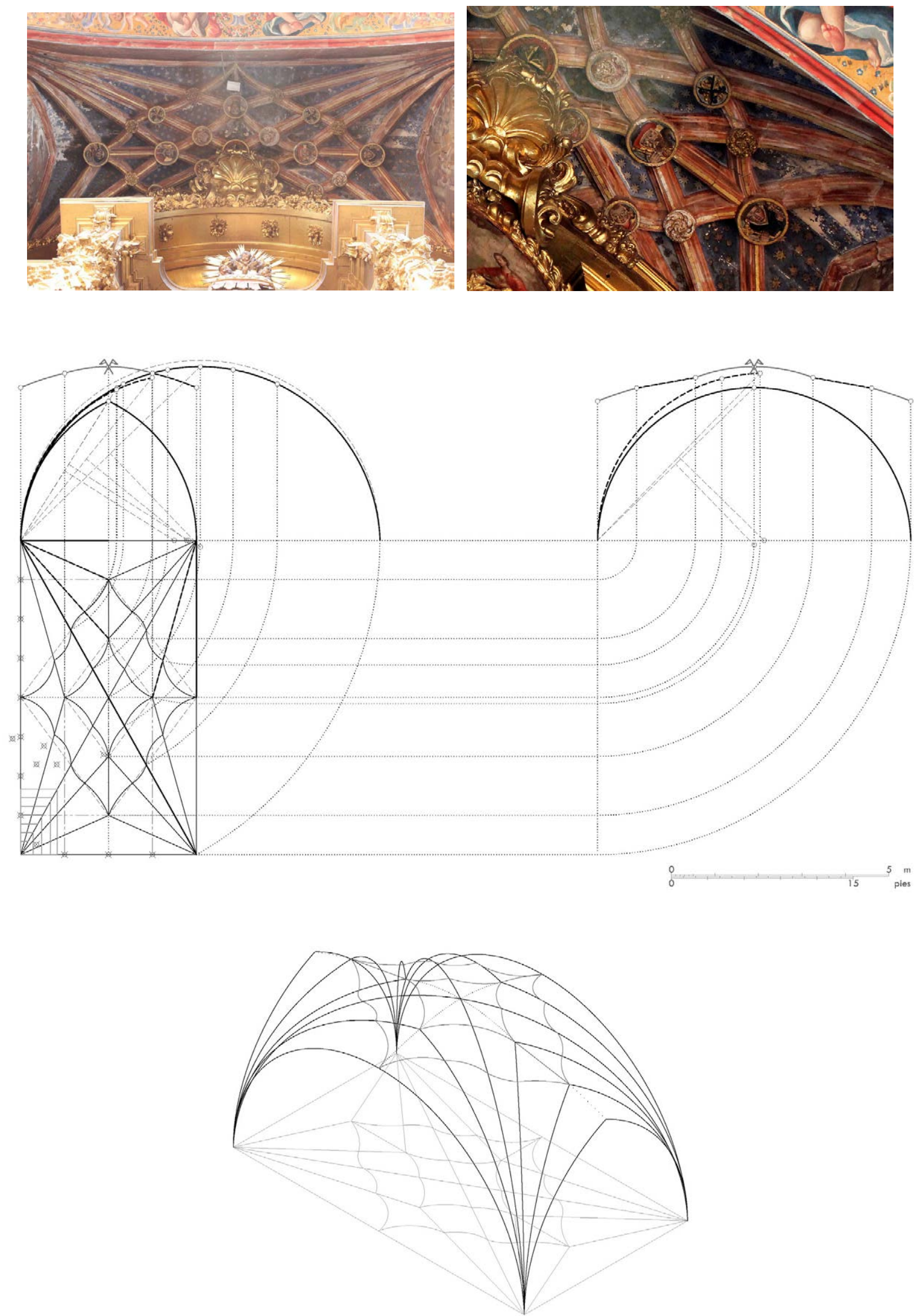

Figura 137. Iglesia del Convento de San Esteban, Salamanca: bóveda de la capilla del Rosario o de los Anaya (costado norte del crucero): (a) Vista en planta. (b) Detalle de los nervios, claves y plementería. (c) Hipótesis de trazado de los nervios. (d) Modelizado de los nervios (c, d: P. Moreno) 


\subsubsection{Bóveda de la escalera de Soto}

Modulación y rangos dimensionales: La bóveda tiene una planta rectangular de dimensiones $35.3 \times 28.8$ pies $(9.83 \times 8.03 \mathrm{~m})$ y proporción entre los lados $1.226(5: 4)$, ambas consideradas a ejes de los arcos del perímetro (coinciden con las interiores). Todos los nervios tienen un punto de arranque común en cada apoyo.

Sistemas de composición: La crucería principal está formada por los dos arcos diagonales y terceletes dobles en la dirección de ambos ejes. Las nervaduras decorativas forman un cuadrifolio de hojas conopiales, en cuyo interior se dispone una figura de lados cóncavos y convexos. En conjunto se obtiene un diseño con 25 claves interiores. - Las claves de los terceletes exteriores se sitúan, sobre ambos ejes, en los puntos que resultan de dividir dichos ejes en ocho partes iguales (a $1 / 8$ del perímetro); cuatro arcos con centros en cada uno de los vértices de la bóveda y radio la mitad del eje mayor permiten obtener sobre este las claves de otros dos terceletes, y cortan a su vez a las diagonales en cuatro puntos; una circunferencia con centro en la clave central y radio la distancia hasta dichos puntos permite obtener sobre el eje menor las claves de los dos terceletes restantes (las claves de los terceletes interiores resultan aproximadamente situadas, sobre ambos ejes, en los puntos medios de los segmentos limitados por las claves de los terceletes exteriores y la central). Las claves secundarias sobre los terceletes más cercanos a los extremos del cuadrifolio quedan alineadas sobre un paralelogramo que une dichos extremos; los centros principales de las hojas del cuadrifolio (uno por cada hoja en el eje mayor y dos en el menor) se disponen aproximadamente en las mediatrices de los segmentos limitados por sus extremos y la clave central, obteniéndose las otras cuatro claves sobre los terceletes.

Arcos: El plano de imposta se sitúa a una altura de 45.1 pies $(12.57 \mathrm{~m})$ del suelo, y la clave central a 22.3 pies $(6.20 \mathrm{~m}$ ) de dicho plano. Todos los arcos parten tangentes a la vertical en el arranque, excepto la diagonal que parte inclinada, no presentando ninguno peraltes. La clave central se encuentra 0.5 pies $(0.15 \mathrm{~m})$ por debajo de la posición que correspondería a la de un arco ojivo semicircular. Un examen visual de la geometría de la diagonal y la comprobación de la posición que ocupan las claves secundarias dispuestas a lo largo de este arco nos hace concluir que su trazado teórico es semicircular rebajado o escarzano, partiendo sin peralte en su arranque. Los arcos se trazarían aparentemente con 3 radios distintos, siendo sus datos geométricos en pies los siguientes:

\begin{tabular}{|c|c|c|}
\hline nervio & tipo & radio \\
\hline diagonal & sc.rb & 22.8 \\
\hline perpiaño & ap & 19.6 \\
\hline formero & ap & 20.5 \\
\hline tercelete per. 1 & ap & 21.0 \\
\hline tercelete per. 2 & ap & 21.8 \\
\hline tercelete for. 1 & ap & 21.8 \\
\hline tercelete for. 2 & ap & 22.1 \\
\hline
\end{tabular}

Rampante: Las claves de los arcos del perímetro se sitúan, en la dirección del eje x (mayor), a 2.7 pies $(0.74 \mathrm{~m}$ ) por debajo de la clave central; en la dirección del eje y (menor), a 2.8 pies $(0.77 \mathrm{~m})$ por debajo de la clave central. El rampante se puede considerar llano en la dirección de ambos ejes.

Características constructivas: Los nervios que forman la crucería interior presentan 3 tipos distintos de sección en cuanto a molduraje y canto (grande para la diagonal; mediano para el tercelete; pequeño para la ligadura y el nervio decorativo). - Las jarjas se componen de 7 y 8 hiladas, dependiendo del nervio considerado. - Las claves tienen su eje central vertical (y su cara inferior paralela a la superficie de la bóveda en cada punto). - La plementería es de cantería, dispuesta a la francesa; sus hiladas se componen de entre 1 y 2 piezas; asienta directamente sobre el trasdós del formero. 

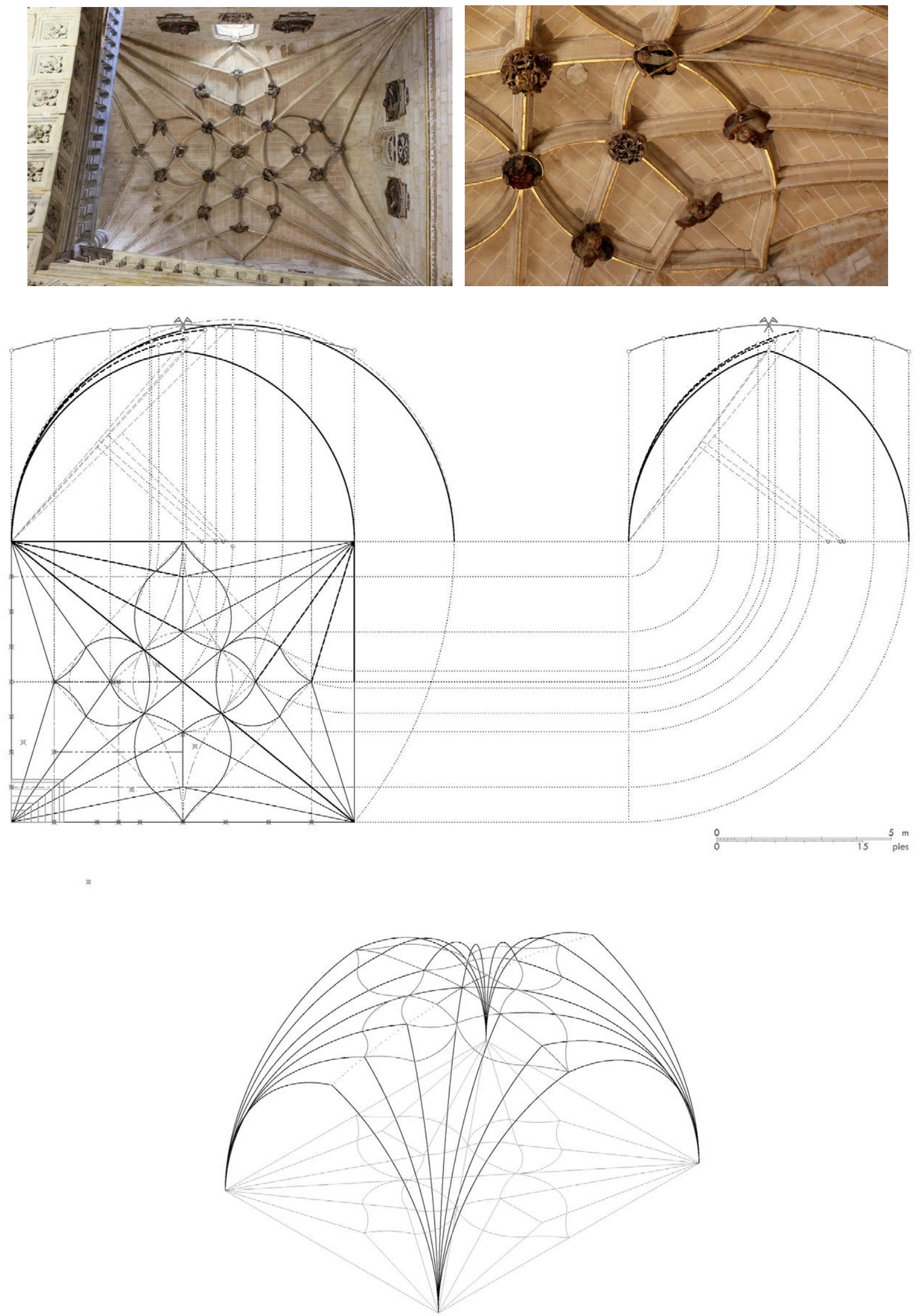

Figura 138. Iglesia del convento de San Esteban, Salamanca: bóveda de la escalera de Soto: (a) Vista en planta. (b) Detalle de los nervios, claves y plementería. (c) Hipótesis de trazado de los nervios. (d) Modelizado de los nervios (c, d: P. Moreno) 


\subsubsection{Salamanca $\cdot$ Iglesia del monasterio de las Bernardas o del Buen Nombre de Jesús}

Datos históricos del edificio: véase página 790 y siguientes

Datos de medición de las bóvedas: véase página 902
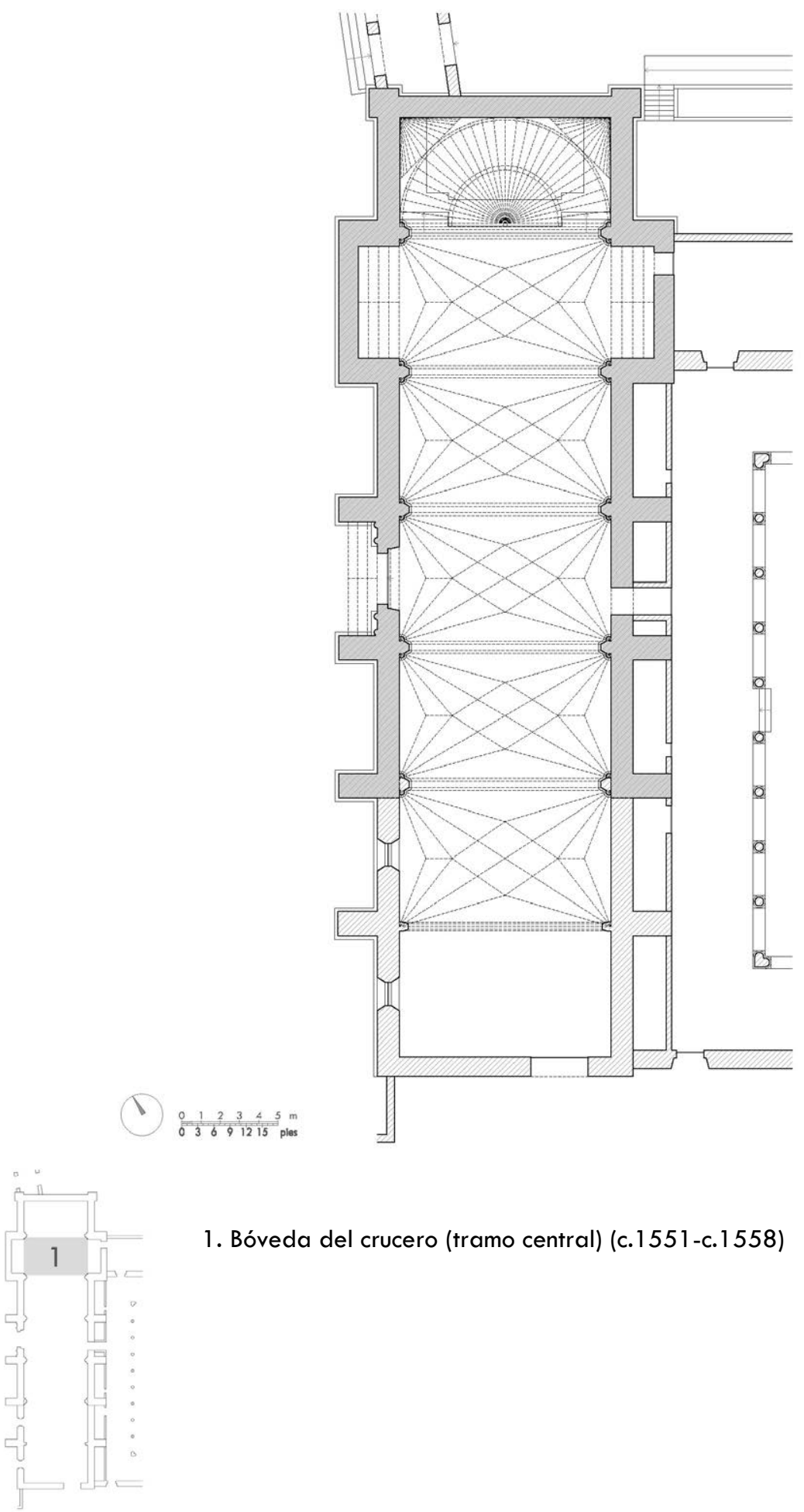

1. Bóveda del crucero (tramo central) (c.1551-c.1558)

Figura 139. Iglesia del monasterio de las Bernardas, Salamanca: (a) Planta (P. Moreno). (b) Indicación de las bóvedas analizadas, con su fecha de ejecución (P. Moreno) 


\subsubsection{Bóveda del crucero (tramo central) ${ }^{450}$}

Modulación y rangos dimensionales: La bóveda tiene una planta rectangular de dimensiones $39.5 \times 25.9$ pies ( $11.00 \times 7.21 \mathrm{~m}$ ) y proporción entre los lados $1.525(3: 2)$, ambas consideradas a ejes de los arcos del perímetro (las interiores son $39.5 \times 23.6$ pies $(11.00 \times 6.57 \mathrm{~m})$ y 1.674 (phi), respectivamente). Los perpiaños tienen un punto de arranque distinto al del resto de los nervios en cada apoyo.

Sistemas de composición: La crucería principal está formada por los dos arcos diagonales, terceletes dobles en la dirección del eje mayor y sencillos en la dirección del eje menor. Las nervaduras decorativas forman un rombo de lados rectos. En conjunto se obtiene un diseño con 11 claves interiores. - Las claves de los terceletes se sitúan, sobre el eje mayor, en los puntos que resultan de dividir dicho eje en ocho partes iguales (a $1 / 8$ y $2 / 8$ del perímetro); sobre el eje menor, en la bisectriz del ángulo formado por la diagonal y los arcos del perímetro. Las claves sobre las diagonales son generadas automáticamente uniendo las claves de los terceletes.

Arcos: El plano de imposta se sitúa a una altura de 39.4 pies $(10.97 \mathrm{~m})$ del suelo, y la clave central a 22.6 pies $(6.31 \mathrm{~m}$ ) de dicho plano. Todos los arcos parten tangentes a la vertical en el arranque, no presentando ninguno peraltes. La clave central se encuentra 0.3 pies $(0.10 \mathrm{~m})$ por debajo de la posición que correspondería a la de un arco ojivo semicircular. Un examen visual de la geometría de la diagonal y la comprobación de la posición que ocupan las claves secundarias dispuestas a lo largo de este arco nos hace concluir que su trazado teórico es efectivamente semicircular, partiendo sin peralte en su arranque. Los arcos se trazarían aparentemente con 2 radios distintos, siendo sus datos geométricos en pies los siguientes:

\begin{tabular}{lccc} 
nervio & tipo & radio & peralte \\
\hline diagonal & sc & 23.0 \\
perpiaño & ap & 21.0 \\
formero & ap & 22.5 \\
tercelete per. & ap & 22.1 \\
tercelete for. 1 & ap & 23.1 \\
tercelete for. 2 & ap & 22.7
\end{tabular}

Rampante: Las claves de los arcos del perímetro se sitúan, en la dirección del eje x (mayor), a 2.8 pies $(0.79 \mathrm{~m}$ ) por debajo de la clave central; en la dirección del eje y (menor), a 1.7 pies $(0.48 \mathrm{~m})$ por debajo de la clave central. El rampante se puede considerar llano en la dirección de ambos ejes.

Características constructivas: Los nervios que forman la crucería interior presentan 2 tipos distintos de sección en cuanto a molduraje y canto (grande para la diagonal; pequeño para el tercelete, la ligadura y el nervio decorativo). - Las jarjas se componen de 7 y 8 hiladas, dependiendo del soporte y del nervio considerado. - Las claves tienen su eje central vertical (y su cara inferior paralela a la superficie de la bóveda en cada punto). - La plementería es probablemente de ladrillo; asienta directamente sobre el trasdós del formero. 450 La bóveda que cubre el primer tramo de nave es idéntica a la analizada en cuanto a características
geométricas y constructivas. 